Variables para el diseño y actualización curricular para la solución de problemas locales-globales mediados por procesos de innovación educativa para básica secundaria

\author{
Jorge Amado Renteria Vera
}

Tesis para optar por el grado de Doctor en Ciencias de la Educación

Director. José Villella. Universidad de San Martín

Codirector. Mauricio Hincapié. Institución Universitaria Americana.

La plata, 10 de febrero de 2020 
Página de dedicatoria

A Dios; a mis grandes amores Sandra

e hijo Juan Camilo, a mis padres

Emiro-Margarita y Jorge-Luz Mery

y a mis queridos Suegritos Edwin y Amparito. 
Página de agradecimientos

Agradezco a Dios, por iluminarme y acompañarme durante cada segundo de este arduo recorrido.

Expreso mi gratitud por la Institución Educativa Monseñor Francisco Cristóbal Toro a cargo del Rector. Mg. Pedro Antonio Agualimpia, a mis colegas Paula Calle y Alejandra Tobón por su apoyo y recomendaciones, a los estudiantes de los grupos 9.1 y 9.2 quienes nos permitieron desarrollar la investigación y estuvieron siempre dispuestos para llevar con éxito la intervención pedagógica.

Agradezco a mi director Dr. José Villella y codirector Dr. Mauricio Hincapié quienes me brindaron su apoyo incondicional y conocimiento de principio a fin.

A mi comae Angie, su experiencia en el tema fue un factor clave para encontrar el camino.

De igual forma, agradezco a mi amada esposa Sandra e hijo Juan Camilo por su acompañamiento, comprensión, paciencia y motivación necesaria para culminar con éxito este proyecto. 


\section{VARIABLES PARA EL DISEÑO Y ACTUALIZACIÓN CURRICULAR PARA LA SOLUCIÓN DE PROBLEMAS LOCALES-GLOBALES MEDIADOS POR PROCESOS DE INNOVACIÓN EDUCATIVA PARA BÁSICA SECUNDARIA}

\section{ÍNDICE}

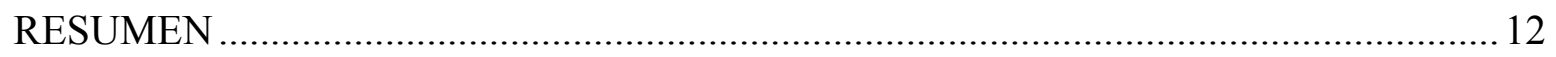

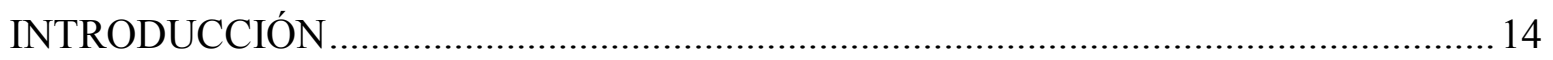

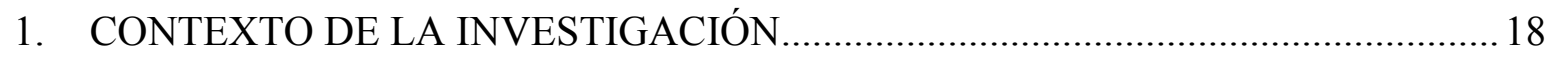

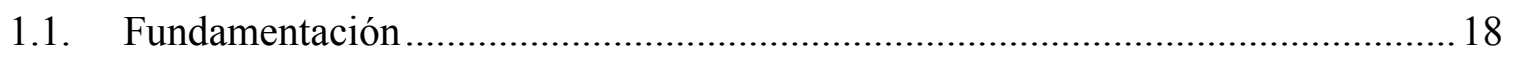

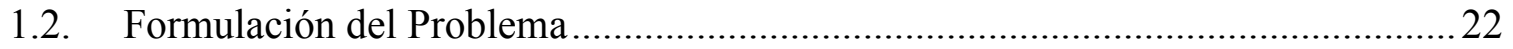

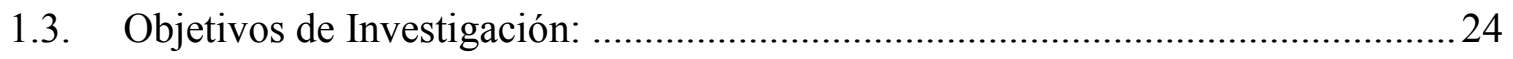

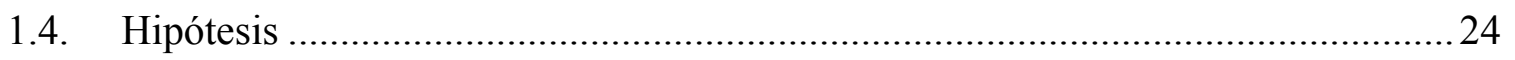

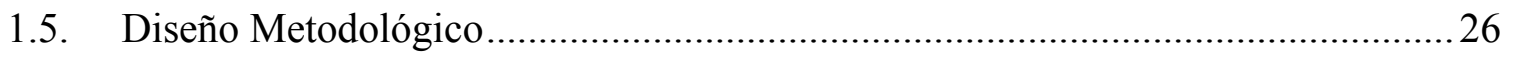

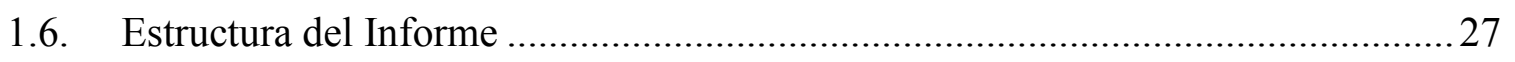

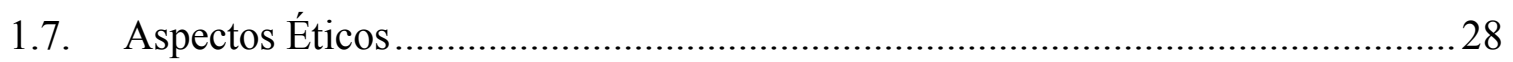

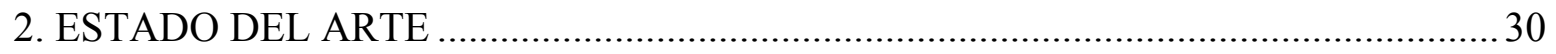

2.1. Categoría 1: Definición y búsqueda de palabras claves.................................... 31

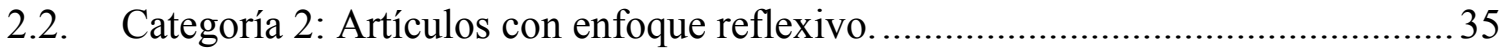

2.3. Categoría 3: Análisis de artículos para currículos disciplinares......................... 39

2.4. Categoría 4: Análisis de artículos con enfoque en la gestión curricular...............43

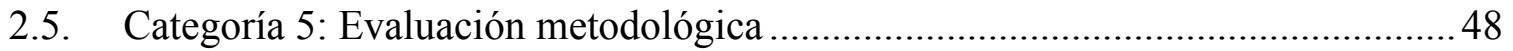

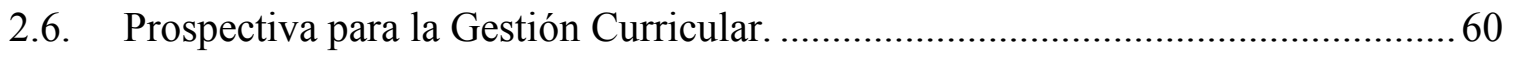

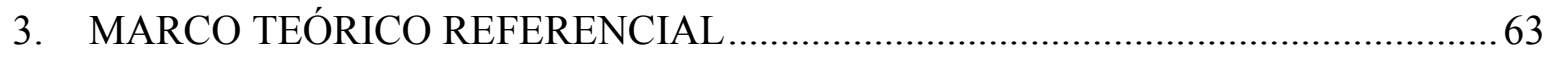

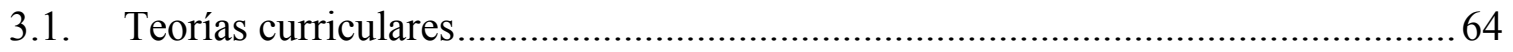

3.1.1. Prospectiva Teórica para el diseño curricular.......................................... 70

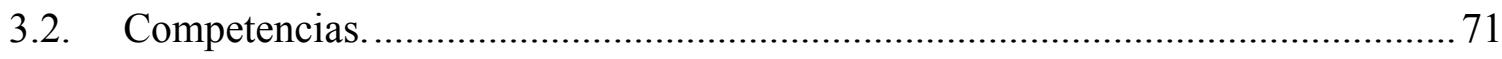

3.2.1. Prospectiva Teórica para el abordaje de las competencias.......................... 77

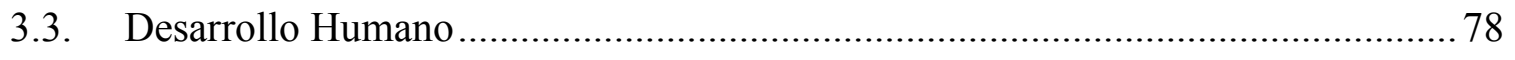

3.3.1. Prospectiva Teórica para el Desarrollo Humano......................................... 82 


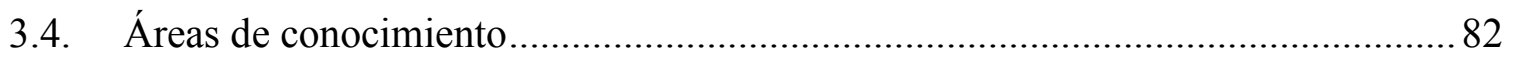

3.4.1. Prospectiva Teórica con relación a las Áreas de Conocimiento......................87

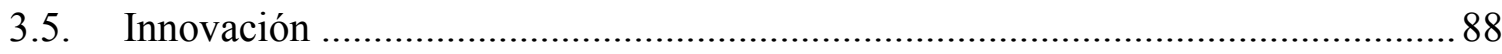

3.5.1. Prospectiva Teórica para la Innovación en la Educación..................................96 INTEGRANDO LAS VARIABLES PARA EL DISEÑO Y ACTUALIZACIÓN

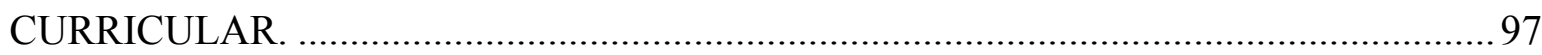

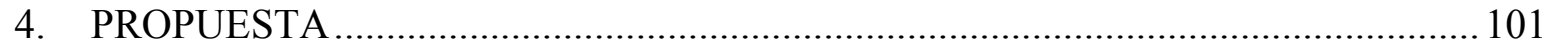

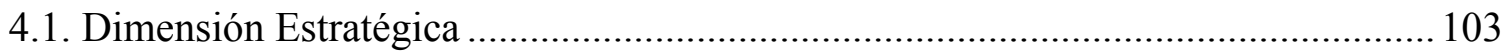

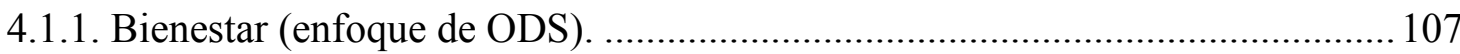

4.1.2. Competencias Global (enfoque desde la propuesta de Organización para el Comercio y Desarrollo Económico-OCDE) ............................................................ 109

4.1.3. Áreas de conocimiento (Asignaturas propuestas desde Ministerio de Educación

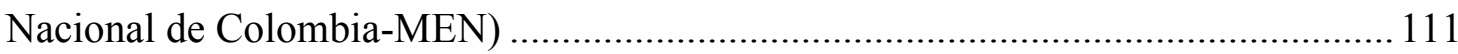

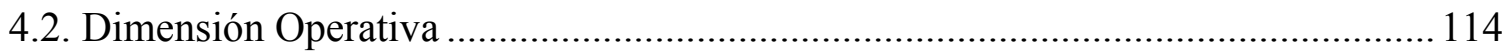

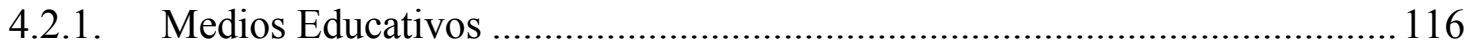

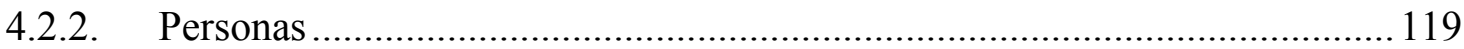

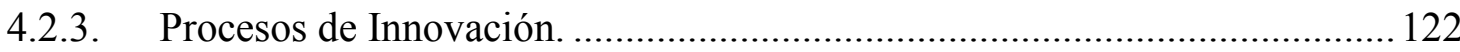

4.3. Dimensión Evaluativa..................................................................................... 124

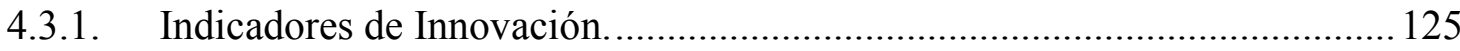

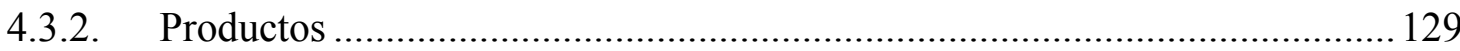

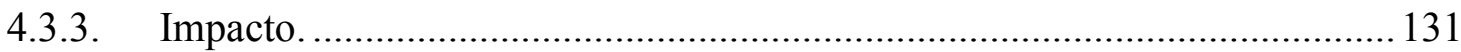

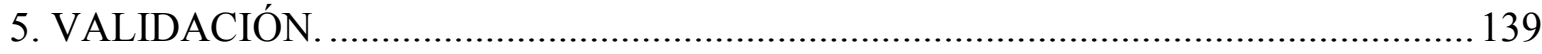

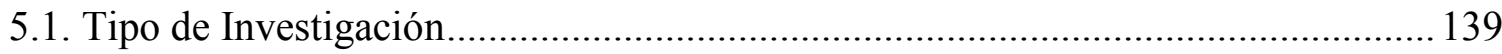

5.2. Implementación del modelo de coordenadas curriculares........................................ 139

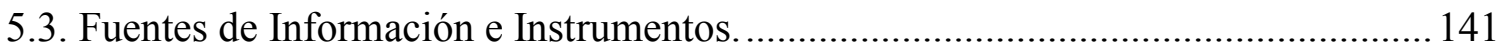

5.4. Tiempo de duración del experimento ………………............................................ 141

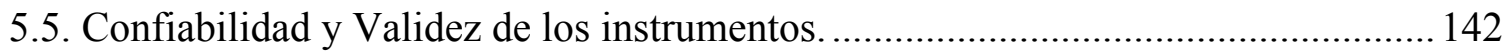

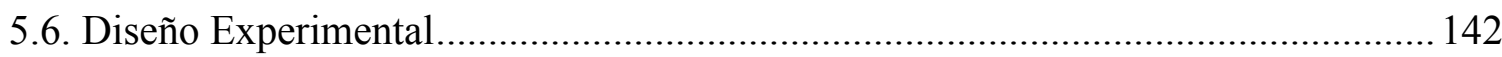

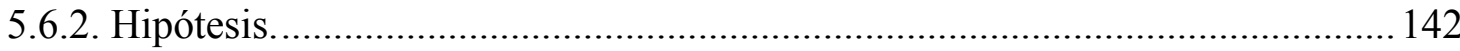

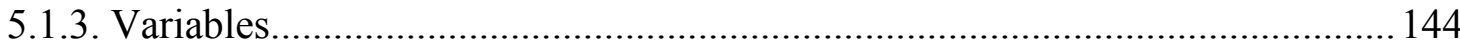

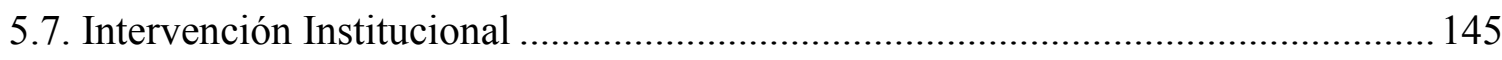

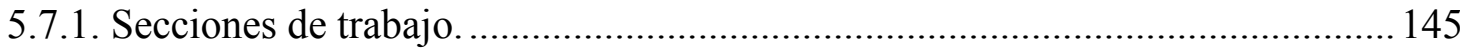




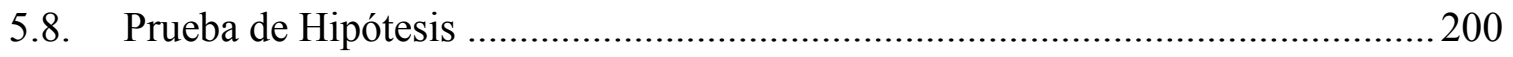

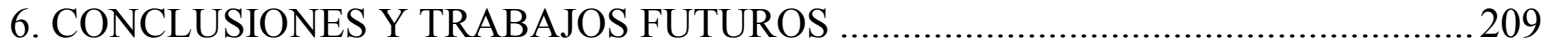

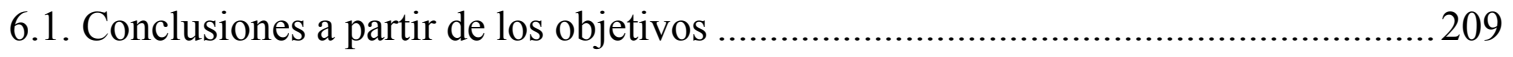

6.2. Conclusiones a partir de la Hipótesis....................................................................... 211

6.3. Conclusiones a partir de las limitantes de investigación. ……………………….....212

6.4. Conclusiones como aporte teórico y prospectiva...................................................213

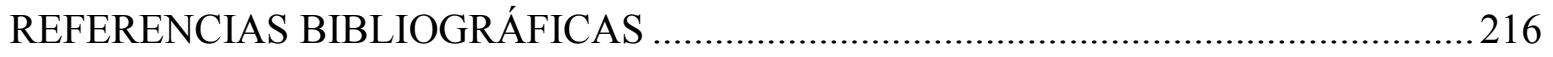

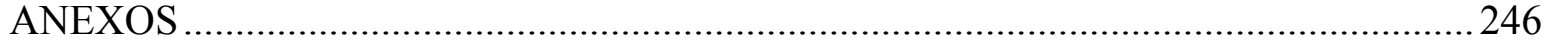

\section{ÍNDICE DE ILUSTRACIONES}

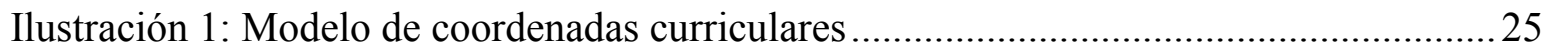

Ilustración 2: Proceso de selección, clasificación y revisión................................................... 31

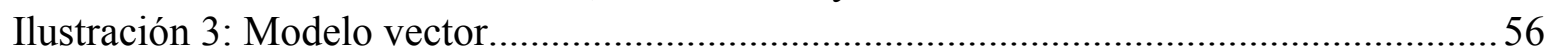

Ilustración 4: Modelo de gestión curricular TE 10I008. .................................................56

Ilustración 5: Modelo de diseño, desarrollo y evaluación de unidades didácticas integradas.

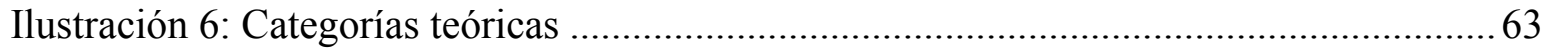

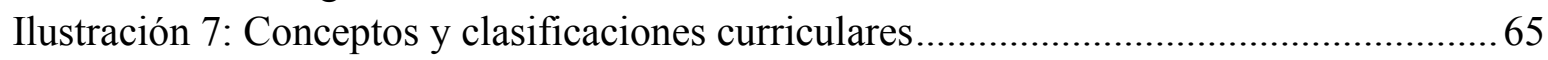

Ilustración 8: Estructura piramidal de las competencias ……………................................73

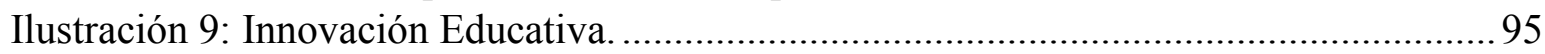

Ilustración 10: Modelo de Coordenadas Curriculares ...........................................................98

Ilustración 11: Dimensiones "Modelo de Coordenadas Curriculares" .................................. 102

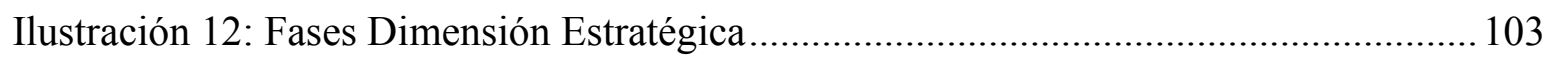

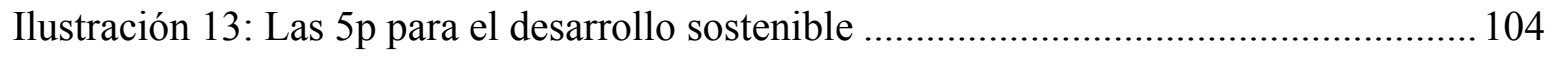

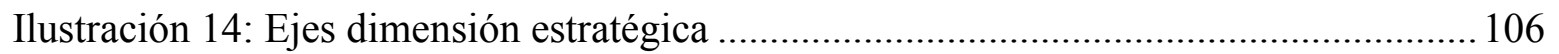

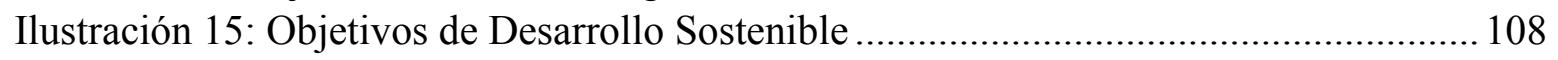

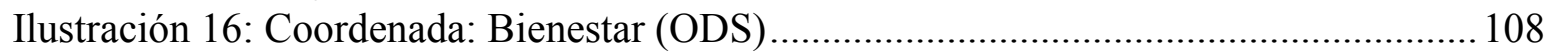

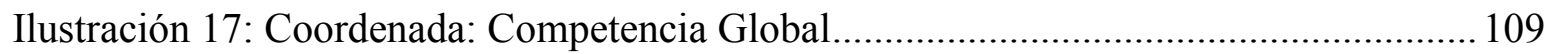

Ilustración 18: Coordenada: Áreas de Conocimiento (MEN) ……………………............. 112

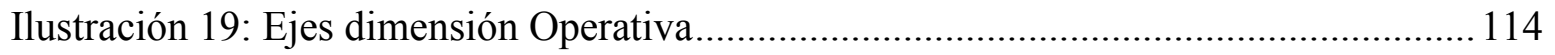

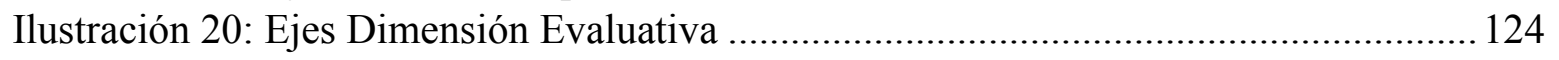

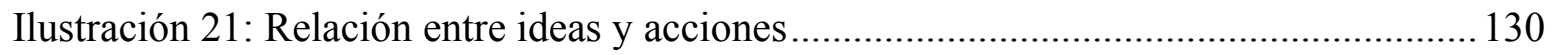

Ilustración 22:Esquema de sostenibilidad de los centros de ciencia en Colombia............. 132

Ilustración 23: Cálculo de error muestral para poblaciones finitas. ..................................... 140

Ilustración 24: Modelo de Coordenadas Curriculares........................................................ 143

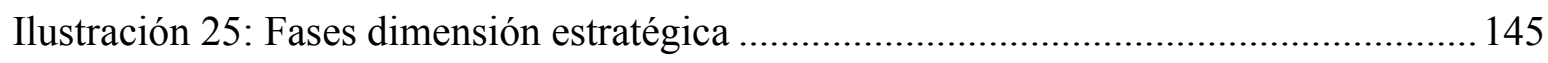

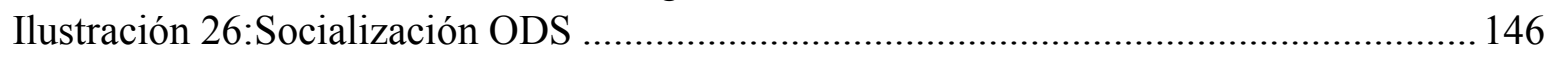

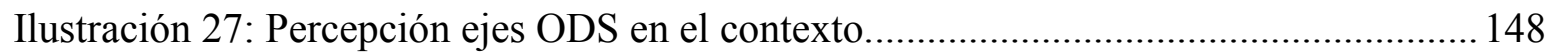

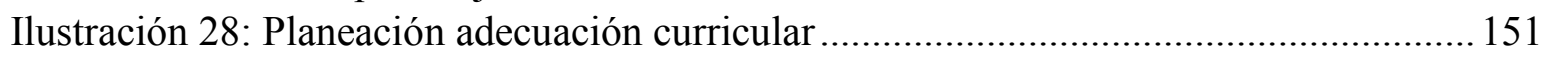




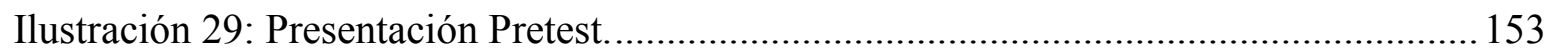

Ilustración 30: Pretest. Constructo: Adopción de perspectivas ...........................................154

Ilustración 31: Pretest. Constructo: Mentalidad Global. ....................................................... 155

Ilustración 32: Pretest: Constructo: Flexibilidad / Adaptabilidad .......................................... 156

Ilustración 33: Pretest. Constructo: Conocimiento de la comunicación intercultural........ 157

Ilustración 34: Pretest. Constructo: Autoeficacia con respecto a asuntos globales............. 158

Ilustración 35: Pretest. Constructo: Conocimiento sobre asuntos globales.......................... 160

Ilustración 36: Pretest. Constructo: Actitudes frente a los inmigrantes. ............................... 161

Ilustración 37: Pretest. Constructo: Clima escolar - Clima escolar multicultural. .............. 162

Ilustración 38: Pretest. Proceso cognitivo: Entender diferencias en la comunicación. ....... 163

Ilustración 39: Pretest. Proceso cognitivo: Evaluar información, formular argumentos y

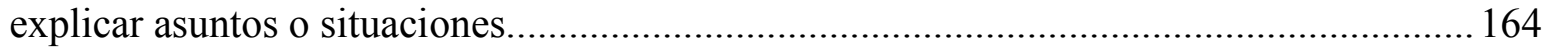

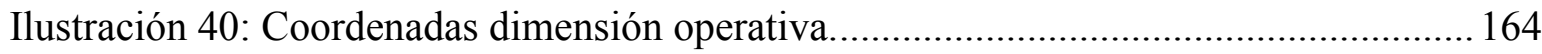

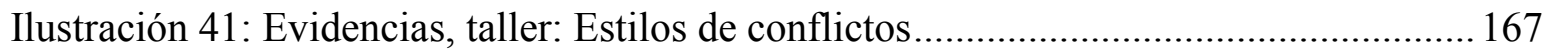

Ilustración 42: Evidencias taller: Mediación escolar......................................................... 171

Ilustración 43: Evidencias taller Calidad del aire en la ciudad de Medellín. ....................... 174

Ilustración 44: Evidencias Taller Análisis percepción de seguridad del entorno................. 177

Ilustración 45: Evidencia Sección Taller Análisis Justicia Especial para la Paz.................. 180

Ilustración 46: Evidencia socialización trabajo final........................................................... 187

Ilustración 47: Postest. Constructo: Adopción de perspectivas............................................. 190

Ilustración 48: Postest. Constructo: Mentalidad Global....................................................... 191

Ilustración 49: Postest: Constructo: Flexibilidad / Adaptabilidad......................................... 192

Ilustración 50: Postest. Constructo: Conocimiento de la comunicación intercultural......... 193

Ilustración 51: Postest. Constructo: Autoeficacia con respecto a asuntos globales. ........... 194

Ilustración 52: Postest. Constructo: Conocimiento sobre asuntos globales. ........................ 196

Ilustración 53: Postest. Constructo: Actitudes frente a los inmigrantes.............................. 197

Ilustración 54: Postest. Constructo: Clima escolar - Clima escolar multicultural............... 198

Ilustración 55: Postest. Proceso cognitivo: Entender diferencias en la comunicación........ 199

Ilustración 56: Postest. Proceso cognitivo: Evaluar información, formular argumentos y

explicar asuntos o situaciones..................................................................................... 200

Ilustración 57: Presentación conclusiones de tesis ............................................................209

\section{ÍNDICE DE TABLAS}

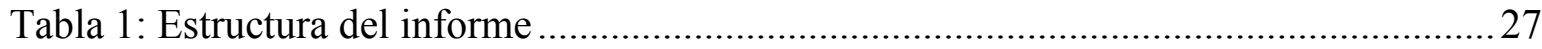

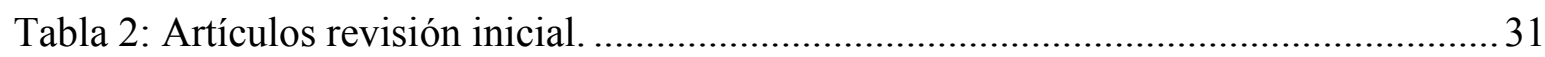

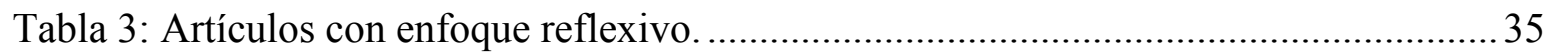

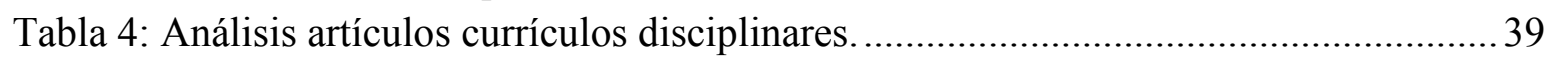

Tabla 5: Artículos Gestión Curricular para la Educación Superior.......................................43 
Tabla 6: Artículos gestión curricular para a educación básica y media. ............................47

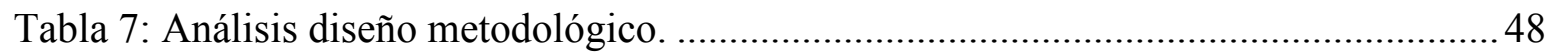

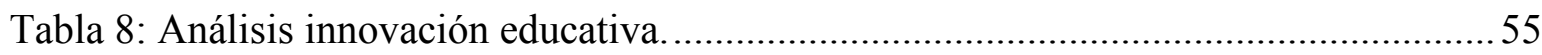

Tabla 9: Características clasificación teorías curriculares según Da Silva. ........................67

Tabla 10: Clasificación de Competencias Básicas ............................................................. 71

Tabla 11: Clasificación de competencias según el contexto ......................................... 72

Tabla 12: Características de competencias según pirámide- Competencias bases.............. 74

Tabla 13: Características de competencias según pirámide- Competencias de procesos..... 74

Tabla 14: Características de competencias según pirámide- Competencias de sistemas.... 74

Tabla 15: Características de competencias según pirámide- Competencias de Telos..........74

Tabla 16: Definición de Competencias ....................................................................... 75

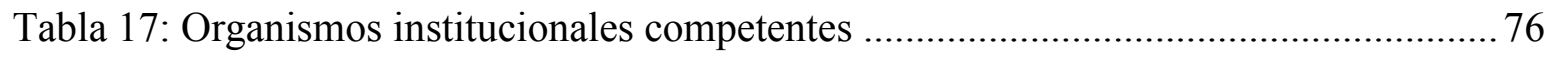

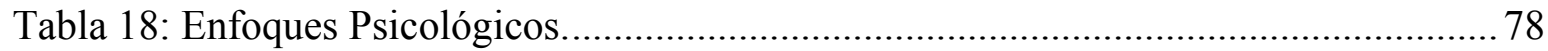

Tabla 19: Campos de Educación según CINE 2011 ......................................................... 86

Tabla 20: Clasificación de modelos sobre el proceso de innovación .................................89

Tabla 21: Metodologías y métodos para Innovar. ......................................................... 90

Tabla 22: Técnicas y Herramientas para la innovación................................................... 91

Tabla 23: Definiciones de Innovación Educativa ........................................................... 93

Tabla 24: Tipologías de innovación Educativa .......................................................... 94

Tabla 25: Descripción dimensiones "Modelo de Coordenadas Curriculares" ................... 101

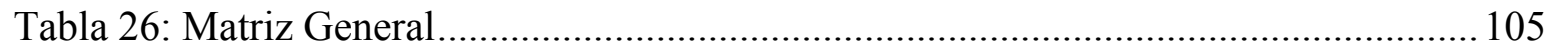

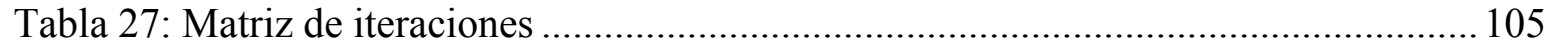

Tabla 28: Coordenadas Dimensión Estratégica.......................................................... 106

Tabla 29: La evaluación cognitiva de la competencia global.......................................... 110

Tabla 30: Áreas fundamentales MEN educación básica secundaria ................................ 112

Tabla 31: Coordenadas Dimensión Operativa............................................................... 115

Tabla 32:Matriz de seguimiento: Identificación del plan de área .................................... 115

Tabla 33: Matriz de seguimiento: Planificación de Acciones Pedagógicas ....................... 116

Tabla 34: Matriz de seguimiento: Planeador de Clase .................................................. 116

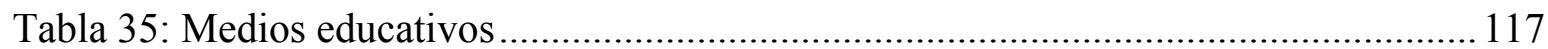

Tabla 36: Aportes al aprendizaje por disciplina ........................................................... 118

Tabla 37: Retos de la tecnología educativa para primaria y secundaria............................ 119

Tabla 38: Autonomía por (García, Ruiz \& García, 2009)............................................... 120

Tabla 39. Coordenadas Dimensión Evaluativa........................................................... 125

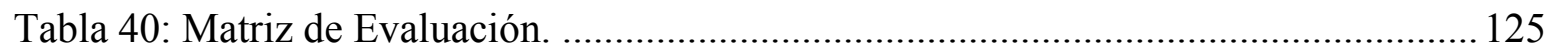

Tabla 41. Criterios de identificación de buenas prácticas. ........................................... 126

Tabla 42: categorías de Sostenibilidad según Banco Mundial ....................................... 129

Tabla 43: Productos según modelo de medición Colciencias para 2017 ......................... 130

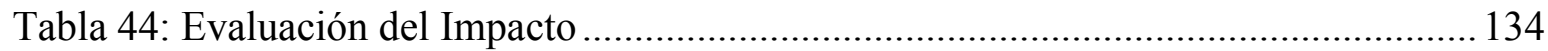

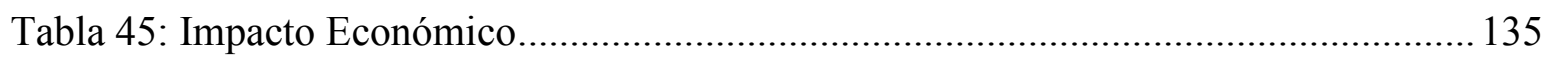

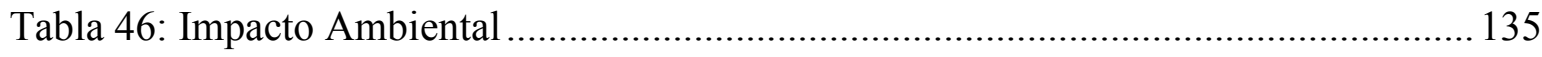




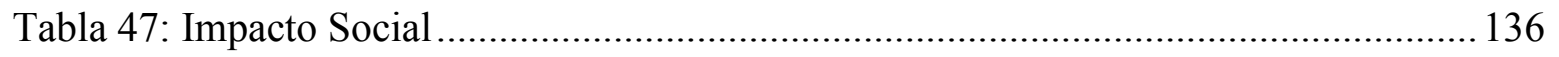

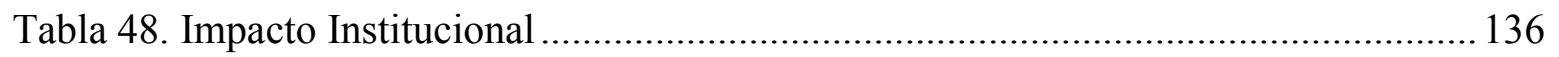

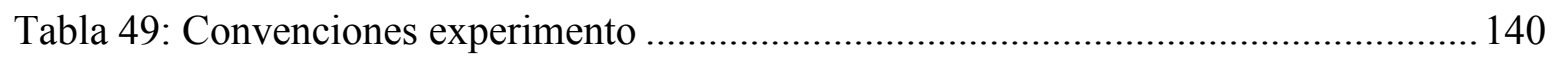

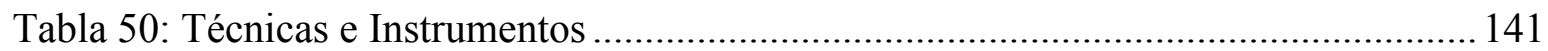

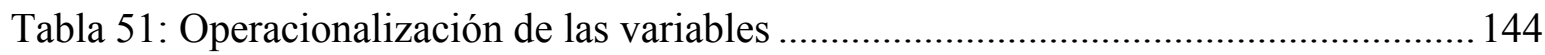

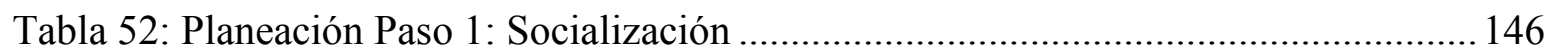

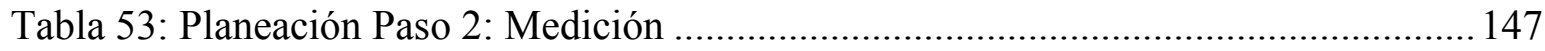

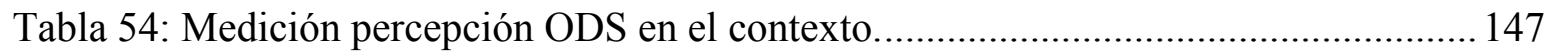

Tabla 55: Pareto resultado de percepción ejes ODS en el contexto ..................................... 148

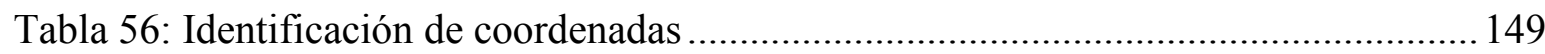

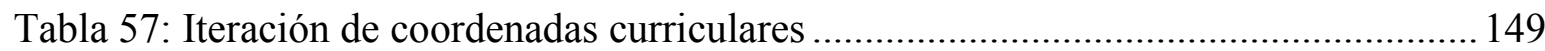

Tabla 58: Planeación Sección 3- Adecuación curricular.................................................... 150

Tabla 59: Planeación Sección 4 - Prueba diagnóstica o Pretest ........................................... 152

Tabla 60: Pretest. ¿Qué tanto lo describen a usted cada una de las siguientes afirmaciones?

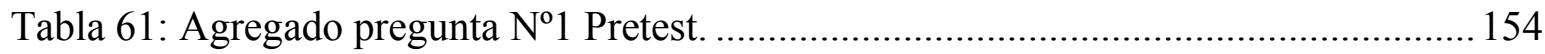

Tabla 62: Pretest. ¿Hasta qué punto está usted de acuerdo con las siguientes afirmaciones?

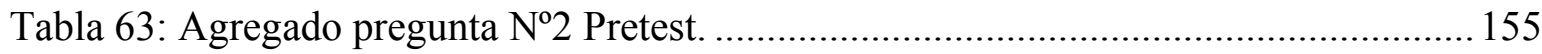

Tabla 64: Pretest. ¿Qué tanto lo describen a usted cada una de las siguientes afirmaciones?

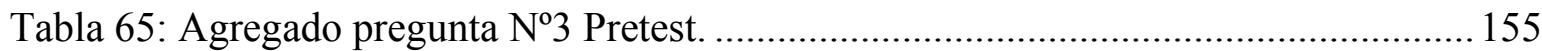

Tabla 66: Pretest. ¿Hasta qué punto está usted de acuerdo con las siguientes afirmaciones?

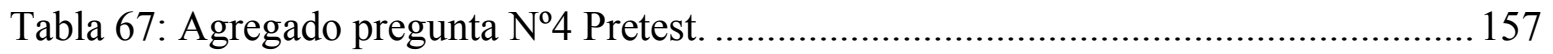

Tabla 68: Pretest. ¿Con qué facilidad piensa usted que podría realizar las siguientes tareas

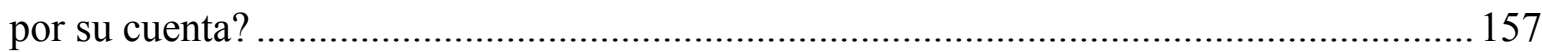

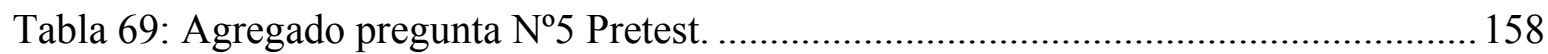

Tabla 70: Pretest. ¿Qué tan informado está usted sobre los siguientes temas? ................... 158

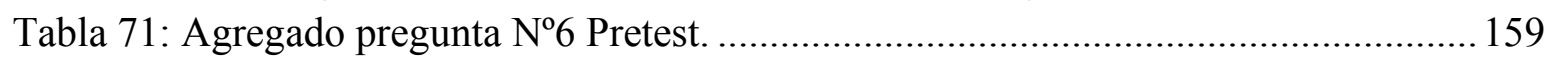

Tabla 72: Pretest. La gente se traslada, cada vez más, de un país a otro ¿Qué tanto está usted de acuerdo con las siguientes afirmaciones sobre los inmigrantes? ........................... 160

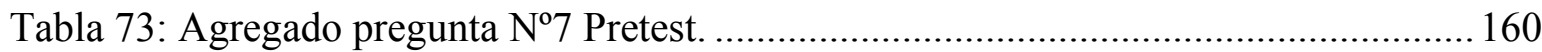

Tabla 74: Pretest. Con respecto a los profesores de su colegio: ¿a cuántos de ellos aplican

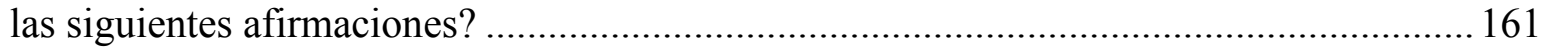

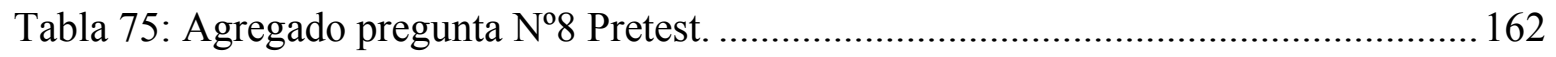

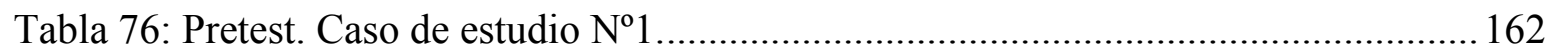

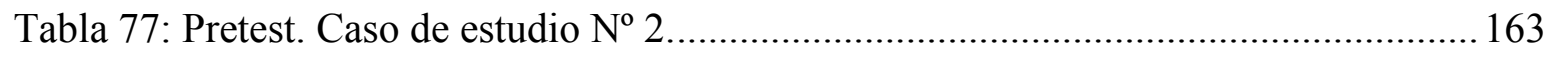

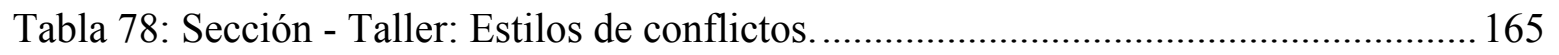

Tabla 79: Sección - Taller: Mediación escolar................................................................ 168

Tabla 80. Sección - Taller Calidad del aire en la ciudad de Medellín................................. 172 
Tabla 81: Sección - Taller: Análisis percepción de seguridad del entorno. ...................... 175

Tabla 82: Sección - Taller Análisis Justicia Especial para la Paz. ................................... 177

Tabla 83: Sección - Taller: Reflexión corrupción en América Latina. .............................. 180

Tabla 84: Sección - Taller Reflexión Victimas de Trata de Personas. ............................. 183

Tabla 85: Dimensión Evaluativa. ...................................................................................... 186

Tabla 86: Matriz de Evaluación. ................................................................................ 187

Tabla 87: Planeación Sección Prueba final- Postest...................................................... 189

Tabla 88: Postest. ¿Qué tanto lo describen a usted cada una de las siguientes afirmaciones?

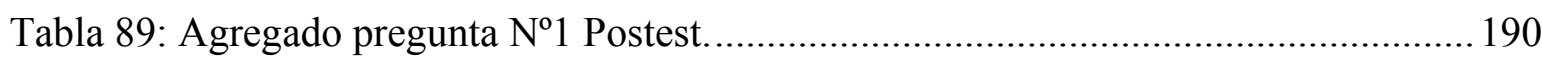

Tabla 90: Postest. ¿Hasta qué punto está usted de acuerdo con las siguientes afirmaciones?

Tabla 91: Agregado pregunta No2 Postest.

Tabla 92: Postest. ¿Qué tanto lo describen a usted cada una de las siguientes afirmaciones?

Tabla 93: Agregado pregunta No3 Postest................................................................... 192

Tabla 94: Postest. ¿Hasta qué punto está usted de acuerdo con las siguientes afirmaciones?

Tabla 95: Agregado pregunta $\mathrm{N}^{\mathrm{o}} 4$ Postest.

Tabla 96: Postest. ¿Con qué facilidad piensa usted que podría realizar las siguientes tareas

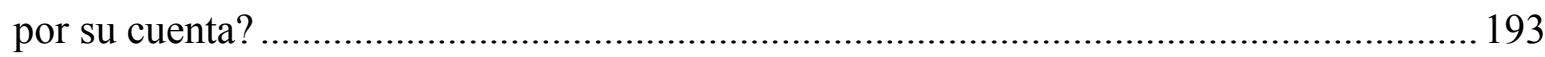

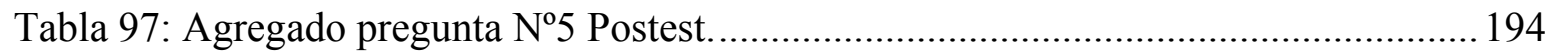

Tabla 98: Postest. ¿Qué tan informado está usted sobre los siguientes temas?................. 195

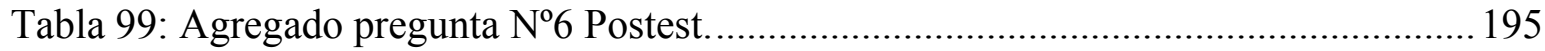

Tabla 100: Postest. La gente se traslada, cada vez más, de un país a otro ¿Qué tanto está usted de acuerdo con las siguientes afirmaciones sobre los inmigrantes? ........................ 196

Tabla 101: Agregado pregunta No 7 Postest.................................................................... 196

Tabla 102: Postest. Con respecto a los profesores de su colegio: ¿a cuántos de ellos aplican

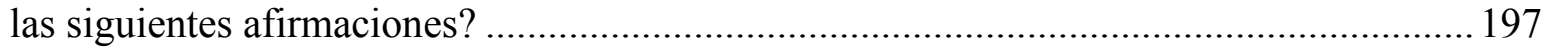

Tabla 103: Agregado pregunta No8 Postest............................................................... 198

Tabla 104: Postest. Caso de estudio $\mathrm{N}^{\mathrm{0}} 1$. ........................................................................ 198

Tabla 105: Postest. Caso de estudio $\mathrm{N}^{\mathrm{o}} 2$....................................................................... 199

Tabla 106: Comparativo Pretest - Postest................................................................ 201

Tabla 107: Análisis de contrastes pregunta 1............................................................201

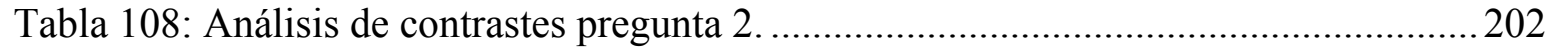

Tabla 109: Análisis de contrastes pregunta 3........................................................... 202

Tabla 110: Análisis de contrastes pregunta 4............................................................203

Tabla 111: Análisis de contrastes pregunta 5 .............................................................. 203

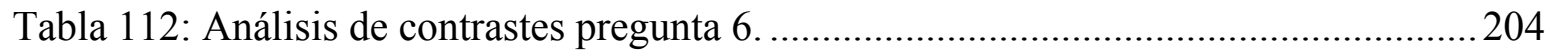

Tabla 113: Análisis de contrastes pregunta 7.......................................................... 205

Tabla 114: Análisis de contrastes pregunta 8 ........................................................... 205 
Tabla 115: Análisis de contrastes pregunta 9............................................................206

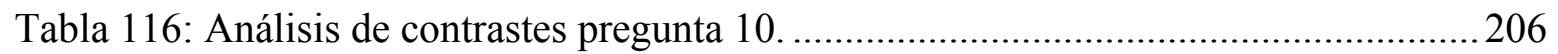

Tabla 117: Conclusiones por objetivos específicos..................................................... 210

\section{INDICE DE ANEXOS}

Anexo 1 "Diagnóstico del Contexto Institucional" .........................................................246

Anexo 2: Clasificación de los Ejes ODS - Pareto- ........................................................... 250

Anexo 3: Metas de los Objetivos de Desarrollo Sostenible. ...........................................251

Anexo 4 Prueba Diagnóstica Institucional ODS ...........................................................262

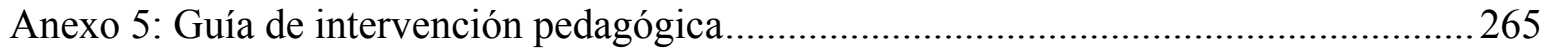

Anexo 6: Prueba Escrita Pretest ............................................................................. 266

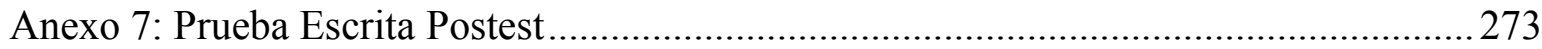

Anexo 8: Validación de instrumento Guía de intervención pedagógica ...........................2279

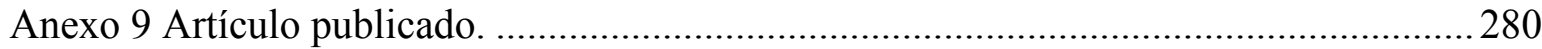

Anexo 10: Certificado ponencia ELE 2018...................................................................28

Anexo 11: certificado capítulo de libro resultado de investigación ELE 2018................282

Anexo 12: Ponencia IV Congreso Internacional de Política educativa en América Latina

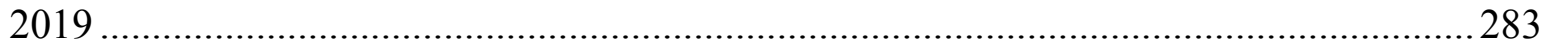

Anexo 13: Marco metodológico para el fortalecimiento de la competencia global...........284

Anexo 14: Certificado Ponencia RAIS 2019............................................................. 285

Anexo 15: Certificado capítulo de libro resultado de investigación RAIS 2019..............286 


\title{
VARIABLES PARA EL DISEÑO Y ACTUALIZACIÓN CURRICULAR PARA LA SOLUCIÓN DE PROBLEMAS LOCALES-GLOBALES MEDIADOS POR PROCESOS DE INNOVACIÓN EDUCATIVA PARA BÁSICA SECUNDARIA
}

\begin{abstract}
RESUMEN
El currículo integra escenarios científicos y culturales entre los que se destaca la filosofía, epistemología, psicología, antropología, sociología, pedagogía, además de la reflexión continua sobre pertinencia, enfoque, dimensión, flexibilidad e interdisciplinariedad que hacen compleja su idoneidad. Se plantea un marco teórico metodológico denominado "Modelo de Coordenadas Curriculares" que permite mediante el uso de técnicas, métodos y metodologías de innovación en educación identificar y solucionar situaciones escolares a partir de las problemáticas del entorno local - global desde un marco colaborativo para la formación de conocimiento útil para la vida en estudiantes de básica secundaria. Los resultados experimentales de la intervención pedagógica determinaron mejoramiento en el desempeño de los estudiantes con relación a la ejecución de la competencia global.
\end{abstract}

\section{Palabras Claves:}

Currículo, diseño curricular, competencia global. 


\section{INTRODUCCIÓN}

La agenda mundial hacia 2030 definida por la Organización de Naciones Unidas (ONU) constituye el eje de reflexión de la actual tesis de investigación sobre las diferentes tensiones y complejidad que presenta el sistema educativo sobre el ¿qué enseñar? ¿cómo enseñar? y ¿para qué enseñar? en tiempos del "desarrollo humano sostenible". En este sentido, los retos en materia de educación incluyen la primera infancia y la formación de jóvenes y adultos. Así mismo, cubre el desarrollo de habilidades para el trabajo; la formación ciudadana global en un mundo plural e interdependiente; el desarrollo de políticas de inclusión e igualdad de sexos y garantizar calidad en el aprendizaje a lo largo de la vida. Asuntos de agenda global que trazan la ruta de los gobiernos de los países socios que deben garantizar seguimiento a los progresos a escala mundial, regional y nacional.

La creciente complejidad determina para los jóvenes de hoy desafíos en el aprendizaje en un mundo más interconectado, global e intercultural (Barrett et al., 2014; Boix-Mansilla y Jackson, 2011; Deardorff, 2009; UNESCO 2013, 2014, 2016).

El Programa de Evaluación Internacional de Alumnos de la OCDE (PISA) evalúa competencias en lectura, matemáticas y ciencias a estudiantes próximos a finalizar la educación básica secundaria. Iniciativa de evaluación que surge como respuesta a los Objetivos de Desarrollo Sostenible relacionados con la educación (OCDE, 2017). Para el año 2018 por primera vez para Colombia se evalúo la competencia global ${ }^{1}$ situación que permite reflexionar sobre ¿qué tipo de información y formación recibieron los directivos, docentes y estudiantes para abordar una prueba internacional que evalúa la competencia global? Del mismo modo, analizar las políticas educativas del ministerio de educación, el material construido y la preparación de los distintos actores para liderar el proceso de evaluación internacional.

En este sentido, las instituciones de educación en especial las de básica secundaria deben diseñar modelos que permitan mejorar las experiencias formativas para el desarrollo de

\footnotetext{
${ }^{1}$ Capacidad de una persona de examinar asuntos globales e interculturales, para tomar múltiples perspectivas bajo un respeto compartido por los Derechos Humanos, para participar en interacciones abiertas apropiadas y efectivas con personas de diferentes culturas y para actuar en pro del bienestar colectivo y del desarrollo sostenible. (OCDE, 2016)
} 
capacidades en estudiantes para comprender su posición en la comunidad y el impacto de las acciones en el mundo. Es decir, formar a individuos para pensar interculturalmente desde su contexto de actuación.

Para ello es fundamental, como lo indicó la UNESCO (2014), la innovación educativa como un acto deliberado y planificado de solución de problemas direccionado a lograr mayor calidad en los aprendizajes superando el paradigma tradicional. Construyendo conocimiento conjunto a partir de la interacción social.

Las tensiones geopolíticas promueven en las instituciones educativas mayor generación de experiencias innovadoras para apoyar el cambio educativo y avanzar en la calidad de la educación contribuyendo con las metas nacionales y globales.

Los anteriores factores motivan un proceso de investigación que pretende encontrar respuestas sobre la articulación del currículo en los contextos de vida mediados por procesos de innovación para desarrollar competencias que contribuyan con la solución de problemas del micro y macroentorno.

En este sentido identificamos una serie de variables de orden global, regional y local que configuraron un modelo de coordenadas curriculares que permitió el desarrollo de la competencia global en estudiantes de básica secundaria.

Es así como en el capítulo 1 "Contexto de la Investigación” configuramos la base de fundamentación para el planteamiento del problema. En él identificamos los desafíos a nivel global y local en términos de desarrollo humano, dignidad, justicia social, inclusión, protección, diversidad cultural, lingüística y étnica. Factores que brindaron luz para el planteamiento de la hipótesis.

En el capítulo 2 "Estado del Arte" analizamos 127 publicaciones para identificar tendencias investigativas que incluyeran técnicas, métodos y/o modelos innovadores para el diseño curricular en básica secundaria. Los hallazgos determinaron que el "currículo" es un concepto en constante evolución que requiere de agentes dinamizadores para que la articulación a los contextos de vida sea significante. Adicional a ello, identificamos en el material analizado que no hay publicaciones que integren los ideales promulgados por la Organización de 
Naciones Unidas (ONU) en relación con los Objetivos de Desarrollo Sostenible (ODS) 2015 - 2030 de la gestión curricular para básica secundaria.

Con los hallazgos anteriores procedimos en el capítulo 3 "Marco Teórico Referencial” a realizar un análisis bibliográfico a las categorías: Teorías curriculares, competencias, desarrollo humano, áreas de conocimiento e innovación. Con relación a las teorías curriculares identificamos la gran polisemia conceptual y la necesidad de concebir el currículo desde dinámicas más horizontales y participativas. Para el caso de las competencias identificamos que para la básica secundaria en Colombia se requiere de aproximaciones pedagógicas para el dominio de destrezas relacionadas con resolución de problemas a partir de dinámicas innovadoras que aborden la competencia global desde las diferentes áreas de conocimiento.

En el análisis bibliográfico sobre el desarrollo humano identificamos una nueva dimensión con enfoque colectivo configurada por tres nuevas categorías: (i) empoderamiento, (ii) vulnerabilidad y sostenibilidad y (iii) desigualdad con relación a la definición del Desarrollo Humano del PNUD² (2010) vs PNUD (1990).

Con relación a las áreas de conocimiento identificamos las políticas globales desde la UNESCO para promocionar los ODS en cuanto al logro de la adopción de estilos de vida sostenibles, igualdad entre los géneros, ciudadanía mundial y la contribución de la cultura de desarrollo sostenible, entre otros medios que forman parte del desarrollo humano.

Para el cierre del marco teórico analizamos la categoría de Innovación en educación. En esta categoría identificamos la necesidad de integrar el uso de métodos, metodologías, técnicas y herramientas de soporte para definir un currículo mediado por procesos de innovación en el planteamiento y resolución de situaciones escolares a partir de problemáticas localesglobales desde un marco colaborativo para garantizar un desarrollo educativo, social y económico sustentable con miras a la formación en conocimientos útiles para la vida de estudiantes de básica secundaria.

En el capítulo 4 "Propuesta" definimos el soporte teórico del Modelo de Coordenadas Curriculares compuesto por tres dimensiones. (i) Dimensión Estratégica: identifica la ruta

${ }^{2}$ Plan de Naciones Unidas para el Desarrollo. 
metodológica para la planificación de los ejes de origen académico. (ii) Dimensión Operativa: define el plan de acción para cada coordenada y (iii) Dimensión Evaluativa: permite conocer el impacto y sistema de seguimiento a las situaciones escolares.

En el capítulo 5 "Validación" sometimos a experimentación el "Modelo de Coordenadas Curriculares" en la Institución Educativa Monseñor Francisco Cristóbal Toro de Medellín en los grupos 9.1 y 9.2 , tal como lo señala cada una de las dimensiones planteadas por el modelo. Los instrumentos utilizados para la elaboración de la prueba pretest y postest fueron tomados de la guía de orientación PISA 2018 para la competencia global en Colombia (PISA Programa Internacional para la Evaluación de Estudiantes). La prueba de hipótesis realizada mediante el test de Wilcoxon determinó que el modelo de coordenadas curriculares contribuyó con el mejoramiento en el desempeño de la competencia global.

Finalizamos la tesis con en el capítulo 6 "Conclusiones y trabajos futuros" definiendo cuatro categorías de análisis con base en los objetivos, hipótesis, limitantes y trabajos futuros. De este modo el modelo de coordenadas curriculares surge como un instrumento que identifica las actuales variables de gobernanza mundial para el desarrollo humano sostenible producto de los nuevos desafíos de la educación. 


\section{VARIABLES PARA EL DISEÑO Y ACTUALIZACIÓN CURRICULAR PARA LA SOLUCIÓN DE PROBLEMAS LOCALES-GLOBALES MEDIADOS POR PROCESOS DE INNOVACIÓN EDUCATIVA PARA BÁSICA SECUNDARIA}

\section{CONTEXTO DE LA INVESTIGACIÓN}

\subsection{Fundamentación}

El esfuerzo dedicado al logro de la Educación para Todos (EPT) ha permitido grandes avances. Son varios los retos que quedan por cumplir teniendo en cuenta las tendencias y aspectos socioeconómicos que afectan a la sociedad moderna, globalizada e interconectada, lo que determina desafíos para la educación. Entre estos retos y tendencias, se pueden considerar las fluctuaciones del crecimiento económico, cambios geopolíticos y demográficos, avances tecnológicos, alto consumos de recursos naturales, sumado a unos elevados índices de jóvenes desempleados. Para resolver lo anterior se requiere de un cambio en la calidad de los niveles de conocimientos, habilidades y competencias que se desarrollan en la escuela (UNESCO, 2014).

En el informe de la UNESCO, se citan preocupaciones por temáticas relacionadas con: (i) la injusticia social, (ii) la desigualdad, (iii) la persistencia de los conflictos, (iv) los disturbios sociales, (v) las presiones demográficas, (vi) el cambio climático, (vii) el deterioro ambiental, (viii) la escases de recursos naturales, y (ix) la pérdida de las dimensiones socioculturales (prácticas culturales y las tradiciones y las identidades étnicas y el idioma). Estos tópicos requieren de un cambio educativo por parte de todas las naciones para que los contenidos académicos sean pertinentes. En este sentido el informe expresa que las sociedades que promuevan estrategias en pro de la cultura, el contexto y las necesidades locales serán sociedades eficaces.

Los imperativos en educación posteriores a 2015 deben centrarse, según el mismo informe, en: (i) acceso equitativo desde la primera infancia hasta la enseñanza superior, (ii) educación 
y aprendizaje de calidad multinivel, (iii) equidad (atención a los grupos marginados), (iv) igualdad de género, (v) mejora de conocimientos y competencias para el desarrollo sostenible y (vi) el aprendizaje a lo largo de la vida. En tal sentido, define como objetivo global "Lograr para todos por igual una educación de calidad y un aprendizaje durante toda la vida para 2030” (p. 4).

El informe Situación Educativa de América Latina y el Caribe: Hacia la educación de calidad para todos al 2015 (Poblete, Sepúlveda, Orellana, \& Abarca, 2013), indica que el principal desafío para la educación básica es la deserción de niños y adolescentes en situación de mayor desventaja social; para la educación secundaria retos como: (i) consolidar su expansión, (ii) transformación de procesos internos y organizacionales, (iii) inminentes reformas educativas, (iv) preocupante nivel de lectura y procesos matemáticos, (v) aguda inequidad para los estudiantes más desfavorecidos, (vi) falta de políticas económicas educativas, (vii) falta de concepción y validación de oportunidades de mejoramiento a la luz de los sistemas externos de evaluación, (viii) salarios y condiciones laborales ineficientes, (ix) formación inicial de baja calidad, (x) opciones de desarrollo profesional limitadas, (xi) falta de educación para la ciudadanía (conocimiento cívico), (xii) falta de competencias digitales, y (xiii) debilidad en formación intercultural bilingüe y diversidad; determinan que los principales retos para América Latina y el Caribe, consisten en: (i) consolidar docentes con formación profesional, (ii) formar docentes y retener a los competentes, (iii) hacer del desarrollo profesional una necesidad y una exigencia, (iv) consolidar la educación ciudadana, (v) generar prácticas de enseñanza con nuevas tecnologías, y (vi) promover conceptos de formación intercultural, entre otros.

Para el caso de la educación superior (Poblete et al., 2013), señala la heterogeneidad, altos índices de crecimiento con sesgados favorecimientos a grupos poblacionales, de tal forma que son retos: (i) revertir la inequidad expansiva, (ii) fortalecer la capacidad y producción científica y tecnológica (aspecto con gran retraso regional) y (iii) mayor sinergia con la sociedad para el favorecimiento a todo nivel. Países como Costa Rica, México, Chile, Argentina, Brasil y Cuba son ejemplo en la región en términos de avance en cuanto a calidad de sistemas educativos. 
Según el Programa Internacional para la Evaluación de Estudiantes (PISA) (OCDE, 2016) Colombia mejoró levemente en los resultados de las pruebas con respecto a años anteriores en ciencias, matemáticas y lectura, ocupando el puesto 57, 61 y 54 respectivamente entre 72 países. Para el país es un resultado que alienta y motiva a seguir en la construcción de políticas que contribuyan con la mejora en: (i) Calidad docente, (ii) remuneración a educadores, (iii) indicadores de pertinencia, (iv) índices de acreditación, (v) presupuestos territoriales para educación, (vi) alfabetismo digital y (vii) nivel de conocimiento en inglés. Por su parte el Ministerio de Educación Nacional (en adelante MEN) centra sus esfuerzos a 2030 en "tener educación secundaria universal, bajar la tasa de analfabetismo a cero y todos los niños de 7 a 17 años deben estar en una institución escolar y deben cursar el grado que corresponde a su edad" (Colombia Aprende (MEN), 2015).

Para el caso de Medellín, ( Vicealcaldía de Educación, Cultura, Participación, Recreación y Deporte, 2015) los indicadores de educación relacionados con la eficiencia interna del sector educativo indican que la tasa de deserción equivale al 3,11\% (2013), la tasa de repitencia en media y secundaria 1\% y 2,7\% respectivamente para el periodo 2012-2015, reprobación $12,02 \%$, aprobación $87,98 \%$ (aprobación en la media de 90,69\% y de extra edad en el sector oficial de 5,57\%); en cuanto a los indicadores de calidad de grado $3^{\circ}, 5^{\circ}$ y $9^{\circ}$ para el área de matemáticas no se avizoran resultados satisfactorios; En el año 2014, comparada con el agregado nacional, Medellín presenta mayores porcentajes de estudiantes en niveles satisfactorio y avanzado en la mayoría de las áreas y grados, exceptuando matemáticas de $5^{\circ}$.

Al analizar otras ciudades del país, Medellín tiene menores niveles de desempeño que Bogotá, Bucaramanga y Manizales en todas las áreas y grados, así mismo frente al promedio nacional en las pruebas Saber 11, tanto en el área de lenguaje como en la de matemáticas, Medellín posee resultados menores que los de Bogotá y Bucaramanga; Con respecto a los resultados por niveles de desempeño, en matemáticas la ciudad tiene el $67 \%$ de sus estudiantes en nivel insuficiente (nivel menor que 2), y entre 2009 y 2012 no se presentaron variaciones en este nivel. No obstante, entre 2009 y 2012 en matemáticas se registra una mejora de dos puntos porcentuales en el porcentaje de estudiantes que tienen niveles superiores a 2 (de 12\% ascendió a 14\%) y una disminución en la misma proporción en el porcentaje de estudiantes en nivel 2 (pasó de 21\% a 19\%), en el periodo 2012-2017 el 
conjunto de instituciones educativas de Medellín tanto oficiales como no oficiales presentaron leve mejoría en los resultados de las pruebas saber aumentando 7 puntos, se pasó de 265 a 272 puntos, el 81,7\% de colegios oficiales mejoraron su puntaje global, cifras alentadoras pero siguen siendo bajas ( Medellín cómo vamos, 2018).

Entre tanto, el MEN a través de la Ley General de Educación (Ley 115 de 1994), los Estándares Básicos de Competencia (EBC) y en la actualidad lo que se conoce como Derechos Básicos de Aprendizajes para la Educación Básica y Media (DBA) además de la Ley 30 de 1992 para las Instituciones de Educación Superior, decreto 2566 de 2003, Ley 1188 de 2008 y la Ley 742 de 2002, establecen los derechos, definen el carácter y autonomía e indican las condiciones de calidad educativa, cuyo alcance comprende, entre otros, introducir las asignaturas optativas, adoptar métodos de enseñanza y determinar el plan de estudios por nivel. Son las instituciones educativas quienes deben definir y estructurar los currículos de competencias acordes con las necesidades del entorno.

Al respecto, el informe diagnóstico del programa por parte de Secretaria de Educación Expedición Currículo ( Secretaria de Educación Medellín, 2014) realizado a 125 instituciones educativas de básica primaria y secundaria en Medellín entre los años 2009 y 2011, identificaron entre otros aspectos, no conformidades en: (i) falta de evidencia de los actos administrativos para la adopción de los planes de estudio, (ii) faltas de cumplimiento a las normas técnicas curriculares con relación a los estándares y lineamientos, (iii) fallas en las políticas administrativas y logísticas para la unificación de criterios en términos de elaboración, evaluación y seguimiento de los planes de área, (iv) falta de transversalidad de los planes de estudio de los proyectos obligatorios definidos en la ley 115, (v) falta de adecuaciones para la flexibilización curricular para estudiantes con necesidades educativas especiales y (vi) falta de fundamentos normativos, pedagógicos, didácticos y disciplinares por área.

La educación por competencias plantea diferentes cuestionamientos, entre ellos describe que los estándares de competencia motivan el aprendizaje individual y grupal, pero también lo condicionan, limitan e incluso puede llegar a desalentarlo. Situaciones como la estandarización de la evaluación no indica necesariamente dar cumplimiento a criterios de 
competencia y generan confusión en múltiples escenarios entre las competencias laborales y educativas, lo que ocasiona ampliar la brecha educativa (Coles, 2007, 20) citado por (Climent, 2010). La misma propuesta del Marco Europeo advierte alcanzar niveles de dominio de las competencias de una destreza avanzada o básica para resolver un problema en una situación o contexto determinado, puede no ser suficiente en otra (País Vasco, 2010) Así mismo advierte, en su publicación de las Competencias Básicas en el Sistema Educativo de la Comunidad Autónoma País Vasco, El aprender "sobre algo" supone atender a dimensiones relativas al "saber" (hechos, conceptos, principios), "saber hacer" (procedimientos, habilidades, destrezas) y "saber ser" (actitudes, motivación, disponibilidad) omitiendo la cuarta dimensión "Saber vivir".

En el sistema educativo colombiano, los lineamientos curriculares señalan que los estándares básicos de competencia plantean el qué y no el cómo, por lo que cada institución adquiere sentido y permite tener en cuenta las diferencias de los diversos contextos de cada institución (MEN-Estándares Básicos de competencia, 2006)

Con relación a lo anterior, se cree necesario profundizar en estudios que permitan fortalecer los mecanismos que promuevan, orienten y validen la innovación en la educación basada por competencias, de forma ágil, participativa e incluyente en las instituciones educativas. Si bien la autonomía genera algún tipo de libertad se hace necesario dotar a los docentes de herramientas teóricas que faciliten el diseño y actualización de los contenidos curriculares.

En este cuadro descriptivo se enmarca este proyecto de investigación curricular.

\subsection{Formulación del Problema}

De acuerdo con la nueva agenda educativa para el año 2030 proclamada por la ONU cuyos pilares surgen de los progresos en la consecución de las metas establecidas en el programa de EPT (Educación Para Todos) y los ODS (Objetivos de Desarrollo Sostenible), se planteó una nueva visión en educación plasmada en el objetivo 4 que indica "Garantizar una educación inclusiva y equitativa de calidad y promover oportunidades de aprendizaje permanente para todos" (UNESCO, 2015). 
Este objetivo genera desafíos a nivel educativo de carácter mundial y nacional en términos del desarrollo humano, dignidad, justicia social, inclusión, protección, diversidad cultural, lingüística y étnica.

En tal sentido, las instituciones educativas juegan un papel fundamental para encontrar solución a los retos que plantea la actual sociedad del conocimiento. Uno de ellos, es el concepto de calidad de la educación en el marco de los nuevos paradigmas, lo que determina ¿cuáles son los fines de la educación? ¿Qué tipo de planes y programas se deben enseñar? y ¿Qué formación deben tener los profesionales de la educación? entre otros.

Esta propuesta de investigación centra su interés en el currículo, asumido como uno de los factores que determinan educación de calidad.

En coincidencia con Müller, (1985) sostenemos que "la educación no constituye un fenómeno neutro" por lo que el currículo se torna participativo, dinámico, crítico, creativo, investigativo, actual, innovador y significante. En este marco nos preguntamos, ¿Qué tipo de características debe contener un currículo para que se denomine innovador bajo los nuevos parámetros de la modernidad?, ¿cómo se definen las competencias para educar con calidad? ¿Qué tipo de metodologías, técnicas y herramientas se deben utilizar para crear los contenidos curriculares con los diferentes actores del entorno?

En especial nuestro interés radica en pensar ¿Cómo articular el currículo a los contextos de vida a través de procesos de innovación para el desarrollo de competencias en estudiantes de básica secundaria en orden a lograr que contribuyan a la solución de los problemas locales y globales? 


\subsection{Objetivos de Investigación:}

\section{Objetivo General:}

Determinar las variables de un modelo de gestión curricular que permita la actualización de currículos mediados por procesos de innovación educativa para el desarrollo de la competencia global en estudiantes de básica secundaria que contribuyan a la solución de los problemas locales y globales.

\section{Objetivos Específicos.}

- Identificar el alcance de los requisitos normativos, en términos académicos, aplicables para las instituciones educativas de básica secundaría

- Analizar los criterios que definen la innovación en los procesos de educación.

- Distinguir los factores que conforman la innovación en educación en los procesos de co-creación curricular.

- Categorizar los principios de funcionamiento de un modelo de gestión curricular creado ad hoc.

\subsection{Hipótesis}

De acuerdo con las preguntas de investigación se determina como hipótesis:

Los procesos de innovación en educación aplicados para la elaboración del diseño curricular mediante el "modelo de coordenadas curriculares" ${ }^{3}$, mejoran el desarrollo de la competencia global para la resolución de los problemas locales y globales en los estudiantes de básica secundaria.

\footnotetext{
${ }^{3}$ Modelo de Coordenadas curriculares contiene los siguientes componentes: Bienestar (para el Desarrollo Humano), Competencia global y Área de conocimiento. Se relacionan entre si formando un hipotético cubo como muestra la figura.
} 


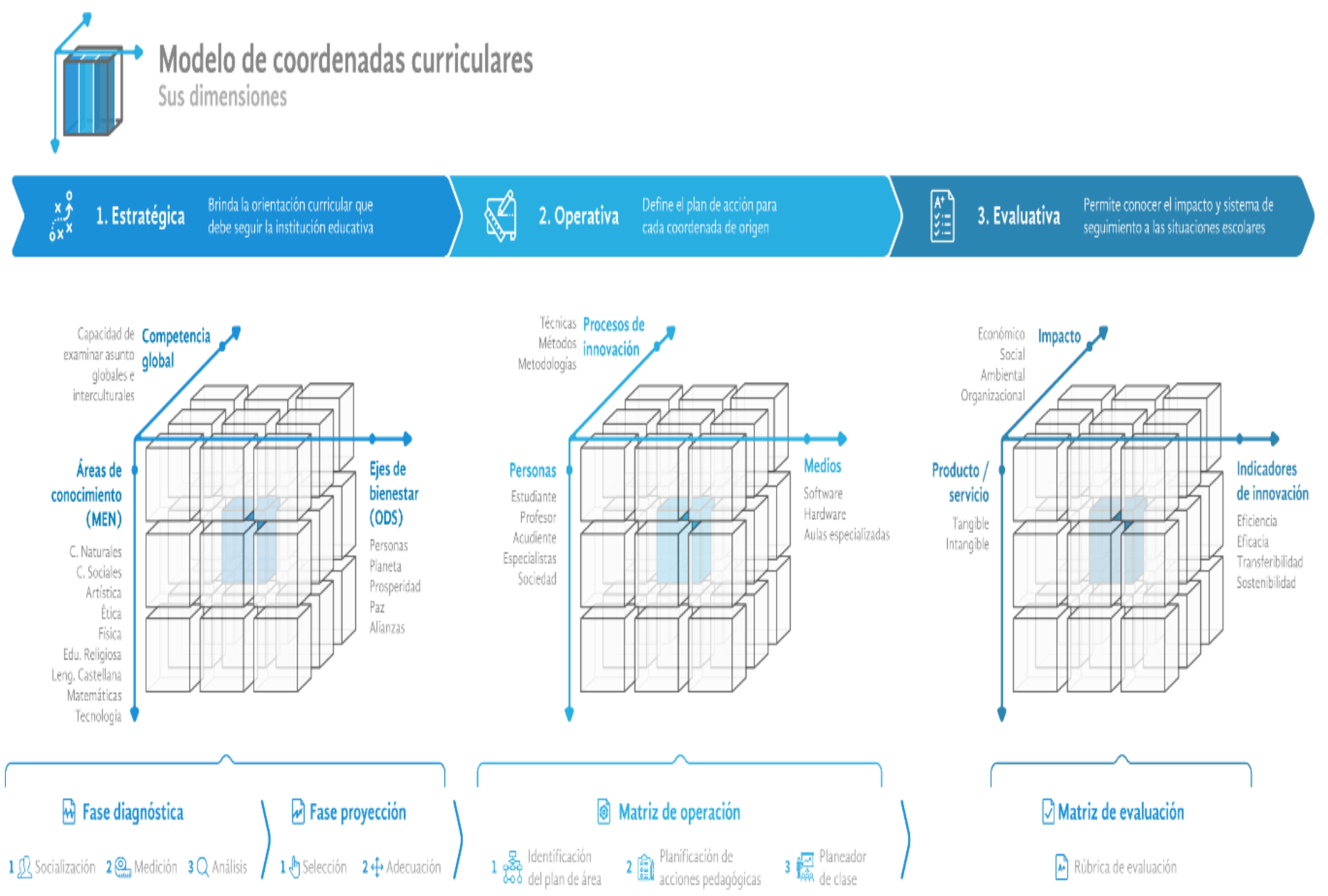

Ilustración 1: Modelo de coordenadas curriculares Fuente: Autor 


\subsection{Diseño Metodológico}

El desarrollo investigativo se asume desde un Enfoque Mixto, en el que se utilizan técnicas cuantitativas y cualitativas debido a la integración de procesos sistemáticos, empíricos y críticos de investigación que implica la recolección y el análisis de datos bajo los dos enfoques (Hernández \& Mendoza, 2008) citados por (Hernández, Fernández \& Baptista, 2014), es así, como los métodos mixtos logran obtener una mayor variedad de perspectivas del fenómeno: frecuencia, amplitud y magnitud (cuantitativa), así como profundidad y complejidad (cualitativa); generalización (cuantitativa) y comprensión (cualitativa). la denominada: "riqueza interpretativa" por la diversidad de fuentes y tipos de datos contextos y ambientes, además de permitir una mayor "exploración y explotación” de los datos (Todd, Nerlich y McKeown, 2004) citado por (Hernandez, et al, 2014)

El Alcance de investigación es de carácter Exploratorio debido a la naturaleza de la observación del fenómeno (Hernandez, et al, 2014), aunque el tema ha sido investigado desde diferentes ópticas, la propuesta de un "modelo de coordenadas curriculares" de tres ejes que integre competencia global, capacidades humanas y áreas de conocimiento es un tema poco explorado, situación identificada a través del rastreo bibliográfico.

A su vez, la ejecución del diseño será secuencial, de acuerdo con (Creswell, 2013) citado por (Hernandez, et al, 2014), en una primera etapa se recolectan y analizan datos cuantitativos o cualitativos, y en una segunda fase se recaban y analizan datos del otro método (para el particular inicia cualitativa y finaliza cuantitativa); con la intención de explorar el planteamiento con un grupo experimental y posteriormente replicar el problema en una muestra mayor para determinar generalizaciones del fenómeno. Así mismo, Chen (2006) citado por (Hernandez, et al, 2014), señala que estos métodos corresponden a "evaluaciones guiadas por teoría", las cuales se pueden abordar desde dos estrategias: i) cambio de estrategia (aplicación de métodos cualitativos para "iluminar" y producir teoría fundamentada y métodos cualitativos para "aquitarla") y ii) Estrategia contextual "revestida" (aproximación cualitativa del contexto para luego mediante métodos cuantitativos "reconciliar" los descubrimientos); En tal sentido, el diseño corresponderá al transformativo 
secuencial, en este diseño se pueden incluir diversos abordajes metodológicos e involucrar a profundidad a los participantes (Creswell, 2009) citado por (Hernandez, et al, 2014).

\subsection{Estructura del Informe}

El desarrollo de las fases metodológicas se ilustra en cada uno de los capítulos que se describen en la tabla 1 .

Tabla 1: Estructura del informe

\begin{tabular}{|c|c|}
\hline Capítulos & Temáticas \\
\hline $\begin{array}{l}\text { Capítulo 1: Contexto de la } \\
\text { investigación }\end{array}$ & $\begin{array}{ll}\text { - } & \text { Fundamentación } \\
\text { - } & \text { Formulación del problema } \\
\text { - } & \text { Objetivos } \\
\text { - } & \text { Hipótesis } \\
\text { - } & \text { Diseño Metodológico } \\
\text { - } & \text { Estructura del informe } \\
\text { - } & \text { Aspectos Éticos } \\
\end{array}$ \\
\hline Capítulo 2: Revisión de la Literatura & $\begin{array}{l}\text { - Categorías de análisis } \\
\text { - Prospectivas para la gestión curricular }\end{array}$ \\
\hline Capítulo 3: Marco Teórico & $\begin{array}{ll}\text { - } & \text { Teorías curriculares } \\
\text { - } & \text { Competencias } \\
\text { - } & \text { Desarrollo humano } \\
\text { - Áreas de conocimiento } \\
\text { - Innovación } \\
\text { - Integración de variables }\end{array}$ \\
\hline Capítulo 4: Propuesta & $\begin{array}{l}\text { - Dimensión Estratégica } \\
\text { - Dimensión operativa } \\
\text { - Dimensión Evaluativa }\end{array}$ \\
\hline Capítulo 5: Validación & $\begin{array}{l}\text { - } \text { Tipo de investigación } \\
\text { - Población y muestra } \\
\text { - Fuentes de información e instrumentos } \\
\text { - Tiempos de duración del experimento } \\
\text { - Confiablidad y validez del experimento } \\
\text { - Intervención institucional } \\
\text { - Análisis de la intervención }\end{array}$ \\
\hline $\begin{array}{l}\text { Capítulo 6: Conclusiones y trabajos } \\
\text { futuros }\end{array}$ & $\begin{array}{ll}\text { - } & \text { Logros Vs. Objetivos } \\
\text { - } & \text { Recomendaciones } \\
\text { - } & \text { Líneas de investigación futuras } \\
\text { - } & \text { Limitaciones de investigación } \\
\end{array}$ \\
\hline
\end{tabular}

Fuente: Autor 
Cada capítulo de investigación da cuenta del proceso llevado a cabo para identificar el problema, analizar los referentes teóricos e investigativos, formular y validar la propuesta para emitir unas conclusiones que permiten abrir nuevas líneas de investigación.

\subsection{Aspectos Éticos}

El desarrollo de la propuesta de investigación respeta los lineamientos contemplados por la constitución política colombiana en su artículo 61, la ley 23 de 1982 y la ley 44 de 1993, los cuales definen los alcances de los derechos de autor y la propiedad intelectual; también son considerados los tratados internacionales como: El convenio de Berna" para la protección de las obras literarias y artísticas" y el tratado de la OMPI referidos a los derechos de autor; se aclara que la información tomada y divulgada a partir de la propuesta, respeta la propiedad intelectual de aquellos que han trabajado previamente en el tema, realizando la adecuada citación de acuerdo con las normas establecidas para tal fin.

En el mismo sentido, se siguieron los procedimientos establecidos en el consentimiento informado, en el que los individuos manifestaron de forma voluntaria su intención de participar de la investigación conociendo los alcances, beneficios y posibles riesgos derivados del estudio, al igual que la libertad de retirarse del mismo cuando lo consideren necesario, conservando los principios de competencia, voluntad, información completa y la comprensión de todas las variables de estudio (Cohen, Manion \& Morrison, 2007).

Cabe resaltar que la investigación se realiza con fines académicos, por tanto, su utilización como soporte teórico para nuevas propuestas es permitida. 


\section{CAPÍTULO 2}

ESTADO DEL ARTE 


\section{ESTADO DEL ARTE}

La revisión de la literatura propuesto busca dar cuenta de la construcción con sentido a partir de la investigación documental. En este sentido, el análisis se subdivide en categorías que permiten develar interpretaciones que originan una postura teórica sobre el estado de la situación.

Para ello, el análisis bibliográfico se abordó desde un enfoque Cualitativo, como lo expresa (Hernández, Baptista \& Collao, 2015) citando a (Esterberg, 2002). ${ }^{4}$ Se buscó identificar las tendencias investigativas que incluyen técnicas, métodos y/o modelos innovadores que definen el diseño curricular para mejorar el desarrollo de competencias en estudiantes de básica secundaria. Para ello se establecieron categorías y subcategorías en el análisis:

Categoría 1: Definición y búsqueda de palabras claves.

Categoría 2: Identificación de artículos con enfoque reflexivo.

Categoría 3: Análisis de artículos para currículos disciplinares.

Categoría 4: Análisis de artículos con enfoque en la gestión curricular

- Subcategoría Gestión curricular para Educación Superior

- Subcategoría Gestión curricular para Educación Básica y Media.

Categoría 5: Evaluación metodológica

${ }^{4}$ Se examinaron los hechos en sí y se desarrolló una teoría coherente para representar lo que se observó. Se realizó un análisis inductivo (explorar, describir y luego teorizar) desde lo particular a lo general. Este enfoque cualitativo se basa en métodos de recolección de datos no estandarizados ni predeterminados completamente (Hernández et al). 


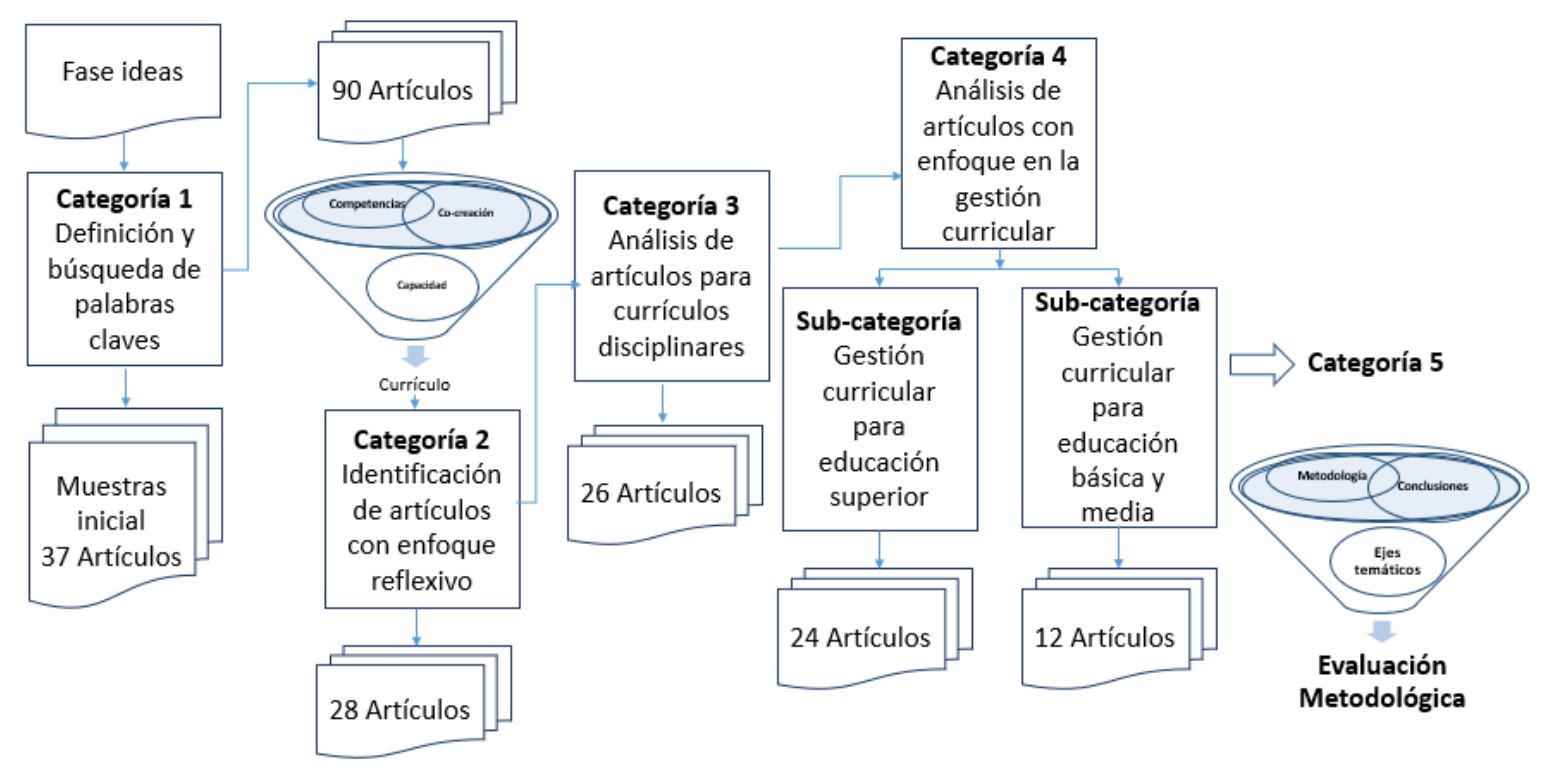

Ilustración 2: Proceso de selección, clasificación y revisión.

Fuente: Autor

2.1. Categoría 1: Definición y búsqueda de palabras claves.

Se consideraron tópicos como: capacidades de desarrollo humano, áreas de conocimiento y competencias específicas, cuyas palabras clave se reagruparon en términos de innovación, co-creación, co-gestión, sociedad del conocimiento, redes de conocimiento, aprendizaje, diseño, calidad de vida, educación, competencias, inteligencia colectiva, metodologías, modelos, capacidades, Objetivos de Desarrollo Sostenible (ODS), capacidades humanas, modelos educativos y framework, dando como resultado un sin número de artículos cuyo contenido, no estaba esencialmente relacionado con la forma de orientar un currículo desde su estructura para que sea innovador.

A continuación, se relacionan los artículos analizados que permitieron dar origen a la definición de las palabras claves:

Tabla 2: Artículos revisión inicial.

\begin{tabular}{|l|l|l|l|l|}
\hline $\mathbf{N}^{\mathbf{0}}$ & \multicolumn{1}{|c|}{ Título } & Base de Datos /Revista & Año & Autor(es) \\
\hline 1 & $\begin{array}{l}\text { Desarrollo de competencias específicas en la } \\
\text { materia tecnología educativa bajo el marco } \\
\text { del Espacio Europeo de Educación }\end{array}$ & $\begin{array}{l}\text { Revista latinoamericana de tecnología } \\
\text { educativa }\end{array}$ & 2004 & Raquel Barragán Sánchez \\
\hline 2 & $\begin{array}{l}\text { Competencia Laboral. Manual de conceptos } \\
\text { y aplicaciones de zen el sector salud. }\end{array}$ & Cinterfor/OIT & 2004 & OIT \\
\hline 3 & $\begin{array}{l}\text { El enfoque de las capacidades de M. } \\
\text { Nussbaum: un análisis comparado con } \\
\text { nuestra teoría de las necesidades Humanas. }\end{array}$ & $\begin{array}{l}\text { Dialnet } \\
\text { Revista: Papeles de relaciones } \\
\text { ecosociales y cambio Global }\end{array}$ \\
\hline
\end{tabular}




\begin{tabular}{|c|c|c|c|c|}
\hline 4 & $\begin{array}{l}\text { Innovación, tecnología y prácticas sociales } \\
\text { en las ciudades: hacia los laboratorios } \\
\text { vivientes. }\end{array}$ & $\begin{array}{l}\text { Redalyc } \\
\text { Revista Iberoamericana de ciencia, } \\
\text { tecnología y sociedad }\end{array}$ & 2007 & Susana Finquelievich. \\
\hline 5 & $\begin{array}{l}\text { El enfoque de competencias en la educación. } \\
\text { ¿Una alternativa o un disfraz de cambio? }\end{array}$ & Revista Unimar & 2008 & Ángel Díaz Barriga \\
\hline 6 & $\begin{array}{l}\text { Las competencias básicas: el nuevo } \\
\text { paradigma curricular en Europa. }\end{array}$ & Foro de Educación & 2010 & Luis Toribio Briñas \\
\hline 7 & $\begin{array}{l}\text { Reflexiones sobre la Educación Basada en } \\
\text { Competencias. }\end{array}$ & Revista Complutense de Educación & 2010 & Juan BaustistaCliment Bonilla \\
\hline 8 & $\begin{array}{l}\text { Un modelo causal de competitividad } \\
\text { empresarial planteado desde la VBR: } \\
\text { capacidades directivas, de innovación, } \\
\text { marketing y calidad }\end{array}$ & ScienceDirect. & 2010 & $\begin{array}{l}\text { Martínez Santa María, R. } \\
\text { CharterinaAbando, J. } \\
\text { Araujo de la Mata, A. }\end{array}$ \\
\hline 9 & $\begin{array}{l}\text { Reflexiones desde los procesos de co-gestión } \\
\text { de los Objetivos de Desarrollo del Milenio } \\
\text { en la localidad de Suba (Bogotá, Colombia) }\end{array}$ & $\begin{array}{l}\text { Revista Universidad Nacional de } \\
\text { Colombia } \\
\text { BDigital Portal de revistan UN }\end{array}$ & 2010 & Ruth Miriam Moreno Aguilar \\
\hline 10 & $\begin{array}{l}\text { Propuesta de modelo de gestión por } \\
\text { competencias para mejorar la productividad } \\
\text { de las empresas en Antioquia. }\end{array}$ & Repositorios Universidad de Medellín & 2010 & $\begin{array}{l}\text { Oscar M. Londoño M., } \\
\text { Robert Henao, } \\
\text { Juan Santiago Posada Toro. }\end{array}$ \\
\hline 11 & $\begin{array}{l}\text { Aplicación de la Lógica Dominante del } \\
\text { servicio (LDS) en el sector turístico: el } \\
\text { marketing interno como antecedente de la } \\
\text { cultura de co-creación de innovaciones con } \\
\text { clientes y empleados. }\end{array}$ & Cuadernos de Gestión & 2010 & $\begin{array}{l}\text { Nuria García Rodríguez, Begoña } \\
\text { Álvarez Álvarez, M. }{ }^{a} \text { Leticia Santos } \\
\text { Vijande }\end{array}$ \\
\hline 12 & $\begin{array}{l}\text { La innovación centrada en el cliente } \\
\text { utilizando el modelo de inferencias en una } \\
\text { estrategia CRM. }\end{array}$ & $\begin{array}{l}\text { Investigaciones Europeas de Dirección y } \\
\text { Economía de la Empresa }\end{array}$ & 2011 & $\begin{array}{l}\text { Anna Gil Lafuente, Carolina Luis } \\
\text { Bassa }\end{array}$ \\
\hline 13 & $\begin{array}{l}\text { Organizaciones, niveles y territorio en la } \\
\text { perspectiva de un modelo de gestión de los } \\
\text { sistemas regionales de ciencia, tecnología e } \\
\text { innovación. }\end{array}$ & $\begin{array}{l}\text { ProQuest } \\
\text { Tecnología E Innovación }\end{array}$ & 2012 & $\begin{array}{l}\text { José Ramiro Bertieri Quintero, Joan } \\
\text { Manuel VillamarínMarentes, Fabiola } \\
\text { Sáenz Blanco }\end{array}$ \\
\hline 14 & $\begin{array}{l}\text { Diseño de un sistema difuso para valoración } \\
\text { de aportes en sistemas colaborativos. }\end{array}$ & $\begin{array}{l}\text { Scielo } \\
\text { Revista ingenierías Universidad de } \\
\text { Medellín. }\end{array}$ & 2012 & $\begin{array}{l}\text { Jaime Echeverri, Miguel Aristizábal, } \\
\text { Francisco Moreno, } \\
\text { Alejandra Bedoya. }\end{array}$ \\
\hline 15 & $\begin{array}{l}\text { ExperienceQuality Management (EQM): la } \\
\text { administración de experiencias de calidad } \\
\text { con la co-creación de valor en la industria } \\
\text { manufacturera automotriz, en ciudad Juárez, } \\
\text { Chihuahua. }\end{array}$ & $\begin{array}{l}\text { Revista internacional Administracion\& } \\
\text { Finanzas }\end{array}$ & 2012 & $\begin{array}{l}\text { Francisco Bribiescas Silva, Ignacio } \\
\text { Francisco Romero Magaña, Francisco } \\
\text { Manuel Solórzano Chavira }\end{array}$ \\
\hline 16 & Pedagogía de la interactividad. & $\begin{array}{l}\text { Comunicar } \\
\text { Revista Científica Iberoamericana }\end{array}$ & 2012 & $\begin{array}{l}\text { Roberto Aparicio } \\
\text { Marco Silva }\end{array}$ \\
\hline 17 & $\begin{array}{l}\text { Implementación del sistema de gestión por } \\
\text { competencias para la Uniagustiniana. }\end{array}$ & Revista Suma de Negocios & 2012 & $\begin{array}{l}\text { Julián Ávila } \\
\text { Francy Bedoya }\end{array}$ \\
\hline 18 & $\begin{array}{l}\text { Métodos y técnicas facilitadoras de la co- } \\
\text { creationinnovation en programas máster para } \\
\text { el mercado del postgrado. }\end{array}$ & $\begin{array}{l}\text { OmniaScienceJournals } \\
\text { Capital Intangible }\end{array}$ & 2013 & $\begin{array}{l}\text { Gabriela Ribes Giner } \\
\text { Agustín PeraltRillo. }\end{array}$ \\
\hline 19 & $\begin{array}{l}\text { Modelo formativo en el Espacio Europeo de } \\
\text { Educación Superior: valoraciones de los } \\
\text { estudiantes. }\end{array}$ & ScienceDirect. & 2014 & Rosa M. Rodríguez Izquierdo. \\
\hline 20 & La teoría de las capacidades en AmartyaSen. & $\begin{array}{l}\text { DIALNET } \\
\text { Edetania. }\end{array}$ & 2014 & Martín J. Urquijo Angarita. \\
\hline 21 & $\begin{array}{l}\text { Diseño y desarrollo de servicios: una nueva } \\
\text { perspectiva desde el ciclo de vida. }\end{array}$ & Interciencia & 2014 & $\begin{array}{l}\text { Carmen Berdugo Correa } \\
\text { Óscar Oviedo } \\
\text { Rita Peñabaena } \\
\text { Carmenza Luna } \\
\text { Wilson Nieto }\end{array}$ \\
\hline 22 & $\begin{array}{l}\text { Análisis de las Relaciones de Co-creación de } \\
\text { valor. Un estudio de casos de crowdfunding }\end{array}$ & $\begin{array}{l}\text { Redalyc } \\
\text { Universia Business }\end{array}$ & 2014 & $\begin{array}{l}\text { María José Quero, } \\
\text { Rafael Ventura. }\end{array}$ \\
\hline 23 & $\begin{array}{l}\text { Las redes de conocimiento como escenarios } \\
\text { para la gestión de conocimiento. Estudio de } \\
\text { caso REDCO. }\end{array}$ & $\begin{array}{l}\text { En1@ce: Revista Venezolana de } \\
\text { Información de, Tecnología y } \\
\text { Conocimiento. }\end{array}$ & 2014 & $\begin{array}{l}\text { Juan Pérez Arias, } \\
\text { Eugenia Ramírez I., } \\
\text { José E. Aedo. }\end{array}$ \\
\hline 24 & $\begin{array}{l}\text { Las redes sociales como factor potenciador } \\
\text { de la co-creación: un experimento en la } \\
\text { Universidad De Medellín. }\end{array}$ & $\begin{array}{l}\text { DIALNET } \\
\text { Revista: Quid: Investigación, ciencia y } \\
\text { tecnología }\end{array}$ & 2014 & $\begin{array}{l}\text { Liliana González, Mauricio González, } \\
\text { Jaime Echeverri, Juan Carlos Herrera }\end{array}$ \\
\hline 25 & $\begin{array}{l}\text { ARG (Alternate Reality Games). } \\
\text { Contributions, Limitations, and Potentialities }\end{array}$ & $\begin{array}{l}\text { DIALNET } \\
\text { Revista: Comunicar } \\
\text { Media EducationResearchJournal. } \\
\end{array}$ & 2015 & $\begin{array}{l}\text { Teresa Piñeiro-Otero, Carmen Costa- } \\
\text { Sánchez. }\end{array}$ \\
\hline
\end{tabular}




\begin{tabular}{|c|c|c|c|c|}
\hline & $\begin{array}{l}\text { to the Service of the Teaching at the } \\
\text { University Level. }\end{array}$ & & & \\
\hline 26 & $\begin{array}{l}\text { Co-creación como metodología para la } \\
\text { apropiación social de la ciencia y la } \\
\text { tecnología (ASCYT) del recurso agua. } \\
\text { Caso Urabá-Antioqueño- Colombia. }\end{array}$ & Scielo & 2015 & $\begin{array}{l}\text { María del Rosario AtuestaVenega, } \\
\text { Andrés Felipe Ceballos Moncada, } \\
\text { Rodrigo Gómez Alvis. }\end{array}$ \\
\hline 27 & $\begin{array}{l}\text { La capacidad de innovación y su relación } \\
\text { con el emprendimiento en las regiones de } \\
\text { México. }\end{array}$ & ScienceDirect. & 2015 & $\begin{array}{l}\text { Yesenia Sánchez Tovar, Francisco } \\
\text { García Fernández, José Esteban } \\
\text { Mendoza Flores }\end{array}$ \\
\hline 28 & $\begin{array}{l}\text { Diseño universal para el aprendizaje como } \\
\text { metodología docente para atender a la } \\
\text { diversidad en la universidad. }\end{array}$ & ScienceDirect. & 2015 & $\begin{array}{l}\text { Emiliano Díez Villoria, Sergio } \\
\text { Sánchez Fuentes. }\end{array}$ \\
\hline 29 & $\begin{array}{l}\text { Objetivos de Desarrollo Sostenible, } \\
\text { Colombia Herramientas de aproximación al } \\
\text { contexto local. }\end{array}$ & $\begin{array}{l}\text { APC Colombia } \\
\text { Agencia Presidencial de cooperación } \\
\text { Internacional }\end{array}$ & 2015 & $\begin{array}{l}\text { APC Colombia. } \\
\text { Agencia Presidencial de cooperación } \\
\text { Internacional }\end{array}$ \\
\hline 30 & $\begin{array}{l}\text { Descripción de un Framework metodológico } \\
\text { para el desarrollo de aplicaciones } \\
\text { relacionadas con el patrimonio cultural. }\end{array}$ & Lámpsakos & 2014 & $\begin{array}{l}\text { Christian Andrés Díaz León } \\
\text { Edwin Mauricio Hincapié Montoya. }\end{array}$ \\
\hline 31 & $\begin{array}{l}\text { Cocreación: una propuesta para la } \\
\text { recolección, sistematización y análisis de la } \\
\text { información en la investigación cualitativa. }\end{array}$ & $\begin{array}{l}\text { Enl@ce: Revista Venezolana de } \\
\text { Información de, Tecnología y } \\
\text { Conocimiento. }\end{array}$ & 2014 & Rubén Nanclares. \\
\hline 32 & $\begin{array}{l}\text { El proceso de co-creación de valor y su } \\
\text { impacto en la estrategia de innovación en } \\
\text { empresas de servicios }\end{array}$ & $\begin{array}{l}\text { OmniaScienceJournals } \\
\text { Capital Intangible }\end{array}$ & 2014 & $\begin{array}{l}\text { Antonia Ruiz Moreno } \\
\text { Teresa Ortega Egea, } \\
\text { Carmen Haro Domínguez } \\
\text { María Roldán Bravo }\end{array}$ \\
\hline 33 & $\begin{array}{l}\text { Aplicabilidad del Service-DominantLogic al } \\
\text { ámbito sanitario: caracterizando el servicio } \\
\text { para la co-creación de valor. }\end{array}$ & Revista Gerencia y Políticas de Salud & 2015 & $\begin{array}{l}\text { Calero Gimeno Remedios, Gallarza } \\
\text { Granizo Martina }\end{array}$ \\
\hline 34 & $\begin{array}{l}\text { Empleo de Twitter en la docencia } \\
\text { universitaria: hacia un modelo de } \\
\text { aprendizaje basado en la co-creación. }\end{array}$ & $\begin{array}{l}\text { In-Red } 2015 \text { - Congreso Nacional de } \\
\text { Innovación Educativa y Docencia en } \\
\text { Red de la UniversitatPolitècnica de } \\
\text { València. }\end{array}$ & 2015 & $\begin{array}{l}\text { Eva Emmanuel Martínez, Pedro } \\
\text { Manuel Gómez Rodríguez. }\end{array}$ \\
\hline 35 & $\begin{array}{l}\text { La co-creación como estrategia para abordar } \\
\text { la gobernanza de } \mathrm{TI} \text { en una organización }\end{array}$ & $\begin{array}{l}\text { Revista lbérica de Sistemas y } \\
\text { Tecnologías de Información }\end{array}$ & 2015 & $\begin{array}{l}\text { Mauricio González } \\
\text { Liliana González }\end{array}$ \\
\hline 36 & $\begin{array}{l}\text { Creacity, una propuesta de índice para medir } \\
\text { la creatividad turística. Aplicación en tres } \\
\text { destinos urbano- culturales españoles. }\end{array}$ & Revista de estudios regionales & 2015 & $\begin{array}{l}\text { José Antonio García Suárez } \\
\text { Juan Ignacio Pulido Fernández }\end{array}$ \\
\hline 37 & $\begin{array}{l}\text { Diseño y Co-Creación Mediante Aprendizaje } \\
\text { y Servicio en Contexto Vulnerable: Análisis } \\
\text { de Percepción de la Experiencia. }\end{array}$ & Scielo. & 2016 & Juan C. Briede W, Marcela L. Mora. \\
\hline
\end{tabular}

Fuente: Autor

De acuerdo con la tabla 2, solo 3 de los artículos relacionados integran los cuatro componentes de la innovación educativa que incluyen Tecnologías, Procesos, Personas y Conocimiento según (Fidalgo, 2011). El estudio de (Nanclares, 2014) deja en evidencia cómo se realimentan los procesos formativos, considerando aportes y experiencias de los participantes, lo que genera un impacto positivo en el desarrollo del proceso de enseñanza y aprendizaje. Por su parte (Aparicio \& Silva, 2012) indica que en los sistemas educativos se observa cómo mientras la escuela se basa en la reflexión, la acción lenta, el trabajo simultáneo, en grupo y promueve una forma de autoría individual de las producciones y las calificaciones. El nuevo ecosistema comunicativo propone la inmediatez, la aceleración, el shock emocional, la intuición, la interacción rápida, la pantalla individual y una forma de autoría grupal como el trabajo colaborativo. (Bertieri, Villamarín \& Sáenz, 2012) destacan que la obsolescencia de los modelos de gestión de la innovación obedece a las transformaciones sociales, económicas, geopolíticas y tecnológicas derivadas de la llamada "sociedad del conocimiento" e inciden en la capacidad de las organizaciones para gestionar la innovación.

Otro elemento clave para destacar como punto de partida es el componente histórico; (Tobón, 2008) plantea tres enfoques en los diseños curriculares: el enfoque conductista (lineal), 
funcionalista (funcional) y constructivista (desarrollo de competencias); en tal sentido el currículo forma parte de la historia de la humanidad que se modifica conforme cambian las condiciones sociales. ${ }^{5}$

Cazares (2008), destaca que entre 1949 y 1950 Ralph Tyler y Herrick, definieron el esquema curricular con mayor importancia en la educación, incluyendo las destrezas y los valores a conseguir en el que todo currículo debe responder a cuatro aspectos claves (i) ¿Qué objetivos educativos trata de alcanzar la escuela? (ii) ¿Qué experiencias educativas aptas para lograr esos objetivos pueden ser proporcionadas? (iii) ¿Cómo pueden organizarse efectivamente estas experiencias educativas y (iv) ¿Cómo podemos determinar si se alcanzan los objetivos?

Hilda Taba (1974) plantea un modelo estructurado en dos niveles de decisión (i) El diseño de unidades de enseñanza o para una materia concreta y (ii) El diseño de todo el programa o currículum total. Wheeler (1976) plantea cinco fases (i) Planteamiento de fines y posterior concreción de objetivos específicos, (ii) Selección de experiencias de aprendizaje adecuadas para lograr los objetivos, (iii) Selección de contenidos, puesto que toda experiencia implica un contenido entendido por tales conocimientos, conceptos, principios, generalizaciones, técnicas, teorías y procedimientos relacionados con una materia, (iv) Organización e integración de las experiencias y de los contenidos en secuencias, existiendo múltiples fórmulas: entorno a centros de organización, núcleos, unidades para clases, etc. y (v) Evaluación de las operaciones realizadas a la luz de los resultados obtenidos. Otro aspecto fundamental para resaltar es el concepto de competencia, puesto que este modifica la forma de aprender y enseñar debido a que el eje no consiste en la acumulación de conocimientos sino en el desarrollo de las posibilidades que posee un individuo en cuanto a saber y saber hacer en contexto. Rué J. citado por (Tobón, 2008).

Luego del análisis preliminar a través de la revisión de las palabras claves y resumen de los artículos y posterior lectura a profundidad sobre los alcances investigativos, se identifica que para la búsqueda de información se debe partir desde la forma en que se diseñan los currículos para la educación. Cuestionamientos como: qué tipo de componentes son tenidos en cuenta en el diseño curricular, cómo se construyen y verifican los currículos, por qué un currículo es innovador y quiénes lo construyen, establecieron las bases conceptuales para determinar las tendencias investigativas que incluyen técnicas, métodos y/o modelos innovadores para definir el diseño curricular en estudiantes de básica secundaria. En tal sentido el rastreo

\footnotetext{
${ }^{5}$ En este sentido destaca (Hamilton y Gibbons, citado por Kemmis, 1988) la necesidad de crear currículos para la formación para predicadores esclavistas. Durante la edad media se hace notoria la necesidad de currículos para grandes cambios en los sistemas de enseñanza. En el siglo XVI, los currículos deben cumplir con la necesidad de desempeñar las tareas administrativas definidas por las monarquías. En el siglo XVII y XVIII, fueron diseñados para cumplir con los retos funcionales que trajeron consigo los descubrimientos geográficos, científicos y nuevas tendencias socio-religiosas. En el siglo XIX, corresponden a los desafíos frente a los nuevos estados nacionales propios de la revolución industrial. Durante el siglo XX, se basa en el pragmatismo en el que el conocimiento debe centrarse a partir de las necesidades de la vida social y según (Lundgren, 1992), predominan en la actualidad el currículo invisible determinado por la tecnología educativa.
} 
bibliográfico se reenfoca en palabras como: microcurrículo, diseño curricular, innovación curricular y gestión curricular.

\subsection{Categoría 2: Artículos con enfoque reflexivo.}

Definidas las palabras claves: micro-currículo, diseño curricular, innovación curricular, gestión curricular y ODS educación, se procede nuevamente a buscar artículos en las bases de datos públicas y privadas (EBSCO, ProQuest, ScienceDirect, SCOPUS, Scielo, Universidad de Antioquia, Fuente Académica Premier, Dialnet y EducationSource).

Luego de la fase heurística y hermenéutica, se observa que existe un importante grupo de artículos enfocados en estudiar el micro-currículo, por lo cual en el análisis inicial se establecen tres categorías: publicaciones con enfoque reflexivo, publicaciones para currículos disciplinares y publicaciones con enfoque en la gestión curricular.

Analizados los artículos con enfoque reflexivo se identifican aportes conceptuales en términos de tendencias sobre diseños curriculares, para efectos de la propuesta dichas publicaciones, se convirtieron en el primer filtro debido a la naturaleza reflexiva y no empírica en cuanto al establecimiento de técnicas, métodos y/o modelos innovadores en el currículo académico.

Tabla 3: Artículos con enfoque reflexivo.

\begin{tabular}{|c|c|c|c|c|}
\hline $\mathbf{N}^{\mathbf{o}}$ & Título & Revista & Año & Autor (Es) \\
\hline 1 & Educación de calidad, escuela y currículo & Revista educación y pedagogía. & 1994 & Santiago Correa Uribe \\
\hline 2 & $\begin{array}{c}\text { Análisis del concepto enseñanza en las } \\
\text { teorías curriculares de Lawrence } \\
\text { Stenhouse y José Gimeno Sacristán. }\end{array}$ & Revista Educación y Pedagogía. & 2004 & $\begin{array}{c}\text { Ana M. Cadavid Rojas } \\
\text { Isabel Cristina Calderón } \\
\text { Palacio. }\end{array}$ \\
\hline 3 & El nuevo currículo educativo británico. & Cuadernos de pedagogía. & 2011 & \\
\hline 4 & $\begin{array}{l}\text { Un currículo más justo para otra } \\
\text { globalización. }\end{array}$ & Cuadernos de pedagogía. & 2012 & Jurjo Torres Santomé \\
\hline 5 & $\begin{array}{l}\text { Reflexiones sobre el plan de estudios: } \\
\text { ¿Reforma o mampostería curricular? }\end{array}$ & Revista diálogos de derecho y política. & 2010 & Roberth Uribe Álvarez \\
\hline 6 & $\begin{array}{l}\text { El currículo y la formación: en los } \\
\text { laberintos de un mundo apalabrado. }\end{array}$ & $\begin{array}{l}\text { Revista latinoamericana de estudios } \\
\text { educativos. }\end{array}$ & 2012 & Portela Guarín, H. \\
\hline 7 & $\begin{array}{l}\text { Logros y desafíos para un currículo } \\
\text { inclusivo. }\end{array}$ & Pedagogía universitaria. & 2012 & $\begin{array}{l}\text { Alfonso Olivera, R. N., } \\
\text { Hernández Días, A., } \\
\text { \&Haramboure, R. ( }\end{array}$ \\
\hline 8 & $\begin{array}{l}\text { Las reformas en la historia del currículo } \\
\text { en Venezuela (el proceso de implantación } \\
\text { de la educación básica 1980-1998). }\end{array}$ & $\begin{array}{c}\text { Revista historia de la educación } \\
\text { latinoamericana. }\end{array}$ & 2013 & Mora-García, J. P \\
\hline 9 & $\begin{array}{l}\text { El currículo en la sociedad del } \\
\text { conocimiento. }\end{array}$ & Educación y educadores. & 2013 & $\begin{array}{c}\text { Avendaño-Castro, W. } \\
\text { W.,Parada-Trujillo, A. A }\end{array}$ \\
\hline 10 & $\begin{array}{l}\text { Perspectivas de pedagogía y currículo con } \\
\text { relación a la intencionalidad formativa de } \\
\text { la educación. }\end{array}$ & Itinerario educativo. & 2013 & $\begin{array}{l}\text { Johany Castro Hoyos, F., } \\
\text { \& Elena Arias Vanegas, } \\
\text { B }\end{array}$ \\
\hline 11 & $\begin{array}{l}\text { Estudios generales y tecnología en un } \\
\text { currículo participativo. }\end{array}$ & Ciencia y sociedad. & 2013 & Córdoba, M. E \\
\hline 12 & $\begin{array}{c}\text { Estudos curriculares génese e } \\
\text { consolidaçãoem Portugal. }\end{array}$ & Educação, sociedade\& culturas. & 2013 & Pacheco, J. J. \\
\hline 13 & $\begin{array}{l}\text { La formulación de los objetivos } \\
\text { instructivos en el contexto del currículo } \\
\text { docente. }\end{array}$ & $\begin{array}{c}\text { Revista cubana de educación médica } \\
\text { superior. }\end{array}$ & 2014 & $\begin{array}{l}\text { González Díaz, C. C., \& } \\
\text { Sánchez Santos, L. }\end{array}$ \\
\hline 14 & $\begin{array}{l}\text { Revisando las prácticas educativas: una } \\
\text { mirada posmoderna a la relación género- } \\
\text { currículo. }\end{array}$ & $\begin{array}{l}\text { Revista latinoamericana de ciencias } \\
\text { sociales, niñez y juventud. }\end{array}$ & 2014 & Elida Giraldo-Gil \\
\hline
\end{tabular}




\begin{tabular}{|c|c|c|c|c|}
\hline 15 & $\begin{array}{l}\text { Las reformas como dispositivos de } \\
\text { cambios curriculares. }\end{array}$ & Uni-pluri/versidad. & 2014 & $\begin{array}{l}\text { Taborda, M. A., \& } \\
\text { Posada, R. R }\end{array}$ \\
\hline 16 & $\begin{array}{l}\text { Entramado del currículo y desarrollo de } \\
\text { innovaciones en educación. }\end{array}$ & $\begin{array}{l}\text { Revista mexicana de investigación } \\
\text { educativa. }\end{array}$ & 2014 & Estévez Nenninger, E. E. \\
\hline 17 & $\begin{array}{l}\text { El curriculum escolar y su abordaje desde } \\
\text { la teoría de la sociedad mundial: revisión } \\
\text { y prospectiva. }\end{array}$ & Educationpolicyanalysis archives. & 2014 & Astiz, M. A. \\
\hline 18 & $\begin{array}{l}\text { Etnomatemáticas y currículo: una } \\
\text { relación necesaria. }\end{array}$ & $\begin{array}{l}\text { Revista latinoamericana de } \\
\text { etnomatemática. }\end{array}$ & 2014 & Peña Rincón, P. A. \\
\hline 19 & $\begin{array}{l}\text { ¿Es el curriculum escolar relevante en la } \\
\text { cultura digital? debates y desafíos sobre } \\
\text { la autoridad cultural contemporánea. }\end{array}$ & Educationpolicyanalysis archives. & 2014 & Dussel, I. I \\
\hline 20 & $\begin{array}{l}\text { El perfil profesional de líder escolar: una } \\
\text { guía para la elaboración de programas y } \\
\text { currículos educativos. }\end{array}$ & $\begin{array}{l}\text { Revista de la universidad del valle de } \\
\text { Guatemala. }\end{array}$ & 2014 & Oliva, J. J. \\
\hline 21 & $\begin{array}{l}\text { Una mirada internacional de la } \\
\text { construcción curricular. Por un currículo } \\
\text { vivo, democrático y deliberativo. }\end{array}$ & $\begin{array}{l}\text { Revista electrónica de investigación } \\
\text { educativa. }\end{array}$ & 2015 & Rangel Torrijo, H. H \\
\hline 22 & Um currículo entre formas e forças. & Educação & 2015 & Alves Paraíso, M \\
\hline 23 & $\begin{array}{l}\text { La reforma curricular en competencias: la } \\
\text { experiencia en las preparatorias federales } \\
\text { por cooperación. }\end{array}$ & Educationpolicyanalysis archives. & 2015 & Silva Montes, C. C. \\
\hline 24 & Un currículo para múltiples adaptaciones & Enseñanza \&Teaching. & 2016 & Sola Martínez, T. \\
\hline 25 & $\begin{array}{l}\text { Educación y desarrollo sostenible: la } \\
\text { creatividad de la naturaleza para innovar } \\
\text { en la formación humana }\end{array}$ & EBSCO & 2017 & Javier Collado \\
\hline 26 & $\begin{array}{l}\text { Más Allá de los Desafios del Decenio de } \\
\text { la Educación para El Desarrollo } \\
\text { Sostenible: Una Reflexión Necesaria }\end{array}$ & EBSCO & 2017 & $\begin{array}{l}\text { Sousa, A. C., \& Uceda- } \\
\text { Maza, F. X. }\end{array}$ \\
\hline 27 & $\begin{array}{l}\text { Los Objetivos de Desarrollo Sostenible y } \\
\text { la academia }\end{array}$ & EBSCO & 2018 & Cosme Casulo jorge \\
\hline 28 & $\begin{array}{l}\text { La "Ciudad Educadora" como Propuesta } \\
\text { Pedagógica para Avanzar en el Logro de } \\
\text { los ODS. }\end{array}$ & Dialnet & 2018 & Miquel Martínez Martin \\
\hline
\end{tabular}

Fuente: Autor

Se obtienen aportes de las publicaciones, como el de (Nenninger, 2014) en donde el autor expresa que una de las clasificaciones más importantes corresponde a las investigaciones que se articulan con las reformas curriculares y los cambios que generan en las instituciones, siendo esta categoría la que tiene más del 50\% de los trabajos recabados, con 762. En contraste, están las investigaciones relacionadas con el currículo, docentes y estudiantes, con el 27\% (372 documentos). Otra clasificación más es la que corresponde a la evaluación y su relación con el currículo, representando el 11\% de las investigaciones, con 148 trabajos. La falta de involucramiento del maestro en el cambio curricular es el origen de la ineficiencia en su aplicación; "queda comprobado que mientras no se considere al maestro como el núcleo social de la dinámica educativa, cualquier cambio no va a terminar de cuajar".

Entre tanto (Correa, 1994), concluye que la tendencia predominante en Colombia ha sido la importación de modelos curriculares que son rápidamente adoptados sin ninguna adecuación, incluidas las características de la cultura de origen que se sobreponen a nuestros propios valores culturales. Del mismo modo (Sacristán, 2002, p. 264) expresa que en el caso colombiano los Estándares de Calidad y los lineamientos curriculares, representan un mecanismo de control instaurado por los sectores políticos al servicio del capitalismo, al convertirse en elementos invariantes de la planeación curricular y una estrategia para el sometimiento de la autonomía del profesorado, que accede con demasiada facilidad a desempeñar un rol de dependencia bien sea por ingenuidad, por conveniencia o por comodidad, en todo caso por tener una conciencia social supremamente débil y mal configurada (Castro \& Arias, 2013). Así mismo (Rangel, 2015), señala que el currículo debe 
realizar un anclaje en las prácticas sociales, como lo propuso Perrenaud (2008); es decir, este no debe ser un circuito cerrado, debe atender a los problemas de la vida cotidiana; los problemas de pobreza y desigualdad, los problemas económicos, las nuevas tecnologías, etc. Es de subrayar que el llamado lo hace, Perrenaud, desde el contexto suizo, uno de los países de mayor calidad de vida en el mundo y que no está exento de problemas diversos. Esto muestra que el anclaje con las prácticas sociales no es un discurso populista, da vida social al currículo, pues no solamente atiende cuestiones abstractas, sino problemas tangibles, además señala que, a menudo las reformas curriculares fracasan a causa de contradicciones conceptuales. De esta manera el currículo debe ser concebido más allá de una simple organización de contenidos.

Otras de las dificultades estudiadas desde el currículo las expuso (Giraldo, 2014), describiendo, en las conclusiones, la necesidad de develar los significados de género y currículo naturalizados en la escuela y de problematizar la mirada descorporalizada del género en la educación y el lugar pasivo asignado a los/as estudiantes en la construcción de sus identidades, indicando que las relaciones de género tienen lugar en contextos específicos y tienen múltiples significados, dependiendo de las prácticas sociales y culturales en las cuales estas son actuadas, citando a (Butler, 2004, Foster, 1999, Harding, 1998) y a (Miller, 1993) indicando que el currículo escolar no puede ser separado de los momentos sociales, políticos, culturales e históricos en los cuales ha sido producido, reproducido.

Entre tanto (Dussel, 2014), argumenta que el currículo todavía conserva relevancia como documento público que busca organizar experiencias educativas en las escuelas, y que no habría que "despachar a la ligera" los debates y desafíos sobre la selección y recreación de la cultura que el currículo moderno había estructurado; señala que, los desafíos contemporáneos al currículo plantean la necesidad de analizar cómo el currículo se ubica hoy en el cruce entre lo público, lo estatal y lo doméstico, a partir del declive de la regulación estatal y la emergencia de públicos cada vez más fragmentados en el cruce entre la industria cultural y el espacio doméstico.

A su vez (Mora, 2013), sintetiza en el estado del arte sobre las tendencias del pensamiento curricular en Venezuela, tres tendencias; (i). Las tendencias del diseño curricular centrado en la didáctica general, (ii). La centrada en las didácticas especiales y (iii). Las centradas en la tradición de las disciplinas, siendo esta última la que mayor producción teórica ha tenido. Destacando la falta de un lenguaje común mínimo a la hora de abordar el tema del currículo en las reformas educativas, situación que proviene de la ambigüedad con que ha sido tratado en el campo intelectual, luego de la turbulencia de las teorías curriculares en el siglo XX, caracterizada por la polisemia del término currículo, y el desencanto que vive la teoría curricular (Moreno, 1999), formulando cuestionamientos tales como ¿acaso estamos en presencia de una visión emergente del currículo? ¿Es posible pensar en un currículo postmoderno? ¿Cuáles son los riesgos y oportunidades que ofrece? o en su defecto ¿Acaso estamos en presencia del agotamiento de uno de los metadiscursos que en la Modernidad fueron el centro de gravedad de la escuela, como lo es el currículo?

En otro sentido (Peña, 2014), plantea que hoy en día resulta imprescindible cambiar la visión de las matemáticas e incluir las etno-matemáticas indígenas en los currículos de 
Latinoamérica puesto que estas están desconectadas de los entornos y de las prácticas sociales, limitando el desarrollo potencial del pensamiento matemático de estudiantes indígenas y no indígenas, acrecentando la pérdida de la identidad cultural de los pueblos originarios, también (Córdoba, 2013), expone al analizar los modelos educativos y diseños curriculares en diversas Instituciones Educativas Superiores de América Latina y el Caribe, que el maestro recibe un programa de asignatura para impartirla sin conocer el perfil de egresado en el que se enmarca, tampoco conoce el diseño curricular y enfoque educativo que lo justifican. Por ende, el dominio de la disciplina no resulta suficiente como para vincular la asignatura con el resto de las que conforman el plan educativo; de tal forma que los contenidos no están integrados, sino que se imparten de manera desarticulada entre sí.

Entre tanto (Silva, 2015), expresa, en su artículo los efectos de la reforma curricular en competencias en las Preparatorias Federales por Cooperación en México, impulsada por la Dirección General del Bachillerato, el propósito de develar cómo el currículo en competencias conecta a la escuela con el mercado laboral, en el marco de la globalización y la sociedad del conocimiento y es incongruente con el ideal de formar ciudadanos comprometidos con la sociedad. Igualmente expresa que, al profesorado se le excluye de la definición curricular de perfiles de egreso, planes y programas de estudio, convirtiéndolo en simple ejecutor de objetivos externos.

Se destaca del rastreo de la información reflexiones en torno a la inserción de los ODS en los estudios de (Cosme, 2018), Collado (2017), (Sousa \& Uceda, 2017) y (Martínez, 2018).

(Cosme, 2018) señala que la universidad en su importante rol de formación debe articular la extensión e investigación para el desarrollo local de las comunidades cumpliendo con el desarrollo de la función social de forma integral; del mismo modo indica Collado (2017) la necesidad de incluir nuevos abordajes biométricos y transdisciplinares en la formación humana para solucionar los desafíos de la insostenibilidad del planeta para el cumplimiento de los ODS.

Entre tanto (Sousa \& Uceda, 2017) reflexionan sobre la importancia de la educación para el impulsar el fortalecimiento del desarrollo sostenible y generar actitudes y responsabilidades como fuentes de inspiración para las generaciones futuras.

(Martínez, 2018) plantea a los ODS como una buena brújula para la visión institucional de largo plazo con compromiso ético al servicio de las personas. Cabe resaltar que la propuesta no diferencia el nivel de formación educativa. Se relaciona en esta categoría al incluir elementos clave: "ODS" y "ciudad educadora" como componente de contexto para una educación de calidad con compromiso de excelencia; aunque el enfoque del artículo promueve una reflexión en materia de avance en el cumplimiento de los ODS y no en función de los logros en el desarrollo de las competencias a nivel educativo.

En síntesis, los artículos con enfoque reflexivo resaltan la importancia de adaptar el currículo, a fin de responder a la sociedad actual y a los intereses de los educandos (Avendaño \& Parada, 2013), acentuando que los contenidos que la escuela debe seleccionar deben proporcionar la posibilidad de diálogo con la sociedad. (Cadavid \& Calderón, 2004), si bien se expresa la necesidad de adaptar los currículos a las problemáticas no se evidencia de forma clara escritos con diseños o modelos curriculares desde las problemáticas sociales "de contexto" para abordarlas a través de procesos de innovación educativa. 


\subsection{Categoría 3: Análisis de artículos para currículos disciplinares.}

Analizados los artículos con enfoque reflexivo se procede a la revisión de aquellas publicaciones que de acuerdo con su título y resumen indican intervención curricular a partir de las disciplinas escolares.

Tabla 4: Análisis artículos currículos disciplinares.

\begin{tabular}{|c|c|c|c|c|}
\hline $\mathrm{N}^{\circ}$ & $\begin{array}{l}\text { Título } \\
\end{array}$ & Revista & Año & Autor(es) \\
\hline 1 & $\begin{array}{l}\text { La solución de situaciones problemáticas: una } \\
\text { estrategia didáctica para la enseñanza de la } \\
\text { química. }\end{array}$ & Innovaciones Didácticas. & 2000 & $\begin{array}{l}\text { García García, José } \\
\text { Joaquín. }\end{array}$ \\
\hline 2 & $\begin{array}{l}\text { Percepciones y acciones de las y los estudiantes de } \\
\text { la Universidad Autónoma del Estado de México } \\
\text { respecto a la educación en el desarrollo sostenible }\end{array}$ & $\begin{array}{l}\text { DIALNET } \\
\text { RIDE: Revista Iberoamérica de } \\
\text { Educación. }\end{array}$ & 2007 & $\begin{array}{l}\text { Jenny García Guerrero } \\
\text { Cristina M. García } \\
\text { Rendón Arteaga }\end{array}$ \\
\hline 3 & $\begin{array}{l}\text { Enseñar ciencias en un mundo en riesgo. } \\
\text { Antecedentes y propuestas curriculares y } \\
\text { didácticas. }\end{array}$ & Uni-Pluri/Versidad. & 2009 & $\begin{array}{l}\text { José Joaquín García } \\
\text { García. }\end{array}$ \\
\hline 4 & $\begin{array}{l}\text { O ensino de história da américa latina no Brasil: } \\
\text { sobre currículos e programas. }\end{array}$ & $\begin{array}{l}\text { Magis, Revista Internacional de } \\
\text { Investigación en Educación. }\end{array}$ & 2011 & $\begin{array}{l}\text { ThamarKalil-Alves } \\
\text { Wellington De Oliveira. }\end{array}$ \\
\hline 5 & $\begin{array}{l}\text { La enseñanza de las ciencias sociales y la } \\
\text { formación para las ciudadanías desde el enfoque de } \\
\text { escuela abierta: un campo significativo para las } \\
\text { prácticas pedagógicas y la investigación formativa. }\end{array}$ & Uni-Pluri/Versidad. & 2011 & Hader Calderón Serna. \\
\hline 6 & $\begin{array}{l}\text { Maestro, traductor y tecnologías de la información } \\
\text { y la comunicación en la escuela de idiomas de la } \\
\text { universidad de Antioquia: realidades y retos. }\end{array}$ & $\begin{array}{l}\text { Íkala, Revista de Lenguaje y } \\
\text { Cultura. }\end{array}$ & 2012 & $\begin{array}{l}\text { María Elena Ardila } \\
\text { Restrepo, Luz María } \\
\text { Becerra Naranjo, Natalia } \\
\text { Isabel Cañas Gil. } \\
\end{array}$ \\
\hline 7 & $\begin{array}{l}\text { Integración curricular de las tic en la enseñanza no } \\
\text { universitaria: modelo de ajuste y hoja de ruta. }\end{array}$ & Cisti & 2012 & $\begin{array}{l}\text { Luis Vilán Crespo } \\
\text { Manuel Pérez Cota }\end{array}$ \\
\hline 8 & $\begin{array}{l}\text { Los retos de la educación bilingüe en inglés y } \\
\text { español en las escuelas públicas de Nueva York: } \\
\text { objetivos, modelos y currículos. }\end{array}$ & Springer. & 2012 & $\begin{array}{l}\text { Patricia Velasco } \\
\text { Herlinda Cancino. }\end{array}$ \\
\hline 9 & $\begin{array}{l}\text { Aprendizaje y enseñanza de la lengua castellana y } \\
\text { literatura: currículo de educación secundaria } \\
\text { obligatoria. }\end{array}$ & Contextos Educativos. & 2012 & $\begin{array}{l}\text { Amando López Valero } \\
\text { Aurora Martínez } \\
\text { Ezquerro. }\end{array}$ \\
\hline 10 & $\begin{array}{l}\text { Idoneidad epistémica del significado de la derivada } \\
\text { en el currículo de bachillerato. }\end{array}$ & Paradigma. & 2013 & $\begin{array}{l}\text { Luis R. Pino-Fan } \\
\text { Walter F. Castro } \\
\text { Juan D. Godino } \\
\text { Vicenç Font. }\end{array}$ \\
\hline 11 & $\begin{array}{l}\text { Caracterización de la integración de las tic en los } \\
\text { currículos escolares de instituciones educativas en } \\
\text { barranquilla. }\end{array}$ & $\begin{array}{l}\text { Revista del Instituto } \\
\text { de Estudios en Educación } \\
\text { Universidad Del Norte }\end{array}$ & 2013 & $\begin{array}{l}\text { Carmen Ricardo } \\
\text { Mónica Borjas } \\
\text { Ingrid Velásquez } \\
\text { Juliana Colmenares } \\
\text { Alejandra Serje. }\end{array}$ \\
\hline 12 & $\begin{array}{l}\text { Contribución de la educación científica a la } \\
\text { apropiación de los objetivos de desarrollo } \\
\text { sostenible }\end{array}$ & EBSCO & 2013 & $\begin{array}{l}\text { Vilches Peña, Amparo; } \\
\text { Gil Pérez, Daniel; } \\
\text { Calero, María }\end{array}$ \\
\hline 13 & $\begin{array}{l}\text { Indicios de estandarización curricular: la } \\
\text { pedagogía del entorno en los currículos oficiales de } \\
\text { educación } \\
\text { primaria de chile y España }\end{array}$ & $\begin{array}{l}\text { Archivos Analíticos de } \\
\text { Políticas Educativas. }\end{array}$ & 2013 & Marta Estellés Frade. \\
\hline 14 & $\begin{array}{l}\text { La construcción de un currículo intercultural a } \\
\text { partir del diálogo de saberes: descripción y análisis } \\
\text { de una experiencia de formación docente continua. }\end{array}$ & $\begin{array}{l}\text { Revista Electrónica de } \\
\text { Enseñanza de Las Ciencias. }\end{array}$ & 2013 & $\begin{array}{l}\text { Ana Dumrauf Y Adriana } \\
\text { Menegaz. }\end{array}$ \\
\hline 15 & $\begin{array}{l}\text { Formación Profesional: Integrando Saberes Éticos } \\
\text { Y De Desarrollo Sostenible. Caso Práctico Para } \\
\text { Ingeniería }\end{array}$ & $\begin{array}{l}\text { EBSCO } \\
\text { Sinéctica. Revista Electrónica } \\
\text { de educación. }\end{array}$ & 2015 & $\begin{array}{l}\text { del Carmen Ramírez } \\
\text { Hernández, D., Ramírez } \\
\text { Montoya, M. S., \& } \\
\text { Ramírez Moreno, P. P. }\end{array}$ \\
\hline 16 & $\begin{array}{l}\text { La Dimensión de la Sostenibilidad en la Enseñanza } \\
\text { de las Ingenierías en Cuba }\end{array}$ & EBSCO & 2015 & Díaz Duque, J. A. \\
\hline 17 & $\begin{array}{l}\text { Análisis de los currículos autonómicos LOMCE de } \\
\text { educación física en educación primaria. }\end{array}$ & Retos. & 2015 & $\begin{array}{l}\text { David Méndez Alonso, } \\
\text { Javier Fernández-Río, }\end{array}$ \\
\hline
\end{tabular}




\begin{tabular}{|c|c|c|c|c|}
\hline & & & & $\begin{array}{l}\text { Antonio Méndez } \\
\text { Giménez, Jose Antonio } \\
\text { Prieto Saborit. }\end{array}$ \\
\hline 18 & $\begin{array}{l}\text { Las tecnologías de la información y } \\
\text { de la comunicación en el currículo de matemáticas: } \\
\text { orientación desde las políticas y los proyectos } \\
\text { educativos. }\end{array}$ & Panorama. & 2015 & $\begin{array}{l}\text { Mayra Alejandra } \\
\text { Arévalo } \\
\text { AudinAloiso Gamboa } \\
\text { Suárez. }\end{array}$ \\
\hline 19 & $\begin{array}{l}\text { Modelo de educación holística: una propuesta para } \\
\text { la formación del ser humano. }\end{array}$ & $\begin{array}{l}\text { Revista Actualidades } \\
\text { Investigativas En Educación. }\end{array}$ & 2015 & $\begin{array}{l}\text { Rosa Isela GluyasFitch } \\
\text { Rodrigo Esparza Parga } \\
\text { María Del Carmen } \\
\text { Romero Sánchez } \\
\text { Julio Ernesto Rubio } \\
\text { Barrios. } \\
\end{array}$ \\
\hline 20 & $\begin{array}{l}\text { Grabado sostenible. Experiencias y prácticas de } \\
\text { medición educativa en primaria. }\end{array}$ & $\begin{array}{l}\text { DIALNET } \\
\text { Educación y Pedagogía }\end{array}$ & 2017 & Marta Aguilar Moreno \\
\hline 21 & $\begin{array}{l}\text { Educación, sostenibilidad y ética: desafios ante los } \\
\text { objetivos de desarrollo sostenible (ODS) }\end{array}$ & DIALNET & 2018 & $\begin{array}{l}\text { Eduardo Vila, } \\
\text { José Cadire, } \\
\text { María Buxarrais }\end{array}$ \\
\hline 22 & $\begin{array}{l}\text { La implicación de la universidad en los objetivos } \\
\text { del desarrollo sostenible. El caso de la Universidad } \\
\text { de Málaga. }\end{array}$ & DIALNET & 2018 & Julio Vera Vila \\
\hline 23 & $\begin{array}{l}\text { La educación para el desarrollo sostenible en la } \\
\text { formación de los profesionales de la educación. }\end{array}$ & DIALNET & 2018 & $\begin{array}{l}\mathrm{M}^{\mathrm{a}} \text { Esther Olveira } \\
\text { Olveira y Antonio } \\
\text { Rodríguez Martínez }\end{array}$ \\
\hline 24 & $\begin{array}{l}\text { ¿Universidad socialmente responsable? : Visiones } \\
\text { del alumnado ante el desarrollo sostenible }\end{array}$ & DIALNET & 2018 & $\begin{array}{l}\text { María Jesús Martínez } \\
\text { Usarralde, María del } \\
\text { Carmen Lloret } \\
\text { Català, Sara Mas Gil } \\
\end{array}$ \\
\hline 25 & $\begin{array}{l}\text { Educación para el Desarrollo Sostenible y } \\
\text { Educación Intercultural como } \\
\text { elementos clave de la Educación para la } \\
\text { Ciudadanía (planetaria) }\end{array}$ & DIALNET & 2018 & García-Blanco, Miriam \\
\hline 26 & $\begin{array}{l}\text { Estudio de un caso de enseñanza de materias } \\
\text { STEM a través del ecourbanismo apoyado por } \\
\text { herramientas avanzadas de diseño, en el horizonte } \\
2030 \text { de objetivos de desarrollo sostenible (ODS). }\end{array}$ & $\begin{array}{l}\text { DIALNET } \\
\text { Revista de Educación a } \\
\text { Distancia. }\end{array}$ & 2018 & $\begin{array}{l}\text { Francisco del Cerro } \\
\text { Velázquez. } \\
\text { Fernando Lozano Rivas. }\end{array}$ \\
\hline
\end{tabular}

Fuente: Autor

Se obtienen aportes de las publicaciones, como en el caso del artículo Enseñar ciencias en un mundo en riesgo. Antecedentes y propuestas curriculares y didácticas (García, 2009), el autor expresa que Derek Hodson (2003) plantea que la pertinencia del currículo para la educación en las ciencias se debe enfocar en la ciencia- tecnología- sociedad y medio ambiente, a su vez propone que el currículo debe incluir ejes temáticos: (i) Salud, (ii) comida y agricultura, (iii) tierra, agua y recursos minerales, (iv) energía, recurso y consumo, (v) industria, (vi) transferencia de información y transporte, (vii) libertad y control de la tecno-ciencia y (viii) preservación del ambiente natural, en este sentido la propuesta aporta hacia la construcción de las identidades culturales nacionales, regionales y locales, firme propósito que busca el (MEN, 2015); además se aclara que la tendencia curricular problematizadora formula una visión que integra lo político, lo social, lo cultural, lo económico y lo disciplinar (García, 2009).

En otro sentido (Calderón, 2011), dice que en la enseñanza de las ciencias sociales la no existencia de currículos preestablecidos, la diversidad de problemáticas sociales y marcos institucionales, y la variedad de objetivos de las distintas propuestas educativas, hacen ver la necesidad de profesionales capaces de pensar pedagógicamente desde escenarios radicalmente diferentes y de promover procesos, de investigación-acción-participativa con las comunidades, que contribuyan a transformar dichas problemáticas desde sus potencialidades e iniciativas. De ahí, que la formación de maestros y maestras para un ámbito tan vasto y diverso como este, de la educación social, en contextos no escolares, se deba 
abordar desde la reflexión propia del campo y a partir de un proceso riguroso de investigación que considere la relación dialéctica entre teoría-práctica. Hoy más que nunca, se debe ampliar la mirada de la escuela para comprenderla como un espacio-tiempo modular, múltiple, abierto, en proceso permanente de construcción por parte de los diferentes sujetos que interactúan, y con otras formas de vivir la experiencia educativa.

Cabe resaltar, en los anteriores artículos para el caso Colombiano que el Ministerio de Educación brinda autonomía y delega a las instituciones educativas la opción de diseñar el currículo de las áreas, teniendo como base la normativa establecida para guiar el diseño curricular, en tal sentido, espera que sean los docentes los que elaboren el currículo, ya que son quienes tienen los conocimientos y la capacidad para contextualizar esta normativa y las políticas educativas a la realidad de sus instituciones educativas; similares apreciaciones son expuestas por (Arévalo \& Gamboa, 2015) en relación con la incorporación de las TIC en los currículos.

Así mismo, indican (Cañas, Ardila \& Becerra, 2012) citando a (Correa et ál., 2002, p. 16; García, 2008, p. 16) la existencia de dos visiones o enfoques del currículo: una que le otorga una dimensión instructiva o centrada en los contenidos y otra que promulga una visión formativa o equilibrada en la que se ve al ser humano integralmente. El currículo se compone de tres elementos inseparables e integrados: el plan de estudio, la parte más visible del currículo y a la cual se restringe algunas veces; su infraestructura reflexiva; o sea, las teorías sobre las que se sustenta un currículo y, por último, el entorno de gestión (García, 2008, pp. 24- 25). Según el mismo autor, este es el aspecto menos desarrollado del currículo, pues los académicos siempre han sido reacios a intervenir en los aspectos administrativos. Sin embargo, si bien es el aspecto de la gestión curricular el que predomina en las instituciones educativas en los temas tendientes a implementación de las TICE (Tecnologías de la Información y Comunicación en Educación) y a la flexibilidad curricular, los profesores universitarios se están quedando al margen de este aspecto por el poco interés en la administración y por la falta de estudios serios sobre el tema (Díaz, 2007, p. 35).

Además, el carácter abierto del currículo requiere, por tanto, una organización didáctica articulada y flexible. Las programaciones correspondientes tendrán que respetar las conexiones entre los contenidos, obedeciendo a criterios analíticos de organización y a la lógica interna de la propia disciplina (López \& Martínez, 2012). De acuerdo con Da Silva (1999), un currículo busca, en última instancia, modificar a las personas que lo van a seguir, construye subjetividad, genera marcos de referencia a partir de los cuales se interpreta, se analiza y se "descubre" la realidad. Según este autor, en muchas ocasiones, al pensar en el currículo se piensa sólo en conocimiento, olvidando que "el conocimiento que constituye el currículo está inextricablemente, centralmente, vitalmente, envuelto en aquello que somos, en aquello en que nos transformamos: en nuestra identidad, en nuestra subjetividad" (Da Silva, 1999). Señalan además (Gluyas, Esparza, Romero \& Rubio, 2015), que la educación tiene que poseer una visión holística del estudiante para establecer una vinculación con otras esferas nunca o poco abordadas en los contextos de aprendizaje, y que la formación artística tiene el potencial para desarrollar la dimensión sensible de la persona para recrear su interacción con el mundo en busca del bienestar de la humanidad; proponen plantear una aproximación al Modelo de Educación Holística (MEH) aplicado a la enseñanza de las artes. 
Entre tanto los artículos que relacionan la categoría de Desarrollo Sostenible corresponde a (García \& García, 2007), (Vilches, Gil \& Calero, 2013), (Ramírez, Ramírez \& Ramírez, 2015), (Diaz, 2015), (Aguilar, 2017), (Vila, Cadire, Buxarrais, 2018), (Vera, 2018), (Olveira \& Rodríguez, 2018), (Martínez, Lloret \& Mas, 2018), (García, 2018), (del Cerro \& Lozano, 2018),

(García \& García, 2007) concluyen en su estudio la necesidad de una educación formal e informal para el desarrollo sostenible que permita a la humanidad resolver las necesidades sin comprometer las necesidades futuras con responsabilidad y solidaridad.

(Vilches, Gil \& Calero, 2013) utilizaron el método Delphi para analizar los aportes de 60 investigadores en el campo de las didácticas de las ciencias. En análisis planteó que los objetivos propuestos han resultado convergentes y pertinentes para el logro de sociedades sostenibles, de este modo demostraron cómo la comunidad educativa puede favorecer el logro de los ODS.

Los autores (Ramírez, Ramírez \& Ramírez, 2015) proponen un caso práctico en la formación profesional abordando los elementos de la ética y el desarrollo sostenible en el área de la ingeniería con el propósito de lograr aprendizajes para la vida profesional, una de las preguntas planteadas corresponde a ¿en qué nivel de aprendizajes perciben los alumnos que se logran los objetivos de la ética y el desarrollo sostenible planteados por el profesor a través de la realización del proyecto.

(Diaz, 2015) propone un decálogo de la sostenibilidad por parte de los programas de ingeniería para la formación de profesionales que contribuyan con el desarrollo sostenible debido a que los aportes de los conocimientos científicos y tecnológicos han provocado grandes impactos negativos a los sistemas naturales.

(Aguilar, 2017) resalta que la responsabilidad de educar bajo modelos de sostenibilidad es tarea de todos y debe iniciar a temprana edad en los ciclos educativos. La propuesta se basa en el uso de fotopolímeros en el aula para sensibilizar sobre conductas para la educación ambiental.

(Vila, Cadire, Buxarrais, 2018) destacan los desafíos éticos de carácter local y global para el tercer milenio en términos de: i) sostenibilidad y desarrollo humano desde la educación ambiental. ii) ODS desde el alcance de la educación. Iii) relación de proyección entre sostenibilidad, educación y desarrollo.

(Vera, 2018) plantea la necesidad de repensar la universidad no solo para la competitividad sino también para la sostenibilidad.

(Olveira \& Rodríguez, 2018) plantea la dicotomía existente entre la educación para el desarrollo sostenible de los profesionales y la construcción de un modelo de convivencia y de producción de acuerdo con el marco conceptual de educación para el desarrollo sostenible o educación para la ciudadanía global y la vinculación a la sostenibilidad. 
(Martínez, Lloret \& Mas, 2018) analizan la relación entre la responsabilidad social universitaria y el desarrollo sostenible desde la visión de los estudiantes. Identificando en el estudio la percepción por parte de los estudiantes sobre la universidad como espacio que brinda formación ética, pero genera pocos espacios para sentirse escuchados. Al igual resaltan que los currículos universitarios son poco dinámicos, determinando la necesidad de generar nuevos espacios para abordar temas sociales, hábitos saludables y aplicación de los principios de la responsabilidad social.

(García, 2018) analiza como factores fundamentales para la formación de la ciudadanía planetaria las bases en educación para el desarrollo sostenible y la educación intercultural.

(del Cerro \& Lozano, 2018) proponen una práctica innovadora en la enseñanza y aprendizaje de las materias STEM, mediante el ecourbanismo como elemento metodológico apoyado en herramientas de diseño avanzado (GIMP, Goolzoom y Sketchup) y los ODS como elemento vinculante para convertirlos en retos.

En definitiva, las publicaciones en la mayoría de casos proponen desde su área de conocimiento definir unos tópicos que sirvan de guía para establecer su desarrollo de contenido, las evidencias de temáticas integradoras desde la gestión curricular se identifica en promedio desde el año 2018, los artículos expresan problemáticas del contexto y la necesidad de un currículo pertinente pero ¿cómo definir un currículo que permee diversidad de contextos para la educación básica y además sea innovador?

\subsection{Categoría 4: Análisis de artículos con enfoque en la gestión curricular}

Las publicaciones referidas en su título a propuestas de intervención curricular, desde la gestión, se analizaron a profundidad para determinar los aspectos esenciales que permitan distinguir los componentes para el desarrollo de un modelo integrador pertinente para las instituciones educativas de básica secundaria, en este sentido se reagruparon los textos en dos enfoques, uno que aplica para la educación superior y otro para la educación básica.

Las propuestas para la educación superior se descartan debido a la naturaleza de la investigación, sin embargo, se retoman aportes importantes que serán tenidos en cuenta para efectos de la construcción del modelo.

- Gestión curricular para Educación Superior

Tabla 5: Artículos Gestión Curricular para la Educación Superior.

\begin{tabular}{|c|c|c|c|c|}
\hline $\mathbf{N}^{\mathbf{0}}$ & Título & Revista & Año & Autor(es) \\
\hline $\mathbf{1}$ & La investigación formativa o la & Plataforma Cybertesis & 2008 & Margarita maria Osorio \\
& posibilidad de generar cultura & & & Alvarez. \\
& $\begin{array}{c}\text { investigativa en l educación superior: El } \\
\text { caso de la práctica pedagógica de la } \\
\text { licenciatura en educación básica con } \\
\text { énfasis en humanidades, lengua } \\
\text { castellana de la universidad de Antioquia. }\end{array}$ & & & \\
\hline
\end{tabular}




\begin{tabular}{|c|c|c|c|c|}
\hline 2 & $\begin{array}{l}\text { Acerca de la participación de los } \\
\text { profesores en el currículo. }\end{array}$ & Uni-Pluri/Versidad & 2009 & $\begin{array}{l}\text { Gloria Eugenia Giraldo } \\
\text { Mejía Elvia María } \\
\text { González Agudelo. }\end{array}$ \\
\hline 3 & $\begin{array}{l}\text { Innovar en el currículo universitario: una } \\
\text { propuesta de observatorio de objetos } \\
\text { curriculares. }\end{array}$ & Uni-Pluri/Versidad & 2009 & $\begin{array}{l}\text { José Ramiro Galeano } \\
\text { Londoño. }\end{array}$ \\
\hline 4 & $\begin{array}{l}\text { La integración curricular en el proceso de } \\
\text { transformación del programa de } \\
\text { odontología de la Universidad de } \\
\text { Antioquia: un problema en la gestión } \\
\text { curricular. }\end{array}$ & Uni-Pluri/Versidad. & 2009 & $\begin{array}{l}\text { Hugo Sánchez Fajardo, } \\
\text { Elvia María González } \\
\text { Agudelo. }\end{array}$ \\
\hline 5 & $\begin{array}{l}\text { Sobre la interdisciplinariedad en los } \\
\text { programas de formación de maestros en } \\
\text { la Facultad de Educación de la } \\
\text { Universidad de Antioquia } \\
\text { Estado actual y proyecciones. }\end{array}$ & Uni-Pluri/Versidad & 2010 & $\begin{array}{l}\text { Teresita María Gallego } \\
\text { Betancur. }\end{array}$ \\
\hline 6 & $\begin{array}{l}\text { La construcción de currículo desde } \\
\text { perspectivas críticas: una producción } \\
\text { cultural. }\end{array}$ & Signo y Pensamiento 56. & 2010 & Nancy Agray Vargas. \\
\hline 7 & $\begin{array}{l}\text { Diseñar el currículo universitario: un } \\
\text { proceso de suma complejidad. }\end{array}$ & Signo y Pensamiento 56. & 2010 & Maria Gladys Álvarez. \\
\hline 8 & $\begin{array}{l}\text { El diseño curricular, una responsabilidad } \\
\text { compartida. }\end{array}$ & Colombia Médica. & 2011 & $\begin{array}{l}\text { María Clara Tovar, } \\
\text { Pedro Sarmiento, }\end{array}$ \\
\hline 9 & $\begin{array}{l}\text { Currículo Integrado: entre o Discurso e a } \\
\text { Prática. }\end{array}$ & Revista Brasileira De Educação Médica. & 2011 & $\begin{array}{l}\text { Patrícia Alves de SouzaI } \\
\text { Angelica Maria } \\
\text { BicudoZeferinoI } \\
\text { Marco Aurélio Da RosII. }\end{array}$ \\
\hline 10 & $\begin{array}{l}\text { Articulación y rediseño curricular: el } \\
\text { eterno desafío institucional. }\end{array}$ & Revista de Docencia Universitaria. & 2012 & $\begin{array}{l}\text { Miguel A. } \\
\text { ZabalzaBeraza }\end{array}$ \\
\hline 11 & $\begin{array}{l}\text { Innovación curricular en los grados de } \\
\text { maestroi en la Facultad } \\
\text { HUHEZI (MondragonUnibertsitatea): la } \\
\text { materia Educación } \\
\text { Intercultural y Educación en Valores. }\end{array}$ & Revista de Docencia Universitaria. & 2012 & $\begin{array}{l}\text { Amelia Barquín } \\
\text { Nerea AlzolaMaiztegi } \\
\text { MonikaMadinabeitia } \\
\text { Medrano }\end{array}$ \\
\hline 12 & $\begin{array}{l}\text { Estado da arte das pesquisas sobre } \\
\text { currículo em cursos de formação de } \\
\text { profissionais da área da saúde: } \\
\text { umlevantamento a partir de artigos } \\
\text { publicados entre } 2005 \text { e } 2011 \text {. }\end{array}$ & $\begin{array}{l}\text { Interfase COMUNICAÇÃO SAÚDE } \\
\text { EDUCAÇÃO. }\end{array}$ & 2012 & $\begin{array}{l}\text { Liana Maria Carvalho } \\
\text { Braid } \\
\text { Maria de Fátima Antero } \\
\text { Sousa Machado } \\
\text { Ágatha Cristina Aranha. }\end{array}$ \\
\hline 13 & $\begin{array}{l}\text { Elementos de diseño de un currículo } \\
\text { basado en el enfoque de procesos. }\end{array}$ & Revista Educación en Ingeniería. & 2012 & $\begin{array}{l}\text { Arturo T. De Zan } \\
\text { Luis A. Paipa G. }\end{array}$ \\
\hline 14 & $\begin{array}{l}\text { Sobre la evaluación de la renovación } \\
\text { curricular puesta en marcha desde } 1997 \\
\text { en la Universidad de Antioquia. }\end{array}$ & Uni-Pluri/Versidad & 2012 & $\begin{array}{l}\text { Elvia María González } \\
\text { Agudelo. }\end{array}$ \\
\hline 15 & $\begin{array}{l}\text { Establecimiento de un modelo educativo } \\
\text { institucional para la orientación del } \\
\text { proceso de innovación curricular de las } \\
\text { carreras de la Universidad de Playa } \\
\text { Ancha }\end{array}$ & Palabra Clave (La Plata). & 2013 & $\begin{array}{l}\text { Sandra Pizarro Barrera } \\
\& \text { Cristián Valenzuela } \\
\text { Urra. }\end{array}$ \\
\hline 16 & $\begin{array}{l}\text { Un nuevo sentido en la educación por } \\
\text { proyectos a través del pensamiento del } \\
\text { mestizaje en el programa de traducción } \\
\text { de la universidad de Antioquia. }\end{array}$ & Mutatis Mutandis & 2013 & $\begin{array}{l}\text { Elvia María González } \\
\text { Agudelo, Miguel } \\
\text { Orlando Betancourt } \\
\text { Cardona. }\end{array}$ \\
\hline 17 & $\begin{array}{l}\text { Formación por competencias } \\
\text { y acreditación de calidad: su } \\
\text { convergencia en el curriculum. }\end{array}$ & ItineRario Educativo. & 2013 & $\begin{array}{l}\text { Ángela María Restrepo } \\
\text { Jaramillo. }\end{array}$ \\
\hline 18 & $\begin{array}{l}\text { Diseño e implementación de un currículo } \\
\text { por competencias para la formación de } \\
\text { médicos. }\end{array}$ & $\begin{array}{l}\text { RevPeruMedExp Salud } \\
\text { Publica. }\end{array}$ & 2014 & $\begin{array}{l}\text { Graciela Risco de } \\
\text { Domínguez. }\end{array}$ \\
\hline 19 & $\begin{array}{l}\text { Diseño y validación de una propuesta de } \\
\text { evaluación auténtica de competencias en } \\
\text { un programa de formación de docentes } \\
\text { de educación básica en México. }\end{array}$ & $\begin{array}{l}\text { Perspectiva Educacional Formación De } \\
\text { Profesores. }\end{array}$ & 2014 & $\begin{array}{l}\text { Frida Díaz Barriga } \\
\text { Arceo, Ramsés Barroso } \\
\text { Bravo. }\end{array}$ \\
\hline 20 & $\begin{array}{l}\text { Modelo de gestión para diseño curricular } \\
\text { basado en prácticas de ingeniería de } \\
\text { software. }\end{array}$ & $\begin{array}{l}\text { Revista Electrónica De Investigación } \\
\text { Educativa. }\end{array}$ & 2015 & $\begin{array}{l}\text { Huizilopoztli Luna- } \\
\text { García } \\
\text { Francisco Javier } \\
\text { Álvarez-Rodríguez. } \\
\text { Ricardo Mendoza- } \\
\text { González. }\end{array}$ \\
\hline
\end{tabular}




\begin{tabular}{|c|c|c|c|c|}
\hline 21 & $\begin{array}{l}\text { La Práctica en la formación de } \\
\text { educadores en Brasil: Currículos } \\
\text { fracturados. }\end{array}$ & $\begin{array}{l}\text { Revista Electronica Universitaria De } \\
\text { Formación Del Profesorado. }\end{array}$ & 2016 & $\begin{array}{l}\text { Palazzo, J, } \\
\text { Gomes, .A. } \\
\text { RêgoPimentel. }\end{array}$ \\
\hline 22 & $\begin{array}{l}\text { Competencias Profesionales en } \\
\text { Educación para la Sostenibilidad desde la } \\
\text { Complejidad. }\end{array}$ & DIALNET & 2017 & $\begin{array}{l}\text { Rosa García, Mercè } \\
\text { Junyent, Marta } \\
\text { Fonolleda. }\end{array}$ \\
\hline 23 & $\begin{array}{l}\text { Integrando la Competencia Intercultural } \\
\text { en el curriculum mediante la } \\
\text { Telecolaboración. Propuesta de una } \\
\text { secuencia de tareas para la Educación } \\
\text { Superior }\end{array}$ & $\begin{array}{l}\text { DIALNET } \\
\text { Revista de Educación a Distancia }\end{array}$ & 2018 & $\begin{array}{l}\text { Luana Ferreira-Lopes, } \\
\text { María José Bezanilla } \\
\text { Iciar Elexpuru }\end{array}$ \\
\hline 24 & $\begin{array}{l}\text { Integración de la Sostenibilidad } \\
\text { Curricular Mediante la Elaboración de } \\
\text { Materiales Didácticos Digitales } \\
\text { Interactivos }\end{array}$ & $\begin{array}{l}\text { DIALNET } \\
\text { Repositorio Institucional Universidad de } \\
\text { la laguna }\end{array}$ & 2018 & $\begin{array}{l}\text { Alberto de la Rosa } \\
\text { Padilla, Ovidia Soto } \\
\text { Martín, Victoria Eugenia } \\
\text { Martín Osorio }\end{array}$ \\
\hline
\end{tabular}

Fuente: Autor.

(Galeano, 2009), en su artículo "Innovar en el currículo universitario: una propuesta de observatorio de objetos curriculares”, plantea algunos cuestionamientos: ¿Cómo innovar en el currículo universitario? ¿Cuáles son las teorías curriculares que alimentan la intención, el interés y cuáles las posibilidades de concreción en la práctica de la actual reforma curricular universitaria? El autor realiza la propuesta para un currículo integral denominado LocalGlobal, en ella se integran las funciones del profesor, del estudiante, la innovación y la aplicación de características del currículo y el conocimiento de lo local-global a través de la metodología de investigación en la que el estudiante plantea una problemática específica; cabe destacar que el método es abierto y su desarrollo corresponde a las etapas del método científico, en dicha propuesta no se definen problemas puntuales; así mismo expresa (González, 2011), que se pueden percibir los conceptos que recorren, ahora, la cultura universitaria desde lo académico, estos son, entre otros: el documento rector, los proyectos, el plan de formación, las innovaciones didácticas, las competencias, los elementos transversales al currículo, el saber hacer, la formación en investigación, la creatividad, las TIC, la evaluación entre pares, la coevaluación y la autoevaluación. Es claro que los profesores ven en la diversidad de estrategias didácticas innovadoras las múltiples posibilidades para desarrollar todos estos nuevos conceptos que están penetrando en el currículo.

(Sánchez \& González, 2009), expresan que la desarticulación y en consecuencia la falta de integración curricular, conllevan a que la educación se transforme en una secuencia de rupturas que se evidencian tanto en el plano pedagógico como administrativo, entre sus características presentan yuxtaposición de áreas y temáticas en el desarrollo de sus cursos, situación que genera la deserción estudiantil. Entre otras consecuencias, la desarticulación limita la educación permanente, genera niveles de calidad no homogéneos y restringe los procesos de certificación (Rama, 2009b, p17). En lo anteriormente descrito se configura un problema que afecta al currículo universitario en los actuales momentos, sobre el cual el planteamiento de un nuevo modelo, de gestión curricular, para un currículo que busca la integración, se debe asumir como una función institucional global e integradora de todas las fuerzas que conforman una organización, articuladas y correlacionadas para el logro de un propósito compartido, o de un objeto común. En el contexto de una institución de educación superior ese propósito común sería el logro de su misión. (Amaya, 1999, p.38). 
(Tovar \& Sarmiento, 2011), concluyen que la formación disciplinar es fundamental para el desempeño del docente universitario, sin embargo, para hacer más integral su labor, se hace necesario que comprenda y se involucre más activa y conscientemente en la fase del diseño curricular. En los procesos formativos de los docentes, se debe fortalecer lo relacionado con el diseño curricular de los programas académicos, en procura de mejorar, con su participación crítica, la pertinencia y la calidad del currículo; también es indispensable cualificar los procesos y mecanismos de participación de los demás actores implicados.

Entre tanto, (Barquín, Maiztegi, \& Medrano, 2012) elaboraron una propuesta curricular para definir los contenidos académicos para la educación superior, en ellos se expresan la necesidad de incluir (1) la Formación del equipo interdisciplinar y acercamiento a la materia, (2) Aportación de la materia al perfil profesional: establecimiento de las competencias, (3) Aportaciones disciplinares: selección de contenidos y establecimiento de objetivos y resultados de aprendizaje, (4) Organización pedagógica de la materia: diseño metodológico y de la evaluación; selección del material de trabajo; elaboración de la guía de la materia, (5) Implementación de la materia y revisión continua, (6) Evaluación de la materia por parte del profesorado y del alumnado. Socialización de las conclusiones y (7) Revisión y rediseño de la materia, estos aspectos son básicos para garantizar un currículo innovador.

Además (Luna, Álvarez \& Mendoza, 2015), proponen un modelo para administrar, coordinar y evaluar el proceso para el diseño de programas educativos. Esta alternativa complementa las metodologías tradicionales de diseño curricular mediante la integración de aspectos formales del modelado de procesos (Modelo de Boehm) propios de la Ingeniería de Software y del Modelo CMMI (CapabilityMaturityModelIntegration). El modelo genera varios formatos como guía para su implementación, en el que concluyen que definir las propuestas curriculares de las licenciaturas y coordinar el equipo de trabajo para su desarrollo se ha convertido en uno de los principales retos para la comunidad académica, ya que hace falta literatura especializada respecto a propuestas que ayuden a solucionar los problemas que ocurren en el proceso de creación de propuestas curriculares (Corvalán, et al., 2013), así como metodologías sistematizadas que hagan probable el logro de metas educativas específicas (Díaz-Barriga, 1984), además, no existe un instrumento que permita a los grupos de trabajo y a los departamentos de diseño y desarrollo curricular, administrar, coordinar y evaluar el proceso en un proyecto curricular (Departamento de Diseño Curricular (DDC) Universidad Autónoma de Aguascalientes (UAA), 2008).

De esta forma la construcción del currículo es fundamental para la comunidad crítica (Grundy, 1998), constituida por un conjunto de personas con preocupaciones mutuas, que interactúan directamente, cuyas relaciones se caracterizan por la solidaridad y la preocupación conjunta y ello es básico para orientar y mostrar los caminos más adecuados del currículo, así como para validar la generación de conocimiento, en términos generales lo que hace la institución educativa de cualquier nivel o enfoque (preescolar, técnica, no formal, posdoctorado, etc.) es "curricularizar", es decir, articular para prefigurar con sentido formativo la práctica educativo-pedagógica; esa es su razón de ser, es lo que la caracteriza como organización educativa, a diferencia de una organización financiera, comercial e industrial, etc. El currículo es uno de los aspectos prioritarios sobre los cuales ha girado gran parte de la discusión "científica" de la educación y que sigue siendo necesario abordar desde 
nuevas perspectivas para reflexionar acerca de la calidad de la educación. Si bien es cierto que hoy se pueden reconocer diversos enfoques y conceptualizaciones con sustanciales variaciones, no parece haber todavía una tematización que permita asumirlo como una categoría propia de la explicación educativa. (Álvarez, 2010).

Entre tanto los estudios de (García, Junyent \& Fonolleda, 2017), (Ferreira, Bezanilla y Elexpuru, 2018) y (de la Rosa, Soto \& Martín, 2018) vinculan la categoría de desarrollo sostenible así:

(García, Junyent \& Fonolleda, 2017) formulan la necesidad de vincular la práctica educativa con el desarrollo sostenible. Lo que implica el desarrollo de competencias profesionales en educación para la sostenibilidad. proponiendo un marco de referencia denominado CESC con base en cuatro dominios competenciales: Learning to know, Learning to live together, Learning to be y Learning to do, Además de seis categorías de complejidad: Conexiones, Diálogo, Creatividad, Innovación, Pensamiento Crítico e Incertidumbre- y cincuenta y tres competencias.

(Ferreira, Bezanilla y Elexpuru, 2018) plantean una secuencia de tareas de telecolaboración para el desarrollo de la competencia intercultural en el currículo universitario a partir de la propuesta de O'Dowd \& Ware (2009), en la actualidad se encuentra en fase experimental en dos proyectos de telecolaboración.

(de la Rosa, Soto \& Martín, 2018) concluyen un elevado éxito y satisfacción por parte del alumnado en las asignaturas de prácticas externas y TFM para las habilidades en los entornos profesionales del siglo XXI mediante la elaboración de material didáctico digital.

Tal como lo expresan las anteriores publicaciones, uno de los retos de la comunidad académica consiste en la actualización pertinente de los currículos, debido a que los estos tienen su propia dinámica y la falta de instrumentos especializados dificultan su homogeneidad.

\section{- Gestión curricular para Educación Básica y Media.}

Las publicaciones cuyo título expresan intervención curricular desde la gestión se analizaron a profundidad para determinar los enfoques investigativos, en tal sentido se encuentran significativos aportes que permiten dar una luz para el diseño de un modelo curricular que permita integrar los diferentes aspectos que se deben considerar para establecer currículos pertinentes para los actuales desafíos educativos.

Tabla 6: Artículos gestión curricular para a educación básica y media.

\begin{tabular}{|l|l|l|l|l|}
\hline $\mathrm{N}^{\mathbf{0}}$ & \multicolumn{1}{|c|}{ Título } & \multicolumn{1}{c|}{ Revista } & \multicolumn{1}{c|}{ Añoror(es) } \\
\hline 1 & $\begin{array}{l}\text { Acortando la distancia entre la escuela } \\
\text { y la comunidad - Experiencia de } \\
\text { construcción de un currículo }\end{array}$ & Visão Global, Joaçaba. & 2010 & $\begin{array}{l}\text { Zayda Sierra } \\
\text { SabineeSiniguí } \\
\text { Alexandra Henao. }\end{array}$ \\
\hline
\end{tabular}




\begin{tabular}{|c|c|c|c|c|}
\hline & $\begin{array}{l}\text { intercultural en la Institución Educativa } \\
\text { Karmata Rúa del Resguardo Indígena } \\
\text { de Cristianía, Colombia. }\end{array}$ & & & \\
\hline 2 & $\begin{array}{l}\text { El enfoque de competencias y el } \\
\text { currículum del bachillerato en México. }\end{array}$ & $\begin{array}{l}\text { Revista Latinoamericana de ciencias } \\
\text { sociales, niñez y juventud. } \\
\text { Rev.latinoam.cienc.soc.niñezjuv. }\end{array}$ & 2010 & $\begin{array}{l}\text { Rocío Adela Andrade } \\
\text { Cázares } \\
\text { Sara Catalina } \\
\text { Hernández Gallardo. }\end{array}$ \\
\hline 3 & $\begin{array}{l}\text { Las competencias clave como elemento } \\
\text { central del currículo de la enseñanza } \\
\text { obligatoria: un repaso a las experiencias } \\
\text { europeas. }\end{array}$ & $\begin{array}{l}\text { Revista Española de Educación } \\
\text { Comparada. }\end{array}$ & 2010 & $\begin{array}{l}\text { Inmaculada Egido } \\
\text { Gálvez. }\end{array}$ \\
\hline 4 & $\begin{array}{l}\text { Los discursos sobre el cuerpo en el } \\
\text { currículo oficial: una aproximación al } \\
\text { Diseño Curricular Nacional. }\end{array}$ & Educación. & 2010 & $\begin{array}{l}\text { José Luis } \\
\text { Rosales Lassús. }\end{array}$ \\
\hline 5 & $\begin{array}{l}\text { Integración Curricular: respuesta al reto } \\
\text { de educar en y desde la diversidad. }\end{array}$ & Educar em Revista. & 2011 & $\begin{array}{l}\text { Nuria IllánRomeu Jesús } \\
\text { Molina Saorín. }\end{array}$ \\
\hline 6 & $\begin{array}{l}\text { Los estándares en el currículo y } \\
\text { La evaluación: ¿relaciones De } \\
\text { medición, control y homogenización o, } \\
\text { posibilidad de formación, diversidad y } \\
\text { evaluación crítica? }\end{array}$ & $\begin{array}{l}\text { Revista Electrónica Interuniversitaria de } \\
\text { Formación del Profesorado. }\end{array}$ & 2013 & $\begin{array}{l}\text { Niño, L.E. \& } \\
\text { Bermúdez, A. }\end{array}$ \\
\hline 7 & $\begin{array}{l}\text { El método interpretativo de Von } \\
\text { Savigny en el análisis de la legislación } \\
\text { educativa: un estudio de casos sobre el } \\
\text { currículo de Primaria. }\end{array}$ & Revista de Educación y Derecho. & 2013 & $\begin{array}{l}\text { Alfredo López De } \\
\text { Sosoaga López De } \\
\text { Robles. }\end{array}$ \\
\hline 8 & $\begin{array}{l}\text { Bogotá bilingüe: tensión entre política, } \\
\text { currículo y realidad escolar. }\end{array}$ & Educ.Educ. & 2014 & $\begin{array}{l}\text { Yamith José Fandiño- } \\
\text { Parra. }\end{array}$ \\
\hline 9 & $\begin{array}{l}\text { Una propuesta para ambientalizar el } \\
\text { currículo. }\end{array}$ & Cuadernos de Pedagogía. & 2015 & $\begin{array}{l}\text { GeninaCalafell, } \\
\text { MercèJunyent Y Josep } \\
\text { Bonil. }\end{array}$ \\
\hline 10 & $\begin{array}{l}\text { Hacia una teoría de acción en gestión } \\
\text { curricular: Estudio de caso de } \\
\text { enseñanza secundaria en matemática. }\end{array}$ & $\begin{array}{l}\text { Psicoperspectivas } \\
\text { Individuo y Sociedad. }\end{array}$ & 2015 & $\begin{array}{l}\text { Paulo Volante, } \\
\text { Francisca Bogolasky, } \\
\text { Fabián Derby, } \\
\text { Gabriel Gutiérrez. }\end{array}$ \\
\hline 11 & $\begin{array}{l}\text { La competencia mediática en el } \\
\text { currículo escolar: ¿espacio para } \\
\text { innovaciones educativas con } \\
\text { tecnologías de la información y la } \\
\text { comunicación? }\end{array}$ & Innovación Educativa. & 2016 & Isabel Pérez Ortega. \\
\hline 12 & $\begin{array}{l}\text { El enfoque intercultural en el currículo } \\
\text { de telesecundaria -elementos para una } \\
\text { reflexión crítica. }\end{array}$ & Sinética Revista Electrónica de Educación. & 2016 & MaikeKreisel. \\
\hline
\end{tabular}

Fuente: Autor

\subsection{Categoría 5: Evaluación metodológica}

De los artículos mencionados en la tabla anterior se analizan a profundidad aspectos tales como palabras clave, preguntas de investigación, ejes temáticos, diseño metodológico, problemáticas sociales, principios de innovación, Modelos gráficos curriculares y conclusiones, así:

Tabla 7: Análisis diseño metodológico.

\begin{tabular}{|c|c|c|c|c|c|}
\hline & \multirow[t]{2}{*}{ Texto } & \multicolumn{4}{|c|}{ Diseño Metodológico } \\
\hline & & Enfoque & Alcance & Tipo & $\begin{array}{l}\text { Instrumentos/ } \\
\text { Técnicas }\end{array}$ \\
\hline 1 & $\begin{array}{l}\text { Acortando la distancia entre la escuela y la } \\
\text { comunidad - Experiencia de construcción de } \\
\text { un currículo intercultural en la Institución } \\
\text { Educativa Karmata Rúa del Resguardo } \\
\text { Indígena de Cristianía, Colombia. }\end{array}$ & Cualitativo. & Descriptivo. & $\begin{array}{l}\text { Experimental } \\
\text { Investigación } \\
\text { acción } \\
\text { participativa. }\end{array}$ & $\begin{array}{lr}\text { No se } & \text { incluyen } \\
\text { instrumentos, pero en la } \\
\text { redacción } & \text { manifiestan } \\
\text { realizar } & \text { juegos } \\
\text { dramáticos } & \text { y otras } \\
\text { actividades } & \text { lúdico-artís- } \\
\text { ticas, que } & \text { implican la }\end{array}$ \\
\hline
\end{tabular}




\begin{tabular}{|c|c|c|c|c|c|}
\hline & & & & & $\begin{array}{lll}\text { elaboración de } & \text { los } \\
\text { mismos. } & & \\
\end{array}$ \\
\hline 2 & $\begin{array}{l}\text { La competencia mediática en el currículo } \\
\text { escolar: ¿espacio para innovaciones } \\
\text { educativas con tecnologías de la } \\
\text { información y la comunicación? }\end{array}$ & Cualitativo. & Exploratorio. & $\begin{array}{l}\text { No } \\
\text { experimental. }\end{array}$ & $\begin{array}{l}\text { Técnicas: } \\
\text { Observación. } \\
\text { Entrevistas. } \\
\text { Instrumentos. }\end{array}$ \\
\hline 3 & $\begin{array}{l}\text { El enfoque intercultural en el currículo de } \\
\text { telesecundaria -elementos para una } \\
\text { reflexión crítica. }\end{array}$ & Cualitativo. & Descriptivo. & $\begin{array}{l}\text { No } \\
\text { experimental } \\
\text { Etnográfico. }\end{array}$ & $\begin{array}{l}\text { Técnicas: } \\
\text { Observación. } \\
\text { Entrevistas. } \\
\text { Instrumentos: } \\
\text { Guías semi-estructuradas } \\
\text { para entrevistas. } \\
\text { Registros } \\
\text { Observación. de }\end{array}$ \\
\hline 4 & $\begin{array}{l}\text { Bogotá bilingüe: tensión entre política, } \\
\text { currículo y realidad escolar. }\end{array}$ & Cualitativo. & Descriptivo. & $\begin{array}{l}\text { Diseño: } \\
\text { No } \\
\text { experimental. }\end{array}$ & $\begin{array}{l}\text { Técnica: } \\
\text { Análisis documental }\end{array}$ \\
\hline 5 & $\begin{array}{l}\text { Los estándares en el currículo y } \\
\text { La evaluación: ¿relaciones De medición, } \\
\text { control y homogenización o, posibilidad de } \\
\text { formación, diversidad y evaluación crítica? }\end{array}$ & Cualitativo. & Descriptivo. & $\begin{array}{l}\text { Diseño } \\
\text { Experimental }\end{array}$ & $\begin{array}{l}\text { Técnicas: } \\
\text { Análisis documental } \\
\text { Entrevistas semi- } \\
\text { estructurada } \\
\text { Encuestas } \\
\text { (talleres evaluativos) }\end{array}$ \\
\hline 6 & $\begin{array}{l}\text { El método interpretativo de Von Savigny en } \\
\text { el análisis de la legislación educativa: un } \\
\text { estudio de casos sobre el currículo de } \\
\text { Primaria. }\end{array}$ & Cualitativo. & $\begin{array}{l}\text { Alcance } \\
\text { Descriptivo. }\end{array}$ & $\begin{array}{l}\text { Diseño } \\
\text { No } \\
\text { experimental. }\end{array}$ & $\begin{array}{l}\text { Técnica: } \\
\text { Análisis documental. }\end{array}$ \\
\hline 7 & $\begin{array}{l}\text { El enfoque de competencias y el currículum } \\
\text { del bachillerato en México. }\end{array}$ & Cualitativo. & Descriptivo. & $\begin{array}{l}\text { No } \\
\text { Experimental } \\
\text { Método } \\
\text { Historial oral } \\
\text { temática. } \\
\end{array}$ & $\begin{array}{l}\text { Técnica } \\
\text { Entrevista. }\end{array}$ \\
\hline 8 & $\begin{array}{l}\text { Las competencias clave como elemento } \\
\text { central del currículo de la enseñanza } \\
\text { obligatoria: un repaso a las experiencias } \\
\text { europeas. }\end{array}$ & Cualitativo. & Exploratorio. & $\begin{array}{l}\text { No } \\
\text { Experimental }\end{array}$ & $\begin{array}{l}\text { Técnica: } \\
\text { Análisis documental. }\end{array}$ \\
\hline 9 & $\begin{array}{l}\text { Acortando la distancia entre la escuela y la } \\
\text { comunidad - Experiencia de construcción de } \\
\text { un currículo intercultural en la Institución } \\
\text { Educativa Karmata Rúa del Resguardo } \\
\text { Indígena de Cristianía, Colombia. }\end{array}$ & Cualitativo. & Descriptivo. & $\begin{array}{l}\text { No } \\
\text { Experimental } \\
\text { Método } \\
\text { Historial oral } \\
\text { temática. } \\
\end{array}$ & $\begin{array}{l}\text { Técnica: } \\
\text { Análisis documental. }\end{array}$ \\
\hline 10 & $\begin{array}{l}\text { La competencia mediática en el currículo } \\
\text { escolar: ¿espacio para innovaciones } \\
\text { educativas con tecnologías de la } \\
\text { información y la comunicación? }\end{array}$ & Mixto. & Explicativa. & Experimental. & $\begin{array}{l}\text { Enuncian elaboración de } \\
\text { talleres para el modelado }\end{array}$ \\
\hline 11 & $\begin{array}{l}\text { El enfoque intercultural en el currículo de } \\
\text { telesecundaria -elementos para una } \\
\text { reflexión crítica. }\end{array}$ & Cualitativo & Explicativa & $\begin{array}{l}\text { Experimental } \\
\text { Estudio de caso. }\end{array}$ & $\begin{array}{l}\text { Análisis documental } \\
\text { Grupos focales } \\
\text { Entrevistas. }\end{array}$ \\
\hline 12 & $\begin{array}{l}\text { Los discursos sobre el cuerpo en el } \\
\text { currículo oficial: una aproximación al } \\
\text { Diseño Curricular Nacional. }\end{array}$ & Mixto. & Descriptivo. & $\begin{array}{l}\text { Diseño } \\
\text { Experimental. }\end{array}$ & $\begin{array}{l}\text { Entrevistas } \\
\text { Estructuradas } \\
\text { Grupos focales. }\end{array}$ \\
\hline
\end{tabular}

Fuente: Autor

\section{- Palabras clave}

Partiendo de "Currículo" como palabra clave que constituye el común denominador en los artículos, también se identifican conceptos como: Proceso organizativos comunitarios, Educación intercultural, políticas educativas, Conocimiento Social y Político, Estándares, Currículo del bachillerato, proceso enseñanza-aprendizaje, Competencias clave, diseño curricular, alineamiento curricular, Gestión curricular, Integración curricular, diversidad 
educativa, entre otras, estas palabras fueron fundamentales en las publicaciones puesto que permitieron identificar el enfoque e intencionalidad del investigador sobre el tema, además al complementarlas con la lectura del resumen, se mejora el análisis para la clasificación de las publicaciones.

\section{- Preguntas de Investigación}

Las preguntas giran alrededor de cómo las instituciones educativas diseñan sus currículos educativos, así mismo formulan interrogantes sobre: ¿Qué alternativas curriculares pueden generarse que permitan el fortalecimiento organizativo comunitario desde la institución escolar? ¿Cómo se desarrolla el Currículum del Bachillerato General por Competencias desde la visión de las personas involucradas en la práctica educativa? ¿Cuáles son las principales áreas donde se vislumbran necesidades en términos de gestión curricular y alineamiento? ¿Cumplen los establecimientos expertos con las expectativas que surgen del levantamiento de necesidades? En este sentido, las preguntas de investigación definen el interés de los investigadores por encontrar solución a los retos que plantea la actual sociedad del conocimiento.

\section{- Ejes temáticos}

Los conceptos temáticos y teóricos abordados en las diferentes investigaciones permitieron identificar los fundamentos que los autores tomaron de referencia para sustentar sus propuestas sobre el currículo, entre ellas se destacan:

Interculturalidad ( Sierra, Siniguí, Henao, 2010), los investigadores indican que ésta se construye de la interrelación de cinco dimensiones (i)Integración de contenido: inclusión de diversas voces en el currículo, en vez de la mera perspectiva eurocéntrica, (ii) Proceso de construcción del conocimiento: reconocimiento del conocimiento como fenómeno socialmente construido, (iii) Reducción del prejuicio: promoción de actitudes positivas hacia grupos de origen étnico diverso, (iv) Pedagogía de la equidad: procesos de enseñanza que se adapten a las necesidades y los talentos únicos de una población estudiantil diversa, (v) Cultura escolar y estructura social de empoderamiento: escuelas que reflejen la naturaleza pluralista de la sociedad a través de reformas a la cultura escolar que promuevan la equidad y una mayor participación de estudiantes de grupos hasta ahora excluidos en las decisiones políticas y educativas.

Sintetizan en la investigación, que el currículo estructurado y organizado por competencias básicas no contribuye por si solo a promover cambios ni mejoras pedagógicas con recursos digitales. Si cumple, sin embargo, con su función de validar determinados saberes escolarizados porque la sola promoción de cambios o mejoras pedagógicas en los currículos escolares no implica su implementación de manera extendida e igualitaria. 
Para el estudio del programa de Bogotá Bilingüe (PBB), los autores describen que el concepto de currículo implica discutir sobre una articulación entre objetivos, modelos y módulos educacionales que busquen desarrollar la habilidad para usar dos o más lenguas con facilidad y eficacia (Siguan, 1986). Para Ferguson, Houghton y Well (1977), dicha articulación se puede dar desde tres tipos de educación bilingüe: transaccional, de mantenimiento y de enriquecimiento. Cada tipo es movido por intencionalidades y actividades que van desde la integración social, la conservación cultural o el enriquecimiento lingüístico; factores que a la vez influyen esencialmente en decisiones sobre la metodología. Al respecto Halbach (2008), afirma que una de las principales características metodológicas de la educación bilingüe debe ser la coordinación entre la enseñanza de lengua y la enseñanza de contenidos (Fandiño,2014).

Según la Comisión de las Comunidades Europeas (2006), las competencias clave deben estar presentes en todos los jóvenes al finalizar su proceso de formación de básica secundaria, en términos de (i) Comunicación en lengua materna, (ii) Comunicación en lenguas extranjeras, (iii) Competencia matemática y competencias básicas en ciencia y tecnología (iv) Competencia digital, (v) Aprender a aprender, (vi) Competencias sociales y cívicas, (vii) Sentido de la iniciativa y espíritu de empresa y (viii) Conciencia y expresión cultural (Egido, 2011).

En la publicación "Los discursos sobre el cuerpo en el currículo oficial: una aproximación al Diseño Curricular Nacional" el autor analiza los discursos sobre el cuerpo en el currículo oficial a lo largo de los tres niveles de la Educación Básica Regular (inicial, primaria y secundaria). El análisis evidencia cinco tipos de cuerpo: (i) el cuerpo que conoce, (ii) el cuerpo expresivo, (iii) el cuerpo como marca de la personalidad, (iv) el cuerpo universal (objetivo), y (v) el cuerpo móvil. El estudio explicita los cambios que ocurren en estos discursos a lo largo de los tres niveles de la educación básica (Rosales, 2010), aspectos a tener en cuenta para cualquier tipo de propuesta curricular. Así mismo, expresan (Calafell, Junyent\&Bonil, 2015), en su artículo "Una propuesta para ambientalizar el currículo" que para avanzar en la ambientalización curricular desde la complejidad (autoría compartida, 2012), se deben tener en cuenta aspectos esenciales como: (i) La transformación del entorno desde la incorporación de la relación medio y sociedad para la sostenibilidad, (ii) El desarrollo del pensamiento crítico y creativo de los alumnos desde un diálogo entre ser profesional y ser ciudadano, (iii) El empoderamiento de los alumnos, los profesores y las instituciones. La esfera metodológica lleva a la reflexión sobre las opciones de cómo se realizará la acción formativa y qué estrategias didácticas se utilizarán en la actividad, manteniendo una coherencia y pertinencia con la idea vector y las esferas conceptual y creativa. Esta dimensión implica decisiones en relación con la dinámica de aula, los instrumentos didácticos, la organización de los participantes, el rol del profesorado, la temporización y secuenciación de la acción y la forma de evaluar.

En la publicación "Hacia una teoría de acción en gestión curricular: Estudio de caso de enseñanza secundaria en matemática" los investigadores realizaron un rastreo bibliográfico en el que destacaron los conceptos de Marzano (2003), Marzano, Waters y McNulty(2005), 
Porter (2004), Webb (2007) y Bambrick-Santoyo (2010); estos representan diferentes niveles de solución tanto a nivel estatal como local y a nivel de establecimiento para el denominado problema de la gestión curricular. Es así como, Marzano, Waters y McNulty (2005), realizan un meta-análisis para evaluar los reportes de tres décadas de investigaciones sobre el efecto liderazgo, las conclusiones del equipo son contundentes respecto a la necesidad de vincular lo que ocurre en el aula con lo que se espera que suceda a nivel de establecimientos, dicho análisis lo aborda bajo 7 pasos: (Paso 1) Identificar y comunicar los contenidos considerados esenciales para todos los estudiantes, (Paso 2) Asegurar que los contenidos esenciales sean entregados en el tiempo necesario y programado para su enseñanza, (Paso 3) Secuenciar y organizar los contenidos esenciales de forma tal que los estudiantes tengan reiteradas oportunidades de aprenderlos, (Paso 4) Asegurar que los profesores del nivel se focalicen en estos contenidos esenciales durante sus sesiones de clases, (Paso 5) Proveer estrategias y recursos para proteger el tiempo de enseñanza de los contenidos esenciales, (Paso 6) Proveer retroalimentación y tiempo recuperativo para asegurar el aprendizaje de los contenidos esenciales en los estudiantes que requieren de soporte adicional y (Paso 7) Distribuir la información en los diversos agentes que están comprometidos con el dominio de los contenido.

Porter (2004), desde una perspectiva macro, se ocupa del alineamiento a nivel nacional y se pregunta cómo las decisiones locales son coherentes con las expectativas de políticas centrales. Así, la evaluación del currículo se definiría como la medición del contenido académico de los currículos pretendido, actuado y evaluado, así como las diferencias y similitudes entre ellos. En la medida que el contenido es el mismo en ellos, se plantea que están efectivamente alineados. Porter y Smithson (2001), desarrollan un set de procedimientos para realizar análisis de contenido y datos para diferentes tipos de material educacional (textos, estándares y evaluaciones). El procedimiento comienza por realizar análisis de contenido de los estándares nacionales (o estatales en ese caso, luego, se genera una estadística única de alineamiento que fluctúa entre 0 (no hay alineamiento) a 1 (alineamiento perfecto). El procedimiento, sin embargo, no señala cuánto alineamiento es suficiente, por lo que se requiere una decisión de política y gestión. El análisis opera con un sistema de encuestas, en las cuales los docentes reportan el contenido enseñado en sus clases. Luego, actúa un panel de tres o más especialistas en contenido que estipulan el nivel de cobertura para las temáticas y sub-temáticas declaradas.

Bambrick-Santoyo (2010), desarrolla un modelo que se sitúa a nivel del establecimiento. En este sentido, propone cuatro principios fundamentales para realizar una instrucción orientada por datos: (i) Evaluación: desarrollar evaluaciones rigurosas que provean datos significativos, (ii) Análisis: se trata de examinar los resultados de las evaluaciones, identificando causas de las fortalezas y de las debilidades para la toma de decisiones y aprendizaje duradero, (iii) Acción: enseñar efectivamente lo que los estudiantes deben aprender, (iv) Cultura: supone generar un ambiente en el que la instrucción orientada por datos pueda prosperar. Esto implica un cambio en los estilos de liderazgo educacional, privilegiando prácticas orientadas al uso y toma de decisiones basadas en la evidencia. En síntesis, estos antecedentes proveen de modelos y prácticas expertas que permiten configurar una lógica y ciertas condiciones para la gestión curricular, la que está orientada a conseguir consistencia en políticas y planes de enseñanza como también a facilitar el alineamiento de 
los agentes en función de aumentar oportunidades de aprendizaje. Estos antecedentes permiten indagar y realizar un contraste inicial con experiencias y casos situados en el sistema escolar nacional (Volante, Bogolasky, Derby \& Gutiérrez, 2015).

Para finalizar, en la investigación de (Illán \& Molina , 2011) citan a (Illán; Pérez, 1999, p. 20), definiendo la integración curricular como [...] una modalidad de diseño del currículo, fundamentado en la concurrencia/colaboración/interconexión de los contenidos de varias disciplinas, para abordar un aspecto de la cultura escolar, a través de un modelo de trabajo cooperativo de profesores que incide, en la metodología, en la evaluación y en el clima general del centro, y señalan diferentes modalidades:

Integración Curricular relacionando varias disciplinas. Supone coordinar las programaciones de varias disciplinas afines.

Integración Curricular a través de tópicos. Las áreas implicadas coordinan sus programaciones alrededor de un centro de interés (tema). A partir de ese momento, no existe relación jerárquica entre ellas, sino que los intereses quedan subordinados a la propia interacción.

Integración Curricular a través de cuestiones de la vida cotidiana. Desarrollando temas transversales difícilmente abordables desde el tratamiento unipolar que ofrece una sola disciplina.

Integración Curricular a través de temas seleccionados por el alumnado. Organizando los contenidos alrededor de aquellos temas que los propios alumnos han seleccionado.

Integración Curricular a través de conceptos. Se utilizan en grupos de alumnos con edades avanzadas (final de la ESO, Bachillerato, etc.), pues requiere una cierta madurez y dominio del pensamiento abstracto asociado a los conceptos (modernidad, tecnología, espacio, marginación, etc.).

Integración Curricular a través de bloques históricos y/o geográficos. Se organizan los contenidos y las áreas a partir de acontecimientos históricos, espacios geográficos o periodos de la humanidad (la cultura egipcia, el Mar Mediterráneo, Afganistán, el Imperialismo Español, etc.).

Integración Curricular a través de culturas o instituciones. Se organiza el currículo tomando como referente algunos grupos humanos significativos o alguna institución, asociación, organismo o corporación creada por las personas (los árabes, las sectas, las asociaciones, las ONG, las residencias para ancianos, las prisiones para menores, etc.).

Integración Curricular a través de grandes descubrimientos o inventos. Se utilizan los descubrimientos e inventos como ejes vertebradores del currículo (la energía solar, el teléfono móvil, la electricidad, el autogiro, la vacuna, la pasteurización, el ordenador, Internet, etc.).

Los conceptos antes mencionados fortalecen los enfoques temáticos de los investigadores y brindan un apoyo conceptual y teórico para la actual propuesta de investigación. 


\section{- Problemáticas sociales}

El rastreo bibliográfico tiene como génesis el currículo educativo, en este sentido emergen diferentes connotaciones por las cuales este debe suplir y atender a las falencias y retos de la sociedad. (Niño \& Bermúdez, 2013) describen que la puesta en marcha de la política de estandarización en América Latina, particularmente en la primera década del siglo XXI, ha sido el resultado de unas políticas educativas pensadas desde la perspectiva económica y política y mediada por el Capitalismo el cual a través de la globalización de la ideología neoliberal viene desplegando todo su poder, con el fin de imponer un dispositivo social capaz de hacer control y vigilancia a todos los sistemas educativos latinoamericanos. Todo esto se hace a través del Currículo Único, la evaluación como rendición de cuentas de las instituciones y de los individuos desde la misma "despedagogización" y desprofesionalización de la profesión docente y la creciente política de desprestigio de la educación pública. Son estas las banderas que han cambiado la brújula de la formación de calidad en la educación.

La enorme desarticulación de las instituciones escolares con los contextos de vida de estudiantes y docentes, ha impactado en poblaciones históricamente sometidas a situaciones de marginalidad y opresión, pues les impide adquirir herramientas de pensamiento y de acción orientadas a explicarse y enfrentar los factores de dominación, pobreza, violencia y alienación que les afectan.

Bajo el argumento de una preparación para la vida del trabajo, el desarrollo y el progreso, se ha venido imponiendo a niños, niñas y jóvenes de sectores pobres de muy distintas latitudes rurales y urbanas, un currículo orientado exclusivamente a perfeccionar ciertas destrezas laborales, mientras se transfiere su capacidad de pensar crítica y creativamente; de explorar alternativas que contribuyan con el mejoramiento de las condiciones de existencia de sus familias y comunidades, según (Baudelot; Establet, 1976; Reimes, 2000; Llach, 2004) citado por (Sierra, Siniguí, Henao, 2010).

(Sierra, Siniguí\& Henao, 2010), proponen un currículo que atienda situaciones locales tales como: alcoholismo y drogadicción, violencia intrafamiliar, pérdida de identidad, medio ambiente y contaminación; situación que no ha sido fácil abordar desde la escuela, debido a la falta de metodologías y capacidad institucional para generar soluciones con el trabajo de la comunidad.

\section{- Consideraciones de innovación educativa}

Se analizaron las publicaciones en términos de la presencia de la innovación educativa mediante la clasificación de componentes que incluyen Tecnologías, Procesos, Personas y Conocimiento (Fidalgo, 2011). Sus consideraciones son: 
Tecnologías: uso de herramientas. Diseño de herramienta para el propio proceso de aprendizaje (poco habitual) o la adaptación de herramientas existentes en el mercado (aplicación de las TIC).

Procesos: uso de metodologías que mejoran las existentes y reducen el esfuerzo en la aplicación, ya sean conocidas y muy utilizadas, o poco utilizadas y no conocidas.

Personas: la innovación docente es integrante, no excluyente. Esto significa que debe tener en cuenta la implicación y repercusión de la propia innovación en todos los actores que intervienen.

Conocimiento: hace relación a los objetivos del proceso de aprendizaje.

Tabla 8: Análisis innovación educativa.

\begin{tabular}{|c|c|c|c|c|c|}
\hline & \multirow[t]{2}{*}{ Texto } & \multicolumn{4}{|c|}{ Innovación Educativa } \\
\hline & & Tecnología & Procesos & Personas & Conocimiento \\
\hline 1 & $\begin{array}{l}\text { Acortando la distancia entre la escuela y la co- } \\
\text { munidad - Experiencia de construcción de un } \\
\text { currículo intercultural en la Institución Educativa } \\
\text { Karmata Rúa del Resguardo Indígena de Cristianía, } \\
\text { Colombia. }\end{array}$ & $\mathrm{X}$ & $\mathrm{X}$ & $\mathrm{X}$ & $\mathrm{X}$ \\
\hline 2 & $\begin{array}{l}\text { El enfoque intercultural en el currículo de } \\
\text { telesecundaria -elementos para una reflexión crítica. }\end{array}$ & $\mathrm{X}$ & $\mathrm{X}$ & $\mathrm{X}$ & $\mathrm{X}$ \\
\hline 3 & $\begin{array}{l}\text { Bogotá bilingüe: tensión entre política, currículo y } \\
\text { realidad escolar. }\end{array}$ & & $\mathrm{X}$ & $\mathrm{X}$ & $\mathrm{X}$ \\
\hline 4 & $\begin{array}{l}\text { La competencia mediática en el currículo escolar: } \\
\text { ¿espacio para innovaciones educativas con } \\
\text { tecnologías de la información y la comunicación? }\end{array}$ & & $\mathrm{X}$ & $\mathrm{X}$ & $\mathrm{X}$ \\
\hline 5 & $\begin{array}{l}\text { El enfoque intercultural en el currículo de } \\
\text { telesecundaria -elementos para una reflexión crítica. }\end{array}$ & $\mathrm{X}$ & $\mathrm{X}$ & $\mathrm{X}$ & $\mathrm{X}$ \\
\hline 6 & $\begin{array}{l}\text { Los discursos sobre el cuerpo en el } \\
\text { currículo oficial: una aproximación al } \\
\text { Diseño Curricular Nacional. }\end{array}$ & & $\mathrm{X}$ & $\mathrm{X}$ & $\mathrm{X}$ \\
\hline
\end{tabular}

Fuente: Autor

En los artículos analizados se evidencia la presencia de conceptos de innovación educativa, según los criterios de (Fidalgo, 2011), se evidencia la necesidad de adelantar un rastreo bibliográfico más crítico que permita determinar cada aspecto y su nivel de complejidad desde los niveles administrativo y operativo.

\section{- Modelos gráficos curriculares}

Las representaciones gráficas expresadas en los artículos indican los siguientes enfoques. 


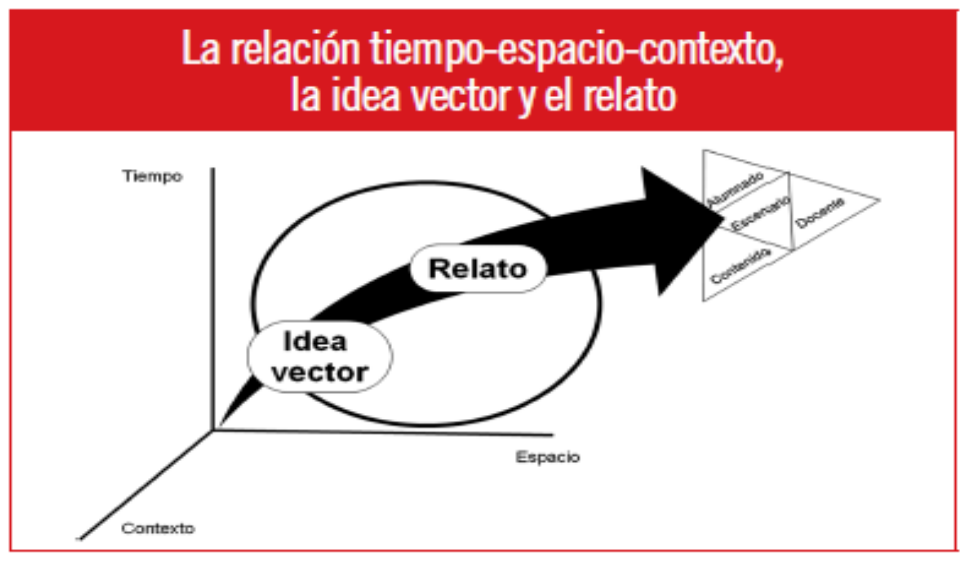

Ilustración 3: Modelo vector.

Fuente: Tomado de: (Calafell, Junyent \& Bonil, 2015)

El modelo educativo que se presenta propone una relación entre tiempo, espacio y contexto en el que emerge una idea principal que puede focalizar la acción educativa. Esta idea principal la denomina el autor "idea vector", la cual orienta y guía toda la acción educativa y es una manera de aproximarse al mundo desde la transformación.

Así mismo (Volante, Bogolasky, Derby, Gutiérrez, 2015) presentan el modelo de gestión curricular TE 10I008:

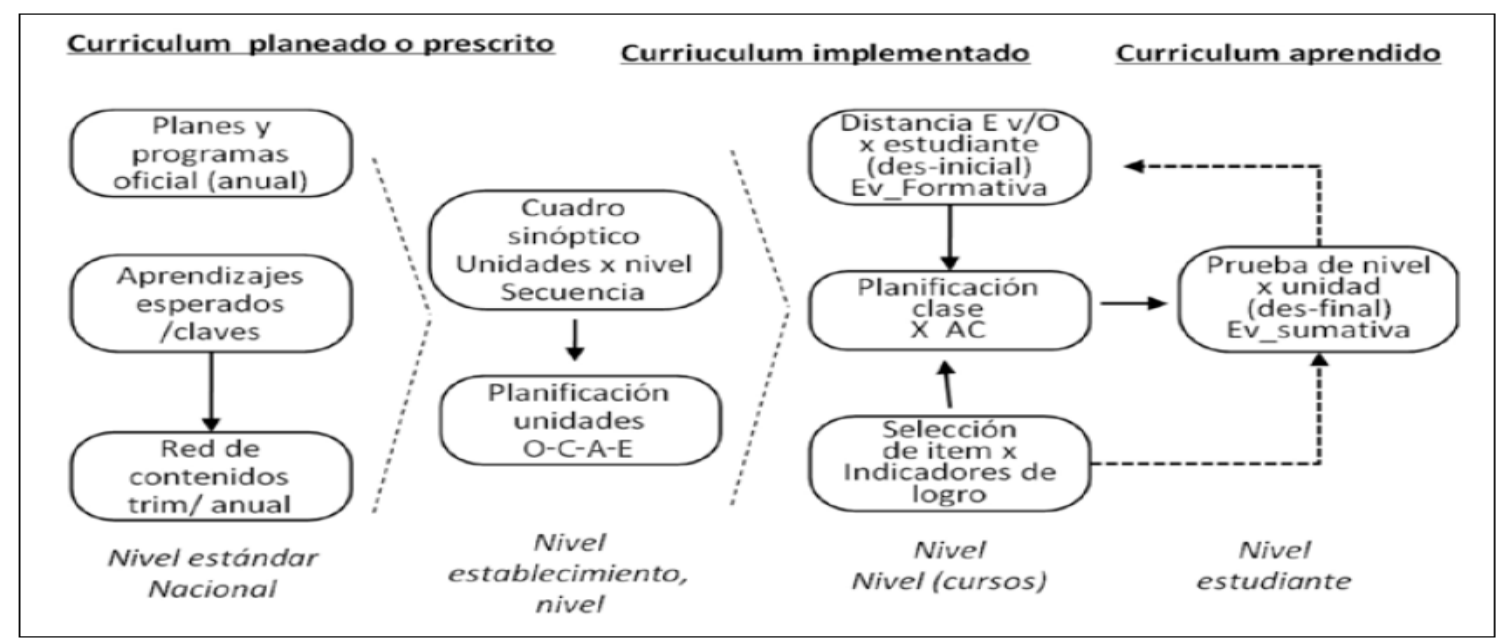

Ilustración 4: Modelo de gestión curricular TE 101008.

Fuente: (Volante, Bogolasky, Derby, Gutiérrez, 2015).

De esta manera, el modelo de Gestión Curricular TE 10I008, versión 1.0, se fundamenta en los conocimientos y experticia situada de gestores y docentes que efectivamente trabajan para implementar y lograr aprendizajes en los estudiantes de modo que se genere una secuencia lógica para el manejo de las unidades temáticas con los respectivos tiempos e hitos asociados a los contenidos curriculares en el que se tienen en cuenta aspectos como: La planificación por unidades, incorporando objetivos $(\mathrm{O})$, contenidos $(\mathrm{C})$, aprendizajes esperados (A) y evaluación (E) para cada unidad (O-C-A-E) 
(Illán, Molina, 2011) presentan el modelo de diseño, desarrollo y evaluación de unidades didácticas integradas bajo un marco metodológico de (i) principios de intervención educativa, (ii) estructura organizativa del aula y (ii) colaboración familia, un modelo que participa plenamente de los presupuestos teóricos en los que se sustenta el constructivismo.

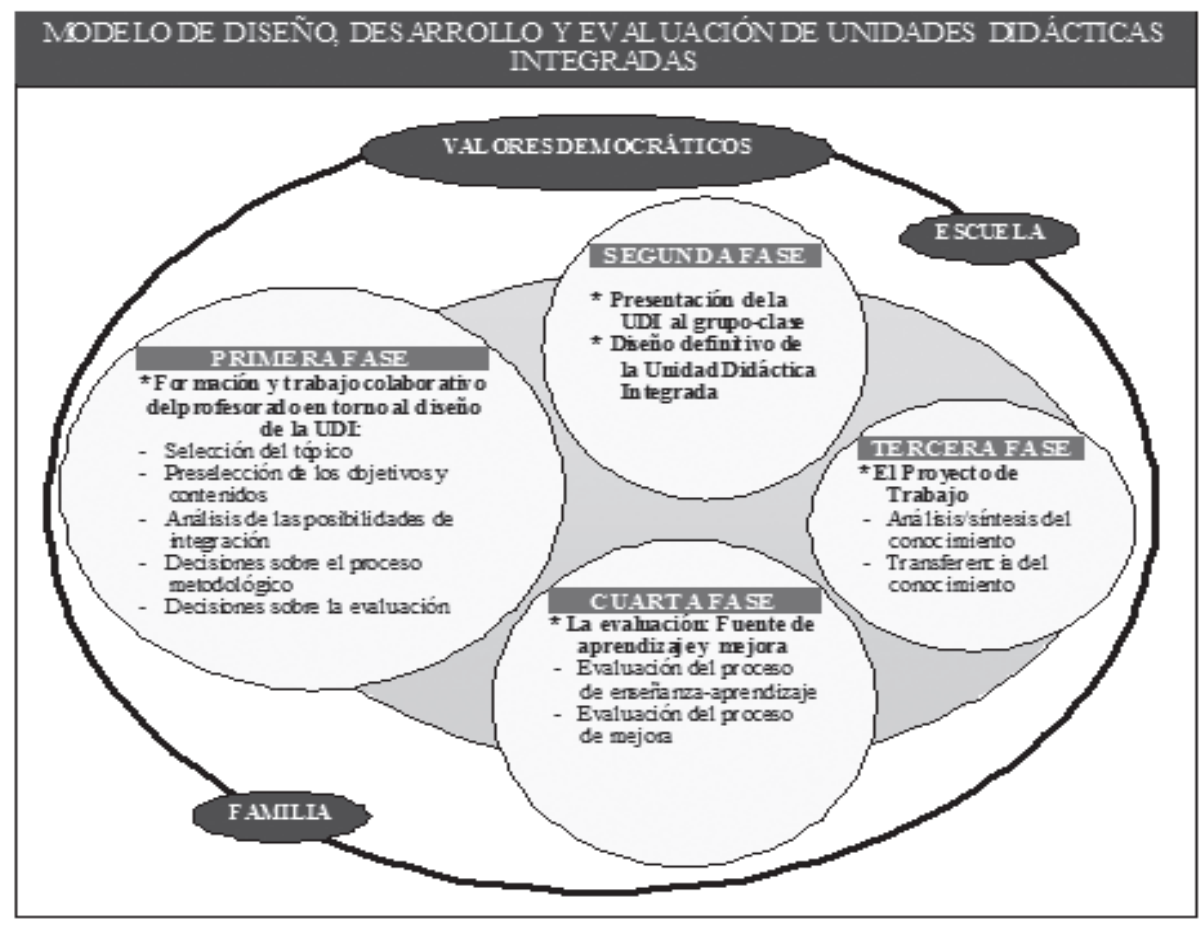

Ilustración 5: Modelo de diseño, desarrollo y evaluación de unidades didácticas integradas. Fuente: tomado de (Illán, Molina, 2011)

\section{- Comentarios y Conclusiones}

Los aspectos representativos en términos de comentarios y conclusiones, de las propuestas analizadas, permiten evidenciar la necesidad de comprender el currículo desde las prácticas situadas y el papel de sus actores en la rearticulación cotidiana de éste, lo cual llevaría a concebir el currículo escolar desde dinámicas más horizontales y participativas en la búsqueda de una mayor justicia social y cognitiva.

(Sierra, Siniguí, Henao, 2010), expresan que el currículo oficial, desafortunadamente, no se articula a los contextos de vida, en la práctica se imponen modelos autoritarios de enseñanza, contenidos segmentados y la presión por responder a unas pruebas nacionales estandarizadas que en nada responden a las realidades de un país tan diverso como Colombia. Un currículo intercultural exige en cambio una articulación con los distintos aspectos de la vida de los estudiantes, para generar procesos de aprendizaje que contribuyan con el mejoramiento de sus condiciones de vida. 
(Area,2008; Díaz, 2006), concluyen que la sola inserción discursiva de un enfoque por competencias o de propuestas de innovación educativas en un currículo escolar, no constituye un motor de cambios en los centros escolares, y mucho menos en el terreno que abarca el uso de Tecnologías de la Información y Comunicación.

Tondeur, Van Braak y Valcke (2007), citado por (Pérez, 2016) señala que no necesariamente hay coherencia entre lo que sugiere el texto curricular y las dinámicas de los centros escolares, porque la sola promoción de cambios o mejoras pedagógicas en los currículos escolares no implica su implementación de manera extendida e igualitaria.

Peña, Flaborea y Guzmán (2011), encontraron una desconexión entre la existencia de ciertas políticas lingüísticas institucionales y la carencia de planes estructurados de implementación. Igualmente, estos autores observaron la existencia de algunas problemáticas relacionadas con los docentes, los estudiantes y los padres de familia sin discusión ni acercamiento suficientes. Para Peña, Flaborea y Guzmán, los planteles educativos deben transformarse en agentes de cambio, capaces de hacer revisiones a su malla curricular y crear planes de acción para el crecimiento institucional, proponiendo: (i) La construcción de un currículo formal que de manera clara y sólida dé cuenta de la dirección, los propósitos, las metodologías, las formas de evaluación y los materiales de instrucción, (ii) La integración del área de español e inglés con el fin de crear ambientes de aprendizaje que fomenten el uso institucional y el crecimiento cultural de las dos lenguas, (iii) La creación de procesos continuos de reflexión pedagógica y autoevaluación a través de espacios de trabajo interdisciplinario, (iv) El involucramiento activo y entusiasta de los estudiantes como co-arquitectos de los contenidos y las prácticas bilingües a través de proyectos de tipo académico y cultural en el aula y fuera de esta (Fandiño, 2014).

(Niño \& Bermúdez, 2013), señalan que Colombia ha adecuado el Sistema Educativo Nacional a las demandas sociales, políticas y económicas que define el modelo de capital y desarrollo humano para la formación de niños, jóvenes y adultos. Este modelo se sustenta en los programas de Gobierno y los planes sectoriales de educación, entre otros; lo que termina por ejercer el control total del currículo, las prácticas pedagógicas, la evaluación y los sujetos que se involucran en la institución educativa, desconociendo las particularidades de su contexto interno y externo, de igual forma los estándares definen un modelo de educación impuesto que desconoce las diferencias entre los estudiantes, así como su contexto y las realidades locales, regionales, nacionales e internacionales; así mismo, la aplicación de los estándares promueve la educación fragmentada en disciplinas, desconociendo el valor de la integración de los conocimientos, segregando las áreas que no son catalogadas como fundamentales. Esto se evidencia en lo expuesto por los profesores, quienes señalan que la política de estándares "no permite que los colegios ni los docentes sean innovadores ni autónomos", porque deben apuntar a una evaluación donde se miden solamente conocimientos y no se tiene en cuenta el desarrollo individual de los estudiantes anulando la creatividad de estos y del docente, lo que hace necesario recurrir a alternativas de autoevaluación y co- evaluación de estudiantes, así como la construcción participativa del currículo. 
(Egido, 2011), concluye que seguramente, aún, es pronto para formular valoraciones sobre el posible éxito de la adopción del enfoque por competencias en la educación obligatoria, ya que en la mayoría de los países se trata de un cambio demasiado reciente como para que sea posible predecir su futuro. No obstante, a la luz de las experiencias europeas, parece claro que hoy, se necesita mayor investigación sobre las competencias clave, especialmente en relación con la forma de trasladar el modelo teórico a la práctica de los centros. De igual modo, se necesita más formación y apoyo para el profesorado y para las escuelas, lo que requiere que la reforma del currículo se acompañe de reformas en otros ámbitos del sistema educativo. Sin esa investigación y sin ese conjunto de medidas de apoyo, existe el riesgo de que el modelo curricular centrado en las competencias quede limitado al plano de la legislación, sin llegar a impregnar la práctica de la enseñanza.

(Volante, Bogolasky, Derby \& Gutiérrez, 2015), elaboraron un modelo conceptual que define como el problema principal de la gestión curricular, al proceso de toma de decisiones y ejecución de prácticas que buscan asegurar que el currículo prescrito sea efectivamente aplicado y que el máximo de estudiantes del grupo objetivo (establecimiento, nivel, curso, etc.) adquiera el dominio de los aprendizajes definidos como claves para un determinado segmento de tiempo escolar. Como aporte adicional a los antecedentes estudiados, el modelo propuesto contribuye a generar consistencia entre niveles macro, meso y micro en gestión curricular. Se promueve un vínculo entre las políticas nacionales y las políticas a nivel de establecimiento, favoreciendo un diálogo en virtud del alineamiento curricular y prácticas de gestión que vayan más allá de las condicionantes previsibles por el tipo de establecimientos. Del mismo modo (Calafell, Junyent\&Bonil, 2015), señalaron que la escuela debe capacitar al alumnado para que comprenda el mundo desde una visión global y compleja, en este sentido elaboraron una propuesta fundamentada en lo que se denomina una idea vector, que orienta y vertebra la acción educativa y las esferas, elementos y estrategias que la concretan en la práctica, de forma que las actividades de ambientalización curricular en el aula, permitan distintas y diversas actividades de los participantes del grupo en términos de Ambientalización Curricular.

Otro modelo analizado es el propuesto por (Illán\& Molina, 2011), denominado "Modelo de diseño, desarrollo y evaluación de Unidades Didácticas Integradas”. Dicho modelo ha sido probado en diferentes escenarios pertenecientes al sistema de educación público y concertado, concretamente en las etapas de educación primaria y secundaria, obteniendo grandes y esperanzadores resultados, a través de los cuales se afirma que la idea de una escuela para todos es completamente posible.

La revisión bibliográfica permitió hacer una relación entre los diferentes conceptos y teorías que se han tenido en cuenta para la construcción de los currículos, cabe resaltar que el diseño y ejecución curricular se fundamenta desde diferentes referentes teóricos que incluyen aspectos filosóficos, epistemológicos, psicológicos, antropológicos, sociológicos y pedagógicos, así como la reflexión sobre pertinencia, enfoque social e investigativo, flexibilidad, interdisciplinariedad, entre otros escenarios que hacen compleja la idoneidad del currículo; en palabras de Martha Nussbaum, la educación debe permitir que la sociedad 
ocupe "su justo lugar" para la formación de sociedades libres, autónomas, compasivas y críticas de las tradiciones. El estado del arte resalta las diferentes tendencias investigativas que incluyen técnicas, métodos y/o modelos innovadores que definen el diseño curricular para el desarrollo de competencias en estudiantes de básica secundaria, para lo cual se establecieron categorías y sub-categorías de análisis, las cuales permitieron identificar entre otros aspectos, la falta de enfoque de capacidades humanas y la necesidad de una mayor articulación del currículo en los contextos de vida; a continuación se detallarán los hallazgos:

\subsection{Prospectiva para la Gestión Curricular.}

El concepto de currículo es un proceso en constante evolución que responde a lineamientos de carácter local con proyección mundial. Una vez realizado el análisis de los diferentes documentos, surge el interrogante ¿Qué tipo de problemáticas locales y globales se deben abordar en el currículo? ¿Cómo aportan las áreas de conocimiento a mejorar las condiciones locales y globales? La mayoría de las investigaciones analizadas no definen una lista de capacidades básicas en virtud de la dignidad humana, como lo plantea (Nusbaum, 2012), así: (i) Vida. Toda persona debería ser capaz de llevar una vida de una duración normal. (ii) Salud corporal. Tener adecuadas condiciones de salud, alimentación y vivienda. (iii) Integridad corporal. Gozar de libertad de movimientos y seguridad. (iv) Sentidos, imaginación y pensamiento. Recibir una educación que permita desarrollar estas capacidades y un ambiente de libertad para manifestar gustos y creencias. (v) Emociones. Capacidad de amar, de estar agradecido en las diversas formas de asociación humana. (vi) Razón práctica. Ser capaz de formular una concepción del bien y un plan de vida. (vii) Afiliación. Capacidad de vivir con otros, de establecer relaciones sociales, de ser respetado y no discriminado. (viii) Otras especies. Ser capaz de respetar a los animales, las plantas y demás especies del mundo natural. (ix) Juego. Ser capaz de jugar y reír y (x) Control sobre el propio ambiente. Gozar de oportunidades de participación política, derechos de propiedad y del trabajo. Para lo cual, cada capacidad debe contener un objetivo que evalúe las políticas locales y en este sentido brindar mayor impacto en la sociedad. A la luz de estos principios, no se evidencia una guía sencilla y funcional que combine competencias y capacidades de desarrollo humano para la educación básica, así mismo (Saracho, 2005), indica que los modelos de competencias distintivas, genéricas y funcionales no contienen una guía clara y práctica de para qué y cómo utilizar cada una de ellas.

Se requiere una mayor articulación del currículo en los contextos de vida, en la que la comunidad educativa juegue un rol dinamizante y significativo para la solución de problemas locales, regionales, nacionales y globales que respondan a estándares internacionales y además contribuyan al mejoramiento de las condiciones de vida.

Si bien los Estándares Básicos de Competencia y los Derechos Básicos de Aprendizaje definen la ruta de aprendizaje por grado de escolaridad para lograr los estándares requeridos en Colombia, no se dicta un procedimiento, método o modelo que conjugue dichos requerimientos, dejando a las instituciones educativas la responsabilidad de revisar los currículos y planes de mejoramiento educativo. "La creatividad de los docentes, sus 
conocimientos de la realidad de los estudiantes, sus experiencias en el diseño de estrategias pedagógicas serán sin duda algunos ingredientes indispensables para que estos estándares de calidad sean alcanzados por los alumnos" (MEN, 2006).

Los Objetivos de Desarrollo Sostenible (ODS) plasman los ideales promulgados por los países miembros de la ONU para los años 2015 a 2030; en tal sentido los programas de formación educativa se convierten en un gran aliado. En el rastreo bibliográfico analizado se requiere mayor nivel de profundidad en la temática para abordar propuestas integradoras desde los ODS en el diseño curricular. solo 14 artículos de 127 analizados relacionan los ODS con la educación. Adicional ninguno de ellos hace relación directa a la gestión curricular en básica secundaria.

Blanco y Messina (2000), citado por (Arias, 2013), afirman que la falta de conceptos teóricos profundos no permite aclarar qué es y no es innovación educativa. Las actuales propuestas bajo el enfoque de (Fidalgo, 2011), presentan debilidad argumentativa en los cuatro pilares, cuyas concepciones de innovación educativa están planteadas en Tecnologías, Procesos, Personas y Conocimiento, denominadas por el autor como "las cuatro patas de la silla de la innovación educativa" y resalta, de manera particular, que la innovación debe reducir el esfuerzo en el proceso de enseñanza-aprendizaje.

La creación conjunta o co-creación genera espacios para la innovación, además reúne conceptos de inteligencia colectiva, trabajo colaborativo y cooperativo, entre otros; lo que permite generar conocimiento conjunto con un enfoque constructivista. La exploración de esta técnica se gesta para el desarrollo de productos y servicios a nivel empresarial; a nivel educativo es una práctica poco explorada que requiere de mayor nivel de análisis y estructura. 


\section{CAPÍTULO 3}

MARCO TEÓRICO REFERENCIAL 


\section{MARCO TEÓRICO REFERENCIAL}

Las categorías y referentes teóricos abordados permitirán identificar las posturas conceptuales que servirán de base argumentativa para el planteamiento del "Modelo de coordenadas curriculares" propuesto en el actual ejercicio de investigación.

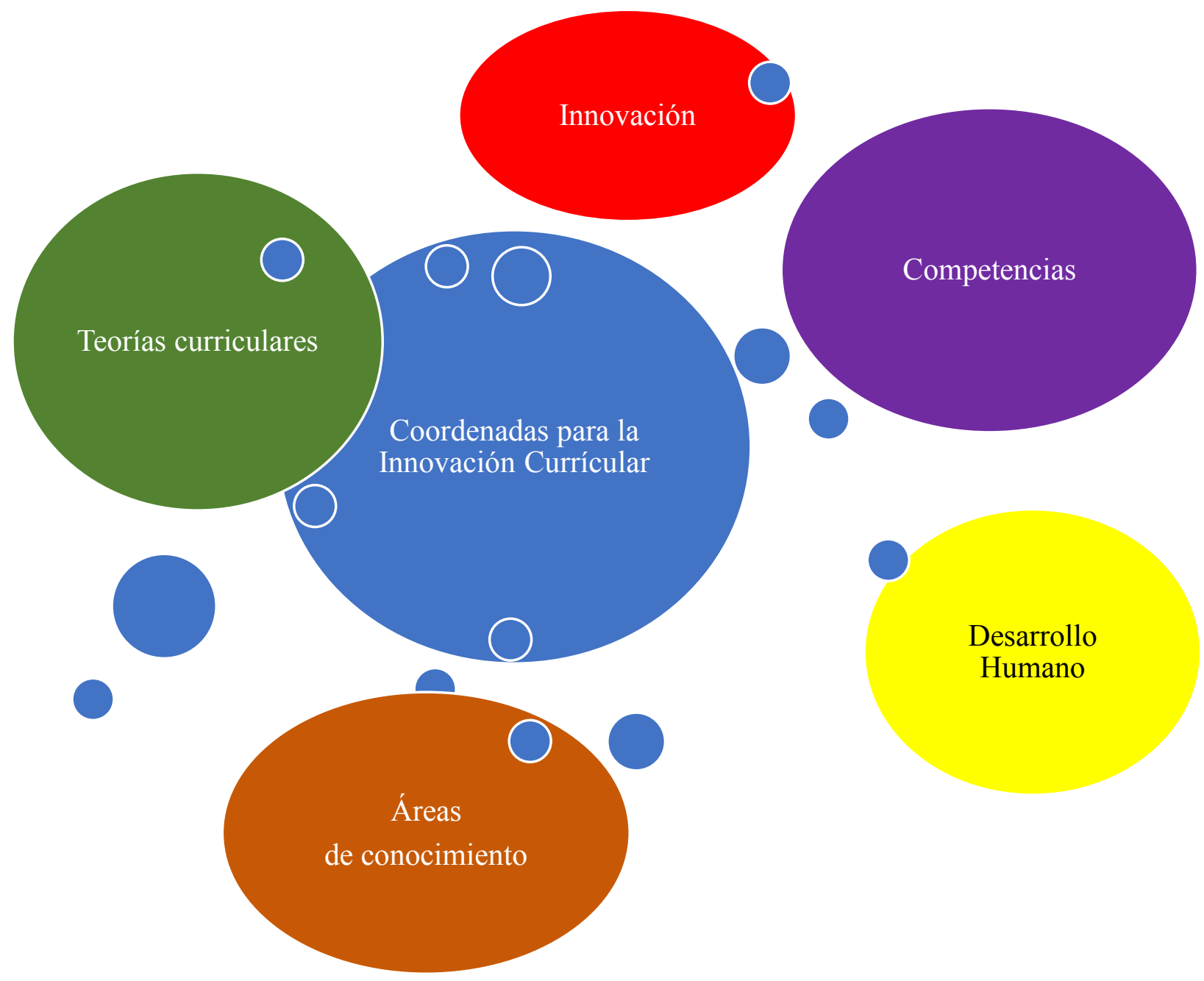

Ilustración 6: Categorías teóricas

Fuente: Autor 


\subsection{Teorías curriculares}

El diccionario de la Real Academia Española ${ }^{6}$ señala que el currículo proviene del latín currículum que hace relación a "carrera" y lo define como: 1. plan de estudios, 2. Conjunto de estudios y prácticas destinadas a que el alumno desarrolle plenamente sus posibilidades y 3. Currículum (de la loc. lat. curriculum [vitae]; literalmente carrera [de la vida]) Relación de los títulos, honores, cargos, trabajos realizados, datos biográficos, etc., que califican a una persona.

Los conceptos de currículo dependen de los discursos teóricos que aproximan la definición hacia lo que se concibe del mismo, aunque el tema central de discusión consiste en determinar qué tipo de conocimiento debe ser enseñado, dada su validez e importancia para merecer consideraciones de carácter formativo para la sociedad y estar inmerso en la planeación que justifique la inclusión o no de un contenido u otro.

Uno de los primeros estudios curriculares fue publicado por Bobbit, El currículum (1918), cuya procedencia conceptual está enmarcada en la teoría de "la administración científica de Frederick Taylor", inspirada en los procesos administrativos y de industrialización propia de la época en los Estados Unidos, en donde el diseño curricular está concebido como un modelo fabril con objetivos, procedimientos, métodos y resultados.

La polisemia conceptual sobre teorías curriculares incluye enfoques filosóficos, epistemológicos, psicológicos, antropológicos, sociológicos y pedagógicos. Dando lugar a variadas categorizaciones como lo muestra la siguiente ilustración.

${ }^{6} \mathrm{http}: / /$ dle.rae.es/?id=Bk4piXs 


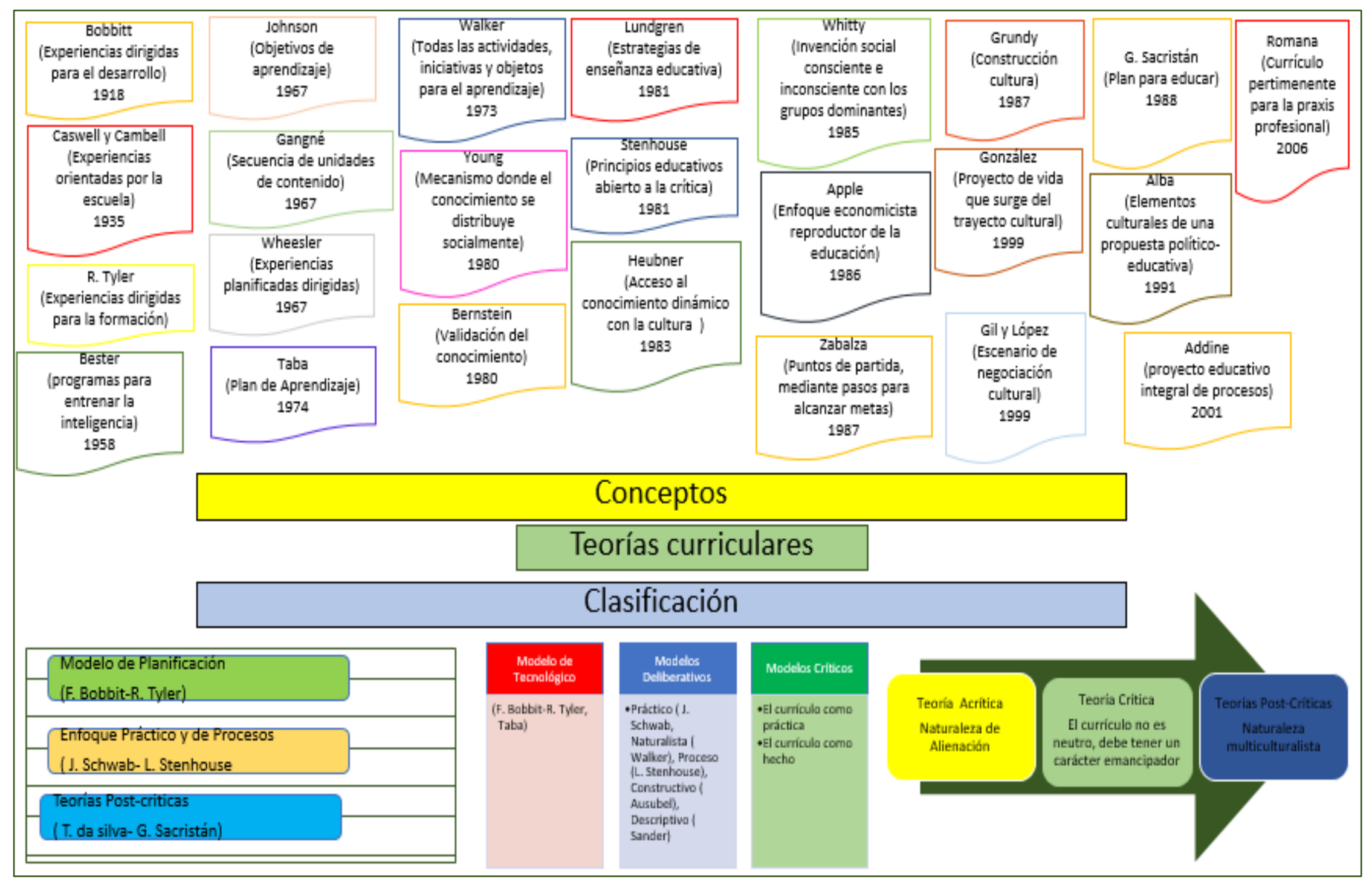

Ilustración 7: Conceptos y clasificaciones curriculares

Fuente: Autor. 
Las definiciones y clasificaciones anteriores permiten generan puntos de encuentro con los conceptos de (Da Silva, 1999) al considerar al currículo como un documento de identidad; propuesta que se desea abordar en el "Modelo de coordenadas curriculares" con relación a la identidad institucional. En sintonía con Da Silva el currículo es lugar, espacio, territorio, relación de poder, trayectoria, viaje, recorrido, autobiografía, nuestra vida, texto y discurso.

Variadas definiciones de "currículo" indican: Mecanismo para formular objetivos de aprendizaje (Tyler, 1973). Plan para el aprendizaje (Taba, 1974). Selección y clasificación de contenidos (Lundgren, 1992). Estructura social de experiencias e interacciones en el ámbito educativo (Magendzo, 1991). "Selección cultural de los contenidos" (Sacristán, 1988) y Proceso que influye el mundo de la vida y el mundo de la escuela González (2000, p.11).

Por su parte (Graff, 1977), plantea que la integración curricular conjuga conceptos de índole Intelectual, Pedagógico y Social, estos hacen relación a los conocimientos diversos, a la integración de los contenidos y a la conformación de comunidades de aprendizaje. Para Mora (1999, p.23) la gestión curricular puede ser lineal o tradicional y global o integradora, en la que intervienen conceptos administrativos de dirección, gobierno y liderazgo, por tanto, la gestión curricular debe planear, hacer, verificar y ajustar; Así mismo (Amaya, 1999, p.38) la define como "Una función institucional global e integradora de todas las fuerzas que conforman una organización, articuladas y correlacionadas para el logro de un propósito compartido, o de un objeto común.

Desde los planteamientos de Alicia de Alba (1995) el currículo es una síntesis de elementos culturales (conocimientos, valores, costumbres, creencias, hábitos) que conforman una propuesta político-educativa impulsado por los diferentes grupos sociales cuyos intereses son diversos y contradictorios, unos a imponer y ejercer hegemonía y otros a resistirse ante tal dominación. Estructura que se conforma en las instituciones sociales educativas y se expresa mediante distintos niveles de significación. En términos de Bourdieu (1970) el currículo es un arbitrario cultural; arbitrario conformado por diversas conformaciones culturales y su carácter es de una estructura dinámica relativamente estable.

Además de ello, De Alba (1995) considera dos tipos de dimensiones en el currículo: la dimensión general y la particular, las generales se enfocan en las relaciones, interrelaciones y mediaciones por el carácter social y político-educativo del currículo conformado por una dimensión social amplia (cultura, política, social, económica e ideológica), dimensión institucional y dimensión didáctico-áulica, mientras que la dimensión particular o específica hace relación a aquellos aspectos puntuales sobre la población a la que va dirigida el currículo como el nivel educativo, tipo de educación, problemáticas del sector, etc.

Las definiciones anteriores muestran variadas posturas teóricas. Así mismo diferentes autores han analizado el currículo desde el enfoque de los objetivos, las relaciones de poder, la participación social y la cultura entre otros aspectos. A continuación, las clasificaciones con mayor relevancia.

Las reflexiones de (Ruiz, 1996) categorizan las teorías curriculares en: Modelos Tecnológicos, Modelos Deliberativos y Modelos Críticos. Bobbit (1918), Tyler (1949) y Taba (1982) representan el Modelo Tecnológico al centrarse según el autor en los objetivos 
y sus componentes. El modelo Deliberativo se centra en la reflexión del educador cuyos máximos exponentes son (Schward, 1978), (Walker, 1972), (Stenhouse, 1984), (Ausubel, 1983) y (Sander, 1992). Por último, el Modelo Crítico o Postmoderno cuya premisa señala: "los educadores deben ser investigadores y los resultados deben servir para su cualificación" lo integran (kemmis \& Mctaggart, 1988), (Carr y 1996), Martinez Bonafe (1996) entre otros.

Por parte de Da Silva (1999) las teorías curriculares las clasifica en tres grupos: Teorías Tradicionales, Teorías Críticas y Teorías Poscríticas. Las teorías tradicionales centran la gestión en la escuela, en ella se plantean conceptos técnicos, científicos, neutros y desinteresados. las Teorías Críticas centradas en el poder y la transformación social, en ella se desconfía del statu quo, responsabilizándolo de las desigualdades e injusticias sociales y las Teorías Poscríticas centradas en la identidad y la intersubjetividad. para Da Silva, las Teorías Críticas y Poscriticas cuestionan los planteamientos de la escuela tradicional y en ellas se plantean interrogantes que fortalecen la selección de conocimientos para la formación de identidad, cultura y poder, para estas teorías la clave no está en crear técnicas para estructurar el currículo sino construir conceptos para comprender la importancia.

Las características de las teorías según la clasificación de Da Silva a continuación se detalla:

Tabla 9: Características clasificación teorías curriculares según Da Silva.

\begin{tabular}{|l|l|l|}
\hline TEORIAS TRADICIONALES & TEORIAS CRÍTICAS & TEORIAS POS-CRÍTICAS \\
Enseñanza & Ideología & Identidad, alteridad, diferencia \\
Aprendizaje & Reproducción cultural y social & Subjetividad \\
Evaluación & Poder & Significación y discurso \\
Metodología & Clase social & Saber-poder \\
Didáctica & Capitalismo & Representación \\
Organización & Relaciones sociales de producción & Cultura \\
Planeamiento & Concientización & Género, Raza, Etnia, Sexualidad \\
Eficiencia & Emancipación y liberación & Multiculturalismo \\
Objetivos & Currículo oculto & \\
& Resistencia & \\
\hline
\end{tabular}

Fuente: Tomado de Da Silva (1999)

Desde la propuesta de (Cuervo, 2014) las teorías curriculares se clasifican de acuerdo con su temporalidad, correspondiente a 4 etapas: La etapa 1 comprendida entre 1920 y 1950 . La etapa 2 entre 1960 y 1975. La etapa 3 entre 1975 y 1990 y la etapa 4 desde 1990 hasta la actualidad. Cabe resaltar que la clasificación retoma los principios de Da Silva (1999).

La etapa 1 denominada Modelo de Planificación Racional cuyos exponentes son F. Bobbit con el Método de Gestión Eficiente y R. Tyler con el Método Racional, en el que denominaron al currículo como un instrumento documento para el diseño de estrategias centralizadas.

La segunda etapa, Sacristán (1991) entre otros autores, la denominan Proyectos Curriculares, mediante El Enfoque Práctico y de Procesos, liderada por los teóricos J. Schawab (Modelo práctico, deliberación) y L. Stenhouse (hipótesis, proceso) en el que definen al profesor como un agente de cambio, por tanto, incluyen conceptos como el currículo prescrito, el currículo 
presentado, el currículo moldeado, el currículo en acción, el currículo realizado y el currículo evaluado.

La tercera etapa denominada Reconceptualización y Teoría Crítica, en la que se define al currículo como un campo de estudio y toma de acción crítica, en la que se destacan a los teóricos W. Pinar (reconceptualización) y M. Apple (Teoría sociocrítica) ejemplo de esta etapa es el currículo oculto por Philip W. Jackson y Jurjo Torres citado por (Sacristán \& Pérez, 1989).

La cuarta etapa relacionada con las teorías Poscríticas en ella se abordan temas sobre identidad, género, lenguaje y subjetivación.

Desde la mirada de M. Apple (1986) se destaca la importancia del currículo determinada por identificar qué conocimiento es considerado verdadero y no en saber qué conocimiento es verdadero; la relación del currículo con las estructuras económicas y sociales determinan que la relación no es desinteresada, es así como los modelos tradicionales sustentan sus argumentos en definir cómo hacer el currículo, a diferencia de los modelos críticos en los que se enfocan en cuestionar y en comprender lo que el currículo hace, sumado a ello, Phillips Jackson (1981) indica que los principales descontentos en el campo curricular, entre otros aspectos, obedecen a que la educación no hace justicia a la complejidad y dignidad de la condición humana, visión compartida por Althusser (1974) señalando que la escuela constituye un aparato ideológico del estado, para Bourdieu y Passeron (1970) el término corresponde a el hábitus para referirse a las estructuras sociales y culturales internalizadas.

Por su parte Bourdieu y Passeron fundamentan en su propuesta pedagógica el término pedagogía racional soportada en que la escuela debe tener una pedagogía y currículo en el que las clases dominadas tengan la misma experiencia cultural que las clases dominantes, para lo cual señalan que el currículo escolar está soportado en una cultura dominante, construido con un lenguaje dominante y transmitido mediante códigos culturales dominantes, por lo tanto, la escuela debe cuestionar ¿ Quiénes se benefician y perjudican con el currículo? ¿Cuáles son los intereses que rodean los contenidos seleccionados? ¿Cuáles son las relaciones de poder resultantes de la selección de contenidos curriculares? Entre otras.

Con respecto a Giroux (1987), influenciado por la escuela de Frankfurt concibe al currículo para la emancipación y liberación, y es mediante los procesos pedagógicos que las personas se hacen conscientes de la función de control y poder de las instituciones, en donde un objetivo de la acción social politizada corresponde a la emancipación, soportada desde tres principios fundamentales: Esfera Pública, Intelectual Transformador y Voz, es decir, la escuela debe ser un espacio democrático abierto para la discusión y participación, el profesor debe ser un intelectual transformador, y el papel del estudiante debe corresponder a un sujeto crítico y activo en las relaciones de poder; el currículo entonces, construye significados y valores culturales fruto de la puja entre la desigualdad en las relaciones sociales de poder, por tanto, Giroux establece una relación de gran semejanza entre la pedagogía, el currículo y la cultura definiendo como eje la política cultural.

Para Da Silva (1999) Paulo Freire no desarrolló una teoría específica sobre currículo, sus diálogos se enfocaron fundamentalmente en determinar ¿qué enseñar? Aportes que sirvieron de base para las nuevas concepciones sobre teorías curriculares en donde la "cultura popular" debe ser tenida en cuenta para el diseño del currículo en la escuela. En otro sentido Saviani 
(1983) separa la educación de la política, a su vez que critica las pedagogías activas y las liberadoras de Freire, señalando que estas no generan conocimiento, sino que obedecen a métodos utilizados para su adquisición de conocimiento. Para Saviani el conocimiento es el otro poder, teoría posestructuralista relegada de acuerdo con las líneas conceptuales de Foucault.

Entre tanto, las teorías poscríticas reclaman para el currículo mayores relaciones sociales de asimetría en términos del multiculturalismo enfocados en el género, raza y sexualidad. Además, incluyen conceptos como identidad, género, subjetivación y las teorías del lenguaje; de forma tal, que exista mayor "justicia curricular" Robert Connell (1997). Estas definiciones buscan acercar las relaciones de género y feminismo y visibilizar las narrativas étnicas y raciales.

El currículo concebido bajo los principios de la teoría Queer "esa cosa extraña" (Da Silva, 1999), es un currículo que no se limita a cuestionar los conocimientos socialmente construidos, se aventura a construirlos. La pedagogía Queer cuestiona los procesos institucionales y discursivos, las estructuras de significación que definen, antes que nada, lo que es correcto y lo que es incorrecto, lo que es moral y lo que es inmoral, lo que es normal y lo que es anormal. También, pretende extender su comprensión y su análisis de la identidad sexual y de la sexualidad para la cuestión más amplia del conocimiento. Pensar Queer significa cuestionar, problematizar, contestar todas las formas de buen comportamiento de conocimiento y de identidad.

Por otra parte, el posestructuralismo ${ }^{7}$ y el posmodernismo ${ }^{8}$ están en desacuerdo con la sistematización, por tanto, no es preciso definir teorías curriculares posestructuralistas, aunque se compartan algunos principios conceptuales. Desde este enfoque Popkewitz (1994) señala que la palabra currículo sintetiza las relaciones estructuradas que conforman la escolarización, adicional cita a (Hamilton, 1991) expresando que la palabra currículo aparece en los siglos XVI y XVII para interrelacionar las filosofías sociales y la economía con las prácticas de gestión que se estaban estableciendo como parte de la jornada escolar, por lo tanto el currículo es una invención que resalta la coherencia racional, el orden y la disciplina calvinista ${ }^{9}$ relacionadas para brindar estructura social y económica.

Del mismo modo Popkewitz cita a Foucault señalando que el saber en el sistema dirigente se toma como un elemento de poder, apropiación y exclusión, en donde, se construyen las subjetividades y se configura la vida social. Los miembros de la administración del Estado se referían al bienestar social en términos de problemas biológicos, como reproducción, enfermedad y educación (desarrollo, crecimiento y evolución individual) para lo cual las necesidades humanas se consideraban instrumentales y empíricas en relación con el funcionamiento del estado, el objetivo social de la educación se definió como la preparación

\footnotetext{
${ }^{7}$ Movimiento teórico y epistemológico que realiza una fuerte crítica a la corriente estructuralista fundamentada en el sentido y el significado. Es decir, la posición del sujeto ante el lenguaje (subjetividad y el significado).

${ }^{8}$ Movimiento artístico, filosófico e histórico surgido a finales del siglo XX que busca nuevas formas de expresión centrados en el culto por el individualismo y critica al racionalismo.

${ }^{9}$ Sistema teológico basado en las enseñanzas de Juan Calvino
} 
del niño para desempeñar un papel útil en la sociedad mediante la disciplina individual y el autogobierno.

El currículo visto desde los estudios culturales también establece que es un campo en disputa de hegemonía. Desde esta perspectiva el currículo es un artefacto cultural en dos sentidos, Institucional y de Contenido, el Institucional hace relación a un currículo como resultado de una invención y construcción social y de Contenido se refiere a un currículo que obedece a una construcción social, pero en este actúan relaciones de poder que hacen que sean incluidos un tipo de contenidos y no otros. Los dos tipos de conocimientos pretenden producir cierto tipo de subjetividad e identidad social. Desde la perspectiva poscolonial el currículo debe ser multicultural y no debe distanciar conocimientos, cultura y estética por el poder y política, desde este enfoque el currículo debe estar descolonizado. Para Da Silva la influencia de los estudios culturales en el posmodernismo, posestructuralismo y el poscolonialismo para la elaboración de políticas de currículo y en el currículo del cotidiano en las aulas es mínima.

Las teorías críticas en síntesis determinan que el currículo es un espacio de poder, es capitalista, reproduce culturalmente las estructuras sociales, es un aparato ideológico del estado, transmite una ideología dominante. El currículo es un territorio político, es una invención social por tanto la pregunta clave no es ¿qué conocimientos son válidos? sino ¿qué conocimientos son considerados válidos? Así mismo, las teorías poscríticas retoman su análisis en las relaciones de poder inmersas en el currículo, pero con una visión descentrada en la cual el poder está en toda la red social, el poder no desaparece se transforma, el poder está presente en los procesos de dominación de raza, etnia, género y sexualidad. Da Silva (1999).

El "modelo de coordenadas curriculares" propuesto en la actual investigación se circunscribe en lo que Da Silva (1999) define Currículo Poscrítico. Al someter a juicio las necesidades del contexto para que sean consideradas en el currículo escolar.

\subsubsection{Prospectiva Teórica para el diseño curricular.}

El tema central del debate desde las diferentes posturas teóricas radica en determinar qué tipo de conocimientos debe ser enseñado. Es necesario profundizar en estudios que evidencien la construcción curricular mediada por procesos de innovación en donde el currículo se hace dinámico y se posiciona de acuerdo con las coordenadas del entorno local con proyección global.

Es necesario crear mecanismos que permitan la generación de espacios de identidad escolar institucional con participación colectiva desde un enfoque sistémico que surja de las problemáticas globales con identidad local, gestada desde el currículo.

Las definiciones y teorías curriculares expuestas con anterioridad permiten comprender la evolución del currículo desde la cotidianidad y el papel de sus actores en la rearticulación, se requiere concebir al currículo escolar desde dinámicas más horizontales y participativas en búsqueda de una mayor justicia social local-global, generando cuestionamientos relacionados con ¿Qué tipo de problemáticas locales y globales se deben abordar en el currículo? ¿Cómo 
aportan las áreas de conocimiento a mejorar las condiciones locales y globales? Aportes que generan mayor articulación del currículo en los contextos de vida, para la solución de problemas que respondan a estándares internacionales, además de contribuir al mejoramiento de las condiciones de vida.

Para profundizar en el ¿qué enseñar? a continuación se expone la categoría competencia con sus diferentes clasificaciones y categorizaciones.

\subsection{Competencias.}

De acuerdo con la definición del diccionario de la Real Academia Española ${ }^{10}$, es la pericia, aptitud o idoneidad para hacer algo o intervenir en un asunto determinado. La Comisión Europea identifica la competencia como una combinación de conocimientos, destrezas y actitudes que incluyen la disposición para aprender y el saber cómo y matiza que una competencia clave, básica o esencial es crucial cuando ésta constituye a diferentes aspectos de la vida (Ministerio de Educación de España, 2011).

Según en (MEN, 2006) el término competencia ha sido definida como un saber hacer flexible que puede actualizarse en distintos contextos, es decir, como la capacidad de usar los conocimientos en situaciones distintas de aquellas en las que se aprendieron. Implica la comprensión del sentido de cada actividad y sus implicaciones éticas, sociales, económicas y políticas. Es entonces, la competencia en términos educativos, cierta capacidad o potencial para actuar de modo eficaz en un contexto, incluye desde luego todo tipo de conocimiento.

De acuerdo con El Proyecto Definición y Selección de Competencias - DeSeCO (OCDE, 2005) una competencia es "la capacidad de responder a demandas complejas y llevar a cabo tareas diversas de forma adecuada. Supone una combinación de habilidades prácticas, conocimientos, motivación, valores éticos, actitudes, emociones y otros componentes sociales y de comportamiento que se movilizan conjuntamente para lograr una acción eficaz", para el Parlamento Europeo (2006) es "una combinación de conocimientos, capacidades y actitudes adecuadas al contexto".

En la siguiente tabla se muestra la clasificación de competencias clave y básicas para el currículo de la educación básica para la Unión Europea, la Comunidad Autónoma País Vasco (C.A.P.V), el ministerio de educación colombiano y la OCDE a través del informe DeSeCo

Tabla 10: Clasificación de Competencias Básicas

\begin{tabular}{|l|l|l|l|}
\hline $\begin{array}{l}\text { Competencias Clave } \\
\begin{array}{l}\text { Unión Europea } \\
\text { Recomendación }\end{array}\end{array}$ & $\begin{array}{l}\text { Competencias Básicas } \\
\text { C.A.P.V. (DECRETO } \\
175 / 2007)\end{array}$ & $\begin{array}{l}\text { Estándares Básicos } \\
\text { de Competencia } \\
\text { (MEN 2006) }\end{array}$ & $\begin{array}{l}\text { Competencias Clave } \\
\text { OCDE } \\
\text { Informe DeSeCo } \\
(2003)\end{array}$ \\
\hline $\begin{array}{l}\text { Comunicación en lengua } \\
\text { materna. }\end{array}$ & $\begin{array}{l}\text { Competencia en } \\
\text { comunicación lingüística. }\end{array}$ & $\begin{array}{l}\text { Competencias del } \\
\text { Lenguaje }\end{array}$ & $\begin{array}{l}\text { Categoría 1: Usar } \\
\text { herramientas } \\
\text { interactivamente }\end{array}$ \\
\hline $\begin{array}{l}\text { Comunicación en lenguas } \\
\text { extranjeras. }\end{array}$ & Competencia matemática. & $\begin{array}{l}\text { Competencia en } \\
\text { Matemáticas }\end{array}$ & \\
\hline
\end{tabular}

${ }^{10}$ http://dle.rae.es/?id=AOfanvT|AOgTnnL 


\begin{tabular}{|c|c|c|c|}
\hline $\begin{array}{l}\text { Competencia matemática } \\
\text { y competencias básicas en } \\
\text { ciencia y tecnología }\end{array}$ & $\begin{array}{l}\text { Competencia en cultura } \\
\text { científica, tecnológica y } \\
\text { de la salud. }\end{array}$ & $\begin{array}{l}\text { Competencias en } \\
\text { Ciencias Sociales y } \\
\text { Ciencias Naturales }\end{array}$ & $\begin{array}{l}\text { Categoría 2: Interactuar } \\
\text { en grupos heterogéneos. }\end{array}$ \\
\hline Competencia digital & $\begin{array}{ll}\text { Tratamiento de la } \\
\text { información } \\
\text { competencia digital }\end{array}$ & \multirow[t]{5}{*}{$\begin{array}{l}\text { Competencias } \\
\text { Ciudadanas }\end{array}$} & \multirow[t]{5}{*}{$\begin{array}{l}\text { Categoría 3: Actuar de } \\
\text { forma autónoma. }\end{array}$} \\
\hline $\begin{array}{l}\text { Competencias sociales y } \\
\text { cívicas }\end{array}$ & $\begin{array}{l}\text { Competencia para } \\
\text { aprender a aprender. }\end{array}$ & & \\
\hline $\begin{array}{l}\begin{array}{l}\text { Conciencia } \\
\text { culturales }\end{array} \\
\end{array}$ & $\begin{array}{l}\begin{array}{l}\text { Competencia social y } \\
\text { ciudadana. }\end{array} \\
\end{array}$ & & \\
\hline Aprender a aprender & $\begin{array}{l}\text { Autonomía e iniciativa } \\
\text { personal. }\end{array}$ & & \\
\hline $\begin{array}{l}\text { Sentido de la iniciativa y } \\
\text { espíritu de empresa }\end{array}$ & $\begin{array}{l}\text { Competencia en cultura } \\
\text { humanística y artística }\end{array}$ & & \\
\hline
\end{tabular}

Fuente: Autor

Dichas competencias clave según la OCDE deben brindarse en la escuela y pueden ser desarrolladas a lo largo de la vida por tanto sirven de marco de referencia para la evaluación escolar y evaluación de competencias de adultos.

A su vez, la UNESCO en su publicación "La educación Encierra un tesoro (Delors et al., 1996) definió los cuatro pilares de la educación como: Aprender a conocer, aprender a hacer, aprender a vivir juntos-aprender a vivir con los demás y aprender a ser”.

- Aprender a conocer: hace referencia a la cultura general de conocimientos.

- Aprender a hacer: Comprende tanto la experiencia social y el trabajo en equipo.

- Aprender a vivir juntos: Describe la realización de proyectos comunes.

- Aprender a ser: Se refiere a la autonomía y juicio de responsabilidad personal.

Principios fundamentales de acuerdo con la UNESCO para la adquisición de conocimientos de tal forma que sirva de inspiración y orientación a las reformas educativas.

Así mismo, una nueva competencia que se integra a los procesos educativos corresponde a la competencia global. Entendida como "la capacidad de examinar asuntos globales e interculturales, para tomar múltiples perspectivas bajo un respeto compartido de los derechos humanos, para participar en interacciones abiertas, apropiadas y efectivas con personas de diferentes culturas y actuar en pro del bienestar colectivo y del desarrollo sostenible" (OCDE, 2016).

A su vez, existen diferentes clasificaciones de competencias y estas varían de acuerdo con el contexto, según (Climent, 2010); ellas son:

Tabla 11: Clasificación de competencias según el contexto

\begin{tabular}{|c|c|c|c|}
\hline $\begin{array}{c}\text { Participación } \\
\text { y rol social }\end{array}$ & Propósito & $\begin{array}{c}\text { Naturaleza y } \\
\text { Características }\end{array}$ & Papel \\
\hline
\end{tabular}




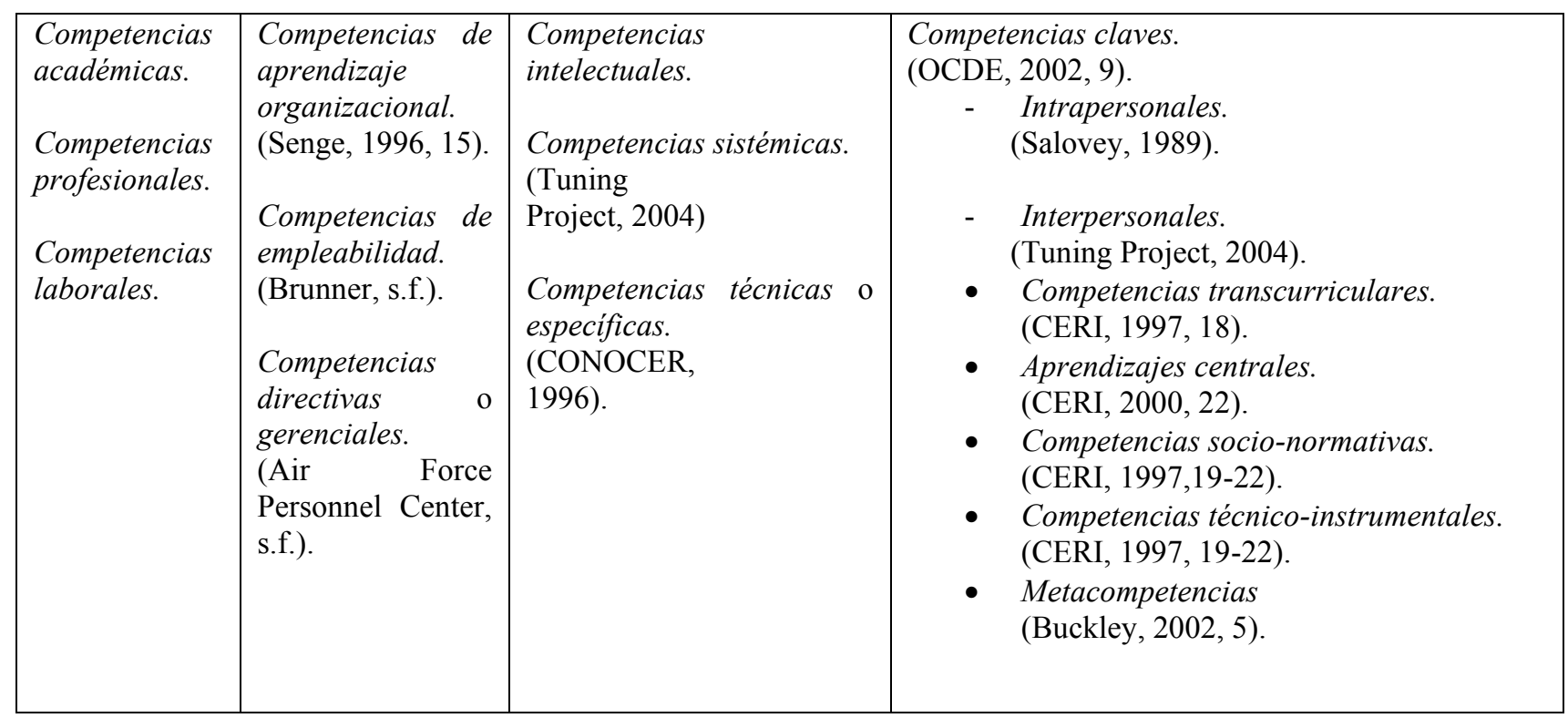

Fuente: Autor basado en (Climent, 2010)

De igual forma, (Climent, 2010) clasifica las competencias bajo la siguiente estructura piramidal, en 4 grupos:

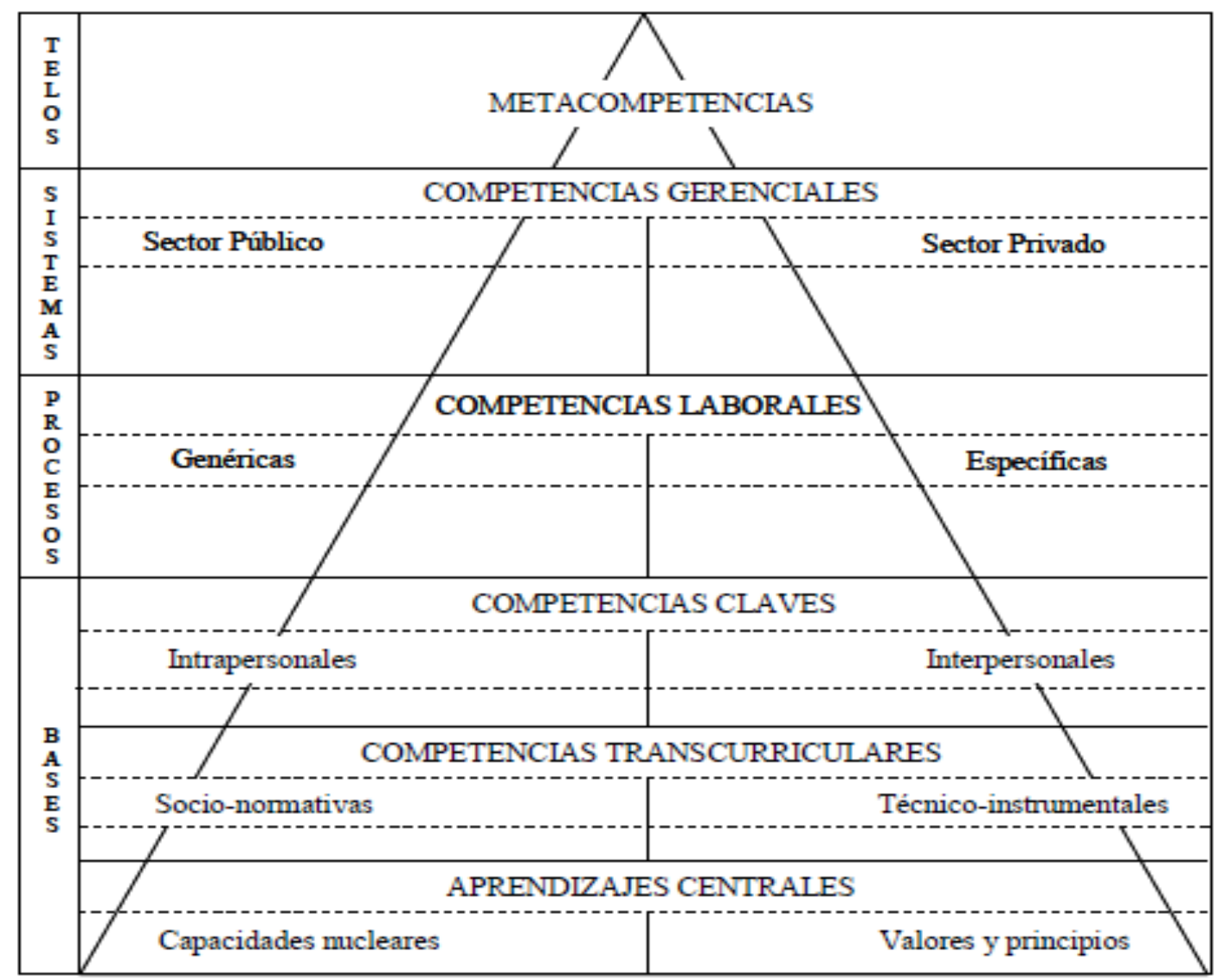

Ilustración 8: Estructura piramidal de las competencias

Fuente: Tomado de (Climent, 2010) 
Las características de cada agrupación corresponden a:

Tabla 12: Características de competencias según pirámide- Competencias bases.

\begin{tabular}{|l|l|}
\hline \multicolumn{1}{|c|}{ Tipo } & \multicolumn{1}{|c|}{ Competencias Bases } \\
\hline Competencias Transcurriculares & $\begin{array}{l}\text { Conocimientos habilidades y valores para el desenvolvimiento } \\
\text { personal, social y laboral. Se aprende durante toda la vida. }\end{array}$ \\
\hline Aprendizajes centrales & $\begin{array}{l}\text { Proceso primario de aprendizaje con mayor importancia niñez, } \\
\text { adolescencia y juventud. }\end{array}$ \\
\hline Competencias Socio normativas & Gran importancia la vida y convivencia en sociedad. \\
\hline Competencias técnico-instrumentales & Fundamentales para el aprendizaje de las disciplinas. \\
\hline Competencias clave & Importantes para el individuo y el funcionamiento social \\
\hline Intrapersonales & Habilidades, destrezas y actitudes individuales. \\
\hline Interpersonales & Interacción con la sociedad. \\
\hline
\end{tabular}

Fuente: Autor a partir de (Climent, 2010)

Tabla 13: Características de competencias según pirámide-Competencias de procesos

\begin{tabular}{|l|l|}
\hline \multicolumn{1}{|c|}{ Tipo } & \multicolumn{1}{c|}{ Característica } \\
\hline Competencias laborales & $\begin{array}{l}\text { Desempeño satisfactorio de las tareas y actividades de un puesto de } \\
\text { trabajo o función productiva. }\end{array}$ \\
\hline Competencias genéricas o transferibles & $\begin{array}{l}\text { Comportamientos asociados con desempeños comunes de las ramas } \\
\text { de la productividad. }\end{array}$ \\
\hline Competencias específicas o técnicas & Asociadas a ocupaciones particulares. \\
\hline
\end{tabular}

Fuente: Autor a partir de (Climent, 2010)

Tabla 14: Características de competencias según pirámide- Competencias de sistemas.

\begin{tabular}{|c|c|}
\hline \multicolumn{2}{|r|}{ Competencias de Sistemas } \\
\hline Tipo & Característica \\
\hline Competencias de directivas o gerenciales & Asociadas a las habilidades de liderazgo para la productividad \\
\hline Competencias sistémicas & Corresponde a los sistemas en su conjunto. \\
\hline
\end{tabular}

Fuente: Autor a partir de (Climent, 2010)

Tabla 15: Características de competencias según pirámide- Competencias de Telos..

\begin{tabular}{|l|l|}
\hline \multicolumn{1}{|c|}{ Tipo } & \multicolumn{1}{c|}{ Competencias de Telos } \\
\hline Metacompetencias & $\begin{array}{l}\text { Competencias de orden superior. Asociadas a la creatividad, sentido } \\
\text { común, pensamiento crítico y reflexivo, análisis sistémico u holístico } \\
\text { y el aprendizaje balanceado de diferentes competencias. }\end{array}$ \\
\hline
\end{tabular}

Fuente: Autor a partir de (Climent, 2010)

Otra clasificación de modelos de competencia corresponde a: El modelo de competencias distintivas, por David McClelland, el modelo de competencias genéricas por William Byham y el modelo funcional por Sydney Fine, distintos del modelo Conductista, funcional y 
constructivista. El modelo conductista se centra en las capacidades de fondo de las personas que conlleva a desempeños superiores, el modelo funcional define las competencias como el desempeño o resultados concretos y predefinidos que la persona debe demostrar en un proceso productivo determinado y el modelo constructivista define las competencias a partir del análisis y proceso de resolución de problemas y disfunciones que se presentan en la organización, según (Saracho, 2005) el modelo constructivista no es un modelo de competencias sino un abordaje para el desarrollo de las mismas, además indica que los modelos de competencias distintivas, genéricas y funcional no contienen una guía clara y funcional de para qué y cómo utilizar cada una de ellas.

A su vez, existen las competencias laborales, según Organización Internacional del Trabajo (OIT), la definen como la capacidad efectiva de llevar a cabo exitosamente una actividad laboral plenamente identificada. "La competencia laboral no es una probabilidad de éxito en la ejecución del trabajo, es una capacidad real y demostrada". También indican que una buena aproximación es la que diferencia tres enfoques, (i) la capacidad de ejecutar tareas, (ii) los atributos personales (actitudes y capacidades) y (iii) el holístico incluye los dos anteriores (2004).

Otros expertos indican como competencias laborales los siguientes conceptos (OIT, 2004).

Tabla 16: Definición de Competencias

\begin{tabular}{|c|c|}
\hline (Agudelo, 1998.) & $\begin{array}{l}\text { Capacidad integral que tiene una persona para desempeñarse eficazmente en situaciones } \\
\text { específicas de trabajo }\end{array}$ \\
\hline (Bunk, 1994) & $\begin{array}{l}\text { Posee competencia profesional quien dispone de los conocimientos, destrezas y } \\
\text { aptitudes necesarios para ejercer una profesión, puede resolver los problemas } \\
\text { profesionales de forma autónoma y flexible, está capacitado para colaborar en su } \\
\text { entorno profesional y en la organización del trabajo }\end{array}$ \\
\hline (Ducci, 1997) & $\begin{array}{l}\text { La competencia laboral es la construcción social de aprendizajes significativos y útiles } \\
\text { para el desempeño productivo en una situación real de trabajo que se obtiene, no sólo a } \\
\text { través de la instrucción, sino también -y en gran medida- mediante el aprendizaje por } \\
\text { experiencia en situaciones concretas de trabajo. }\end{array}$ \\
\hline $\begin{array}{l}\text { (Gallart \& } \\
\text { Jacinto, 1997) }\end{array}$ & $\begin{array}{l}\text { Un conjunto de propiedades en permanente modificación que deben ser sometidas a la } \\
\text { prueba de la resolución de problemas concretos en situaciones de trabajo que entrañan } \\
\text { ciertos márgenes de incertidumbre y complejidad técnica }[\ldots] \text { no provienen de la } \\
\text { aplicación de un currículum }[\ldots] \text { sino de un ejercicio de aplicación de conocimientos en } \\
\text { circunstancias críticas }\end{array}$ \\
\hline $\begin{array}{l}\text { (Gonzci \& } \\
\text { Athanasou, 1996) }\end{array}$ & $\begin{array}{l}\text { Una compleja estructura de atributos necesarios para el desempeño en situaciones } \\
\text { específicas. Este ha sido considerado un enfoque holístico en la medida en que integra } \\
\text { y relaciona atributos y tareas, permite que ocurran varias acciones intencionales } \\
\text { simultáneamente y toma en cuenta el contexto y la cultura del lugar de trabajo. Nos } \\
\text { permite incorporar la ética y los valores como elementos del desempeño competente }\end{array}$ \\
\hline (Le Boterf, 1998) & $\begin{array}{l}\text { Una construcción, a partir de una combinación de recursos (conocimientos, saber hacer, } \\
\text { cualidades o aptitudes, y recursos del ambiente (relaciones, documentos, informaciones } \\
\text { y otros) que son movilizados para lograr un desempeño }\end{array}$ \\
\hline (Mertens, 1996) & $\begin{array}{l}\text { Aporta una interesante diferenciación entre los conceptos de calificación y competencia. } \\
\text { Mientras por calificación se entiende el conjunto de conocimientos y habilidades que } \\
\text { los individuos adquieren durante los procesos de socialización y formación, la } \\
\text { competencia se refiere únicamente a ciertos aspectos del acervo de conocimientos y } \\
\text { habilidades: los necesarios para llegar a ciertos resultados exigidos en una circunstancia } \\
\text { determinada; la capacidad real para lograr un objetivo o resultado en un contexto dado }\end{array}$ \\
\hline
\end{tabular}




\begin{tabular}{|l|l|}
\hline (Miranda, 2003) & $\begin{array}{l}\text { De un modo genérico se suele entender que la competencia laboral comprende las } \\
\text { actitudes, los conocimientos y las destrezas que permiten desarrollar exitosamente un } \\
\text { conjunto integrado de funciones y tareas de acuerdo con criterios de desempeño } \\
\text { considerados idóneos en el medio laboral. Se identifican en situaciones reales de trabajo } \\
\text { y se las describe agrupando las tareas productivas en áreas de competencia (funciones } \\
\text { más o menos permanentes), especificando para cada una de las tareas los criterios de } \\
\text { realización a través de los cuales se puede evaluar su ejecución como competente }\end{array}$ \\
\hline $\begin{array}{l}\text { (Muñoz de } \\
\text { Priego Alvear, } \\
1998)\end{array}$ & $\begin{array}{l}\text { Aquellas cualidades personales que permiten predecir el desempeño excelente en un } \\
\text { entorno cambiante que exige la multifuncionalidad. La capacidad de aprendizaje, el } \\
\text { potencial en el sentido amplio, la flexibilidad y capacidad de adaptación son más } \\
\text { importantes en este sentido que el conocimiento o la experiencia concreta en el manejo } \\
\text { de un determinado lenguaje de programación o una herramienta informática específica. }\end{array}$ \\
\hline $\begin{array}{l}\text { (Kochansky, } 1998) \\
\text { Las competencias son las técnicas, las habilidades, los conocimientos y las } \\
\text { características que distinguen a un trabajador destacado, por su rendimiento, sobre un } \\
\text { trabajador normal dentro de una misma función o categoría laboral. }\end{array}$ \\
\hline (SCANS, 1991) & $\begin{array}{l}\text { Las competencias se encuentran en dos grandes grupos: uno de base y el otro de } \\
\text { competencias transversales; Las básicas: Habilidades básicas, Aptitudes analíticas, } \\
\text { Cualidades personales; y las competencias transversales: Gestión de recursos, } \\
\text { Relaciones interpersonales, Gestión de información, Comprensión sistémica y Dominio } \\
\text { tecnológico. }\end{array}$ \\
\hline
\end{tabular}

Fuente: Autor

A nivel institucional quienes trabajan en la normalización y certificación de competencias e instituciones de formación profesional de la región, indican:

\section{Tabla 17: Organismos institucionales competentes}

\begin{tabular}{|c|c|}
\hline $\begin{array}{l}\text { (Australian National } \\
\text { Training Authority) }\end{array}$ & $\begin{array}{l}\text { Competencia es la capacidad para desempeñar tareas y obligaciones de } \\
\text { acuerdo con el estándar esperado en el empleo }\end{array}$ \\
\hline $\begin{array}{l}\text { (Qualifications and } \\
\text { Curriculum Authority) }\end{array}$ & $\begin{array}{l}\text { Reflejan las habilidades y conocimientos necesarios para realizar un trabajo } \\
\text { efectivamente, y demuestran que el candidato es competente en el área de } \\
\text { trabajo }\end{array}$ \\
\hline $\begin{array}{l}\text { (Consejo de } \\
\text { Normalización y } \\
\text { Certificación de } \\
\text { Competencia Laboral } \\
\text { (CONOCER), 1997) }\end{array}$ & $\begin{array}{l}\text { Capacidad productiva de un individuo que se define y mide en términos de } \\
\text { desempeño en un determinado contexto laboral, y no solamente de } \\
\text { conocimientos, habilidades, destrezas y actitudes; estas son necesarias, pero } \\
\text { no suficientes por sí mismas para un desempeño efectivo. }\end{array}$ \\
\hline $\begin{array}{l}\text { Ministerio de Educación } \\
\text { de Brasil }\end{array}$ & $\begin{array}{l}\text { Capacidad de articular, movilizar y colocar en acción, valores, conocimientos } \\
\text { y habilidades necesarias para el desempeño eficiente y eficaz de actividades } \\
\text { requeridas por la naturaleza del trabajo. La Ley de directrices básicas de la } \\
\text { educación establece que una persona es competente cuando "constituye, } \\
\text { articula y moviliza valores, conocimientos y habilidades para la solución de } \\
\text { problemas, no solo rutinarios, sino también inesperados, en su campo de } \\
\text { actuación" (BRASIL. Ley 9.394. 1996) }\end{array}$ \\
\hline $\begin{array}{l}\text { Sistema Nacional de } \\
\text { Cualificaciones y } \\
\text { Formación Profesional de } \\
\text { España. }\end{array}$ & $\begin{array}{l}\text { La competencia profesional es el conjunto de conocimientos y capacidades que } \\
\text { permiten el ejercicio de la actividad profesional, conforme a las exigencias de } \\
\text { la producción y el empleo. (Ley } 5 \text { del } 19 \text { de junio de 2002) }\end{array}$ \\
\hline $\begin{array}{l}\text { Consejo Federal de } \\
\text { Cultura y Educación de } \\
\text { Argentina }\end{array}$ & $\begin{array}{l}\text { (Res. N }{ }^{\circ} 55 / 96 \text {, Consejo Federal de Cultura y Educación, Argentina, Boletín } \\
\text { Cinterfor/OIT) "Un conjunto identificable y evaluable de conocimientos, } \\
\text { actitudes, valores y habilidades relacionados entre sí, que permiten } \\
\text { desempeños satisfactorios en situaciones reales de trabajo, según estándares } \\
\text { utilizados en el área ocupacional." }\end{array}$ \\
\hline SENAI (Brasil) & $\begin{array}{l}\text { Define la competencia como la capacidad de un trabajador para movilizar los } \\
\text { conocimientos, habilidades y actitudes necesarias para alcanzar los resultados }\end{array}$ \\
\hline
\end{tabular}




\begin{tabular}{|l|l|}
\hline & $\begin{array}{l}\text { pretendidos en un determinado contexto profesional, según patrones de calidad } \\
\text { y productividad. Implica entonces, la capacidad de actuar, intervenir y decidir } \\
\text { en situaciones imprevistas, movilizando el máximo de saberes y } \\
\text { conocimientos para dominar situaciones concretas de trabajo, aplicando } \\
\text { experiencias adquiridas de un contexto para otro (SENAI, 2002) }\end{array}$ \\
\hline SENA (Colombia) & $\begin{array}{l}\text { el conjunto de capacidades socio-afectivas y habilidades cognoscitivas, } \\
\text { sicológicas y motrices, que permiten a la persona llevar a cabo de manera } \\
\text { adecuada, una actividad, un papel, una función, utilizando los conocimientos, } \\
\text { actitudes y valores que posee (SENA, 2002) }\end{array}$ \\
\hline INTECAP (Guatemala) & $\begin{array}{l}\text { Competencia profesional es la habilidad para realizar los roles o puestos de } \\
\text { trabajo a los niveles requeridos según las normas establecidas en el empleo. } \\
\text { Conlleva la capacidad de realizar un conjunto de actividades o funciones } \\
\text { específicas en el desempeño de un puesto de trabajo } \\
\text { (www.intecap.org.gt/glosario, s.f.) }\end{array}$ \\
\hline
\end{tabular}

Fuente: Autor

Retomando los conceptos de McClelland, "una competencia es una combinación de características que le permiten a alguien comportarse de cierta manera para conseguir resultados extraordinarios o de nivel superior", el modelo de competencias genéricas por William Byham destaca "existen ciertas conductas típicas que permiten a una persona desempeñarse correctamente en un puesto determinado" y el modelo funcional por Sydney Fine, indica los comportamientos mínimos necesarios para un desempeño aceptable, en los tres casos las competencias hacen referencia a comportamientos determinados para alcanzar desempeños superiores, estándar o mínimos (Saracho, 2005).

\subsubsection{Prospectiva Teórica para el abordaje de las competencias.}

La preocupación por la calidad de la educación es la razón principal de la atención a las competencias básicas que subrayan la puesta en práctica de los aprendizajes, así mismo lo expresa la UNESCO (2005) en donde resalta "con la rapidez de los progresos técnicos, las competencias pierden rápidamente actualidad, es conveniente fomentar en los distintos ámbitos de conocimiento la adquisición de mecanismos de aprendizaje flexibles, en vez de imponer un conjunto de conocimientos muy definidos"

El "modelo de coordenadas curriculares" pretende profundizar en el desarrollo de la competencia global, competencia transversal en las áreas de conocimiento de básica secundaria para ahondar en la propuesta de la OCDE que surge del interrogante ¿Qué competencias necesitamos para el bienestar personal, social y económico?

La competencia global busca identificar asuntos o temas relevantes de significancia local, global y cultural para todos los niños de 15 años en el mundo. Las instituciones educativas requieren aproximaciones pedagógicas innovadoras. Se requiere marcos de referencia para abordar los temas complejos y construir visión crítica y multiperpectivista sobre los asuntos globales e interculturales.

La globalización y modernización han creado un mundo más interconectado que requiere la comprensión de grandes volúmenes de información, el balance económico y ambiental y la equidad social. Razón para repensar lo básico de las competencias básicas en niveles 
educativos en donde se debe elegir "ampliar, reducir o eliminar" contenidos que vinculen el mundo de la educación y el entorno; es necesario desarrollar guías claras que permitan operativizar el modelo de competencias bajo lineamiento de innovación con identidad local pensadas desde lo global.

Se requiere de un marco de referencia que permita retomar de las áreas de conocimiento la competencia global para un mundo que cambia con rapidez, en donde la sociedad transforma sus interrelaciones y los impactos son cada vez más globales, se necesitan herramientas de apoyo para el dominio de destrezas para la resolución de problemas de contextos vinculados desde lo global.

La competencia global involucra entre otros "valores" a continuación se describe la categoría de Desarrollo Humano que detalla los aspectos que el individuo considera importante para la vida en términos de normativas sobre lo que se debe hacer o pensar, actitudes, juicios y acciones.

\subsection{Desarrollo Humano}

Las teorías de desarrollo humano se han fundamentado desde diferentes referentes teóricos incluyendo enfoques filogénicos, psicológicos, económicos, sociológicos, filosóficos y pedagógicos, reflexiones desde distintos escenarios que hacen compleja la clasificación e interpretación conceptual.

El enfoque filogénico centra sus estudios en las características de los seres humanos como una especie en evolución, Charles Darwin es el científico más influyente en relación con las teorías evolutivas cuyo despliegue teórico es conocido en su obra "El origen de las especies" (1859), título que aborda la teoría científica en la que explica que las poblaciones evolucionan de generación en generación mediante un proceso conocido como selección natural; Los estudios actuales del enfoque filogénico también han planteado una mirada desde la psicología evolutiva en la que los individuos pueden alcanzar su grado de madurez desde las diferentes áreas.

Desde el enfoque psicológico (teorías con un amplio abanico de referentes teóricos influyentes) las teorías de desarrollo humano intentan explicar el desarrollo de los individuos desde la conducta y la personalidad, en algunos casos estudiadas desde factores internos de la persona y otros desde el ambiente y la sociedad.

Tabla 18: Enfoques Psicológicos.

\begin{tabular}{|l|l|l|}
\hline \multicolumn{1}{|c|}{ Enfoque } & \multicolumn{1}{c|}{ Orientación } & \multicolumn{1}{c|}{ Exponentes } \\
\hline $\begin{array}{l}\text { Enfoque } \\
\text { Psicodinámico }\end{array}$ & Estudia de la personalidad & $\begin{array}{l}\text { Sigmund Freud con la teoría del desarrollo } \\
\text { psicosexual (1905) y Erik Erikson con la teoría } \\
\text { del desarrollo psicosocial (2000) }\end{array}$ \\
\hline $\begin{array}{l}\text { Enfoque } \\
\text { Cognoscitivo, }\end{array}$ & $\begin{array}{l}\text { Estudia el desarrollo del } \\
\text { pensamiento. }\end{array}$ & $\begin{array}{l}\text { Jean Piaget (Desarrollo Cognoscitivo,1936), } \\
\text { Lawrence Kohlberg (Desarrollo Moral, 1981) } \\
\text { Vygotsky (Perspectiva Sociocultural,1978) y }\end{array}$ \\
\hline
\end{tabular}




\begin{tabular}{|l|l|l|}
\hline & & $\begin{array}{l}\text { Chomsky (teoría de la visión sistémica } \\
\text { ecológica,2003). }\end{array}$ \\
\hline $\begin{array}{l}\text { Enfoque } \\
\text { Sociocultural }\end{array}$ & $\begin{array}{l}\text { Estudios enfocados en la } \\
\text { influencia del ambiente }\end{array}$ & $\begin{array}{l}\text { Bandura (1977) con la Teoría del Aprendizaje } \\
\text { Social y Bowlby con la Teoría del Apego (1998) }\end{array}$ \\
\hline $\begin{array}{l}\text { Enfoque } \\
\text { Conductista }\end{array}$ & $\begin{array}{l}\text { Estudia el proceso de } \\
\text { aprendizaje }\end{array}$ & $\begin{array}{l}\text { Watson (1955) y Skinner (1970) con la teoría } \\
\text { conductual al igual que los conceptos de } \\
\text { Bandura y Bowlby }\end{array}$ \\
\hline $\begin{array}{l}\text { El Enfoque } \\
\text { Ecológico } \\
\text { Sistémico }\end{array}$ & $\begin{array}{l}\text { Estudia el desarrollo humano en } \\
\text { relación con el entorno }\end{array}$ & $\begin{array}{l}\text { Bronfenbenner con la perspectiva del ciclo vital } \\
(2005) .\end{array}$ \\
\hline
\end{tabular}

Fuente: Autor

El desarrollo Humano visto desde el enfoque económico (interés de la actual propuesta), tiene sus orígenes en el pensamiento clásico, concebido desde las ideas de Aristóteles quien expresa que el hombre busca como fin la felicidad que consiste en una vida contemplativa, así mismo señala que el ser humano como individuo florece completamente y alcanza la realización plena de desarrollo cuando es considerado ciudadano, denominado Kalos Kagathos (ser noble y virtuoso), un ciudadano funcional como parte de un todo perteneciente a la Polis o Estado, el desarrollo humano para Aristóteles (384-322 a.C) incluye diversos medios entre los cuales incluye un cierto bienestar material, entendido como desarrollo pleno de las capacidades.

Posturas teóricas de Desarrollo Humano como es el caso del economista Manfred Max Neef, centran su mirada en lo que él denomina Desarrollo a escala humana (1994) en ella, sus aportes están por encima de las organizaciones, las estadísticas y los datos de calidad de vida de las persona, señalando que el desarrollo no debe ser impuesto sino que debe nacer desde la base, para lo cual define una matriz de nueve necesidades fundamentales (subsistencia, protección, afecto, entendimiento, participación, ocio, creación, identidad y libertad) y cuatro categorías de satisfacción de dichas necesidades (ser, tener, hacer y estar), de acuerdo con el autor el cambio cultural es consecuencia -entre otros- de abandonar los satisfactores tradicionales para reemplazarlos por otros nuevos y diferentes.

El interés particular de la actual propuesta de investigación se centra en la postura del Desarrollo Humano desde la óptica del desarrollo social y económico como políticas de estado y de los organismos internacionales, indicadores presentes en el Informe del Desarrollo Humano del programa de Naciones Unidas para el Desarrollo debido a su gran influencia a nivel mundial asociando a más de 190 países, lo que ratifica su gran influencia, vigencia y homogenización.

Desde la base conceptual de las teorías clásicas del crecimiento económico del siglo XVIII y XIX y a partir de la Segunda Guerra Mundial y junto al Plan Marshall surge el concepto de Desarrollo, término incluido en el discurso del presidente Truman en 1949 haciendo referencia a los países más pobres, preocupaciones abordadas en las teorías clásicas de crecimiento económico (creación de Adam Smith en 1777 y desarrollada por Malthus en 1798) y de las teorías ortodoxas de desarrollo como lo es la Teoría de la Modernización de Rostow (1960) y la teorías de Dependencia impulsadas por la CEPAL (Comisión Económica de América Latina). 
En otro sentido, La Asamblea General de Naciones Unidas en 1986 proclama la Declaración del Derecho al Desarrollo (DDD, Resol. 41/128), entendido como un proceso global, social, cultural y político que tiene como objeto el mejoramiento constante del bienestar de toda la población y de todos los individuos sobre la base de su participación, libre y significativa en el desarrollo y en la distribución justa de los beneficios, declaración soportada en diez artículos que confirman que el derecho al desarrollo es inalienable y la igualdad de oportunidades debe ser un compromiso de las naciones (ACNUDH, 1996-2018).

Hablar de Desarrollo Humano incluye entre otros componentes Capacidad y Bienestar, Sen (2002) define Capacidad como la oportunidad que tiene un individuo para conseguir funcionamientos de valor, los funcionamientos corresponden a las cosas que una persona logra ser o hacer para vivir y las libertades para que las personas puedan vivir una vida larga y saludable, tener acceso a la educación, a una vida digna, y a participar en la vida de su comunidad y en las decisiones que los afecten. El enfoque de las capacidades de Amartya Sen ha desplegado nuevas líneas de pensamiento entorno al Bienestar Social y al Desarrollo Humano Sostenible, aunque el enfoque de las capacidades de Sen difiere en términos de libertad a la tenencia de los bienes primarios de la Teoría de la Justicia de Ralws (1990) y de la Igualdad de Recursos de Dworkin (1981).

La significación de Desarrollo Humano ha evolucionado con el paso del tiempo, de acuerdo con Popkewitz (2000) los miembros de la administración del Estado se referían al bienestar social en términos de problemas biológicos, como reproducción, enfermedad y educación (desarrollo, crecimiento y evolución individual) para lo cual las necesidades humanas se consideraban instrumentales y empíricas en relación con el funcionamiento del estado, el Informe del Desarrollo Humano (IDH) de 1990 (PNUD, 1990) lo definió como "el derecho de expansión de las oportunidades del ser humano entre las cuales las tres más esenciales son disfrutar de una vida prolongada y saludable, adquirir conocimientos y lograr un nivel de vida decente" y para el 2010 el IDH (2010) (PNUD, 2010) lo definió como “ la expansión de las libertades de las personas para llevar una vida prolongada, saludable y creativa; consiguiendo las metas que consideran valiosas y participar activamente en darle forma al desarrollo de manera equitativa y sostenible en un planeta compartido. Las personas son cada vez beneficiarias y agentes motivadores del desarrollo humano, como individuos y colectivamente" en este sentido se exponen tres grandes dimensiones sociales colectivas para el desarrollo humano, (i) el empoderamiento, (ii) la vulnerabilidad y sostenibilidad y (iii) la desigualdad.

En la actualidad (2019) y desde 1990 el programa de Naciones Unidas para el Desarrollo (PNUD o UNDP) ha publicado el informe de Desarrollo Humano a los países miembros de la ONU a través del denominado Índice de Desarrollo Humano (IDH), parámetro establecido internacionalmente por el PNUD desde 2002 que sirve para determinar las condiciones generales de vida promedio de la población, con base en tres criterios: a) el Producto Interno Bruto (PIB) per cápita, medido en dólares; b) la esperanza de vida, cuantificada en años promedio al nacimiento; y c) el nivel de alfabetización, expresado en porcentaje (\%). 
Los aportes de Amartya Sen con relación al Informe de Desarrollo Humano son valiosos, puesto que recogen el espíritu de los clásicos en términos de la utilización de distintos instrumentos de análisis, contribuciones soportadas en tres conceptos fundamentales: Libertades, Capacidades y Agencia, configuración para una nueva perspectiva para el desarrollo fundada en el aumento de la riqueza de la vida humana en lugar de la riqueza económica, teorías denominadas amables (Pedrajas, 2006) que consideran el desarrollo como un proceso amigable, destacando la cooperación entre los individuos y para consigo mismos. En esta modalidad se incluyen las reflexiones sobre el desarrollo sostenible, las teorías del capital humano y capital social, el enfoque de la satisfacción de las necesidades humanas y, finalmente, el desarrollo humano.

Los Objetivos de Desarrollo Sostenible (2015) promulgado por las Naciones Unidas cuyos principios están enmarcados en el enfoque de las capacidades de Amartya Sen son un soporte para el desarrollo humano, puesto que estos hacen un llamado para la adopción de medidas para erradicar la pobreza, proteger el planeta y garantizar que las personas gocen de paz y prosperidad, a través de: (i) Fin de la Pobreza, (ii) Hambre Cero, (iii) Salud y Bienestar, (iv) Educación de Calidad, (v) Igualdad de Género, (vi) Agua Limpia y Saneamiento, (vii) Energía Asequible y no Contaminante, (ix) Industria Innovación e Infraestructura, (x) Reducción de las desigualdades, (xi) Ciudades y Comunidades Sostenibles, (xii) Producción y Consumo Sostenible, (xiii) Acción por el Clima, (xiv) Vida Submarina, (xv) Vida de Ecosistemas Terrestres, (xvi) Paz, Justicia y Instituciones Sólidas y (xvii) Alianzas para Lograr los Objetivos.

En la misma vía Martha Nussbaum, realiza contribuciones particulares de su visión, señalando que es posible acordar unos mínimos en la democratización de la sociedad diferenciándose de Sen. Crear Capacidades: Propuesta para el Desarrollo Humano (2012) es una obra en la que incluye nuevas categorías a las Capacidades Humanas Centrales; Afirma Nussbaum (2005), que la educación es adecuada para la libertad si produce ciudadanos libres, no por la riqueza o nacimiento, sino porque son dueños de sus propias mentes. Plantea tres habilidades para el cultivo de la humanidad: (i) la capacidad de hacer un examen crítico de uno mismo y de sus propias tradiciones, (ii) que las personas nos sintamos miembros pertenecientes "ciudadanos" de una gran comunidad que abarca a todos los seres humanos, más allá de nuestras identificaciones regionales, étnicas, religiosas o de cualquier otro tipo, y (iii) la capacidad de situarnos en el plano de otras personas, de comprender las emociones, sentimientos y aspiraciones de otros; Estos conceptos Nussbaum (2012) son también mencionados en el Enfoque de Las Diez Capacidades Funcionales Humanas Centrales que apuntan hacia el mejoramiento de la calidad de vida, sintetizadas en (i) vida, (ii) Salud corporal, (iii) integridad corporal, (iv) sentimiento, imaginación y pensamiento, (v) emociones, (vi) razón práctica, (vii) afiliación, (viii) otras especies, (ix) capacidad para jugar $\mathrm{y}(\mathrm{x})$ control sobre el entorno de cada uno.

Los enfoques expuestos de Desarrollo Humano orientan hacia nuevas dimensiones de la vida y de las condiciones para lograrlas, en ella la libertad juego un papel fundamental desde lo individual y colectivo, la perspectiva economicista cambia levemente reconociendo que la acumulación de riqueza de los países y personas no dependen exclusivamente de la economía. 


\subsubsection{Prospectiva Teórica para el Desarrollo Humano.}

El movimiento constante generado por la globalización y los avances tecnológicos han determinado en la humanidad profundos cambios en las concepciones del desarrollo humano propias de la contemporaneidad. La actual definición de Desarrollo Humano por el Plan de Naciones Unidas para el Desarrollo-PNUD (2010) plantea nuevas dimensiones sociales colectivas de bienestar ${ }^{11}$, dimensiones que requieren de soporte metodológico para la inserción en el diseño curricular de las instituciones de básica secundaria que promueven objetivos compartidos de futuro mediante procesos de participación colectiva para la innovación en la educación.

La educación para el desarrollo humano define al hombre que se desea formar y con ello el tipo de sociedad. La actual demanda social requiere de aprendizajes más significativos, con mayor participación, en donde el dialogo a partir de los problemas e intereses colectivos mediados por ambientes de aprendizajes más significativos generan mayor apropiación del conocimiento. Las sociedades deben definir sus prioridades mediante procesos de participación colectiva que les permita su emancipación sin perder la capacidad de decidir su propio futuro.

La escuela como entorno protector y actor protagónico para el desarrollo humano debe apropiarse de las necesidades, interés y problemas sin perder la globalidad desde el currículo como un documento de identidad en donde confluyen relaciones de poder que se transversalizan con el objetivo de bridar soluciones desde posturas colectivas que forman al individuo.

El currículo debe absorber las dimensiones de bienestar colectivas como elemento integrador para el desarrollo humano, para ello se requiere de metodologías dinámicas que hagan operativo la subjetividad, intersubjetividad y la autonomía necesaria de la escuela para una cultura en movimiento con nuevas lógicas de comunicación e interacción.

La construcción del currículo requiere de áreas o disciplinas de conocimiento para su pertinencia, a continuación, se descompone la categoría teórica que permite identificar ¿qué tipo de conocimiento se debe considerar válido?

\section{4. Áreas de conocimiento}

La enseñanza de la religión y de las tradiciones corresponden a las disciplinas inicialmente abordadas en el antiguo Oriente (India, China, Persia, Egipto) y la Grecia antigua, influencia

${ }^{11}$ (i) El empoderamiento: Las sociedades deben estar en la capacidad de desarrollar su propia visión de bienestar, (ii) la vulnerabilidad y sostenibilidad: Desarrollo de sociedades con corresponsabilidad compartida para que los resultados de bienestar se puedan mantener y (iii) la desigualdad: Planteamiento de objetivos colectivos de igualdad. 
también adoptada en occidente a partir de la tradición religiosa judía y cristiana, en donde Sócrates, Platón y Aristóteles son los pensadores más influyentes de la Grecia Antigua. El objetivo educativo griego se situó en la formación intelectual de los jóvenes para asumir el liderazgo que requería la dirección del Estado y la sociedad, siglos posteriores estos enfoques se situaron en el desarrollo de las artes, las áreas de la filosofía, los ideales y la instrucción atlética para las olimpiadas.

De acuerdo con la obra de Martianus Capella (410-429) citado por Da Costa (2006) el concepto de Trivium et Cuadrivium ${ }^{12}$, nace de la Grecia antigua, para denominar a las artes (disciplinas académicas) diferenciándose de las artes serviles (propias de los esclavos); "Las Siete Artes Liberales" como se les denomina, se adoptaron como currículo educativo por Alcuino de York en la Escuela Palatina de Arquisgrán a finales del siglo VIII; Trivium agrupaba tres disciplinas: gramática, dialéctica y retorica (disciplinas de la elocuencia) y Cuadrivium reúne disciplinas relacionadas con las matemáticas como lo son la Aritmética, geometría, astronomía y música.

Existen distintas posturas teóricas relacionadas con el origen del conocimiento, entre ellas se encuentran El Racionalismo y El Empirismo, el primero sostiene que es la razón la fuente del conocimiento humano y el segundo sustenta que el conocimiento se origina de la experiencia; Platón, Plotino, San Agustín, Malebranche, Descartes, Leibnitz, Bergson, Pascal y Dilthey representan el Racionalismo, mientras que Locke y Hume, Condillac y John Stuart Mill representan El Empirismo.

La transmisión de valores (ser) y saberes técnicos (hacer) en la antigua Grecia se le conoció como Paideia (Werner, 2001) incluía conceptos de gimnasia, gramática, retorica, matemáticas y filosofía conocimientos denominados dignos; años más tarde los Humanitas ${ }^{13}$ de acuerdo con los escritos de Cicerón (Sobre Leyes) ${ }^{14}$ a Paideia se le conoce como cultura, educación y pedagogía, cuyo objetivo consistía en civilizar al hombre a través de la cultura dejando atrás el barbarismo, buscando la armonía entre la educación: corporal, intelectual, moral y la justicia. Surgen entonces, Las Humanidades cuyos estudios se enfocaron en la cultura, filosofía, pedagógica e ideologías entendiéndose como el cultivo global de las capacidades del hombre (García, 1970); mientras que para Foucault (1999) las ciencias humanas nacen en el siglo XIX bajo el modelo de racionalidad científica.

La historia reciente de las disciplinas escolares en la actualidad se instaura a partir de los años 70, en Gran Bretaña y Francia, por distintos autores, siendo Ivor F. Goodson, Dominique Julia y André Chervel, teóricos con gran reconocimiento en las líneas de investigación tanto anglosajona-inglesa y francesa; para Goodson \& Dowbiggin (2003) las disciplinas escolares obedecen a amalgamas cambiantes de subgrupos rivales y tradiciones que influyen en la

\footnotetext{
12 Pilares de la Edad Media

${ }^{13}$ Palabra latina relacionada con los conceptos griegos sobre filantropía, amar lo que nos hace humanos.

14 “De Legibus” Texto escrito durante los últimos años de la Republica Romana
} 
dirección del cambio que permanecen o son segregadas por distintas motivaciones ya sean prestigio, respetabilidad, recursos, clase social, poder, entre otras.

Así mismo Goodson (2000) apoyado de la enseñanza primaria inglesa por (Blyth, 1998) diferencia tres tipos de tradiciones en las asignaturas de la básica primaria y secundaria: la "académica" con énfasis preparatorio o propedéutico, la "utilitaria" orientada hacia las salidas laborales y la "pedagógica" enfocada hacia el desarrollo infantil para conectar las disciplinas con los estudiantes; De este modo rompe con la idea, habitualmente mantenida, que halla el origen de las materias de la enseñanza secundaria en las disciplinas universitarias (un proceso de abajo hacia arriba) tal es el caso de las artes ( origen claramente pedagógico) y estudios rurales que han tenido que presentarse como asignaturas académicas teóricas para tener prestigio de nivel avanzado.

Para Bruno Belhoste (1990) uno de los grandes cambios en la enseñanza de la secundaria en Europa está dada en el siglo XIX luego de la Segunda Guerra Mundial al pasar el bachillerato tradicional a la "Enseñanza Secundaria para Todos", situación de gran controversia en el campo académico; Desde otro enfoque, para Dominique Julia (quien centra sus estudios en Europa entre los siglos XVI al XVIII) y André Chervel (Investigaciones realizadas en Francia Siglos XIX y XX) las disciplinas escolares están inmersas en la cultura escolar, lo que conlleva a la institución escolar a pensarla como un espacio de producción de saberes y no de reproducción de conocimientos, para Julia (1996) la cultura escolar corresponde a un conjunto de normas que definen los saberes a enseñar y los comportamientos, además de las prácticas a seguir, mientras que para Chervel (1993) la escuela adapta la cultura externa, luego crea y transforma una cultura propia y resultado de ello, responde a las disciplinas fruto de las mediciones escolares.

Para Dominique Julia (2000) se debe tener presente los tres escollos en la historia de las disciplinas: (i) Tratar a toda costa de encontrar el origen de las disciplinas ${ }^{15}$, (ii) Pensar que una disciplina no se enseña porque no aparezca en los textos de programación o porque no existen cátedras oficialmente creadas bajo ese nombre e (iii) Imaginar un funcionamiento idéntico en el tiempo de las disciplinas escolares, cuando éstas se designan bajo el mismo rótulo.

Retomando a Goodson, él plantea una distinción entre asignatura o materia y disciplina, señalando que dicha naturalización implica un proceso de academización, formalización y abstracción, incluso algunas asignaturas no se les puede aplicar la expresión de disciplina, similares cuestionamientos planteados por Chervel con relación a ¿cómo se sabe que se está ante una disciplina, materia, actividad o ejercicio?

Para Chervel (1993) las disciplinas son cuerpos de conocimiento, con una lógica interna, con temas específicos, con planes periódicos diferenciados para llegar a ideas concretas para la solución de problemas complejos, mientas que en palabras de Julia (2000) las disciplinas

\footnotetext{
${ }^{15}$ tal es el caso de Ratio Studiorum jesuita, cuyo nombre completo es Plan oficial de estudios de la Compañía de Jesús, plan estándar con finalidad retorica y moral en los colegios nobles del siglo XVIII de acuerdo con los escritos de Julia (2000).
} 
escolares son una "Alquimia" y un "Transito" construidos en el "Espacio social de la escuela" permeado como también lo expresa Popkewitz (1994) por las sinergias planteadas por el currículo escolar en términos de horario, edad, operacionalización de la enseñanza, entre otras; así mismo, señala Julia que un acto fundacional de una disciplina está dada por la sistematización y secuenciación por escrito de un manual o texto del ámbito escolar convertido en objeto de enseñanza. En este sentido, las materias o áreas curriculares son el vínculo generador de la profesionalización del docente, la cultura escolar académica y los sistemas educativos en los que las disciplinas, con sus correspondientes códigos, se visibilizan y arraigan.

Las disciplinas académicas para (Krishnan, 2009) deben tener un objeto particular de estudio, conocimientos especializados con teorías que lo sustenten, un lenguaje propio y presencia institucional, a lo que agrega Bazerman y Prior (2005) identidad social, audiencias particulares, relaciones interpersonales e institucionales y las formas de vida y discursos socioculturales, los autores en mención consideran a las disciplinas como objetos cambiantes que requieren de componentes estabilizadores para cobrar mayor sentido; a su vez, Gee (2010) plantea una diferencia entre campo, disciplina y especialidad disciplinar, refiriéndose a campos académicos como áreas menos integradas pero más amplias que las disciplinas, ejemplo de ello es la educación, la disciplina la asocia el autor con las facultades universitarias ${ }^{16}$ y la especialidad disciplinar como especialidad académica en función de investigaciones reales de temáticas particulares.

En la actualidad, un referente de importancia a nivel educativo corresponde a la Organización de Naciones Unidas para la Educación, la Ciencia y la Cultura- UNESCO- Organismo especializado de las Naciones Unidas cuyo compromiso consiste en velar por la educación de calidad en el mundo entero para el desarrollo humano, social y económico, tiene como funciones principales (i) convertirse en un espacio para la generación de ideas, en este sentido, prever y responder hacia los nuevos requerimientos en el ámbito educativo y elaborar políticas educativas para la investigación y las prioridades de cada país; (ii) Acción normativa: elaborar criterios, normas y directrices educativas y definir los instrumentos jurídicos y normativos pertinentes; (iii) Intercambio de información: promover el desarrollo, la aplicación y la difusión de políticas y prácticas educativas ejemplarizantes; (iv) Aumento de capacidades: permitir la cooperación técnica para alcanzar los objetivos nacionales educativos; y (v) Catalizador de la cooperación internacional: Fomentar el dialogo e intercambio de información en el ámbito educativo (UNESCO, 2011a).

Es así como la UNESCO (2011b) a través la Clasificación Internacional Normalizada de la educación ( en adelante CINE) estandariza los parámetros que se deben considerar para asignar un programa a un nivel de estudios, para lo cual determina los sectores de la educación en términos de "variables de clasificación cruzada" para la creación de los niveles de educación y campos de educación, en este sentido, establece nueve (9) niveles en

${ }^{16}$ El enfoque de disciplina de Gee (proceso de arriba hacia abajo) dista del enfoque de Goodson (un proceso de abajo hacia arriba) con relación al origen de las materias de la enseñanza secundaria en las disciplinas universitarias. 
educación ${ }^{17}$, de los cuales dos corresponden a secundaria (CINE 2 y CINE 3);para el caso de educación secundaria baja - CINE 2, los programas deben estar orientados en asignaturas cuyo enfoque consiste en el desarrollo humano y el aprendizaje a lo largo de la vida, además de ello, plantea dos dimensiones complementarias: Orientación a los programas (General y vocacional) y Conclusión del nivel y acceso a un nivel CINE más avanzado (Nivel CINE 2 inconcluso, Conclusión parcial del nivel CINE 2 sin acceso directo a un nivel CINE más avanzado, Conclusión del nivel CINE 2 sin acceso directo a un nivel CINE más avanzado, y Conclusión del nivel CINE 2 con acceso directo a programas de un nivel CINE más avanzado), y para el caso del Nivel CINE 3 correspondiente a la educación secundaria alta cuyo objetivo es consolidar la educación secundaria como preparación a la educación terciaria, o bien proporcionar destrezas pertinentes al empleo o ambos, al igual que el CINE 2 plantea dos dimensiones complementarias.

De igual modo define el CINE 2011 en comunión con la Eurostat (Oficina Europea de Estadística) y la OCDE (Organización para la Cooperación y el Desarrollo Económico), 25 campos de educación en torno a 9 grupos, así:

Tabla 19: Campos de Educación según CINE 2011.

\begin{tabular}{|c|c|}
\hline Grupos Educativos & Campos de Educación \\
\hline \multirow{3}{*}{ Programas generales } & Programas básicos \\
\hline & Programas de alfabetización y de aritmética \\
\hline & Desarrollo personal \\
\hline Educación & $\begin{array}{l}\text { Formación de personal docente y ciencias de la } \\
\text { educación }\end{array}$ \\
\hline \multirow[t]{2}{*}{ Humanidades y artes } & Artes \\
\hline & Humanidades \\
\hline \multirow[t]{4}{*}{ Ciencias sociales, educación comercial y derecho } & Ciencias sociales y del comportamiento \\
\hline & Periodismo e información \\
\hline & Educación comercial y administración \\
\hline & Derecho \\
\hline \multirow[t]{4}{*}{ Ciencias } & Ciencias de la vida \\
\hline & Ciencias físicas \\
\hline & Matemáticas y estadística \\
\hline & Informática \\
\hline \multirow[t]{3}{*}{ Ingeniería, industria y construcción } & Ingeniería y profesiones afines \\
\hline & Industria y producción \\
\hline & Arquitectura y construcción \\
\hline \multirow[t]{2}{*}{ Agricultura } & Agricultura, silvicultura y pesca \\
\hline & Veterinaria \\
\hline \multirow[t]{2}{*}{ Salud y servicios sociales } & Medicina \\
\hline & Servicios sociales \\
\hline Servicios & Servicios personales \\
\hline
\end{tabular}

${ }^{17}$ Nivel CINE 0 - Educación de la primera infancia, Nivel CINE 1 - Educación primaria, Nivel CINE 2 - Educación secundaria baja, Nivel CINE 3 - Educación secundaria alta, Nivel CINE 4 - Educación post-secundaria no terciaria, Nivel CINE 5 - Educación terciaria de ciclo corto, Nivel CINE 6 - Grado de educación terciaria o nivel equivalente, Nivel CINE 7 - Nivel de maestría, especialización o equivalente, y Nivel CINE 8 - Nivel de doctorado o equivalente. 


\begin{tabular}{|l|l|}
\hline \multirow{2}{*}{ Sectores desconocidos o no especificados } & Servicios de transporte \\
\cline { 2 - 2 } & Protección del medio ambiente \\
\cline { 2 - 2 } & Servicios de seguridad \\
\hline & $\begin{array}{l}\text { No forma parte, pero es tenido en cuenta } \\
\text { para las estadísticas. }\end{array}$ \\
\hline
\end{tabular}

Fuente: Autor, adaptado de CINE 2011

Desde esta perspectiva el artículo 23 de la Ley General de Educación Colombiana (Ley 115, 1994) establece como áreas obligatorias y fundamentales para la educación básica con un mínimo del 80\% en el plan de estudio: (i) Ciencias Naturales y Educación Ambiental, (ii) Ciencias sociales, historia, geografía, constitución política y democracia, (iii) Educación artística, (iv) Educación ética y en valores humanos, (v) Educación física, recreación y deportes, (vi) Educación religiosa, (vii) Humanidades, lengua castellana e idiomas extranjeros, (viii) Matemáticas, y (ix) Tecnología e informática; y para la educación medía que corresponde a los grados 10 y 11, se le suman a las áreas de la educación básica, (x) ciencias económicas, (xi) política y (xii) filosofía.

En sintonía con lo anterior, la Ley General de Educación (Ley 115, 1994) en el artículo 79 define como elementos constitutivos de un Plan de Estudios: (i) los Objetivos por nivel y grado, (ii) la metodología, (iii) distribución de tiempo y (iv) los criterios de evaluación y administración, así mismo el artículo 76 define a "el currículo" como un conjunto de criterios, planes de estudios, programas, metodología y procesos que contribuyen a la formación integral y a la construcción de identidad cultural nacional, regional y local..." lo que denota, que para la legislación nacional, el currículo contiene el Plan de estudios.

Con base en las distintas clasificaciones educativas en términos de estructura y contenidos a nivel mundial la Clasificación Internacional Normalizada de la Educación (CINE) por parte de la UNESCO proporciona un marco de referencia para los países miembros, así mismo, diseña parámetros para el establecimiento de estándares de cumplimiento a nivel global, local y regional.

\subsubsection{Prospectiva Teórica con relación a las Áreas de Conocimiento.}

La declaración de Incheon le encargó a la UNESCO como organismo especializado en educación de las Naciones Unidas la dirección de la agenda educativa para 2030 para los países asociados (UNESCO, 2015) agenda busca garantizar educación inclusiva y equitativa a partir de la adquisición de conocimientos teóricos y prácticos para la promoción y educación de los Objetivos de Desarrollo Sostenible al igual que la adopción de estilos de vida sostenibles, igualdad entre los géneros, ciudadanía mundial y la contribución de la cultura al desarrollo sostenible, entre otros medios que forman parte del desarrollo humano.

Partiendo desde la perspectiva de Dominique Julia en el que las disciplinas escolares son una "Alquimia" y un "Transito" construido en el "Espacio social de la escuela" y estas requieren de sistematización y secuenciación por escrito, el "Modelo de coordenadas curriculares" 
pretende aportar desde la instrumentalización de estructuras metodológica de carácter institucional como mecanismo vinculante entre las áreas de conocimiento de básica secundaria y el contexto a partir de la participación conjunta en el diseño curricular para la solución de los problemas locales con enfoque global promovidos por las metas educativas para el Desarrollo Humano Sostenible.

La problematización a partir de las áreas de conocimiento de básica secundaria desde diferentes escenarios permitirá ampliar el espectro en términos de nuevas categorías de bienestar colectivo ${ }^{18}$ presentes en los escenarios educativos. la seguridad humana, el capital social y los bienes públicos, entre otros aspectos, vislumbran categorías desde posturas teóricas influyentes aportadas por Amartya Sen, Sadako Ogata, Martha Nussbaum y el mismo PNUD que el currículo educativo requiere para su integralidad de acuerdo con las nuevas dinámicas de desarrollo humano retomadas en el plan educativo que rigen a más de 190 países.

Contextualizar los aprendizajes y potenciar a la escuela requiere nuevas herramientas pedagógicas, a continuación, la categoría innovación permitirá identificar la importancia de la innovación en los procesos de escolarización.

\subsection{Innovación}

El vocablo innovación proviene del sustantivo latino innovatio. Cuya raíz procede de la palabra novus que contiene entre otras a novo, renovo, renovator equivalentes a los verbos innovar o renovar (Rivas, 2000). A su vez el prefijo latino in (dentro) aporta al lexema nov un sentido de interioridad, es decir, innovación corresponde al ingreso de algo nuevo, procedente de la actualidad, lo que denota que la innovación es motivada por una intención de cambio por factores internos y externos para la transformación.

De acuerdo con la comisión Europea de la Innovación (Comisión europea, 1995) la innovación es la transformación de una idea en un producto o en un servicio comerciable nuevo o mejorado, un procedimiento de fabricación o distribución operativo nuevo o mejorado, o un método para proporcionar un servicio social, es decir el termino innovación implica procesos y resultados.

Existen diferentes clasificaciones de modelos para explicar la innovación, entre otros se destacan:

${ }^{18}$ Las propuesta por el (PNUD , 2010) corresponden a: (i) el empoderamiento, (ii) la vulnerabilidad y sostenibilidad y (iii) la desigualdad 
Tabla 20: Clasificación de modelos sobre el proceso de innovación

\begin{tabular}{|c|c|}
\hline Teóricos & Clasificación de modelos de procesos de innovación \\
\hline $\begin{array}{l}\text { Saren M.A. } \\
(1983)\end{array}$ & $\begin{array}{ll}\text { - } & \text { Modelos de Etapas Departamentales (Departamental- Stage- Models) } \\
\text { - } & \text { Modelos de Etapas de Actividades (Activity-Stage Models) } \\
\text { - } & \text { Modelos de Etapas de Decisión (Decisión- Stage Models) } \\
\text { - } & \text { Modelos de Procesos de Conversión (Conversion Process Models) } \\
\text { - } & \text { Modelos de Respuestas (Response Models) } \\
\end{array}$ \\
\hline Forrest, J. (1991) & $\begin{array}{ll}\text { - } & \text { Modelos de Etapas (Stage Models) } \\
\text { - } & \text { Modelos de Conversión y Modelos de Empuje de la Tecnología/ Tirón de la } \\
& \text { Demanda (Conversion Models and Tecnology - Push/Market-Pull Models) } \\
\text { - } & \text { Modelos Integradores (Integrative Models) } \\
\text { - } & \text { Modelos de Decisión (Decision Models) } \\
\end{array}$ \\
\hline $\begin{array}{l}\text { Rothwell, R. } \\
\text { (1994) }\end{array}$ & $\begin{array}{l}\text { - Proceso de Innovación de primera Generación: Empuje de la Tecnología } \\
\text { (tecnology- Push) } \\
\text { Procesos de Innovación de Segunda Generación: Tirón de la Demanda } \\
\text { - } \quad \text { Procesos de Innovación de Tercera Generación: Modelo Interactivo } \\
\text { (Coupling Models) } \\
\text { - Procesos de Innovación de Cuarta Generación: Proceso de innovación } \\
\text { Integrado ( Integrated Innovation Process) } \\
\text { Procesos de Innovación de Quinta Generación: (Sistem Integration and } \\
\text { Networking) }\end{array}$ \\
\hline $\begin{array}{l}\text { Altshuller, G } \\
(1996)\end{array}$ & $\begin{array}{l}\text { - Modelo TRIZ (Modelo Ruso denominado de Innovación Sistémica también } \\
\text { conocido como de Sexta Generación) }\end{array}$ \\
\hline $\begin{array}{l}\text { Padmore, T., } \\
\text { Shuetze, H., y } \\
\text { Gibson, H. (1998) }\end{array}$ & $\begin{array}{ll} & \text { Modelo Lineal (Linear Models) } \\
- & \text { Modelo de Enlaces en Cadena (Chain Link Models) } \\
\text { - } & \text { Modelo en Ciclo (Cycle Models) } \\
\end{array}$ \\
\hline $\begin{array}{l}\text { Hidalgo, A., león, } \\
\text { G., Pavón, J. } \\
(2002)\end{array}$ & $\begin{array}{ll}\text { - } & \text { Modelo Lineal: Empuje de la tecnología/ Tirón de la Demanda } \\
\text { - } & \text { Modelo Mixto (Markis, Kline, Rothwell y Zegveld) } \\
\text { - } & \text { Modelo Integrado }\end{array}$ \\
\hline Trott, P. (2002) & $\begin{array}{ll}\text { - } & \text { Serendipia (Serendipity) } \\
\text { - } & \text { Modelos Lineales (Linear Models) } \\
\text { - } & \text { Modelos simultáneos de acoplamiento (Simoltaneous Couplig Models) } \\
\text { - } & \text { Modelos Interactivos (Interactive Models) } \\
\end{array}$ \\
\hline $\begin{array}{l}\text { Escorsa, P y } \\
\text { Valls, J. (2003) }\end{array}$ & $\begin{array}{ll} & \text { Modelo Lineal } \\
\text { - } & \text { Modelo de Marquis } \\
\text { - } & \text { Modelo de London Business School } \\
\text { - } & \text { Modelo de Kline } \\
\end{array}$ \\
\hline $\begin{array}{l}\text { Europen } \\
\text { Commissions } \\
(2004)\end{array}$ & $\begin{array}{l}\text { - Innovación derivada de la ciencia (tecnology Push) } \\
\text { - Innovación derivada de las necesidades del mercado (Market Pull) } \\
\text { - Innovación derivada de los vínculos entre los actores de los mercados } \\
\text { - Innovación derivada de las redes tecnológicas } \\
\text { - Innovación derivada de las redes sociales } \\
\text { Nota: La comisión europea no habla directamente de los modelos de innovación sino } \\
\text { de la gestión e importancia creciente social en la explicación de la sociedad }\end{array}$ \\
\hline
\end{tabular}

Fuente: Tomado de (Velasco E., Zamanillo, I., Elguezabal., Gurutze I, M., 2007) y Altshuller, G. (1996)

La anterior clasificación evidencia cómo la innovación es una actividad que ha evolucionado y ha permeado diferentes modelos de negocio. En un entorno competitivo como el actual la innovación requiere aportar resultados concretos en el menor tiempo posible. Para ello se ha 
valido entre otras, del uso de las redes tecnológicas para dinamizar las fuentes de solución a través del trabajo en equipo desde la innovación abierta y colaborativa.

La cultura de la innovación al interior de las organizaciones se ha valido de diferentes métodos, metodologías, técnicas y herramientas para potenciar la inspiración.

Tabla 21: Metodologías y métodos para Innovar.

\begin{tabular}{|c|c|c|}
\hline Metodología/método & Características & Teórico(s) \\
\hline Desing Thinking & $\begin{array}{l}\text { Método de generación de ideas para dar solución a } \\
\text { las necesidades reales, desde un enfoque de diseño de } \\
\text { producto. }\end{array}$ & Brown, Tim (2009) \\
\hline Lean Start Up & $\begin{array}{l}\text { Metodología de lanzamiento de nuevos proyectos de } \\
\text { negocio busca crear compañías rentables y escalables } \\
\text { reduciendo al mínimo el riesgo }\end{array}$ & Ries, Eric (2012) \\
\hline $\begin{array}{l}\text { Forth Innovation } \\
\text { Method }\end{array}$ & $\begin{array}{l}\text { Combina Design Thinking, creatividad y el mundo } \\
\text { real de los negocios. } \\
\text { Las siglas denotan: (Full Steam Ahead, Observe \& } \\
\text { Learn, Raise Ideas, Test Ideas, and Homecoming). } \\
\text { Proceso diseñando para } 20 \text { semanas }\end{array}$ & Wulfen, Gijs (2011) \\
\hline $\begin{array}{l}\text { La Estrategia del } \\
\text { Océano Azul }\end{array}$ & $\begin{array}{l}\text { Busqueda de nuevos mercados mediante la } \\
\text { innovación }\end{array}$ & $\begin{array}{l}\text { Chan, K W. \& } \\
\text { Maubourgne, R (2008) }\end{array}$ \\
\hline $\begin{array}{l}\text { Innovación } \\
\text { disruptiva }\end{array}$ & $\begin{array}{l}\text { Creación de un nuevo producto o servicio y } \\
\text { transformar el mercado reemplazando a las normas } \\
\text { habituales e incluso las tecnologías existentes }\end{array}$ & $\begin{array}{l}\text { (Clayton M. } \\
\text { Christensen, Michael E. } \\
\text { Raynor, Jeff Dyer, Hal } \\
\text { Gregersen, 2011) }\end{array}$ \\
\hline Intraemprendimiento & $\begin{array}{l}\text { Actividad emprendedora para fomentar empleo y } \\
\text { competitividad con enfoque en la innovación de } \\
\text { productos o servicios }\end{array}$ & Pinchot, Gifford (1985) \\
\hline Agile & $\begin{array}{l}\text { Marco del trabajo para el desarrollo de software con } \\
\text { principios de work in progress }\end{array}$ & $\begin{array}{l}\text { Kaliym A. Islam \& M. } \\
\text { Ed. (2013) }\end{array}$ \\
\hline Scrum & $\begin{array}{l}\text { Promoción de estrategias con entregas parciales y } \\
\text { regulares para beneficio del destinatario del proyecto. }\end{array}$ & Singhal, Anju (2013) \\
\hline $\begin{array}{l}\text { SAFe } \\
\text { Scaled Agile } \\
\text { Framework }\end{array}$ & $\begin{array}{l}\text { Basado en principios de Agile y Lean; plantea tres } \\
\text { niveles de abstracción: el nivel de equipo, el nivel de } \\
\text { programa y el nivel de portafolio. }\end{array}$ & Leffingwell, Dean (2018) \\
\hline Kanbam & $\begin{array}{l}\text { Gestión del trabajo de forma fluida para hacer } \\
\text { eficiente el proceso de las personas. } \\
\text { Visualización de los procesos de producción en } \\
\text { Toyota por Taiichi Onho }\end{array}$ & $\begin{array}{l}\text { Cimorelli, Stephen } \\
\text { (2016) }\end{array}$ \\
\hline Kaizen & $\begin{array}{l}\text { Proceso de eliminación de desperdicios del sistema } \\
\text { productivo. }\end{array}$ & $\begin{array}{l}\text { Sistema de producción de } \\
\text { Toyota. William } \\
\text { Lareau, Kaufman, Roger } \\
(2003)\end{array}$ \\
\hline $\begin{array}{l}\text { JTBD } \\
\text { Jobs to be done o } \\
\text { "tareas por realizar" }\end{array}$ & $\begin{array}{l}\text { Permite encontrar soluciones innovadoras para las } \\
\text { necesidades de sus clientes. }\end{array}$ & $\begin{array}{l}\text { Wunker. } \\
\text { Stephen, Wattman. } \\
\text { Jessica, Farber, David } \\
\text { (2016) }\end{array}$ \\
\hline $\begin{array}{l}\text { OKR } \\
\text { Objectives and Key } \\
\text { Results, objetivos y } \\
\text { resultados clave. }\end{array}$ & $\begin{array}{l}\text { metodología orientada a mejorar el trabajo realizado } \\
\text { por las personas dentro de una organización y obtener } \\
\text { lo mejor de ellas. }\end{array}$ & Ismail, Salim (2016) \\
\hline Teoría U & $\begin{array}{l}\text { Metodología para fomentar la innovación a nivel } \\
\text { personal y dentro de las empresas. }\end{array}$ & Scharmer, C. Otto (2016) \\
\hline
\end{tabular}




\begin{tabular}{|l|l|l|}
\hline Kotter & $\begin{array}{l}\text { metodología para facilitar el proceso de cambio } \\
\text { dentro de una organización. }\end{array}$ & Kotter, John (2015) \\
\hline Design Sprint & $\begin{array}{l}\text { Metodología que consiste en un proceso de cinco } \\
\text { días en los que se trata de responder las cuestiones } \\
\text { críticas que afectan a un negocio a través del diseño, } \\
\text { el prototipado y el testeo con los clientes. }\end{array}$ & $\begin{array}{l}\text { Banfield. Richard, Todd. } \\
\text { C, Wax. Trace (2015) }\end{array}$ \\
\hline $\begin{array}{l}\text { Customer } \\
\text { Development }\end{array}$ & $\begin{array}{l}\text { Ideal para obtener la información del entorno y de } \\
\text { los posibles clientes. Fuente para validar hipótesis o } \\
\text { retirarlas. }\end{array}$ & $\begin{array}{l}\text { Blank, Steve. \& Dorf Bob } \\
\text { (2013) }\end{array}$ \\
\hline Co-creación & $\begin{array}{l}\text { Integración de recursos del cliente y empresa para } \\
\text { crear valor durante el proceso de interacción de } \\
\text { forma conjunta. }\end{array}$ & (Vargo \& Lusch, 2011) \\
\hline
\end{tabular}

Fuente: Autor

Tabla 22: Técnicas y Herramientas para la innovación.

\begin{tabular}{|c|c|c|}
\hline Técnicas/Herramientas & Característica & Teóricos \\
\hline Mapa de Actores & $\begin{array}{l}\text { Identifica los usuarios que } \\
\text { participan del diseño del producto } \\
\text { para el establecimiento de } \\
\text { conexiones }\end{array}$ & Freeman, Edwar (2010) \\
\hline Inversión Cognitiva & $\begin{array}{l}\text { Comprender la realidad del } \\
\text { usuario }\end{array}$ & Weinschenk, Susan M (2013) \\
\hline Interacción constructiva & $\begin{array}{l}\text { Conocer sobre la experiencia del } \\
\text { usuario }\end{array}$ & $\begin{array}{l}\text { Gotehlf Jeff \& Seiden Josh } \\
\text { (2014) }\end{array}$ \\
\hline Mapa Mental & $\begin{array}{l}\text { Relacionar variables con el tema } \\
\text { central }\end{array}$ & Buzan Tonny (2017) \\
\hline Moodboard & $\begin{array}{l}\text { Comunicación de conceptos } \\
\text { complejos. }\end{array}$ & Sibett David (2013) \\
\hline Observación Encubierta & $\begin{array}{l}\text { Obtener información objetivo sin } \\
\text { influenciar el objeto de análisis }\end{array}$ & $\begin{array}{l}\text { Clayton M.; Gregersen, Hal; } \\
\text { Dyer, Jeff Christensen (2012) }\end{array}$ \\
\hline Qué, cómo y por qué & $\begin{array}{l}\text { Aumento de la observación e } \\
\text { identificación de supuestos }\end{array}$ & $\begin{array}{l}\text { Clayton M.; Gregersen, Hal; } \\
\text { Dyer, Jeff Christensen (2012) }\end{array}$ \\
\hline Entrevista cualitativa & $\begin{array}{l}\text { Comprender las motivaciones en } \\
\text { las formas de pensar. }\end{array}$ & FLICK, UWE (2004) \\
\hline Usuarios Extremos & $\begin{array}{l}\text { Identificación de necesidades de } \\
\text { usuarios }\end{array}$ & Moore, Geoffrey A. (2015) \\
\hline Storytelling & $\begin{array}{l}\text { Contar la historia del proceso } \\
\text { desde la creación hasta el } \\
\text { prototipado. }\end{array}$ & Guber, Peter (2011) \\
\hline Customer Journey & $\begin{array}{l}\text { Definir la experiencia del cliente } \\
\text { en el uso del producto o servicio }\end{array}$ & $\begin{array}{l}\text { Reichheld. Fred, Markey. Rob } \\
\text { (2012) }\end{array}$ \\
\hline Flor de loto & $\begin{array}{l}\text { Generar alternativas con un } \\
\text { concepto central }\end{array}$ & $\begin{array}{l}\text { Teórico Yasuo Matsumura } \\
\text { (Fernández, Andrés, 2010) }\end{array}$ \\
\hline Word Café & $\begin{array}{l}\text { Conocerse, integrase, aceptar las } \\
\text { ideas del otro }\end{array}$ & $\begin{array}{l}\text { Brown. Juanita, Isaacs. David, } \\
\text { World Cafe Community, Senge. } \\
\text { Peter, Wheatley. Margaret (2005) }\end{array}$ \\
\hline $\begin{array}{l}\text { Grupos de discusión "focus } \\
\text { groups" }\end{array}$ & $\begin{array}{l}\text { Identificar comportamientos, } \\
\text { dinámicas y necesidades. }\end{array}$ & Barbour. Rosaline (2013) \\
\hline Los 5 ¿por qué? & $\begin{array}{l}\text { Alcanzar las respuestas mediante } \\
\text { cuestionamientos }\end{array}$ & Kvale, Steinar (2011) \\
\hline Tollkit & $\begin{array}{l}\text { Facilitar objetivos concretos } \\
\text { bridando material auxiliar }\end{array}$ & Michalko, Michael (2006) \\
\hline
\end{tabular}




\begin{tabular}{|c|c|c|}
\hline Diagrama Causa Efecto & $\begin{array}{l}\text { Análisis de problema de gran } \\
\text { magnitud } \\
\text { Desarrollado en } 1943 \text { por el } \\
\text { Profesor Kaoru Ishikawa. }\end{array}$ & (Galgano,1995) \\
\hline Matriz DOFA o DAFO & $\begin{array}{l}\text { Generación de Estrategias } \\
\text { Originaria de la Universidad de } \\
\text { Stanford }\end{array}$ & Francés, A (2006) \\
\hline Los 5 ¿Para qué? & Generar reflexiones & Kvale, Steinar (2011) \\
\hline Diagrama de Porter & $\begin{array}{l}\text { Visualizar los aspectos de la } \\
\text { salud de la industria }\end{array}$ & Porter, Michael E. (2017) \\
\hline $\begin{array}{l}\text { Lienzo del modelo de negocio } \\
\text { "business model canvas" }\end{array}$ & $\begin{array}{l}\text { Definir y visualizar de forma } \\
\text { sintética la estrategia de la } \\
\text { empresa }\end{array}$ & $\begin{array}{l}\text { Osterwalder Alexander, Pigneur } \\
\text { Yves (2011) }\end{array}$ \\
\hline Mapa de atracción de clientes & $\begin{array}{l}\text { Identificar acciones para captar y } \\
\text { desarrollo de nuevas estrategias }\end{array}$ & Pais Joaquín, Font,Luis. (2016) \\
\hline Diagrama de Prioridades & $\begin{array}{l}\text { Consensuar la priorización de } \\
\text { acciones }\end{array}$ & Duncan, Kevin (2015) \\
\hline Curvas de valor & $\begin{array}{l}\text { Esquema gráfico de la estrategia } \\
\text { de la competencia }\end{array}$ & $\begin{array}{l}\text { Chan Kim, W. \& Mauborgne, } \\
\text { Renée (2014) }\end{array}$ \\
\hline Glocal & Comprender el contexto del reto & Riveros, Paula (2014) \\
\hline $\begin{array}{l}\text { AEIOU } \\
\text { Activities (Actividades) } \\
\text { Environments (Lugares) } \\
\text { Interactions(Interacciones), } \\
\text { Objects (Objetos), } \\
\text { Users (Usuarios) }\end{array}$ & Conocer el contexto del reto & Guber, Rosana (2011) \\
\hline Phillips 6/6 & $\begin{array}{l}\text { Definir Consensos grupales } \\
\text { Creado por J.Donald Phillips }\end{array}$ & $\begin{array}{l}\text { Innovación y Cualificación } \\
(2003)\end{array}$ \\
\hline
\end{tabular}

Fuente: Autor

Las etapas de los procesos de innovación relacionadas con la identificación del problema, formulación, desarrollo, evaluación e implementación requieren de diferentes métodos, metodologías, técnicas y herramientas, a las anteriores bien se le pueden sumar estudios de confiabilidad, la casa de la calidad (QFD), investigación de mercados, tormenta de ideas, prueba y error, análisis de confiabilidad, entre otros, para generar valor y obtener ventajas competitivas en el mercado de cualquier tipo de organización.

\section{- Innovación en educación}

La innovación entonces se convierte en el eje central de la educación para los cambios sociales visibles a mediados del siglo XX. Proceso que inicia a partir de los años 60 con la incorporación de conocimientos de las ciencias de la administración, en los años 70 y 80 con la participación de los docentes en los cambios educativos, en los años 90 con las reformas educativas que promovieron innovaciones asociadas a modelos de descentralización y autonomía, y para los años 2000 y 2010 con la incorporación de las nuevas Tecnologías de la Información y la Comunicación, además de las nuevas dinámicas de intercambio y trabajo compartido. Escenarios que han generado la necesidad de adecuar la educación hacia el uso de nuevas tecnologías, incorporación de sistemas de información y de comunicación, nuevos 
lenguajes y procedimientos de investigación, entre otros factores para el mejoramiento de la calidad del sistema escolar (UNESCO, 2016).

La innovación educativa por su parte es vista desde diferentes ópticas, entre otros se resaltan:

Tabla 23: Definiciones de Innovación Educativa

\begin{tabular}{|c|c|}
\hline Autores & Definición "Innovación Educativa" \\
\hline Miles (1964) & $\begin{array}{l}\text { La innovación educativa es una idea que produce un cambio planificado en } \\
\text { los procesos y servicios educativos que conducen a la mejora de los objetivos } \\
\text { de aprendizaje. }\end{array}$ \\
\hline $\begin{array}{l}\text { Havelock. K. y Huberman. } \\
\text { A. (1980). }\end{array}$ & $\begin{array}{l}\text { La innovación educativa es el estudio de las estrategias o procesos de } \\
\text { cambio. }\end{array}$ \\
\hline MEC (1987) & $\begin{array}{l}\text { La innovación educativa constituye el resultado de numerosas acciones } \\
\text { paralelas y coordinadas, cuya lenta incidencia en el sistema educativo } \\
\text { contribuye a mejorar la práctica pedagógica en su contexto real; es, por tanto, } \\
\text { un elemento central en la calidad de la enseñanza> }\end{array}$ \\
\hline Torre, S. De La (1992). & Una innovación educativa es un proyecto que mira hacia adelante \\
\hline $\begin{array}{l}\text { Francisco Imbernón (1996: } \\
\text { 64) }\end{array}$ & $\begin{array}{l}\text { la innovación educativa es la actitud y el proceso de indagación de nuevas } \\
\text { ideas, propuestas y aportaciones, efectuadas de manera colectiva, para la } \\
\text { solución de situaciones problemáticas de la práctica, lo que comportará un } \\
\text { cambio en los contextos y en la práctica institucional de la educación. }\end{array}$ \\
\hline Carbonell, J. (2001) & $\begin{array}{l}\text { La innovación educativa corresponde a una serie de intervenciones, } \\
\text { decisiones y procesos, con cierto grado de intencionalidad y sistematización } \\
\text { que tratan de modificar actitudes, ideas, culturas, contenidos, modelos y } \\
\text { prácticas pedagógicas }\end{array}$ \\
\hline $\begin{array}{l}\text { Robalino, M. y Eroles, D. } \\
\text { (2010) }\end{array}$ & $\begin{array}{l}\text { La innovación educativa es como un proceso en espiral, en el que cada fase } \\
\text { está íntimamente relacionada con la anterior y la siguiente, por tanto, } \\
\text { requiere de fases de desarrollo para alcanzar su consolidación. }\end{array}$ \\
\hline Escudero, Juan (2012) & $\begin{array}{l}\text { Hablar de innovación educativa significa referirse a proyectos } \\
\text { socioeducativos de transformación de nuestras ideas y prácticas educativas } \\
\text { en una dirección social e ideológicamente legitimada, y que esa } \\
\text { transformación merece ser analizada a la luz de criterios de eficacia, } \\
\text { funcionalidad, calidad y justicia y libertad social. }\end{array}$ \\
\hline UNESCO (2014) & $\begin{array}{l}\text { "la innovación educativa es un acto deliberado y planificado de solución de } \\
\text { problemas, que apunta a lograr mayor calidad en los aprendizajes de los } \\
\text { estudiantes, superando el paradigma tradicional. Implica trascender el } \\
\text { conocimiento academicista y pasar del aprendizaje pasivo del estudiante a } \\
\text { una concepción donde el aprendizaje es interacción y se construye entre } \\
\text { todos". }\end{array}$ \\
\hline $\begin{array}{l}\text { Fidalgo Blanco, Á., } \\
\text { Conde, M. Á., Sein- } \\
\text { Echaluce, M., García- } \\
\text { Peñalvo, F. J. (2014). }\end{array}$ & $\begin{array}{l}\text { La innovación educativa es la aplicación de una idea que produce cambio } \\
\text { planificado en procesos, servicios o productos que generan mejora en los } \\
\text { objetivos formativos. }\end{array}$ \\
\hline
\end{tabular}

Fuente: Autor

Angel Fidalgo (2007) por su parte plantea que la innovación educativa debe contener características de (i) eficacia, (ii) eficiencia, (iii) transferibilidad, y (iv) sostenibilidad entendidas como el logro de los objetivos de aprendizaje con menor esfuerzo aplicados en diferentes contextos y perdurables en el tiempo, además de ello, destaca que la innovación educativa está compuesta por Tecnologías, Procesos, Personas y Conocimiento (Fidalgo, 2011).

Estos principios hacen relación a: 
- Tecnologías: como el uso y diseño de herramientas para el propio proceso de aprendizaje (poco habitual) o la adaptación de herramientas existentes en el mercado (aplicación de las TIC).

- Proceso: como el uso de metodologías que mejoran las existentes y reducen el esfuerzo en la aplicación, ya sean conocidas y muy utilizadas, o poco utilizadas y no conocidas.

- Personas: la innovación docente es integrante, no excluyente. Esto significa que debe tener en cuenta la implicación y repercusión de la propia innovación en todos los actores que intervienen.

- Conocimiento: relacionado con los objetivos del proceso de aprendizaje.

En otro sentido, las “experiencias educativas innovadoras" comprenden diversos elementos que permean los patrones culturales de cada entorno, lo que determina que la innovación es un proceso social con múltiples impactos que van desde el desarrollo de las capacidades humanas, sostenibilidad de las tradiciones y construcción de sujetos sociales, entre otros.

La innovación educativa y calidad de la educación son conceptos que están muy relacionados con el enfoque de derechos humanos en la última década (OREALC/UNESCO, 2007), según el informe la "calidad de la educación”, va más allá de la eficacia y eficiencia, comprende Educación para la igualdad y la equidad (social), Educación relevante (importancia), Educación pertinente (adecuada), Educación contextualizada en el territorio, y Educación afincada en las matrices culturales y sociales (interculturalidad), en donde toda innovación presume ingresar a un terreno desconocido lo que implica riesgo, incertidumbre, contradicciones y conflicto.

De igual forma Blanco (2005), destaca como señales de una escuela innovadora la capacidad institucional de diferenciarse y descubrir, búsqueda constante de nuevas ideas y propuestas, voluntad de cambio de las prácticas educativas, compromiso y voluntad de las partes interesadas, capacidad de reflexión crítica, actitud de cambio, intercambio de saberes mediante ambientes colaborativos y un clima favorable para el surgimiento de puntos de vista convergentes y divergente de la realidad.

Por su parte Rivas (2000) propone una tipología propia de la innovación educativa que surge inicialmente de lo él llama "Componente" del sistema educativo ${ }^{19}$, que afecta la "intensidad" de los cambios, así como el "modo" de producción que varía de acuerdo con la "cantidad" de elementos que comprende; estos se podrían sintetizar bajo la siguiente representación.

Tabla 24: Tipologías de innovación Educativa

\begin{tabular}{|l|l|l|l|}
\hline Tipología & \multicolumn{3}{|c|}{ Características } \\
\hline $\begin{array}{c}\text { Innovaciones según los } \\
\text { componentes }\end{array}$ & $\begin{array}{l}\text { 1. Innovaciones en las } \\
\text { operaciones para el } \\
\text { mantenimiento de los } \\
\text { límites del sistema }\end{array}$ & $\begin{array}{l}\text { 2. Innovaciones } \\
\text { concernientes al tamaño } \\
\text { y la extensión }\end{array}$ & $\begin{array}{l}\text { 3. Innovaciones en las } \\
\text { instalaciones escolares }\end{array}$ \\
\hline
\end{tabular}

\footnotetext{
${ }^{19} \mathrm{El}$ componente es tomando de la propuesta de Matrew B. Miles
} 


\begin{tabular}{|c|c|c|c|}
\hline & $\begin{array}{l}\text { 4.Innovaciones } \\
\text { concernientes al tiempo } \\
\text { escolar }\end{array}$ & $\begin{array}{l}\text { 5. Innovaciones en los } \\
\text { objetivos instructivo- } \\
\text { formativos. }\end{array}$ & $\begin{array}{l}\text { 6. Innovaciones en la } \\
\text { definición de los roles }\end{array}$ \\
\hline & $\begin{array}{l}\text { 7. Innovaciones que } \\
\text { afectan a los valores, } \\
\text { concepciones y } \\
\text { creencias. }\end{array}$ & $\begin{array}{l}\text { 8. Innovaciones } \\
\text { concernientes a la } \\
\text { estructura y relaciones } \\
\text { entre las partes. }\end{array}$ & $\begin{array}{l}\text { 9. Innovaciones en los } \\
\text { métodos de } \\
\text { socialización }\end{array}$ \\
\hline & $\begin{array}{l}\text { 10. Innovaciones de la } \\
\text { conexión entre los } \\
\text { sistemas. }\end{array}$ & \multicolumn{2}{|c|}{$\begin{array}{l}\text { 11. Innovaciones concernientes a los } \\
\text { procedimientos: (i) didácticos, (ii) curricular, (iii) } \\
\text { uso de materiales y (iv) estructura de clase }\end{array}$} \\
\hline \multirow{2}{*}{$\begin{array}{l}\text { Innovaciones según el } \\
\text { modo de realización }\end{array}$} & $\begin{array}{l}\text { 1. Adición: Incluir algo } \\
\text { nuevo al sistema } \\
\text { educativo }\end{array}$ & $\begin{array}{l}\text { 2. Reforzamiento: } \\
\text { Intensificación de lo } \\
\text { existente. }\end{array}$ & $\begin{array}{l}\text { 3. Eliminación: } \\
\text { Sustracción de viejos } \\
\text { hábitos. }\end{array}$ \\
\hline & $\begin{array}{l}\text { 4. Sustitución: } \\
\text { Reemplazo de } \\
\text { elementos }\end{array}$ & $\begin{array}{l}\text { 5. Alteración: } \\
\text { Modificación de los } \\
\text { modos de operación }\end{array}$ & $\begin{array}{l}\text { 6. Reestructuración: } \\
\text { Reorganizaciones del } \\
\text { sistema }\end{array}$ \\
\hline $\begin{array}{l}\text { Innovaciones según la } \\
\text { intensidad del cambio }\end{array}$ & $\begin{array}{l}\text { 1. Innovaciones } \\
\text { marginales }\end{array}$ & $\begin{array}{l}\text { 2. Innovaciones } \\
\text { adicionales }\end{array}$ & $\begin{array}{l}\text { 3. Innovaciones } \\
\text { fundamentales }\end{array}$ \\
\hline $\begin{array}{l}\text { Según la amplitud de } \\
\text { las innovaciones }\end{array}$ & \multicolumn{3}{|c|}{$\begin{array}{l}\text { La innovación puede implicar a todos los miembros del sistema escolar, } \\
\text { (conjunto del centro educativo, departamento o a un grupo docente o al } \\
\text { comportamiento docente en su aula) }\end{array}$} \\
\hline
\end{tabular}

Fuente: Autor adaptado de Rivas (2000)

Para (Robalino, M. y Elores, D. 2010) la innovación es un proceso siempre inconcluso que debe someterse a revisión constante, por lo tanto, no es un producto. De igual forma requiere de un sistema educativo flexible, autónomo, autocrítico, que le permita tomar decisiones con inmediatez, debido a que las instituciones educativas están condicionadas por normativas y disposiciones de las autoridades. La UNESCO (2016) retoma estos principios de los autores en el informe de Innovación Educativa y propone un proceso de desarrollo y consolidación de la innovación como herramienta de apoyo para las instituciones educativas representado bajo el siguiente ciclo

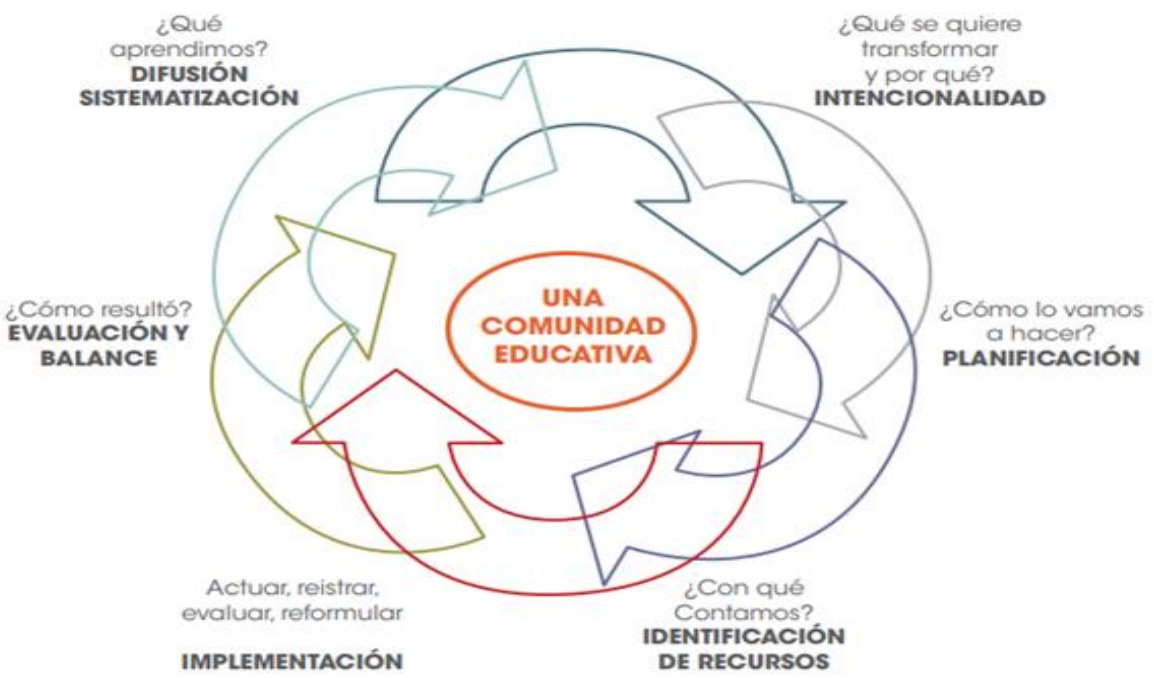

Ilustración 9: Innovación Educativa.

Fuente: Tomado de UNESCO (2016). 
En otro sentido, un estudio publicado por el instituto Teachers Insurance and Annuity Association of America (TIAA) destaca tres factores claves para promover la innovación estratégica: una gran diversidad de personas que aporten variedad de conocimientos y opiniones; la necesidad de dedicar recursos al apoyo de las motivaciones individuales de tipo intrínseco; y autonomía, para que los individuos expresen opiniones basadas en sus experiencias (INTEF, 2017).

De igual forma, el programa Great Colleges to Work for de The Chronicle of Higher Education identificó cinco aspectos claves en la innovación, (i) comunicación abierta, (ii) colaboración en los departamentos, (iii) seguridad laboral ante los cambios en el status quo, (iv) responsabilidad compartida, y (v) apoyo de arriba hacia abajo; componentes que necesarios para avanzar en una cultura de innovación y creatividad, es así como las instituciones educativas que reconocen estas tendencias encuentran soluciones a los problemas del mundo real, mediante las habilidades de colaboración multidisciplinar.

Tal es el caso del enfoque $\mathrm{STEM}^{20}$, tendencia pedagógica de aprendizaje que vincula al aula la investigación mediante el aprendizaje basado en problemas y proyectos, vinculando ambientes dinámicos para el trabajo flexible "makerspaces" o talleres creativos, abordando casos reales mediante la creación de productos completos para proporcionar a los estudiantes las habilidades necesarias para el éxito laboral y generar un impacto social.

Las consideraciones de Innovación Educativa anteriores permiten pensar en una educación consiente de la rigurosidad que exige el medio, en donde los cambios sociales se han convertido en el eje dinamizador para transitar hacia un mundo más justo y equitativo.

\subsubsection{Prospectiva Teórica para la Innovación en la Educación.}

En el marco de los procesos de innovación en la escuela el enfoque de la educación STEM cobra gran importancia en el desarrollo de competencias para que una persona sea innovadora, metodología creada en los Estados Unidos (White, 2014) y de gran difusión a nivel mundial. Enfoque que la actual secretaria de educación de la ciudad de Medellín "educación para el futuro" (Alcaldía de Medellín,2016) propone convertir a la escuela en territorio $\mathrm{STEM}+\mathrm{H}^{21}$ para liderar procesos académicos con metodologías provenientes de las ciencias y las humanidades para convertir a la escuela en fuente de apropiación de las problemáticas.

El modelo de coordenadas curriculares plantea profundizar desde un enfoque de gestión curricular mediado por estos principios de innovación mediante uso de métodos, metodologías, técnicas y herramientas de soporte como eje de las coordenadas que permiten definir a un currículo innovador en el planteamiento y resolución de situaciones escolares a partir de problemáticas locales-globales desde un marco colaborativo para garantizar un

20 Dimensiones relacionadas con: S Science, Ciencia; T Technology, Tecnología; E Engineering, Ingeniería; M Mathematics, Matemáticas; H Desarrollo humano y social

${ }^{21}$ Se incluye una nueva dimensión “H” Desarrollo Humano y Social 
desarrollo educativo, social y económico sustentable para la formación de conocimientos útiles para la vida en estudiantes de básica secundaria.

Recomendaciones de expertos como Marianne Cutler, directora de Innovación del Currículo de la Association of Science Education y Nelly Gochicoa, coordinadora de Cooperación e Innovación del Departamento de Desarrollo Humano, Educación y Empleo de la OEA en el foro 'Educación STEM para el futuro' 2016 aportaron como un elemento fundamental para el sistema educativo el aprendizaje basado en la indagación por proyectos y la articulación con las nuevas metas de Desarrollo Sostenible, planteamientos que señalan aristas claves de instrumentalización para repensar el diseño curricular en las instituciones educativas, particularmente para las instituciones educativas de básica secundaria.

\section{INTEGRANDO LAS VARIABLES PARA EL DISEÑO Y ACTUALIZACIÓN CURRICULAR.}

Una vez definidas las categorías anteriormente abordadas se integran en un Modelo de Coordenadas Curriculares que contienen: Bienestar (desde el enfoque de los Objetivos de Desarrollo Sostenible), Competencia global (enfoque desde la propuesta de OCDE) y Áreas de conocimiento (Asignaturas propuestas desde MEN). Se relacionan entre si formando un hipotético cubo como muestra la siguiente figura. 

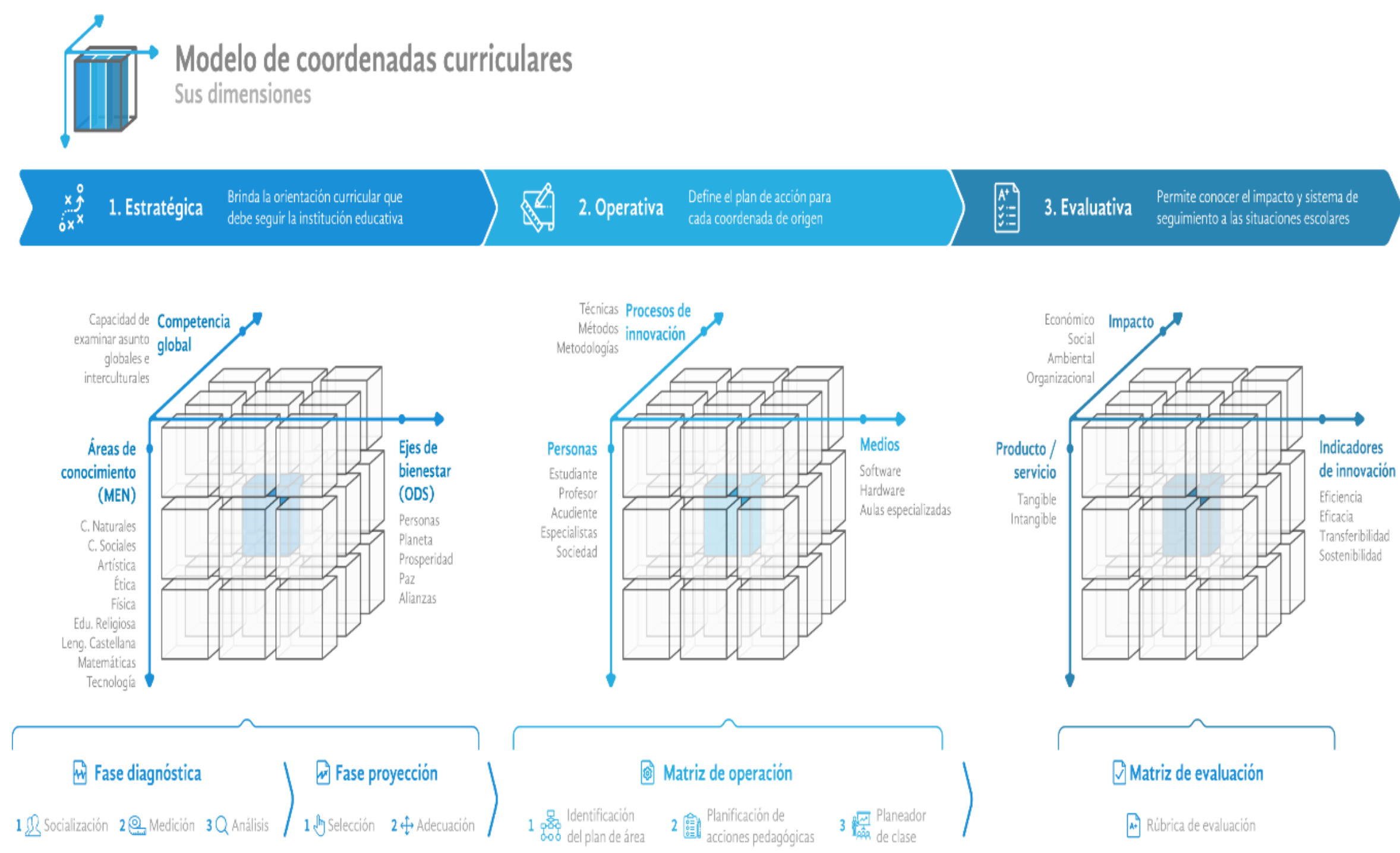

Q Matriz de evaluación

Rin. Ríbrica de evaluación

Ilustración 10: Modelo de Coordenadas Curriculares

Fuente: Autor. 
El modelo de coordenadas curriculares deberá dar respuesta a los principios de innovación que requiere la actual sociedad del conocimiento en términos de desarrollo educativo, social y económico sustentable, además de brindar guías claras para operativizar la competencia global, las dimensiones sociales colectivas y un elemento de prospectiva para la instrumentalización curricular como principio fundacional de una catedra del desarrollo humano sostenible, entre otras posibilidades que se profundizará en el próximo capítulo.

Como aporte al conocimiento se plantea un Modelo de coordenadas para el diseño de currículos mediado por procesos de innovación que le permitan a las instituciones educativas de básica secundaria generar situaciones escolares de participación colectiva para fortalecer la competencia global y brindar alternativas de solución a los problemas locales-globales. modelo de gestión curricular dinámico puesto que se posicionará de acuerdo con el contexto.

Además de ello, el modelo de coordenadas curriculares brinda alternativas de contextualización para el desarrollo de la competencia global en Colombia. Se requiere una guía instruccional para abordar la competencia global en el país. Poca o nula información publicada se registra para alcanzar niveles de desarrollo de la competencia a partir de material pedagógico. 
CAPÍTULO 4

PROPUESTA 


\section{PROPUESTA}

El abordaje de la propuesta se fundamenta desde la revisión documental que permite clasificar los hallazgos en dimensiones de análisis. El funcionamiento metodológico del "Modelo de coordenadas curriculares" a continuación se describe.

Los constantes cambios del escenario mundial en términos del desarrollo obligan a que los países generen políticas que permitan adaptarse a los entornos cambiantes definidos por los retos para reducir la contaminación ambiental, mejorar la educación, generar empleo digno, contribuir con la salud e igualdad de la sociedad, entre otros. Educar a las generaciones futuras para que puedan afrontar estos retos obliga a repensar los modelos educativos actuales y a generar modelos más innovadores de acuerdo con las circunstancias.

El modelo de coordenadas curriculares brinda respuesta a los principios de innovación que requiere la actual sociedad del conocimiento en términos de desarrollo educativo, social y económico sustentable, además de brindar una guía clara para operativizar la competencia global, las dimensiones sociales colectivas y un elemento de prospectiva para la instrumentalización curricular como principio fundacional de una catedra del desarrollo humano sostenible.

Es así como el modelo de coordenadas curriculares mediante uso de métodos, metodologías, técnicas y herramientas de innovación permite definir un currículo para el planteamiento y resolución de situaciones escolares a partir de problemáticas locales-globales desde un marco colaborativo para garantizar el desarrollo educativo, social y económico para la formación de conocimientos útiles para la vida en estudiantes de básica secundaria.

El modelo de coordenadas curriculares está compuesto por tres dimensiones. Estas surgen con forme se identifican las coordenadas que trazan la ruta estratégica para el establecimiento del plan de acción y evaluación para el diseño y actualización de los contenidos curriculares.

Tabla 25: Descripción dimensiones "Modelo de Coordenadas Curriculares"

\begin{tabular}{|l|l|}
\hline Dimensión & \multicolumn{1}{|c|}{ Descripción } \\
\hline Estratégica & $\begin{array}{l}\text { Identifica la ruta metodológica a través de la cual las instituciones de básica } \\
\text { secundaria deben planificar las coordenadas de origen académico para el } \\
\text { desarrollo humano sostenible. }\end{array}$ \\
\hline Operativa & Define el plan de acción para cada coordenada. \\
\hline Evaluativa & $\begin{array}{l}\text { Determina el impacto de los procesos educativos con relación a las acciones } \\
\text { propuestas por parte de los estudiantes para contribuir con el desarrollo } \\
\text { humano sostenible. }\end{array}$ \\
\hline
\end{tabular}

Fuente: Autor 


\section{$\underset{\substack{\text { Modelo de coordenadas curriculares } \\ \text { Sus dimensiones }}}{\longrightarrow}$}

\begin{tabular}{|cll}
$x_{j}^{0}$ & 1. Estratégica & $\begin{array}{l}\text { Brinda la orientación curricular que } \\
\text { debe seguirla institución educativa }\end{array}$
\end{tabular}
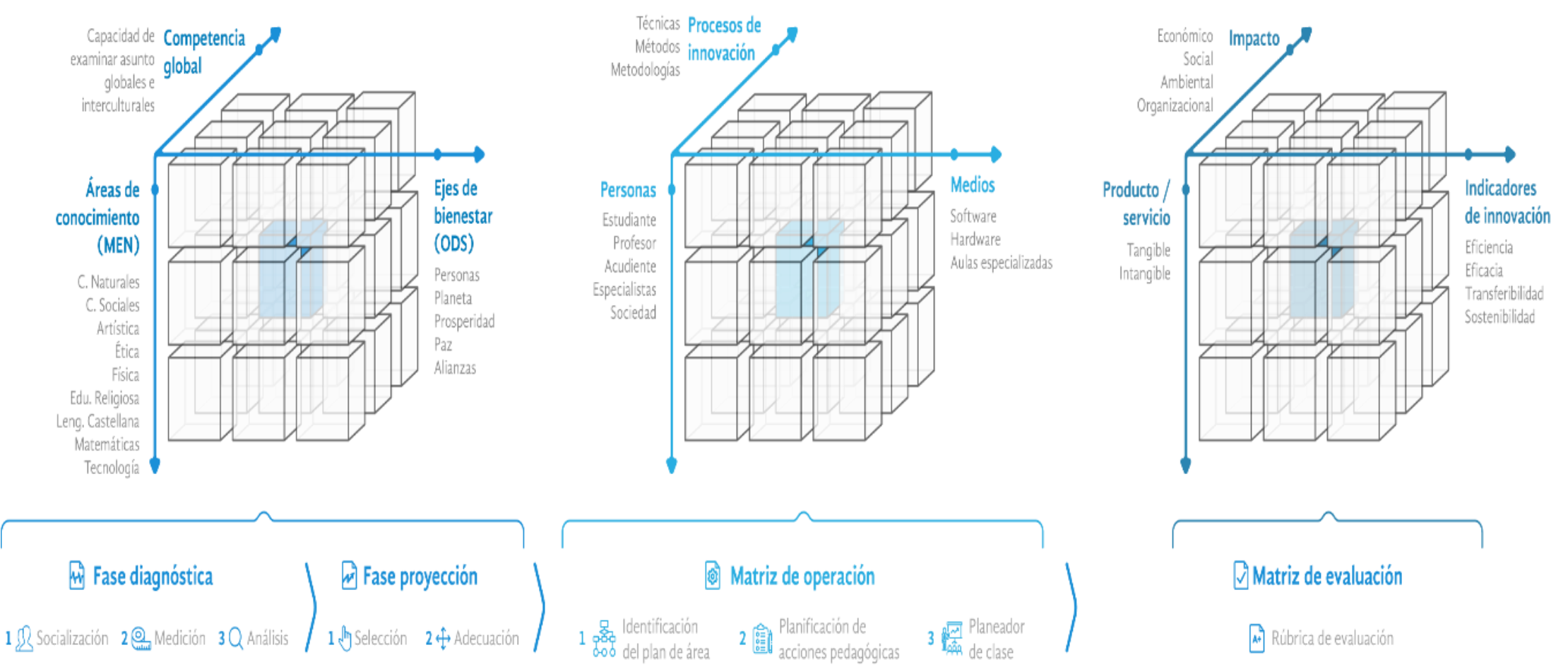

Ilustración 11: Dimensiones "Modelo de Coordenadas Curriculares"

Fuente: Autor 


\subsection{Dimensión Estratégica}

La dimensión estratégica identifica la ruta metodológica a través del cual las instituciones de básica secundaria deben planificar las coordenadas de origen académico para el desarrollo humano sostenible.

La dimensión estratégica está compuesta de tres ejes de las coordenadas cartesianas (X,Y, Z): Bienestar (desde el enfoque de los Objetivos de Desarrollo Sostenible), Áreas de Conocimiento de básica secundaria y Competencia Global.

Esta dimensión comprende dos componentes, la Fase diagnóstica (origen) y Fase de Proyección (destino).

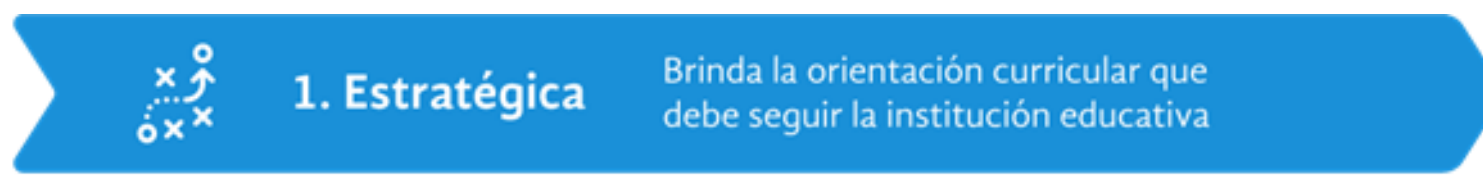

\section{Fase diagnóstica}

1 \& Socialización
2 으 Medición 3(

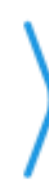

\section{Fase proyección}

2 † Adecuación

Ilustración 12: Fases Dimensión Estratégica

Fuente: Autor.

\section{Fase Diagnóstica (Origen)}

La fase diagnóstica permite identificar las coordenadas de origen en términos del desarrollo humano sostenible del contexto de la institución educativa, en este sentido la fase se subdivide en tres Pasos: Socialización, Medición y Análisis.

La Socialización tiene como objetivo brindar información para que la comunidad educativa conozca sobre el alcance, metas y ejes de los ODS. Es decir, la socialización se enfoca en un llamado mundial para tomar medidas en términos de reducción de la pobreza, protección del planeta y contribución con la paz y la prosperidad. 


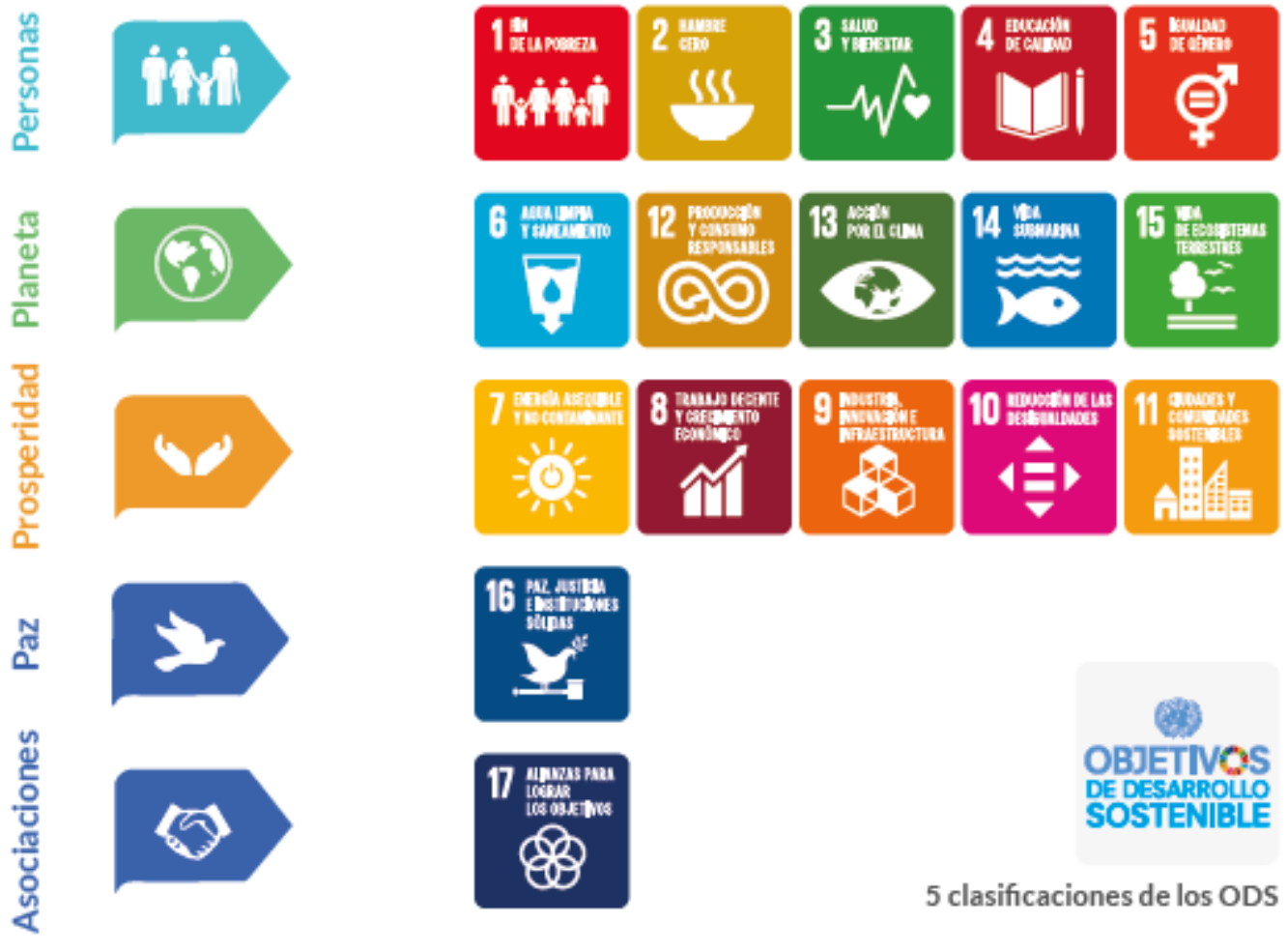

Ilustración 13: Las 5 p para el desarrollo sostenible Fuente: Tomado de los17.org

La Medición cuantifica los niveles de percepción del impacto de los ODS en el área de influencia de la comunidad académica de la Institución Educativa.

La medición permite a cada miembro de la comunidad educativa brindar una calificación cuantitativa de acuerdo con la percepción (cualitativa) del impacto de los 5 ejes centrales (Personas, Prosperidad, Planeta, Paz y Alianzas) de los ODS (UN, 2015). Para ello, se utiliza el instrumento "Diagnóstico del Contexto Institucional" (ver anexo 1).

El Análisis permite identificar los niveles de percepción sobre el eje (o ejes) de aplicabilidad del desarrollo sostenible en el contexto de actuación de la institución educativa. Surge a partir de los resultados obtenidos de la aplicación del instrumento "Diagnóstico del Contexto Institucional" soportado desde los principios de Pareto (ver anexo 2) permitiendo determinar el eje o ejes mediante el cual la institución educativa debe enfocar sus esfuerzos para articular la actualización de los contenidos curriculares y sus respectivas áreas de conocimiento.

En este sentido, la fase diagnóstica permite como lo expresa (ISI, García, Borja, \& Fundación Vicente Ferrer, 2017) (i) Reflexionar sobre la situación mundial y la postura local. (ii) Conocer la agenda mundial, (iii) Relacionar los compromisos organizacionales y (iv) Generar compromisos locales.

Lo anterior promueve: 
- Conocer los problemas de impacto global con actuación local e identificar causas y efectos de la situación de vulnerabilidad de los grupos humanos.

- Examinar el modelo de sociedad anhelada desde el plano social, económico y ambiental.

- Reconocer los desafíos y limitantes como sociedad para edificar.

- Autoevaluar la postura institucional para logar una vida soñada.

\section{Fase de Proyección o Destino}

La fase de proyección o destino corresponde a las actividades que la institución educativa planifica para orientar los contenidos curriculares acordes con las coordenadas de origen.

La fase de Proyección o destino comprende dos pasos: Selección y Adecuación.

La Selección son todas aquellas combinaciones posibles de parejas ordenadas a partir de las coordenadas identificadas del eje X (ejes ODS) definidos en el diagnóstico u origen.

En primer lugar, se ubican las coordenadas en la Matriz General y luego se combinan en la matriz de iteraciones como se muestran en las tablas a continuación.

Tabla 26: Matriz General

\begin{tabular}{|c|c|c|}
\hline Eje $x$ & Eje y & Eje $z$ \\
\hline $\begin{array}{l}\left(\mathrm{X}_{1}\right) \\
\left(\mathrm{X}_{2}\right) \\
\left(\mathrm{X}_{3}\right) \\
\left(\mathrm{X}_{17}\right)\end{array}$ & $\begin{array}{l}\left(\mathrm{Y}_{1}\right) \\
\left(\mathrm{Y}_{2}\right) \\
\left(\mathrm{Y}_{3}\right) \\
\left(\mathrm{Y}_{9}\right)\end{array}$ & $\left(Z_{1}\right)$ \\
\hline
\end{tabular}

Fuente: Autor

Tabla 27: Matriz de iteraciones

\begin{tabular}{|l|l|l|}
\hline $\begin{array}{c}\text { No } \\
\text { combinación }\end{array}$ & \multicolumn{1}{|c|}{ Coordenada } & \multicolumn{1}{c|}{ Descripción de la coordenada } \\
\hline 1 & $\left(\mathrm{X}_{1}, \mathrm{Y}_{1}, \mathrm{Z}_{1}\right)$ & $\left(\mathrm{ODS} \mathrm{N}^{\mathrm{o}} 1 ;\right.$ Asignatura MEN No 1 ; Competencias global $)$ \\
\hline 2 & $\left(\mathrm{X}_{1}, \mathrm{Y}_{2}, \mathrm{Z} 1\right)$ & $\left(\mathrm{ODS} \mathrm{N}^{\mathrm{o}} 1 ;\right.$ Asignatura MEN No 2 ; Competencias global $)$ \\
\hline 3 & $\left(\mathrm{X}_{1}, \mathrm{Y}_{3}, \mathrm{Z} 1\right)$ & $\left(\mathrm{ODS} \mathrm{N}^{\mathrm{o}} 1 ;\right.$ Asignatura MEN No $3 ;$ Competencias global $)$ \\
\hline$\ldots \mathrm{n}(17)$ & $\ldots\left(\mathrm{X}_{17}, \mathrm{Y}_{9}, \mathrm{Z1}\right)$ & $\ldots\left(\mathrm{ODS} \mathrm{N}^{\mathrm{o}} \mathrm{n}(17) ;\right.$ Asignatura MEN N $\mathrm{n}_{9}$; Competencias global $)$ \\
\hline
\end{tabular}

Fuente: Autor

La Adecuación. El paso de adecuación determina las actividades de enseñanza y aprendizaje mediadas por procesos de innovación a partir de situaciones reales del contexto para cada asignatura en sintonía con las metas asociadas a los ODS para la Institución Educativa. 
Las secciones de trabajo deben estar medidas por técnicas, métodos o metodología de innovación (ver capítulo 2) para la promoción del trabajo cooperativo y análisis dimensional entre las metas de los ODS y los referentes legales (estándares básicos de aprendizaje).

La dimensión estratégica se representa gráficamente mediante el siguiente cubo
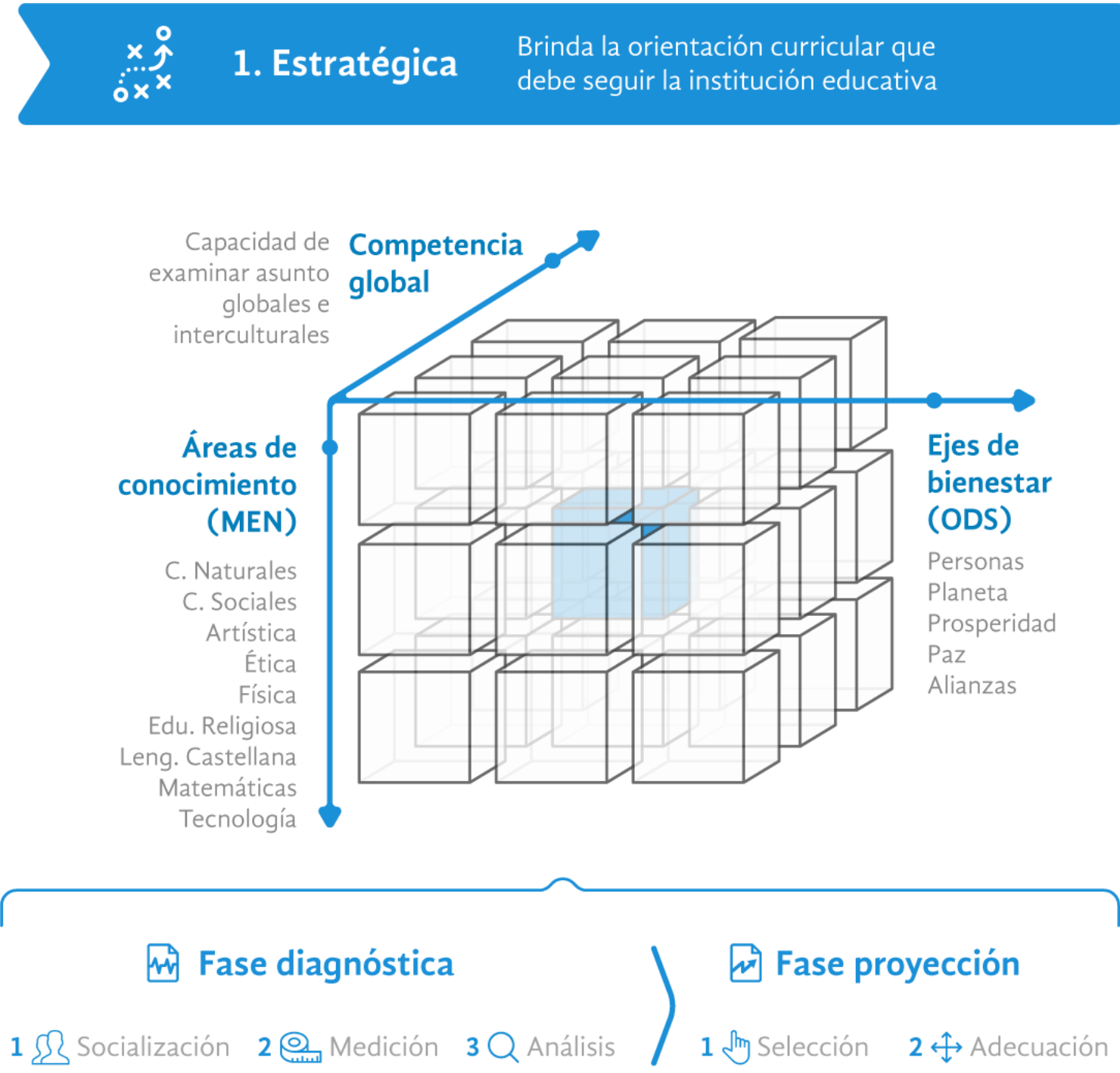

Ilustración 14: Ejes dimensión estratégica

Fuente: Autor

Las iteraciones surgen de la relación de coordenadas de los ejes del plano cartesiano: Bienestar, Áreas de conocimiento y Competencia Global, como la siguiente tabla.

Tabla 28: Coordenadas Dimensión Estratégica

Bienestar (desde el enfoque de los

Objetivos de Desarrollo Sostenible-

ODS). Eje X
Coordenadas Dimensión Estratégica

Áreas de conocimiento

(Asignaturas propuestas desde
Competencia Global (enfoque desde la propuesta de Organización para el Comercio y 


\begin{tabular}{|c|c|c|}
\hline & $\begin{array}{l}\text { Ministerio de Educación Nacional } \\
\text { de Colombia-MEN) Eje Y }\end{array}$ & $\begin{array}{l}\text { Desarrollo Económico-OCDE) Eje } \\
\qquad Z\end{array}$ \\
\hline $\begin{array}{l}\text { Ejes ODS } \\
\text { Personas }(1,2,3,4,5) \\
\text { Planeta }(6,12,13,14,15) \\
\text { Prosperidad }(7,8,9,10,11) \\
\text { Paz }(16) \\
\text { Planeta (17) } \\
\text { ODS } \\
\text { 1. Fin de la Pobreza. } \\
\text { 2. Hambre Cero. } \\
\text { 3. Salud y Bienestar. } \\
\text { 4. Educación de Calidad. } \\
\text { 5. Igualdad de Género. } \\
\text { 6. Agua Limpia y } \\
\text { Saneamiento } \\
\text { 7. Energía Asequible y no } \\
\text { Contaminante. } \\
\text { 8. Trabajo Decente y } \\
\text { Crecimiento Económico } \\
\text { 9. Industria Innovación e } \\
\text { Infraestructura. } \\
\text { 10. Reducción de las } \\
\text { desigualdades } \\
\text { 11. Ciudades y Comunidades } \\
\text { Sostenibles } \\
\text { 12. Producción y Consumo } \\
\text { Sostenible } \\
\text { 13. Acción por el Clima. } \\
\text { 14. Vida Submarina. } \\
\text { 15. Vida de Ecosistemas } \\
\text { Terrestres. } \\
\text { 16. Paz, Justicia e } \\
\text { Instituciones Sólidas. } \\
\text { 17. Alianzas para Lograr los } \\
\text { Objetivos. }\end{array}$ & $\begin{array}{l}\text { 1. } \begin{array}{l}\text { Ciencias naturales y } \\
\text { educación ambiental. } \\
\text { 2. } \\
\text { Ciencias sociales, } \\
\text { historia, geografía, } \\
\text { constitución política y } \\
\text { democracia. }\end{array} \\
\text { 3. Educación artística. } \\
\text { 4. Educación ética y en } \\
\text { valores humanos. } \\
\text { 5. Educación física, } \\
\text { recreación y deportes. } \\
\text { 6. Educación religiosa. } \\
\text { 7. Humanidades, lengua } \\
\text { castellana e idiomas } \\
\text { extranjeros } \\
\text { 8. Matemáticas. } \\
\text { 9. Tecnología e } \\
\text { informática. }\end{array}$ & $\begin{array}{l}\quad \text { 1. Competencia Global } \\
\text { (Capacidad de examinar asunto } \\
\text { globales e interculturales, para } \\
\text { tomar múltiples perspectivas bajo } \\
\text { un respeto compartido por los } \\
\text { derechos humanos, para participar } \\
\text { en interacciones abiertas, } \\
\text { apropiadas y efectivas con } \\
\text { personas de diferentes culturas y } \\
\text { para actuar en pro del bienestar } \\
\text { colectivo y del Desarrollo } \\
\text { Sostenible) }\end{array}$ \\
\hline
\end{tabular}

Fuente: Autor

A continuación, la definición de cada uno de los componentes de las coordenadas.

\subsubsection{Bienestar (enfoque de ODS).}

Los ODS, son un llamado universal a la adopción de medidas para poner fin a la pobreza, proteger el planeta y garantizar que todas las personas gocen de paz y prosperidad. soporte para el desarrollo humano y Bienestar Social. 

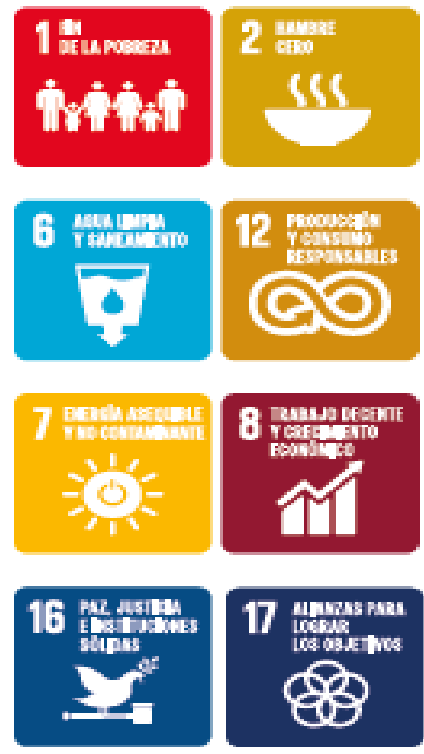
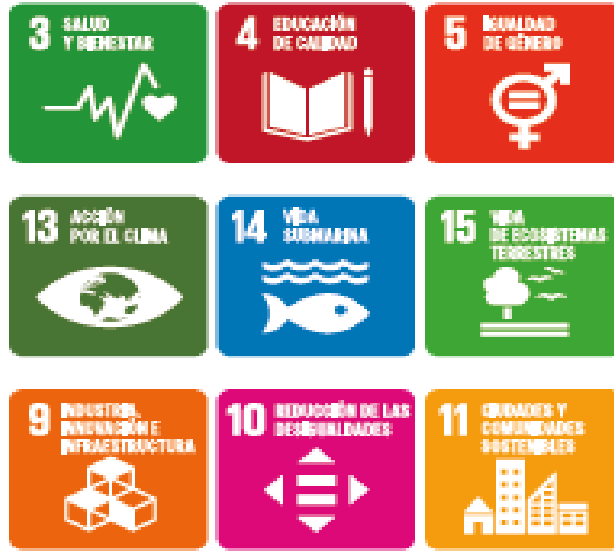

Ilustración 15: Objetivos de Desarrollo Sostenible Fuente: Tomado de ONU

En el plano cartesiano se ubica sobre el eje X, y está compuesto por 17 subcoordenadas agrupados en 5 categorías denominadas las 5P de la sostenibilidad, como lo muestra la ilustración 16:

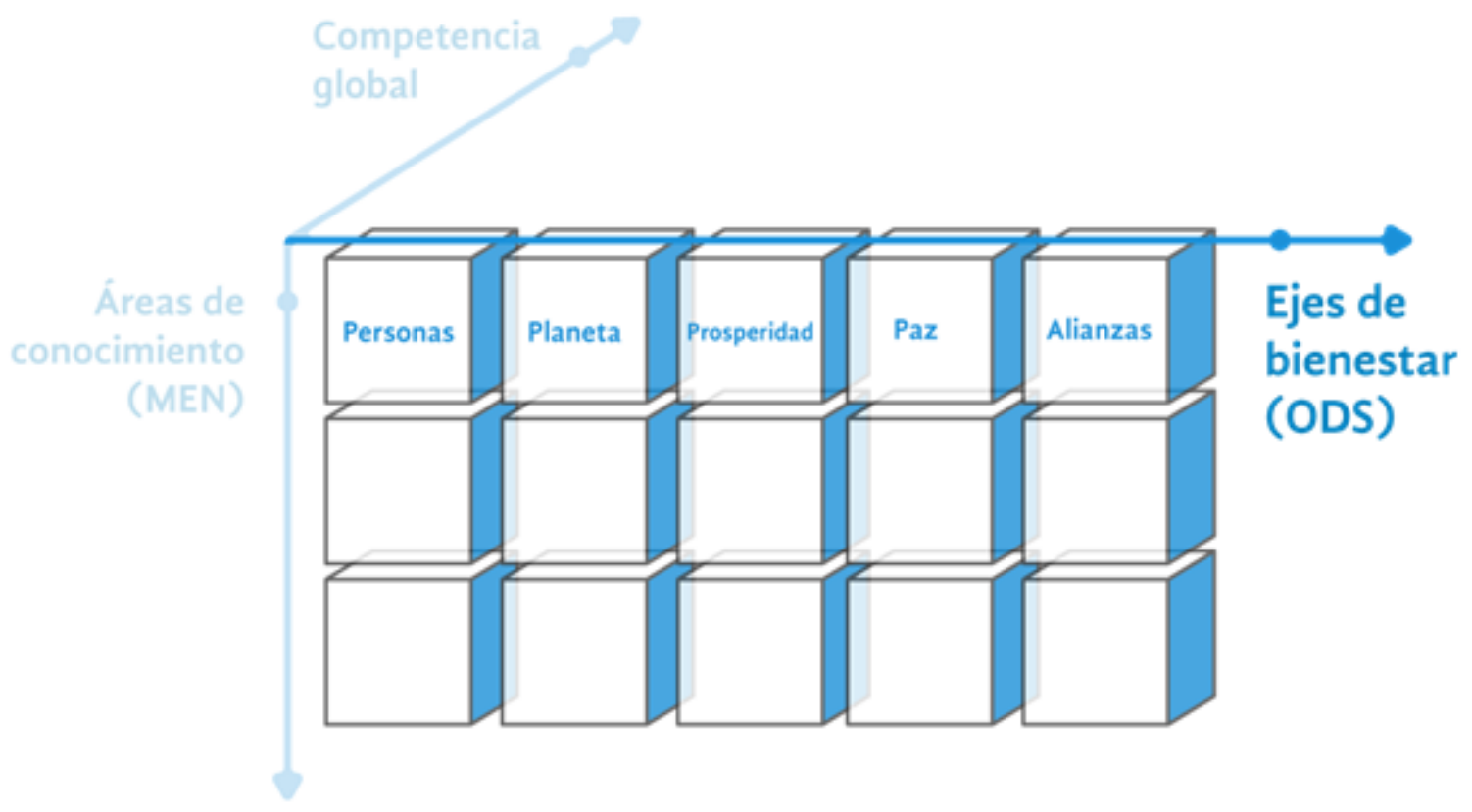

Ilustración 16: Coordenada: Bienestar (ODS)

Fuente: Autor 
De acuerdo con la información publicada por la Asamblea General de Naciones Unidas en la resolución 70/1 (UN, 2015) los 17 ODS tienen establecido 169 metas de cumplimiento para el periodo 2015 a 2030 (anexo 3).

Las coordenadas del eje $\mathrm{X}$ asociadas a los 17 ODS deberán contribuir al cumplimiento de las metas de cada objetivo mediante las iteraciones con los ejes $\mathrm{Y}$ y Z en la actualización de las temáticas relacionadas con las competencias a desarrollar para los grados de 6 a 9 de básica secundaria en Colombia.

A su vez, las coordenadas del plano cartesiano para eje Y corresponde a la Competencia global, a continuación, se describirá al detalle el soporte conceptual.

4.1.2. Competencias Global (enfoque desde la propuesta de Organización para el Comercio y Desarrollo Económico-OCDE)

Retomando la definición que surge desde la OCDE corresponde a la "capacidad de entender y actuar en asuntos globales e interculturales" en el mismo sentido, evalúa la competencia en el Programa de Evaluación Internacional de Estudiantes (PISA, siglas en ingles) en donde define la competencia como "Capacidad de examinar asunto globales e interculturales, para tomar múltiples perspectivas bajo un respeto compartido por los derechos humanos, para participar en interacciones abiertas, apropiadas y efectivas con personas de diferentes culturas y para actuar en pro del bienestar colectivo y del Desarrollo Sostenible" (ICFES, 2017).

En el plano cartesiano se ubica sobre el eje Z, está compuesto por 1 subcoordenada como lo muestra la ilustración 17:

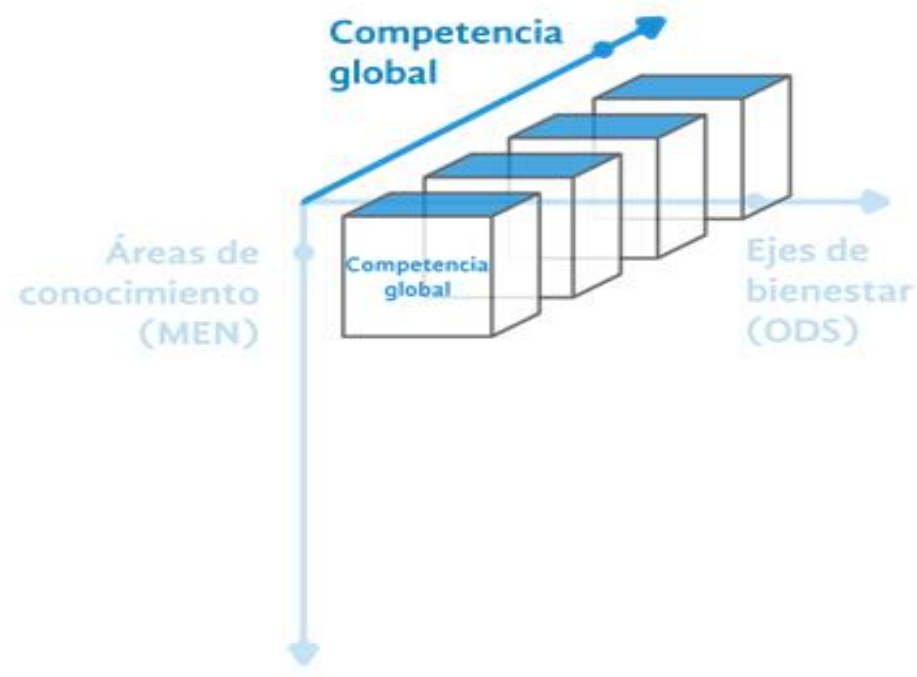

Ilustración 17: Coordenada: Competencia Global

Fuente: Autor 
Bajo este enfoque la competencia global se compone de 4 dimensiones:

- Examinar problemas y situaciones de relevancia local, global e intercultural.

- Comprender y apreciar perspectivas y cosmovisiones de los demás.

- Participar en interacciones abiertas, apropiadas y efectivas entre todas las personas.

- Actuar en pro del bienestar colectivo y del desarrollo sostenible.

Las cuatro dimensiones a su vez se derivan de una visión integrada de conocimientos, habilidades, actitudes y valores.

- Conocimiento sobre el mundo y sus culturas:

- Relaciones interculturales

- Desarrollo socioeconómico e interdependencia

- Sostenibilidad ambiental

- Instituciones globales, conflictos y derechos humanos

- Habilidades para entender el mundo y actuar:

- Razonamiento informado

- Comunicación en contextos interculturales

- Toma de perspectiva

- Habilidades de resolución de conflictos

- Adaptabilidad

- Actitudes de respeto por las personas de diferentes procedencias culturales y mentalidad global

- Apertura hacia personas de otros orígenes culturales

- Respeto por las personas de diferentes procedencias culturales

- Mentalidad global, posicionamiento del individual y responsable del espacio que lo rodea.

- Valores relacionados con el procesamiento e interacción de la información con el mundo

- Valoración de los derechos humanos (dignidad humana).

- Valoración de la diversidad cultural.

La evaluación cognitiva de la competencia global por parte de PISA incluye diferentes niveles de complejidad como lo muestra la tabla 29.

Tabla 29: La evaluación cognitiva de la competencia global.

\begin{tabular}{|c|c|c|}
\hline $\begin{array}{l}\text { Proceso cognitivo } \\
\text { principal }\end{array}$ & $\begin{array}{l}\text { El contenido o conocimiento global e } \\
\text { intercultural de los escenarios }\end{array}$ & El contexto de actuación \\
\hline $\begin{array}{l}\text { Evaluar información, } \\
\text { formular argumentos } \\
\text { y explicar problemas } \\
\text { o situaciones }\end{array}$ & $\begin{array}{ll}\text { - } & \text { Conocimiento y alfabetización } \\
& \text { Conocimiento del dominio } \\
& \text { específico } \\
& \text { Conocimiento general } \\
\text { - } & \text { Actitudes }\end{array}$ & $\begin{array}{l}\text { - Contenidos Interrelacionados } \\
\qquad \quad \begin{array}{l}\text { Cultura y relaciones } \\
\text { interculturales }\end{array}\end{array}$ \\
\hline
\end{tabular}




\begin{tabular}{|c|c|c|}
\hline $\begin{array}{ll}\text { - } & \text { Identificar y analizar } \\
\text { diferentes } \\
\text { perspectivas } \\
\text { Comprender las } \\
\text { diferencias en la } \\
\text { comunicación } \\
\text { Evaluar acciones y } \\
\text { consecuencias }\end{array}$ & $\begin{array}{cl} & \text { Apertura } \\
\circ & \text { Respeto } \\
\circ & \text { Mentalidad global } \\
\cdot & \text { Valores } \\
\circ & \text { Valoración de los derechos } \\
& \text { humanos fundamentales } \\
\circ & \text { Valoración diversidad cultural. }\end{array}$ & $\begin{array}{cl}\circ & \text { Conflictos, instituciones } \\
& \text { y derechos humanos } \\
\circ & \text { Sostenibilidad ambiental } \\
\circ & \text { Desarrollo e } \\
& \text { interdependencia } \\
& \text { socioeconómica } \\
\text { - Contextos de los escenarios } \\
\\
\\
\therefore \quad \text { Personal } \\
\circ \quad \text { Local } \\
\circ \quad \text { Global }\end{array}$ \\
\hline
\end{tabular}

Fuente: Autor, a partir de (ICFES, 2017).

Desde la conceptualización de la competencia global abordada por PISA, se define que es posible identificar un conjunto de asuntos relevantes desde lo local, global y cultural para estudiantes de 15 años. Si bien la competencia global se desarrolla tras un proceso a lo largo de la vida (ICFES, 2017), esto implica para la escuela desarrollar aproximaciones pedagógicas con una visión crítica de asuntos globales e interculturales de acuerdo con el nivel de formación.

Las disciplinas o áreas de conocimiento para básica secundaria permiten profundizar progresivamente en procesos, conocimientos, contextos, entre otros, para el desarrollo del humano. a continuación, se describe el alcance de las áreas de conocimiento para básica secundaria en Colombia.

\subsection{3. Áreas de conocimiento (Asignaturas propuestas desde Ministerio de Educación Nacional de Colombia-MEN)}

De acuerdo con el artículo 23 (Ley $\mathrm{N}^{\circ} 115,1994$ ) las áreas obligatorias y fundamentales son necesarias para el logro de los objetivos de la educación de básica secundaria y estas deberán estar en el currículo y el Proyecto Educativo Institucional.

En el plano cartesiano se ubica sobre el eje Y, está compuesto por 9 subcoordenadas enumeradas en el orden correspondiente a las enunciadas en Ley General de Educación (Ley $\left.\mathrm{N}^{\mathrm{o}} 115,1994\right)$, como lo muestra la ilustración 18. 


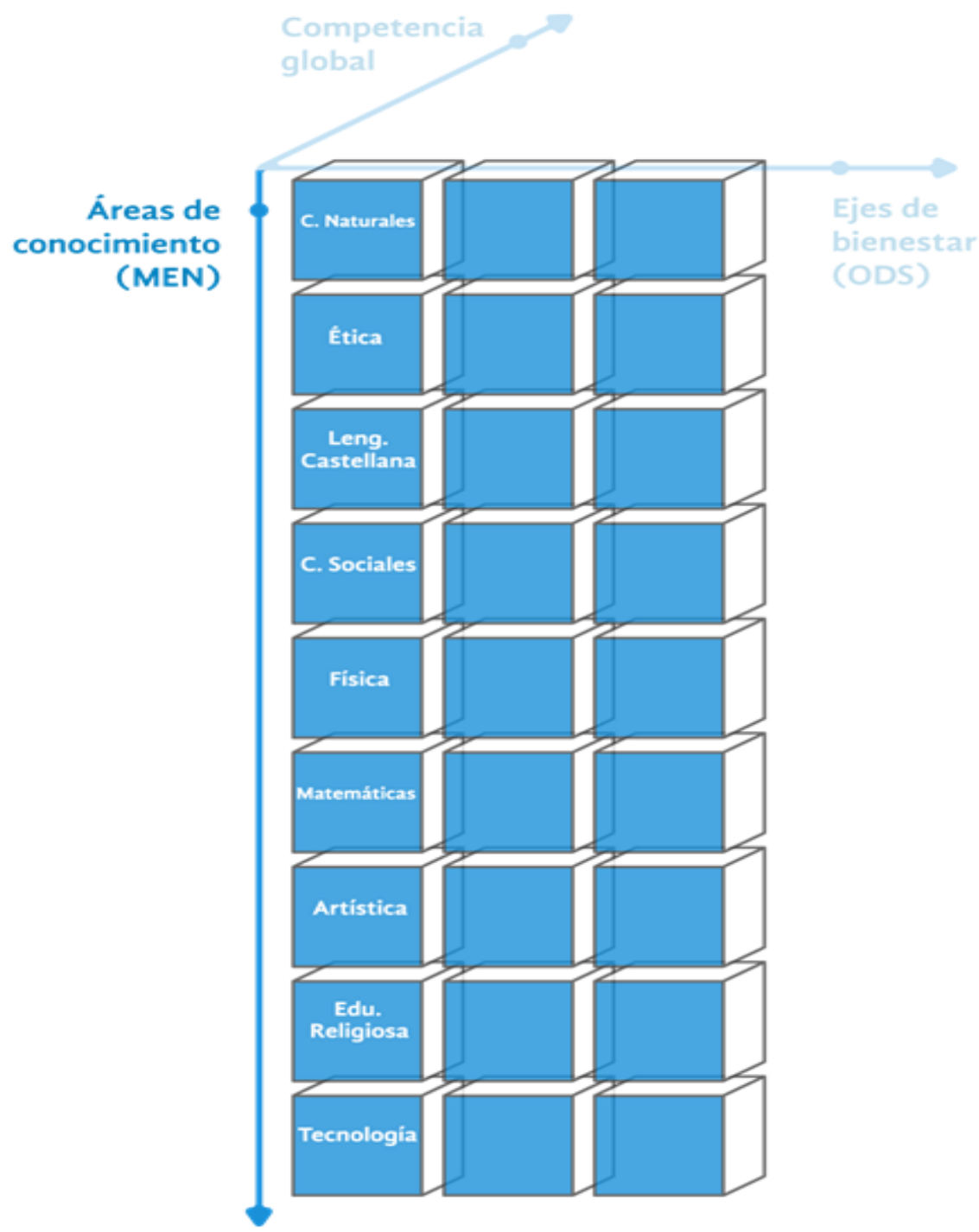

Ilustración 18: Coordenada: Áreas de Conocimiento (MEN) Fuente: Autor.

Ley General de Educación (Ley $\left.{ }^{\circ} 115,1994\right)$ señala para básica secundaria los grupos de áreas obligatorias y fundamentales (art. 23), estas deben comprender un mínimo del $80 \%$ del plan de estudios y contener los objetivos específicos (art. 22, 24 y 25) como se muestra a continuación:

Tabla 30: Áreas fundamentales MEN educación básica secundaria

\begin{tabular}{|l|l|}
\hline $\begin{array}{c}\text { Áreas Obligatorias } \\
\text { y Fundamentales }\end{array}$ & \multicolumn{1}{c|}{ Objetivos Art 22, 24 y 25 } \\
\hline $\begin{array}{l}\text { 1. Ciencias naturales } \\
\text { y educación } \\
\text { ambiental. }\end{array}$ & $\begin{array}{l}\text { d) El avance en el conocimiento científico de los fenómenos físicos, químicos y } \\
\text { biológicos, mediante la comprensión de las leyes, el planteamiento de problemas y } \\
\text { la observación experimental; }\end{array}$ \\
& $\begin{array}{l}\text { e) El desarrollo de actitudes favorables al conocimiento, valoración y } \\
\text { conservación de la naturaleza y el ambiente; }\end{array}$ \\
\hline
\end{tabular}




\begin{tabular}{|c|c|}
\hline $\begin{array}{l}\text { 2. Ciencias sociales, } \\
\text { historia, geografía, } \\
\text { constitución política } \\
\text { y democracia. }\end{array}$ & $\begin{array}{l}\text { h) El estudio científico de la historia nacional y mundial dirigido a comprender el } \\
\text { desarrollo de la sociedad, y el estudio de las ciencias sociales, con miras al análisis } \\
\text { de las condiciones actuales de la realidad social; } \\
\text { i) El estudio científico del universo, de la tierra, de su estructura física, de su } \\
\text { división y organización política, del desarrollo económico de los países y de las } \\
\text { diversas manifestaciones culturales de los pueblos; } \\
\text { j) La formación en el ejercicio de los deberes y derechos, el conocimiento de la } \\
\text { Constitución Política y de las relaciones internacionales; }\end{array}$ \\
\hline $\begin{array}{l}\text { 3. Educación } \\
\text { artística. }\end{array}$ & $\begin{array}{l}\text { k) La apreciación artística, la comprensión estética, la creatividad, la } \\
\text { familiarización con los diferentes medios de expresión artística y el conocimiento, } \\
\text { valoración y respeto por los bienes artísticos y culturales; }\end{array}$ \\
\hline $\begin{array}{l}\text { 4. Educación ética y } \\
\text { en valores humanos. }\end{array}$ & $\begin{array}{l}\text { n) La utilización con sentido crítico de los distintos contenidos y formas de } \\
\text { información y la búsqueda de nuevos conocimientos con su propio esfuerzo, } \\
\text { ARTICULO 25. Formación ética y moral. La formación ética y moral se } \\
\text { promoverá en el establecimiento educativo a través del currículo, de los } \\
\text { contenidos académicos pertinentes, del ambiente, del comportamiento honesto de } \\
\text { directivos, educadores, y personal administrativo, de la aplicación recta y justa de } \\
\text { las normas de la institución, y demás mecanismos que contemple el Proyecto } \\
\text { Educativo Institucional }\end{array}$ \\
\hline $\begin{array}{l}\text { 5. Educación física, } \\
\text { recreación y deportes. }\end{array}$ & $\begin{array}{l}\text { m) La valoración de la salud y de los hábitos relacionados con ella; } \\
\text { ñ) La educación física y la práctica de la recreación y los deportes, la participación } \\
\text { y organización juvenil y la utilización adecuada del tiempo libre. }\end{array}$ \\
\hline $\begin{array}{l}\text { 6. Educación } \\
\text { religiosa. }\end{array}$ & $\begin{array}{l}\text { ARTICULO 24. Educación religiosa. Se garantiza el derecho a recibir educación } \\
\text { religiosa; los establecimientos educativos la establecerán sin perjuicio de las } \\
\text { garantías constitucionales de libertad de conciencia, libertad de cultos y el derecho } \\
\text { de los padres de familia de escoger el tipo de educación para sus hijos menores, } \\
\text { así como del precepto constitucional según el cual en los establecimientos del } \\
\text { Estado ninguna persona podrá ser obligada a recibir educación religiosa. En todo } \\
\text { caso la educación religiosa se impartirá de acuerdo con lo establecido en la ley } \\
\text { estatutaria que desarrolla el derecho de libertad religiosa y de cultos. }\end{array}$ \\
\hline $\begin{array}{l}\text { 7. Humanidades, } \\
\text { lengua castellana e } \\
\text { idiomas extranjeros. }\end{array}$ & $\begin{array}{l}\text { a) El desarrollo de la capacidad para comprender textos y expresar correctamente } \\
\text { mensajes complejos, orales y escritos en lengua castellana, así como para } \\
\text { entender, mediante un estudio sistemático, los diferentes elementos constitutivos } \\
\text { de la lengua; } \\
\text { b) La valoración y utilización de la lengua castellana como medio de expresión } \\
\text { literaria y el estudio de la creación literaria en el país y en el mundo; } \\
\text { 1) La comprensión y capacidad de expresarse en una lengua extranjera; }\end{array}$ \\
\hline 8. Matemáticas. & $\begin{array}{l}\text { c) El desarrollo de las capacidades para el razonamiento lógico, mediante el } \\
\text { dominio de los sistemas numéricos, geométricos, } \\
\text { métricos, lógicos, analíticos, de conjuntos de operaciones y relaciones, así como } \\
\text { para su utilización en la interpretación y solución de los problemas de la ciencia, } \\
\text { de la tecnología y los de la vida cotidiana; } \\
\text { f) La comprensión de la dimensión práctica de los conocimientos teóricos, así } \\
\text { como la dimensión teórica del conocimiento práctico y la capacidad para utilizarla } \\
\text { en la solución de problemas; }\end{array}$ \\
\hline $\begin{array}{l}\text { 9. Tecnología e } \\
\text { informática. }\end{array}$ & $\begin{array}{l}\text { g) La iniciación en los campos más avanzados de la tecnología moderna y el } \\
\text { entrenamiento en disciplinas, procesos y técnicas que le permitan el ejercicio de } \\
\text { una función socialmente útil; }\end{array}$ \\
\hline
\end{tabular}

Fuente: Autor

Las 9 áreas obligatorias señaladas por el MEN permiten relacionar la problemática de la comunidad (desafíos de la vida) con los campos de las ciencias asociados a las áreas de conocimiento, estas a su vez se reflejan en los contenidos curriculares con alcance de básica secundaria. 
En síntesis: la dimensión estratégica identifica las coordenadas $X, Y, Z$ que debe seguir la institución educativa que deseé vincularse al desarrollo sostenible y contribuir con el bienestar de la comunidad local e impactar en la globalidad.

La dimensión estratégica orienta hacia la actualización de los contenidos curriculares con situaciones escolares que permiten sensibilizar y brindar soluciones para el contexto mediante el desarrollo de la competencia global.

Identificadas las coordenadas de origen se procede con la segunda etapa que corresponde a la Dimensión Operativa, esta se hace funcional mediante la siguiente estructura.

\subsection{Dimensión Operativa}

La dimensión operativa instrumentaliza las coordenadas de destino para insertarlas en el diseño curricular; en esta se define el plan de acción a ejecutar para cada coordenada.

La dimensión operativa está compuesta por los ejes de coordenadas Medios (eje X), Personas (eje Y) y Procesos de Innovación (eje Z) como los muestra la ilustración 19.

\section{Operativa Define el plan de acción para \\ 2. Operativa cada coordenada de origen}

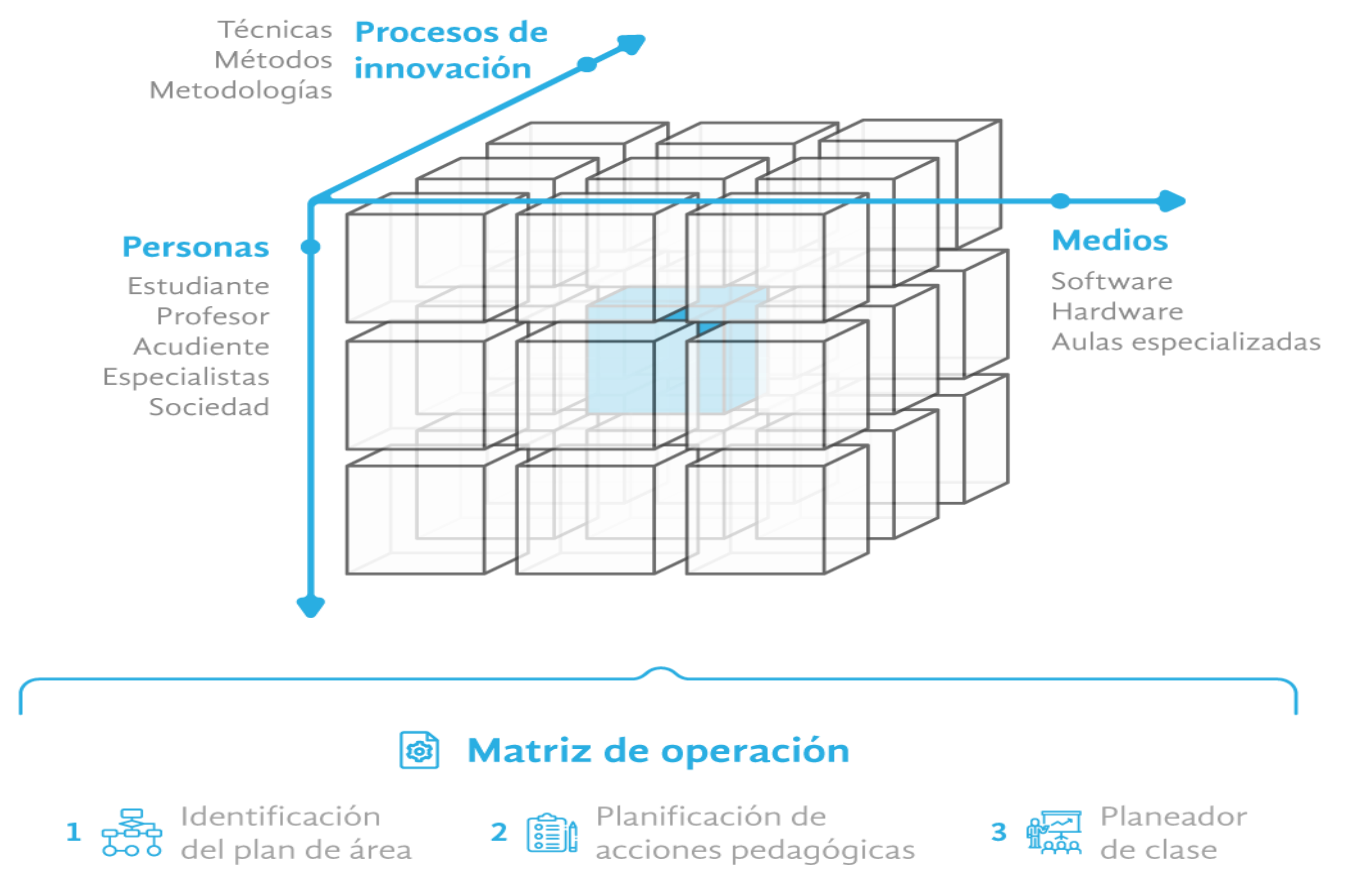

Ilustración 19: Ejes dimensión Operativa

Fuente: Autor 
Las combinaciones que surgen de la relación de los ejes del plano cartesiano: Medios Educativos, Personas, Procesos de Innovación, definen el plan de acción para cada coordenada identificada en la dimensión estratégica, esta se hace operativa mediante el análisis de combinaciones como lo muestra la tabla 31.

Tabla 31: Coordenadas Dimensión Operativa

\begin{tabular}{|c|c|c|}
\hline \multicolumn{3}{|c|}{ Coordenadas Dimensión Operativa } \\
\hline Medios Educativos & Personas & $\begin{array}{l}\text { Procesos de } \\
\text { Innovación }\end{array}$ \\
\hline $\begin{array}{l}\text { 1. Software } \\
\text { 2. Hardware } \\
\text { 3. Aulas especializadas }\end{array}$ & $\begin{array}{ll}\text { 1. } & \text { Estudiante } \\
\text { 2. } & \text { Profesor } \\
\text { 3. } & \text { Acudiente } \\
\text { 4. Especialistas } \\
\text { 5. }\end{array}$ & $\begin{array}{l}\text { 1. Técnicas } \\
\text { 2. Métodos } \\
\text { 3. Metodología. }\end{array}$ \\
\hline
\end{tabular}

Fuente: Autor

El proceso de modelado de cada eje del plano cartesiano se efectúa de la Matriz de Seguimiento compuesta por Identificación del plan de área, Planificación de Acciones Pedagógicas y Planeador de Clase, como lo muestran las tablas 32, 33 y 34. Cabe resaltar el diligenciamiento de las tablas deben ser producto de las secciones de trabajo conjunto mediado por procesos de innovación.

- La identificación del plan de área: corresponde a los lineamientos y estándares curriculares para contribuir con la formación del estudiante para lograr los fines de la educación en función del desarrollo humano sostenible.

- La planificación de acciones pedagógicas: brinda la información para lograr los propósitos de la enseñanza y el aprendizaje para operar y actuar en un mundo biológico, social y cultural.

- El planeador de clase: es un documento que orientada al docente hacia cómo impartir el desarrollo de la clase, en él se integra la relación de tiempo, actividades y recursos necesarios para la acción de educar.

Tabla 32:Matriz de seguimiento: Identificación del plan de área

\begin{tabular}{|l|l|}
\hline $\begin{array}{l}\text { Asignatura } \\
\text { (Secuencias Didácticas) }\end{array}$ & $\begin{array}{l}\text { Asignatura Base: } \\
\text { Asignaturas complementarias: }\end{array}$ \\
\hline Objetivo Área & \\
\hline Objetivo Específico & \\
\hline ODS & \\
\hline Meta ODS & \\
\hline
\end{tabular}

Fuente: Autor 
Tabla 33: Matriz de seguimiento: Planificación de Acciones Pedagógicas

\begin{tabular}{|l|l|l|}
\hline \multicolumn{1}{|c|}{ Qué } & Proceso Cognitivo & \\
\cline { 2 - 3 } & Mediadores de Desempeño & \\
\cline { 2 - 3 } & Dominios de Contenido & \\
\hline & Contexto \\
\hline Cómo & Procesos de Innovación & \\
\hline Por qué & Evidencia de Aprendizaje & \\
\hline Dónde & Medios Educativos & \\
\hline Quién & Personas & \\
\hline Cuánto & Materiales & \\
\hline Cuándo & Tiempo & \\
\hline
\end{tabular}

Fuente: Autor

Tabla 34: Matriz de seguimiento: Planeador de Clase

\begin{tabular}{|c|c|c|c|}
\hline $\begin{array}{c}\text { Etapa Clase/ } \\
\text { Tiempo }\end{array}$ & Actividad & $\begin{array}{c}\text { Evidencia } \\
\text { Aprendizaje }\end{array}$ & Materiales \\
\hline $\begin{array}{c}\text { Inicio } \\
\text { (duración actividad } \\
\text { en minutos) }\end{array}$ & $\begin{array}{c}\text { 1. Distribución de actividades: } \\
\text { 2. Identificación de aprendizajes } \\
\text { previos: }\end{array}$ & & \\
\hline $\begin{array}{c}\text { Desarrollo } \\
\text { duración actividad } \\
\text { en minutos) }\end{array}$ & 3. Actividades de desarrollo: & & \\
\hline $\begin{array}{c}\text { Cierre } \\
\text { (duración actividad } \\
\text { en minutos) }\end{array}$ & 4. Conclusiones: & & \\
\hline
\end{tabular}

Fuente: Autor

A continuación, se detallan los componentes de los ejes de coordenadas de la dimensión operativa y la metodología de desarrollo de la matriz de seguimiento.

\subsubsection{Medios Educativos}

Existen diferentes clasificaciones de recursos didácticos que se subdividen por niveles educativos, áreas de enseñanza, naturaleza de la tecnología, costo económico, entre otras; partiendo de la definición de Mederith (1988) citado por (Guillermo \& Alonso, 1977) un medio educativo es una organización de recursos que media la expresión de acción entre maestro y alumno. De igual modo un medio no puede separarse del método ni de los componentes de la acción educativa como lo son los objetivos, la evaluación y el contenido. 
De acuerdo con Cubero (1991) un medio de enseñanza es todo componente material del proceso docente que el maestro utiliza como apoyo para la consecución de los objetivos de aprendizaje.

Estos medios educativos pueden presentar diferentes clasificaciones, a continuación, una muestra de ellos

Tabla 35: Medios educativos

\begin{tabular}{|c|c|c|c|c|c|}
\hline \multicolumn{2}{|c|}{ John Bachman (1972) } & \multicolumn{2}{|c|}{ Cubero (1991) y Porto (1995) } & \multicolumn{2}{|c|}{$\begin{array}{l}\text { Castañeda (1987), Dörr (1997), } \\
\text { Heinich (1990) y Romiszowski } \\
\text { (1988) }\end{array}$} \\
\hline Clasificación & Ejemplo & Clasificación & Ejemplo & Clasificación & Ejemplo \\
\hline 1. Audibles & $\begin{array}{l}\text { Cassettes, } \\
\text { discos, CD }\end{array}$ & \multirow[t]{2}{*}{ Objeto natural } & \multirow{2}{*}{$\begin{array}{l}\text { Materiales } \\
\text { encontrados en } \\
\text { la naturaleza: } \\
\text { una hoja, un } \\
\text { animal, una } \\
\text { balanza, etc. }\end{array}$} & \multirow{3}{*}{$\begin{array}{l}\text { Medios de } \\
\text { comunicación } \\
\text { de información }\end{array}$} & \multirow{3}{*}{$\begin{array}{l}\text { Tecnologías } \\
\text { tangibles, } \\
\text { medios para } \\
\text { llevar el } \\
\text { mensaje sea } \\
\text { natural o } \\
\text { artificial. } \\
\text { Libros, tv, pc, } \\
\text { voz, tacto, etc }\end{array}$} \\
\hline $\begin{array}{l}\text { 2. Visuales } \\
\text { proyectados }\end{array}$ & $\begin{array}{l}\text { Filminas, } \\
\text { diapositivas, } \\
\text { cuerpos } \\
\text { opacos, etc }\end{array}$ & & & & \\
\hline $\begin{array}{l}\text { 3. Visuales no } \\
\text { proyectados }\end{array}$ & $\begin{array}{l}\text { Libros, } \\
\text { revistas, } \\
\text { carteles, fotos, } \\
\text { etc. }\end{array}$ & \multirow[t]{2}{*}{ Reproducción } & \multirow{2}{*}{$\begin{array}{l}\text { Representación } \\
\text { material de un } \\
\text { objeto real } \\
\text { concreto o } \\
\text { abstracto: } \\
\text { Filmina, } \\
\text { diapositiva, etc. }\end{array}$} & & \\
\hline $\begin{array}{l}4 . \\
\text { Audiovisuales } \\
\text { no } \\
\text { Proyectados }\end{array}$ & $\begin{array}{l}\text { Programas de } \\
\text { televisión, } \\
\text { videos, } \\
\text { sonoramas, } \\
\text { etc. }\end{array}$ & & & \multirow[t]{2}{*}{$\begin{array}{l}\text { Método de } \\
\text { Instrucción }\end{array}$} & \multirow{2}{*}{$\begin{array}{l}\text { Tecnologías } \\
\text { Intangibles, } \\
\text { Procedimientos } \\
\text { de instrucción } \\
\text { para alcanzar } \\
\text { los objetivos de } \\
\text { aprendizaje }\end{array}$} \\
\hline $\begin{array}{l}5 . \\
\text { Audiovisuales } \\
\text { no proyectados }\end{array}$ & $\begin{array}{l}\text { Marionetas, } \\
\text { simulaciones, } \\
\text { excursiones, } \\
\text { etc. }\end{array}$ & Instrumento & $\begin{array}{l}\text { Objetos } \\
\text { materiales para } \\
\text { representar el } \\
\text { objeto de } \\
\text { estudio: } \\
\text { Retroproyector, } \\
\text { tv, computador, } \\
\text { etc. }\end{array}$ & & \\
\hline
\end{tabular}

Fuente: Autor

De acuerdo con las anteriores definiciones cabe resaltar que la elección del medio educativo forma parte de las diferentes posturas teóricas del aprendizaje, desde las teorías conductistas $^{22}$, $\operatorname{cognitivistas}^{23}$ y constructivistas $^{24}$.

Los aportes al aprendizaje de los medios de enseñanza en sintonía con (González, 1989) permean diferentes disciplinas, así:

\footnotetext{
22 Relación estimulo respuesta desde las características observables en el aprendizaje.

${ }^{23}$ Procesos de interpretación, procesamiento y almacenamiento de conocimiento.

${ }^{24}$ Procesos internos de construcción de conocimiento a partir de la interacción con el medio para construir su conocimiento.
} 
Tabla 36: Aportes al aprendizaje por disciplina

\begin{tabular}{|c|l|}
\hline Disciplina & \multicolumn{1}{|c|}{ Aportes al Aprendizaje } \\
\hline \multirow{4}{*}{ Filosofía } & Representación de los materiales de difícil acceso \\
\cline { 2 - 3 } & Comparativo entre percepción y proceso lógico de pensamiento \\
\hline \multirow{4}{*}{ Psicológico } & Exploración de los canales sensoriales \\
\cline { 2 - 2 } & Participación individual \\
\cline { 2 - 2 } & Atención activa \\
\cline { 2 - 2 } & Intereses cognoscitivos \\
\cline { 2 - 2 } & Emotividad al proceso de aprendizaje \\
\cline { 2 - 2 } & Diversidad metodológica \\
\cline { 2 - 2 } & Captura de atención \\
\cline { 2 - 2 } & Promueve la motivación \\
\hline \multirow{5}{*}{ Pedagógico } & Sistematización del proceso \\
\cline { 2 - 2 } & Incentivos para el aprendizaje \\
\cline { 2 - 2 } & Productividad del trabajo \\
\cline { 2 - 2 } & Retroalimentación del proceso \\
\cline { 2 - 2 } & Participación creativa \\
\cline { 2 - 2 } & Fortalecimiento de la personalidad \\
\cline { 2 - 2 } & Desarrollo de las cualidades y capacidades \\
\cline { 2 - 2 } & Análisis dimensional \\
\cline { 2 - 2 } & Pensamiento lógico \\
\cline { 2 - 2 } & Control del conocimiento \\
\cline { 2 - 2 } & Aprendizaje teórico práctico \\
\hline Físico & Materialización del imaginario \\
\hline
\end{tabular}

Fuente: A partir de (González, 1989)

Los medios de enseñanza en comunión con las nuevas tecnologías (tendencias de globalización) configuran un componente fundamental para la apropiación de conocimientos desde las disciplinas. En esta materia, el uso de la tecnología en el aula es un aliado estratégico. Por tanto, es necesario hablar de software y hardware.

Software. Corresponde a los programas informáticos que posibilitan la ejecución de las tareas de un dispositivo electrónico.

Hardware. Son todas aquellas partes físicas de los dispositivos electrónicos

Aulas Especializadas. Retomando el Informe Horizont 2017 para Educación Primaria y Secundaria elaborado por el Departamento de Proyectos Europeos del Instituto Nacional de Tecnologías Educativas y de Formación del Profesorado (INTEF,2017) los MakerSpaces han tomado gran importancia en los sistemas educativos a nivel mundial para el desarrollo de competencias del siglo XXI, en cuanto a exploración y el juego, fomentando la creatividad y la colaboración además del aprendizaje autodirigido y entre pares.

Los MakerSpaces no es solo la asignación de un espacio abierto, este debe estar dotado de elementos para contribuir con la creatividad y el trabajo colaborativo, en el que las diferentes disciplinas aporte hacia el aprendizaje multi e interdisciplinar.

Así mismo el informe Horizont 2017 clasifica los retos de las instituciones educativas para primaria y secundaria así: 
Tabla 37: Retos de la tecnología educativa para primaria y secundaria

\begin{tabular}{|c|c|c|c|c|c|c|}
\hline $\begin{array}{l}\text { Factor de } \\
\text { análisis }\end{array}$ & \multicolumn{6}{|c|}{ Características } \\
\hline $\begin{array}{l}\text { Tecnologías } \\
\text { para adoptar }\end{array}$ & $\begin{array}{l}\text { Makerspace } \\
\mathbf{s} \\
\text { (corto plazo } \\
1 \text { año o } \\
\text { menos) }\end{array}$ & $\begin{array}{l}\text { Robótica } \\
\text { (corto plazo } \\
1 \text { año o } \\
\text { menos) }\end{array}$ & $\begin{array}{l}\text { Tecnología } \\
\text { s } \\
\text { Analíticas } \\
\text { (mediano } \\
\text { plazo de } 2 \text { a } \\
3 \text { años) }\end{array}$ & $\begin{array}{l}\text { Realidad } \\
\text { Virtual } \\
\\
\text { (mediano } \\
\text { plazo de } 2 \text { a } \\
3 \text { años) }\end{array}$ & $\begin{array}{l}\text { Inteligenc } \\
\text { ia } \\
\text { Artificial } \\
\text { (largo } \\
\text { plazo de } 4 \\
\text { a } 5 \text { años) }\end{array}$ & $\begin{array}{l}\text { Internet de } \\
\text { las cosas } \\
\text { (largo plazo } \\
\text { de } 4 \text { a } 5 \\
\text { años) }\end{array}$ \\
\hline $\begin{array}{l}\text { Desafíos } \\
\text { Significativos }\end{array}$ & \multicolumn{2}{|c|}{$\begin{array}{l}\text { Desafíos fáciles de abordar } \\
\text { - } \quad \begin{array}{l}\text { Experiencias de } \\
\text { aprendizaje auténtico }\end{array} \\
\text { - } \quad \begin{array}{l}\text { Mejora de la } \\
\text { alfabetización digital. }\end{array}\end{array}$} & \multicolumn{2}{|c|}{$\begin{array}{ll}\begin{array}{l}\text { Desafíos difíciles de } \\
\text { abordar }\end{array} \\
\text { - } & \begin{array}{l}\text { Replanteamiento del } \\
\text { rol de los docentes }\end{array} \\
& \\
\text { - } & \text { Enseñanza del } \\
& \text { Pensamiento } \\
& \text { Computacional }\end{array}$} & \multicolumn{2}{|c|}{ 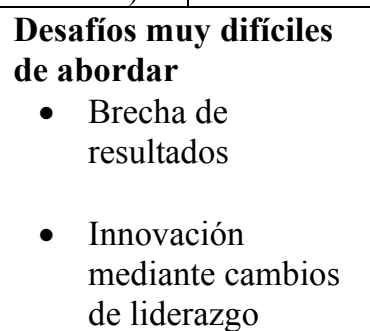 } \\
\hline $\begin{array}{l}\text { Tendencias de } \\
\text { adopción }\end{array}$ & \multicolumn{2}{|c|}{$\begin{array}{l}\text { Tendencias a corto plazo } \\
\text { - Avances en la cultura } \\
\text { de la innovación } \\
\text { - Enfoques de } \\
\text { aprendizaje profundo }\end{array}$} & \multicolumn{2}{|c|}{$\begin{array}{l}\text { Tendencias a mediano } \\
\text { plazo } \\
\text { - Interés creciente en la } \\
\text { medición del } \\
\text { aprendizaje }\end{array}$} & \multicolumn{2}{|c|}{$\begin{array}{l}\text { Tendencias a largo } \\
\text { plazo } \\
\text { - Alfabetización en } \\
\text { Programación } \\
\text { - Aumento del } \\
\begin{array}{l}\text { aprendizaje } \\
\text { STEAM }\end{array}\end{array}$} \\
\hline
\end{tabular}

Fuente: Elaboración propia a partir de (INTEF,2017)

De acuerdo con lo anterior, las tecnologías emergentes, tendencias claves y desafíos significativos surgen como respuesta para el apoyo de las instituciones educativas en la toma de decisiones en el proceso de formación. Para ello es necesario del apoyo de los diferentes actores que a continuación se detallará.

\subsubsection{Personas}

Partiendo del principio del proceso educativo como un equilibrio entre el desarrollo de las aptitudes particulares de la persona y su integración en el contexto, se logran identificar dos principios básicos de la acción educadora, la individualización y la socialización. Estas dimensiones en el proceso educativo buscan el perfeccionamiento de la autonomía con la capacidad de responder de sus decisiones y actuaciones siendo responsable con su comunidad. Esta autonomía de acuerdo con (García, Ruiz \& García, 2009) debe estar soportada desde la actividad, creatividad y participación para el desarrollo integral de la persona. 


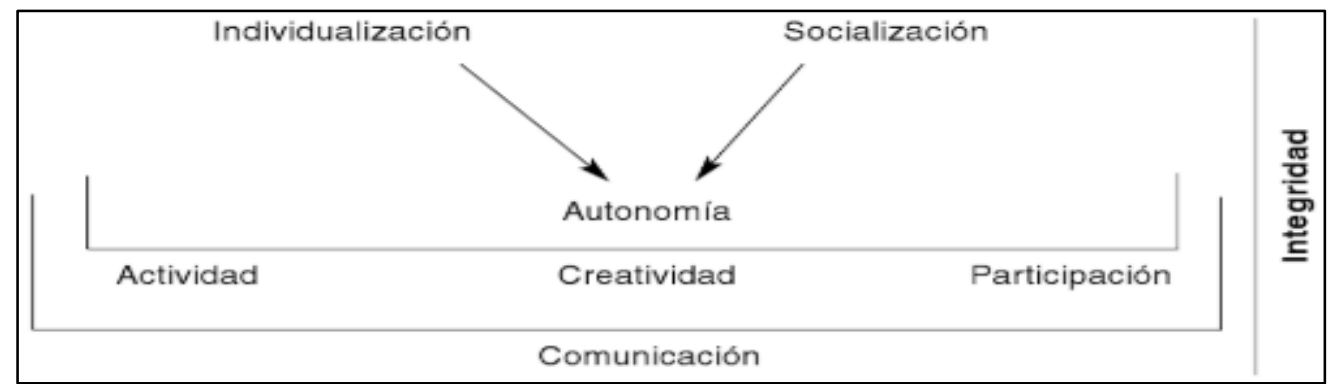

Tabla 38: Autonomía por (García, Ruiz \& García, 2009).

Fuente: Tomado de (García, Ruiz \& García, 2009).

A partir de ello, los actores en el proceso de enseñanza y aprendizaje cobran un papel fundamental siendo estudiantes, profesores, acudientes, especialistas y Sociedad en general los protagonistas.

Estudiante. Es el actor principal del propio aprendizaje, para ello en necesario que posea dedicación y compromiso, además de dedicarse a actividades tales como:

- Analizar situaciones reales que le generen retos.

- Aplicar la información de diferentes fuentes para encontrar la solución

- Compartir la información para encontrar la solución compartida

- Utilizar las TIC para hacer más eficiente el proceso.

- Asumir y delegar responsabilidades

- Participar del consenso de las soluciones

Profesor. El rol del profesor no es solo proporcionar información y controlar la disciplina, es un mediador entre el estudiante y el ambiente, sirviendo de guía o acompañante en la apropiación de los conocimientos.

De acuerdo con Brooks y Brooks (1999) el maestro como sinónimo de profesor debe:

- Estimular la iniciativa de los estudiantes.

- Utilizar las fuentes de información y materiales para facilitar el aprendizaje significativo.

- Flexibilizar los contenidos educativos en términos de orientar las clases con base en los intereses y respuestas de los estudiantes.

- Indagar sobre los conocimientos previos para fortalecer el autoconcepto.

- Orientar hacia el uso de un vocabulario que estimule el pensamiento cognitivo.

- Estimular el trabajo colaborativo

- Promover el aprendizaje en los estudiantes mediante sus propios cuestionamientos.

- Promover el pensamiento científico.

- Alimentar la curiosidad mediante el ciclo de aprendizaje 
Acudiente o Familia. Los acudientes conforman un papel fundamental puesto que estos ayudan a configurar la identidad y personalidad, además de establecer prioridades, normas de convivencia, valores, bridar afecto y autoestima, entre otros.

La familia asume dos funciones fundamentales: Garantizar la supervivencia de sus miembros y labrar las cualidades humanas. Del mismo modo la familia asume los siguientes deberes sociales de acuerdo con los estudios de (Hoover, Dempsey y Sandler, 1995)

- Cubrir las necesidades materiales básicas.

- Permitir la solidaridad social

- Desarrollar la identidad personal

- Preparar para las funciones sexuales.

- Estimular la creatividad

- Fortalecer la unidad familiar

Adicional, el involucramiento parental en los procesos cognitivos ha demostrado relación de importante influencia en el logro de los estudiantes, al igual que la formulación de expectativas y aspiraciones sobre el aprendizaje por parte de los padres y la supervisión de los deberes escolares (Deslandes, 2009).

Especialistas. Los especialistas o expertos poseen una capacidad superior para codificar, elaborar y analizar información, además de ponderar la importancia de esta por su gran capacidad de inferencia y de abstracción eficiente (Tachon, 1991).

(Smith, 1988; Carter \& Doyle, 1990) Destacan dos generalidades claves (i) la pericia es materia de especialización y de conocimiento específico y (ii) El conocimiento del experto se deriva de su capacidad de interpretar hechos y ser eficiente. Bajo este análisis los autores indican que la actividad del experto es metacognitiva debido a que procede del estudio del conocimiento por el conocimiento.

Los aportes reflexivos por parte de los especialistas implican un acercamiento a las ciencias aplicadas como lo indica Dewey y la escuela de investigación social de Frankfurt, en el sentido de que la experiencia es la fuente de la selección y del tratamiento de la información (Russell, 1987).

Desde la perspectiva sociocultural vygotskiana el aprendizaje es un proceso constructivo de carácter social, interpersonal y comunicativo (Coll \& Onrubia, 2001) que depende de los actos comunicativos de personas expertas y aprendices que se someten a experimentación, por tanto, el aprendizaje es una actividad situada (Lave y Wegner, 2002), las situaciones reales de modelado acompañada de profesores y expertos aportan grandes beneficios para el aprendizaje al ser una actividad autentica.

Sociedad. Los actuales discursos de la sociedad, interculturalidad por multiculturalidad, integración por segregación y seguridad por convivencia (Marcelo, 2001) llevan a la escuela a repensar su quehacer debido a los fenómenos migratorios. Igual sucede con la economía, según (Castel, 1997) las características de la nueva economía están más asociadas a la 
generación, procesamiento y transmisión de la información que a la transformación de las materias primas.

La función educativa se ha dispersado por la gran cantidad de información y los nuevos códigos y símbolos, las ciudades son un espacio más para la socialización y formación (Noguera, Álvarez y Castro, 2000). Los nuevos paradigmas indican que la escuela no es la única y principal responsable de la educación de un país; así como la valoración de lo que es importante saber para poder vivir en sociedad.

La cultura juvenil esta permeada por la libertad para la movilidad, generando nuevas formas de relacionamiento, moda, autoridad, poder y sexualidad (Luengo, 2006), además del papel del sector productivo. En este sentido, la responsabilidad de la educación cobra vigencia al definir la influencia de los diferentes actores sociales, así como los núcleos del fenómeno educativo como responsabilidad social que para (Cajiao, 2001) corresponde a:

- La responsabilidad social colectiva y el sentido de lo público en la educación.

- El papel del Estado en el desarrollo del horizonte educativo.

- La labor de los educadores y la diferencia entre la acción sindical y la acción gremial. El papel del maestro como intelectual.

- La función de la sociedad civil organizada en el desarrollo educativo.

- El influjo de los medios de comunicación e información.

- Los niños y las niñas como protagonistas de los procesos educativos y sociales.

Del mismo modo señala al autor, el papel de los centros educativos ha pasado de ser el centro por excelencia donde se encuentra la información a ser el centro por excelencia donde se procesa la información adquirida de fuentes sociales diversas y extensas.

\subsubsection{Procesos de Innovación.}

Como se mencionó en el capítulo dos, la comisión Europea de la Innovación (Comisión europea, 1995) define la innovación como la transformación de una idea en un producto o en un servicio comerciable nuevo o mejorado, un procedimiento de fabricación o distribución operativo nuevo o mejorado, o un método para proporcionar un servicio social, es decir, el termino innovación implica procesos y resultados.

La cultura de la innovación al interior de las organizaciones se ha valido de diferentes técnicas, métodos, metodologías, (ver capítulo 3) para potenciar la inspiración.

A continuación, se describe las diferencias de cada concepto.

Técnicas. Corresponde al conjunto de operaciones o normas creados por el hombre para realizar una actividad. Para (Gallino, 1978) “complejo más o menos codificado de normas y formas de proceder reconocido por una colectividad, transmitido o transmisible por aprendizaje, elaborado con el fin de desarrollar una actividad manual e intelectual de carácter recurrente" 
Método. Proviene del prefijo griego "met" que significa "más allá" o "en lugar de”, y "odo" "con" o "camino por el cual", es decir, su definición de acuerdo con el origen griego es el camino para conseguir un fin o la sucesión de pasos, de acuerdo con las reglas establecidas. El concepto de método es aplicable para cualquier campo del conocimiento científico, en el sentido de la elaboración de procedimientos prácticos y teóricos del hombre para asimilar un objeto.

Metodología. La metodología es la esfera de la ciencia que estudia los métodos generales y particulares de la investigación científica. Para (Alcaide, 2004) la metodología explica los procedimientos que fueron utilizados para explicar un fenómeno de forma descriptiva o prescriptiva.

Cada uno de estos conceptos fueron teorizados en el capítulo 3 para identificar técnicas, métodos y metodologías aplicables a la innovación.

\section{Matriz de Seguimiento.}

La matriz de seguimiento se estructura de tres componentes: Identificación del plan de área, Planificación de acciones pedagógicas y Planeador de clase.

La Identificación del plan de área relaciona las coordenadas de las áreas de conocimiento que determinan las secuencias didácticas asociados a los ODS con las respectivas metas como lo muestra la tabla 32.

La Planificación de acciones pedagógicas está basada en el modelo $5 \mathrm{~W} 2 \mathrm{H}$, herramienta administrativa utilizada en las organizaciones para la ejecución de la planificación y solución de problemas permitiendo la focalización sobre las causas generadoras de las situaciones objeto de mejora.

Las coordenadas identificadas en el Pareto serán objeto de análisis a partir del modelo 5W2H, en ella se define el plan de acción para cada coordenada identificada en el diagnóstico y se hace operativa mediante la resolución de la matriz. (Ver tabla 33).

La ejecución del modelo busca dar respuesta a las 7 preguntas que inician con las letras $\mathrm{W}$ y H de las palabras en inglés: What? (¿Qué?), Why? (¿Por qué?), When? (¿Cuándo?), Where? (¿Dónde?), Who? ¿Quién?, (How) ¿Cómo? y (How much) ¿Cuánto? (Koa, 2013).

Las respuestas a cada una de las preguntas se enfocan en:

- ¿Qué? ¿Qué se hará? Acción, etapas, descripción.

- ¿Por qué? ¿Por qué se hará? Justificación, motivo.

- ¿Dónde? ¿Dónde se hará? Lugar.

- ¿Cuándo? ¿Cuándo se hará? Tiempo, fechas, plazos.

- ¿Quién? ¿Quién lo hará? Responsabilidad de la acción.

- ¿Cómo? ¿Cómo se hará? Método, proceso. 
- ¿Cuánto? ¿Cuánto costará hacerlo? Costo o gasto que supone.

El Planeador de clase es una guía que orienta a los docentes en la ejecución de las actividades para el desarrollo de las competencias que se desean abordar en los tiempos definidos para las secciones de clase. La guía se compone de Etapas/tiempo, actividades, evidencia de aprendizaje y materiales (ver tabla 34). El diligenciamiento de la guía corresponde al producto de las secciones de innovación para la construcción del diseño curricular.

Luego de definido el plan de acción para cada coordenada se procede a definir el seguimiento mediante la dimensión evaluativa que a continuación se detalla.

\subsection{Dimensión Evaluativa.}

La dimensión evaluativa tiene como propósito determinar el impacto de los procesos educativos con relación a las acciones propuestas por parte de los estudiantes para contribuir con el desarrollo humano sostenible.

La Dimensión Evaluativa está compuesta por los ejes de coordenadas Indicadores de Innovación (eje X), Productos/Servicios (eje Y) e Impacto (eje Z) como se muestra a continuación.

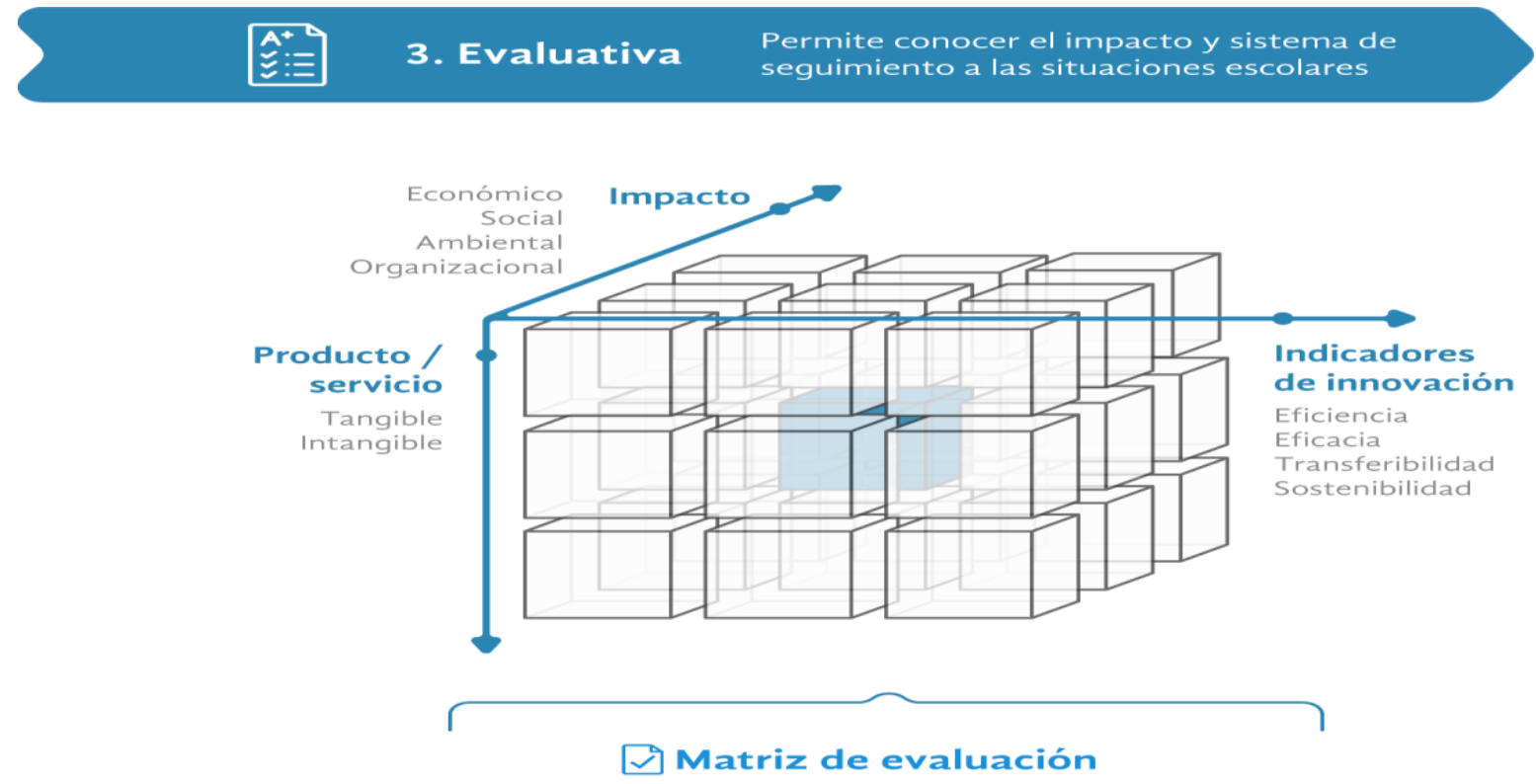

Ilustración 20: Ejes Dimensión Evaluativa

Fuente: Autor 
Las combinaciones que surgen de la relación de los ejes del plano cartesiano: Indicadores de Innovación, Producto/Servicio e Impacto, define el resultado esperado de las acciones desarrolladas para cada coordenada operativa con su respectivo sistema de medición. La fase evaluativa se itera bajo el siguiente sistema de coordenadas como lo muestra la tabla 39.

Tabla 39. Coordenadas Dimensión Evaluativa

\begin{tabular}{|c|c|c|}
\hline \multicolumn{3}{|c|}{ Coordenadas Dimensión Evaluativa } \\
\hline Producto & Impacto & $\begin{array}{l}\text { Indicadores de } \\
\text { Innovación }\end{array}$ \\
\hline $\begin{array}{ll}\text { 1. } & \text { Tangible } \\
\text { 2. } & \text { Intangible }\end{array}$ & $\begin{array}{ll}\text { 1. } & \text { Económico } \\
\text { 2. } & \text { Social } \\
\text { 3. } & \text { Ambiental } \\
\text { 4. } & \text { Organizacional }\end{array}$ & $\begin{array}{ll}\text { 1. Eficiencia } \\
\text { 2. Eficacia } \\
\text { 3. Transferibilidad } \\
\text { 4. } & \text { Sostenibilidad }\end{array}$ \\
\hline
\end{tabular}

Fuente: Autor.

El proceso de modelado de cada eje del plano cartesiano se efectúa mediante la Matriz de Evaluación, así:

Tabla 40: Matriz de Evaluación.

\begin{tabular}{|l|l|l|l|l|l|l|l|l|}
\hline \multicolumn{9}{|c|}{ Matriz de Evaluación } \\
\hline \multirow{2}{*}{ Productos } & \multicolumn{3}{|c|}{ Impacto } & \multicolumn{4}{c|}{ Indicadores } \\
\cline { 2 - 9 } & Económico & Social & Ambiental & Institucional & Eficacia & Eficiencia & Transferibilidad & Sostenibilidad \\
\hline Tangible & & & & & & & & \\
\hline Intangible & & & & & & & & \\
\hline
\end{tabular}

Fuente: Autor.

A continuación, se detallan los componentes de los ejes de coordenadas de la dimensión evaluativa.

La matriz de evaluación es una herramienta que permite a las instituciones educativas identificar la integración de los procesos de innovación asociado al Bienestar mediante las metas planeadas para su cumplimiento desde los objetivos de desarrollo sostenible 20152030 incluyendo la planeación, desarrollo y validación de los contenidos curriculares.

\subsubsection{Indicadores de Innovación.}

El instrumento permite identificar el impacto generado por la planificación de las situaciones escolares mediante los criterios de sostenibilidad, transferibilidad, eficacia del aprendizaje y eficiencia de la eficacia como características propias de la innovación en educación de acuerdo con Fidalgo (2007). Principios con grandes similitudes a las propuestas por la UNESCO (2003) en el marco del programa "Gestión de las Transformaciones Sociales" sobre las "buenas prácticas" en el ámbito social en función de la Innovación, eficacia, sostenibilidad y replicabilidad de las iniciativas. 
Un estudio de (Gradaille \& Caballo, 2015) identificó las siguientes características de "buenas prácticas de la acción comunitaria" a través de diferentes organizamos de influencia internacional. Ver tabla (41)

Tabla 41. Criterios de identificación de buenas prácticas.

\begin{tabular}{|c|c|c|c|c|}
\hline Unesco (2003) & OIT (2003) & $\begin{array}{l}\text { Agencia Andaluza de } \\
\text { Innovación Educativa } \\
(2012)\end{array}$ & CEPAIM (2014) & $\begin{array}{l}\text { Observatorio } \\
\text { Internacional de } \\
\text { Democracia } \\
\text { Participativa (2015) }\end{array}$ \\
\hline $\begin{array}{ll}\text { - } & \text { Innovación } \\
\text { - } & \text { Efectividad } \\
\text { - } & \text { Sostenibilid } \\
& \text { ad } \\
\text { - } & \text { Replicabilid } \\
& \text { ad }\end{array}$ & $\begin{array}{ll}\text { - } & \text { Innovación- } \\
& \text { Creatividad } \\
\text { - } & \text { Eficacia- } \\
& \text { Impacto } \\
\text { - } & \text { Replicabilidad } \\
\text { - } & \text { Sostenibilidad } \\
\text { - } & \text { Pertinencia } \\
\text { - } & \text { Ética y } \\
& \text { responsable } \\
\text { - } & \text { Trabajo en red } \\
\text { - } & \text { Eficiencia }\end{array}$ & $\begin{array}{ll}\text { - } & \text { Hechos contables } \\
& \text { Responde a las } \\
\text { necesidades } \\
\text { - } & \text { Innovación } \\
\text { - } & \text { Secuenciada y } \\
\text { - } & \text { Deflexiva } \\
\text { - } & \text { Documentada } \\
& \text { Efectiva y } \\
\text { - eficiente } \\
\text { - } \\
\text { Participación } \\
\text { ciudadana } \\
\text { Recursos } \\
\text { suficientes y } \\
\text { definidos } \\
\text { Seguimiento } \\
\text { riguroso; } \\
\text { retroalimentación } \\
\text { Código ético }\end{array}$ & $\begin{array}{ll}\text { - } & \text { Sostenible } \\
\text { - } & \text { Efectiva } \\
\text { - Innovadora } & \text { Transferible } \\
\text { - } & \text { Genera } \\
\text { cohesión } \\
\text { - Potencia el } \\
\text { empoderami } \\
\text { ento } \\
\text { - Redes } \\
\text { - } \text { sociales } \\
\text { Perspectiva } \\
\text { de género }\end{array}$ & $\begin{array}{ll}\text { - } & \text { Objetivos } \\
& \text { relacionados con la } \\
& \text { participación } \\
\text { - } & \text { Innovación } \\
\text { - } & \text { Transferibilidad } \\
\text { - } & \text { Factibilidad } \\
\text { - } & \text { Planificación de las } \\
\text { prácticas en el } \\
\text { gobierno local } \\
\text { - } \text { Corresponsabilidad } \\
\text { - Liderazgo político } \\
\text { - Responsabilidades } \\
\text { - definidas } \\
\text { - Proceso educativo } \\
\text { Impacto y } \\
\text { transformación } \\
\text { - evolución } \\
\text { - Devolución de la } \\
\text { información }\end{array}$ \\
\hline
\end{tabular}

Fuente: Autor tomado de (Gradaille \& Caballo, 2015)

La eficacia, eficiencia, equidad y sostenibilidad son los criterios claves para el análisis de iniciativas apoyadas con recursos públicos (BID,2001).

Eficacia. Según Fidalgo (2007) la eficacia del aprendizaje corresponde al mejoramiento en los resultados académicos. Es decir, la apropiación de las competencias. Eficacia proviene del Latín efficacia cuyo significado es "hacer o lograr". Para la RAE significa "capacidad de logar el efecto que se desea o se espera" ${ }^{25 "}$.

Para (Gradaille \& Caballo, 2015) una iniciativa es eficaz cuando brinda resultados positivos y tangibles en el territorio, la comunidad observa y valora los resultados de las acciones emprendidas, esta se obtiene del comparativo cualitativo o cuantitativo entre lo anterior y posterior.

El BID (2001) resalta el "objetivo" como un elemento clave en la eficacia indicando que "una iniciativa es eficaz, cuando se cumplen los objetivos esperados en el tiempo previsto y con la calidad esperada" esta definición no incluye costos ni uso de recursos.

${ }^{25}$ Definición en http://dle.rae.es/?id=EPQzi07 
Desde la perspectiva de Cohen y Franco (1993) la eficacia y la efectividad no son sinónimos. Señalan a la eficacia como elemento que "mide el grado en el que se alcanzan los objetivos y metas de una población en un periodo determinado" mientras que la efectividad es la relación entre resultados (previstos y no previstos) y los objetivos. Por tanto, para los autores la efectividad reconoce resultados diferentes a los planeados desde los objetivos.

Igual situación surgen con el concepto eficiencia, término de gran relación con eficacia, cuya distinción obedece a:

Eficiencia. Proceso de planeación y ejecución para el diseño curricular con menor esfuerzo en la consecución de los resultados (Fidalgo, 2007). La eficiencia proviene del latín efficientia. Para la RAE significa "Capacidad de disponer de alguien o algo para conseguir un efecto determinado ${ }^{26}$ ".

El diccionario Larousse plantea dos definiciones (i) "capacidad para lograr un efecto determinado" y (ii) "competencia que se demuestra en el trabajo desempeñado 27 ".

Para (Gradaille \& Caballo, 2015) la eficiencia es la relación de los recursos utilizados y los logros obtenidos. Es decir, se es eficaz cuando se satisfacen los objetivos planteados y se es eficiente cuando se consiguen utilizando mejor los recursos.

Así mismo, (Cohen \& Franco, 1993) definen la eficiencia como la "relación entre costos y productos obtenidos" y (Lockheed \& Hanuskeck, 1998) destacan como un sistema eficiente aquel que obtiene más productos con un determinado uso de recursos o logra con menos insumos iguales resultados.

Los términos antes mencionados permiten considerar el incumplimiento de los objetivos y la perdida de recursos como una iniciativa ineficiente y los costos no necesariamente obedece a una unidad económica. Los costos pueden ser tangibles e intangibles en términos de tiempo, recursos ambientales, capital social, solidaridad, confianza, entre otros, que adelante se detallarán.

Transferibilidad. Para Fidalgo (2007) corresponde a los resultados de apropiación del conocimiento que son aplicables en otros contextos. La definición de la RAE indica "cualidad de transferible 28 " y por "Transferible" define "que puede ser transferido o pasado" 29 ",

Para (Gradaille \& Caballo, 2015) es la capacidad de una experiencia repetirla en un contexto distinto al de su origen, con elevadas probabilidades de éxito. Ello implica, viabilidad y factibilidad, conforme a mayor compatibilidad de las características del entorno, mayor viabilidad en la ejecución.

\footnotetext{
${ }^{26}$ Definición en http://dle.rae.es/?id=EPVwpUD

${ }^{27}$ Definición en https://www.larousse.mx/resultados/?diccionario=esp\&palabra=eficiencia

${ }^{28}$ Tomado de http://dle.rae.es/?id=aJBuz8V

${ }^{29}$ Tomado de http://dle.rae.es/?id=aJFZQyl
} 
Para la UNESCO (2003) la factibilidad evalúa la adaptación de la iniciativa en términos de necesidades y recursos para el contexto, mientras que la viabilidad en términos de "buenas prácticas" pude ser:

- Viabilidad económica: Eficacia y economía de los recursos con que se cuenta

- Viabilidad interna: Distribución de las actividades y tareas.

- Viabilidad técnica: Propuestas ajustadas a la disponibilidad de los recursos.

- Viabilidad medio Ambiental: Preservación de los recursos ambientales. Sostenibilidad.

- Viabilidad social: Conciliación entre las necesidades de la ciudadanía y las propias.

La transferibilidad debe concebirse bajo un marco de simplicidad y universalidad para que pueda ser replicable con éxito.

Sostenibilidad. Para la OIT (2003) la sostenibilidad corresponde al potencial de continuidad de la experiencia después de finalizada su implementación o el potencial de creación de nuevas acciones a partir de la inicial. En coincidencia con Fidalgo (2007) la sostenibilidad garantiza durabilidad en el tiempo.

Así mismo (Gradaille \& Caballo, 2015) indican que una iniciativa es sostenible cuando cuenta con una organización técnica, económica y social para que funcione armónicamente a lo largo del tiempo.

Desde la RAE existen dos definiciones, (i) "que se puede sostener" y (ii) "especialmente en ecología y economía, que se puede mantener durante largo tiempo sin agotar los recursos o causar grave daño al medio ambiente ${ }^{30,}$

El enfoque ambientalista publicado por la RAE coincide con el BID (2001) en señalar el termino sostenibilidad con un pensamiento ambientalista propio del discurso de los años sesenta. Mientras que la dimensión económica es ocasionada por la deuda externa y crisis fiscal de los años ochenta, al traer preocupaciones de duración en el tiempo de las iniciativas al no contar con recursos económicos de financiamiento internacional.

Del mismo modo el BID (2001) indica que el termino sostenibilidad ha sido definido de forma tan ambigua en las aplicaciones de la política pública, al punto que cualquier persona puede sentirse identificada con el término al existir unidades de análisis de modelo macro ${ }^{31}$ y micro $^{32}$.

El Banco Mundial (1996) califica la sostenibilidad de sus programas mediante un conjunto de ocho categorías calificadas como "probable, incierta o improbable" a:

\footnotetext{
${ }^{30}$ Tomado de http://dle.rae.es/?id=YSE9w6H

${ }^{31}$ Análisis de consumo, crecimiento y desarrollo social, desde estrategias globales y nacionales.

${ }^{32}$ Análisis de un determinado proceso, programa o proyecto financiados con periodos delimitados.
} 
Tabla 42: categorías de Sostenibilidad según Banco Mundial

\begin{tabular}{|l|l|}
\hline \multicolumn{1}{|c|}{ Factor } & \multicolumn{1}{c|}{ Característica } \\
\hline Económico & Dependencia de políticas macroeconómicas \\
\hline $\begin{array}{l}\text { Elementos } \\
\text { externos }\end{array}$ & $\begin{array}{l}\text { Factores exógenos de volatilidad política y económica que afecten los } \\
\text { precios. }\end{array}$ \\
\hline Financiero & Generación de recursos propios o externos. \\
\hline Técnico & Uso de recursos tecnológicos para aumentar la productividad \\
\hline Sociales & Participación social para la apropiación de las iniciativas. \\
\hline Ambiental & Afectación a los recursos renovables y no renovables. \\
\hline Institucional & Consolidación de las instituciones. \\
\hline Gobernabilidad & Políticas para la apropiación y duración en el tiempo \\
\hline
\end{tabular}

Fuente: Autor a partir de BID (2001)

Las anteriores coordenadas, permiten identificar el enfoque de las iniciativas sociales. A continuación, se relacionan las definiciones para las coordenadas a nivel de "Productos o Servicios" que hacen cuantificable las propuestas.

\subsubsection{Productos}

Desde el derecho romano se ha visto la necesidad de diferenciar lo material de lo inmaterial, lo corpóreo de lo incorpóreo, lo tangible de lo intangible, distinción plasmada por Biondi (2003) en el Corpus Iuris "son corporales aquellas cosas quae tangi non possunt, ejemplo de ello, plata y oro. Las inmateriales por el contrario quae in iure consistunt, como la herencia y el usufructo" es decir, las cosas corporales poseen entidad material, son perceptibles y ocupan un lugar en el espacio.

El producto del latín produtus, se define como aquello que ha sido fabricado. El producto material (tangible) es un término genérico que aplica desde una silla a una computadora. Desde el marketing el producto es un objeto ofrecido en el mercado para satisfacer al consumidor y en las matemáticas un producto es el resultado de una operación aritmética resultante de una multiplicación.

De acuerdo con (Grundy, 1987) el producto es el resultado de la acción, disposición y orientación. Es decir, la acción procede del interés técnico (disposición de la tekné), luego la idea orientadora (eidos) y la disposición orientadora (tekné) consolidan la base de la acción "el hacer" (poitiké), como lo muestra la siguiente ilustración: 


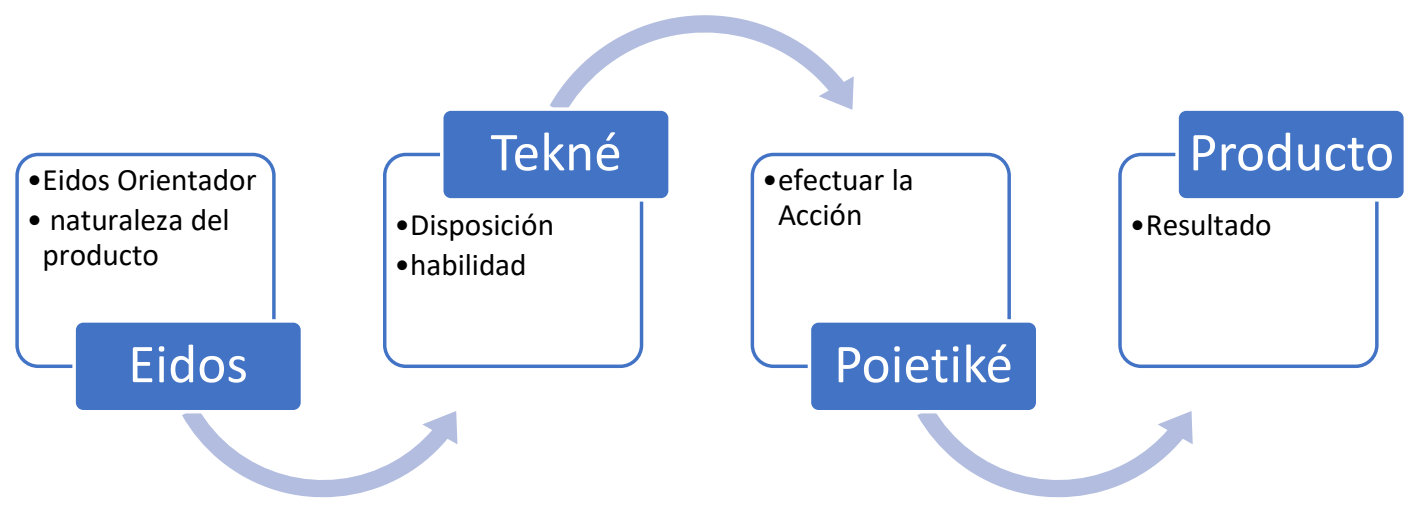

Ilustración 21: Relación entre ideas y acciones

Fuente: Elaboración propia a partir de (Grundy, 1987)

Un factor clave a destacar, corresponde a que no siempre el producto es el resultado de la idea inicial, porque depende de cada resultado del proceso. El producto será juzgado en la medida de la semejanza del Eidos orientador.

Desde el enfoque de Tyler (1973) fundador del moderno movimiento del currículo, se identifican las posiciones y prácticas lineales orientadas al producto desde el interés técnico, denominado por el autor “diseño curricular” (Grundy, 1987).

Desde el plano académico aplicable para Colombia, en términos de "productos" el Departamento Administrativo de Ciencia, Tecnología e Innovación (Colciencias) es la entidad encargada de direccionar la política pública en esta materia. Bajo este alcance la ciencia, tecnología e innovación en el país en la última versión (Colciencias,2017) estipuló las directrices para estimular a partir del conocimiento e innovación dar respuesta a los problemas sociales y económicos.

Desde el enfoque teórico del modelo de medición de (Colciencias,2017) se citan los principios del "Nuevo Crecimiento" de (Rommer, 1990) destacando de la tesis, el principio por el cual las ideas se convierten en la raíz de la transformación social y motor del crecimiento económico, al interactuar la investigación aplicada y básica para el desarrollo desde los diferentes sectores, partiendo de las necesidades sociales.

Bajo el modelo de medición de (Colciencias,2017) se consideran productos aquellos resultados de las siguientes actividades, como se muestra en la tabla (43):

Tabla 43: Productos según modelo de medición Colciencias para 2017

\begin{tabular}{|l|l|}
\hline \multicolumn{1}{|c|}{ Productos } & \multicolumn{1}{c|}{ Características } \\
\hline $\begin{array}{l}\text { Generación de nuevo } \\
\text { conocimiento }\end{array}$ & $\begin{array}{l}\text { Aportes significativos al estado del arte discutidos por la comunidad } \\
\text { científica para que puedan ser incorporados en (i) discusión científica, (ii) } \\
\text { desarrollo de actividades de investigación, (iii) desarrollo tecnológico y (iv) } \\
\text { ser fuente de innovaciones. Adicional a ello, aportes nuevos, originales e } \\
\text { inéditos en materia de creación de artes, arquitectura y diseño. }\end{array}$ \\
\hline $\begin{array}{l}\text { Desarrollo tecnológico e } \\
\text { innovación }\end{array}$ & $\begin{array}{l}\text { Generación de ideas, métodos y herramientas desde la solución de } \\
\text { problemas sociales, técnicos y económicos. }\end{array}$ \\
\hline
\end{tabular}




\begin{tabular}{|l|l|}
\hline $\begin{array}{l}\text { Apropiación social del } \\
\text { conocimiento }\end{array}$ & $\begin{array}{l}\text { Proceso y práctica social de construcción colectiva para intercambiar } \\
\text { saberes y experiencias de conocimientos para ser llevado a la realidad. }\end{array}$ \\
\hline $\begin{array}{l}\text { Formación de recurso } \\
\text { humano CTel }\end{array}$ & $\begin{array}{l}\text { Formación de nuevos investigadores para el servicio de los grupos de } \\
\text { investigación. }\end{array}$ \\
\hline
\end{tabular}

Fuente: Autor a partir de (Colciencias,2017)

Bajo el modelo anterior, se identifican productos, procesos, personas, relacionamiento y dinámicas para la generación de conocimiento. En este sentido, se definen dos categorías como componentes de la coordenada "producto" de acuerdo con los intereses de la investigación.

Tangible. Palabra cuyo origen proviene del término latino tangibilis utilizado para aquello "que puede ser tocado o que se puede percibir de manera precisa" ${ }^{33}$.

Se puede indicar que todas las cosas físicas son tangibles: un ensayo, prototipo, maqueta o artículo de investigación entre otros, para las coordenadas curriculares lo tangibles hace relación a los elementos producto de procesos académicos que brinden como resultado un elemento que se pueda percibir con el tacto.

Intangible. La definición de la RAE indica "que no debe o puede tocarse" ${ }^{34}$, desde esta óptica y como resultado de los procesos académicos corresponde a aquello que no puede percibirse físicamente. Una canción, poesía, marca e ideas son elementos intangibles que no se pueden medir físicamente. Desde el plano económico tiene un tratamiento distinto, análisis que no es objeto de la actual propuesta.

Identificado los productos para cada coordenada, se procede a analizar qué tipo de impacto se espera para cada propuesta, a continuación, la definición para cada componente.

\subsubsection{Impacto.}

La agenda global de los Objetivos de Desarrollo Sostenible busca un equilibrio entre las dimensiones económicas, social, ambiental e institucional con el propósito de mejorar los niveles de bienestar en el mundo (DNP, 2017).

Desde los ODS la dimensión social explora todos aquellos aspectos que garanticen igualdad de oportunidades y centra su enfoque en los derechos humanos. Las necesidades básicas como educación, salud, trabajo, pobreza, saneamiento, agua potable y vivienda corresponden a las prioridades en esta materia.

La dimensión económica impulsa el crecimiento del país en materia de productividad y competitividad. Además de ello, la dignificación laboral y el fomento a la eficiencia e innovación en armonía con el medio ambiente como pilares del crecimiento económico.

\footnotetext{
${ }^{33}$ Tomado de http://dle.rae.es/?id=Z59rFHV

${ }^{34}$ Tomado de http://dle.rae.es/?id=LptFOaT
} 
La dimensión ambiental promueve la protección sobre los recursos naturales en materia de seguridad alimentaria, energética y producción sostenible.

Los principios rectores del (World Commision on Environment and Development, 1987) sobre sostenibilidad es compartido en el modelo de Marck Moore y John Benington (2011) cuyo soporte teórico es adoptado en las "buenas prácticas de sostenibilidad en los centros de ciencia en Colombia" (ver ilustración 22). Principios promulgados por Naciones Unidas en materia económica, social, ambiental y organizacional.

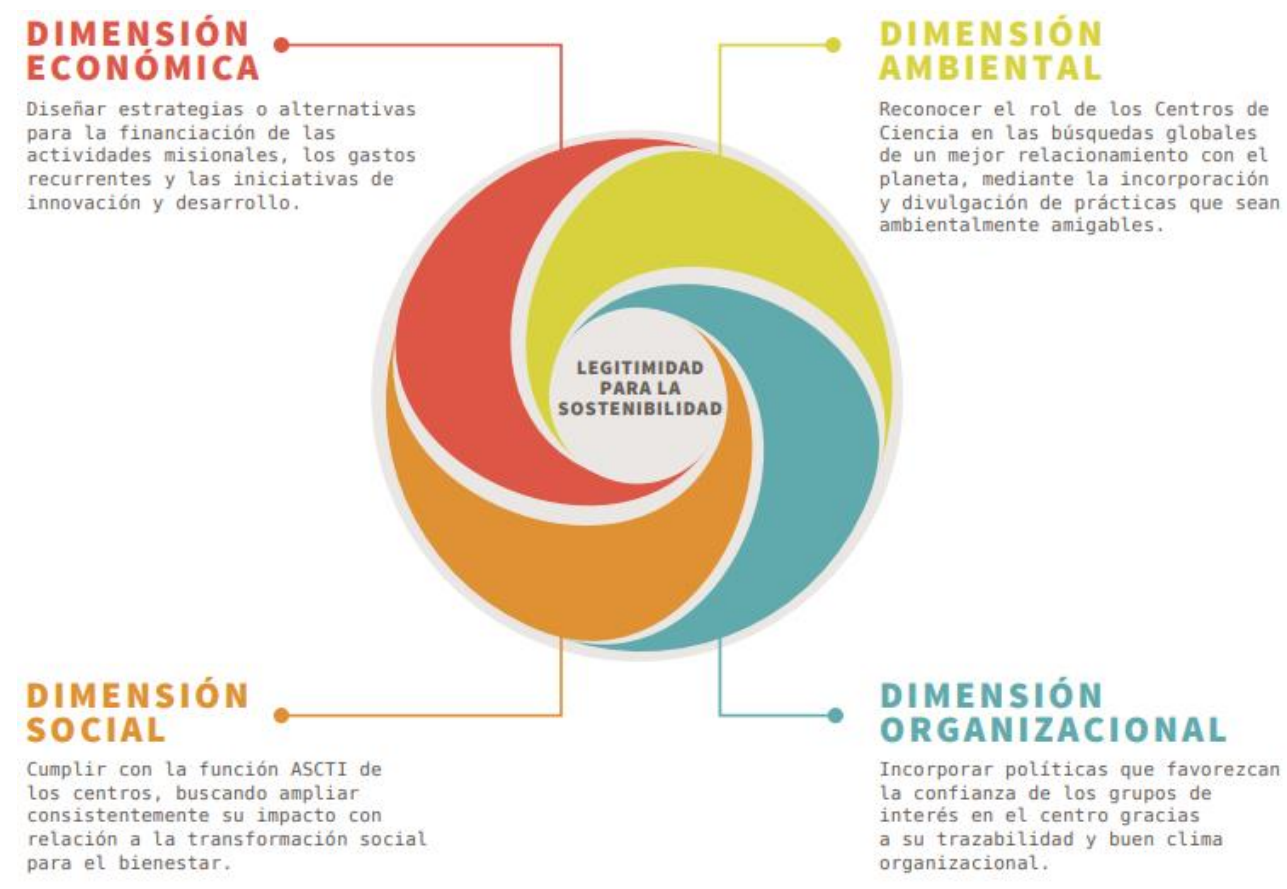

Ilustración 22:Esquema de sostenibilidad de los centros de ciencia en Colombia Fuente: Tomado de (Colciencias, 2018)

A continuación, se detalla cada componente con base en las buenas prácticas de Moore y Benington (2011).

Dimensión Económica. Corresponde a la gestión de recursos necesarios para el desarrollo de la propuesta. además de ello, al uso de los recursos y adopción de cultura de ahorro para la sostenibilidad económica.

Las buenas prácticas en los centros de ciencia recomiendan para gestionar los recursos.

- Realizar lectura constante del entorno de tendencias, oportunidades y retos económicos a nivel local, nacional e internacional.

- Diseñar e implementar un esquema de ingresos que permita la diversificación de fuentes de financiación. 
- Diseñar e implementar un esquema de búsqueda y gestión de recursos que permita contar con fuentes de financiación de largo plazo.

- Definir un esquema de gestión de relaciones con aliados estratégicos.

Dimensión Social. Corresponde al ejercicio participativo mediante acciones que motiven y generen confianza para la apropiación de las iniciativas.

En este sentido, las buenas prácticas recomiendan.

- Descentralización de las actividades de los centros de ciencia.

- Diseño y ejecución de proyectos enfocados en ciencia, tecnología e innovación.

- Involucrar a los visitantes en la conservación y cuidado del centro de ciencia.

- Implementar planes y protocolos de riesgos de los trabajadores.

- Incorporar procesos de diseño, medición, evaluación y aprendizaje de los proyectos.

- Incorporar procesos de comunicación.

- Participar activamente de metodologías, prácticas y modelos para la innovación en la educación.

- Adecuar de espacios para la accesibilidad.

- Diseñar e implementar planes para la rendición de cuentas.

- Incorporar cultura digital para el dialogo.

- Pertenecer y liderar comunidades de pensamiento.

Dimensión Ambiental. Su enfoque corresponde a la conservación de la naturaleza para la sostenibilidad en términos de (i) divulgación de contenidos y (ii) apropiación de prácticas sostenibles.

Para ello, las buenas prácticas recomiendan.

- Identificar la matriz de normatividad ambiental y sus niveles de cumplimiento

- Diseñar e implementar un sistema de gestión ambiental

- Implementar estrategias de conexión ciudadana con el territorio, biodiversidad, servicios ecosistémicos.

- Calcular la huella de carbono (HC) y huella hídrica (HH) para la mitigación y compensación.

- Adecuar espacios y diseñar estrategias para el transporte intermodal.

- Construir y adaptar nuevos centros de ciencia con principios de arquitectura sostenible.

Dimensión Organizacional: Corresponde a aquellas prácticas organizadas de gobierno, para mejorar la precepción de confiabilidad en los grupos de interés. En este sentido el objetivo central de gobernanza institucional es incrementar la confianza de los interesados y eliminar las prácticas fraudulentas (Castro \& Cano, 2004), ello se logra realizando seguimiento y control al desempeño de las organizaciones (Acero \& Alcalde; 2012) citado por (Colciencias, 2018).

Las buenas prácticas recomiendan: 
- Establecer esquemas de gobierno que permitan decisiones autónomas e independientes.

- Diseñar y adaptar modelos estatutarios que favorezcan la innovación, diversificación de recursos e incorporación de prácticas de sostenibilidad.

- Establecer políticas para fortalecer las capacidades del talento humano.

- Definir políticas con proveedores que incorporen prácticas sociales y ambientales.

- Definir estrategias de relacionamiento.

- Considerar esquemas de asociatividad público-privada.

- Medir la percepción de los grupos de interés.

- Incorporar políticas de buen gobierno.

- Incluir procesos de lectura analítica del entorno que faciliten tendencias, retos y oportunidades.

- Contar con un centro de curaduría para asegurar la información.

- Gestionar el conocimiento.

- Diseñar y adoptar arquitectura organizacional estratégica.

- Generar cohesión de los trabajadores con base en la planeación estratégica de la organizacionales

- Gestionar clima organizacional.

- Adoptar estándares de sostenibilidad y calidad

- Crear procesos de comunicación interna que promuevan el trabajo colaborativo y la comunicación

De acuerdo con lo anterior, la evaluación del impacto en términos de indicadores de innovación se valora bajo la siguiente representación:

Tabla 44: Evaluación del Impacto

\begin{tabular}{|c|c|c|c|c|}
\hline Impacto & Eficacia & Eficiencia & Transferibilidad & Sostenibilidad \\
\hline $\begin{array}{l}\text { Económico } \\
\text { (Gestión de } \\
\text { Recursos) }\end{array}$ & \multirow{4}{*}{$\begin{array}{l}\text { La propuesta } \\
\text { brinda } \\
\text { respuesta a la } \\
\text { gestión de los } \\
\text { recursos. }\end{array}$} & \multirow{4}{*}{$\begin{array}{l}\text { La propuesta cumple } \\
\text { los objetivos con } \\
\text { menor inversión de } \\
\text { recursos. }\end{array}$} & \multirow{4}{*}{$\begin{array}{l}\text { La propuesta } \\
\text { permite gestionar } \\
\text { recursos con aliados } \\
\text { estratégicos. }\end{array}$} & \multirow{4}{*}{$\begin{array}{l}\text { La propuesta } \\
\text { permite contar con } \\
\text { fuentes de } \\
\text { financiación a } \\
\text { largo plazo. }\end{array}$} \\
\hline $\begin{array}{l}\text { Social } \\
\text { (Acciones } \\
\text { apropiación } \\
\text { colectiva) }\end{array}$ & & & & \\
\hline $\begin{array}{l}\text { Ambiental } \\
\text { (conservación } \\
\text { de la naturaleza) }\end{array}$ & & & & \\
\hline $\begin{array}{l}\text { Organizacional } \\
\text { (Gobernanza) }\end{array}$ & & & & \\
\hline
\end{tabular}

Fuente: Autor. 
Para ello, cada impacto deberá dar respuesta a indicadores asociados a las Naciones Unidas como se muestra en las tablas que a continuación se describen.

Tabla 45: Impacto Económico

\begin{tabular}{|c|c|c|}
\hline \multicolumn{3}{|r|}{ Impacto Económico } \\
\hline Tema & Subtema & Indicador \\
\hline \multirow{5}{*}{$\begin{array}{l}\text { Estructura } \\
\text { Económica }\end{array}$} & \multirow{2}{*}{$\begin{array}{l}\text { Actividad } \\
\text { económica }\end{array}$} & PIB per cápita \\
\hline & & Inversión como parte del PIB \\
\hline & Comercio & Balance comercial de bienes y servicios \\
\hline & \multirow{2}{*}{$\begin{array}{l}\text { Estatus } \\
\text { Financiero }\end{array}$} & Razón deuda PNB (Producto Nacional Bruto) \\
\hline & & $\begin{array}{l}\text { Total de asistencia oficial para el desarrollo dada o recibida como } \\
\% \text { del PNB }\end{array}$ \\
\hline \multirow{9}{*}{$\begin{array}{l}\text { Patrones de } \\
\text { consumo y } \\
\text { producción }\end{array}$} & $\begin{array}{l}\text { Consumo de } \\
\text { materiales }\end{array}$ & Intensidad de uso de materiales \\
\hline & \multirow{3}{*}{$\begin{array}{l}\text { Consumo de } \\
\text { energía }\end{array}$} & Consumo per cápita de energía anual \\
\hline & & Proporción de consumo de recursos de energía renovables \\
\hline & & Intensidad en el uso de energías \\
\hline & \multirow{4}{*}{$\begin{array}{l}\text { Generación y } \\
\text { manejo de } \\
\text { residuos }\end{array}$} & Generación de residuos sólidos municipales e industriales \\
\hline & & Generación de residuos peligrosos \\
\hline & & Generación de residuos radioactivos \\
\hline & & Reciclaje y re-uso de residuos \\
\hline & Transporte & Distancia viajada per cápita por tipo de transporte \\
\hline
\end{tabular}

Fuente: Autor a partir de Naciones Unidas (2001, p15)

Tabla 46: Impacto Ambiental

\begin{tabular}{|c|c|c|}
\hline \multicolumn{3}{|r|}{ Impacto Ambiental } \\
\hline Tema & Subtema & Indicador \\
\hline \multirow[t]{3}{*}{ Atmósfera } & Cambio climático & Emisión de gases de invernadero \\
\hline & $\begin{array}{l}\text { Reproducción de } \\
\text { la capa de ozono }\end{array}$ & Consumo de sustancias reproductoras de ozono \\
\hline & Calidad de Aire & $\begin{array}{l}\text { Concentración ambiental de contaminantes de aire en áreas } \\
\text { urbanas }\end{array}$ \\
\hline \multirow[t]{7}{*}{ Tierra } & \multirow[t]{3}{*}{ Agricultura } & Áreas de tierra permanentemente cultivable y arable \\
\hline & & Uso de fertilizantes \\
\hline & & Uso de pesticidas agrícolas \\
\hline & \multirow[t]{2}{*}{ Bosques } & $\%$ de área de bosques \\
\hline & & Intensidad de extracción de la madera \\
\hline & Desertificación & Tierra afectada por desertificación \\
\hline & Urbanización & Área de asentamientos urbanos formales e informales \\
\hline \multirow{2}{*}{$\begin{array}{l}\text { Océanos, } \\
\text { mares y } \\
\text { costas }\end{array}$} & Zonas costares & Concentración de algas en zonas costares \\
\hline & Pesquerías & Pesca anual de especies mayores \\
\hline \multirow[t]{3}{*}{ Agua dulce } & Cantidad de agua & $\begin{array}{l}\text { Supresión anual de agua subterránea y superficie como porcentaje } \\
\text { del total de agua disponible }\end{array}$ \\
\hline & \multirow[t]{2}{*}{ Calidad del agua } & DBO* en cuerpos de agua *(Demanda Biológica de Oxígeno $)$ \\
\hline & & Concentración de coliformes fecales en agua dulce \\
\hline \multirow[t]{3}{*}{ Biodiversidad } & \multirow[t]{2}{*}{ Ecosistemas } & Área de ecosistemas claves seleccionados \\
\hline & & Área protegida como \% del total del área \\
\hline & Especies & Abundancia de especies claves seleccionados \\
\hline
\end{tabular}


Fuente: Autor a partir de Naciones Unidas (2001, p15)

Tabla 47: Impacto Social

\begin{tabular}{|c|c|c|}
\hline \multicolumn{3}{|r|}{ Impacto Social } \\
\hline Tema & Subtema & Indicador \\
\hline \multirow[t]{4}{*}{ Equidad } & \multirow[t]{3}{*}{ Pobreza } & $\%$ de población viviendo de la línea de la pobreza \\
\hline & & Índice de GINI de la desigualdad del ingreso \\
\hline & & Tasa de desempleo \\
\hline & Igualdad de género & Razón entre el promedio salarial entre mujeres y hombre \\
\hline \multirow[t]{8}{*}{ Salud } & Estatus nutricional & Estatus nutricional en niños \\
\hline & \multirow[t]{2}{*}{ Mortalidad } & Tasa de mortalidad menores de 5 años \\
\hline & & Expectativa de vida al nacer \\
\hline & Saneamiento & $\begin{array}{l}\% \text { de personas con adecuadas facilidades de depuración de } \\
\text { aguas residuales }\end{array}$ \\
\hline & $\begin{array}{l}\text { Agua para el consumo } \\
\text { humano }\end{array}$ & $\%$ de personas con acceso al agua potable \\
\hline & \multirow[t]{3}{*}{$\begin{array}{l}\text { Servicios de cuidado } \\
\text { para la salud }\end{array}$} & $\begin{array}{l}\% \text { de personas con acceso a facilidades de cuidado de } \\
\text { salud primarias }\end{array}$ \\
\hline & & Inmunización contra enfermedades infecciosas infantiles \\
\hline & & Tasa de prevalencia anticonceptiva \\
\hline \multirow[t]{2}{*}{ Educación } & Nivel educativo & Tasa de culminación de primaria o secundaria \\
\hline & Alfabetización & Tasa de alfabetización \\
\hline Vivienda & Condiciones de vivienda & Área de piso por persona \\
\hline Seguridad & Crimen & $\begin{array}{l}\text { Número de crímenes reportados por cada } 100 \text { mil } \\
\text { habitantes }\end{array}$ \\
\hline \multirow[t]{2}{*}{ Población } & \multirow[t]{2}{*}{ Cambio en la población } & Tasa de crecimiento de la población \\
\hline & & Población en asentamientos urbanos formales e informales \\
\hline
\end{tabular}

Fuente: Autor a partir de Naciones Unidas (2001, p15)

Tabla 48. Impacto Institucional

\begin{tabular}{|l|l|l|}
\hline \multicolumn{2}{|c|}{ Impacto Institucional } \\
\hline \multicolumn{1}{|c|}{ Tema } & \multicolumn{1}{|c|}{ Subtema } & \multicolumn{1}{c|}{ Indicador } \\
\hline $\begin{array}{l}\text { Estructura } \\
\text { Institucional }\end{array}$ & $\begin{array}{l}\text { Implementación } \\
\text { estratégica de desarrollo } \\
\text { sostenible }\end{array}$ & Estrategia nacional de desarrollo sostenible \\
\cline { 2 - 3 } & $\begin{array}{l}\text { Cooperación } \\
\text { internacional }\end{array}$ & Implementación de acuerdos globales ratificados \\
\hline $\begin{array}{l}\text { Capacidad } \\
\text { Institucional }\end{array}$ & Acceso a información & $\begin{array}{l}\text { Número de suscriptores de internet por cada 100 mil } \\
\text { habitantes }\end{array}$ \\
\cline { 2 - 3 } & $\begin{array}{l}\text { Infraestructura de } \\
\text { información }\end{array}$ & $\begin{array}{l}\text { Líneas telefónicas principales por cada 100 mil } \\
\text { habitantes }\end{array}$ \\
\cline { 2 - 4 } & Ciencia y tecnología & $\begin{array}{l}\text { Gasto en investigación y desarrollo como porcentaje del } \\
\text { PIB }\end{array}$ \\
\cline { 2 - 4 } & $\begin{array}{l}\text { Preparación y respuesta a } \\
\text { Desastres }\end{array}$ & $\begin{array}{l}\text { Pérdida económica y humana debido a los desastres } \\
\text { naturales }\end{array}$ \\
\hline
\end{tabular}

Fuente: Autor a partir de Naciones Unidas (2001, p15)

En síntesis, las coordenadas de la dimensión evaluativa analizadas bajo la matriz de evaluación permiten gestionar las acciones encaminadas en cada asignatura del pensum de básica secundaria para contribuir con el Bienestar de la comunidad y alinear la 
institución hacia la consecución y promoción de prácticas de sustentabilidad y sostenibilidad.

En el siguiente capítulo se realizará un caso de estudios para ejecutar las acciones del "modelo de coordenadas curriculares" propuesto y comprobar la hipótesis planeada en términos del desarrollo de competencias para la resolución de problemas locales y globales desde el diseño del currículo de básica secundaria. 


\section{CAPÍTULO 5}

\section{VALIDACIÓN.}




\section{VALIDACIÓN.}

El desarrollo del capítulo pretende mostrar los resultados de la aplicación del "modelo de coordenadas curriculares" para el diseño del currículo en una institución educativa de básica secundaria en la ciudad de Medellín. En este sentido, la implementación permitirá demostrar el desarrollo de la competencia global para la solución de problemas locales y globales.

\subsection{Tipo de Investigación}

La intervención pedagógica a partir del modelo de coordenadas curriculares como se mencionó en el capítulo 1 se abordó desde los principios teóricos de (Hernández, Fernández \& Baptista, 2014) cuyo enfoque mixto utilizó técnicas cuantitativas y cualitativas para analizar la información. Del mismo modo el alcance de investigación fue de carácter Exploratorio al considerarse como poco explorado el modelo como lo plantea la tesis. En términos de diseño correspondió al transformativo secuencial al incluir diferentes abordajes metodológicos e involucrar a profundidad a los participantes.

\subsection{Implementación del modelo de coordenadas curriculares.}

El modelo se implementó en la Institución Educativa Monseñor Francisco Cristóbal Toro de Medellín, ubicada en la carrera 50D No 90 - 49. La institución cuenta con tres secciones conformada por 2205 estudiantes de básica primaria, secundaria y media. 62 docentes y 5 directivos docentes.

El total de la población de noveno grado corresponde a 61 estudiantes, distribuidos en 3 grupos: 9.1 y 9.2 en la jornada de la mañana $(6: 15 \mathrm{am}$ hasta $12: 15 \mathrm{pm})$ y 9.3 jornada de la tarde (12:30 pm a 6:30 pm). La investigación se desarrolló con los 45 estudiantes de los grupos 9.1 y 9.2 tomados como muestra de población no probabilística.

Los 45 estudiantes pertenecen a la jornada de la mañana de la sede principal denominada Cristóbal Toro, los grupos son mixtos, con edades que oscilan entre los 14 y 16 años, pertenecientes a los estratos socioeconómicos ${ }^{35} 1,2$ y 3 del barrio Aranjuez y sus alrededores.

El nivel de confianza del estudio corresponde a un $90 \%$, con un error deseado del 6,5\%, luego de determinar la población objeto de experimentación mediante el análisis del resultado para poblaciones finitas como lo muestra la siguiente ilustración.

\footnotetext{
${ }^{35}$ De acuerdo con la Ley 142 de 1994 la estratificación socioenómica de Colombia se refiere a la clasificación de los inmuebles para que puedan recibir los servicios públicos domiciliarios. Esta clasificación (por estratos) de manera diferencial permite asignar subsidios y cobrar contribuciones. Aquellos estratos con mayor capacidad económica subsidian a los de menor clasificación. La clasificación por estratos corresponde a: 1 Bajo- bajo; 2 Bajo; 3 Medio- bajo; 4 Medio; 5 Alto y 6 Alto-alto. Las políticas
} 


\section{CÁLCULO DEL TAMAÑO DE UNA MUESTRA PARA POBLACIÓN FINITA}

PARA POBLACION CONOCIDA FINITA, MENOR A 10.000

INTRODUZCA EL MARGEN DE ERROR DESEADO e INTRODUZCA EL TAMAÑO DE LA POBLACION (N)

INTRODUZCA EL VALOR DE $\mathbf{p}$

INTRODUZCA EL VALOR DE $q$

$$
n=\frac{N * p * q * Z^{2}}{e^{2}(N-1)+p * q * z^{2}}
$$

Error maximo recomendado $7 \%$

SI NO CONOCE $p$ Y q SE DEJA 0,5 Y 0,5

SIEMPRE $p+q=1$

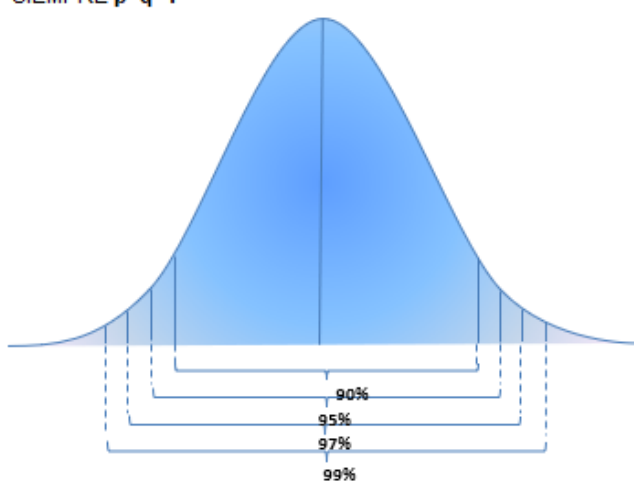

TAMAÑO DE LA MUESTRA DE ACUERDO AL ERROR Y AL NIVEL DE CONFIANZA DESEADO

\begin{tabular}{|l|l|}
\hline TAMAÑO DE LA MUESTRA PARA UN N. DE CONF. DEL $90 \%=$ & 44
\end{tabular}
TAMAÑO DE LA MUESTRA PARA UN N. DE CONF. DEL $95 \%=\quad 48$

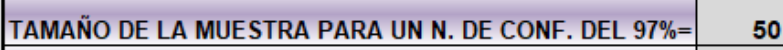

TAMAÑO DE LA MUESTRA PARA UN N. DE CONF. DEL $99 \%=\quad 53$

$\mathbf{p}=$ PROPORCION ESPERADA QUE CUMPLE LA CARACTERISTICA DESEADA $q=$ PROPORCION ESPERADA QUE NO CUMPLE LA CARACTERISTICA DESEADA 50

Ilustración 23: Cálculo de error muestral para poblaciones finitas.

Fuente: Tomado de muestreo estadístico diseño y aplicaciones.

Los sujetos no fueron escogidos al azar, su selección fue por conveniencia (jornada), a los estudiantes se les aplicó el pretest, estrategia pedagógica y postest.

\section{Tabla 49: Convenciones experimento}

\begin{tabular}{|l|l|l|l|}
\hline Grupo & Medición & $\begin{array}{l}\text { Fortalecimiento de la } \\
\text { competencia global }\end{array}$ & Medición \\
\hline GE & $\mathrm{O} 1$ & $\mathrm{X} 1$ & $\mathrm{O} 2$ \\
\hline
\end{tabular}

Fuente: Autor

Convenciones

GE: Grupo experimental

O1: Observaciones y mediciones al iniciar el estudio (Pretest)

O2: Observaciones y mediciones al finalizar el estudio (Postest)

X1: Variable independiente: Fortalecimiento de la competencia global. Grupo experimental 
5.3. Fuentes de Información e Instrumentos.

Las fuentes primarias permitieron obtener información producto de la observación, entrevistas, pruebas y encuestas. El método de contacto correspondió al personal tomado en los diferentes espacios escolares.

El instrumento de investigación es de tipo cuestionario en donde la comunidad educativa le brindó respuesta a las preguntas planeadas en el marco metodológico de la prueba.

Las fuentes secundarias correspondieron a todos aquellos documentos legales e institucionales de regulación del sistema escolar a nivel nacional e internacional. entre otros se encuentra: Ley general de educación, lineamientos curriculares, Proyecto Educativo Institucional (contexto), mallas curriculares, manual de convivencia, resultados de pruebas internacionales (PISA).

Los instrumentos para obtener la información de las diferentes técnicas como la entrevista, observación, análisis de contenido y pruebas de desarrollo constituyen un papel clave como fuente primaria.

Tabla 50: Técnicas e Instrumentos

\begin{tabular}{|l|l|l|}
\hline \multicolumn{1}{|c|}{ Téenica } & \multicolumn{1}{|c|}{ Instrumentos } & \multicolumn{1}{c|}{ Anexo } \\
\hline Encuesta & $\begin{array}{l}\text { Prueba Diagnóstica } \\
\text { Institucional ODS }\end{array}$ & Anexo 4 \\
\hline Análisis de contenido & $\begin{array}{l}\text { Trabajo de estudiantes } \\
\text { (Guía de intervención } \\
\text { pedagógica) }\end{array}$ & Anexo 5 \\
\hline Pruebas de desarrollo & $\begin{array}{l}\text { Pruebas escritas (Pre-test y } \\
\text { Pos-test) }\end{array}$ & $\begin{array}{l}\text { Anexo 6 } \\
\text { Anexo 7 }\end{array}$ \\
\hline $\begin{array}{l}\text { Encuesta - Validación de de intervención } \\
\text { instrumento }\end{array}$ & $\begin{array}{l}\text { Guía de } \\
\text { Anedagógica }\end{array}$ \\
\hline
\end{tabular}

Fuente: Autor

Las bases argumentativas corresponden a la metodología propuesta por el modelo de coordenadas curriculares descrito y se constituye en un elemento creativo, original y propio de esta investigación.

5.4. Tiempo de duración del experimento

La intervención en institución se proyecta a 4 meses (inicia en enero hasta abril de 2019) 
5.5. Confiabilidad y Validez de los instrumentos.

El instrumento de intervención metodológica "Guía de intervención pedagógica" fue sometido a la validez cualitativa por parte de expertos (anexo 8).

El material utilizado para la elaboración del Pretest (anexo 6) y Postest (anexo 7), fue recuperado de los textos liberados por la OCDE: (i) Marco de competencia global. Estudio Pisa. Preparar a nuestros Jóvenes para un mundo inclusivo y sostenible. Pisa 2018, (ii) Guía de Orientación PISA 2018: Competencia Global Colombia y (iii) Marco de Referencia Preliminar para la Competencia Global PISA 2018. En este sentido, el material utilizado no requiere de confiabilidad ni validez al estar avalado por una prueba de aplicación internacional.

\subsection{Diseño Experimental}

En sintonía con la definición de experimento de (Hernández, Fernández \& Baptista, 2014) se plantea manipular intencionalmente las variables independientes (causas) para analizar las consecuencias sobre las variables dependientes (efectos), mediante una situación de control definida en el "modelo de coordenadas curriculares".

\subsubsection{Nombre del experimento.}

Aplicación del "modelo de coordenadas curriculares".

\subsubsection{Hipótesis.}

De acuerdo con las preguntas formuladas desde el inicio de la investigación se determina como hipótesis:

- Hipótesis de investigación

(HI) Los procesos de innovación en educación aplicados para la elaboración del diseño curricular mediante el "modelo de coordenadas curriculares" ${ }^{36}$, mejoran el desarrollo de la competencia global para la resolución de los problemas locales y globales en los estudiantes de noveno grado de básica secundaria.

\footnotetext{
${ }^{36}$ Modelo de Coordenadas curriculares contiene los siguientes componentes: Bienestar (para el Desarrollo Humano), Competencia global y Área de conocimiento. Se relacionan entre si formando un hipotético cubo como muestra la figura.
} 

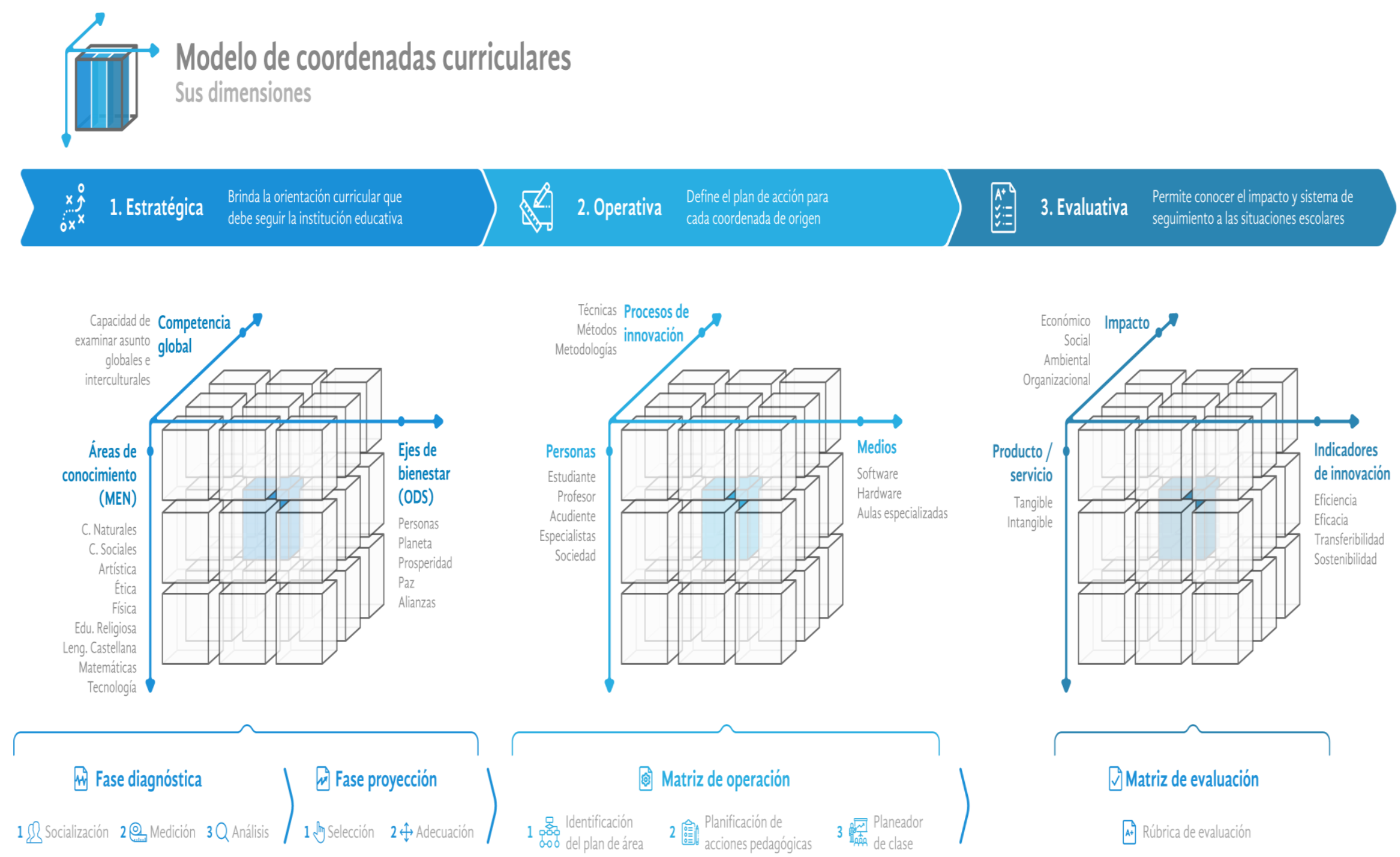

Ilustración 24: Modelo de Coordenadas Curriculares.

Fuente: Autor 
- Hipótesis Nula

(Ho) Los procesos de innovación en educación aplicados para la elaboración del diseño curricular mediante el "modelo de coordenadas curriculares", no logra mejorar el desarrollo de la competencia global para la resolución de los problemas locales y globales en los estudiantes de noveno grado de básica secundaria.

\subsubsection{Variables.}

- Variable Independiente

Modelo de coordenadas curriculares

- Variables Dependiente

Mejoramiento en el desarrollo de la competencia global.

Resolución de problemas locales y globales.

- Operacionalización de las variables

Tabla 51: Operacionalización de las variables

\begin{tabular}{|c|c|c|c|}
\hline Variable & Subvariable & Indicadores & Instrumentos \\
\hline $\begin{array}{l}\text { Independiente: } \\
\text { - Modelo de } \\
\text { coordenadas } \\
\text { curriculares }\end{array}$ & $\begin{array}{l}\text { Evaluar } \\
\text { información, } \\
\text { formular } \\
\text { argumentos y } \\
\text { explicar }\end{array}$ & $\begin{array}{l}\text { Conocimiento y } \\
\text { alfabetización } \\
\cdot \text { Conocimiento de } \\
\text { asuntos globales } \\
\cdot \text { Conocimiento }\end{array}$ & $\begin{array}{l}\text { Test Diagnóstico } \\
\text { (Pretest) } \\
\text { Taller No1: Estilo de conflictos. } \\
\text { Taller No2: Mediación escolar. }\end{array}$ \\
\hline $\begin{array}{l}\text { Dependiente: } \\
\text { - Mejoramiento de la } \\
\text { competencia global. } \\
\text { - Resolución de } \\
\text { problemas locales y } \\
\text { globales. }\end{array}$ & $\begin{array}{l}\text { problemas o } \\
\text { situaciones. } \\
\text { Identificar y } \\
\text { analizar } \\
\text { diferentes } \\
\text { perspectivas. } \\
\text { Comprender las } \\
\text { diferencias en la } \\
\text { comunicación. } \\
\text { Evaluar acciones } \\
\text { y consecuencias. }\end{array}$ & $\begin{array}{l}\text { intercultural } \\
\text { Actitudes } \\
\text {-Apertura } \\
\text { - Respeto } \\
\text { - Mentalidad global } \\
\text { Valores } \\
\text {-Valoración de los } \\
\text { derechos humanos } \\
\text { fundamentales (dignidad } \\
\text { humana) } \\
\text {-Valoración de la } \\
\text { diversidad cultural }\end{array}$ & $\begin{array}{l}\text { Taller } N^{\circ} 3 \text { : Calidad del aire en la } \\
\text { ciudad de Medellín. } \\
\text { Taller } N^{\circ} 4 \text { : Análisis de } \\
\text { percepción de seguridad en el } \\
\text { entorno. } \\
\text { Taller } N^{\circ} 5 \text { : Análisis Justicia } \\
\text { Especial para la Paz. } \\
\text { Taller No6: Reflexión corrupción } \\
\text { en América Latina } \\
\text { Taller No7: Reflexión víctimas } \\
\text { de trata de personas. } \\
\text { Test Final } \\
\text { (Postest) }\end{array}$ \\
\hline
\end{tabular}

Fuente: Autor. 


\subsection{Intervención Institucional}

De acuerdo con la metodología planteada a continuación se evidencia las diferentes secciones de trabajo con base en las dimensiones formuladas por el "modelo de coordenadas curriculares".

\subsubsection{Secciones de trabajo.}

El modelo de coordenadas curriculares plantea como etapa inicial definir la dimensión estratégica compuesta a su vez por la fase diagnóstica y de proyección como lo muestra la siguiente tabla.
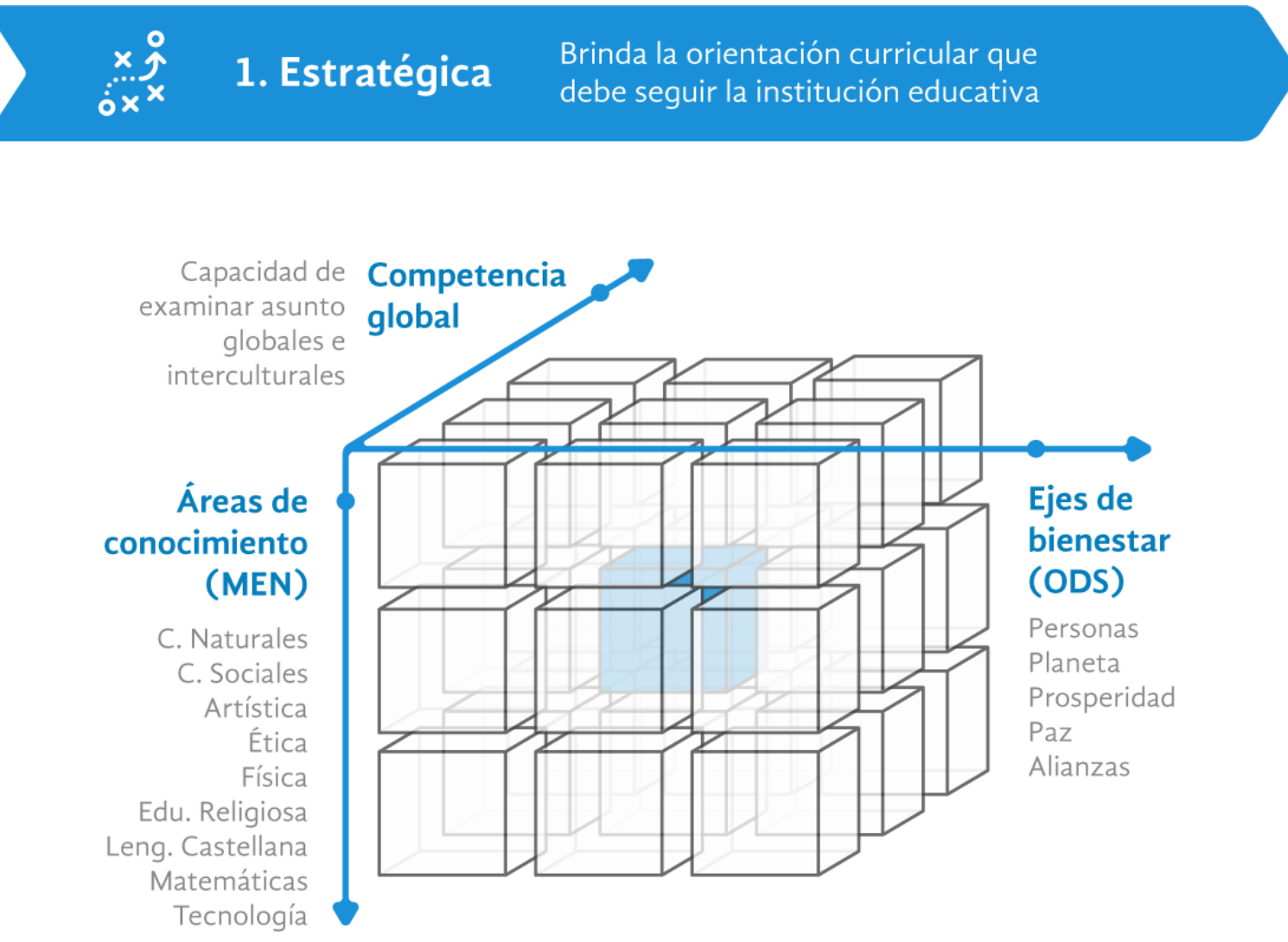

\section{Fase diagnóstica}

\section{SS Socialización 2 Q Medición}

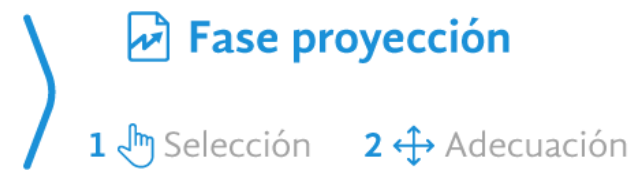

Ilustración 25: Fases dimensión estratégica Fuente: Autor. 


\section{Sección 1: Dimensión Estratégica-Fase Diagnóstica}

La fase diagnóstica permite identificar las coordenadas de origen, en este sentido la sección 1se subdivide en tres Pasos: Socialización, Medición y Análisis.

\section{- Paso 1: Socialización}

El paso de socialización se planificó bajo las siguientes características como lo muestra la tabla (52):

Tabla 52: Planeación Paso 1: Socialización

\begin{tabular}{|l|l|}
\hline $\mathrm{N}^{\mathrm{o}}$ Participantes & 70 personas \\
\hline $\begin{array}{l}\text { Clasificación de } \\
\text { participantes }\end{array}$ & $\begin{array}{l}\text { Docentes sedes: Principal (Monseñor Francisco Cristóbal Toro) y 2 secciones } \\
\text { escuela (Epifanio Mejía y Ana Frank), Representantes estudiantiles y padres } \\
\text { de familia. }\end{array}$ \\
\hline Objetivo & $\begin{array}{l}\text { Socializar el alcance de los objetivos de desarrollo sostenible acerca del } \\
\text { llamado mundial para tomar medidas en términos de reducción de la pobreza, } \\
\text { protección del planeta y contribución con la paz y la prosperidad. }\end{array}$ \\
\hline Duración & 2 horas \\
\hline
\end{tabular}

Fuente: Autor.

El ejercicio de divulgación de los Objetivos de Desarrollo Sostenible se realizó en la sede principal con 70 miembros de la comunidad educativa, en donde se despejaron dudas en torno al alcance de los ODS. Se plantearon diferentes interrogantes alrededor de ¿cómo la Institución Educativa Monseñor Francisco Cristóbal Toro aporta hacia el logro de los ODS? ¿qué puede hacer la comunidad educativa para impactar positivamente hacia los ODS? ¿cuál es el ODS que mayor impacta a la comunidad educativa? ¿cómo articular los ODS a la planeación estratégica de la institución? Y ¿cómo articular los ODS al currículo? Entre otras, las imágenes que a continuación se muestran corresponden a la sección de socialización.
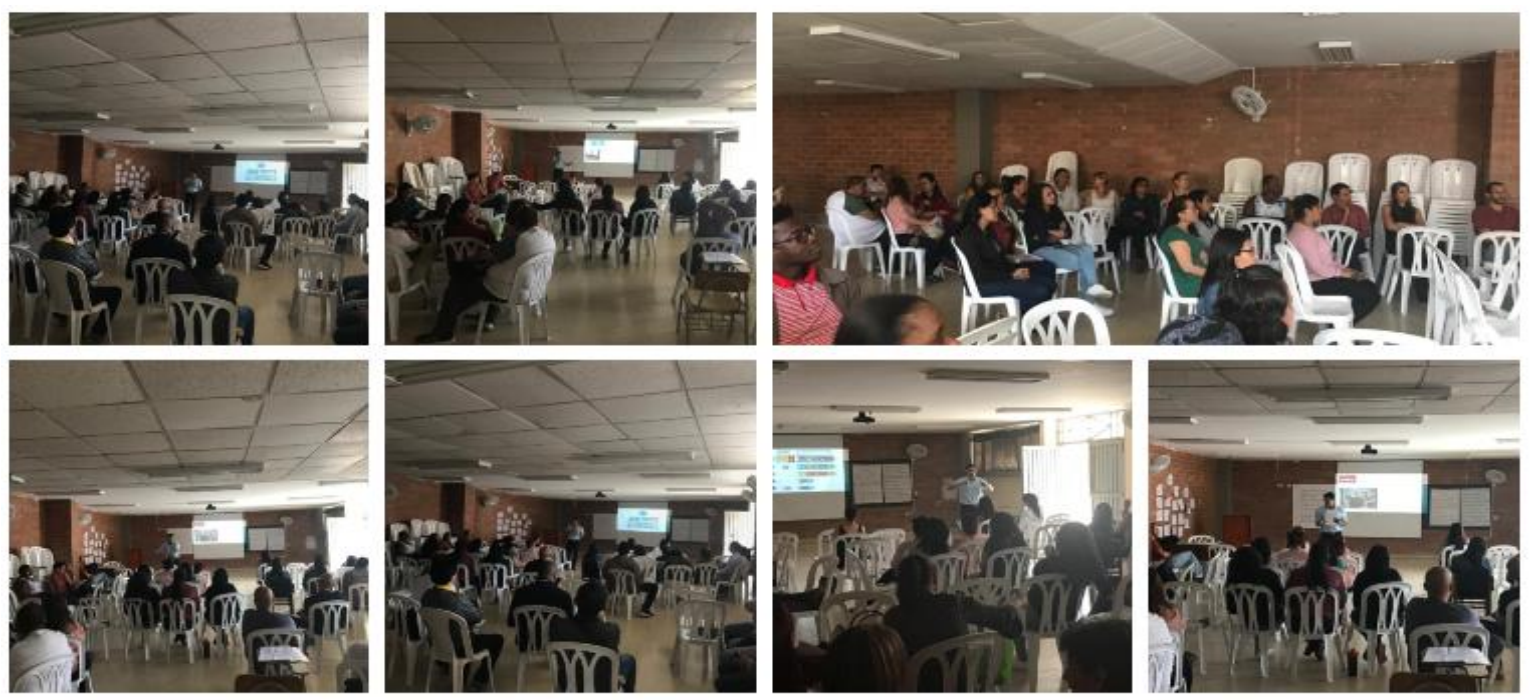

Ilustración 26:Socialización ODS

Fuente: Autor. 
Los miembros de la comunidad educativa participaron de manera activa. La información permitió reflexionar frente al tema y formular inquietudes con relación al quehacer institucional.

Luego de la socialización se procedió con el paso de medición.

\section{- Paso 2: Medición}

La medición propone tomar evidencia de la situación actual como lo muestra la tabla (53):

Tabla 53: Planeación Paso 2: Medición

\begin{tabular}{|l|l|}
\hline $\mathrm{N}^{\text {o Participantes }}$ & 70 personas \\
\hline $\begin{array}{l}\text { Clasificación de } \\
\text { participantes }\end{array}$ & $\begin{array}{l}\text { Docentes sedes: Principal (Monseñor Francisco Cristóbal Toro) y 2 secciones } \\
\text { escuela (Epifanio Mejía y Ana Frank), Representantes estudiantiles y padres } \\
\text { de familia. }\end{array}$ \\
\hline Objetivo & $\begin{array}{l}\text { Identificar la precepción sobre el nivel de impacto de los ODS en el área de } \\
\text { influencia de la comunidad académica de la Institución Educativa Monseñor } \\
\text { Francisco Cristóbal Toro. }\end{array}$ \\
\hline Duración & 30 minutos. \\
\hline
\end{tabular}

Fuente: Autor.

La medición se desarrolló en el segundo momento de la intervención, en ella se buscó que cada miembro de la comunidad académica valorara el impacto de cada ODS en el área de influencia de la institución educativa mediante la encuesta "Prueba Diagnóstica Institucional ODS" (Anexo 4). Las imágenes que a continuación se muestran indican el momento de la presentación de la prueba.
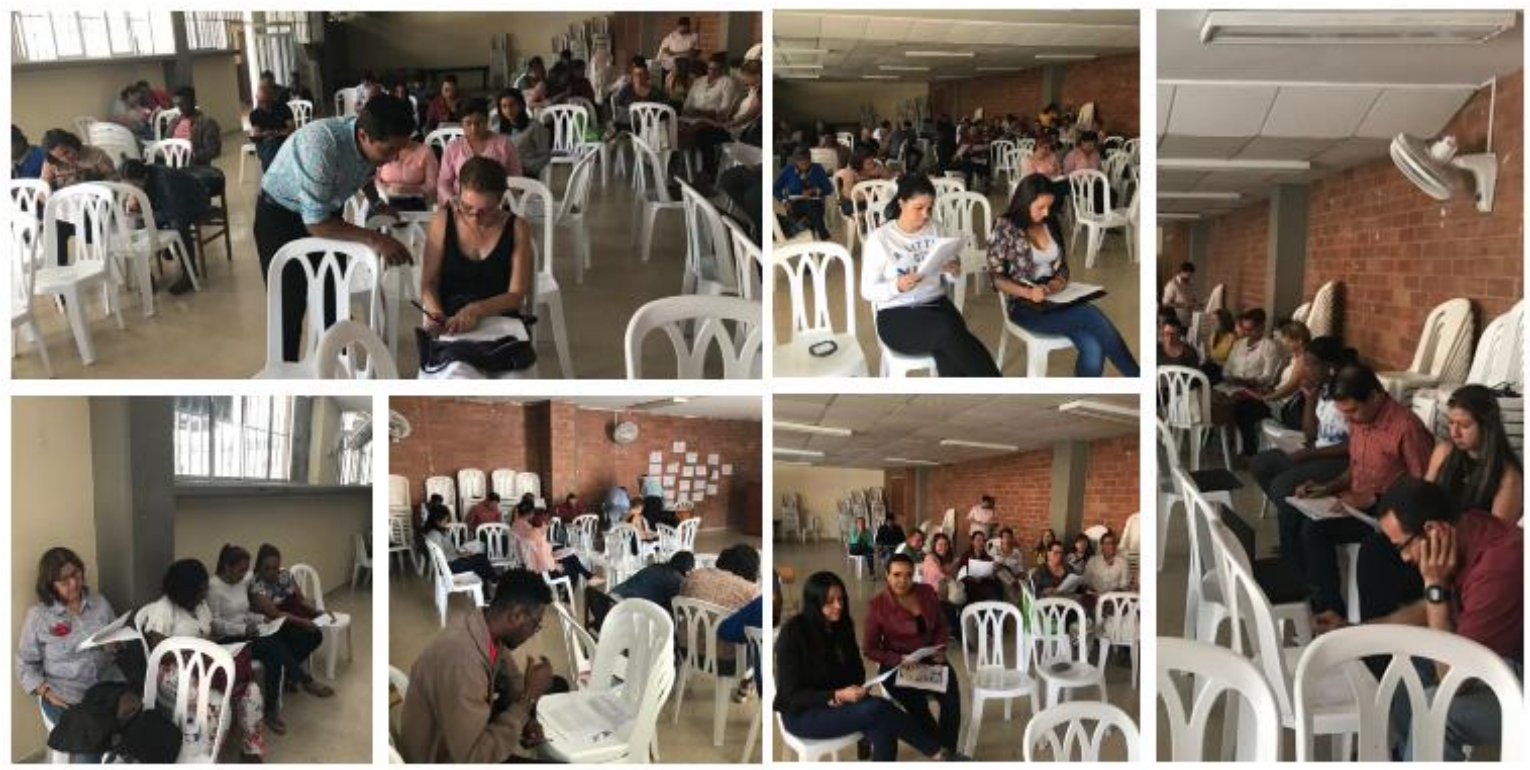

Tabla 54: Medición percepción ODS en el contexto.

Fuente: Autor. 
La prueba diagnóstica registró la percepción de la comunidad educativa. Durante la prueba se resolvieron inquietudes para el diligenciamiento del registro.

Finalizada la sección de intervención en la institución, se continuó con el procesamiento de la información obtenida de la medición.

- Paso 3: Análisis.

Los resultados producto de la valoración de cada miembro de la comunidad académica bajo la metodología de análisis propuesta por el modelo de coordenadas curriculares se incluyen en el anexo (5).

Los resultados muestran que el eje Paz obtuvo la mayor calificación como lo muestra la tabla (55) y la ilustración (27).

Tabla 55: Pareto resultado de percepción ejes ODS en el contexto

\begin{tabular}{|l|c|c|c|c|c|c|}
\hline \multicolumn{1}{|c|}{ Eje } & $\begin{array}{c}\text { Promedio } \\
\text { Calificación }\end{array}$ & Valoración & $\begin{array}{c}\text { Valoración } \\
\text { acumulada }\end{array}$ & $\begin{array}{c}\text { \% } \\
\text { Calificación }\end{array}$ & $\begin{array}{c}\text { \% calificación } \\
\text { acumulada }\end{array}$ & Clasificación \\
\hline Paz & 3,74285714 & 20 & 20 & 22,3 & 22,3 & 20 \\
\hline Planeta & 3,34285714 & 20 & 40 & 20,0 & 42,3 & 62,2 \\
\hline Personas & 3,33142857 & 20 & 60 & 19,9 & 81,4 & 80 \\
\hline Prosperidad & 3,22285714 & 20 & 80 & 19,2 & 100,0 & \\
\hline Alianzas & 3,11428571 & 20 & 100 & 18,6 & & \\
\hline \multicolumn{1}{|c|}{ Total } & 16,7542857 & 100 & & 100 & - & \\
\hline
\end{tabular}

Fuente: Autor.

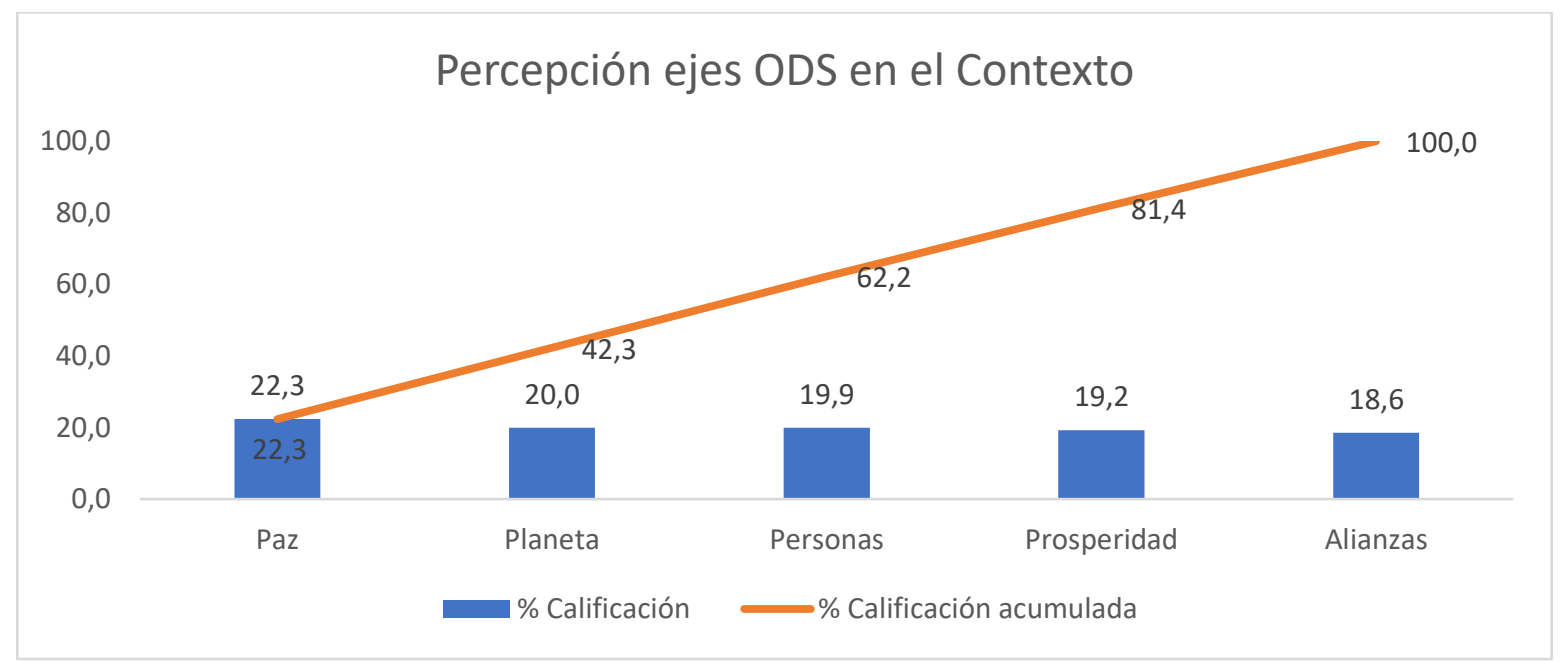

Ilustración 27: Percepción ejes ODS en el contexto.

Fuente: Autor. 
La coordenada Paz, con un 22,2\% correspondió al eje de mayor frecuencia absoluta, seguida de Planeta (20\%), Personas (19.9\%), Prosperidad (19,2\%) y Alianzas con un 18,6\%.

De acuerdo con los resultados obtenidos se elige la coordenada Paz como eje para transversalizar la estrategia pedagógica para el desarrollo de la competencia global en las asignaturas del currículo para noveno grado de la Institución Educativa Monseñor Francisco Cristóbal Toro.

Cabe aclarar que el análisis de ponderación recomienda el eje sobre el cual se debe dar prioridad en el contexto particular. Aunque cada institución podrá elegir cuantos ejes considere para fortalecer el desarrollo de la competencia global para la resolución de los problemas locales y globales.

Sección 2: Dimensión Estratégica- Fase Proyección.

\section{Paso 4: Selección.}

Identificada la coordenada del eje ODS (X) y la competencia global (Y), se procede a realizar las diferentes combinaciones con las asignaturas del pensum para noveno (eje Z)

Tabla 56: Identificación de coordenadas

\begin{tabular}{|c|c|c|}
\hline Eje $x$ & Eje y & Eje $z$ \\
\hline $\begin{array}{l}\left(\mathrm{X}_{1}\right) 16-\mathrm{Paz} \text {, justicia e } \\
\text { instituciones sólidas }\end{array}$ & $\begin{array}{l}\text { (Y1) Ciencias naturales y educación ambiental. } \\
\text { (Y2) Ciencias sociales, historia, geografía, constitución } \\
\text { política y democracia. } \\
\text { (Y3) Educación artística. } \\
\text { (Y4) Educación ética y en valores humanos. } \\
\text { (Y5) Educación física, recreación y deportes. } \\
\text { (Y6) Educación religiosa. } \\
\text { (Y7) Humanidades, lengua castellana e idiomas } \\
\quad \text { extranjeros } \\
\text { (Y8) Matemáticas. } \\
\text { (Y9) Tecnología e informática. }\end{array}$ & $\begin{array}{l}\left(Z_{1}\right) \text { Competencia } \\
\text { global }\end{array}$ \\
\hline
\end{tabular}

Fuente: Autor.

Las iteraciones resultantes se muestran en la siguiente tabla.

Tabla 57: Iteración de coordenadas curriculares

\begin{tabular}{|l|l|l|}
\hline $\begin{array}{c}\mathbf{N}^{\mathbf{0}} \\
\text { combinación }\end{array}$ & Coordenada & \multicolumn{1}{c|}{ Descripción de la coordenada } \\
\hline 1 & $\left(\mathrm{X}_{1}, \mathrm{Y}_{1}, \mathrm{Z}_{1}\right)$ & $\begin{array}{l}\text { (Paz, justicia e instituciones sólidas; Ciencias naturales y educación } \\
\text { ambiental; Competencia global) }\end{array}$ \\
\hline 2 & $\left(\mathrm{X}_{1}, \mathrm{Y}_{1}, \mathrm{Z}_{2}\right)$ & $\begin{array}{l}\text { (Paz, justicia e instituciones sólidas; Ciencias sociales, historia, geografía, } \\
\text { constitución política y democracia; Competencia global) }\end{array}$ \\
\hline
\end{tabular}




\begin{tabular}{|l|l|l|}
\hline 3 & $\left(\mathrm{X}_{1}, \mathrm{Y}_{1}, \mathrm{Z}_{3}\right)$ & $\begin{array}{l}\text { (Paz, justicia e instituciones sólidas; Educación artística; Competencia } \\
\text { global) }\end{array}$ \\
\hline 4 & $\left(\mathrm{X}_{1}, \mathrm{Y}_{1}, \mathrm{Z}_{4}\right)$ & $\begin{array}{l}\text { (Paz, justicia e instituciones sólidas; Educación ética y en valores humanos; } \\
\text { Competencia global) }\end{array}$ \\
\hline 5 & $\left(\mathrm{X}_{1}, \mathrm{Y}_{1}, \mathrm{Z}_{5}\right)$ & $\begin{array}{l}\text { (Paz, justicia e instituciones sólidas; Educación física, recreación y } \\
\text { deportes; Competencia global) }\end{array}$ \\
\hline 6 & $\left(\mathrm{X}_{1}, \mathrm{Y}_{1}, \mathrm{Z}_{6}\right)$ & $\begin{array}{l}\text { (Paz, justicia e instituciones sólidas; Educación religiosa; Competencia } \\
\text { global) }\end{array}$ \\
\hline 7 & $\left(\mathrm{X}_{1}, \mathrm{Y}_{1}, \mathrm{Z}_{7}\right)$ & $\begin{array}{l}\text { (Paz, justicia e instituciones sólidas; Humanidades, lengua castellana e } \\
\text { idiomas extranjeros; Competencia global) }\end{array}$ \\
\hline 8 & $\left(\mathrm{X}_{1}, \mathrm{Y}_{1}, \mathrm{Z}_{8}\right)$ & (Paz, justicia e instituciones sólidas; Matemáticas; Competencia global) \\
\hline 9 & $\left(\mathrm{X}_{1}, \mathrm{Y}_{1}, \mathrm{Z}_{9}\right)$ & $\begin{array}{l}\text { (Paz, justicia e instituciones sólidas; Tecnología e informática; } \\
\text { Competencia global) }\end{array}$ \\
\hline
\end{tabular}

Fuente: Autor.

Luego de las combinaciones se identifican 9 coordenadas como recomendación para la Institución Educativa Monseñor Francisco Cristóbal Toro.

\section{Paso 5: Adecuación.}

Para efectos del experimento se elige la coordenada $\mathrm{N}^{0} 2 .\left(\mathrm{X}_{1}, \mathrm{Y}_{1}, \mathrm{Z}_{2}\right.$ ) (Paz, justicia e instituciones sólidas; Ciencias sociales, historia, geografía, constitución política y democracia; Competencia global) como recomendación por parte del Rector de la Institución (Mg. Pedro Antonio Agualimpia Perea) por concepto de horario y disponibilidad del docente.

En la Institución Educativa el área de Ciencias Sociales, historia, geografía, constitución política y democracia se aborda con una intensidad horaria de 4 horas semanales en una sola asignatura denominada Ciencias Social.

En este sentido, se realizó una sección de trabajo para realizar las adecuaciones curriculares con directivos docentes, docentes de Ciencias Sociales, padres de familia, estudiantes y expertos.

Sección 3- Adecuación curricular.

La sección de trabajo se detalla como lo muestra la tabla (58).

Tabla 58: Planeación Sección 3- Adecuación curricular

\begin{tabular}{|l|l|}
\hline $\mathrm{N}^{\mathrm{o}}$ Participantes & \multicolumn{1}{|c|}{10 personas } \\
\hline $\begin{array}{l}\text { Clasificación de } \\
\text { participantes }\end{array}$ & $\begin{array}{l}\text { Directivos docentes } \\
\text { Docentes área de Ciencias Sociales } \\
\text { Estudiantes representantes grados novenos } \\
\text { Padres de familia. } \\
\text { Expertos en pedagogía }\end{array}$ \\
\hline Objetivo & $\begin{array}{l}\text { Determinar las actividades de enseñanza y aprendizaje mediadas por procesos } \\
\text { de innovación a partir de situaciones reales del contexto en sintonía con las }\end{array}$ \\
\hline
\end{tabular}




\begin{tabular}{|l|l|}
\hline & $\begin{array}{l}\text { metas asociadas a los ODS para la Institución Educativa Monseñor Francisco } \\
\text { Cristóbal Toro. }\end{array}$ \\
\hline Duración & 2 horas. \\
\hline
\end{tabular}

Fuente: Autor.

Evidencia Planeación adecuación curricular.
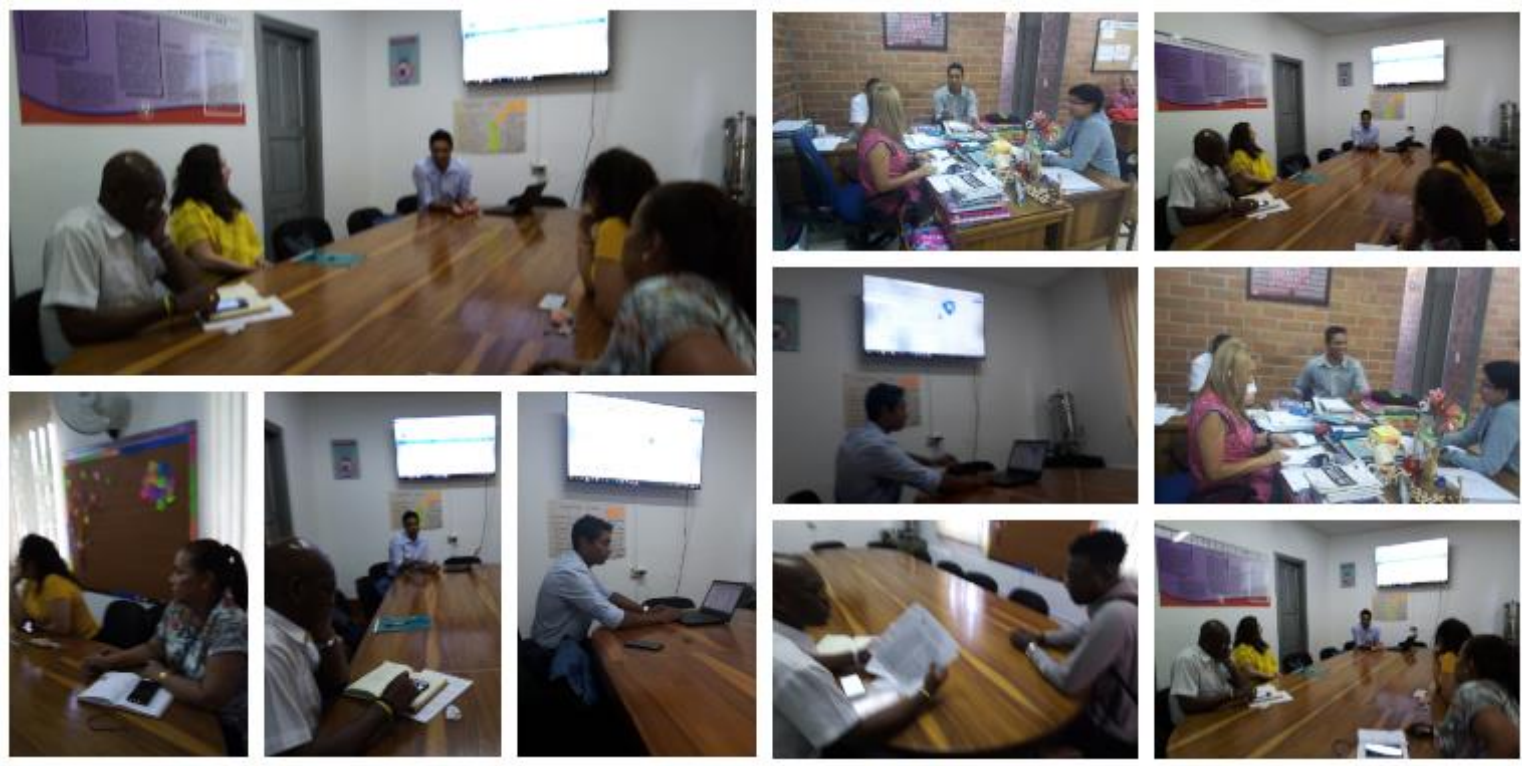

Ilustración 28: Planeación adecuación curricular Fuente: Autor.

El resultado del ejercicio de co-creación curricular se muestra en la Guía de Intervención Pedagógica (anexo 5).

La sección de adecuación fue mediada por procesos de innovación educativa para retomar el trabajo cooperativo y análisis dimensional entre las metas de los ODS y los referentes legales de la asignatura (estándares básicos de aprendizaje).

En este sentido, la sección de trabajo se abordó bajo la metodología de innovación social Word Café cuyas características son promover la conversación cálida y significativa mediante preguntas poderosas en un ambiente acogedor y amigable; uno de los principios de la metodología señala "en la medida que hablamos juntos, podemos tener acceso a la sabiduría superior, que solo se encuentra en la colectividad” (Brown \& Isaac,2007).

Las preguntas orientadoras de la sección de trabajo fueron: ¿Cómo la Institución Educativa Monseñor Francisco Cristóbal Toro aporta hacia el logro del ODS 16? ¿qué puede hacer la comunidad educativa para impactar positivamente el cumplimiento del ODS 16? ¿cómo articular el ODS 16 a la planeación curricular de la asignatura de ciencias sociales? ¿cuáles son los temas de mayor interés de la comunidad para contribuir con el cumplimiento de las metas del ODS $16 ?$ 
El resultado de la metodología Word Café permitió identificar 7 temáticas para abordar el desarrollo de la competencia en el aula de clases (Estilo de conflictos, Mediación escolar, Calidad del aire en la ciudad de Medellín, Seguridad en el entorno, Justicia Especial para la Paz, Corrupción en América Latina y Victimas de trata de personas) temáticas soportadas en la guía de intervención pedagógica como lo muestra el anexo 5.

Definida la propuesta de intervención pedagógica desde la "dimensión estratégica" se procede a continuar con la segunda dimensión del modelo de coordenadas.

\section{Dimensión Operativa}

\section{- Prueba Diagnóstica - Pretest.}

La dimensión operativa para el caso de estudio particular está precedida de una prueba diagnóstica o Pretest (Anexo 6), punto de partida del método experimental para identificar los niveles iniciales del desarrollo de la competencia global en los estudiantes de noveno grado.

\section{Sección 4- Prueba diagnóstica o Pretest}

La prueba diagnóstica como lo muestra la tabla (59) detalla:

Tabla 59: Planeación Sección 4 - Prueba diagnóstica o Pretest

\begin{tabular}{|l|l|}
\hline$N^{\circ}$ Participantes & 45 personas \\
\hline $\begin{array}{l}\text { Clasificación de } \\
\text { participantes }\end{array}$ & $\begin{array}{l}\text { Estudiantes de noveno grado Institución Educativa Monseñor Francisco } \\
\text { Cristóbal Toro }\end{array}$ \\
\hline Objetivo & $\begin{array}{l}\text { Identificar los niveles de desarrollo de la competencia global en los } \\
\text { estudiantes de noveno grado de la Institución Educativa Monseñor Francisco } \\
\text { Cristóbal Toro }\end{array}$ \\
\hline Duración & 1 hora. \\
\hline
\end{tabular}

Fuente: Autor.

Evidencia Prueba Diagnóstica - Pretest. 

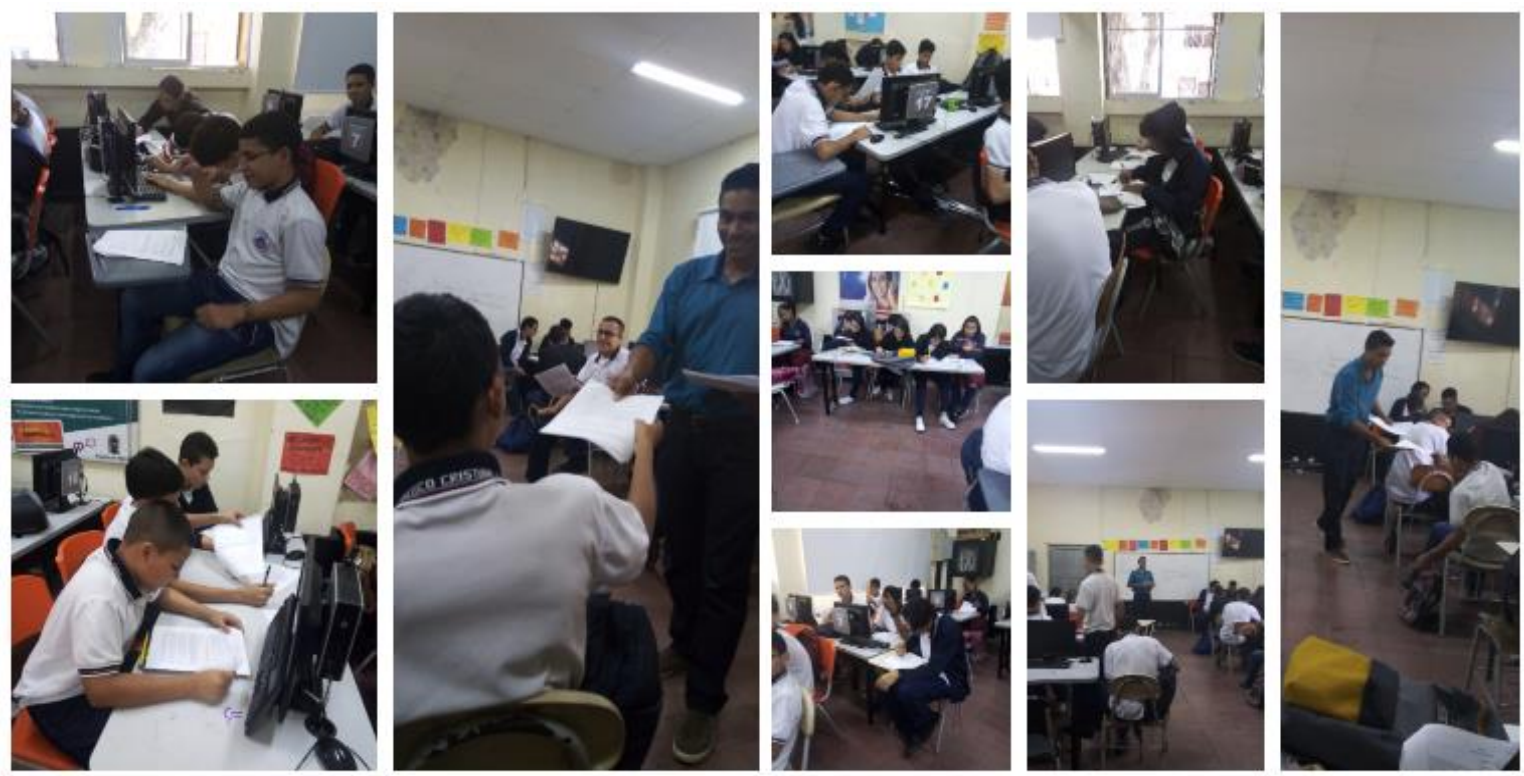

Ilustración 29: Presentación Pretest.

Fuente: Autor.

El instrumento evaluativo como se mencionó con anterioridad fue retomado a partir de la guía de orientación PISA 2018.

Los resultados de la prueba diagnóstica indican las siguientes tendencias a las 10 preguntas formuladas:

\section{1. ¿Qué tanto lo describen a usted cada una de las siguientes afirmaciones?}

Tabla 60: Pretest. ¿Qué tanto lo describen a usted cada una de las siguientes afirmaciones?

\begin{tabular}{|l|c|c|c|c|c|}
\hline Pregunta 1 & Bastante & Mucho & Algo & $\begin{array}{c}\text { No } \\
\text { mucho }\end{array}$ & $\begin{array}{c}\text { Para } \\
\text { nada }\end{array}$ \\
\hline $\begin{array}{l}\text { Ante un desacuerdo, trato de ver el } \\
\text { punto de vista de cada uno antes de } \\
\text { tomar una decisión. }\end{array}$ & 6 & 15 & 17 & 6 & 1 \\
\cline { 2 - 6 } & $13.3 \%$ & $33.3 \%$ & $37.8 \%$ & $13.3 \%$ & $2.2 \%$ \\
\hline $\begin{array}{l}\text { Creo que hay dos lados en cada } \\
\text { problema y trato de verlos a los dos. }\end{array}$ & 4 & 17 & 10 & 12 & 2 \\
\cline { 2 - 6 } & $8.9 \%$ & $37.8 \%$ & $22.2 \%$ & $26.7 \%$ & $4.4 \%$ \\
\hline
\end{tabular}

Fuente: Autor

El constructo evaluado corresponde a: Adopción de Perspectivas. El análisis patrones de puntos agregado ${ }^{37}$ indica.

${ }^{37}$ La densidad de los puntos es muy elevada en ciertas zonas. (Ripley, 1978) 
Tabla 61: Agregado pregunta $N^{\circ} 1$ Pretest.

\begin{tabular}{|l|c|l|l|c|c|}
\hline & Bastante & Mucho & Algo & No mucho & Para nada \\
\hline Recuento & 2 & 15 & 15 & 11 & 2 \\
\hline$\%$ & $4.4 \%$ & $33.3 \%$ & $33.3 \%$ & $24.4 \%$ & $4.4 \%$ \\
\hline
\end{tabular}

Fuente: Autor

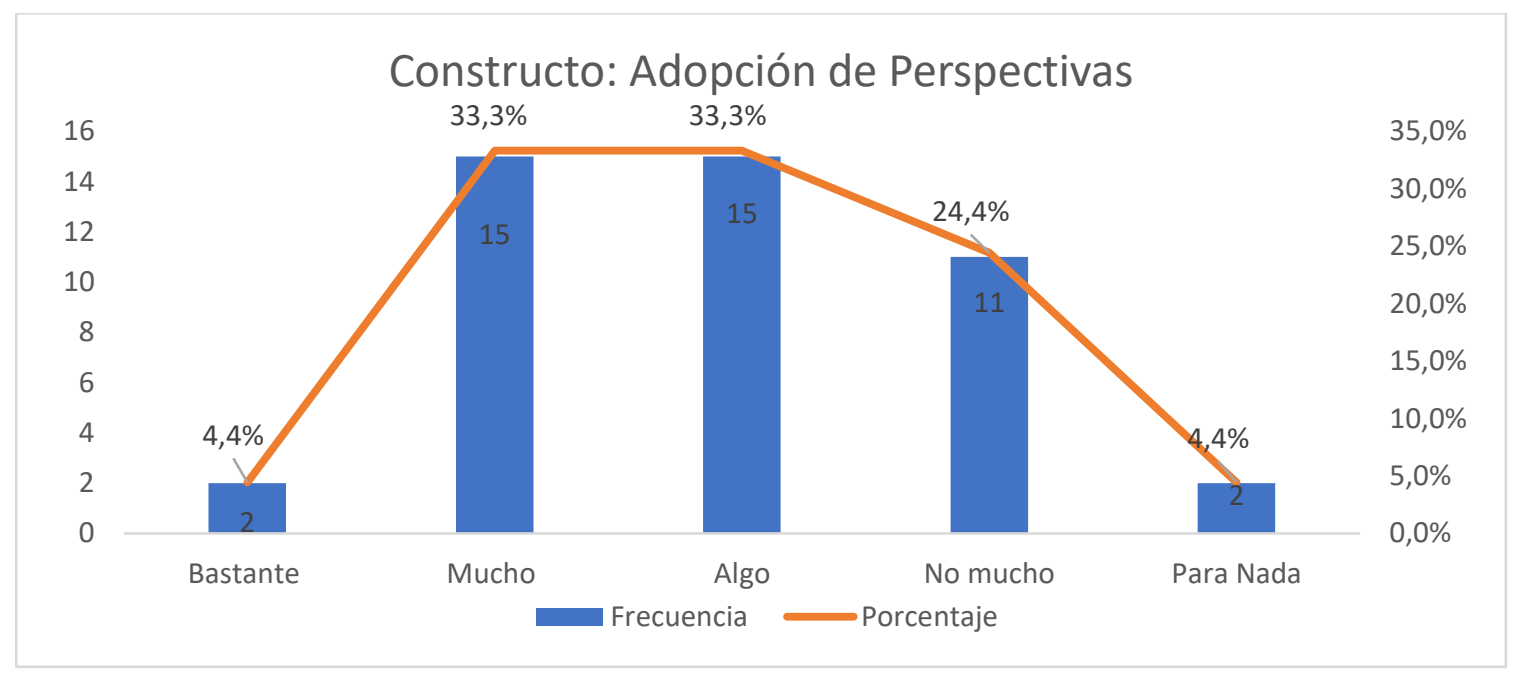

Ilustración 30: Pretest. Constructo: Adopción de perspectivas

Fuente: Autor.

Los resultados muestran que el constructo Adopción de perspectivas en la escala Mucho $(35,3 \%)$ y Algo $(33,3 \%)$ son las agrupaciones que predominan positivamente en el grupo con un $66,6 \%$.

\section{2. ¿Hasta qué punto está usted de acuerdo con las siguientes afirmaciones?}

Tabla 62: Pretest. ¿Hasta qué punto está usted de acuerdo con las siguientes afirmaciones?

\begin{tabular}{|l|c|c|c|c|}
\hline \multirow{2}{*}{ Pregunta 2 } & $\begin{array}{c}\text { Totalmente } \\
\text { en } \\
\text { desacuerdo }\end{array}$ & $\begin{array}{c}\text { En } \\
\text { desacuerdo }\end{array}$ & $\begin{array}{c}\text { De } \\
\text { acuerdo }\end{array}$ & $\begin{array}{c}\text { Totalmente } \\
\text { de acuerdo }\end{array}$ \\
\hline Pienso en mí mismo como un ciudadano del & 5 & 8 & 23 & 9 \\
\cline { 2 - 5 } mundo. & $11.1 \%$ & $17.8 \%$ & $51.1 \%$ & $20.0 \%$ \\
\hline $\begin{array}{l}\text { Cuando veo las malas condiciones en que } \\
\text { viven algunas personas en el mundo, siento } \\
\text { responsabilidad de hacer algo al respecto. }\end{array}$ & 2 & 17 & 19 & 7 \\
\hline Pienso que mi comportamiento puede tener & $4.4 \%$ & $37.8 \%$ & $42.2 \%$ & $15.6 \%$ \\
\cline { 2 - 5 } impacto sobre la gente en otros países. & $26.7 \%$ & $26.7 \%$ & $37.8 \%$ & $8.9 \%$ \\
\hline
\end{tabular}

Fuente: Autor.

El constructo evaluado corresponde a: Mentalidad Global. El análisis patrones de puntos agregado indica. 
Tabla 63: Agregado pregunta $N^{\circ} 2$ Pretest.

\begin{tabular}{|l|c|c|c|c|}
\hline & $\begin{array}{l}\text { Totalmente en } \\
\text { desacuerdo }\end{array}$ & En desacuerdo & De acuerdo & $\begin{array}{l}\text { Totalmente de } \\
\text { acuerdo }\end{array}$ \\
\hline Recuento & 8 & 6 & 29 & 2 \\
\hline$\%$ & $17.8 \%$ & $13.3 \%$ & $64.4 \%$ & $4.4 \%$ \\
\hline
\end{tabular}

Fuente: Autor

\section{Constructo: Mentalidad Global}

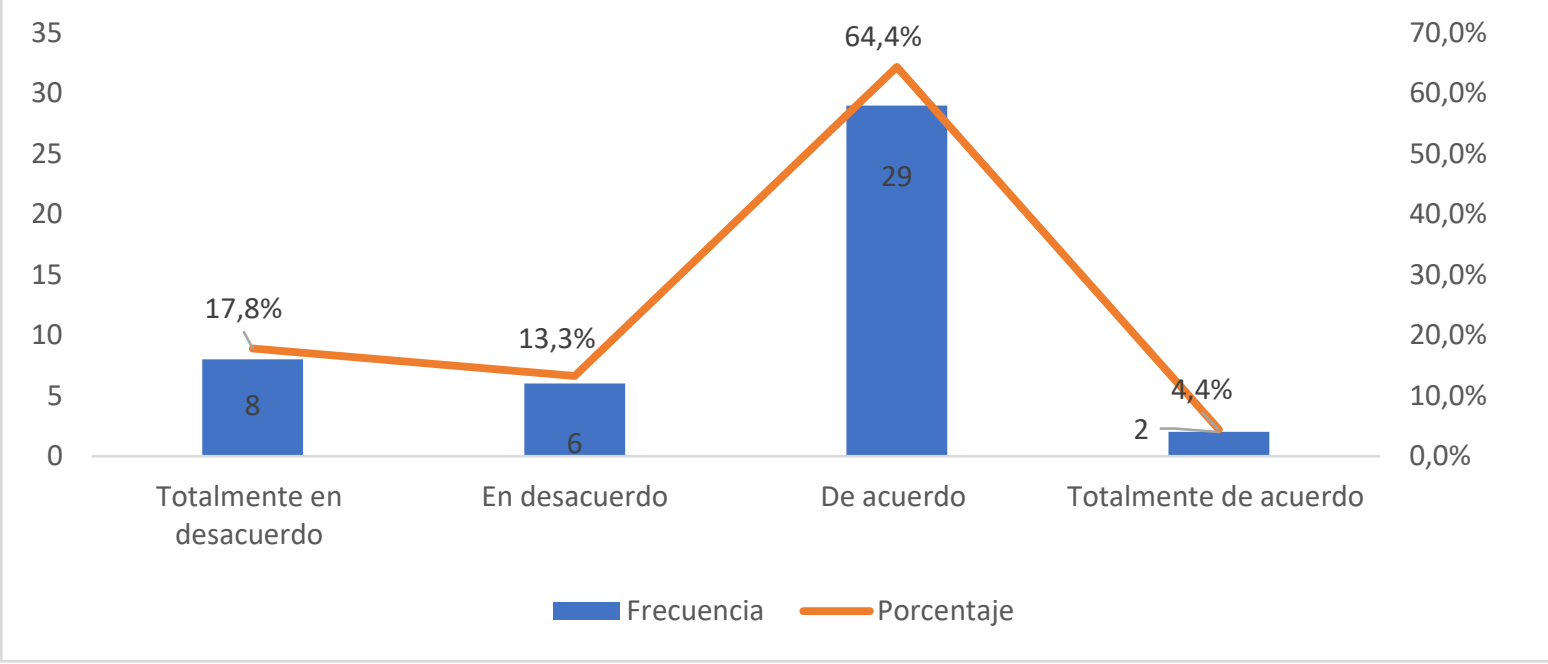

Ilustración 31: Pretest. Constructo: Mentalidad Global.

Fuente: Autor.

El 64,4\% de los datos se agruparon en la escala De acuerdo.

\section{3. ¿Qué tanto lo describen a usted cada una de las siguientes afirmaciones?}

Tabla 64: Pretest. ¿Qué tanto lo describen a usted cada una de las siguientes afirmaciones?

\begin{tabular}{|l|c|c|c|c|c|}
\hline \multirow{2}{*}{ Pregunta 3 } & Bastante & Mucho & Algo & $\begin{array}{c}\text { No } \\
\text { mucho }\end{array}$ & $\begin{array}{c}\text { Para } \\
\text { nada }\end{array}$ \\
\hline Puedo lidiar con situaciones inusuales. & 5 & 10 & 12 & 16 & 2 \\
\hline Puedo cambiar mi comportamiento para \\
cubrir las necesidades de nuevas situaciones. & $11.1 \%$ & $22.2 \%$ & $26.7 \%$ & $35.6 \%$ & $4.4 \%$ \\
\hline $\begin{array}{l}\text { Puedo adaptarme a diferentes situaciones } \\
\text { incluso cuando estoy bajo presión o estrés. }\end{array}$ & $22.2 \%$ & $26.7 \%$ & $22.2 \%$ & $26.7 \%$ & $2.2 \%$ \\
\cline { 2 - 6 } & $20.0 \%$ & $13.3 \%$ & $33.3 \%$ & $26.7 \%$ & $6.7 \%$ \\
\hline
\end{tabular}

Fuente: Autor.

El constructo evaluado corresponde a: Flexibilidad / Adaptabilidad. El análisis patrones de puntos agregado indica.

Tabla 65: Agregado pregunta $N^{\circ} 3$ Pretest. 


\begin{tabular}{|l|c|l|l|c|c|}
\hline & Bastante & Mucho & Algo & No mucho & Para nada \\
\hline Recuento & 4 & 10 & 16 & 13 & 2 \\
\hline$\%$ & $8.9 \%$ & $22.2 \%$ & $35.6 \%$ & $28.9 \%$ & $4.4 \%$ \\
\hline
\end{tabular}

Fuente: Autor

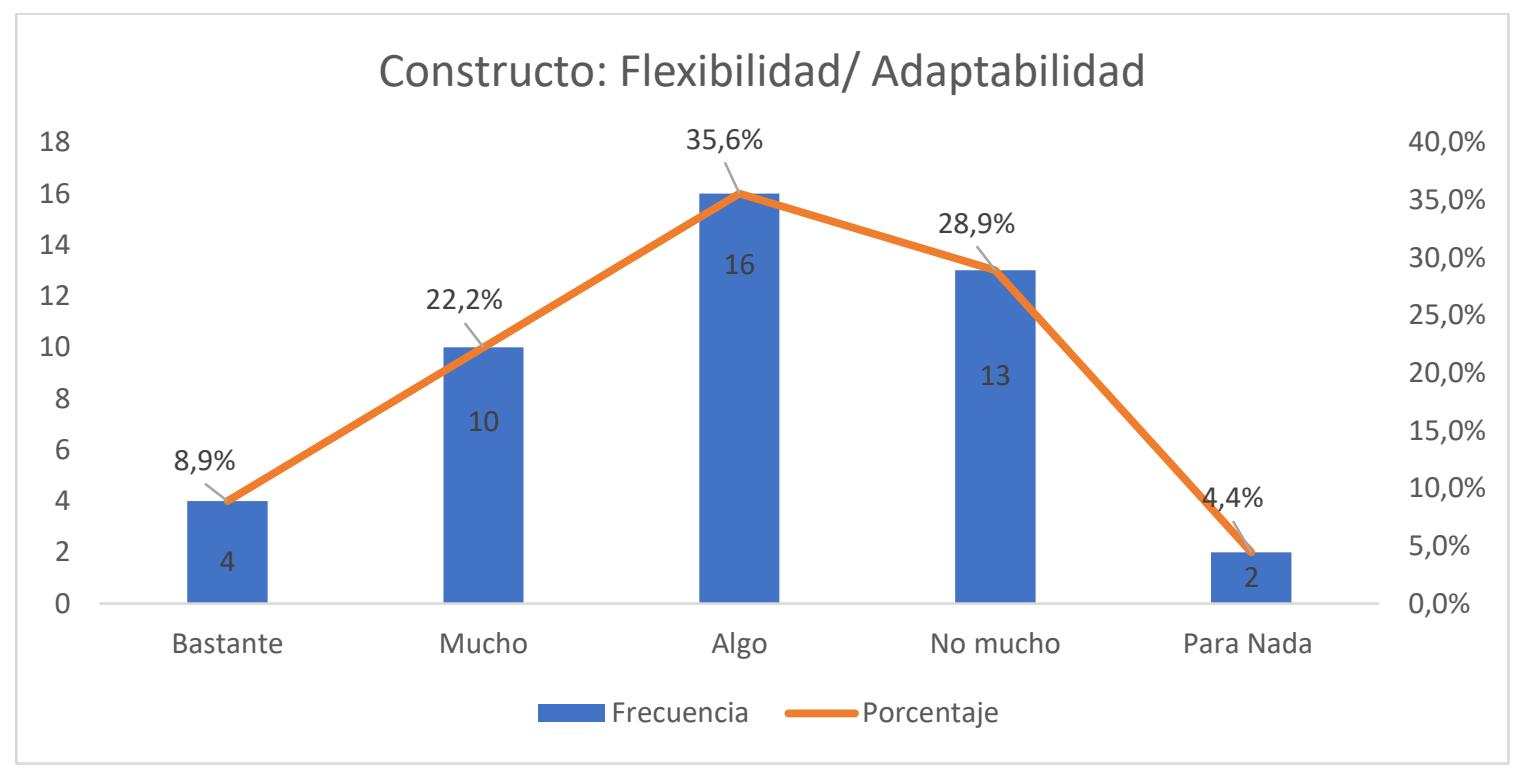

Ilustración 32: Pretest: Constructo: Flexibilidad / Adaptabilidad

Fuente: Autor.

El constructo Flexibilidad / Adaptabilidad indica gran dispersión entre los datos de respuesta, siendo la agrupación Para nada la de menor agrupación.

\section{4. ¿Hasta qué punto está usted de acuerdo con las siguientes afirmaciones?}

Tabla 66: Pretest. ¿Hasta qué punto está usted de acuerdo con las siguientes afirmaciones?

\begin{tabular}{|l|c|c|c|c|}
\hline \multirow{2}{*}{ Pregunta 4 } & $\begin{array}{c}\text { Totalmente } \\
\text { en } \\
\text { desacuerdo }\end{array}$ & $\begin{array}{c}\text { En } \\
\text { desacuerdo }\end{array}$ & $\begin{array}{c}\text { De } \\
\text { acuerdo }\end{array}$ & $\begin{array}{c}\text { Totalmente } \\
\text { de acuerdo }\end{array}$ \\
\hline $\begin{array}{l}\text { Observo cuidadosamente sus } \\
\text { reacciones. }\end{array}$ & 4 & 9 & 24 & 8 \\
\hline \multirow{2}{*}{$\begin{array}{l}\text { Verifico con frecuencia que nos } \\
\text { estemos entendiendo mutuamente. }\end{array}$} & $8.9 \%$ & $20.0 \%$ & $53.3 \%$ & $17.8 \%$ \\
\hline \multirow{2}{*}{ Escucho cuidadosamente lo dicen. } & $2.2 \%$ & $33.3 \%$ & $42.2 \%$ & $22.2 \%$ \\
\cline { 2 - 5 } & 3 & 6 & 26 & 10 \\
\hline
\end{tabular}

Fuente: Autor.

El constructo evaluado corresponde a: Conocimiento de la comunidad intercultural. El análisis patrones de puntos agregado indica. 
Tabla 67: Agregado pregunta $N^{\circ} 4$ Pretest.

\begin{tabular}{|l|c|c|c|c|}
\hline & $\begin{array}{l}\text { Totalmente en } \\
\text { desacuerdo }\end{array}$ & En desacuerdo & De acuerdo & $\begin{array}{l}\text { Totalmente de } \\
\text { acuerdo }\end{array}$ \\
\hline Recuento & 3 & 9 & 26 & 7 \\
\hline$\%$ & $6.7 \%$ & $20.0 \%$ & $57.8 \%$ & $15.6 \%$ \\
\hline
\end{tabular}

Fuente: Autor

\section{Constructo: Conocimiento de la comunicación intercultural}

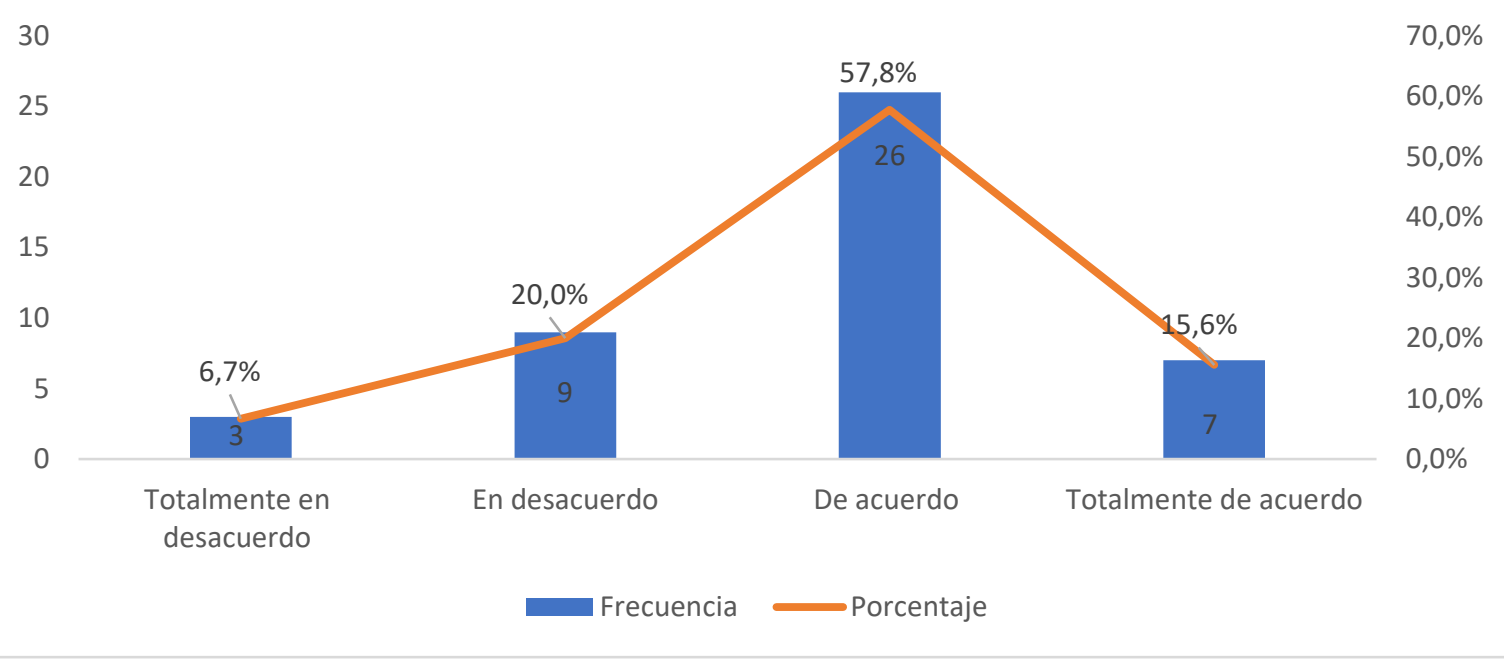

Ilustración 33: Pretest. Constructo: Conocimiento de la comunicación intercultural.

Fuente: Autor.

El constructo Conocimiento de la comunidad intercultural con un 57,8\% presentó mayor frecuencia de datos agrupados en la escala De acuerdo.

\section{5. ¿Con qué facilidad piensa usted que podría realizar las siguientes tareas por su cuenta?}

Tabla 68: Pretest. ¿Con qué facilidad piensa usted que podría realizar las siguientes tareas por su cuenta?

\begin{tabular}{|l|c|c|c|c|}
\hline & $\begin{array}{l}\text { No podría } \\
\text { hacer esto }\end{array}$ & $\begin{array}{l}\text { Me costaría } \\
\text { mucho trabajo } \\
\text { hacerlo solo }\end{array}$ & $\begin{array}{l}\text { Podría hacerlo } \\
\text { con algo de } \\
\text { esfuerzo }\end{array}$ & $\begin{array}{l}\text { Podría hacerlo } \\
\text { con fácilmente }\end{array}$ \\
\hline $\begin{array}{l}\text { Predecir cómo los cambios en un } \\
\text { entorno afectarán la supervivencia de } \\
\text { ciertas especies. }\end{array}$ & 7 & 20 & 16 & 2 \\
\hline \multirow{2}{*}{$\begin{array}{l}\text { Explicar cómo las emisiones de } \\
\text { dióxido de carbono influyen sobre el } \\
\text { cambio climático a nivel global. }\end{array}$} & $15.6 \%$ & $44.4 \%$ & $35.6 \%$ & $4.4 \%$ \\
\hline \multirow{nyyyy}{*}{$\begin{array}{l}\text { Establecer una relación entre los } \\
\text { precios de los textiles y las }\end{array}$} & 10 & 17 & 15 & 3 \\
\cline { 2 - 5 } & $26.7 \%$ & $37.8 \%$ & $33.3 \%$ & $6.7 \%$ \\
\hline
\end{tabular}


condiciones laborales en los países

productores.

Fuente: Autor.

El constructo evaluado corresponde a: Autoeficacia con respecto a asuntos globales. El análisis patrones de puntos agregado indica.

Tabla 69: Agregado pregunta $N^{\circ} 5$ Pretest.

\begin{tabular}{|l|c|c|c|c|}
\hline & $\begin{array}{l}\text { No podría } \\
\text { hacer esto }\end{array}$ & $\begin{array}{l}\text { Me costaría } \\
\text { mucho trabajo } \\
\text { hacerlo solo }\end{array}$ & $\begin{array}{l}\text { Podría hacerlo } \\
\text { con algo de } \\
\text { esfuerzo }\end{array}$ & $\begin{array}{l}\text { Podría hacerlo } \\
\text { con fácilmente }\end{array}$ \\
\hline Recuento & 6 & 26 & 13 & 0 \\
\hline$\%$ & $13.3 \%$ & $57.8 \%$ & $28.9 \%$ & $0.0 \%$ \\
\hline
\end{tabular}

Fuente: Autor

\section{Constructo: Autoeficacia con respecto a asuntos globales}

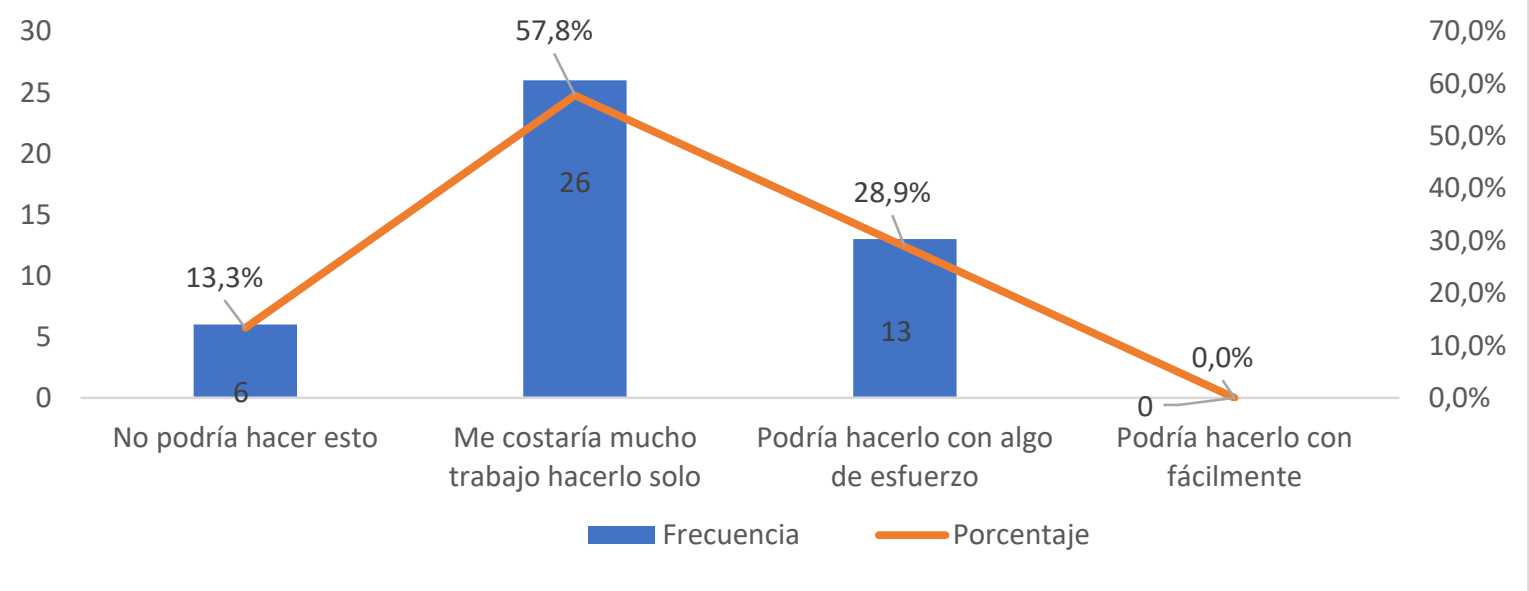

Ilustración 34: Pretest. Constructo: Autoeficacia con respecto a asuntos globales. Fuente: Autor.

El constructo Autoeficacia con respecto a asuntos globales indica una tendencia negativa con un $71.1 \%$ (No podría hacer esto y me costaría mucho trabajo hacerlo solo).

\section{6. ¿Qué tan informado está usted sobre los siguientes temas?}

Tabla 70: Pretest. ¿Qué tan informado está usted sobre los siguientes temas? 


\begin{tabular}{|c|c|c|c|c|}
\hline Pregunta 6 & $\begin{array}{l}\text { Nunca he } \\
\text { oído sobre } \\
\text { esto }\end{array}$ & $\begin{array}{l}\text { He oído sobre } \\
\text { esto, pero no } \\
\text { podría } \\
\text { explicar de } \\
\text { qué se trata } \\
\text { realmente } \\
\end{array}$ & $\begin{array}{l}\text { Sé algo sobre } \\
\text { esto y podría } \\
\text { explicar el } \\
\text { asunto en } \\
\text { general }\end{array}$ & \begin{tabular}{|l|} 
Estoy \\
familiarizado \\
sobre con esto y y \\
sería capaz de \\
explicarlo bien
\end{tabular} \\
\hline \multirow{2}{*}{$\begin{array}{l}\text { Cambio climático y calentamiento } \\
\text { global }\end{array}$} & 4 & 14 & 19 & 8 \\
\hline & $8.9 \%$ & $31.1 \%$ & $42.2 \%$ & $17.8 \%$ \\
\hline \multirow{2}{*}{$\begin{array}{l}\text { Salud en el mundo (p. ej., } \\
\text { epidemias) }\end{array}$} & 6 & 22 & 13 & 4 \\
\hline & $13.3 \%$ & $48.9 \%$ & $28.9 \%$ & $8.9 \%$ \\
\hline \multirow[b]{2}{*}{ Crecimiento poblacional } & 3 & 15 & 18 & 9 \\
\hline & $6.7 \%$ & $33.3 \%$ & $40.0 \%$ & $20.0 \%$ \\
\hline \multirow{2}{*}{$\begin{array}{l}\text { Migración (desplazamiento de } \\
\text { personas) }\end{array}$} & 2 & 11 & 26 & 6 \\
\hline & $4.4 \%$ & $24.4 \%$ & $57.8 \%$ & $13.3 \%$ \\
\hline \multirow{2}{*}{$\begin{array}{l}\text { Impactos de los desarrollos en la } \\
\text { economía global }\end{array}$} & 11 & 23 & 11 & 0 \\
\hline & $24.4 \%$ & $51.1 \%$ & $24.4 \%$ & $0.0 \%$ \\
\hline \multirow[b]{2}{*}{ Contaminación del aire } & 1 & 16 & 15 & 13 \\
\hline & $2.2 \%$ & $35.6 \%$ & $33.3 \%$ & $28.9 \%$ \\
\hline
\end{tabular}

Fuente: Autor.

El constructo evaluado corresponde a: conocimiento sobre asuntos globales. El análisis patrones de puntos agregado indica.

Tabla 71: Agregado pregunta $N^{\circ} 6$ Pretest.

\begin{tabular}{|l|l|l|l|l|}
\hline & $\begin{array}{l}\text { Nunca he } \\
\text { oído } \\
\text { sobre } \\
\text { esto }\end{array}$ & $\begin{array}{l}\text { He oído sobre esto, } \\
\text { pero no podría } \\
\text { explicar de qué se } \\
\text { trata realmente }\end{array}$ & $\begin{array}{l}\text { Sé algo sobre esto } \\
\text { y podría explicar } \\
\text { el asunto en } \\
\text { general }\end{array}$ & $\begin{array}{l}\text { Estoy } \\
\text { familiarizado } \\
\text { sobre con esto y } \\
\text { sería capaz de } \\
\text { explicarlo bien }\end{array}$ \\
\hline Recuento & 8 & 16 & 16 & 5 \\
\hline$\%$ & $17.8 \%$ & $35.6 \%$ & $35.6 \%$ & $11.1 \%$ \\
\hline
\end{tabular}

Fuente: Autor 


\section{Constructo: Conocimiento sobre asuntos globales}

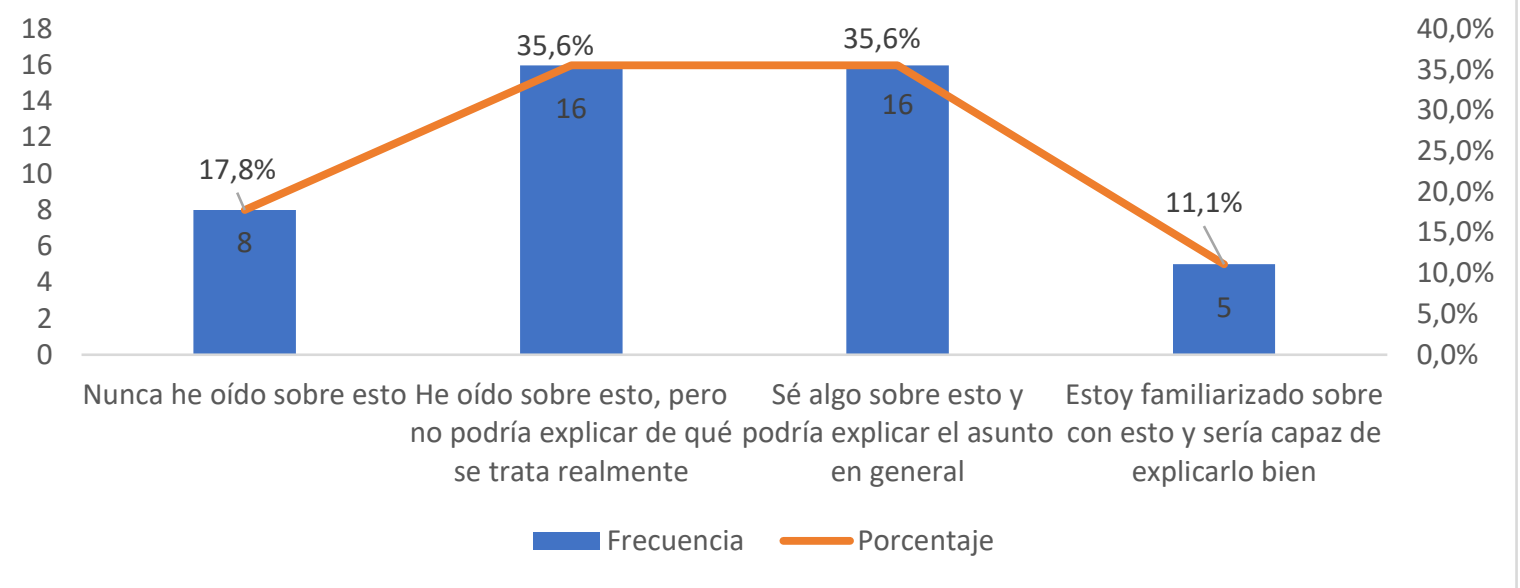

Ilustración 35: Pretest. Constructo: Conocimiento sobre asuntos globales.

Fuente: Autor.

El constructo Conocimiento sobre asuntos globales indican resultados con gran similitud en términos de tendencia negativa y positiva con un $53,4 \%$ y $46,6 \%$ respectivamente.

\section{La gente se traslada, cada vez más, de un país a otro ¿Qué tanto está usted de acuerdo con las siguientes afirmaciones sobre los inmigrantes?}

Tabla 72: Pretest. La gente se traslada, cada vez más, de un país a otro ¿Qué tanto está usted de acuerdo con las siguientes afirmaciones sobre los inmigrantes?

\begin{tabular}{|l|c|c|c|c|}
\hline \multirow{2}{*}{ Pregunta 7 } & $\begin{array}{l}\text { Totalmente en } \\
\text { desacuerdo }\end{array}$ & $\begin{array}{l}\text { En } \\
\text { desacuerdo }\end{array}$ & $\begin{array}{l}\text { De } \\
\text { acuerdo }\end{array}$ & $\begin{array}{l}\text { Totalmente de } \\
\text { acuerdo }\end{array}$ \\
\hline $\begin{array}{l}\text { Se debería animar a los inmigrantes a que } \\
\text { continúen hablando su propio idioma. }\end{array}$ & 9 & 9 & 21 & 6 \\
\cline { 2 - 5 } $\begin{array}{l}\text { Los niños inmigrantes deberían tener las } \\
\text { mismas oportunidades para la educación } \\
\text { que otros niños en el país. }\end{array}$ & $20.0 \%$ & $20.0 \%$ & $46.7 \%$ & $13.3 \%$ \\
\cline { 2 - 5 } $\begin{array}{l}\text { Los inmigrantes que viven en el país } \\
\text { durante varios años deberían tener } \\
\text { derecho a votar en las elecciones. }\end{array}$ & $2.2 \%$ & 7 & 20 & 17 \\
\cline { 2 - 5 } & $13.3 \%$ & $15.6 \%$ & $44.4 \%$ & $37.8 \%$ \\
\hline
\end{tabular}

Fuente: Autor.

El constructo evaluado corresponde a: Actitudes frente a los inmigrantes. El análisis patrones de puntos agregado indica.

Tabla 73: Agregado pregunta $N^{\circ} 7$ Pretest. 


\begin{tabular}{|l|c|c|c|c|}
\hline & $\begin{array}{l}\text { Totalmente en } \\
\text { desacuerdo }\end{array}$ & En desacuerdo & De acuerdo & $\begin{array}{l}\text { Totalmente de } \\
\text { acuerdo }\end{array}$ \\
\hline Recuento & 4 & 16 & 20 & 5 \\
\hline$\%$ & $8.9 \%$ & $35.6 \%$ & $44.4 \%$ & $11.1 \%$ \\
\hline
\end{tabular}

Fuente: Autor

\section{Constructo: Actitudes frente a los inmigrantes}

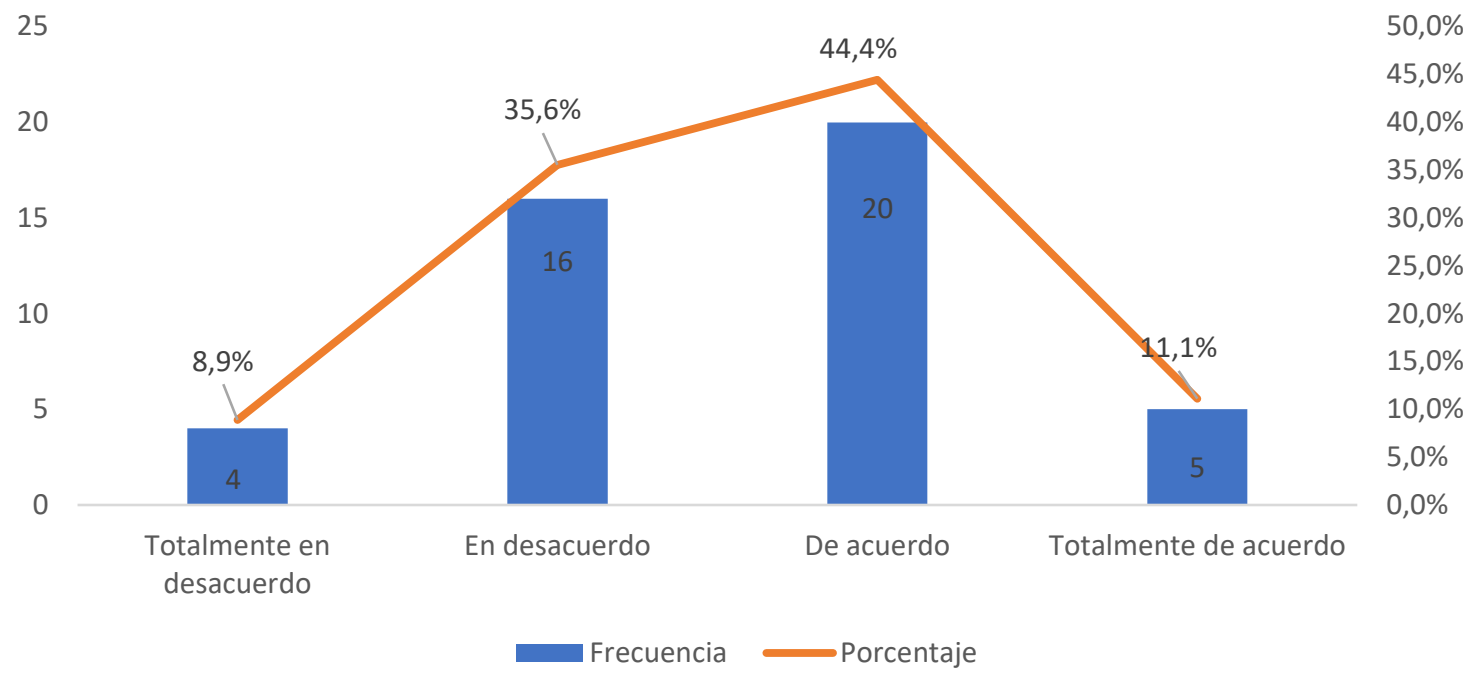

Ilustración 36: Pretest. Constructo: Actitudes frente a los inmigrantes.

Fuente: Autor.

No se evidencia una tendencia en el constructo Actitudes frente a los inmigrantes definida en términos positivos o negativos.

\section{Con respecto a los profesores de su colegio: ¿a cuántos de ellos aplican las siguientes afirmaciones?}

Tabla 74: Pretest. Con respecto a los profesores de su colegio: ¿a cuántos de ellos aplican las siguientes afirmaciones?

\begin{tabular}{|l|c|c|c|c|}
\hline \multirow{2}{*}{ Pregunta 8 } & $\begin{array}{l}\text { A ninguno o } \\
\text { casi ninguno } \\
\text { de ellos }\end{array}$ & $\begin{array}{l}\text { Alguno de } \\
\text { ellos }\end{array}$ & $\begin{array}{l}\text { A la } \\
\text { mayoría de } \\
\text { ellos }\end{array}$ & $\begin{array}{l}\text { A todos o } \\
\text { casi a todos } \\
\text { ellos }\end{array}$ \\
\hline \multirow{2}{*}{$\begin{array}{l}\text { Hablan de forma respetuosa sobre las personas } \\
\text { de todos los grupos culturales. }\end{array}$} & 4 & 11 & 16 & 14 \\
\cline { 2 - 5 } $\begin{array}{l}\text { Tienen ideas erróneas sobre la historia de } \\
\text { algunos grupos culturales. }\end{array}$ & $8.9 \%$ & $24.4 \%$ & $35.6 \%$ & $31.1 \%$ \\
\hline \multirow{2yyyy}{*}{$\begin{array}{l}\text { Están abiertos al contacto personal con } \\
\text { personas de todos los grupos culturales. }\end{array}$} & $40.0 \%$ & 17 & 9 & 1 \\
\cline { 2 - 5 } & $24.4 \%$ & $11.8 \%$ & $20.0 \%$ & $2.2 \%$ \\
\hline
\end{tabular}


Dicen cosas negativas sobre las personas de algunos grupos culturales.

Culpan a las personas de algunos grupos culturales por los problemas que enfrenta <país de la prueba>

\begin{tabular}{|c|c|c|c|}
27 & 12 & 5 & 1 \\
\hline $60.0 \%$ & $26.7 \%$ & $11.1 \%$ & $2.2 \%$ \\
\hline 23 & 15 & 5 & 2 \\
\hline $51.1 \%$ & $33.3 \%$ & $11.1 \%$ & $4.4 \%$ \\
\hline
\end{tabular}

Fuente: Autor.

El constructo evaluado corresponde a: Clima escolar - clima escolar multicultural. El análisis patrones de puntos agregado indica.

Tabla 75: Agregado pregunta No8 Pretest.

\begin{tabular}{|l|c|c|c|c|}
\hline & $\begin{array}{l}\text { A ninguno o casi } \\
\text { ninguno de ellos }\end{array}$ & Alguno de ellos & $\begin{array}{l}\text { A la mayoría de } \\
\text { ellos }\end{array}$ & $\begin{array}{l}\text { A todos o casi a } \\
\text { todos ellos }\end{array}$ \\
\hline Recuento & 8 & 27 & 10 & 0 \\
\hline$\%$ & $17.8 \%$ & $60.0 \%$ & $22.2 \%$ & $0.0 \%$ \\
\hline
\end{tabular}

Fuente: Autor

\section{Constructo: Clima escolar - Clima escolar multicultural}

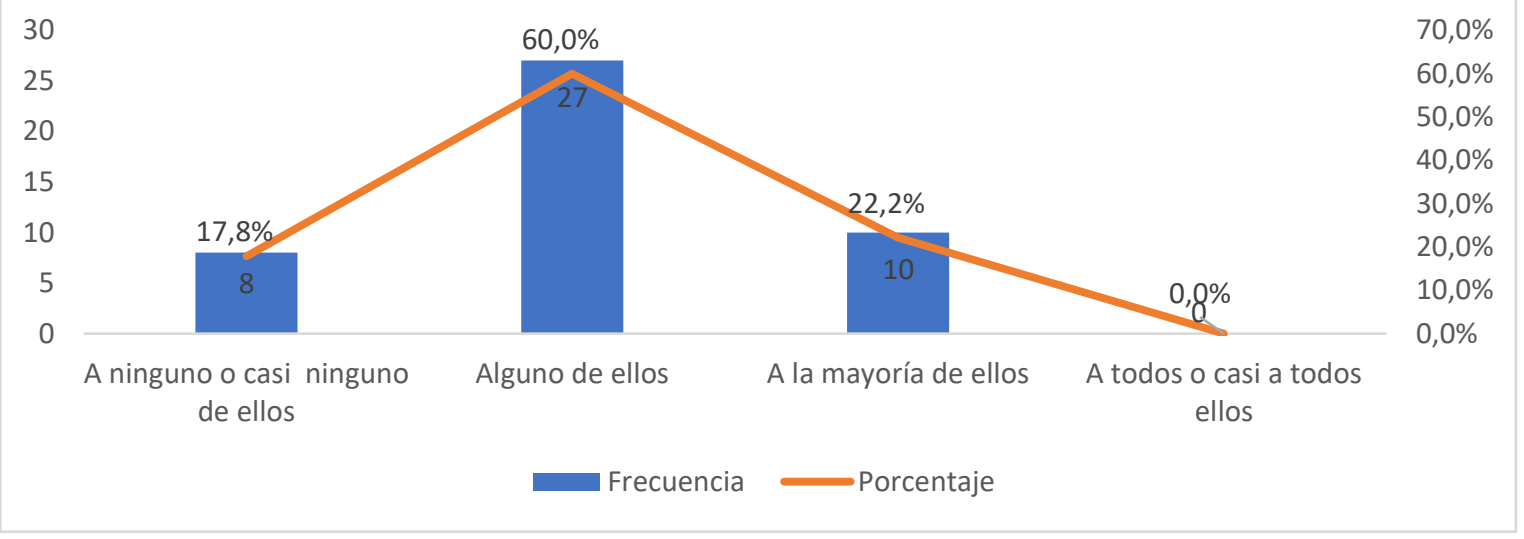

Ilustración 37: Pretest. Constructo: Clima escolar - Clima escolar multicultural.

Fuente: Autor.

Los datos agrupados indican tendencia hacia las escalas de ninguna, poca o alguna ocurrencia

9. Caso de estudio 1.

Tabla 76: Pretest. Caso de estudio $N^{\circ} 1$.

\begin{tabular}{|l|c|c|}
\hline \multirow{2}{*}{ Pregunta 9 } & \multicolumn{2}{|c|}{$\begin{array}{c}\text { Entender diferencias en la } \\
\text { comunicación }\end{array}$} \\
\cline { 2 - 3 } & Frec. & $\%$ \\
\hline Crédito total & 16 & 35.56 \\
\hline Crédito parcial & 4 & 8.89 \\
\hline Sin crédito & 25 & 55.56 \\
\hline
\end{tabular}

Fuente: Autor. 
El proceso cognitivo evaluado corresponde a: Entender diferencias en la comunicación. El análisis estadístico agregado indica.

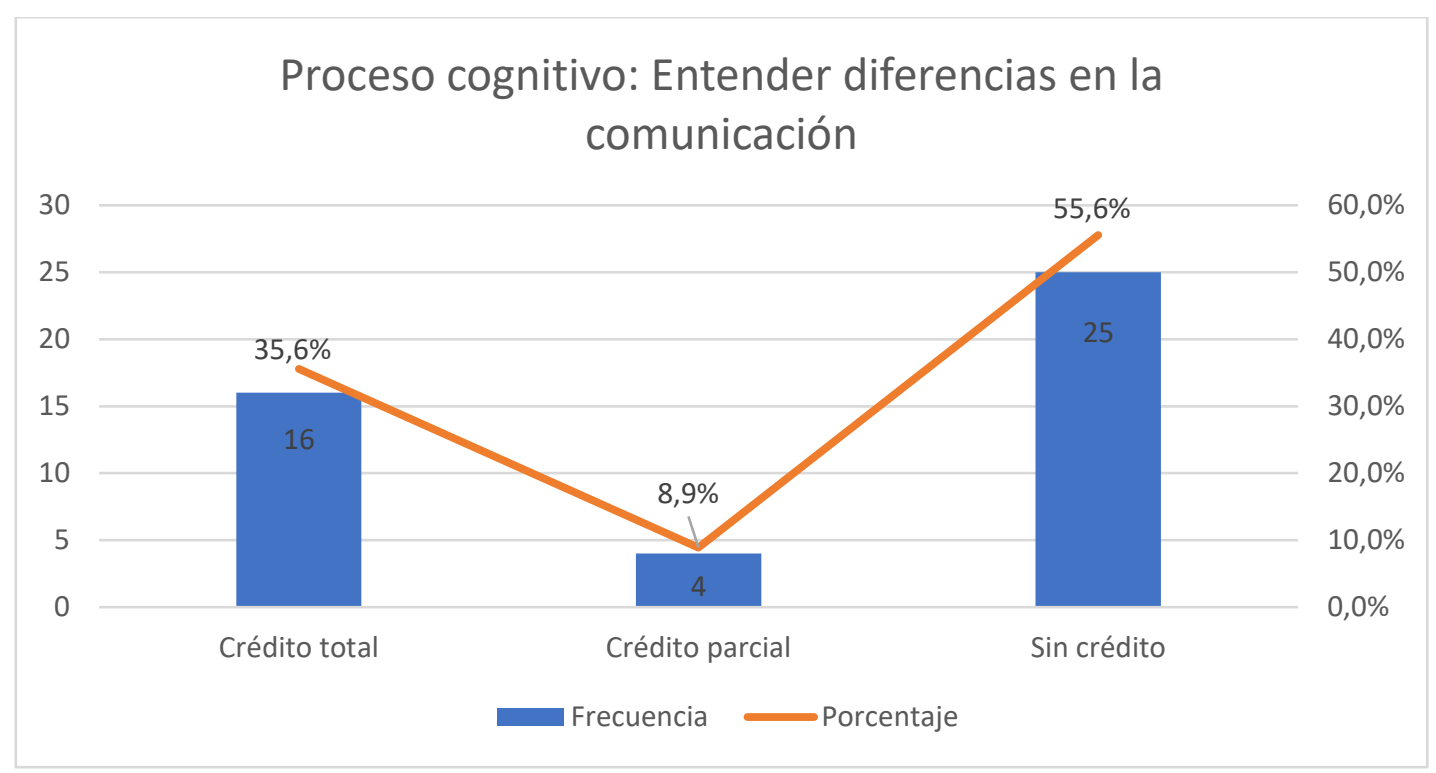

Ilustración 38: Pretest. Proceso cognitivo: Entender diferencias en la comunicación. Fuente: Autor.

El proceso cognitivo Entender diferencias en la comunicación, mostró un resultado desfavorable con mayor frecuencia en el grupo con un 55,6\% al no tener créditos las respuestas.

10. Caso de estudio 2.

Tabla 77: Pretest. Caso de estudio $N^{\circ} 2$.

\begin{tabular}{|c|c|c|}
\hline \multirow{2}{*}{ Pregunta 10 } & \multicolumn{2}{|c|}{$\begin{array}{c}\text { Evaluar información, formular } \\
\text { argumentos y explicar asuntos o } \\
\text { situaciones. }\end{array}$} \\
\cline { 2 - 3 } Crédito total & Frec. & $\%$ \\
\hline Sin crédito & 9 & 20.00 \\
\hline
\end{tabular}

Fuente: Autor. 
El proceso cognitivo evaluado corresponde a: Evaluar información, formular argumentos y explicar asuntos o situaciones. El análisis estadístico agregado indica.

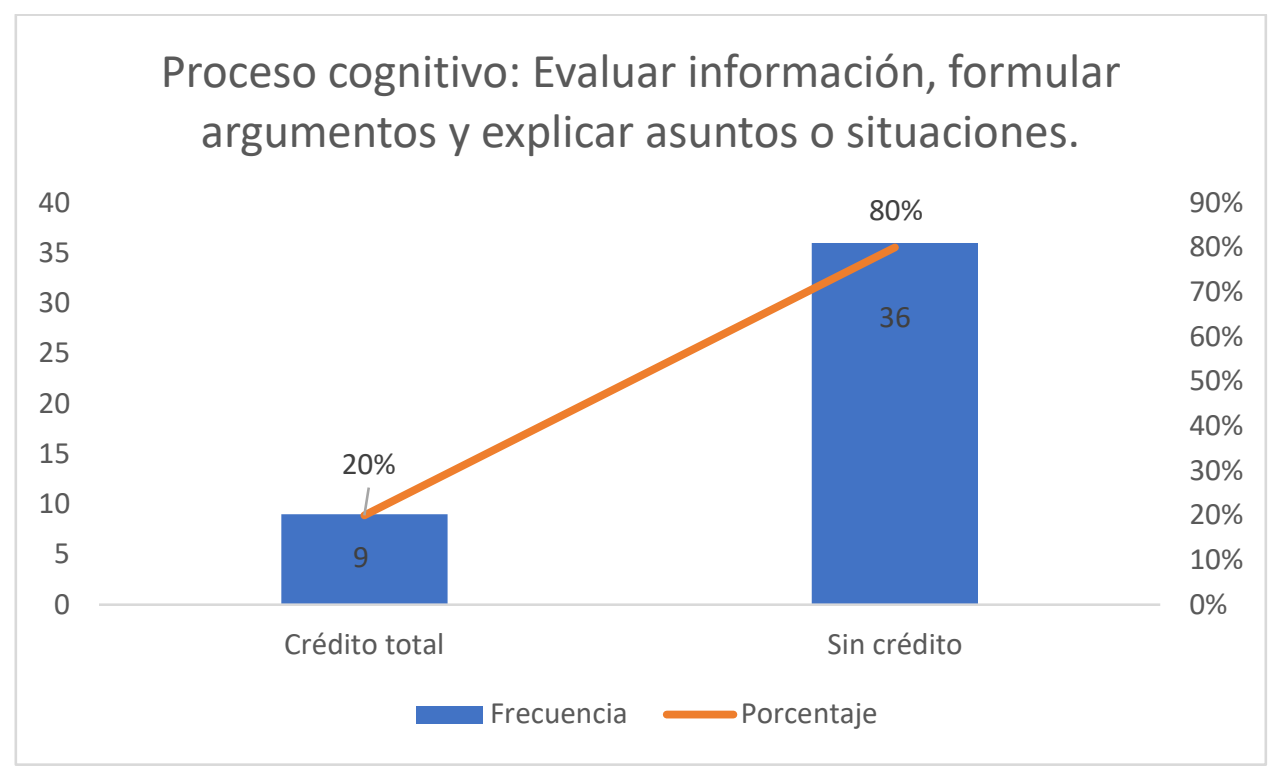

Ilustración 39: Pretest. Proceso cognitivo: Evaluar información, formular argumentos y explicar asuntos o situaciones.

Fuente: Autor.

El proceso cognitivo Evaluar información, formular argumentos y explicar asuntos o situaciones, mostró un resultado desfavorable con mayor frecuencia en el grupo con un $80 \%$ al no tener créditos las respuestas.

Identificado los niveles de desarrollo de la competencia global se procede a dar continuidad a la intervención pedagógica a partir del modelo de coordenadas curriculares.

\section{- Intervención Pedagógica}

La dimensión operativa corresponde a las 7 secciones de trabajo planteadas para abordar las temáticas para el desarrollo de la competencia global y contribuir con el desarrollo sostenible desde la asignatura de ciencias sociales.

En este sentido, la matriz de la dimensión operativa considera las siguientes categorías para ejecutar las acciones al interior del aula de clase.

Ilustración 40: Coordenadas dimensión operativa.

\begin{tabular}{|c|c|c|}
\hline \multicolumn{3}{|c|}{ Coordenadas Dimensión Operativa } \\
\hline Medios Educativos & Personas & $\begin{array}{l}\text { Procesos de } \\
\text { Innovación }\end{array}$ \\
\hline
\end{tabular}




\begin{tabular}{|l|l|l|}
\hline 4. Software & 6. Estudiante & 4. Técnicas \\
5. Hardware & 7. Profesor & 5. Métodos \\
6. Aulas especializadas & 8. Acudiente & 6. Metodología. \\
& 9. Especialistas & \\
\hline
\end{tabular}

Fuente: Autor.

Las secciones de clase se orientan bajo la guía de intervención pedagógica (anexo 2) como material de apoyo.

Sección 5: Taller: Estilos de conflictos.

La sección de clase sigue los siguientes criterios metodológicos.

Tabla 78: Sección - Taller: Estilos de conflictos.

Identificación del plan de área

\begin{tabular}{|l|l|}
\hline $\begin{array}{l}\text { Asignatura } \\
\text { (Secuencias Didácticas) }\end{array}$ & $\begin{array}{l}\text { Asignatura Base: Ciencias sociales. } \\
\text { Asignaturas complementarias: Humanidades-Lengua Castellana, matemáticas, } \\
\text { ciencias naturales. }\end{array}$ \\
\hline $\begin{array}{l}\text { Objetivo Área } \\
\text { (DBA) }\end{array}$ & $\begin{array}{l}\text { Analizar críticamente los elementos constituyentes de la democracia, los derechos } \\
\text { de las personas y la identidad en Colombia, reconociendo la interacción permanente } \\
\text { entre el espacio geográfico y el ser humano, los avances y limitaciones de esta } \\
\text { relación. }\end{array}$ \\
\hline Objetivo Específico & Identificar los estilos de conflictos. \\
\hline ODS & $\begin{array}{l}\text { Paz, justicia e instituciones sólidas. } \\
\text { Meducir considerablemente todas las formas de violencia y las tasas de } \\
\text { mortalidad conexas en todo el mundo. } \\
\text { Garantizar la adopción de decisiones inclusivas, participativas y representativas } \\
\text { que respondan a las necesidades a todos los niveles. }\end{array}$ \\
\hline
\end{tabular}

\section{Planificación de Acciones Pedagógicas}

\begin{tabular}{|l|l|l|}
\hline \multicolumn{1}{|c|}{ Qué } & $\begin{array}{l}\text { Proceso } \\
\text { Cognitivo }\end{array}$ & $\begin{array}{l}\text { Comprender las diferencias en la comunicación. } \\
\text { Evaluar acciones y consecuencias. }\end{array}$ \\
\cline { 2 - 3 } & $\begin{array}{l}\text { Mediadores de } \\
\text { Desempeño }\end{array}$ & $\begin{array}{l}\bullet \quad \text { Conocimiento intercultural. } \\
\bullet \quad \text { Respeto. }\end{array}$ \\
\cline { 2 - 3 } & $\begin{array}{l}\text { Dominios de } \\
\text { Contenido }\end{array}$ & Conflictoración de los derechos humanos fundamentales (dignidad humana). \\
\cline { 2 - 4 } & Contexto & Personal. \\
\hline Cómo & $\begin{array}{l}\text { Procesos de } \\
\text { Innovación }\end{array}$ & Técnica: Árbol de problemas. \\
\hline \multirow{2}{*}{ Por qué } & $\begin{array}{l}\text { Evidencia de } \\
\text { Aprendizaje }\end{array}$ & $\begin{array}{l}\text { Clasifica su estilo personal para la resolución de conflictos de acuerdo con la } \\
\text { teoría de Tomas - Kilmann. }\end{array}$ \\
\hline Dónde & $\begin{array}{l}\text { Medios } \\
\text { Educativos }\end{array}$ & Aula especializada. \\
\hline
\end{tabular}




\begin{tabular}{|l|l|l|}
\hline Quién & Personas & Profesor; Estudiante. \\
\hline Cuánto & Materiales & $\begin{array}{l}\text { Prueba "Estilos de conflicto de Thomas - Kilmann", copias Plantilla Árbol de } \\
\text { Problemas, papel periódico, cuaderno, lápiz, lapicero, borrador cuaderno, tablero, } \\
\text { marcadores, borrador tablero, computador y video proyector. }\end{array}$ \\
\hline Cuándo & Tiempo & 120 minutos \\
\hline
\end{tabular}

\section{Planeador de Clase}

\begin{tabular}{|c|c|c|c|}
\hline $\begin{array}{c}\text { Etapa } \\
\text { Clase/ } \\
\text { Tiempo }\end{array}$ & Actividad & $\begin{array}{c}\text { Evidencia } \\
\text { Aprendizaje }\end{array}$ & Materiales \\
\hline $\begin{array}{c}\text { Inicio } \\
(20 / 120)\end{array}$ & $\begin{array}{l}\text { Distribución de grupos } \\
\text { Se organizan los estudiantes en grupos de } 4 \\
\text { integrantes. En cada grupo se distribuyen los } \\
\text { roles de la siguiente manera: } \\
\text { - Vocero: comunica los resultados del } \\
\text { equipo. } \\
\text { - Relojero: controla el tiempo de la } \\
\text { actividad y recoge el material. } \\
\text { - Dinamizador: Se encarga de que todos } \\
\text { participen y se respeten los turno. } \\
\text { - Lector: Realiza la lectura. } \\
\text { Identificación de Aprendizajes previos } \\
\text { En los grupos se discute alrededor de las } \\
\text { siguientes preguntas, mediante el árbol de } \\
\text { - ¿Qroblemas: } \\
\text { ¿Cuáles son los factores que originan } \\
\text { conflicto? } \\
\text { 2. El dinamizador modera la discusión } \\
\text { sobre las dos preguntas guía. } \\
\text { El vocero de cada grupo socializa las } \\
\text { respuestas de cada pregunta. } \\
\text { - }\end{array}$ & $\begin{array}{c}\text { Identifican las } \\
\text { motivaciones que } \\
\text { generan el } \\
\text { conflicto desde } \\
\text { las perspectivas } \\
\text { de la moral y la } \\
\text { justicia. }\end{array}$ & $\begin{array}{l}\text { copias Plantilla } \\
\text { Árbol de } \\
\text { Problemas, papel } \\
\text { periódico, } \\
\text { cuaderno, lápiz, } \\
\text { lapicero, borrador } \\
\text { cuaderno, tablero, } \\
\text { marcadores, } \\
\text { borrador tablero, } \\
\text { computador y video } \\
\text { proyector. }\end{array}$ \\
\hline $\begin{array}{c}\text { Desarrollo } \\
(\mathbf{7 0 / 1 2 0 )}\end{array}$ & $\begin{array}{l}\text { Presentación de la Prueba "Estilos de } \\
\text { conflicto de Thomas - Kilmann" } \\
\text { 1. El docente explica cómo se debe } \\
\text { diligenciar la prueba. } \\
\text { 2. El relojero recibe las pruebas y las } \\
\text { entrega a cada uno de los miembros } \\
\text { del grupo para su diligenciamiento. } \\
\text { (Anexo al protocolo de planeación). } \\
\text { Cada miembro de grupo diligencia la } \\
\text { prueba identificando su clasificación } \\
\text { personal y la del subgrupo. }\end{array}$ & $\begin{array}{l}\text { El estudiante } \\
\text { identifica su estilo } \\
\text { de resolución de } \\
\text { conflictos de } \\
\text { acuerdo con la } \\
\text { clasificación de } \\
\text { Thomas - } \\
\text { Kilmann" y } \\
\text { establece la } \\
\text { predominancia en } \\
\text { el grupo de } \\
\text { acuerdo con la } \\
\text { misma. }\end{array}$ & $\begin{array}{l}\text { Fotocopias de la } \\
\text { prueba "Estilos de } \\
\text { conflicto de } \\
\text { Thomas - } \\
\text { Kilmann" }\end{array}$ \\
\hline
\end{tabular}




\begin{tabular}{|c|c|c|c|}
\hline & $\begin{array}{l}\text { 4. El docente organiza la plenaria para } \\
\text { que cada grupo exponga la } \\
\text { clasificación según la prueba. }\end{array}$ & & \\
\hline $\begin{array}{c}\text { Cierre } \\
(\mathbf{3 0} / 120)\end{array}$ & $\begin{array}{l}\text { Socialización } \\
\text { 1. El vocero presenta la predominancia del } \\
\text { equipo de trabajo para la resolución de } \\
\text { conflictos según la clasificación de resolución } \\
\text { de conflictos de Thomas - Kilmann. } \\
\text { 2. El docente dirige la plenaria y toma nota } \\
\text { sobre la clasificación de cada subgrupo para } \\
\text { explicar la predominancia del grupo para la } \\
\text { resolución de conflictos. } \\
\text { Conclusiones del ejercicio } \\
\text { 3. El docente totaliza las clasificaciones para } \\
\text { realimentar sobre la clasificación general } \\
\text { del grupo en relación con los estilos de } \\
\text { conflictos. }\end{array}$ & $\begin{array}{l}\text { El estudiante } \\
\text { identifica su estilo } \\
\text { de resolución de } \\
\text { conflictos de } \\
\text { acuerdo con la } \\
\text { clasificación de } \\
\text { Thomas - } \\
\text { Kilmann"y } \\
\text { establece la } \\
\text { predominancia en } \\
\text { el grupo de } \\
\text { acuerdo con la } \\
\text { misma. }\end{array}$ & $\begin{array}{l}\text { Tablero, } \\
\text { marcadores, } \\
\text { borrador tablero, } \\
\text { computador y video } \\
\text { proyector. }\end{array}$ \\
\hline
\end{tabular}

Fuente: Autor.

\section{Evidencia trabajo en clase}
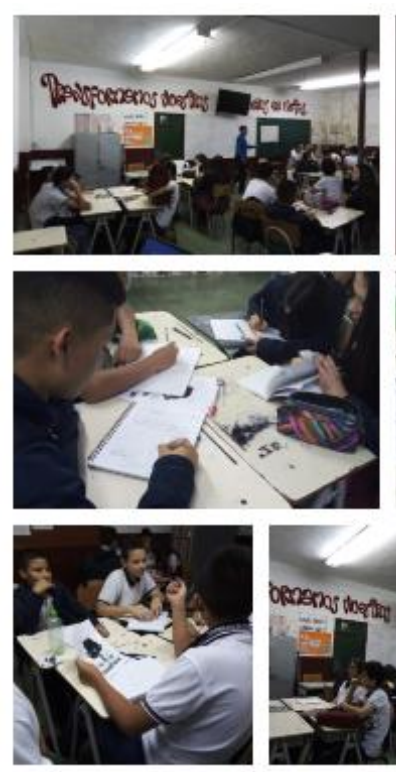
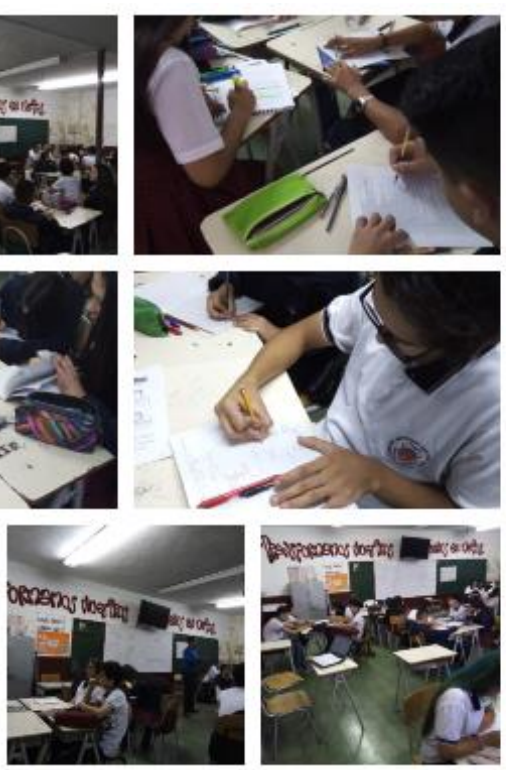
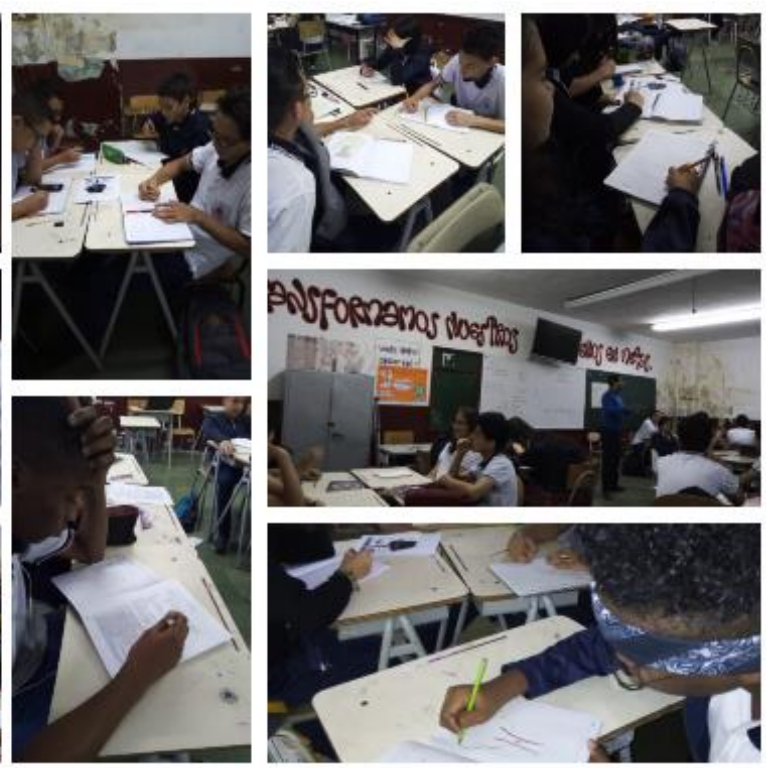

Ilustración 41: Evidencias, taller: Estilos de conflictos Fuente: Autor.

La utilización de la técnica del árbol de problemas permitió identificar las situaciones negativas (problema central) en el grupo, además del reconocimiento de las debilidades a partir de la lluvia de ideas, identificando las causas y efectos a partir del problema central. 
La técnica del árbol de problemas promueve la innovación al cobrar relevancia la transferencia y difusión de ideas (OCDE, 2005).

La clasificación de resolución de conflictos de Thomas - Kilmann permitió identificar el estilo individual, el equipo de trabajo y grupo en general, dicha clasificación correspondió al estilo Competitivo "ganar a toda costa y hacer valer la posición de uno mismo" (Thomas \& Kilmann, 1974)

La reflexión final del grupo determinó la importancia de resolver los conflictos en el que se satisfagan todas las partes.

Sección 6: Taller: Mediación escolar.

La sección de clase se orienta bajo los siguientes criterios metodológicos.

Tabla 79: Sección - Taller: Mediación escolar.

\section{Identificación del plan de área}

\begin{tabular}{|l|l|}
\hline $\begin{array}{l}\text { Asignatura } \\
\text { (Secuencias Didácticas) }\end{array}$ & $\begin{array}{l}\text { Asignatura Base: Ciencias sociales } \\
\text { Asignaturas complementarias: Humanidades-Lengua Castellana, matemáticas, } \\
\text { ciencias naturales. }\end{array}$ \\
\hline $\begin{array}{l}\text { Objetivo Área } \\
\text { (DBA) }\end{array}$ & $\begin{array}{l}\text { Analizar críticamente los elementos constituyentes de la democracia, los derechos } \\
\text { de las personas y la identidad en Colombia, reconociendo la interacción permanente } \\
\text { entre el espacio geográfico y el ser humano, los avances y limitaciones de esta } \\
\text { relación. }\end{array}$ \\
\hline Objetivo Específico & Identificar el alcance de los mecanismos de mediación escolar. \\
\hline ODS & Paz, justicia e instituciones sólidas. \\
\hline Meta ODS & $\begin{array}{l}\text { Promover el estado de derecho en los planos nacional e internacional y } \\
\text { garantizar la igualdad de acceso a la justicia para todos. } \\
\text { Crear instituciones eficaces, responsables y transparentes a todos los } \\
\text { niveles. } \\
\text { Garantizar la adopción de decisiones inclusivas, participativas y } \\
\text { representativas que respondan a las necesidades a todos los niveles. }\end{array}$ \\
\hline
\end{tabular}

\section{Planificación de Acciones Pedagógicas}

\begin{tabular}{|c|c|c|}
\hline \multirow{4}{*}{ Qué } & $\begin{array}{l}\text { Proceso } \\
\text { Cognitivo }\end{array}$ & Evaluar acciones y consecuencias. \\
\hline & $\begin{array}{l}\text { Mediadores de } \\
\text { Desempeño }\end{array}$ & $\begin{array}{l}\text { - } \text { Conocimiento intercultural. } \\
\text { - } \text { Respeto. } \\
\text { - Valoración de los derechos humanos fundamentales (dignidad humana). }\end{array}$ \\
\hline & $\begin{array}{l}\text { Dominios de } \\
\text { Contenido }\end{array}$ & Conflictos, instituciones y derechos humanos. \\
\hline & Contexto & Local. \\
\hline Cómo & $\begin{array}{l}\text { Procesos de } \\
\text { Innovación }\end{array}$ & Técnica: "lluvia de ideas" \\
\hline Por qué & $\begin{array}{l}\text { Evidencia de } \\
\text { Aprendizaje }\end{array}$ & Conoce el alcance de los centros de mediación escolar. \\
\hline Dónde & $\begin{array}{l}\text { Medios } \\
\text { Educativos }\end{array}$ & Aula especializada. \\
\hline
\end{tabular}




\begin{tabular}{|l|l|l|}
\hline Quién & Personas & Profesor; Especialista; Estudiante. \\
\hline Cuánto & Materiales & $\begin{array}{l}\text { Manual de convivencia, código penal, papel periódico, cuaderno, lápiz, lapicero, } \\
\text { borrador cuaderno, tablero, marcadores, borrador tablero. }\end{array}$ \\
\hline Cuándo & Tiempo Total & 120 minutos. \\
\hline
\end{tabular}

\section{Planeador de Clase}

\begin{tabular}{|c|c|c|c|}
\hline $\begin{array}{c}\text { Etapa } \\
\text { Clase/ } \\
\text { Tiempo }\end{array}$ & Actividad & $\begin{array}{c}\text { Evidencia } \\
\text { Aprendizaje }\end{array}$ & Materiales \\
\hline $\begin{array}{c}\text { Inicio } \\
(20 / 120)\end{array}$ & $\begin{array}{l}\text { Distribución de grupos } \\
\text { Se organizan los estudiantes en grupos de } 4 \\
\text { integrantes. En cada grupo se distribuyen los roles de } \\
\text { la siguiente manera: } \\
\text { - Vocero: comunica los resultados del equipo } \\
\text { - Relojero: controla el tiempo de la actividad y } \\
\text { recoge el material } \\
\text { - Dinamizador: Se encarga de que todos } \\
\text { participen y se respeten los turnos } \\
\text { Lector: Realiza la lectura } \\
\text { Identificación de Aprendizajes previos } \\
\text { En los grupos se discute alrededor de la } \\
\text { siguiente pregunta: } \\
\text { - De acuerdo con el manual de convivencia } \\
\text { escolar de la institución ¿Cuáles son las } \\
\text { situaciones escolares tipo } 1 \text { y } 2 \text { ? } \\
\text { 2. El dinamizador modera la discusión sobre } \\
\text { las preguntas guía. } \\
\text { El vocero de cada grupo socializa las respuestas } \\
\text { de cada pregunta. }\end{array}$ & $\begin{array}{c}\text { Definen las } \\
\text { situaciones } \\
\text { escolares tipo } 1 \text { y } \\
2 \text { de acuerdo con } \\
\text { el manual de } \\
\text { convivencia. }\end{array}$ & $\begin{array}{c}\text { Manual de } \\
\text { convivencia, } \\
\text { código penal, } \\
\text { papel periódico, } \\
\text { cuaderno, lápiz, } \\
\text { lapicero, } \\
\text { borrador } \\
\text { cuaderno, } \\
\text { tablero, } \\
\text { marcadores, } \\
\text { borrador } \\
\text { tablero. }\end{array}$ \\
\hline $\begin{array}{c}\text { Desarrollo } \\
(\mathbf{7 0} / \mathbf{1 2 0})\end{array}$ & $\begin{array}{l}\text { Charla con Abogado especialista } \\
\text { Paralelo: Situaciones tipo III de acuerdo con el } \\
\text { manual de convivencia escolar Vs Tratamiento a } \\
\text { delitos contemplados en el código penal } \\
\text { colombiano. } \\
\text { 1. El docente explica cómo se abordará la } \\
\text { clase a partir de la intervención del } \\
\text { especialista invitado para explicar las } \\
\text { situaciones constitutivas de delitos en el } \\
\text { código penal colombiano y el sentido de } \\
\text { proporcionalidad del delito. } \\
\text { El especialista brinda la charla realizando } \\
\text { el paralelo entre las acciones tipificadas } \\
\text { como tipo III de la institución y el }\end{array}$ & $\begin{array}{l}\text { Demuestran } \\
\text { comprensión } \\
\text { sobre los } \\
\text { procedimientos } \\
\text { del sistema penal } \\
\text { colombiano. }\end{array}$ & $\begin{array}{c}\text { Manual de } \\
\text { convivencia, } \\
\text { código penal, } \\
\text { papel periódico, } \\
\text { cuaderno, lápiz, } \\
\text { lapicero, } \\
\text { borrador } \\
\text { cuaderno, } \\
\text { tablero, } \\
\text { marcadores, } \\
\text { borrador } \\
\text { tablero. }\end{array}$ \\
\hline
\end{tabular}




\begin{tabular}{|c|c|c|c|}
\hline & $\begin{array}{l}\text { procedimiento del sistema penal } \\
\text { colombiano. } \\
\text { 3. El relojero toma nota de las preguntas } \\
\text { realizadas por los compañeros } \\
\text { 4. Cada miembro de grupo registra en su } \\
\text { cuaderno los procedimientos para el } \\
\text { manejo de las situaciones del sistema } \\
\text { penal colombiano. }\end{array}$ & $\begin{array}{l}\text { Demuestran } \\
\text { comprensión } \\
\text { sobre los } \\
\text { procedimientos } \\
\text { institucionales } \\
\text { para la solución. }\end{array}$ & \\
\hline $\begin{array}{l}\text { Cierre } \\
(30 / 120)\end{array}$ & 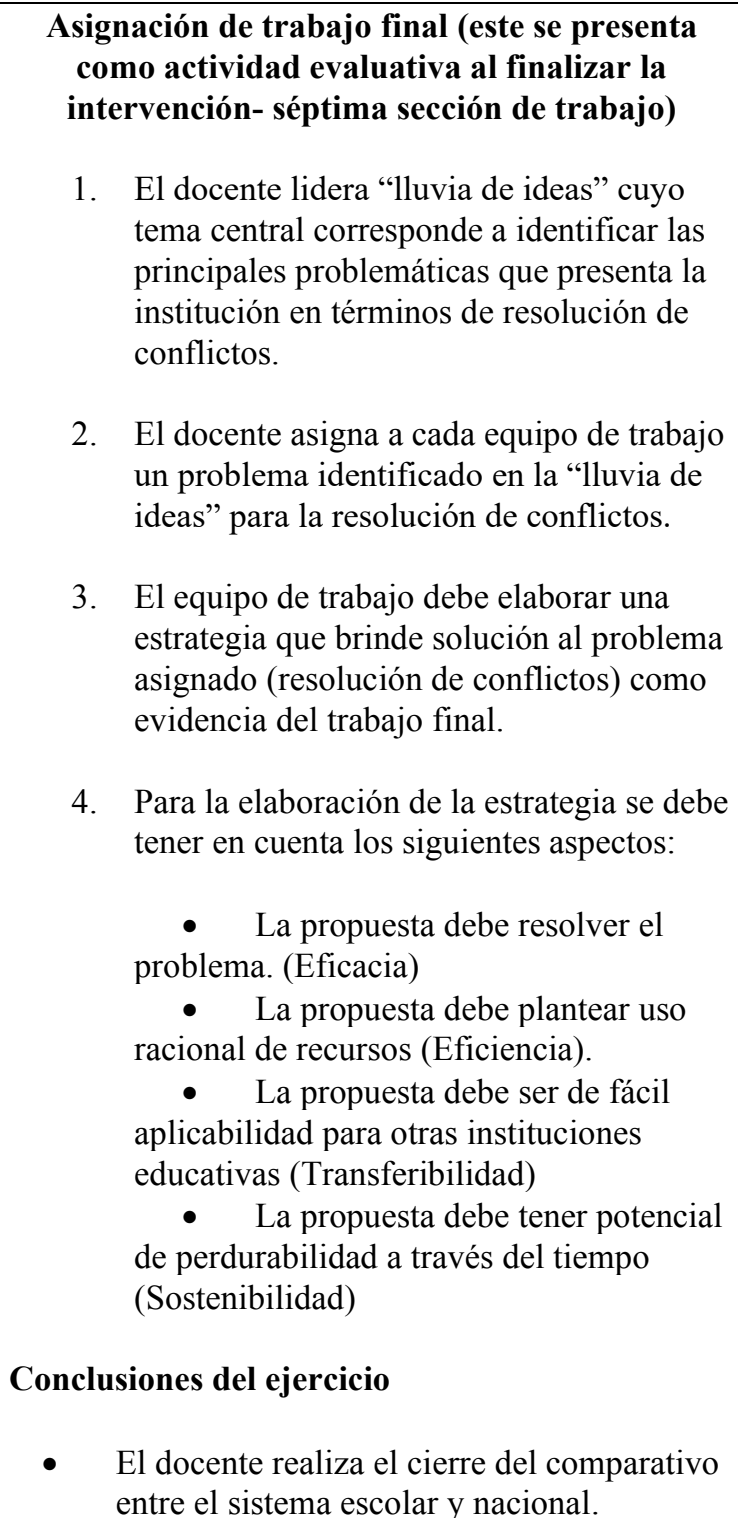 & $\begin{array}{l}\text { Desarrollo de la } \\
\text { competencia } \\
\text { global. }\end{array}$ & $\begin{array}{c}\text { Tablero, } \\
\text { marcadores, } \\
\text { borrador } \\
\text { tablero. }\end{array}$ \\
\hline
\end{tabular}




\begin{tabular}{|l|ll|l|l|}
\hline & $\begin{array}{l}\text { El docente ilustra sobre el sentido de } \\
\text { proporcionalidad de la aplicación de la } \\
\text { justicia. }\end{array}$ & & \\
$\bullet \quad \begin{array}{l}\text { El docente define la fecha de entrega del } \\
\text { trabajo definitivo. }\end{array}$ & & \\
\hline
\end{tabular}

Fuente: Autor.

\section{Evidencia trabajo en clase}
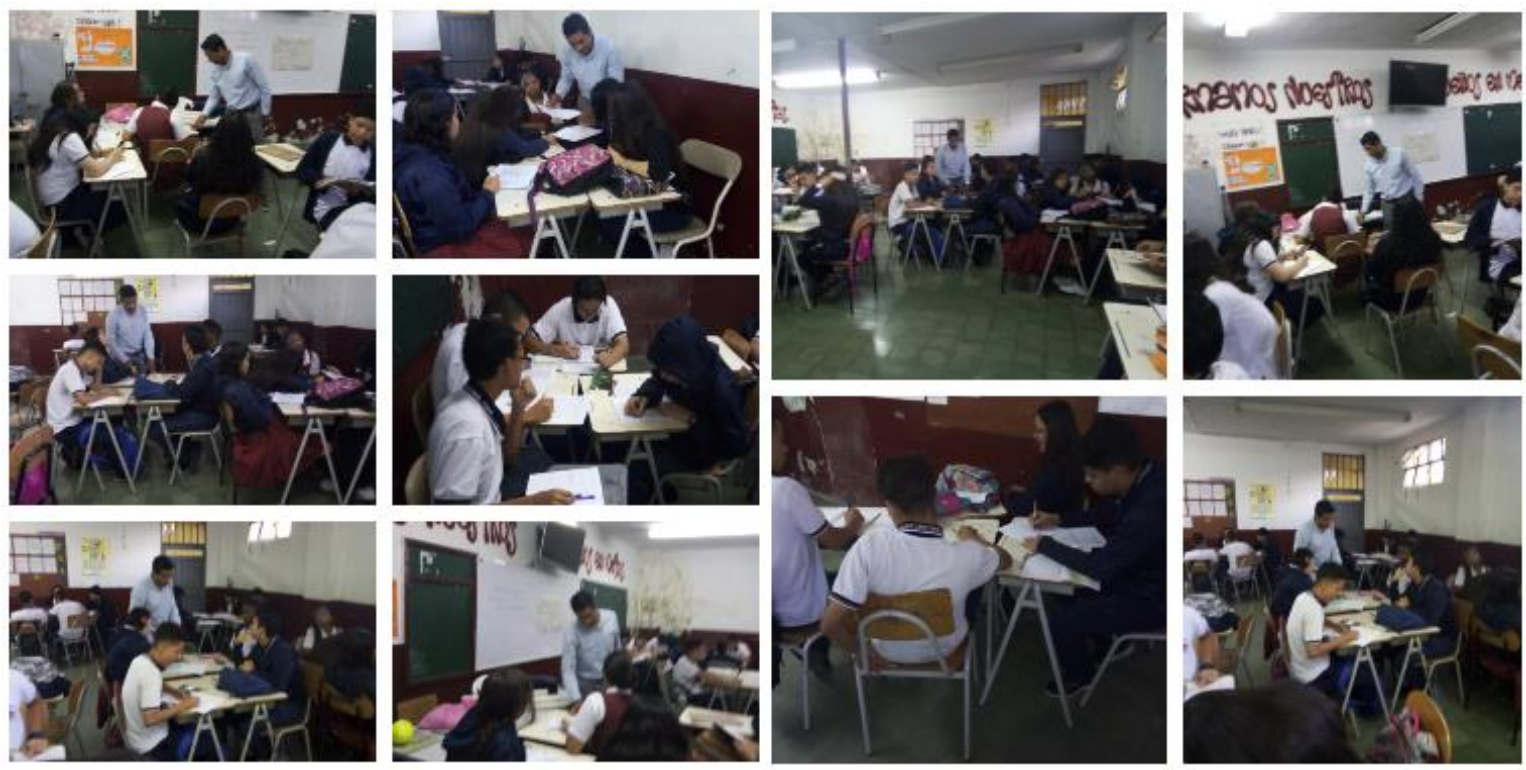

Ilustración 42: Evidencias taller: Mediación escolar. Fuente: Autor.

La técnica de la lluvia de ideas permitió dinamizar la actividad en el sentido de generación de ideas en poco tiempo, contribuyó con la estimulación de la creatividad del grupo e identificación y validación de la información a nivel grupal para la resolución de conflictos.

(Osborn, 1953) Desarrolló la técnica para permitir ideas creativas y originales para la resolución de problemas, al analizar que ciertas ideas eran descartadas sin haber sido mínimamente evaluadas.

Así mismo, la aplicación de la técnica en el grupo como lo indica la teoría se soportó de los cuatro (4) principios fundamentales: (i) La crítica no está permitida, (ii) la libertad de pensamiento es indispensable, (iii) la cantidad es fundamental y (iv) la combinación y la mejora deben ponerse en práctica (Osborn, 1953).

El resultado de la identificación de los problemas en la institución será evaluado en la última sección de clases para analizar las soluciones propuestas por los grupos de trabajo como lo indica el planeador de clase. 
Sección 7: Taller: Calidad del aire en la ciudad de Medellín.

La sección de clase se orienta bajo los siguientes criterios metodológicos.

Tabla 80. Sección - Taller Calidad del aire en la ciudad de Medellín.

\section{Identificación del plan de área}

\begin{tabular}{|l|l|}
\hline $\begin{array}{l}\text { Asignatura } \\
\text { (Secuencias Didácticas) }\end{array}$ & $\begin{array}{l}\text { Asignatura Base: Ciencias sociales. } \\
\text { Asignaturas complementarias: Humanidades-Lengua Castellana, matemáticas, } \\
\text { ciencias naturales. }\end{array}$ \\
\hline $\begin{array}{l}\text { Objetivo Área } \\
\text { (DBA) }\end{array}$ & $\begin{array}{l}\text { Analizar críticamente los elementos constituyentes de la democracia, los derechos } \\
\text { de las personas y la identidad en Colombia, reconociendo la interacción permanente } \\
\text { entre el espacio geográfico y el ser humano, los avances y limitaciones de esta } \\
\text { relación. }\end{array}$ \\
\hline Objetivo Específico & $\begin{array}{l}\text { Identificar el compromiso de ciudad para mejorar la calidad del aire. } \\
\text { ODS }\end{array}$ Paz, justicia e instituciones sólidas. \\
\hline Meta ODS & $\begin{array}{l}\text { Crear instituciones eficaces, responsables y transparentes a todos los } \\
\text { niveles. } \\
\text { Promover y aplicar leyes y políticas no discriminatorias en favor del } \\
\text { desarrollo sostenible. }\end{array}$ \\
\hline
\end{tabular}

\section{Planificación de Acciones Pedagógicas}

\begin{tabular}{|c|c|c|}
\hline \multirow{4}{*}{ Qué } & $\begin{array}{l}\text { Proceso } \\
\text { Cognitivo }\end{array}$ & 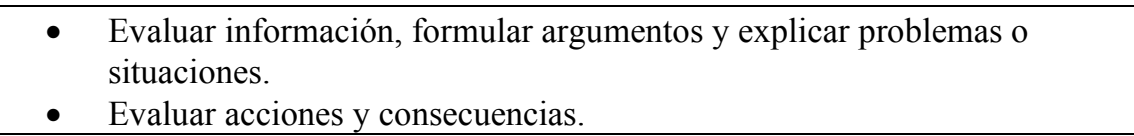 \\
\hline & $\begin{array}{l}\text { Mediadores de } \\
\text { Desempeño }\end{array}$ & $\begin{array}{l}\text { - Conocimientos de asuntos globales. } \\
\text { - Mentalidad global. } \\
\text { - Valoración de los derechos humanos fundamentales (dignidad humana). }\end{array}$ \\
\hline & $\begin{array}{l}\text { Dominios de } \\
\text { Contenido }\end{array}$ & Sostenibilidad Ambiental. \\
\hline & Contexto & Local. \\
\hline Cómo & $\begin{array}{l}\text { Procesos de } \\
\text { Innovación }\end{array}$ & Técnica: "Relaciones Forzadas" \\
\hline Por qué & $\begin{array}{l}\text { Evidencia de } \\
\text { Aprendizaje }\end{array}$ & Identifica el compromiso de ciudad para mejorar la calidad del aire. \\
\hline Dónde & $\begin{array}{l}\text { Medios } \\
\text { Educativos } \\
\end{array}$ & Aula especializada. \\
\hline Quién & Personas & Profesor; Especialista; Estudiante \\
\hline Cuánto & Materiales & $\begin{array}{l}\text { Fotocopias artículo periodístico, fotocopia estrategias para el "Plan Integral Para } \\
\text { La Gestión De La Calidad Del Aire", tarjetas de cartulina, marcadores, lápiz, } \\
\text { lapicero, borrador cuaderno, tablero, borrador de tablero. }\end{array}$ \\
\hline Cuándo & Tiempo Total & 120 minutos \\
\hline
\end{tabular}

\section{Planeador de Clase}




\begin{tabular}{|c|c|c|c|}
\hline $\begin{array}{c}\text { Etapa Clase/ } \\
\text { Tiempo }\end{array}$ & Actividad & $\begin{array}{l}\text { Evidencia } \\
\text { Aprendizaje }\end{array}$ & Materiales \\
\hline $\begin{array}{c}\text { Inicio } \\
(20 / 120)\end{array}$ & $\begin{array}{l}\text { Distribución de grupos } \\
\text { 1. Se organizan los estudiantes en grupos de } 4 \\
\text { integrantes. En cada grupo se distribuyen los } \\
\text { roles de la siguiente manera: } \\
\text { - Vocero: comunica los resultados del equipo. } \\
\text { - Relojero: controla el tiempo de la actividad y } \\
\text { recoge el material. } \\
\text { - Dinamizador: Se encarga de que todos } \\
\text { participen y se respeten los turno. } \\
\text { - Lector: Realiza la lectura. } \\
\text { Identificación de Aprendizajes previos } \\
\text { 1. En los grupos se discute alrededor de las } \\
\text { siguientes preguntas: } \\
\text { - ¿Cuáles son los factores generadores de } \\
\text { contaminación ambiental? } \\
\text { 2. El dinamizador modera la discusión sobre las } \\
\text { preguntas guía. } \\
\text { 3. El vocero de cada grupo socializa las } \\
\text { respuestas de cada pregunta. }\end{array}$ & $\begin{array}{l}\text { Define factores } \\
\text { generadores de } \\
\text { contaminación } \\
\text { ambiental }\end{array}$ & $\begin{array}{l}\text { Marcadores, lápiz, } \\
\text { lapicero, borrador } \\
\text { cuaderno, tablero, } \\
\text { borrador de tablero. }\end{array}$ \\
\hline $\begin{array}{c}\text { Desarrollo } \\
\text { (70/120) }\end{array}$ & 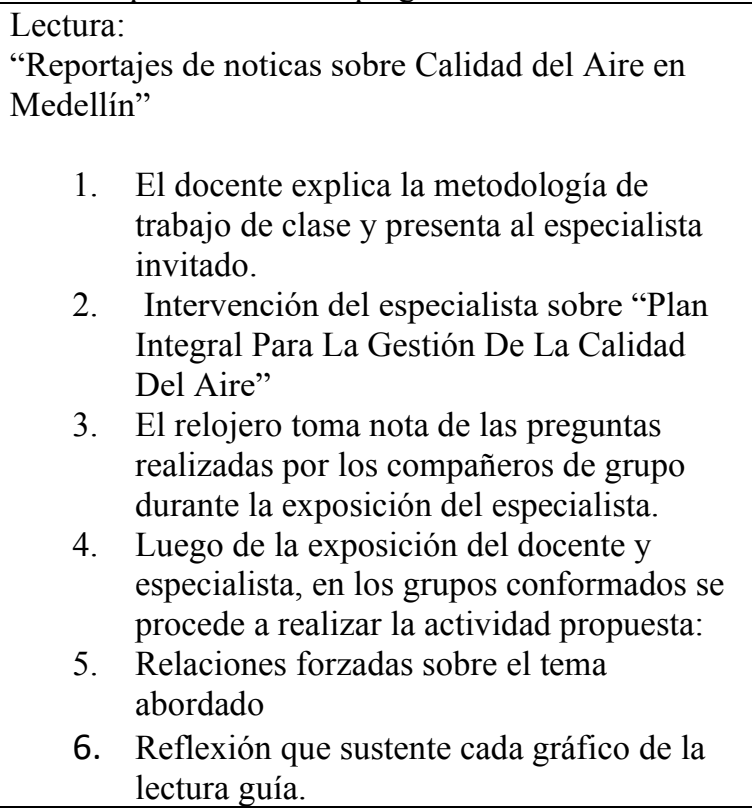 & $\begin{array}{l}\text { Define factores } \\
\text { generadores de } \\
\text { contaminación } \\
\text { ambiental }\end{array}$ & $\begin{array}{l}\text { Fotocopias artículo } \\
\text { periodístico, } \\
\text { fotocopia estrategias } \\
\text { para el "Plan } \\
\text { Integral Para La } \\
\text { Gestión De La } \\
\text { Calidad Del Aire", } \\
\text { tarjetas de cartulina, } \\
\text { marcadores, lápiz, } \\
\text { lapicero, borrador } \\
\text { cuaderno, tablero, } \\
\text { borrador de tablero. }\end{array}$ \\
\hline $\begin{array}{l}\text { Cierre } \\
(\mathbf{3 0} / \mathbf{1 2 0})\end{array}$ & $\begin{array}{l}\text { Conclusiones del ejercicio } \\
\text { 1. Cada grupo expone su propuesta a partir del } \\
\text { ejercicio sobre las Relaciones Forzadas y } \\
\text { reflexión final. } \\
\text { 2. El docente realiza una conclusión con base en } \\
\text { las intervenciones de cada grupo. }\end{array}$ & & $\begin{array}{l}\text { Marcadores, lápiz, } \\
\text { lapicero, borrador } \\
\text { cuaderno, tablero, } \\
\text { borrador de tablero. }\end{array}$ \\
\hline
\end{tabular}


Fuente: Autor.

Evidencia trabajo en clase
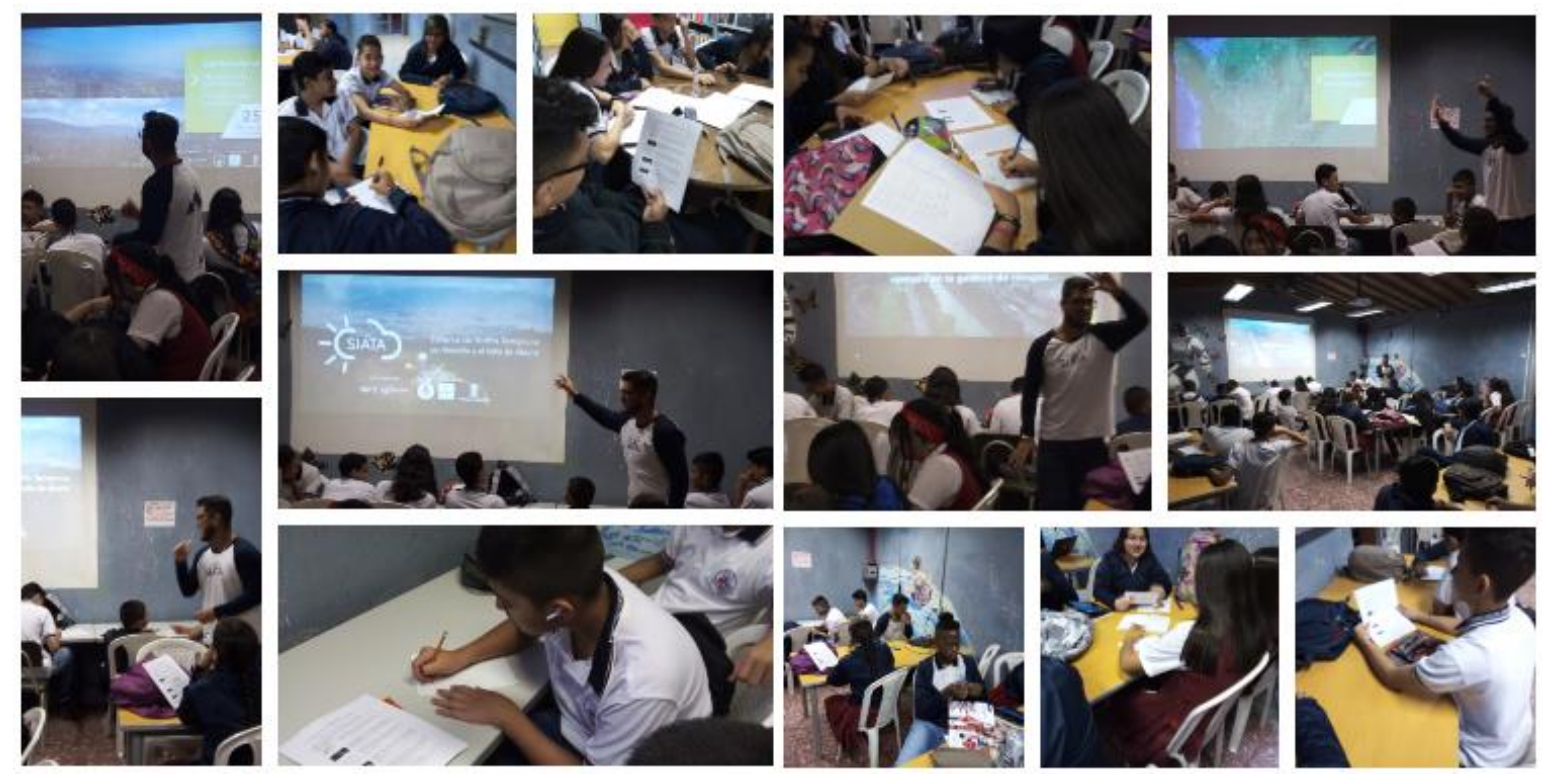

Ilustración 43: Evidencias taller Calidad del aire en la ciudad de Medellín.

Fuente: Autor.

La técnica de relaciones forzadas fue desarrollada por Charles Whiting (1958) para relacionar problemas con elementos elegidos al azar, para encontrar soluciones. La técnica permite forzar nuevas dimensiones de solución cuando la lluvia de ideas se acorta.

La actividad se desarrolló mediante la elección de una (1) palabra en la que cada grupo representara la problemática de ciudad abordada por el SIATA. Luego a partir de la palabra elegida se identificaron las características asociadas a la misma para generar soluciones acordes a las asociaciones realizadas.

La técnica permitió a los estudiantes generar nuevas conexiones de solución de problemas, al mismo tiempo identificar el impacto ambiental que vive la ciudad y los mecanismos de monitoreo y control para su cuidado.

\section{Sección 8: Taller: Análisis percepción de seguridad del entorno}

La sección de clase se orienta bajo los siguientes criterios metodológicos. 
Tabla 81: Sección - Taller: Análisis percepción de seguridad del entorno.

\section{Identificación del plan de área}

\begin{tabular}{|l|l|}
\hline $\begin{array}{l}\text { Asignatura } \\
\text { (Secuencias Didácticas) }\end{array}$ & $\begin{array}{l}\text { Asignatura Base: Ciencias sociales. } \\
\text { Asignaturas complementarias: Humanidades-Lengua Castellana, matemáticas, } \\
\text { ciencias naturales. }\end{array}$ \\
\hline $\begin{array}{l}\text { Objetivo Área } \\
\text { (DBA) }\end{array}$ & $\begin{array}{l}\text { Analizar críticamente los elementos constituyentes de la democracia, los derechos } \\
\text { de las personas y la identidad en Colombia, reconociendo la interacción permanente } \\
\text { entre el espacio geográfico y el ser humano, los avances y limitaciones de esta } \\
\text { relación. }\end{array}$ \\
\hline Objetivo Específico & Identificar los niveles de percepción de seguridad del entorno. \\
\hline ODS & $\begin{array}{l}\text { Paz, justicia e instituciones sólidas. } \\
\text { Meta ODS }\end{array}$ \\
$\begin{array}{l}\text { Promover el estado de derecho en los planos nacional e internacional y } \\
\text { garantizar la igualdad de acceso a la justicia para todos. } \\
\text { Garantizar la adopción de decisiones inclusivas, participativas y representativas } \\
\text { que respondan a las necesidades a todos los niveles. }\end{array}$ \\
\hline
\end{tabular}

\section{Planificación de Acciones Pedagógicas}

\begin{tabular}{|c|c|c|}
\hline \multirow{4}{*}{ Qué } & $\begin{array}{l}\text { Proceso } \\
\text { Cognitivo }\end{array}$ & $\begin{array}{l}\text { Evaluar información, formular argumentos y explicar problemas o } \\
\text { situaciones. }\end{array}$ \\
\hline & $\begin{array}{l}\text { Mediadores de } \\
\text { Desempeño }\end{array}$ & $\begin{array}{l}\text { - } \text { Conocimiento intercultural. } \\
\text { - } \quad \text { Respeto. } \\
\text { - Valoración de los derechos humanos fundamentales (dignidad } \\
\text { humana). }\end{array}$ \\
\hline & $\begin{array}{l}\text { Dominios de } \\
\text { Contenido }\end{array}$ & $\begin{array}{l}\text { - } \quad \text { Cultura y relaciones interculturales. } \\
\text { - } \quad \text { Desarrollo e interdependencia socioeconómica. } \\
\text { - Conflictos, instituciones y derechos humanos. } \\
\end{array}$ \\
\hline & Contexto & Local. \\
\hline Cómo & $\begin{array}{l}\text { Procesos de } \\
\text { Innovación }\end{array}$ & Técnica: Los 5 por qué. \\
\hline Por qué & $\begin{array}{l}\text { Evidencia de } \\
\text { Aprendizaje }\end{array}$ & Conoce la percepción de seguridad del entorno. \\
\hline Dónde & $\begin{array}{l}\text { Medios } \\
\text { Educativos }\end{array}$ & Aula especializada. \\
\hline Quién & Personas & Profesor; Estudiante. \\
\hline Cuánto & Materiales & $\begin{array}{l}\text { Fotocopias informe Medellín Cómo vamos, cuaderno, lápiz, lapicero, } \\
\text { borrador cuaderno, tablero, marcadores, borrador tablero. }\end{array}$ \\
\hline Cuándo & Tiempo Total & 120 minutos. \\
\hline
\end{tabular}

\section{Planeador de Clase}

\begin{tabular}{|c|c|c|c|}
\hline Etapa & Actividad & Evidencia & Materiales \\
Clase/ & & & \\
Tiempondizaje & & & \\
\hline
\end{tabular}




\begin{tabular}{|c|c|c|c|}
\hline $\begin{array}{c}\text { Inicio } \\
(20 / 120)\end{array}$ & $\begin{array}{l}\text { Se organizan los estudiantes en grupos de } 4 \\
\text { integrantes. En cada grupo se distribuyen los roles de } \\
\text { la siguiente manera: } \\
\text { - Vocero: comunica los resultados del equipo } \\
\text { - Relojero: controla el tiempo de la actividad y } \\
\text { recoge el material } \\
\text { - Dinamizador: Se encarga de que todos } \\
\text { participen y se respeten los turno } \\
\text { - Lector: Realiza la lectura } \\
\text { Identificación de Aprendizajes previos } \\
\text { 1. En los grupos se discute alrededor de } \\
\text { las siguientes preguntas: } \\
\text { - ¿Qué es la convivencia escolar? } \\
\text { - ¿Cuál es la diferencia entre la convivencia } \\
\text { escolar y la convivencia ciudadana? } \\
\text { 2. El dinamizador modera la discusión } \\
\text { sobre las preguntas guía. } \\
\text { El vocero de cada grupo socializa las respuestas } \\
\text { de cada pregunta. }\end{array}$ & $\begin{array}{c}\text { Definen } \\
\text { manual de } \\
\text { convivencia. }\end{array}$ & $\begin{array}{c}\text { Cuaderno, lápiz, } \\
\text { lapicero, borrador } \\
\text { cuaderno, tablero, } \\
\text { marcadores, } \\
\text { borrador tablero. }\end{array}$ \\
\hline $\begin{array}{c}\text { Desarrollo } \\
50 / 120\end{array}$ & $\begin{array}{l}\text { Informe Medellín cómo vamos 2018: "Seguridad, } \\
\text { Informe de Análisis Encuesta de Percepción } \\
\text { Ciudadana Medellín 2018" } \\
\begin{array}{l}\text { 1. El docente expone material guía } \\
\text { "Seguridad, Informe de Análisis Encuesta } \\
\text { de Percepción Ciudadana Medellín 2018" } \\
\text { 2. El relojero toma nota de las preguntas } \\
\text { realizadas por los compañeros de grupo } \\
\text { durante la exposición del docente. }\end{array} \\
\text { 3. Luego de la exposición del docente, en los } \\
\text { grupos conformados se procede a realizar } \\
\text { una reflexión que sustente cada gráfico de la } \\
\text { lectura. }\end{array}$ & $\begin{array}{l}\text { Identificación } \\
\text { del conflicto y } \\
\text { la afectación } \\
\text { en las } \\
\text { instituciones y } \\
\text { en los } \\
\text { derechos } \\
\text { humanos. }\end{array}$ & $\begin{array}{l}\text { Fotocopias } \\
\text { informe Medellín } \\
\text { Cómo vamos, } \\
\text { cuaderno, lápiz, } \\
\text { lapicero, borrador } \\
\text { cuaderno, tablero, } \\
\text { marcadores, } \\
\text { borrador tablero. }\end{array}$ \\
\hline $\begin{array}{l}\text { Cierre } \\
(40 / 120)\end{array}$ & $\begin{array}{l}\text { Conclusión informe de percepción } \\
\text { 4. } \begin{array}{l}\text { Elaborar en los grupos conformados un } \\
\text { análisis de los } 5 \text { por qué, de un problema de } \\
\text { ciudad que más le genere preocupación al } \\
\text { equipo de trabajo. }\end{array} \\
\text { Conclusiones del ejercicio } \\
\text { 5. Cada grupo expone la causa raíz del } \\
\text { problema identificado. }\end{array}$ & $\begin{array}{l}\text { Comprensión } \\
\text { del conflicto y } \\
\text { la afectación } \\
\text { en las } \\
\text { instituciones y } \\
\text { en los } \\
\text { derechos } \\
\text { humanos. }\end{array}$ & $\begin{array}{c}\text { Cuaderno, lápiz, } \\
\text { lapicero, borrador } \\
\text { cuaderno, tablero, } \\
\text { marcadores, } \\
\text { borrador tablero. }\end{array}$ \\
\hline
\end{tabular}

Fuente: Autor. 
Evidencia trabajo en clase
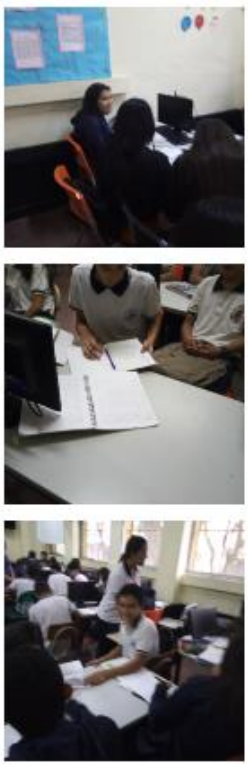
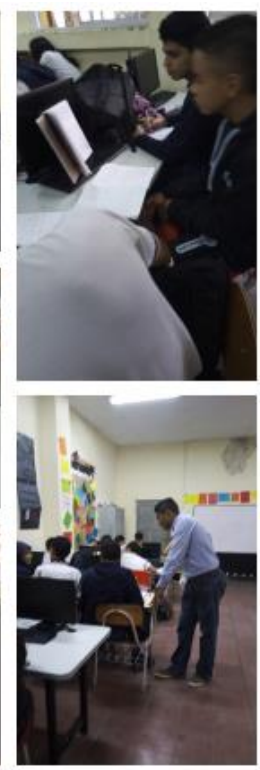
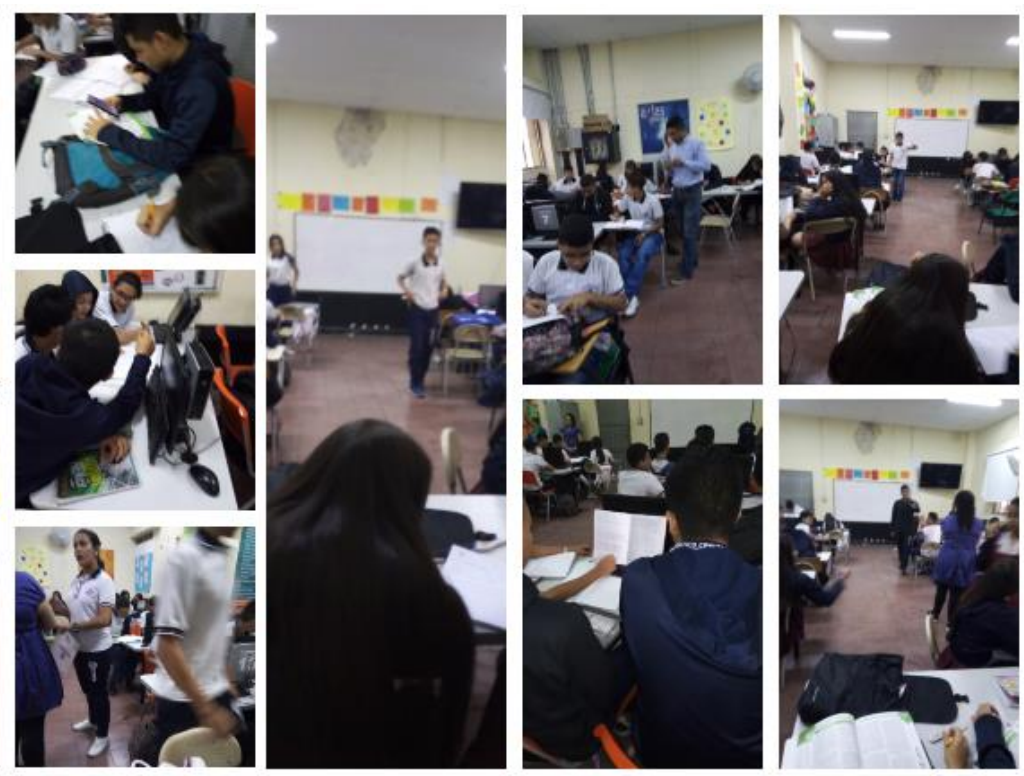

Ilustración 44: Evidencias Taller Análisis percepción de seguridad del entorno Fuente: Autor.

El análisis de los 5 por qué permitió a cada grupo explorar las relaciones causa-efecto generados por los problemas de ciudad.

La técnica permite identificar la causa raíz (causa inicial) generador del efecto de interés para implementar medidas de intervención que permitan prevenir los resultados no deseados (Ohno, 1991).

Los hallazgos a partir de la técnica para encontrar la causa raíz del problema identificó a nivel grupal la desigualdad, falta de educación, pobreza, discriminación, drogadicción, políticas sociales, acceso a la salud pública, entre otros factores detonantes de la percepción de seguridad del entorno.

Sección 9: Taller: Análisis Justicia Especial para la Paz.

La sección de clase se orienta bajo los siguientes criterios metodológicos.

Tabla 82: Sección - Taller Análisis Justicia Especial para la Paz.

\section{Identificación del plan de área}

\begin{tabular}{|l|l|}
\hline $\begin{array}{l}\text { Asignatura } \\
\text { (Secuencias Didácticas) }\end{array}$ & Asignatura Base: Ciencias sociales. \\
\hline
\end{tabular}




\begin{tabular}{|c|c|}
\hline & $\begin{array}{l}\text { Asignaturas complementarias: Humanidades-Lengua Castellana, matemáticas, } \\
\text { ciencias naturales. }\end{array}$ \\
\hline $\begin{array}{l}\text { Objetivo Área } \\
\text { (DBA) }\end{array}$ & $\begin{array}{l}\text { Analizar críticamente los elementos constituyentes de la democracia, los derechos } \\
\text { de las personas y la identidad en Colombia, reconociendo la interacción permanente } \\
\text { entre el espacio geográfico y el ser humano, los avances y limitaciones de esta } \\
\text { relación. }\end{array}$ \\
\hline Objetivo Específico & $\begin{array}{l}\text { Identificar los retos en la implementación del nuevo Modelo de Justicia en } \\
\text { Colombia "Justicia Especial para la Paz" }\end{array}$ \\
\hline ODS & Paz, justicia e instituciones sólidas. \\
\hline Meta ODS & $\begin{array}{l}\text { Promover el estado de derecho en los planos nacional e internacional y } \\
\text { garantizar la igualdad de acceso a la justicia para todos. } \\
\text { - Crear instituciones eficaces, responsables y transparentes a todos los } \\
\text { niveles. } \\
\text { - Garantizar la adopción de decisiones inclusivas, participativas y } \\
\text { representativas que respondan a las necesidades a todos los niveles. } \\
\text { - Fortalecer las instituciones nacionales pertinentes, incluso mediante la } \\
\text { cooperación internacional, con miras a crear capacidad a todos los niveles, } \\
\text { en particular en los países en desarrollo, para prevenir la violencia y } \\
\text { combatir el terrorismo y la delincuencia. }\end{array}$ \\
\hline
\end{tabular}

\section{Planificación de Acciones Pedagógicas}

\begin{tabular}{|c|c|c|}
\hline \multirow{4}{*}{ Qué } & $\begin{array}{l}\text { Proceso } \\
\text { Cognitivo }\end{array}$ & $\begin{array}{l}\text { - Evaluar información, formular argumentos y explicar problemas o } \\
\text { situaciones. } \\
\text { - Identificar y analizar diferentes perspectivas. } \\
\text { - } \quad \text { Comprender las diferencias en la comunicación. } \\
\text { - Evaluar acciones y consecuencias. }\end{array}$ \\
\hline & $\begin{array}{l}\text { Mediadores de } \\
\text { Desempeño }\end{array}$ & Conocimiento intercultural. \\
\hline & $\begin{array}{l}\text { Dominios de } \\
\text { Contenido } \\
\end{array}$ & $\begin{array}{l}\text { - Cultura y relaciones interculturales. } \\
\text { - Conflictos, instituciones y derechos humanos. }\end{array}$ \\
\hline & Contexto & Local. \\
\hline Cómo & $\begin{array}{l}\text { Procesos de } \\
\text { Innovación }\end{array}$ & Metodología: "Mapa de Actores". \\
\hline Por qué & $\begin{array}{l}\text { Evidencia de } \\
\text { Aprendizaje }\end{array}$ & Identifica el modelo de Justicia Especial para la Paz en Colombia. \\
\hline Dónde & $\begin{array}{l}\text { Medios } \\
\text { Educativos }\end{array}$ & Aula especializada. \\
\hline Quién & Personas & Profesor; Estudiante \\
\hline Cuánto & Materiales & $\begin{array}{l}\text { Fotocopias Artículo Periodístico, fotocopia ejemplo "mapa de actores", } \\
\text { papel periódico, marcadores, lápiz, lapicero, borrador cuaderno, tablero, } \\
\text { borrador de tablero. }\end{array}$ \\
\hline Cuándo & Tiempo Total & 120 minutos \\
\hline
\end{tabular}

\section{Planeador de Clase}

\begin{tabular}{|c|c|c|c|}
\hline $\begin{array}{c}\text { Etapa } \\
\text { Clase/ } \\
\text { Tiempo }\end{array}$ & Actividad & $\begin{array}{c}\text { Evidencia } \\
\text { Aprendizaje }\end{array}$ & Materiales \\
\hline Inicio & Distribución de grupos & $\begin{array}{c}\text { Identifican } \\
\text { variables }\end{array}$ & $\begin{array}{c}\text { Papel periódico, } \\
\text { marcadores, }\end{array}$ \\
\hline
\end{tabular}




\begin{tabular}{|c|c|c|c|}
\hline$(20 / 120)$ & $\begin{array}{l}\text { 1. Se organizan los estudiantes en grupos de } 4 \\
\text { integrantes. En cada grupo se distribuyen } \\
\text { los roles de la siguiente manera: } \\
\text { - Vocero: comunica los resultados del equipo. } \\
\text { - Relojero: controla el tiempo de la actividad y } \\
\text { recoge el material. } \\
\text { - Dinamizador: Se encarga de que todos } \\
\text { participen y se respeten los turno. } \\
\text { Lector: Realiza la lectura. } \\
\text { Identificación de Aprendizajes previos } \\
\text { 2. En los grupos se discute alrededor de las } \\
\text { siguientes preguntas: } \\
\text { ¿QQué es la Justicia transicional? } \\
\text { ¿Por qué crear un modelo de Justicia } \\
\text { Transicional? } \\
\text { El dinamizador modera la discusión sobre las } \\
\text { preguntas guía. } \\
\text { El vocero de cada grupo socializa las } \\
\text { respuestas de cada pregunta. }\end{array}$ & $\begin{array}{l}\text { generadoras de } \\
\text { regímenes de } \\
\text { excepción }\end{array}$ & $\begin{array}{l}\text { lápiz, lapicero, } \\
\text { borrador } \\
\text { cuaderno, } \\
\text { tablero, borrador } \\
\text { de tablero. }\end{array}$ \\
\hline $\begin{array}{c}\text { Desarrollo } \\
(\mathbf{7 0} / \mathbf{1 2 0})\end{array}$ & $\begin{array}{l}\text { Lectura Artículo: } \\
\text { "Duro año para la justicia de paz" } \\
\text { 1. } \begin{array}{l}\text { El docente explica la metodología de } \\
\text { trabajo haciendo énfasis en cómo elaborar } \\
\text { un "Mapa de Actores" y sus respectivas }\end{array} \\
\text { conexiones. } \\
\text { 2. } \quad \begin{array}{l}\text { El relojero toma nota de las preguntas } \\
\text { realizadas por los compañeros de grupo }\end{array} \\
\text { durante la exposición del docente. } \\
\text { 3. } \quad \begin{array}{l}\text { Luego de la exposición del docente, en los } \\
\text { grupos conformados se procede a realizar }\end{array} \\
\text { la actividad propuesta: } \\
\text { Mapa de actores sobre la lectura guía } \\
\text { Reflexión que sustente cada gráfico de la } \\
\text { lectura guía. }\end{array}$ & $\begin{array}{l}\text { Identifica el } \\
\text { modelo de } \\
\text { Justicia Especial } \\
\text { para la Paz en } \\
\text { Colombia }\end{array}$ & $\begin{array}{l}\text { Fotocopias } \\
\text { Artículo } \\
\text { Periodístico, } \\
\text { fotocopia } \\
\text { ejemplo "mapa } \\
\text { de actores", } \\
\text { papel periódico, } \\
\text { marcadores, } \\
\text { lápiz, lapicero, } \\
\text { borrador } \\
\text { cuaderno, } \\
\text { tablero, borrador } \\
\text { de tablero. }\end{array}$ \\
\hline $\begin{array}{l}\text { Cierre } \\
(\mathbf{3 0} / \mathbf{1 2 0})\end{array}$ & $\begin{array}{l}\text { Conclusiones del ejercicio } \\
\text { 1. Cada grupo expone su propuesta sobre el } \\
\text { "mapa de actores" y reflexión gráficos } \\
\text { estadísticos. } \\
\text { 2. El docente realiza una conclusión con base en } \\
\text { las intervenciones de cada grupo. }\end{array}$ & $\begin{array}{l}\text { Comprende el } \\
\text { modelo de } \\
\text { Justicia Especial } \\
\text { para la Paz en } \\
\text { Colombia }\end{array}$ & $\begin{array}{l}\text { Marcadores, } \\
\text { lápiz, lapicero, } \\
\text { borrador } \\
\text { cuaderno, } \\
\text { tablero, borrador } \\
\text { de tablero. }\end{array}$ \\
\hline
\end{tabular}

Fuente: Autor. 


\section{Evidencia trabajo en clase}

Ilustración 45: Evidencia Sección Taller Análisis Justicia Especial para la Paz
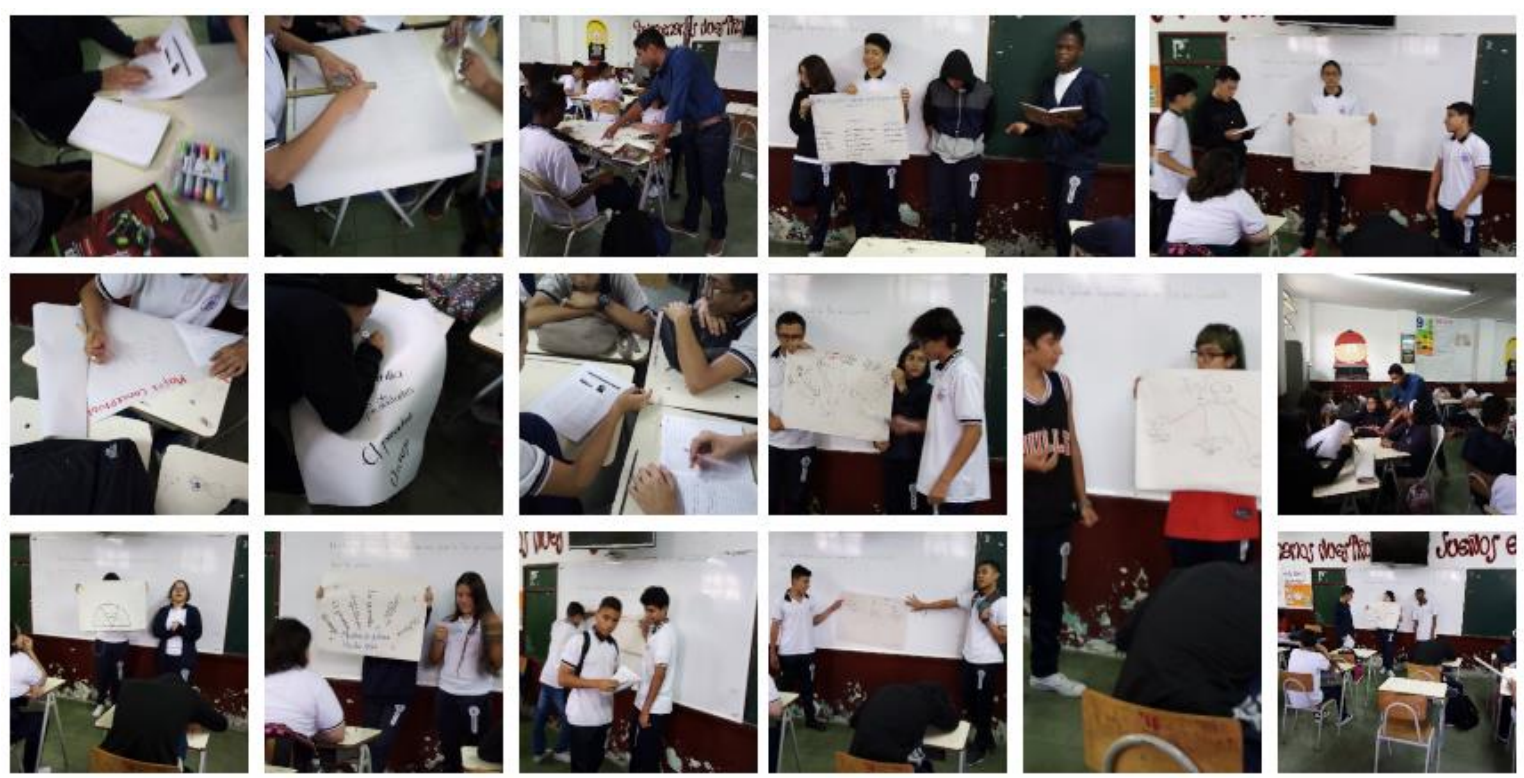

Fuente: Autor.

El mapeo de actores es una metodología que permite identificar gráficamente los grupos de interés para analizar la influencia en los resultados de intervención (Gutiérrez, 2007). además de ello, conocer sus acciones, saber por qué forman parte y cuáles son las perspectivas para el futuro inmediato (Ceballos, 2004).

Del mismo modo la metodología permitió al grupo de trabajo identificar y comprender el contexto social, políticos y económico para la creación del modelo de Justicia Especial para la Paz en Colombia y cómo se debe incluir la participación de las diferentes partes interesadas para la gobernanza de las organizaciones.

La utilidad del mapa de actores brinda fundamentos para fomentar la participación colectiva en el diseño e implementación de proyectos y programas a todo nivel; en el caso particular para las políticas de desarrollo. La implementación promueve el enfoque participativo.

\section{Sección 10: Taller: Reflexión corrupción en América Latina.}

La sección de clase se orienta bajo los siguientes criterios metodológicos.

Tabla 83: Sección - Taller: Reflexión corrupción en América Latina. 


\section{Identificación del plan de área}

\begin{tabular}{|c|c|}
\hline $\begin{array}{l}\text { Asignatura } \\
\text { (Secuencias Didácticas) }\end{array}$ & $\begin{array}{l}\text { Asignatura Base: Ciencias sociales. } \\
\text { Asignaturas complementarias: Humanidades-Lengua Castellana, matemáticas, } \\
\text { ciencias naturales. }\end{array}$ \\
\hline $\begin{array}{l}\text { Objetivo Área } \\
\text { (DBA) }\end{array}$ & $\begin{array}{l}\text { Analizar críticamente los elementos constituyentes de la democracia, los derechos } \\
\text { de las personas y la identidad en Colombia, reconociendo la interacción permanente } \\
\text { entre el espacio geográfico y el ser humano, los avances y limitaciones de esta } \\
\text { relación. }\end{array}$ \\
\hline Objetivo Específico & $\begin{array}{l}\text { Identificar el panorama regional en términos de percepción de corrupción en } \\
\text { América Latina. }\end{array}$ \\
\hline ODS & Paz, justicia e instituciones sólidas. \\
\hline Meta ODS & $\begin{array}{l}\text { - Crear instituciones eficaces, responsables y transparentes a todos los niveles. } \\
\text { - Reducir sustancialmente la corrupción y el soborno en todas sus formas. } \\
\text { - Fortalecer las instituciones nacionales pertinentes, incluso mediante la } \\
\text { cooperación internacional, con miras a crear capacidad a todos los niveles, en } \\
\text { particular en los países en desarrollo, para prevenir la violencia y combatir el } \\
\text { terrorismo y la delincuencia. }\end{array}$ \\
\hline
\end{tabular}

\section{Planificación de Acciones Pedagógicas}

\begin{tabular}{|c|c|c|}
\hline \multirow{4}{*}{ Qué } & $\begin{array}{l}\text { Proceso } \\
\text { Cognitivo }\end{array}$ & $\begin{array}{l}\text { - Evaluar información, formular argumentos y explicar problemas o } \\
\text { situaciones. } \\
\text { - Identificar y analizar diferentes perspectivas. } \\
\text { - Evaluar acciones y consecuencias. }\end{array}$ \\
\hline & $\begin{array}{l}\text { Mediadores de } \\
\text { Desempeño }\end{array}$ & $\begin{array}{l}\text { - Conocimiento de asuntos globales. } \\
\text { - Conocimiento intercultural. } \\
\text { - Valoración de la diversidad multicultural. }\end{array}$ \\
\hline & $\begin{array}{l}\text { Dominios de } \\
\text { Contenido }\end{array}$ & $\begin{array}{l}\text { - Cultura y relaciones interculturales. } \\
\text { - Desarrollo e interdependencia socioeconómica. } \\
\text { - Conflictos, instituciones y derechos humanos. }\end{array}$ \\
\hline & Contexto & Global. \\
\hline Cómo & $\begin{array}{l}\text { Procesos de } \\
\text { Innovación }\end{array}$ & Técnica: "World Café. \\
\hline Por qué & $\begin{array}{l}\text { Evidencia de } \\
\text { Aprendizaje }\end{array}$ & $\begin{array}{l}\text { Identifica el panorama regional en términos de percepción de corrupción en } \\
\text { América Latina. }\end{array}$ \\
\hline Dónde & $\begin{array}{l}\text { Medios } \\
\text { Educativos }\end{array}$ & Aula especializada. \\
\hline Quién & Personas & Profesor; Estudiante. \\
\hline Cuánto & Materiales & $\begin{array}{l}\text { Fotocopias artículo periodístico, papel periódico, marcadores, lápiz, } \\
\text { lapicero, borrador cuaderno, tablero, borrador de tablero, post it. }\end{array}$ \\
\hline Cuándo & Tiempo Total & 120 minutos \\
\hline
\end{tabular}

\section{Planeador de Clase}

\begin{tabular}{|c|c|c|c|}
\hline Etapa & Actividad & $\begin{array}{c}\text { Evidencia } \\
\text { Aprendizaje }\end{array}$ & Materiales \\
Clase/ & & & \\
\hline
\end{tabular}




\begin{tabular}{|c|c|c|c|}
\hline $\begin{array}{c}\text { Inicio } \\
(20 / 120)\end{array}$ & $\begin{array}{l}\text { Distribución de grupos } \\
\text { 1. Se organizan los estudiantes en grupos de } 4 \\
\text { integrantes. En cada grupo se distribuyen los } \\
\text { roles de la siguiente manera: } \\
\text { - Vocero: comunica los resultados del equipo } \\
\text { - Relojero: controla el tiempo de la actividad y } \\
\text { recoge el material } \\
\text { - Dinamizador: Se encarga de que todos } \\
\text { participen y se respeten los turno } \\
\text { - Lector: Realiza la lectura } \\
\text { Identificación de Aprendizajes previos } \\
\text { En los grupos se discute alrededor de la } \\
\text { siguiente pregunta: } \\
\text { - ¿Qué es corrupción? } \\
\text { El dinamizador modera la discusión sobre las } \\
\text { preguntas guía. } \\
\text { El vocero de cada grupo socializa las } \\
\text { respuestas de cada pregunta. } \\
\text { 4. }\end{array}$ & $\begin{array}{l}\text { Identifican } \\
\text { factores } \\
\text { corrupción. }\end{array}$ & $\begin{array}{l}\text { Marcadores, } \\
\text { lápiz, lapicero, } \\
\text { borrador } \\
\text { cuaderno, } \\
\text { tablero, borrador } \\
\text { de tablero. }\end{array}$ \\
\hline $\begin{array}{c}\text { Desarrollo } \\
\text { (70/120) }\end{array}$ & $\begin{array}{l}\text { Lectura Artículo: } \\
\text { "Índice Sobre Corrupción Deja a } 16 \text { Países de } \\
\text { América Latina en Rojo" } \\
\begin{aligned} \text { 1. El docente explica la metodología de } \\
\text { trabajo "World Café" para abordar el } \\
\text { tema. } \\
\text { 2. El relojero toma nota de las preguntas } \\
\text { realizadas por los compañeros de grupo } \\
\text { durante la exposición del docente. } \\
\text { 3. Luego de la exposición del docente, en los } \\
\text { grupos conformados se procede a realizar } \\
\text { la actividad propuesta: } \\
\text { "World Café sobre la lectura guía }\end{aligned}\end{array}$ & $\begin{array}{l}\text { Identifica el } \\
\text { panorama } \\
\text { regional en } \\
\text { términos de } \\
\text { percepción de } \\
\text { corrupción en } \\
\text { América Latina. }\end{array}$ & $\begin{array}{l}\text { Fotocopias } \\
\text { artículo } \\
\text { periodístico, } \\
\text { papel periódico, } \\
\text { marcadores, } \\
\text { lápiz, lapicero, } \\
\text { borrador } \\
\text { cuaderno, } \\
\text { tablero, borrador } \\
\text { de tablero. }\end{array}$ \\
\hline $\begin{array}{l}\text { Cierre } \\
(30 / 120)\end{array}$ & $\begin{array}{l}\text { Conclusiones del ejercicio } \\
\text { 5. Cada líder de mesa (vocero) socializa las } \\
\text { iniciativas de los visitantes. } \\
\text { 6. Cada estudiante en el tablero de propuestas } \\
\text { divulga "su propósito para evitar la corrupción" }\end{array}$ & $\begin{array}{c}\text { Propone } \\
\text { alternativas de } \\
\text { solución para } \\
\text { disminuir } \\
\text { prácticas de } \\
\text { corrupción. }\end{array}$ & $\begin{array}{l}\text { Marcadores, } \\
\text { lápiz, lapicero, } \\
\text { borrador } \\
\text { cuaderno, } \\
\text { tablero, borrador } \\
\text { de tablero, post } \\
\text { it. }\end{array}$ \\
\hline
\end{tabular}

Fuente: Autor. 


\section{Evidencia trabajo en clase}

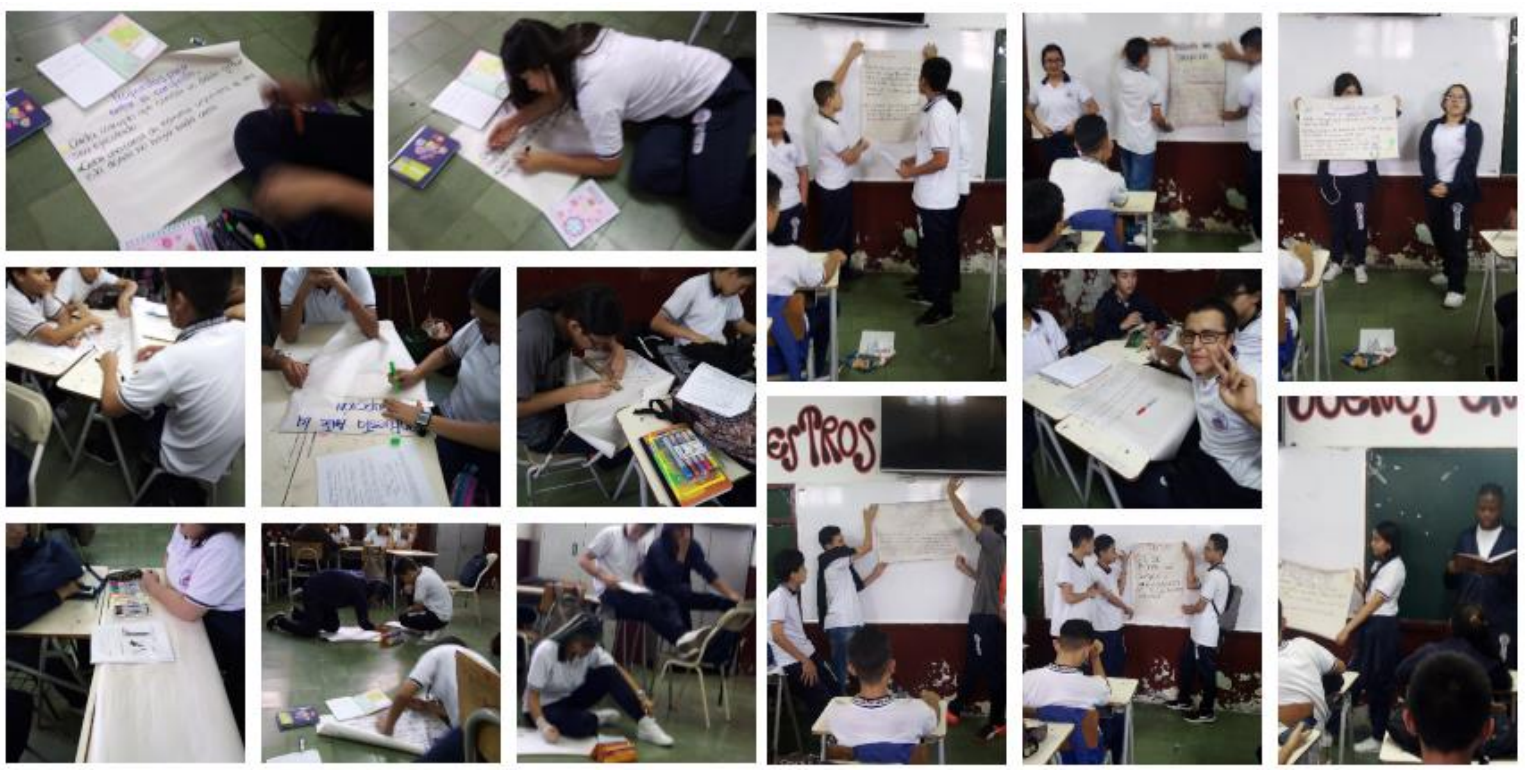

La metodología de innovación social Word Café permitió el dialogo grupal mediante las preguntas guías para cada grupo, la reflexión generó conciencia sobre los factores de corrupción que afectan la nación, la región y el mundo. Como se mencionó con anterioridad la sabiduría superior se logra con el dialogo generado por la colectividad (Brown \& Isaac,2007).

La participación de los estudiantes mediante la metodología generó mayor conexión grupal. Las contribuciones de los grupos y la sensibilidad sobre el tema de la corrupción plasmaron ideas creativas y variadas ante un problema generado de forma individual que se legítima en el colectivo.

La propuesta de visión conjunta de país y el vencimiento de las adversidades para reducir la corrupción promueven la toma de decisiones para el bienestar colectivo, genera visión crítica para la identificación de las fallas operacionales en las instituciones y genera ideales de sociedad basadas en la transparencia, equidad y sostenibilidad.

\section{Sección 11: Taller: Reflexión Victimas de Trata de Personas.}

La sección de clase se orienta bajo los siguientes criterios metodológicos.

Tabla 84: Sección - Taller Reflexión Victimas de Trata de Personas.

\section{Identificación del plan de área}




\begin{tabular}{|l|l|}
\hline $\begin{array}{l}\text { Asignatura } \\
\text { (Secuencias Didácticas) }\end{array}$ & $\begin{array}{l}\text { Asignatura Base: Ciencias sociales. } \\
\text { Asignaturas complementarias: Humanidades-Lengua Castellana, matemáticas, } \\
\text { ciencias naturales. }\end{array}$ \\
\hline $\begin{array}{l}\text { Objetivo Área } \\
\text { (DBA) }\end{array}$ & $\begin{array}{l}\text { Analizar críticamente los elementos constituyentes de la democracia, los derechos } \\
\text { de las personas y la identidad en Colombia, reconociendo la interacción permanente } \\
\text { entre el espacio geográfico y el ser humano, los avances y limitaciones de esta } \\
\text { relación. }\end{array}$ \\
\hline Objetivo Específico & Identificar el panorama mundial sobre la trata de personas. \\
\hline ODS & \begin{tabular}{l} 
Paz, justicia e instituciones sólidas. \\
\hline Meta ODS
\end{tabular} \\
$\begin{array}{l}\text { Reducir considerablemente todas las formas de violencia y las tasas de } \\
\text { mortalidad conexas en todo el mundo. } \\
\text { Reducir sustancialmente la corrupción y el soborno en todas sus formas. } \\
\text { Poner fin al maltrato, la explotación, la trata, la tortura y todas las } \\
\text { formas de violencia contra los niños. } \\
\text { Promover el estado de derecho en los planos nacional e internacional y } \\
\text { garantizar la igualdad de acceso a la justicia para todos. }\end{array}$ \\
\hline
\end{tabular}

\section{Planificación de Acciones Pedagógicas}

\begin{tabular}{|c|c|c|}
\hline \multirow{4}{*}{ Qué } & $\begin{array}{l}\text { Proceso } \\
\text { Cognitivo }\end{array}$ & $\begin{array}{l}\text { - } \quad \text { Evaluar información, formular argumentos y explicar problemas } \\
\text { o situaciones. } \\
\text { - } \quad \text { Identificar y analizar diferentes perspectivas. } \\
\text { - } \quad \text { Comprender las diferencias en la comunicación. } \\
\text { - Evaluar acciones y consecuencias. }\end{array}$ \\
\hline & $\begin{array}{l}\text { Mediadores de } \\
\text { Desempeño }\end{array}$ & $\begin{array}{l}\text { - } \quad \text { Conocimiento de asuntos globales. } \\
\text { - } \quad \text { Conocimiento intercultural. } \\
\text { - } \quad \text { Respeto. } \\
\text { Valoración de los derechos humanos fundamentales (dignidad } \\
\text { humana). }\end{array}$ \\
\hline & $\begin{array}{l}\text { Dominios de } \\
\text { Contenido }\end{array}$ & $\begin{array}{l}\text { - Desarrollo e interdependencia socioeconómica. } \\
\text { - } \quad \text { Conflictos, instituciones y derechos humanos. }\end{array}$ \\
\hline & Contexto & Global. \\
\hline Cómo & $\begin{array}{l}\text { Procesos de } \\
\text { Innovación }\end{array}$ & "Análisis Dimensional" \\
\hline Por qué & $\begin{array}{l}\text { Evidencia de } \\
\text { Aprendizaje }\end{array}$ & Identifica el panorama mundial sobre la trata de personas. \\
\hline Dónde & $\begin{array}{l}\text { Medios } \\
\text { Educativos }\end{array}$ & Aula especializada. \\
\hline Quién & Personas & Profesor, Estudiante. \\
\hline Cuánto & Materiales & $\begin{array}{l}\text { Fotocopias Artículo especializado, papel periódico, marcadores, lápiz, } \\
\text { lapicero, borrador cuaderno, tablero, borrador de tablero, post it. }\end{array}$ \\
\hline Cuándo & Tiempo Total & 120 minutos \\
\hline
\end{tabular}

\section{Planeador de Clase}

\begin{tabular}{|c|c|c|c|}
\hline $\begin{array}{c}\text { Etapa } \\
\text { Clase/ } \\
\text { Tiempo }\end{array}$ & Actividad & $\begin{array}{c}\text { Evidencia } \\
\text { Aprendizaje }\end{array}$ & Materiales \\
\hline Inicio & Distribución de grupos & $\begin{array}{l}\text { Identifica } \\
\text { problemáticas }\end{array}$ & $\begin{array}{c}\text { Fotocopias } \\
\text { Artículo }\end{array}$ \\
\hline
\end{tabular}




\begin{tabular}{|c|c|c|c|}
\hline$(20 / 120)$ & \begin{tabular}{|l} 
1. Se organizan los estudiantes en grupos de 4 \\
integrantes. En cada grupo se distribuyen los roles \\
de la siguiente manera: \\
- Vocero: comunica los resultados del equipo \\
- Relojero: controla el tiempo de la actividad y \\
recoge el material \\
- Dinamizador: Se encarga de que todos \\
participen y se respeten los turno \\
- Lector: Realiza la lectura \\
Identificación de Aprendizajes previos \\
2. En los grupos se discute alrededor de la \\
siguiente pregunta: \\
- iQué es la trata de personas? \\
3. El dinamizador modera la discusión sobre las \\
preguntas guía. \\
4. El vocero de cada grupo socializa las \\
respuestas de cada pregunta.
\end{tabular} & $\begin{array}{l}\text { relacionadas } \\
\text { con los } \\
\text { derechos } \\
\text { humanos } \\
\text { fundamentales } \\
\text { (dignidad } \\
\text { humana). }\end{array}$ & $\begin{array}{l}\text { especializado, } \\
\text { papel periódico, } \\
\text { marcadores, } \\
\text { lápiz, lapicero, } \\
\text { borrador } \\
\text { cuaderno, } \\
\text { tablero, borrador } \\
\text { de tablero, post } \\
\text { it. }\end{array}$ \\
\hline $\begin{array}{c}\text { Desarrollo } \\
\text { (70/120) }\end{array}$ & $\begin{array}{l}\text { Lectura Artículo: } \\
\text { "La OIM prestó asistencia a } 7.000 \text { víctimas de trata } \\
\text { de personas a nivel mundial en } 2015 \text { " } \\
\text { 1. El docente explica la metodología de } \\
\text { trabajo "Análisis Dimensional" para } \\
\text { abordar el tema. } \\
\text { 2. } \begin{array}{l}\text { El relojero toma nota de las preguntas } \\
\text { realizadas por los compañeros de grupo } \\
\text { durante la exposición del docente. }\end{array} \\
\text { 3. Luego de la exposición del docente, en los } \\
\text { grupos conformados se procede a realizar el } \\
\text { análisis dimensional al tema propuesto: } \\
\text { "La OIM prestó asistencia a } 7.000 \text { víctimas de trata } \\
\text { de personas a nivel mundial en } 2015 \text { " }\end{array}$ & $\begin{array}{l}\text { Identifica el } \\
\text { panorama } \\
\text { mundial sobre } \\
\text { las victimas de } \\
\text { trata de } \\
\text { personas }\end{array}$ & $\begin{array}{l}\text { Fotocopias } \\
\text { Artículo } \\
\text { especializado, } \\
\text { papel periódico, } \\
\text { marcadores, } \\
\text { lápiz, lapicero, } \\
\text { borrador } \\
\text { cuaderno, } \\
\text { tablero, borrador } \\
\text { de tablero. }\end{array}$ \\
\hline $\begin{array}{l}\text { Cierre } \\
(30 / 120)\end{array}$ & $\begin{array}{l}\text { Conclusiones del ejercicio } \\
\text { 1. Cada líder de mesa (vocero) socializa el análisis } \\
\text { dimensional del equipo. } \\
\text { 2. El docente sintetiza las diferentes intervenciones } \\
\text { para definir una conclusión conjunta. }\end{array}$ & $\begin{array}{l}\text { Comprende el } \\
\text { panorama } \\
\text { mundial sobre } \\
\text { las víctimas de } \\
\text { trata de } \\
\text { personas. }\end{array}$ & $\begin{array}{c}\text { Marcadores, } \\
\text { lápiz, lapicero, } \\
\text { borrador } \\
\text { cuaderno, } \\
\text { tablero, borrador } \\
\text { de tablero, post } \\
\text { it. }\end{array}$ \\
\hline
\end{tabular}

Fuente: Autor. 


\section{Evidencia trabajo en clase}
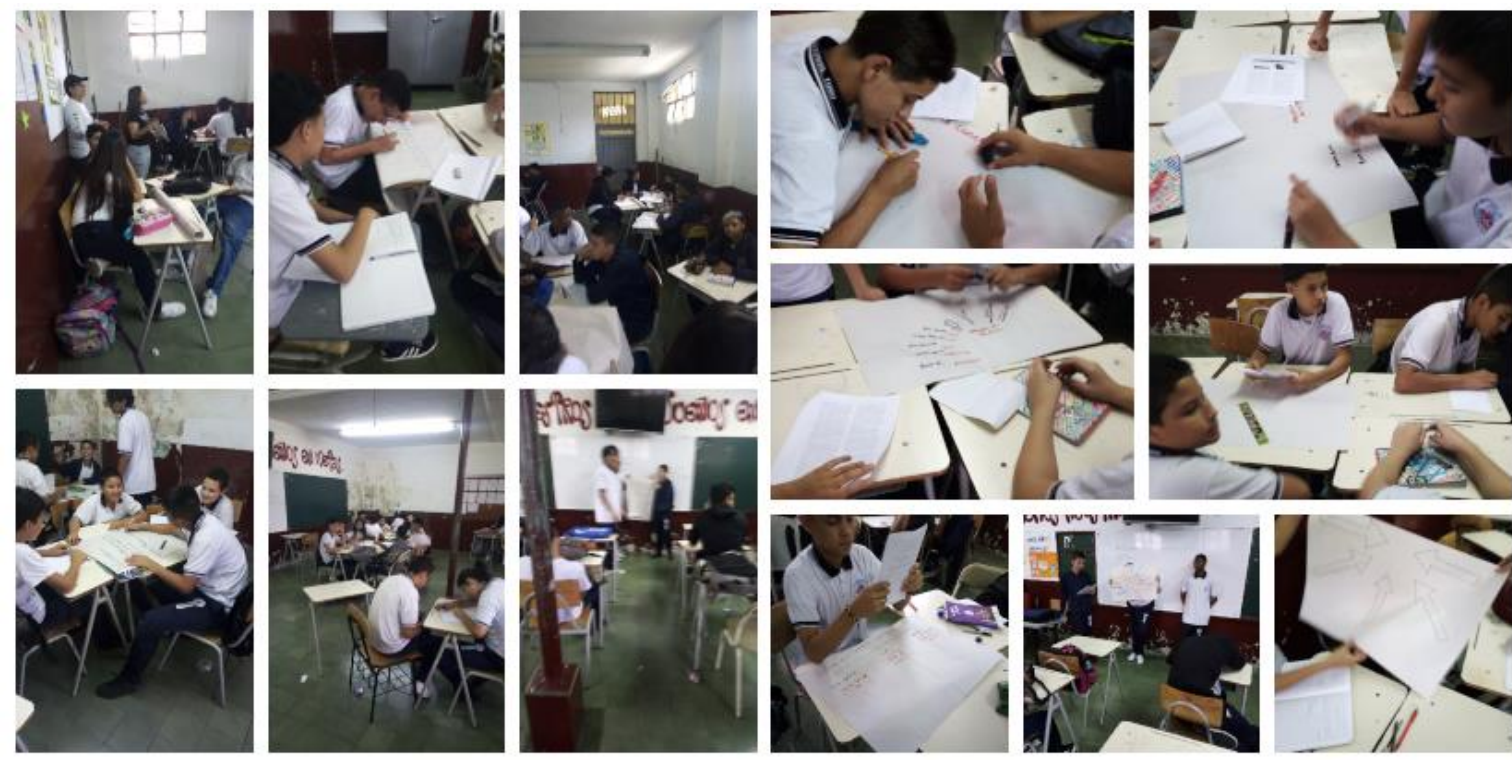

El análisis dimensional es un método analítico diseñado para clarificar y explorar las dimensiones y límites del problema mediante 7 dimensiones: En qué consiste el problema, quién lo produce o a quién lo afecta, para qué resolvemos el problema, cuándo o desde cuándo se presenta el problema, cuánto importa el problema, cómo se presenta el problema y dónde se presenta el problema (Fernández, 2010).

Bajo este enfoque los estudiantes analizaron el problema mundial sobre "la trata de personas permitiendo identificar las múltiples variables causa- efecto.

Del mismo modo, la técnica promueve la creatividad en el sentido que estimula la improvisación, la intuición, la imaginación, la invención y el talento (Fernández, 2010).

Finalizadas las secciones de intervención directa, se procede a analizar los niveles de desarrollo de la competencia a partir de la actividad propuesta como trabajo final.

En este sentido, emerge la dimensión evaluativa para identificar a partir de las métricas la apropiación de la competencia global.

\section{Dimensión Evaluativa}

La dimensión evaluativa comprende las coordenadas de la tabla 30.

Tabla 85: Dimensión Evaluativa.

\section{Coordenadas Dimensión Evaluativa}




\begin{tabular}{|l|l|l|}
\hline Producto & \multicolumn{1}{|c|}{ Impacto } & \multicolumn{1}{c|}{$\begin{array}{c}\text { Indicadores de } \\
\text { Innovación }\end{array}$} \\
\hline 3. Tangible & 1. Económico & 1. Eficiencia \\
4. Intangible & 2. Social & 2. Eficacia \\
& 3. Ambiental & 3. Transferibilidad \\
& 4. Organizacional & 4. Sostenibilidad \\
\hline
\end{tabular}

Fuente: Autor.

La sección de clase se desarrolló bajo los siguientes procedimientos.

\section{Sección 12: Apropiación de la competencia global.}

La matriz de evaluación utilizada para la revisión del trabajo final (producto) por parte de los estudiantes consideró los aspectos señalados en la tabla 31, de este modo la rúbrica relaciona el impacto y los respectivos indicadores de viabilidad de la propuesta.

Los indicadores de evaluación a partir de los principios de (Fidalgo; 2007) permiten considerar niveles de innovación en la propuesta de solución.

Tabla 86: Matriz de Evaluación.

\begin{tabular}{|l|l|l|l|l|l|l|l|l|}
\hline \multicolumn{9}{|c|}{ Matriz de Evaluación } \\
\hline \multirow{2}{*}{ Productos } & \multicolumn{3}{|c|}{ Impacto } & \multicolumn{5}{c|}{ Indicadores } \\
\cline { 2 - 9 } & Económico & Social & Ambiental & Institucional & Eficacia & Eficiencia & Transferibilidad & Sostenibilidad \\
\hline Tangible & & & & & & & & \\
\hline Intangible & & & & & & & & \\
\hline
\end{tabular}

Fuente: Autor.

\section{Evidencia trabajo en clase}

Ilustración 46: Evidencia socialización trabajo final. 

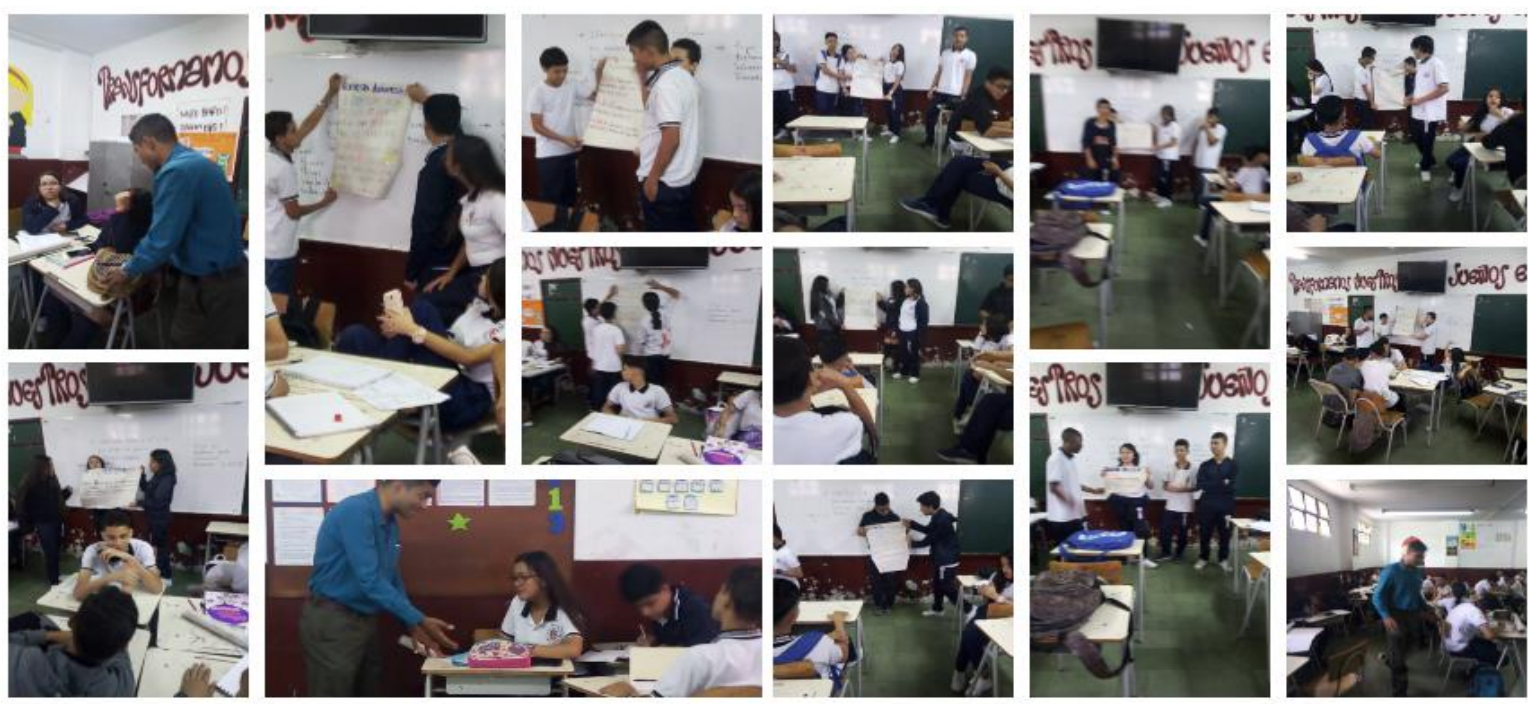

Fuente: Autor.

El resultado del ejercicio final para dar solución a la metodología para la Resolución de Conflictos Escolares en la Institución Educativa Monseñor Francisco Cristóbal Toro permitió ideas creativas, en el grupo se destacan dos propuestas por parte de los estudiantes.

1. El comité de convivencia escolar deberá generar alianzas con las instituciones penitenciarias y carcelarias de la ciudad para que los estudiantes sancionados por faltas tipo I, II y III visiten las instalaciones y realicen un servicio social.

2. Las horas de servicio social estudiantil obligatorio ${ }^{38}$ mejor conocidas como horas de alfabetización escolar que corresponde a 80 horas de acuerdo con la legislación en Colombia para los grados 10 y 11, deberán realizarse en centros de resocialización de la ciudad.

Las propuestas fueron sometidas a la valoración grupal, cada equipo de trabajo expuso su propuesta e identificó, cómo resolver el problema (Eficacia), el uso racional de recursos (Eficiencia), aplicabilidad (Transferibilidad) y perdurabilidad a través del tiempo (Sostenibilidad).

\section{Sección 13: Prueba final-Postest.}

Luego de la intervención pedagógica se procede a realizar la prueba final de conocimiento para identificar los niveles de desarrollo de la competencia a partir del proceso de intervención en el aula.

\footnotetext{
${ }^{38}$ El servicio social estudiantil obligatorio está contemplado en la Ley 115 de 1994 en el artículo 97. Por su parte la resolución 4210 del 12 de septiembre de 1996 por el MEN establece las reglas para organizar el funcionamiento del servicio social obligatorio.
} 
Tabla 87: Planeación Sección Prueba final-Postest.

\begin{tabular}{|l|l|}
\hline $\mathrm{N}^{\circ}$ Participantes & 45 personas \\
\hline $\begin{array}{l}\text { Clasificación de } \\
\text { participantes }\end{array}$ & $\begin{array}{l}\text { Estudiantes de noveno grado Institución Educativa Monseñor Francisco } \\
\text { Cristóbal Toro }\end{array}$ \\
\hline Objetivo & $\begin{array}{l}\text { Identificar los niveles de desarrollo de la competencia global a partir del } \\
\text { modelo de coordenadas curriculares aplicada en los estudiantes de noveno } \\
\text { grado de la Institución Educativa Monseñor Francisco Cristóbal Toro }\end{array}$ \\
\hline Duración & 1 hora. \\
\hline
\end{tabular}

Fuente: Autor.

\section{Evidencia Prueba final- Postest.}
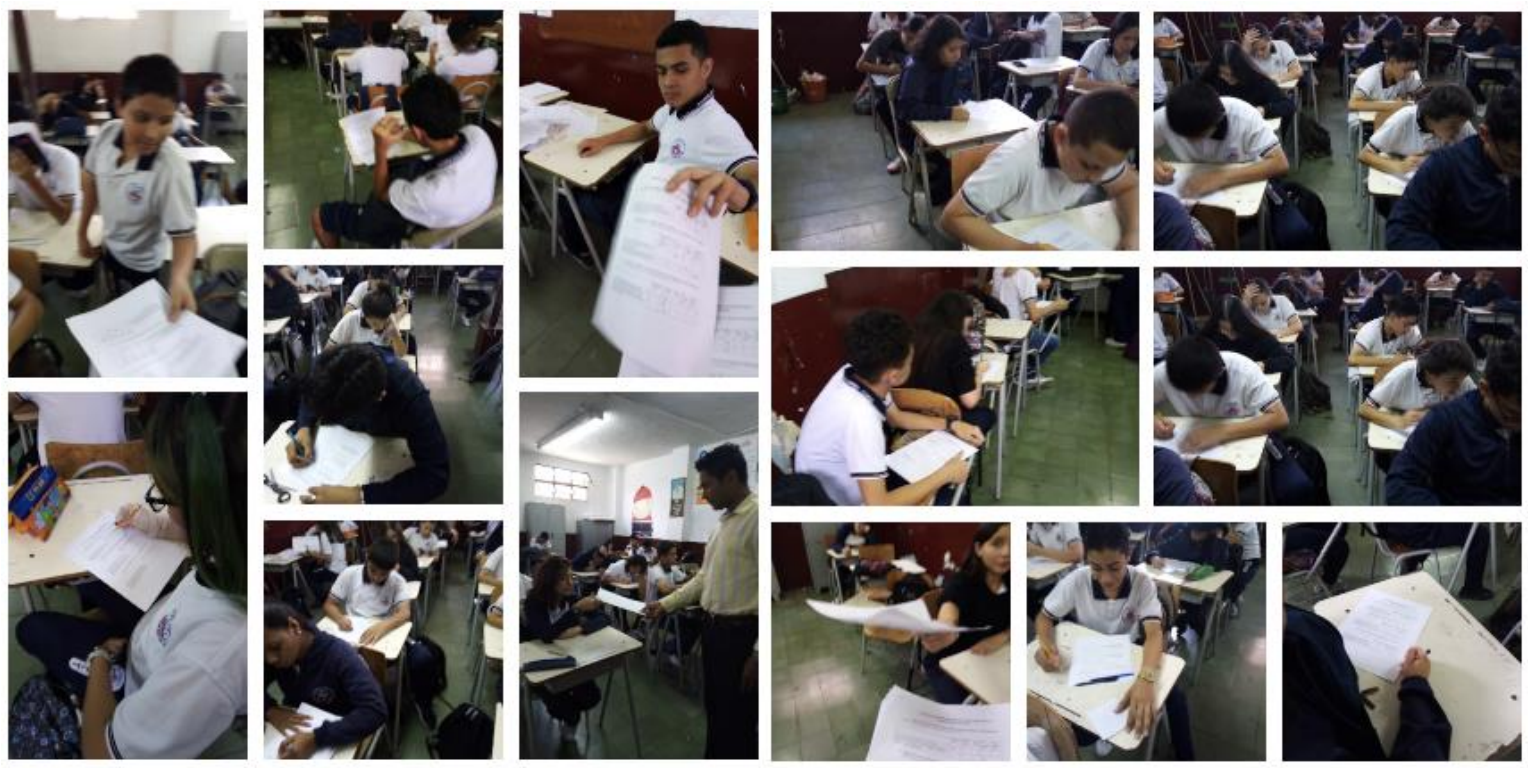

Cabe resaltar, el instrumento como se relacionó en el pretest se retoma de la guía de orientación PISA 2018. Los resultados de la prueba final a continuación se detallan.

1. ¿Qué tanto lo describen a usted cada una de las siguientes afirmaciones?

Tabla 88: Postest. ¿Qué tanto lo describen a usted cada una de las siguientes afirmaciones?

\begin{tabular}{|l|c|c|c|c|c|}
\hline & Bastante & Mucho & Algo & $\begin{array}{l}\text { No } \\
\text { mucho }\end{array}$ & $\begin{array}{l}\text { Para } \\
\text { nada }\end{array}$ \\
\hline $\begin{array}{l}\text { Pregunta 1 veces trato de entender mejor a mis amigos } \\
\text { imaginando cómo se ven las cosas desde su } \\
\text { perspectiva. }\end{array}$ & 12 & 21 & 10 & 2 & 0 \\
\cline { 2 - 6 } & $26.7 \%$ & $46.7 \%$ & $22.2 \%$ & $4.4 \%$ & $0.0 \%$ \\
\hline
\end{tabular}


Antes de criticar a alguien, trato de imaginar cómo me sentiría si estuviera en su lugar.

\begin{tabular}{|c|c|c|c|c|}
\hline 13 & 21 & 9 & 2 & 0 \\
\hline $28.9 \%$ & $46.7 \%$ & $20.0 \%$ & $4.4 \%$ & $0.0 \%$ \\
\hline
\end{tabular}

Fuente: Autor

El constructo evaluado corresponde a: Adopción de Perspectivas. El análisis patrones agregado indica.

Tabla 89: Agregado pregunta $N^{\circ} 1$ Postest.

\begin{tabular}{|l|c|l|l|c|c|}
\hline & Bastante & Mucho & Algo & No mucho & Para nada \\
\hline Recuento & 12 & 30 & 3 & 0 & 0 \\
\hline$\%$ & $26.7 \%$ & $66.7 \%$ & $6.7 \%$ & $0.0 \%$ & $0.0 \%$ \\
\hline
\end{tabular}

Fuente: Autor

\section{Constructo: Adopción de Perspectivas}

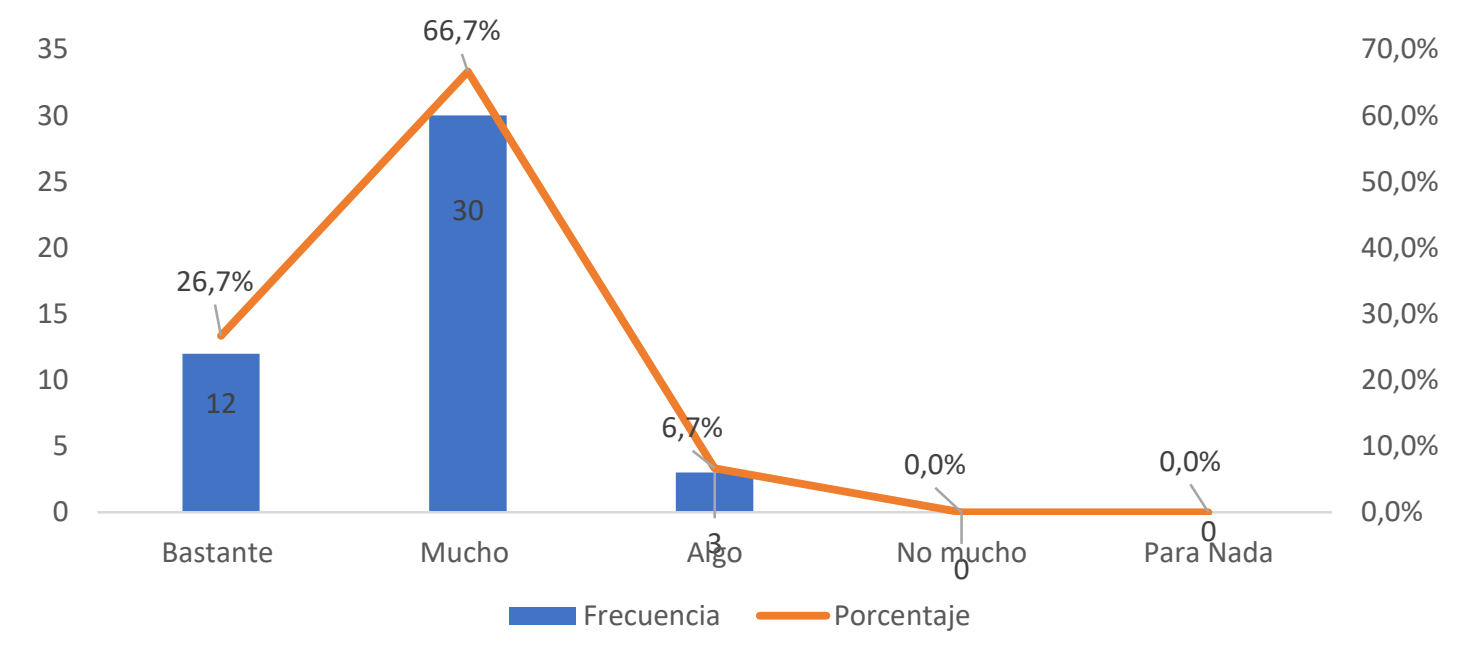

Ilustración 47: Postest. Constructo: Adopción de perspectivas Fuente: Autor.

Los resultados muestran que el constructo Adopción de perspectivas en la escala Mucho $(66,7 \%)$ y Bastante $(26,7 \%)$ son las frecuencias que predominan positivamente en el grupo con un $93,4 \%$.

\section{2. ¿Hasta qué punto está usted de acuerdo con las siguientes afirmaciones?}

Tabla 90: Postest. ¿Hasta qué punto está usted de acuerdo con las siguientes afirmaciones?

\begin{tabular}{|l|c|c|c|c|}
\hline Pregunta 2 & $\begin{array}{l}\text { Totalmente en } \\
\text { desacuerdo }\end{array}$ & $\begin{array}{l}\text { En } \\
\text { desacuerdo }\end{array}$ & $\begin{array}{l}\text { De } \\
\text { acuerdo }\end{array}$ & $\begin{array}{l}\text { Totalmente de } \\
\text { acuerdo }\end{array}$ \\
\hline $\begin{array}{l}\text { Es correcto boicotear las empresas de las que se } \\
\text { sabe que ofrecen malas condiciones en el sitio } \\
\text { de trabajo para sus empleados. }\end{array}$ & 11 & 14 & 16 & 4 \\
\hline & $24.4 \%$ & $31.1 \%$ & $35.6 \%$ & $8.9 \%$ \\
\hline
\end{tabular}




\begin{tabular}{|l|c|c|c|c|}
$\begin{array}{l}\text { Puedo hacer algo sobre los problemas del } \\
\text { mundo. }\end{array}$ & $2.2 \%$ & $8.9 \%$ & $71.1 \%$ & $17.8 \%$ \\
\hline $\begin{array}{l}\text { Cuidar del ambiente global es importante para } \\
\text { mí. }\end{array}$ & 5 & 1 & 14 & 25 \\
\cline { 2 - 5 } & $11.1 \%$ & $2.2 \%$ & $31.1 \%$ & $55.6 \%$ \\
\hline
\end{tabular}

Fuente: Autor.

El constructo evaluado corresponde a: Mentalidad Global. El análisis patrones de puntos agregado indica.

Tabla 91: Agregado pregunta $N^{\circ} 2$ Postest.

\begin{tabular}{|l|c|c|c|c|}
\hline & $\begin{array}{l}\text { Totalmente en } \\
\text { desacuerdo }\end{array}$ & En desacuerdo & De acuerdo & $\begin{array}{l}\text { Totalmente de } \\
\text { acuerdo }\end{array}$ \\
\hline Recuento & 0 & 18 & 25 & 2 \\
\hline$\%$ & $0.0 \%$ & $40.0 \%$ & $55.6 \%$ & $4.4 \%$ \\
\hline
\end{tabular}

Fuente: Autor

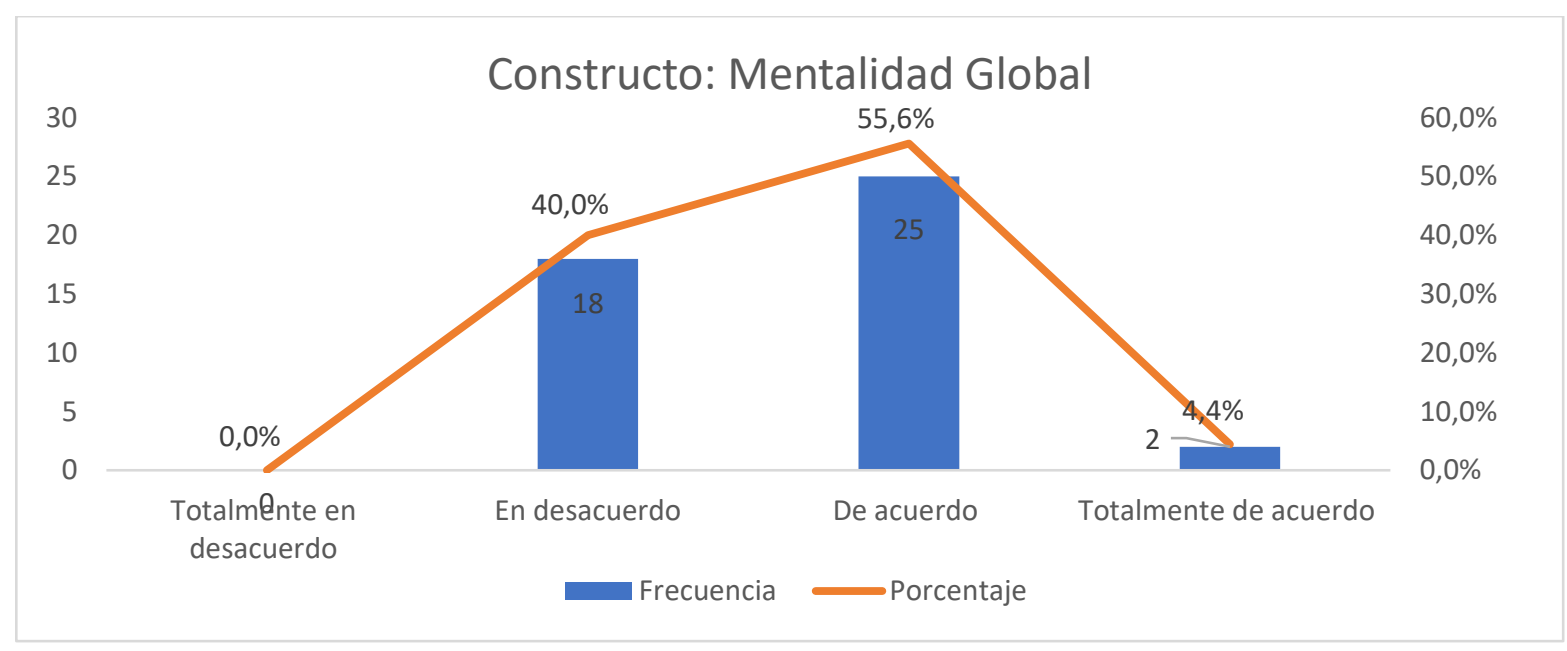

Ilustración 48: Postest. Constructo: Mentalidad Global.

Fuente: Autor.

El constructo Mentalidad global indicó mayor tendencia positiva con un 60\% (de acuerdo y totalmente de acuerdo).

\section{3. ¿Qué tanto lo describen a usted cada una de las siguientes afirmaciones?}

Tabla 92: Postest. ¿Qué tanto lo describen a usted cada una de las siguientes afirmaciones?

\begin{tabular}{|c|c|c|c|c|c|}
\hline Pregunta 3 & Bastante & Mucho & Algo & \begin{tabular}{|l|} 
No \\
mucho
\end{tabular} & $\begin{array}{l}\text { Para } \\
\text { nada }\end{array}$ \\
\hline \multirow[b]{2}{*}{ Puedo adaptarme fácilmente a una nueva cultura. } & 8 & 12 & 12 & 12 & 1 \\
\hline & $17.8 \%$ & $26.7 \%$ & $26.7 \%$ & $26.7 \%$ & $2.2 \%$ \\
\hline \multirow{2}{*}{$\begin{array}{l}\text { Cuando me encuentro situaciones difíciles con otras } \\
\text { personas, puedo pensar en una manera de resolverlas. }\end{array}$} & 11 & 20 & 11 & 3 & 0 \\
\hline & $24.4 \%$ & $44.4 \%$ & $24.4 \%$ & $6.7 \%$ & $0.0 \%$ \\
\hline \multirow{2}{*}{$\begin{array}{l}\text { Soy capaz de superar mis dificultades al interactuar } \\
\text { con personas de otras culturas. }\end{array}$} & 9 & 13 & 12 & 10 & 1 \\
\hline & $20.0 \%$ & $28.9 \%$ & $26.7 \%$ & $22.2 \%$ & $2.2 \%$ \\
\hline
\end{tabular}

Fuente: Autor. 
El constructo evaluado corresponde a: Flexibilidad / Adaptabilidad. El análisis patrones de puntos agregado indica.

Tabla 93: Agregado pregunta $N^{\circ} 3$ Postest.

\begin{tabular}{|l|c|c|c|c|c|}
\hline & Bastante & Mucho & Algo & No mucho & Para nada \\
\hline Recuento & 16 & 21 & 8 & 0 & 0 \\
\hline$\%$ & $35.6 \%$ & $46.7 \%$ & $17.8 \%$ & $0.0 \%$ & $0.0 \%$ \\
\hline
\end{tabular}

Fuente: Autor

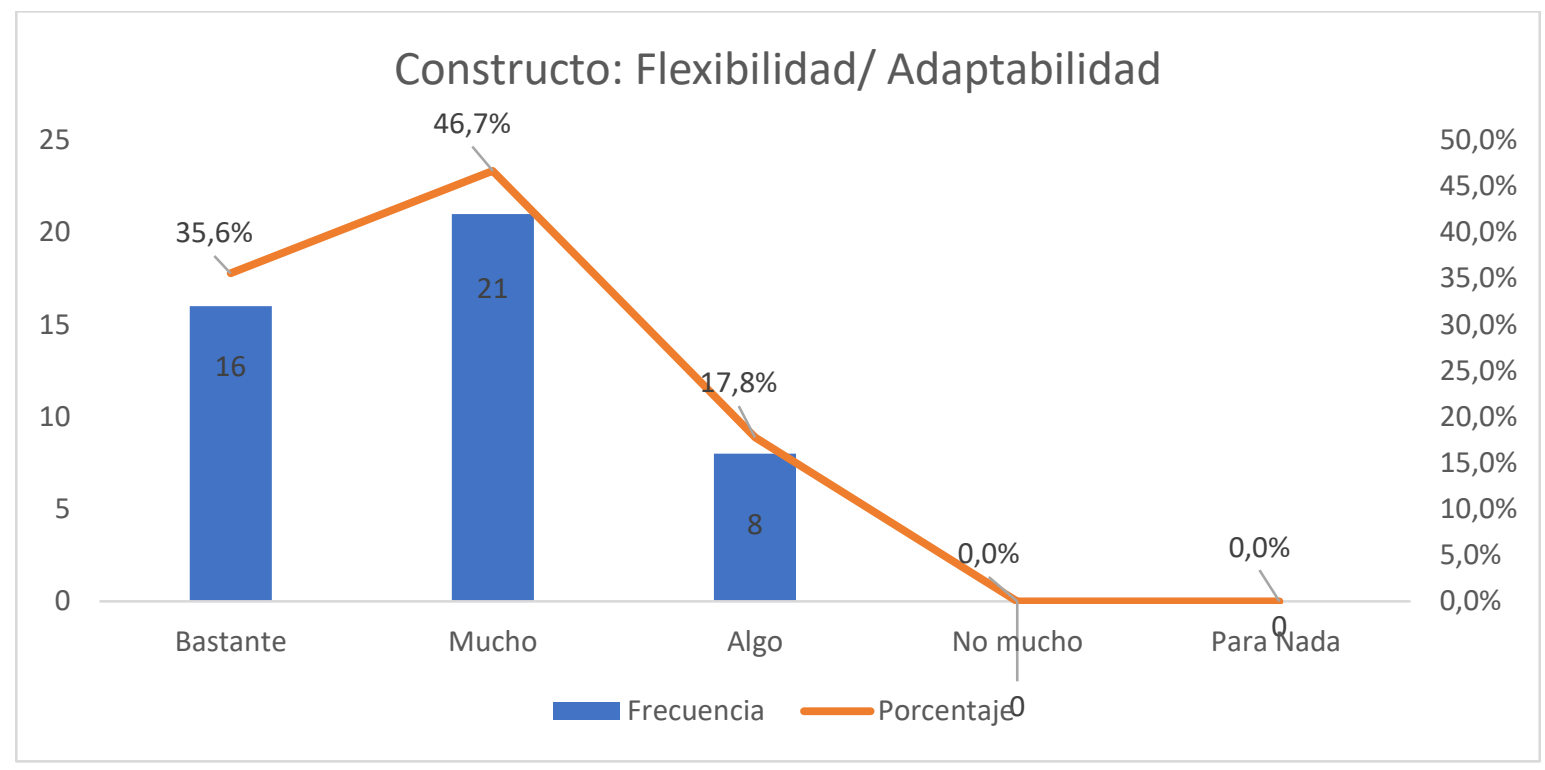

Ilustración 49: Postest: Constructo: Flexibilidad / Adaptabilidad Fuente: Autor.

El constructo Flexibilidad / Adaptabilidad indicó la mayor tendencia positiva (bastante y mucho) con un $82,3 \%$.

\section{4. ¿Hasta qué punto está usted de acuerdo con las siguientes afirmaciones?}

Tabla 94: Postest. ¿Hasta qué punto está usted de acuerdo con las siguientes afirmaciones?

\begin{tabular}{|l|c|c|l|c|}
\hline \multirow{2}{*}{ Pregunta 4 } & $\begin{array}{l}\text { Totalmente en } \\
\text { desacuerdo }\end{array}$ & $\begin{array}{l}\text { En } \\
\text { desacuerdo }\end{array}$ & $\begin{array}{l}\text { De } \\
\text { acuerdo }\end{array}$ & $\begin{array}{l}\text { Totalmente } \\
\text { de acuerdo }\end{array}$ \\
\hline \multirow{2}{*}{$\begin{array}{l}\text { Elijo mis palabras } \\
\text { cuidadosamente. }\end{array}$} & 2 & 4 & 29 & 10 \\
\hline \multirow{2}{*}{$\begin{array}{l}\text { Doy ejemplos concretos para } \\
\text { explicar mis ideas. }\end{array}$} & $4.4 \%$ & $8.9 \%$ & $64.4 \%$ & $22.2 \%$ \\
\hline \multirow{2}{*}{$\begin{array}{l}\text { Explico las cosas con mucho } \\
\text { cuidado. }\end{array}$} & $0.0 \%$ & 9 & 21 & 15 \\
\cline { 2 - 5 } & 0 & $6.0 \%$ & $46.7 \%$ & $33.3 \%$ \\
\hline
\end{tabular}


Fuente: Autor.

El constructo evaluado corresponde a: Conocimiento de la comunidad intercultural. El análisis del estadístico agregado indica.

Tabla 95: Agregado pregunta $N^{\circ} 4$ Postest.

\begin{tabular}{|l|l|r|r|r|}
\hline & $\begin{array}{l}\text { Totalmente en } \\
\text { desacuerdo }\end{array}$ & En desacuerdo & De acuerdo & \multicolumn{2}{|l|}{$\begin{array}{l}\text { Totalmente de } \\
\text { acuerdo }\end{array}$} \\
\hline Recuento & 0 & 0 & 26 & 19 \\
\hline$\%$ & $0.0 \%$ & $0.0 \%$ & $57.8 \%$ & $42.2 \%$ \\
\hline
\end{tabular}

Fuente: Autor

\section{Constructo: Conocimiento de la comunicación intercultural}

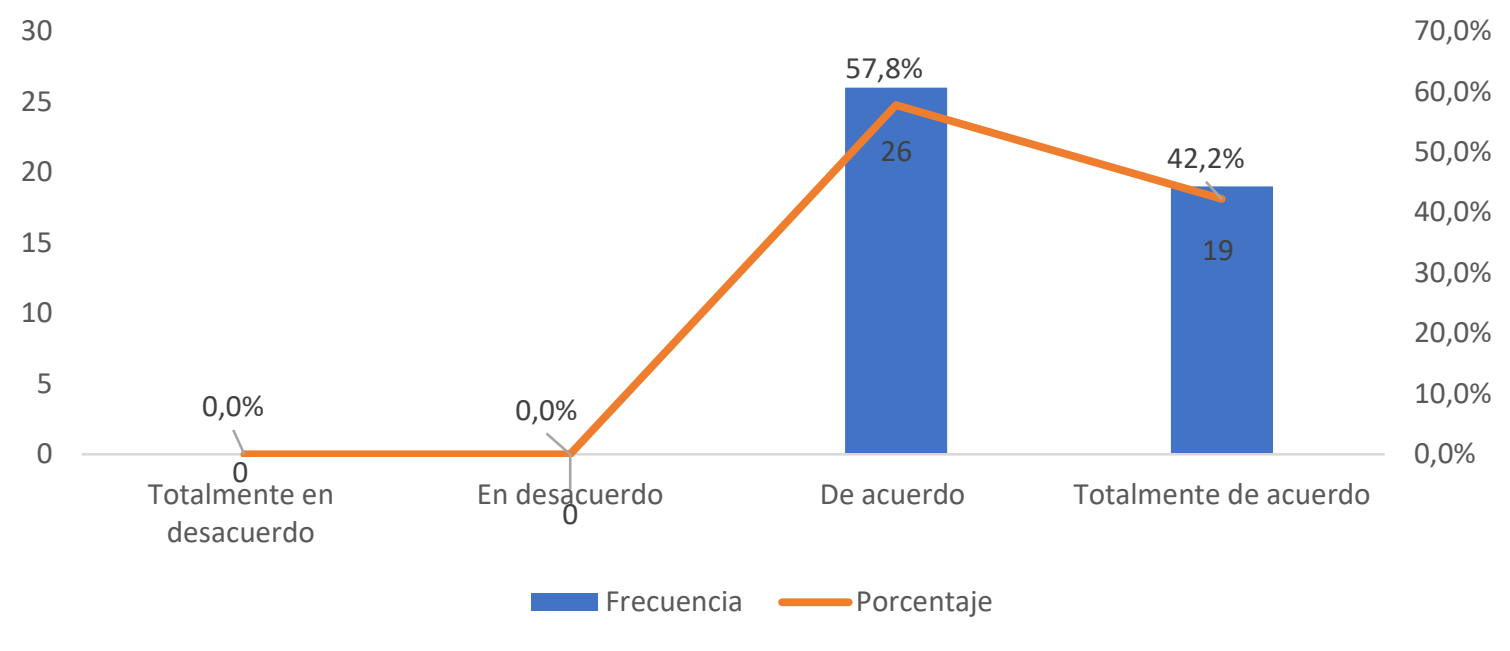

Ilustración 50: Postest. Constructo: Conocimiento de la comunicación intercultural.

Fuente: Autor.

El constructo Conocimiento de la comunidad intercultural con un 100\% presentó mayor tendencia positiva (de acuerdo y totalmente de acuerdo).

\section{5. ¿Con qué facilidad piensa usted que podría realizar las siguientes tareas por su cuenta?}

Tabla 96: Postest. ¿Con qué facilidad piensa usted que podría realizar las siguientes tareas por su cuenta?

\begin{tabular}{|l|c|l|l|l|}
\hline & $\begin{array}{l}\text { No podría } \\
\text { hacer esto }\end{array}$ & $\begin{array}{l}\text { Me costaría } \\
\text { mucho } \\
\text { trabajo } \\
\text { hacerlo solo }\end{array}$ & $\begin{array}{l}\text { Podría hacerlo } \\
\text { con algo de } \\
\text { esfuerzo }\end{array}$ & $\begin{array}{l}\text { Podría } \\
\text { hacerlo con } \\
\text { fácilmente }\end{array}$ \\
\hline & 7 & 8 & 26 & 4 \\
\hline
\end{tabular}




\begin{tabular}{|c|c|c|c|c|}
\hline $\begin{array}{l}\text { Discutir las diferentes razones por las } \\
\text { que las personas se convierten en } \\
\text { refugiados. }\end{array}$ & $15.6 \%$ & $17.8 \%$ & $57.8 \%$ & $8.9 \%$ \\
\hline \multirow{2}{*}{$\begin{array}{l}\text { Explicar por qué algunos países sufren } \\
\text { más que otros por el cambio climático } \\
\text { global. }\end{array}$} & 4 & 4 & 27 & 10 \\
\hline & $8.9 \%$ & $8.9 \%$ & $60.0 \%$ & $22.2 \%$ \\
\hline \multirow{2}{*}{$\begin{array}{l}\text { Explicar cómo las crisis económicas de } \\
\text { cada país afectan la economía mundial. }\end{array}$} & 3 & 9 & 22 & 11 \\
\hline & $6.7 \%$ & $20.0 \%$ & $48.9 \%$ & $24.4 \%$ \\
\hline
\end{tabular}

Fuente: Autor.

El constructo evaluado corresponde a: Autoeficacia con respecto a asuntos globales. El análisis del estadístico agregado indica.

Tabla 97: Agregado pregunta N5 Postest.

\begin{tabular}{|l|c|c|c|c|}
\hline & $\begin{array}{l}\text { No podría } \\
\text { hacer esto }\end{array}$ & $\begin{array}{l}\text { Me costaría } \\
\text { mucho trabajo } \\
\text { hacerlo solo }\end{array}$ & $\begin{array}{l}\text { Podría hacerlo } \\
\text { con algo de } \\
\text { esfuerzo }\end{array}$ & $\begin{array}{l}\text { Podría hacerlo } \\
\text { con fácilmente }\end{array}$ \\
\hline Recuento & 0 & 2 & 38 & 5 \\
\hline$\%$ & $0.0 \%$ & $4.4 \%$ & $84.4 \%$ & $11.1 \%$ \\
\hline
\end{tabular}

Fuente: Autor

\section{Constructo: Autoeficacia con respecto a asuntos globales}

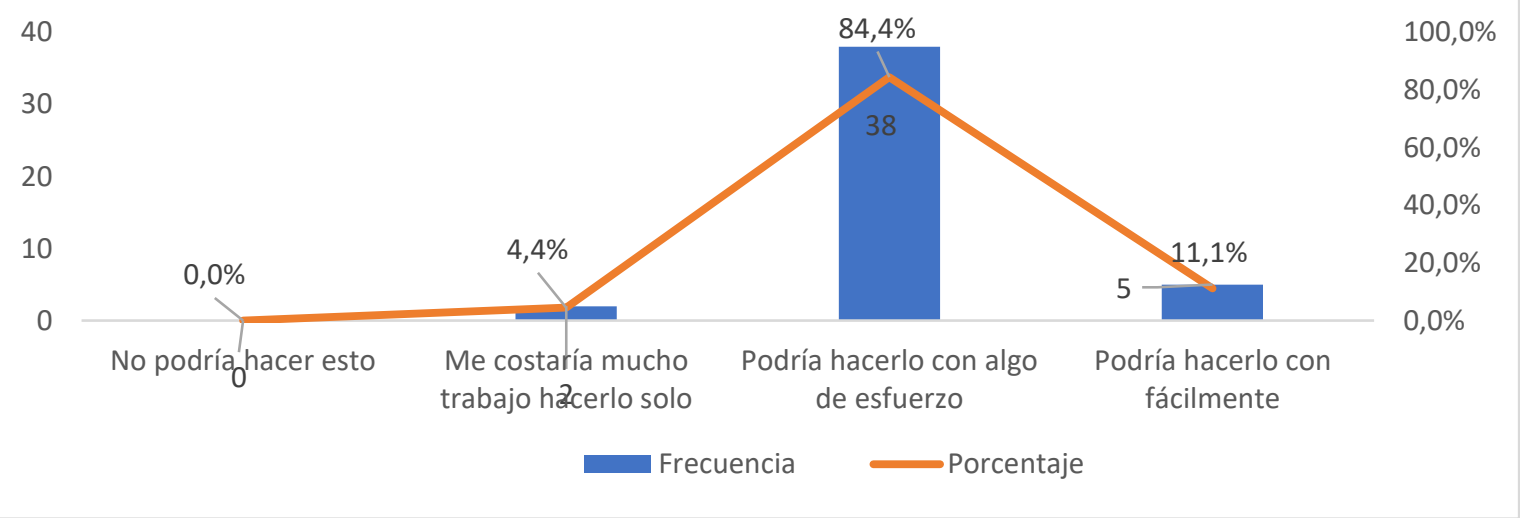

Ilustración 51: Postest. Constructo: Autoeficacia con respecto a asuntos globales.

Fuente: Autor.

El constructo Autoeficacia con respecto a asuntos globales indica una tendencia positiva con un 96,4\% (Podría hacerlo con algo de esfuerzo y podría hacerlo fácilmente).

\section{6. ¿Qué tan informado está usted sobre los siguientes temas?}


Tabla 98: Postest. ¿Qué tan informado está usted sobre los siguientes temas?

\begin{tabular}{|c|c|c|c|c|}
\hline Pregunta 6 & \begin{tabular}{|l|} 
Nunca he \\
oído \\
sobre esto
\end{tabular} & $\begin{array}{l}\text { He oído sobre esto, } \\
\text { pero no podría } \\
\text { explicar de qué se } \\
\text { trata realmente }\end{array}$ & \begin{tabular}{|l} 
Sé algo sobre \\
esto y podría \\
explicar el \\
asunto en \\
general \\
\end{tabular} & $\begin{array}{l}\text { Estoy familiarizado } \\
\text { sobre con esto y sería } \\
\text { capaz de explicarlo } \\
\text { bien }\end{array}$ \\
\hline \multirow[b]{2}{*}{ Conflictos internacionales } & 5 & 18 & 21 & 1 \\
\hline & $11.1 \%$ & $40.0 \%$ & $46.7 \%$ & $2.2 \%$ \\
\hline \multirow{2}{*}{$\begin{array}{l}\text { Hambruna o desnutrición } \\
\text { en distintos lugares del } \\
\text { mundo }\end{array}$} & 0 & 16 & 22 & 7 \\
\hline & $0.0 \%$ & $35.6 \%$ & $48.9 \%$ & $15.6 \%$ \\
\hline \multirow[b]{2}{*}{ Causas de la pobreza } & 1 & 9 & 25 & 10 \\
\hline & $2.2 \%$ & $20.0 \%$ & $55.6 \%$ & $22.2 \%$ \\
\hline \multirow{2}{*}{$\begin{array}{l}\text { El ritmo del desarrollo } \\
\text { tecnológico en el mundo }\end{array}$} & 3 & 16 & 20 & 6 \\
\hline & $6.7 \%$ & $35.6 \%$ & $44.4 \%$ & $13.3 \%$ \\
\hline \multirow{2}{*}{$\begin{array}{l}\text { El impacto del } \\
\text { envejecimiento en las } \\
\text { poblaciones }\end{array}$} & 10 & 17 & 12 & 6 \\
\hline & $22.2 \%$ & $37.8 \%$ & $26.7 \%$ & $13.3 \%$ \\
\hline \multirow{2}{*}{$\begin{array}{l}\text { La igualdad entre mujeres } \\
\text { y hombres en diferentes } \\
\text { partes del mundo }\end{array}$} & 3 & 13 & 17 & 12 \\
\hline & $6.7 \%$ & $28.9 \%$ & $37.8 \%$ & $26.7 \%$ \\
\hline
\end{tabular}

Fuente: Autor.

El constructo evaluado corresponde a: conocimiento sobre asuntos globales. El análisis patrones de puntos agregado indica.

Tabla 99: Agregado pregunta $N^{\circ} 6$ Postest.

\begin{tabular}{|l|c|c|c|c|}
\hline & $\begin{array}{l}\text { Nunca he oído } \\
\text { sobre esto }\end{array}$ & $\begin{array}{l}\text { He oído sobre esto, } \\
\text { pero no podría } \\
\text { explicar de qué se } \\
\text { trata realmente }\end{array}$ & $\begin{array}{l}\text { Sé algo sobre esto } \\
\text { y podría explicar el } \\
\text { asunto en general }\end{array}$ & $\begin{array}{l}\text { Estoy familiarizado } \\
\text { sobre con esto y } \\
\text { sería capaz de } \\
\text { explicarlo bien }\end{array}$ \\
\hline Recuento & 0 & 3 & 25 & 17 \\
\hline$\%$ & $0.0 \%$ & $6.7 \%$ & $55.6 \%$ & $37.8 \%$ \\
\hline
\end{tabular}

Fuente: Autor 


\section{Constructo: Conocimiento sobre asuntos globales}

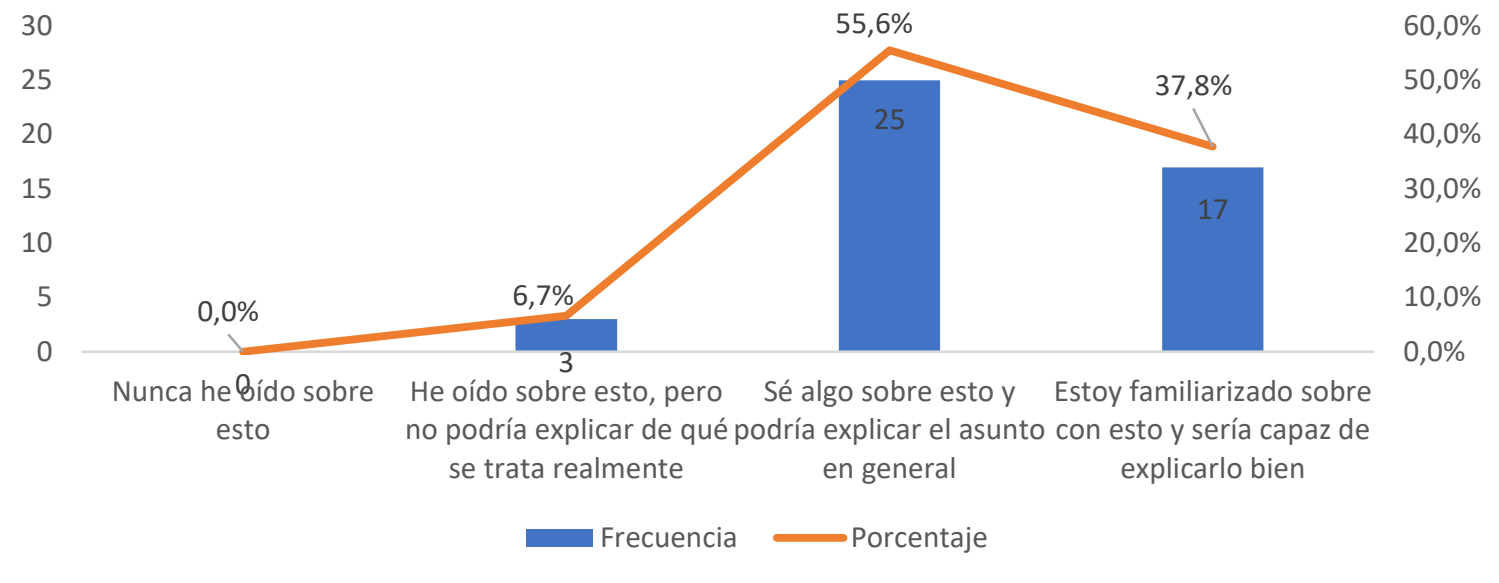

Ilustración 52: Postest. Constructo: Conocimiento sobre asuntos globales.

Fuente: Autor.

El constructo Conocimiento sobre asuntos globales indican una marcada tendencia positiva con un $93,4 \%$.

\section{La gente se traslada, cada vez más, de un país a otro ¿Qué tanto está usted de acuerdo con las siguientes afirmaciones sobre los inmigrantes?}

Tabla 100: Postest. La gente se traslada, cada vez más, de un país a otro ¿Qué tanto está usted de acuerdo con las siguientes afirmaciones sobre los inmigrantes?

\begin{tabular}{|l|c|c|c|c|}
\hline \multirow{2}{*}{ Pregunta 7 } & $\begin{array}{l}\text { Totalmente en } \\
\text { desacuerdo }\end{array}$ & $\begin{array}{l}\text { En } \\
\text { desacuerdo }\end{array}$ & $\begin{array}{l}\text { De } \\
\text { acuerdo }\end{array}$ & $\begin{array}{l}\text { Totalmente } \\
\text { de acuerdo }\end{array}$ \\
\hline $\begin{array}{l}\text { Los inmigrantes deberían tener la } \\
\text { oportunidad de continuar con sus costumbres } \\
\text { y estilo de vida. }\end{array}$ & 0 & 3 & 31 & 11 \\
\cline { 2 - 5 } $\begin{array}{l}\text { Los inmigrantes deberían tener los mismos } \\
\text { derechos que cualquier otra persona en el } \\
\text { país. }\end{array}$ & $0.0 \%$ & $6.7 \%$ & $68.9 \%$ & $24.4 \%$ \\
\hline \multirow{2yyyy}{*}{$\begin{array}{l}\text { Se debería restringir la inmigración cuando } \\
\text { no hay muchos empleos disponibles. }\end{array}$} & $0.0 \%$ & $11.1 \%$ & $55.6 \%$ & $33.3 \%$ \\
\cline { 2 - 5 } & $11.1 \%$ & $44.4 \%$ & $24.4 \%$ & $20.0 \%$ \\
\hline
\end{tabular}

Fuente: Autor.

El constructo evaluado corresponde a: Actitudes frente a los inmigrantes. El análisis patrones de puntos agregado indica.

Tabla 101: Agregado pregunta $N^{\circ} 7$ Postest. 


\begin{tabular}{|l|c|c|c|c|}
\hline & $\begin{array}{l}\text { Totalmente en } \\
\text { desacuerdo }\end{array}$ & En desacuerdo & De acuerdo & $\begin{array}{l}\text { Totalmente de } \\
\text { acuerdo }\end{array}$ \\
\hline Recuento & 0 & 1 & 26 & 18 \\
\hline$\%$ & $0.0 \%$ & $2.2 \%$ & $57.8 \%$ & $40.0 \%$ \\
\hline
\end{tabular}

Fuente: Autor

\section{Constructo: Actitudes frente a los inmigrantes}

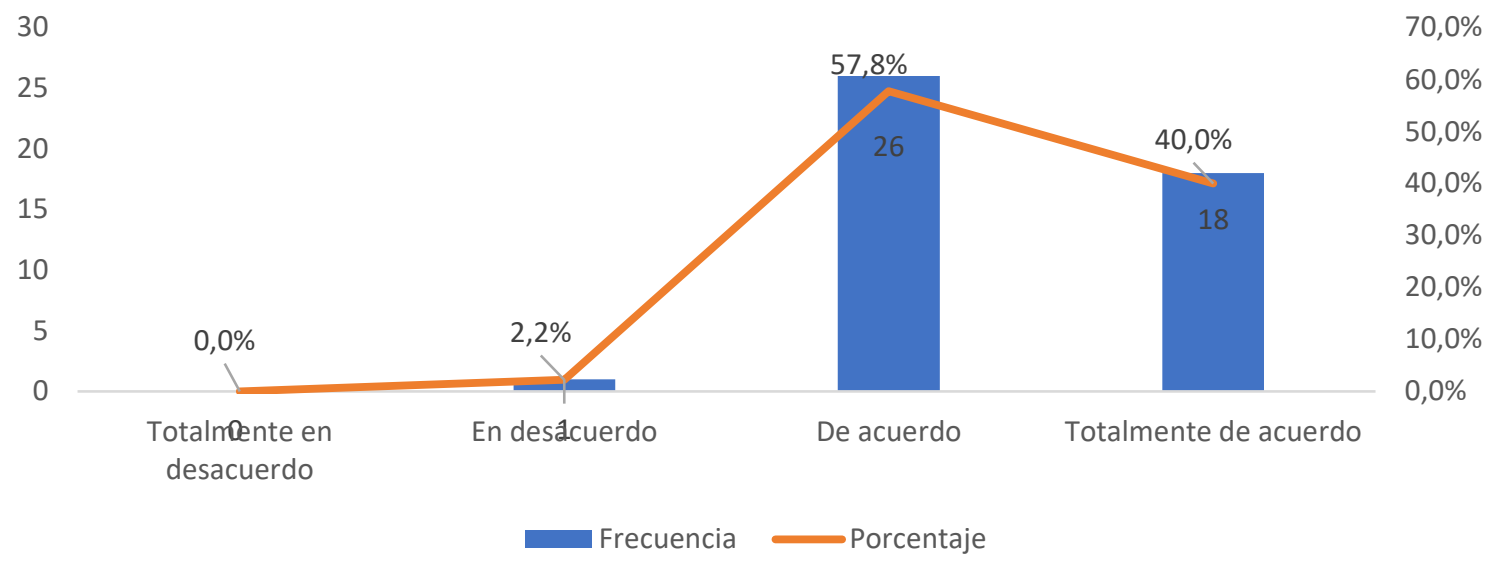

Ilustración 53: Postest. Constructo: Actitudes frente a los inmigrantes.

Fuente: Autor.

La tendencia muestra que el constructo Actitudes frente a los inmigrantes presenta una frecuencia marcada en estar De acuerdo y Totalmente de acuerdo con las preguntas.

\section{Con respecto a los profesores de su colegio: ¿a cuántos de ellos aplican las siguientes afirmaciones?}

Tabla 102: Postest. Con respecto a los profesores de su colegio: ¿a cuántos de ellos aplican las siguientes afirmaciones?

\begin{tabular}{|l|c|c|c|c|}
\hline \multirow{2}{*}{ Pregunta 8 } & $\begin{array}{l}\text { A ninguno o } \\
\text { casi ninguno } \\
\text { de ellos }\end{array}$ & $\begin{array}{l}\text { Alguno } \\
\text { de ellos }\end{array}$ & $\begin{array}{l}\text { A la } \\
\text { mayoría de } \\
\text { ellos }\end{array}$ & $\begin{array}{l}\text { A todos o } \\
\text { casi a todos } \\
\text { ellos }\end{array}$ \\
\hline $\begin{array}{l}\text { Demuestran comprensión de la diversidad de } \\
\text { mentalidades dentro de distintos grupos } \\
\text { culturales. }\end{array}$ & 6 & 19 & 16 & 4 \\
\cline { 2 - 5 } & $13.3 \%$ & $42.2 \%$ & $35.6 \%$ & $8.9 \%$ \\
\hline \multirow{2}{*}{$\begin{array}{l}\text { Tratan por igual a los estudiantes de todos los } \\
\text { grupos culturales. }\end{array}$} & 2 & 15 & 17 & 11 \\
\cline { 2 - 5 } $\begin{array}{l}\text { Tienen menores expectativas académicas sobre } \\
\text { los estudiantes de algunos grupos culturales. }\end{array}$ & $4.4 \%$ & $33.3 \%$ & $37.8 \%$ & $24.4 \%$ \\
\hline \multirow{2}{*}{$\begin{array}{l}\text { Aplican los mismos criterios para calificar a los } \\
\text { estudiantes, sin importar su grupo cultural. }\end{array}$} & $17.8 \%$ & $26.7 \%$ & $51.1 \%$ & $4.4 \%$ \\
\hline & $2.2 \%$ & 11 & 17 & 16 \\
\hline
\end{tabular}




\begin{tabular}{|l|c|c|c|c|}
\begin{tabular}{|l|c|c|} 
Aplican los mismos criterios para castigar el \\
mal comportamiento de los estudiantes sin \\
importar su grupo cultural.
\end{tabular} & $2.2 \%$ & $17.8 \%$ & $37.8 \%$ & $42.2 \%$ \\
\hline
\end{tabular}

Fuente: Autor.

El constructo evaluado corresponde a: Clima escolar - clima escolar multicultural. El análisis patrones de puntos agregado indica.

Tabla 103: Agregado pregunta $N^{\circ} 8$ Postest.

\begin{tabular}{|l|c|c|c|c|}
\hline & $\begin{array}{l}\text { A ninguno o casi } \\
\text { ninguno de ellos }\end{array}$ & Alguno de ellos & $\begin{array}{l}\text { A la mayoría de } \\
\text { ellos }\end{array}$ & $\begin{array}{l}\text { A todos o casi a } \\
\text { todos ellos }\end{array}$ \\
\hline Recuento & 0 & 7 & 37 & 1 \\
\hline$\%$ & $0.0 \%$ & $15.6 \%$ & $82.2 \%$ & $2.2 \%$ \\
\hline
\end{tabular}

Fuente: Autor

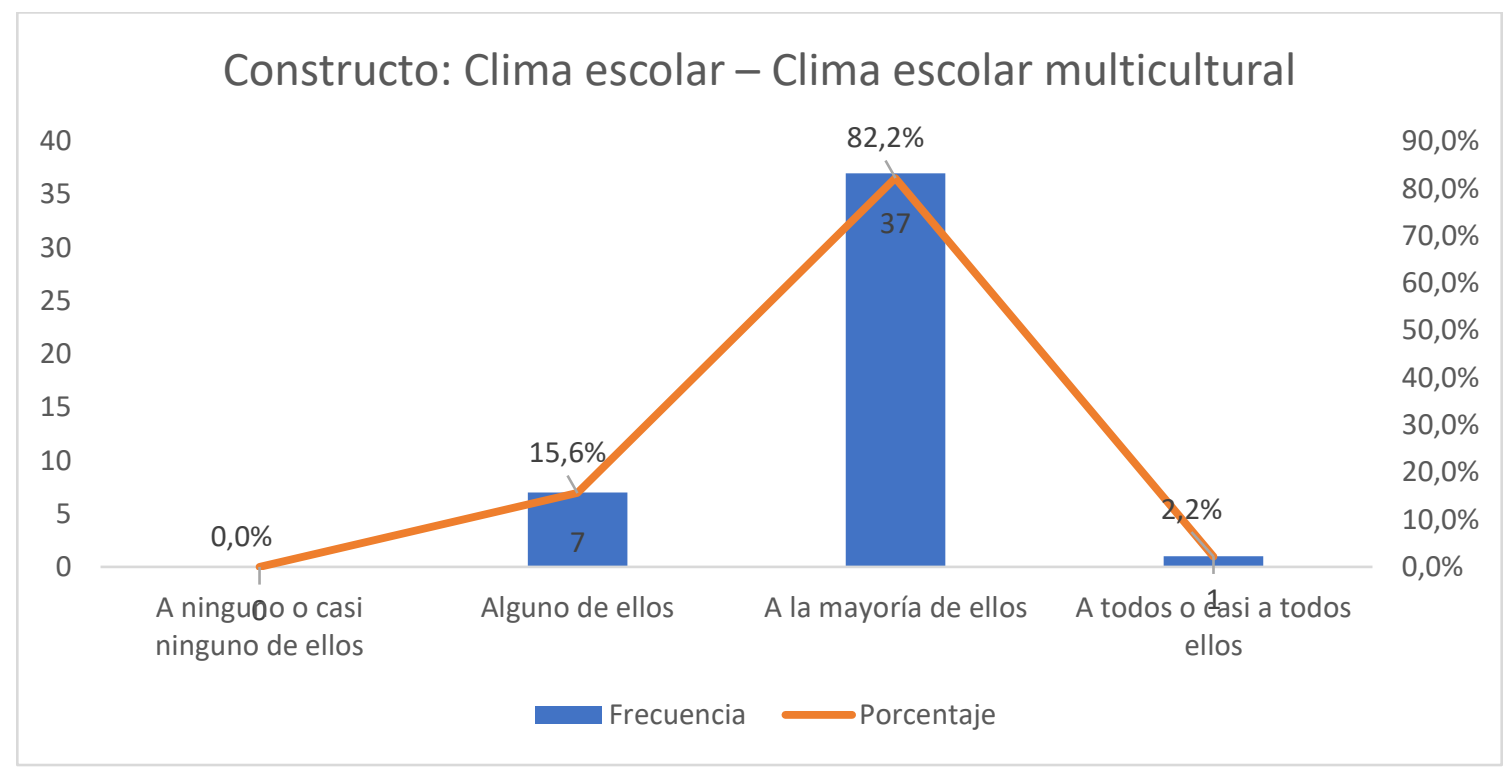

Ilustración 54: Postest. Constructo: Clima escolar - Clima escolar multicultural.

Fuente: Autor.

El constructo Clima escolar - clima escolar multicultural muestra una tendencia relativamente alta de forma positiva.

9. Caso de estudio 1.

Tabla 104: Postest. Caso de estudio $N^{o} 1$. 


\begin{tabular}{|l|r|r|}
\hline & Crédito Total & Sin crédito \\
\hline & 38 & 7 \\
\cline { 2 - 3 } Pregunta 9 & $84.4 \%$ & $15.6 \%$ \\
\hline
\end{tabular}

Fuente: Autor.

El proceso cognitivo evaluado corresponde a: Entender diferencias en la comunicación. El análisis patrones de puntos agregado indica.

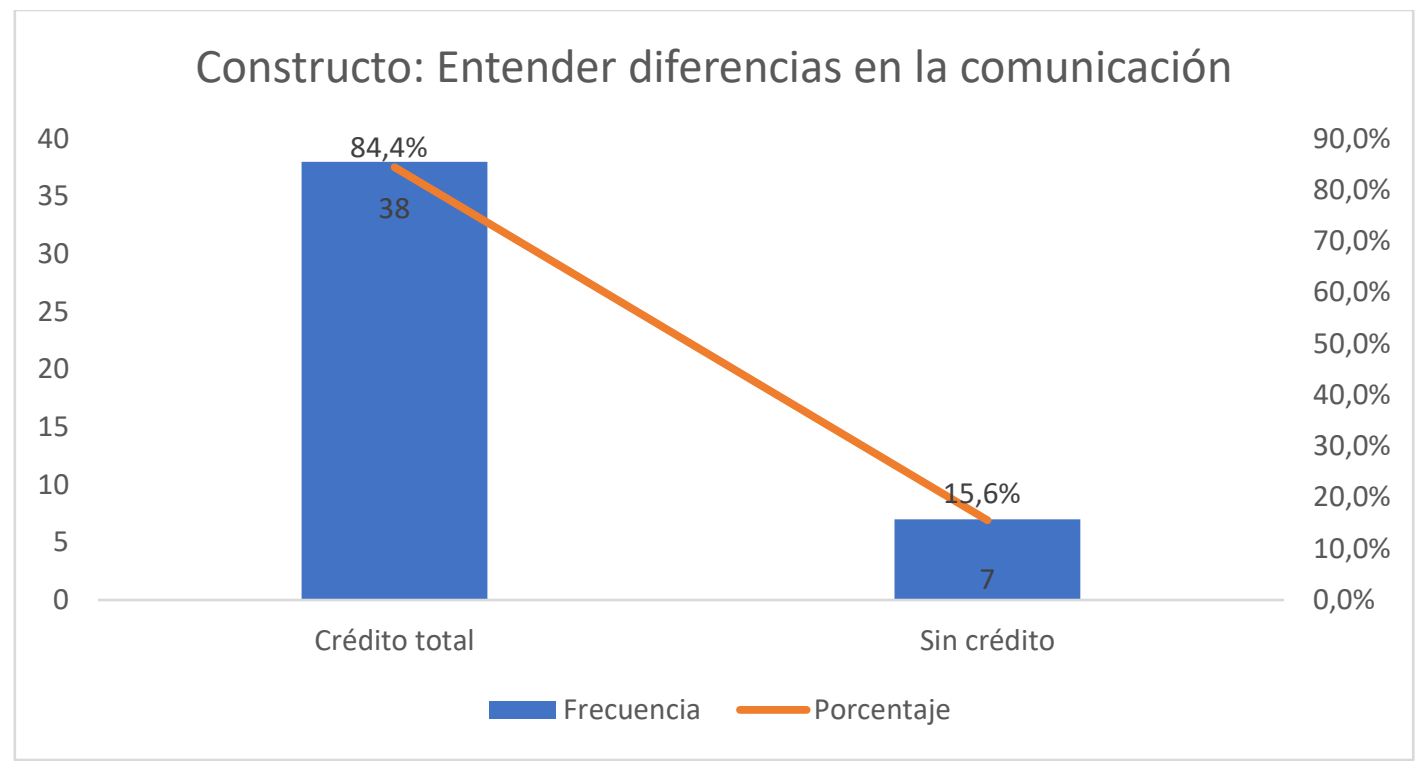

Ilustración 55: Postest. Proceso cognitivo: Entender diferencias en la comunicación.

Fuente: Autor.

El proceso cognitivo Entender diferencias en la comunicación, mostró un resultado favorable con mayor frecuencia en el grupo con un $84,4 \%$ al obtener créditos las respuestas.

10. Caso de estudio 2.

Tabla 105: Postest. Caso de estudio $N^{\circ} 2$.

\begin{tabular}{|c|c|c|}
\hline & Crédito total & Sin crédito \\
\hline \multirow{3}{*}{ Pregunta 10 } & 33 & 12 \\
\cline { 2 - 3 } & $73.3 \%$ & $26.7 \%$ \\
\hline \multicolumn{3}{|c|}{ Fuente: Autor. }
\end{tabular}

El proceso cognitivo evaluado corresponde a: Evaluar información, formular argumentos y explicar asuntos o situaciones. El análisis patrones de puntos agregado indica 


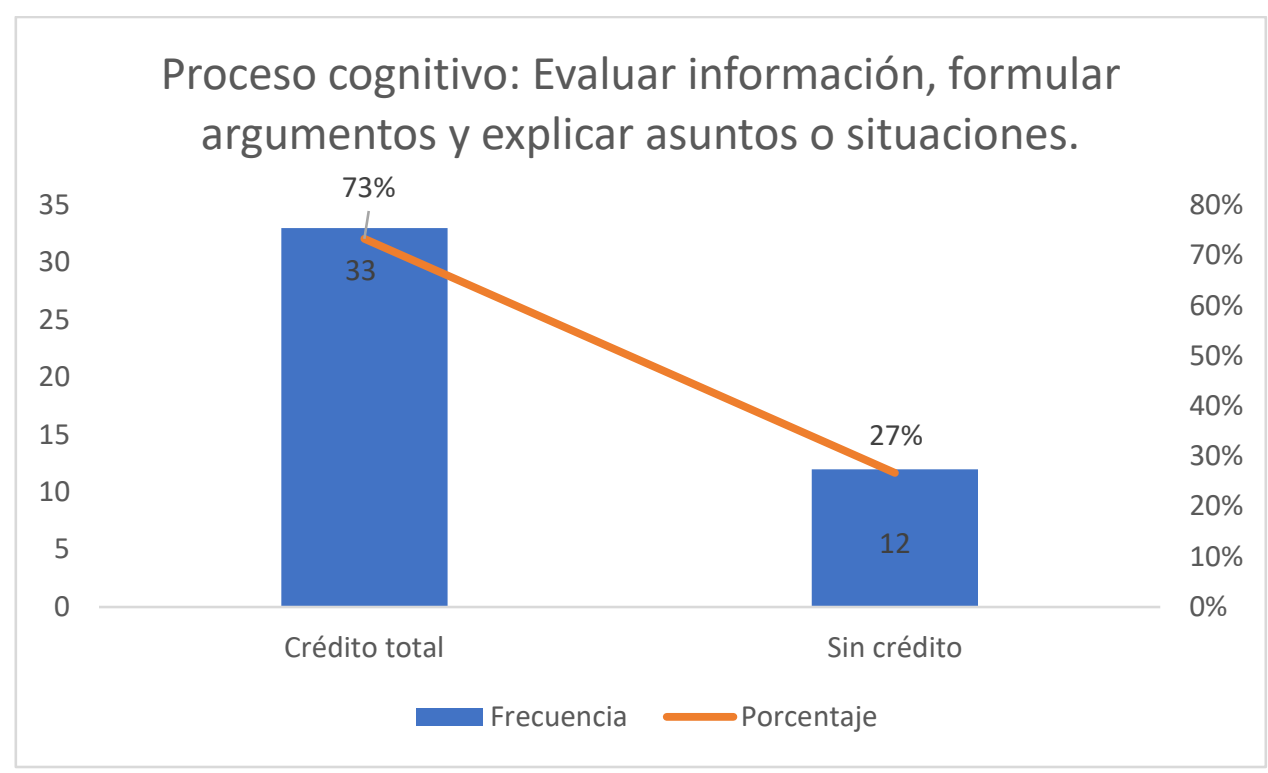

Ilustración 56: Postest. Proceso cognitivo: Evaluar información, formular argumentos y explicar asuntos o situaciones.

Fuente: Autor.

El proceso cognitivo, Evaluar información, formular argumentos y explicar asuntos o situaciones, mostró un resultado positivo con mayor frecuencia en el grupo con un $73 \%$ al tener créditos las respuestas.

Realizada la intervención pedagógica se procederá a analizar el desarrollo de la competencia global a partir del comparativo entre Pretest o Postest, que a continuación se detalla.

\subsection{Prueba de Hipótesis}

Para analizar la información inicialmente se procede a realizar la prueba de rangos con signo de Wilcoxon, prueba no paramétrica para comparar el rango medio de dos muestras relacionadas y determinar si existen diferencias entre ellas. Se utiliza como alternativa a la prueba $\mathrm{T}$ de Student cuando no se puede suponer la normalidad de las muestras (Wilcoxon, 1945), para el análisis se utiliza el comando wilcox.test de $\mathrm{R}^{39}$

Los resultados del test de Wilcoxon, son:

Data: Postest - Pretest

$\mathrm{V}=953$, $\mathrm{p}$-value $=4.552 \mathrm{e}-07$

alternative hypothesis: true location is greater than 0

\footnotetext{
${ }^{39}$ R Development Core Team. 2006. R: A Language and Environment for Statistical Computing. R Foundation for Statistical Computing, Vienna, Austria. http://www.R-project.org.
} 
De acuerdo con el test de Wilcoxon, existe evidencia que el rango medio de la puntuación mediana en el Postest es mayor que la del Pretest con un p-valor de $4.552 \times 10^{-7}$ menor del $5 \%$, para un nivel de confianza del 95\%. Es decir, la intervención pedagógica logró mejorar el desempeño de la competencia global en los estudiantes.

Estadística descriptiva global del Postest y el Pretest

Tabla 106: Comparativo Pretest - Postest

Estadísticos Descriptivos
\begin{tabular}{|l|r|r|r|r|r|r|}
\hline GLOBAL & N & Mínimo & Máximo & Media & Desv. típ. & Mediana \\
\hline Puntuación Pretest & 45 & 1,01 & 4,64 & 2,9863 &, 90840 & 3,00 \\
Puntuación Postest & 45 & 2,32 & 5,01 & 3,9004 &, 61847 & 4,00 \\
\hline
\end{tabular}

Fuente: Autor

A continuación, se procede a realizar el análisis de contraste para cada una de las preguntas entre el antes y el después para identificar el desarrollo de la competencia global con la metodología de intervención. usando el test de Wilcoxon. Los resultados fueron:

Tabla 107: Análisis de contrastes pregunta 1.

1. ¿Qué tanto lo describen a usted cada una de las siguientes afirmaciones?

\begin{tabular}{|c|c|c|c|c|}
\hline Pregunta & $\begin{array}{l}\text { Hipótesis } \\
\text { nula }\end{array}$ & $\begin{array}{l}\text { Hipótesis } \\
\text { alternativa }\end{array}$ & $\begin{array}{l}\text { Test de } \\
\text { Wilcoxon } \\
\text { p-valor }\end{array}$ & Conclusión \\
\hline $\begin{array}{l}\text { A veces trato de entender mejor a mis } \\
\text { amigos imaginando cómo se ven las } \\
\text { cosas desde su perspectiva. - Ante un } \\
\text { desacuerdo, trato de ver el punto de vista } \\
\text { de cada uno antes de tomar una decisión. }\end{array}$ & \multirow[t]{3}{*}{$\begin{array}{l}\text { El rango } \\
\text { medio del } \\
\text { Pretest es }= \\
\text { a el rango } \\
\text { medio del } \\
\text { Postest }\end{array}$} & \multirow[t]{3}{*}{$\begin{array}{l}\text { El rango } \\
\text { medio del } \\
\text { Pretest es }< \\
\text { que el rango } \\
\text { medio del } \\
\text { Postest }\end{array}$} & $7.849 \mathrm{e}-07$ & $\begin{array}{l}\text { Se rechaza la } \\
\text { hipótesis nula en } \\
\text { favor de la } \\
\text { hipótesis } \\
\text { alternativa }\end{array}$ \\
\hline $\begin{array}{l}\text { Antes de criticar a alguien, trato de } \\
\text { imaginar cómo me sentiría si estuviera } \\
\text { en su lugar. - Creo que hay dos lados en } \\
\text { cada problema y trato de verlos a los dos. }\end{array}$ & & & $1.528 \mathrm{e}-07$ & $\begin{array}{l}\text { Se rechaza la } \\
\text { hipótesis nula en } \\
\text { favor de la } \\
\text { hipótesis } \\
\text { alternativa }\end{array}$ \\
\hline Total & & & $6.131 \mathrm{e}-08$ & $\begin{array}{l}\text { Se rechaza la } \\
\text { hipótesis nula en } \\
\text { favor de la } \\
\text { hipótesis } \\
\text { alternativa }\end{array}$ \\
\hline
\end{tabular}

Fuente: Autor 
El constructo Adopción de perspectivas asociado a la pregunta $\mathrm{N}^{\circ} 1$, señala que Si se mejoró el desempeño del postest comparado con el pretest.

Tabla 108: Análisis de contrastes pregunta 2.

\begin{tabular}{|c|c|c|c|c|}
\hline Pregunta & $\begin{array}{l}\text { Hipótesis } \\
\text { nula }\end{array}$ & $\begin{array}{l}\text { Hipótesis } \\
\text { alternativa }\end{array}$ & $\begin{array}{l}\text { Test de } \\
\text { Wilcoxon } \\
\text { p-valor }\end{array}$ & Conclusión \\
\hline $\begin{array}{l}\text { Es correcto boicotear las empresas de las que } \\
\text { se sabe que ofrecen malas condiciones en el } \\
\text { sitio de trabajo para sus empleados. - Pienso } \\
\text { en mí mismo como un ciudadano del mundo. }\end{array}$ & \multirow{4}{*}{$\begin{array}{l}\text { El rango } \\
\text { medio del } \\
\text { Pretest es } \\
=\text { a el } \\
\text { rango } \\
\text { medio del } \\
\text { Postest }\end{array}$} & \multirow{4}{*}{$\begin{array}{l}\text { El rango } \\
\text { medio del } \\
\text { Pretest es }> \\
\text { que el } \\
\text { rango } \\
\text { medio del } \\
\text { Postest }\end{array}$} & $2.279 \mathrm{e}-07$ & $\begin{array}{l}\text { Se rechaza la } \\
\text { hipótesis nula en } \\
\text { favor de la } \\
\text { hipótesis } \\
\text { alternativa }\end{array}$ \\
\hline $\begin{array}{l}\text { Puedo hacer algo sobre los problemas del } \\
\text { mundo. - Cuando veo las malas condiciones } \\
\text { en que viven algunas personas en el mundo, } \\
\text { siento la responsabilidad de hacer algo al } \\
\text { respecto. }\end{array}$ & & & $4.238 \mathrm{e}-06$ & $\begin{array}{l}\text { Se rechaza la } \\
\text { hipótesis nula en } \\
\text { favor de la } \\
\text { hipótesis } \\
\text { alternativa } \\
\end{array}$ \\
\hline $\begin{array}{l}\text { Cuidar del ambiente global es importante para } \\
\text { mí. - Pienso que mi comportamiento puede } \\
\text { tener impacto sobre la gente en otros países. }\end{array}$ & & & $2.144 \mathrm{e}-08$ & $\begin{array}{l}\text { Se rechaza la } \\
\text { hipótesis nula en } \\
\text { favor de la } \\
\text { hipótesis } \\
\text { alternativa }\end{array}$ \\
\hline Total & & & $\begin{array}{l}\text { p-value }= \\
0.04256\end{array}$ & $\begin{array}{l}\text { Se rechaza la } \\
\text { hipótesis nula en } \\
\text { favor de la } \\
\text { hipótesis } \\
\text { alternativa }\end{array}$ \\
\hline
\end{tabular}

Fuente: Autor

El constructo Mentalidad Global asociado a la pregunta No22, señala Si se mejoró el desempeño entre postest con el pretest.

Tabla 109: Análisis de contrastes pregunta 3.

\begin{tabular}{|l|l|l|l|l|}
\hline \multicolumn{3}{|c|}{ 3. Qué tanto lo describen a usted cada una de las siguientes afirmaciones? } \\
\hline Pregunta & $\begin{array}{l}\text { Hipótesis } \\
\text { nula }\end{array}$ & $\begin{array}{l}\text { Hipótesis } \\
\text { alternativa }\end{array}$ & $\begin{array}{l}\text { Test de } \\
\text { Wilcoxon } \\
\text { p-valor }\end{array}$ & Conclusión \\
\hline $\begin{array}{l}\text { Puedo adaptarme fácilmente a una nueva } \\
\text { cultura. - Puedo lidiar con situaciones } \\
\text { inusuales. }\end{array}$ & $\begin{array}{l}\text { El rango } \\
\text { medio del } \\
\text { Pretest es } \\
\text { a el rango } \\
\text { medio del } \\
\text { Postest }\end{array}$ & $\begin{array}{l}\text { El rango } \\
\text { medio del } \\
\text { Pretest es }< \\
\text { que el rango } \\
\text { medio del } \\
\text { Postest }\end{array}$ & 3.739 e-07 & $\begin{array}{l}\text { Se rechaza la } \\
\text { hipótesis nula } \\
\text { en favor de la } \\
\text { hipótesis } \\
\text { alternativa }\end{array}$ \\
\cline { 2 - 6 } $\begin{array}{l}\text { Cuando me encuentro situaciones difíciles con } \\
\text { otras personas, puedo pensar en una manera de } \\
\text { resolverlas. - Puedo cambiar mi } \\
\text { comportamiento para cubrir las necesidades de } \\
\text { nuevas situaciones. }\end{array}$ & & $3.696 e-06$ & $\begin{array}{l}\text { Se rechaza la } \\
\text { hipótesis nula } \\
\text { en favor de la } \\
\text { hipótesis } \\
\text { alternativa }\end{array}$ \\
\hline
\end{tabular}




\begin{tabular}{|l|l|l|l|l|}
\hline $\begin{array}{l}\text { Soy capaz de superar mis dificultades al } \\
\text { interactuar con personas de otras culturas. - } \\
\text { Puedo adaptarme a diferentes situaciones } \\
\text { incluso cuando estoy bajo presión o estrés. }\end{array}$ & & $3.544 \mathrm{e}-07$ & $\begin{array}{l}\text { Se rechaza la } \\
\text { hipótesis nula } \\
\text { en favor de la } \\
\text { hipótesis } \\
\text { alternativa }\end{array}$ \\
\hline Total & & & $1.843 \mathrm{e}-08$ & $\begin{array}{l}\text { Se rechaza la h } \\
\text { ipótesis nula en } \\
\text { favor de la hip } \\
\text { ótesis alternati } \\
\text { va }\end{array}$ \\
\hline
\end{tabular}

Fuente: Autor

El constructo Flexibilidad/ Adaptabilidad asociado a la pregunta Nº3, señala Si se mejoró el desempeño entre postest con el pretest.

Tabla 110: Análisis de contrastes pregunta 4.

\begin{tabular}{|c|c|c|c|c|}
\hline \multicolumn{5}{|c|}{ 4. ¿Hasta qué punto está usted de acuerdo con las siguientes afirmaciones } \\
\hline Pregunta & \begin{tabular}{|l|} 
Hipótesis \\
nula
\end{tabular} & $\begin{array}{l}\text { Hipótesis } \\
\text { alternativa }\end{array}$ & $\begin{array}{l}\text { p-valor } \\
\text { Test de } \\
\text { Wilcoxon } \\
\end{array}$ & Conclusión \\
\hline $\begin{array}{l}\text { Elijo mis palabras cuidadosament } \\
\text { e. - Observo cuidadosamente sus } \\
\text { reacciones. }\end{array}$ & \multirow{4}{*}{$\begin{array}{l}\text { El rango } \\
\text { medio del } \\
\text { Pretest es =a } \\
\text { el rango } \\
\text { medio del } \\
\text { Postest }\end{array}$} & \multirow{4}{*}{$\begin{array}{l}\text { El rango } \\
\text { medio del } \\
\text { Pretest es }> \\
\text { que el rango } \\
\text { medio del } \\
\text { Postest }\end{array}$} & $6.122 \mathrm{e}-05$ & $\begin{array}{l}\text { Se rechaza la hipótesis } \\
\text { nula en favor de la hipót } \\
\text { esis alternativa }\end{array}$ \\
\hline $\begin{array}{l}\text { Doy ejemplos concretos para expl } \\
\text { icar mis ideas. - Verifico con frec } \\
\text { uencia que nos estemos entendien } \\
\text { do mutuamente. }\end{array}$ & & & $9.742 \mathrm{e}-05$ & $\begin{array}{l}\text { Se rechaza la hipótesis } \\
\text { nula en favor de la hipót } \\
\text { esis alternativa }\end{array}$ \\
\hline $\begin{array}{l}\text { Explico las cosas con mucho cuid } \\
\text { ado. - Escucho cuidadosamente } 1 \\
\text { o que dicen. }\end{array}$ & & & $\begin{array}{l}0.000241 \\
3\end{array}$ & $\begin{array}{l}\text { Se rechaza la hipótesis } \\
\text { nula en favor de la hipót } \\
\text { esis alternativa }\end{array}$ \\
\hline Total & & & $7.623 \mathrm{e}-07$ & $\begin{array}{l}\text { Se rechaza la hipótesis } \\
\text { nula en favor de la hipót } \\
\text { esis alternativa }\end{array}$ \\
\hline
\end{tabular}

Fuente: Autor

El constructo Conocimiento de la comunicación intercultural asociado a la pregunta $\mathrm{N}^{\circ} 4$, señala que Si se mejoró el desempeño entre postest con el pretest.

Tabla 111: Análisis de contrastes pregunta 5

\begin{tabular}{|c|c|c|c|c|}
\hline \multicolumn{5}{|c|}{$\begin{array}{l}\text { 5. ¿ Con qué facilidad piensa usted que podría realizar las siguientes tareas por } \\
\text { su cuenta? }\end{array}$} \\
\hline Pregunta & $\begin{array}{l}\text { Hipótesis } \\
\text { nula }\end{array}$ & $\begin{array}{l}\text { Hipótesis } \\
\text { alternativa }\end{array}$ & $\begin{array}{l}\text { p-valor } \\
\text { Test de } \\
\text { Wilcoxon }\end{array}$ & Conclusión \\
\hline $\begin{array}{l}\text { Discutir las diferentes razones por las que } 1 \\
\text { as personas se convierten en refugiados. - } \\
\text { Predecir cómo los cambios en un entorno a } \\
\text { fectarán la supervivencia de ciertas especie } \\
\text { s. }\end{array}$ & $\begin{array}{l}\text { El rango } \\
\text { medio del } \\
\text { Pretest es } \\
=\mathrm{a} \text { el } \\
\text { rango }\end{array}$ & $\begin{array}{l}\text { El rango } \\
\text { medio del } \\
\text { Pretest es }> \\
\text { que el rango }\end{array}$ & $3.913 \mathrm{e}-06$ & $\begin{array}{l}\text { Se rechaza la hipót } \\
\text { esis nula en favor d } \\
\text { e la hipótesis altern } \\
\text { ativa }\end{array}$ \\
\hline
\end{tabular}




\begin{tabular}{|l|l|l|l|l|}
\hline $\begin{array}{l}\text { Explicar por qué algunos países sufren má } \\
\text { s que otros por el cambio climático global. } \\
\text { - Explicar cómo las emisiones de dióxido d } \\
\text { e carbono influyen sobre el cambio climáti } \\
\text { co a nivel global. }\end{array}$ & $\begin{array}{l}\text { medio del } \\
\text { Postest }\end{array}$ & $\begin{array}{l}\text { medio del } \\
\text { Postest }\end{array}$ & $2.897 \mathrm{e}-06$ & $\begin{array}{l}\text { Se rechaza la hipót } \\
\text { esis nula en favor d } \\
\text { e la hipótesis altern } \\
\text { ativa }\end{array}$ \\
\hline $\begin{array}{l}\text { Explicar cómo las crisis económicas de ca } \\
\text { da país afectan la economía mundial. - Est } \\
\text { ablecer una relación entre los precios de lo } \\
\text { s textiles y las condiciones laborales en los } \\
\text { países productores }\end{array}$ & & & $8.987 \mathrm{e}-06$ & $\begin{array}{l}\text { Se rechaza la hipót } \\
\text { esis nula en favor d } \\
\text { e la hipótesis altern } \\
\text { ativa }\end{array}$ \\
\hline Total & & $2.819 \mathrm{e}-08$ & $\begin{array}{l}\text { Se rechaza la hipót } \\
\text { esis nula en favor d } \\
\text { e la hipótesis altern } \\
\text { ativa }\end{array}$ \\
\hline
\end{tabular}

Fuente: Autor

El constructo Autoeficacia con respecto a asuntos globales asociado a la pregunta $\mathrm{N}^{\circ} 5$, señala que Si se mejoró el desempeño entre postest con el pretest.

Tabla 112: Análisis de contrastes pregunta 6.

\begin{tabular}{|c|c|c|c|c|}
\hline \multicolumn{5}{|c|}{ 6. ¿qué tan informado está usted sobre los siguientes temas? } \\
\hline Pregunta & $\begin{array}{l}\text { Hipótesis } \\
\text { nula }\end{array}$ & $\begin{array}{l}\text { Hipótesis } \\
\text { alternativa }\end{array}$ & $\begin{array}{l}\text { Test de } \\
\text { Wilcoxon } \\
\text { p-valor }\end{array}$ & Conclusión \\
\hline $\begin{array}{l}\text { Conflictos internacionales - } \mathrm{Ca} \\
\text { mbio climático y calentamiento } \\
\text { global }\end{array}$ & \multirow{7}{*}{$\begin{array}{l}\text { El rango } \\
\text { medio del } \\
\text { Pretest es = } \\
\text { a el rango } \\
\text { medio del } \\
\text { Postest }\end{array}$} & \multirow{7}{*}{$\begin{array}{l}\text { El rango } \\
\text { medio del } \\
\text { Pretest es }> \\
\text { que el rango } \\
\text { medio del } \\
\text { Postest }\end{array}$} & 0.1058 & $\begin{array}{l}\text { No se rechaza la hip } \\
\text { ótesis nula }\end{array}$ \\
\hline $\begin{array}{l}\text { Hambruna o desnutrición en dist } \\
\text { intos lugares del mundo - Salud } \\
\text { en el mundo (p. ej., epidemias) }\end{array}$ & & & $3.123 \mathrm{e}-06$ & $\begin{array}{l}\text { Se rechaza la hipótes } \\
\text { is nula en favor de la } \\
\text { hipótesis alternativa }\end{array}$ \\
\hline $\begin{array}{l}\text { Causas de la pobreza - Crecimie } \\
\text { nto poblacional }\end{array}$ & & & $6.496 \mathrm{e}-05$ & $\begin{array}{l}\text { Se rechaza la hipótes } \\
\text { is nula en favor de la } \\
\text { hipótesis alternativa }\end{array}$ \\
\hline $\begin{array}{l}\text { El ritmo del desarrollo tecnológi } \\
\text { co en el mundo - Migración (des } \\
\text { plazamiento de personas) }\end{array}$ & & & 0.001844 & $\begin{array}{l}\text { Se rechaza la hipótes } \\
\text { is nula en favor de la } \\
\text { hipótesis alternativa }\end{array}$ \\
\hline $\begin{array}{l}\text { El impacto del envejecimiento e } \\
\mathrm{n} \text { las poblaciones - Impactos de } \\
\text { los desarrollos en la economía g } \\
\text { lobal }\end{array}$ & & & $1.582 \mathrm{e}-05$ & $\begin{array}{l}\text { Se rechaza la hipótes } \\
\text { is nula en favor de la } \\
\text { hipótesis alternativa }\end{array}$ \\
\hline $\begin{array}{l}\text { La igualdad entre mujeres y ho } \\
\text { mbres en diferentes partes del m } \\
\text { undo - Contaminación del aire }\end{array}$ & & & $7.5 \mathrm{e}-05$ & $\begin{array}{l}\text { Se rechaza la hipótes } \\
\text { is nula en favor de la } \\
\text { hipótesis alternativa }\end{array}$ \\
\hline Total & & & $1.549 \mathrm{e}-07$ & $\begin{array}{l}\text { Se rechaza la hipótes } \\
\text { is nula en favor de la } \\
\text { hipótesis alternativa }\end{array}$ \\
\hline
\end{tabular}

Fuente: Autor

El constructo Conocimiento sobre asuntos globales asociado a la pregunta $\mathrm{N}^{\mathrm{o}} 6$, señala que Si se mejoró el desempeño entre postest con el pretest. 
Tabla 113: Análisis de contrastes pregunta 7.

\begin{tabular}{|c|c|c|c|c|}
\hline Pregunta & Hipótesis nula & $\begin{array}{l}\text { Hipótesis } \\
\text { alternativa }\end{array}$ & $\begin{array}{l}\text { Test de } \\
\text { Wilcoxon } \\
\text { p-valor }\end{array}$ & Conclusión \\
\hline $\begin{array}{l}\text { Los inmigrantes deberían tener la } \\
\text { oportunidad de continuar con sus } \\
\text { costumbres y estilo de vida. - Se } \\
\text { debería animar a los inmigrantes a que } \\
\text { continúen hablando su propio idioma. }\end{array}$ & \multirow[t]{2}{*}{$\begin{array}{l}\text { El rango medio } \\
\text { del Pretest es = a } \\
\text { el rango medio } \\
\text { del Postest }\end{array}$} & \multirow[t]{2}{*}{$\begin{array}{l}\text { El rango } \\
\text { medio del } \\
\text { Pretest es }> \\
\text { que el rango } \\
\text { medio del } \\
\text { Postest }\end{array}$} & $2.655 \mathrm{e}-06$ & $\begin{array}{l}\text { Se rechaza la h } \\
\text { ipótesis nula e } \\
\mathrm{n} \text { favor de la hi } \\
\text { pótesis alternat } \\
\text { iva }\end{array}$ \\
\hline $\begin{array}{l}\text { Los inmigrantes deberían tener los } \\
\text { mismos derechos que cualquier otra } \\
\text { persona en el país. - Los niños } \\
\text { inmigrantes deberían tener las mismas } \\
\text { oportunidades para la educación que } \\
\text { otros niños en el país. }\end{array}$ & & & 0.02264 & $\begin{array}{l}\text { Se rechaza la h } \\
\text { ipótesis nula e } \\
\mathrm{n} \text { favor de la hi } \\
\text { pótesis alternat } \\
\text { iva }\end{array}$ \\
\hline $\begin{array}{l}\text { Se debería restringir la inmigración } \\
\text { cuando no hay muchos empleos } \\
\text { disponibles. - Los inmigrantes que } \\
\text { viven en el país durante varios años } \\
\text { deberían tener derecho a votar en las } \\
\text { elecciones. }\end{array}$ & $\begin{array}{l}\text { El rango medio } \\
\text { del Pretest es = a } \\
\text { el rango medio } \\
\text { del Postest }\end{array}$ & $\begin{array}{l}\text { El rango } \\
\text { medio del } \\
\text { Pretest es }< \\
\text { que el rango } \\
\text { medio del } \\
\text { Postest }\end{array}$ & 1.00 & $\begin{array}{l}\text { No se rechaza } 1 \\
\text { a hipótesis nul } \\
\text { a }\end{array}$ \\
\hline Total & $\begin{array}{l}\text { El rango medio } \\
\text { del Pretest es = a } \\
\text { el rango medio } \\
\text { del Postest }\end{array}$ & $\begin{array}{l}\text { El rango } \\
\text { medio del } \\
\text { Pretest es }> \\
\text { que el rango } \\
\text { medio del } \\
\text { Postest }\end{array}$ & $1.004 \mathrm{e}-06$ & $\begin{array}{l}\text { Se rechaza la h } \\
\text { ipótesis nula e } \\
\mathrm{n} \text { favor de la hi } \\
\text { pótesis alternat } \\
\text { iva }\end{array}$ \\
\hline
\end{tabular}

Fuente: Autor

El constructo Actitudes frente a los inmigrantes asociado a la pregunta $\mathrm{N}^{\circ} 7$, señala que $\mathrm{Si}$ se mejoró el desempeño entre postest con el pretest.

Tabla 114: Análisis de contrastes pregunta 8.

8. Con respecto a los profesores de su colegio: ¿a cuántos de ellos aplican las siguientes afirmaciones?

\begin{tabular}{|c|c|c|c|c|}
\hline Pregunta & Hipótesis nula & $\begin{array}{l}\text { Hipótesis } \\
\text { alternativa }\end{array}$ & $\begin{array}{l}\text { Test de } \\
\text { Wilcoxon } \\
\text { p-valor }\end{array}$ & Conclusión \\
\hline $\begin{array}{l}\text { Demuestran comprensión de la } \\
\text { diversidad de mentalidades dentro } \\
\text { de distintos grupos culturales. - } \\
\text { Hablan de forma respetuosa sobre } \\
\text { las personas de todos los grupos } \\
\text { culturales. }\end{array}$ & \multirow[t]{2}{*}{$\begin{array}{l}\text { El rango medio } \\
\text { del Pretest es = } \\
\text { a el rango medio } \\
\text { del Postest }\end{array}$} & \multirow[t]{2}{*}{$\begin{array}{l}\text { El rango } \\
\text { medio del } \\
\text { Pretest es }> \\
\text { que el rango } \\
\text { medio del } \\
\text { Postest }\end{array}$} & 0.0003783 & $\begin{array}{l}\text { Se rechaza la } \\
\text { hipótesis nula en } \\
\text { favor de la } \\
\text { hipótesis } \\
\text { alternativa }\end{array}$ \\
\hline $\begin{array}{l}\text { Tratan por igual a los estudiantes de } \\
\text { todos los grupos culturales. - } \\
\text { Tienen ideas erróneas sobre la } \\
\text { historia de algunos grupos } \\
\text { culturales. }\end{array}$ & & & $1.251 \mathrm{e}-08$ & $\begin{array}{l}\text { Se rechaza la } \\
\text { hipótesis nula en } \\
\text { favor de la } \\
\text { hipótesis } \\
\text { alternativa }\end{array}$ \\
\hline
\end{tabular}




\begin{tabular}{|l|l|l|l|l|}
\hline $\begin{array}{l}\text { Tienen menores expectativas } \\
\text { académicas sobre los estudiantes de } \\
\text { algunos grupos culturales. - Están } \\
\text { abiertos al contacto personal con } \\
\text { personas de todos los grupos } \\
\text { culturales. }\end{array}$ & $\begin{array}{l}\text { El rango medio } \\
\text { del Pretest es } \\
\text { a el rango medio } \\
\text { del Postest }\end{array}$ & $\begin{array}{l}\text { El rango } \\
\text { medio del } \\
\text { Pretest es }< \\
\text { que el rango } \\
\text { medio del } \\
\text { Postest }\end{array}$ & 5.778e-06 & $\begin{array}{l}\text { Se rechaza la } \\
\text { hipótesis nula en } \\
\text { favor de la } \\
\text { hipótesis } \\
\text { alternativa }\end{array}$ \\
\hline $\begin{array}{l}\text { Aplican los mismos criterios para } \\
\text { calificar a los estudiantes, sin } \\
\text { importar su grupo cultural. - Dicen } \\
\text { cosas negativas sobre las personas } \\
\text { de algunos grupos culturales. }\end{array}$ & $\begin{array}{l}\text { El rango medio } \\
\text { del Pretest es } \\
\text { a el rango medio } \\
\text { del Postest }\end{array}$ & $\begin{array}{l}\text { El rango } \\
\text { medio del } \\
\text { Pretest es }> \\
\text { que el rango } \\
\text { medio del } \\
\text { Postest }\end{array}$ & $1.069 \mathrm{e}-08$ & $\begin{array}{l}\text { Se rechaza la } \\
\text { hipótesis nula en } \\
\text { favor de la } \\
\text { hipótesis } \\
\text { alternativa }\end{array}$ \\
\hline $\begin{array}{l}\text { Aplican los mismos criterios para } \\
\text { castigar el mal comportamiento de } \\
\text { los estudiantes sin importar su } \\
\text { grupo cultural. - Culpan a las } \\
\text { personas de algunos grupos } \\
\text { culturales por los problemas que } \\
\text { enfrenta }<\text { país de la prueba> }\end{array}$ & & $6.077 \mathrm{e}-09$ & $\begin{array}{l}\text { Se rechaza la } \\
\text { hipótesis nula en } \\
\text { favor de la } \\
\text { hipótesis } \\
\text { alternativa }\end{array}$ \\
\hline Total & & & & $\begin{array}{l}\text { Se rechaza la } \\
\text { hipótesis nula en } \\
\text { favor de la } \\
\text { hipótesis } \\
\text { alternativa }\end{array}$ \\
\hline
\end{tabular}

Fuente: Autor

El constructo Clima escolar - Clima escolar multicultural asociado a la pregunta $\mathrm{N}^{\circ} 8$, señala que Si se mejoró el desempeño entre postest con el pretest.

Tabla 115: Análisis de contrastes pregunta 9.

\begin{tabular}{|l|l|l|l|l|}
\hline \multicolumn{2}{|c|}{ 9. Caso de estudio $\mathbf{N}^{\mathbf{0}}$ 1. } \\
\hline Pregunta & Hipótesis nula & $\begin{array}{l}\text { Hipótesis } \\
\text { alternativa }\end{array}$ & $\begin{array}{l}\text { Test de } \\
\text { Wilcoxon } \\
\text { p-valor }\end{array}$ & Conclusión \\
\hline $9-9$ & $\begin{array}{l}\text { El rango medio del } \\
\text { Pretest es }=\text { a el } \\
\text { rango medio del } \\
\text { Postest }\end{array}$ & $\begin{array}{l}\text { El rango medio del } \\
\text { Pretest es }<\text { que el } \\
\text { rango medio del } \\
\text { Postest }\end{array}$ & 0.000 & $\begin{array}{l}\text { Se rechaza la hipótesis nula en } \\
\text { favor de la hipótesis alternativa }\end{array}$ \\
\hline
\end{tabular}

Fuente: Autor

El proceso cognitivo Entender diferencias en la comunicación asociado a la pregunta $\mathrm{N}^{\circ}$, señala que Si se mejoró el desempeño entre postest con el pretest.

Tabla 116: Análisis de contrastes pregunta 10.

\begin{tabular}{|c|c|c|c|c|}
\hline \multicolumn{5}{|c|}{ 10. Caso de estudio $\mathrm{N}^{\circ} 2}$. \\
\hline Pregunta & Hipótesis nula & $\begin{array}{l}\text { Hipótesis } \\
\text { alternativa }\end{array}$ & $\begin{array}{l}\text { Test de Wilcoxon } \\
\text { p-valor }\end{array}$ & Conclusión \\
\hline $10-10$ & $\begin{array}{l}\text { El rango medio del } \\
\text { Pretest es = a el rango } \\
\text { medio del Postest }\end{array}$ & $\begin{array}{l}\text { El rango medio del } \\
\text { Pretest es }<\text { que el } \\
\text { rango medio del } \\
\text { Postest }\end{array}$ & 0.000 & $\begin{array}{l}\text { Se rechaza la hipótesis } \\
\text { nula en favor de la } \\
\text { hipótesis alternativa }\end{array}$ \\
\hline
\end{tabular}

Fuente: Autor 
El proceso cognitivo Evaluar información, formular argumentos y explicar asuntos o situaciones asociado a la pregunta $\mathrm{N}^{\circ} 10$, señala que Si se mejoró el desempeño entre postest con el pretest.

En síntesis, la aplicación del modelo de coordenadas curriculares contribuyó con el mejoramiento en el desempeño de la competencia global. Además de ello, cada uno de los 10 constructos intervenidos en la propuesta indicaron mejora en el desempeño. 


\section{CAPÍTULO 6}

\section{CONCLUSIONES Y TRABAJOS FUTUROS}




\section{CONCLUSIONES Y TRABAJOS FUTUROS}

Las conclusiones de la tesis doctoral se presentan a partir de los hallazgos obtenidos en el desarrollo de los objetivos de investigación, el planteamiento de la hipótesis, limitantes y los trabajos futuros que se derivan de la actual propuesta.

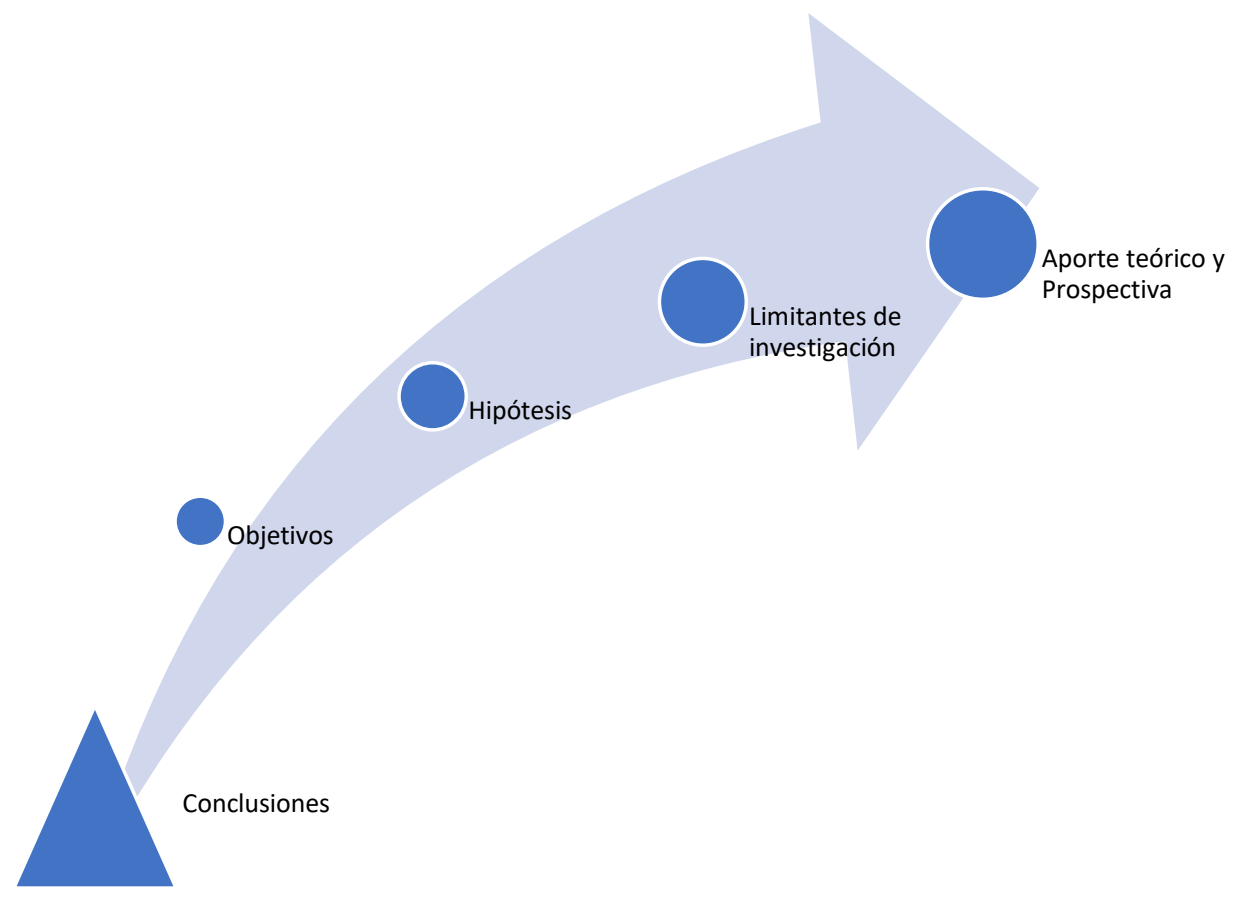

Ilustración 57: Presentación conclusiones de tesis

Fuente: Autor.

\subsection{Conclusiones a partir de los objetivos}

El desarrollo de la propuesta de investigación resalta la importancia de la participación colectiva en la construcción del currículo para básica secundaria. La institucionalidad de la escuela fortalece el desarrollo humano sostenible a partir del desarrollo local y global.

La tesis validada aporta hacia la identificación de las coordenadas que tensionan las actuales políticas locales educativas.

Además de ello, se propone un modelo de coordenadas curriculares para el desarrollo de la competencia global, que impulsa hacia: 
- La resolución de situaciones escolares desde las problemáticas del contexto local para la generación de centros educativos con filosofías de mejoramiento continuo con proyección hacia la comunidad en donde se incuban propuestas de solución.

- La integración con la comunidad educativa brindando solución de los problemas del entorno local con proyección global, generando comunidades de aprendizaje. Esto implica instituciones educativas eficientes al vincular sus recursos en la cadena de valor de la formación.

- El Vínculo con el entorno local a partir de la solución de las problemáticas con los miembros de la comunidad promoviendo el empoderamiento, afinidad y sentido de pertenencia de cada uno de los miembros.

- Los Niveles de apropiación para la solución de los problemas escolares, motivando el desarrollo de las competencias en contexto, en donde los resultados de aprendizaje son validados en campo.

- El compromiso hacia el desarrollo sostenible, promoviendo prácticas de transparencia con relación a la formulación del Proyecto Educativo Institucional, diseño curricular y proyección hacia la comunidad.

Los objetivos planteados permitieron consolidar el modelo de coordenadas curriculares. A continuación, la descripción de los indicadores de cumplimiento:

Tabla 117: Conclusiones por objetivos específicos

\begin{tabular}{|c|c|}
\hline Objetivos específicos & Indicador de cumplimiento \\
\hline $\begin{array}{l}\text { Identificar el alcance de los } \\
\text { requisitos normativos, en } \\
\text { términos académicos, aplicables } \\
\text { para las instituciones educativas } \\
\text { de básica secundaría. }\end{array}$ & $\begin{array}{l}\text { - Análisis histórico sobre disciplinas académicas y } \\
\text { las actuales clasificaciones en grupos educativos y } \\
\text { campos de educación. } \\
\text { - Identificación de las políticas de gobernanza } \\
\text { mundial para la formación educativa. } \\
\text { - Caracterización áreas fundamentales de básica } \\
\text { secundaria según ley general de educación (ley } \\
115 \text { de 1994). } \\
\text { - Prospectiva sobre las tendencias de formación a } \\
\text { 2030. "Educación para el Desarrollo Humano } \\
\text { Sostenible" }\end{array}$ \\
\hline $\begin{array}{l}\text { Analizar los criterios que definen } \\
\text { la innovación en los procesos de } \\
\text { educación. }\end{array}$ & $\begin{array}{l}\text { - Clasificación de modelos sobre procesos de } \\
\text { innovación. } \\
\text { - Clasificación de los metodologías y métodos para } \\
\text { innovar } \\
\text { - Identificación de las técnicas y herramientas para } \\
\text { innovar. }\end{array}$ \\
\hline $\begin{array}{l}\text { Distinguir los factores que } \\
\text { conforman la innovación en } \\
\text { educación en los procesos de co- } \\
\text { creación curricular. }\end{array}$ & $\begin{array}{l}\text { - Estado del Arte sobre modelos de gestión } \\
\text { curricular para básica secundaria. } \\
\text { - Rastreo bibliográfico sobre definiciones de } \\
\text { innovación en educación. } \\
\text { - Identificación de tipologías de innovación } \\
\text { educativa. }\end{array}$ \\
\hline
\end{tabular}




\begin{tabular}{|l|l|}
\hline & $\bullet$ Prospectiva para la innovación en educación. \\
\hline $\begin{array}{l}\text { Categorizar los principios de } \\
\text { funcionamiento de un modelo de } \\
\text { gestión curricular creado ad hoc. }\end{array}$ & $\begin{array}{l}\text { • Teorización de las dimensiones curriculares. } \\
\text { - Identificación de coordenadas curriculares. } \\
\text { • Validación del modelo de coordenadas } \\
\text { curriculares para básica secundaria. }\end{array}$ \\
\hline
\end{tabular}

Fuente: Autor.

Como se evidencia en la tabla anterior, el desarrollo de la investigación brinda cumplimiento a cada una de las etapas propuestas.

Como productos de investigación tangibles la revista Universidad Católica Luis Amigo con ISSN (en línea) 2590- 7565 publicó el artículo denominado "El currículo para el contexto: análisis bibliográfico sobre tendencias para diseñar el currículo de básica secundaria" en la edición $\mathrm{N}^{\mathrm{o}} 3$ de 2019. (anexo No 9, Artículo publicado).

Adicional a ello, se participó en el Encuentro Latinoamericano de Educación 2018 (ELE) del Instituto Antioqueño de Investigación que permitió dos productos de investigación (i) ponencia y (ii) capítulo de libro resultado de investigación con la propuesta "Framework metodológico para el diseño curricular en básica secundaria” (anexo 10 y 11).

De igual forma se participó en el IV Congreso Internacional de Política educativa en América Latina 2019 organizado por CEDALC, UNLP y CLASCO otorgando dos productos de investigación a los avances de tesis presentados con (i) ponencia y (ii) capítulo de libro resultado de investigación para publicación en 2020 (anexo 12).

La tesis formulada brinda un potencial de productos de investigación a futuro que permitirá la participación en diferentes eventos científicos.

\subsection{Conclusiones a partir de la Hipótesis.}

De acuerdo con la hipótesis de investigación planteada (HI) "Los procesos de innovación en educación aplicados para la elaboración del diseño curricular mediante el <modelo de coordenadas curriculares $>$ mejoran el desarrollo de la competencia global para la resolución de los problemas locales y globales en los estudiantes de noveno grado de básica secundaria" se concluye:

La intervención pedagógica a partir de los resultados entre el pretest y postest indican que existen diferencias estadísticamente significativas, es decir, la aplicación del "modelo de coordenadas curriculares" logró mejorar el desempeño de los estudiantes de noveno grado con relación a la competencia global.

Del mismo modo la intervención pedagógica mejoró el desempeño de los estudiantes al realizar el análisis estadístico de contraste a cada uno de los constructos y procesos cognitivos de la competencia global en términos de: 
- Adopción de perspectivas

- Mentalidad Global

- Flexibilidad/ Adaptabilidad

- Conocimiento de la comunicación intercultural

- Autoeficacia con respecto a asuntos globales

- Conocimiento sobre asuntos globales

- Actitudes frente a los inmigrantes

- Clima escolar - Clima escolar multicultural

- Entender diferencias en la comunicación

- Evaluar información

El desarrollo de la competencia global promueve la convivencia en armonía de la comunidad. Las temáticas abordadas en la intervención pedagógica fomentaron la conciencia cultural y las interrelaciones de forma respetuosa en una sociedad cada vez más polarizada y diversa. De acuerdo con (Delors et al., UNESCO 2014c) la gran afluencia de inmigrantes en los diferentes países, hacen que las comunidades tiendan a redefinir su identidad y su cultura local. Las sociedades contemporáneas exigen nuevas formas de pertenencia y ciudadanía en orden a lograr a que contribuyan con la reducción de prejuicios y estereotipos culturales.

El desarrollo de la competencia global contribuye con la vinculación hacia un mundo laboral en donde los individuos comprenden la complejidad de la globalización. Ello implica, la apertura hacia diferentes contextos culturales, la generación de confianza y el respeto por los demás (British Council, 2013).

Las tecnologías de la comunicación han acercado a las sociedades y han generado nuevas formas de aprendizaje sobre el qué y cómo aprender. El desarrollo de la competencia global fortalece la apropiación del uso de las TIC, contribuye con la responsabilidad de informar con veracidad y objetividad. Además de analizar el impacto de las opiniones.

Del mismo modo la competencia global fomenta la conciencia hacia los asuntos de trascendencia social, política, económica y ambiental. Además de promover el desarrollo sostenible, los derechos humanos y el respeto por la diferencia.

\subsection{Conclusiones a partir de las limitantes de investigación.}

La competencia global se ha proyectado como un elemento clave para vivir en armonía en un mundo cada vez más multicultural tanto en los centros educativos como en la comunidad. Se requiere por parte de la escuela la elaboración de proyectos de carácter global que no solo integre las asignaturas o la institución, sino que logre vincular el trabajo colaborativo entre distintas nacionalidades para ampliar la base de perspectivas de la realidad cultural y social. 
El modelo de coordenadas curriculares contribuye con los procesos de escolarización de básica secundaria con relación a difusión y aplicación los derechos humanos, el respeto por la diferencia y la autonomía institucional para contribuir con la formación de una sociedad que anhela un pensamiento integrador con perspectivas comunes soportadas desde la libertad para el desarrollo local y global.

Así mismo el modelo de coordenadas curriculares, aporta hacia la visión global de formación desde los pilares del desarrollo humano sostenible. En donde la variable "competencia global" es un nuevo actor que ingresa a la ecuación del proceso educacional. En este sentido los campos educativos presentan un desafío al integrar un nuevo componente de formación para una sociedad más justa y equitativa.

El informe del Programa Internacional para la Evaluación de Estudiantes conocido como informe PISA ha liberado solo 1 guía de orientación de la competencia global para Colombia, documento adaptado del "Marco de Competencia Global: Estudio Pisa. Preparar a nuestros jóvenes para un mundo inclusivo y sostenible". Lo que determina:

Pocos instrumentos validados para ampliar el margen de preguntas que se pueden utilizar en una prueba con estudiantes de básica secundaria.

Solo ha habido una prueba oficial de PISA elaborada en 2018 que avaluó la competencia Global. No existe a la fecha resultados publicados a nivel mundial sobre estudios del desarrollo de la competencia global de acuerdo con en el informe PISA. La información de la página oficial de la OCDE indica publicación de resultados en noviembre de 2019.

No existe en Colombia una catedra o guía metodológica que promueva desde el Ministerio de Educación Nacional el desarrollo de la Competencia Global en cada uno de los ciclos de educación: Inicial, Preescolar, Básica primaria, Básica secundaria, Media y Educación Superior.

No existen métricas oficiales para determinar las políticas educativas en Colombia que determinen los niveles de apropiación de las dimensiones de la competencia global por ciclos de educación: Inicial, Preescolar, Básica primaria, Básica secundaria, Media y Educación Superior.

A nivel global existe poca información publicada por los entes gubernamentales de educación para la formación de la competencia global.

A nivel institucional el modelo de coordenadas curriculares se aplicó solo a la asignatura de Ciencias Sociales durante 7 sección de intervención. En este sentido, se formulan nuevas hipótesis no demostradas orientadas a determinar la correlación a mayor número de asignaturas y tiempo de intervención se obtienen mejores desempeños en el desarrollo de la competencia global.

\subsection{Conclusiones como aporte teórico y prospectiva.}


El modelo de coordenadas curriculares surge como un instrumento que identifica las actuales variables de gobernanza mundial para el desarrollo humano sostenible y las integra en los procesos de formación curricular para básica secundaria.

De este modo el modelo permite la creación de un marco teórico metodológico que fortalece la competencia global en estudiantes de básica secundaria generando alternativas de solución a los problemas locales de carácter global (anexo 4).

Así mismo, el modelo de coordenadas curriculares contribuye con el proceso de cambio hacia la calidad de vida del ser humano en términos de trabajo en equipo para el crecimiento económico con equidad social, transformación hacia la co-ideación de métodos eficientes de administración y producción, además de la generación de conciencia sobre los patrones de consumo para el equilibrio ambiental como soporte para el desarrollo local.

A nivel institucional el modelo aporta hacia la visión de un pensamiento estratégico para las instituciones que busca generar valor para el desarrollo humano sostenible. Principios compartidos con (Moore \& Benington, 2011); las instituciones deben tener como propósito crear valor para el público en general, de este modo se crea legitimidad en los grupos de interés.

Aportar en función del desarrollo sostenible desde la institucionalidad de la escuela incluye el cumplimiento de la misión social de la educación. Además de ello, incluye prácticas de buen gobierno en términos de transparencia, eficiencia y gestión estratégica de recursos.

Desde el enfoque de la innovación el modelo contribuye con el desarrollo de habilidades para el pensamiento crítico en entornos que simulan el mundo real. De este modo se aporta para con el trabajo en equipo, la creatividad, autonomía, sostenibilidad y la eficiencia de los procesos en modelos efectivos de aprendizaje.

En términos de prospectiva, el modelo de coordenadas curriculares presenta variadas opciones de investigación en temáticas relacionadas con:

Cuestiones ambientales, de acuerdo con el informe de la (UNESCO, 2016d) "La educación al servicio de los pueblos y del planeta" en la mitad de los planes de estudio de los países del mundo no se mencionan los problemas ambientales de forma explícita. Así mismos, en los países de la OCDE el $40 \%$ de los estudiantes de 15 años posee conocimientos básicos sobre temas ambientales.

Del mismo modo, el modelo de coordenadas curriculares plantea desafíos en materia de:

- Desarrollo de portafolio de instrumentos de validación de la competencia global.

- Diseño y desarrollo metodológico mediante modelos de software que operacionalicen las dimensiones: estratégica, operativa y evaluativa para el desarrollo sostenible. 
- Diseño y desarrollo de ambientes virtuales de co-creación para ampliar la participación de la comunidad en la planeación estratégica de las instituciones de educación.

- Diseño y desarrollo de software para integrar las necesidades intereses, problemas o soluciones (NIPS) entre las instituciones de educación con relación al desarrollo y evaluación de la competencia global para el desarrollo humano sostenible.

- Análisis comparativo de formación en la competencia global para los ciclos de educación en Colombia (Inicial, Preescolar, Básica primaria, Básica secundaria, Media y Educación Superior).

- Diseño y desarrollo de modelos de coordenadas curriculares para niveles educativos: Inicial, Preescolar, Básica primaria y Media.

- Profundización en el desarrollo teórico metodológico y validación del Modelo de coordenadas curriculares para la educación superior.

Resultado de las aristas que propone el modelo de coordenadas curriculares se han abordado en escenarios como el II Simposio Internacional RAIS 2019 "Cultura solidaria, base de la innovación social" organizado por la Red Amigomaniana de Innovación Social de la Universidad Católica Luis Amigó. Cuya participación entregó 2 productos de investigación. (i) Ponencia (anexo 13) y (ii) Capitulo de libro resultado de investigación con la propuesta "Modelo de referencia para el diseño curricular en educación superior: ODS, Industria 4.0 y grupos educativos como direccionamiento de estratégico de país" (Anexo 14).

Las anteriores conclusiones permiten generar aportes originales a las fronteras del conocimiento posibilitando nuevas categorías de análisis y reflexión en torno al diseño y construcción del currículo para básica secundaria mediado por procesos de innovación. Un diseño curricular orientado al desarrollo humano sostenible, categoría propia de los nuevos desafíos de la educación. 


\section{REFERENCIAS BIBLIOGRÁFICAS}

ACNUDH, Naciones Unidas Derechos Humanos (1996-2018). Declaración sobre el derecho al desarrollo. ACNUDH 1996-2018. Tomado el 6 de febrero de 2018 de http://www.ohchr.org/SP/Professionallnterest/Pages/RightToDevelopment.aspx

Agencia Andaluza de evaluación educativa (2012) Guía de buenas prácticas docentes. Junta de Andalucía: Sevilla. Recuperado de http://goo.gl/LNyvTW

Agudelo, S. (1998.). Certificación de competencias laborales. Aplicación en Gatronomía . Montevideo,: Cinterfor/OIT.

Aguilar, Martha ( 2017) Grabado sostenible. Experiencias y prácticas de mediación educativa en primaria. Revista Educación y pedagogía. No 18. Pag. 55- 77.

Agray Vargas, N. (2010). La construcción de currículo desde perspectivas críticas: una producción cultural. Signo Y Pensamiento, 29(56), 420-427. Recuperado a partir de https://revistas.javeriana.edu.co/index.php/signoypensamiento/article/view/2571

Alcaide, Jorge. (2004): Diseño de productos, Métodos y técnicas (Primera ed.). Valencia: Alfaomega.

Alcaldía de Medellín (2016) Plan de Desarrollo Medellín cuenta con vos 2016-2019.

Tomado de

https://www.medellin.gov.co/irj/go/km/docs/pccdesign/SubportaldelCiudadano_2/Plan deDesarrollo_0_17/Publicaciones/Shared\%20Content/Documentos/2016/Plandedesarr olloMunicipalConsolidadov229FEB16.pdf

Altshuller, H (1996). Innovación sistémica: TRIZ De repente apareció el inventor. Technical Innovation Center.

Althusser, L (1974) ideología y aparatos ideológicos del estado, en: La filosofía como arma de la revolución, México, siglo XXI.

Álvarez Besabe, M. (2010). Diseñar el currículo universitario: un proceso de suma complejidad. Signo Y Pensamiento, 29(56), 68-85. Recuperado a partir de https://revistas.javeriana.edu.co/index.php/signoypensamiento/article/view/2550

Alves Paraíso, M. (2015). Um currículo entre formas e forças. Educação, 49-58

Amaya De Ochoa, Graciela. (1999). La gestión del currículo. Universidad de Antioquia

Andrade, R., Hernández, S (2010) El enfoque de competencias y el currículum del bachillerato en México. Revista Latinoamericana de ciencias sociales, niñez y juventud. 8(1): 481-508

Anju Singhal (2013) Scrum Guide - Your Guide to the Most Popular Agile Methodology: Agile Project Management Series. Agiliants Incorporated 
Aparici, R., y Silva, M. (2012). Pedagogía de la interactividad. Comunicar: Revista Científica Iberoamericana, 19(38), 51-58. http://doi.org/10.3916/C38-2011-02-05

APC Colombia - Agencia Presidencial de Cooperación Internacional (2015). Objetivos de Desarrollo Sostenible, Colombia Herramientas de aproximación al contexto local. Recuperado el 16 de junio de 2017 del sitio web de la Agencia Presidencial de Cooperación Internacional de gobierno de colombiana: https://www.apccolombia.gov.co/publicaciones/objetivos-de-desarrollo-sosteniblecolombia-herramientas-de-aproximacion-al-contexto-local

Apple, M. (1979) Ideología y currículo. Madrid, España, Akal 1986.

Área, M. (2008). La innovación pedagógica con TIC y el desarrollo de las competencias informacionales y digitales. Investigación en la escuela, 64, 517

Arévalo Duarte, M. A., y Gamboa Suárez, A. A. (2015). Las tecnologías de la información y de la comunicación en el currículo de matemáticas: orientación desde las políticas y los proyectos educativos. Revista Panorama, 21-30

Aristóteles (384-322 a.C) La política. Traducción Pedro Simón Abril. Ediciones Nuestra Raza. Madrid. Versión digital http://fama2.us.es/fde/ocr/2006/politicaAristoteles.pdf

Astiz, M. a. (2014). El Curriculum Escolar y su Abordaje desde la Teoría de la Sociedad Mundial: Revisión y Prospectiva. (Spanish). Education Policy Analysis Archives, 22(21-25), 1-12. doi:10.14507/epaa.v22n25.2014

Atuesta, María., Ceballos, Ándres. \& Gòmez, Rodrigo (2015). Co-creación como metodología para la apropiación social de la ciencia y la tecnología (ASCYT) del recurso agua. Caso Urabá-Antioqueño- Colombia. Scielo pag. 277-286

Australian National Training Authority. (s.f.). www.anta.gov.au.

Avendaño-Castro, W., y Parada-Trujillo, A. (2013). El currículo en la sociedad del conocimiento. (Spanish). Educación y Educadores, 16(1), 159-174.

Ávila, Julián. \& Bedoya, Julián. (2012) Implementación del sistema de gestión por competencias para la Uniagustiniana. Revista Suma de Negocios. Vol. $3 \mathrm{~N}^{\circ}$ 1: 139147

Bachman, John (1972). Cómo usar materiales audiovisuales. Diana México

Bandura, A. (1977). Social Learning Theory. General Learning Press.

Banfield. Richard, Todd. C, Wax. Trace (2015) Design Sprint: A Practical Guidebook for Building Great Digital Products. O'Reilly Media, Inc

Bambrick-Santoyo, P. (2010). Driven by data: A practical guide to improve instruction. San Francisco: John Wiley and Sons Inc 
Barbour, Rosaline (2013) Los grupos de discusión en Investigación Cualitativa. Ed Morata.

Barquín, A., Alzola Maiztegi, N., \& Madinabeitia Medrano, M. (2012). Innovación curricular en los grados de maestro en la facultad HUHEZI (Mondragon Unibertsitatea): la materia Educación intercultural y educación en valores. REDU. Revista de Docencia Universitaria, 10(3), 171-194. doi:https://doi.org/10.4995/redu.2012.6019

Barrett, M., Byram, M., Lázár, I., Mompoint-Gaillard, P., \& Philippou, S. (2014). Developing Intercultural Competence through Education. Strasbourg: Council of Europe Publishing.

Baudelot, Christian; Establet, Roger. (1976) La escuela capitalista en Francia. Madrid: Siglo XXI.

Bazerman, Charles y Prior, Paul (2005). "Participating in emergent socialiterate worlds. Genre, disciplinarity, interdisciplinarity”, en R. Beach, J. Green, M. Kamil y T. Shanahan (eds.), Multidisciplinary perspectives on literary research, 2a ed., Nueva Jersey: Hampton Press Inc

Belhoste, B., (1990). "La educación secundaria y la ciencia francesa a principios del siglo XX. La reforma de 1902 de los planes y programas de estudio ", Revista de Historia de la Ciencia, Vol. 43, No. 4, PUF

Benington, J. and M. Moore (2011) 'Public value in complex and changing times', in enington and Moore (eds), Public Value: theor y and practice, Basingstoke: Palgrave Macmillan, pp.1-30

Berdugo Correa, C., Oviedo-Trespalacios, Ó., Peña baena Niebles, R., Luna Amaya, C., \& Nieto Bernal, W. (2014). Diseño y desarrollo de servicios: una nueva perspectiva desde el ciclo de vida. Interciencia, 39 (2), 111-115.

Bertieri Quintero, José \& Villamarín Marentes, J. \& Sáenz Blanco, Fabiola. (2012). Organizaciones, Niveles y Territorio en la Perspectiva de un Modelo de Gestión de los Sistemas Regionales de Ciencia, Tecnología e Innovación. 10.13140/2.1.3934.5922.

BID-Banco Interamericano de Desarrollo (2001) Eficacia, eficiencia, equidad y sostenibilidad: ¿Qué queremos decir? Tomado el 9 de nov. de 18 de https://publications.iadb.org/handle/11319/1193?localeattribute=es\#sthash.i4yKgWWb.dpuf

Biondi, Biondo (2003) Los bienes. Barcelona, Bosch, 2 a ed.

Blanco, R. (2005). La escuela como centro de la innovación educativa - Versión Preliminar. OREALC/UNESCO - Innovemos, Red de Innovaciones Educativas. Curso Taller: Investigación y Sistematización de Innovaciones Educativas 2005-2006. 
Blanco, Rosa y Messina Raimondi, Graciela (2000), Estado del Arte sobre las Innovaciones Educativas en América Latina. Santiago de Chile, Convenio Andrés Bello

Blank, Steve \& Dorf Bob (2013). The four steps to the ephiphany. Ed. Kindle

Blyth, W. A. L.(1998). Three traditions in English primary education. Taylor \& Francis

Boix Mansilla, V., \& Jackson, A. (2011). Educating for Global Competence: Preparing Our Youth to Engage the World. Asia Society and Council of Chief State School Officers, 2011.

Bourdieu, P \& Passeron, J. (1970) La reproducción: Elementos de una teoría del sistema de enseñanza, Barcelona, Laia.

Bowlby, J.(1998). El apego y la perdida, Edit. Paidos Barcelona

Braid, Liana Maria Carvalho; Machado, Maria de Fátima Antero Sousa e Aranha, Ágatha Cristina.(2012) Estado da arte das pesquisas sobre currículo em cursos de formação de de profissionais da área da saúde: um levantamento a partir de artigos publicados entre 2005 e 2011.Interface (Botucatu) [online]. 2012, vol.16, n.42, pp.679-692. ISSN 1414-3283. http://dx.doi.org/10.1590/S1414-32832012000300008.

BRASIL. Ley 9.394. 1996. (s.f.).

Briede, J. C., \& Marcela, W. (2016). Diseño y Co-Creación Mediante Aprendizaje y Servicio en Contexto Vulnerable: Análisis de Percepción de la Experiencia. Formación universitaria, 9(1), 57-70. https://dx.doi.org/10.4067/S0718-50062016000100007

British Council (2013). Culture at Work : The Value of Intercultural Skills in the Workplace, British Council, Reino Unido.

Bronfenbrenner. (2005). Urie Making Human Beings Human: Bioecological Perpectives on Human Developmen. Sage Publications

Brooks, J.G. y Brooks, M.G. (1999). In search of unders tanding: The case for constructivist classrooms. Alexandria, VA: Association for Supervision and Curriculum Development (ASCD).

Brown J \& Isaacs D (2007). Reseña de "World Café. El nuevo paradigma de comunicación organizacional y social" de Juanita Brown, David Isaacs y la Comunidad del World Café. Innovación Educativa, 7 (38), 78

Brown. Juanita, Isaacs. David, World Cafe Community, Senge. Peter, Wheatley. Margaret (2005) The World Café: Shaping Our Futures Through Conversations That Matter

Brown, Tim (2009). Change by Design: How Design Thinking Transforms Organizations and Inspires Innovation. Harper Collins. 
Bunk, G. P. (1994). La transmisión de las competencias en la formación y perfeccionamiento profesionales en la RFA. CEDEFOP $N^{\circ} 1$.

Buzan, Tonny (2017) El libro de los mapas mentales. Cómo utilizar al máximo las capacidades de la mente. Urano.

Buzón-García, Olga \& Barragán Sánchez, Raquel. (2004). Desarrollo de competencias específicas en la materia tecnología educativa bajo el marco del espacio europeo de educación superior. RELATEC: Revista Latinoamericana de Tecnología Educativa, ISSN 1695-288X, Vol. 3, No. 1.

Cadavid Rojas, Ana y Calderón Palacio, Isabel, “Análisis del concepto enseñanza en las teorías curriculares de Lawrence Stenhouse y José Gimeno Sacristán”, Revista Educación y Pedagogía, Medellín, Universidad de Antioquia, Facultad de Educación, Vol. XVI, No. 40, (septiembre-diciembre),2004, pp. 143-152.

Cajiao, Francisco (2001). Sociedad educadora. OIE. Revista Iberoamericana de educación.. Ed 26.

Calafell, G., Junyent, M., \& Bonil, J. (2015). Una propuesta para ambientalizar el currículo. Cuadernos de Pedagogía, (460), 56-60

Calderón, Hader (2011). La enseñanza de las ciencias sociales y la formación para las ciudadanías desde el enfoque de escuela abierta: un campo significativo para las prácticas pedagógicas y la investigación formativa. Uni-Pluri/Versidad. Vol.11 No.2, -Versión Digital. Facultad de Educación- Universidad de Antioquia. Medellín, Col.

Calero Gimeno, R., \& Gallarza-Granizo, M. (2015). Aplicabilidad del Service-Dominant Logic al ámbito sanitario: caracterizando el servicio para la co-creación de valor. Gerencia y Políticas De Salud, 14(29). https://doi.org/10.11144/Javeriana.rgyps14-29.asdl

Cañas, N., Ardila, M., \& Becerra, L. (2012). Maestro, traductor y tecnologías de la información y la comunicación en la Escuela de Idiomas de la Universidad de Antioquia: Realidades y retos. Íkala, Revista de Lenguaje y Cultura, 17(1), 61-79

Carbonell, J. (2001). La aventura de innovar. El cambio en la escuela. Madrid: Morata

Carter K. \& Doyle W. 1990 Classroom research as a resource for the graduate preparation of teachers (Estudio de la clase como base para una formación gradual de los profesores), Tucson, Arizona

Castañeda, Margarita (1987). Los medios de la comunicación y la tecnología educativa. Trillas. México. 
Castells, M. (1997). La era de la información. Economía, sociedad y cultura. Vol. 1. La Sociedad Red. Madrid: Alianza.

Castro Hoyos, J, \& Elena Arias Vanegas, B. (2013). Perspectivas de pedagogía y currículo con relación a la intencionalidad formativa de la educación.Itinerario Educativo, 27(61), 225-240

Cazares, M. (2008). MEN.Colombia Aprende: La red del conocimiento. Obtenido de http://www.colombiaaprende.edu.co/html/mediateca/1607/article-170863.html: http://www.colombiaaprende.edu.co/html/mediateca/1607/article-170863.html

Ceballos, M. M. (2004) "Manual para el desarrollo del mapeo de actores claves -MAC", elaborado en el marco de la consultoría técnica GITEC-SERCITEC

CEPAIM (2014) Convivencia y cohesión social (2014) Herramientas para la cohesión social. Un proceso de reflexión y sistematización entre buenas prácticas en acción comunitaria intercultural de España y Portugal. Murcia: fundación CEPAIM.

CEPAL (1951) Conceptos básicos acerca del desarrollo y la dependencia, publicación de las Naciones Unidas, Nueva York. Ibíd., pág. 40

Chan, K W. \& Maubourgne, R. (2008). La Estrategia Del Oceano Azul. Carvajal Education

Chervel, A. (1993). Histoire de l'agrégation, Contribution à l'histoire de la culture scolaire. Paris: Institut national de recherche pédagogique-Editions Kimé.

Chomsky, N. (2000). Sobre Democracia y Educación: Escritos sobre ciencia y antropología del entorno cultural. Paidos.

Cimorelli, Stephen (2016) Kanban for the Supply Chain: Fundamental Practices for Manufacturing Management. CRC Press.

Clayton M, Gregersen, Hal; Dyer, Christensen, Jeff. (2012) El ADN del innovador. Ed. Deusto.

Clayton M. Christensen, Michael E. Raynor, Jeff Dyer, Hal Gregersen (2011) Disruptive Innovation: The Christensen Collection. Harvar Business Review press.

Climént Bonilla, J. (2010). Reflexiones sobre la Educación Basada en Competencias. Revista Complutense de Educación, 21(1), 91 - 106.

Cohen, Ernesto y Rolando Franco. 1992. Evaluación de proyectos sociales. México: Siglo Veintiuno.

Cohen, L., Manion, L. y Morrison, K. (2007). ResearchMethods in Education. Nueva York: Routledge-Taylor and Francis Group.

Colciencias (2018) Modelo General de Buenas Prácticas de Sostenibilidad en Centros de Ciencias. Centros de ciencias. Tomado el 20 de noviembre de 2018 de http://colciencias.gov.co/sites/default/files/ckeditor files/modelo-buenas-practicas.pdf 
Colombia Aprende (MEN). (14 de 01 de 2015). Colombia Aprende la red de conocimiento. Obtenido de Colombia Aprende la red de conocimiento: http://www.colombiaaprende.edu.co/html/home/1592/article-87521.html

Coll, C. \& Onrubia, J. (2001). Estrategias discursivas y recursos semióticos en la construcción de sistemas de significados compartidos entre profesores y alumnos. Investigación en la escuela, 45, 21-31. Recuperado de http://investigacionenlaescuela.es/articulos/45/R45 2.pdf

Comisión Europea (1995) Libro verde de Innovación.

Comunidades europeas (2006). Competencias clave para el aprendizaje permanente. Un marco de referencia europeo. Educación y Formación. Tomado de https://www.mecd.gob.es/dctm/ministerio/educacion/mecu/movilidadeuropa/competenciasclave.pdf?documentld=0901e72b80685fb1

Congreso de Colombia. (8 de febrero de 1994). Artículo 23 y 79 [Titulo I y III]. Ley General de Educación. [Ley 115 de 1194]. DO: 41.214

Connell, R. (1997). Escuelas y justicia social. Editorial Morata. Madrid.

Consejo de Normalización y Certificación de Competencia Laboral (CONOCER). (1997). La normalización y certificación de competencia laboral: Medio para incrementar.

Collado-Ruano, J. (2017). Educación y desarrollo sostenible: la creatividad de la naturaleza para innovar en la formación humana. Educación y Educadores, 20(2), 229-248. https://doi.org/10.5294/edu.2017.20.2.4

Córdoba, M. E. (2013). Estudios generales y tecnología en un currículo participativo. Ciencia y Sociedad, 38(1), 9-25

Correa Uribe, Santiago (1994), Educación de calidad, escuela y currículo. Revista Educación y Pedagogía Nos. 12 y 13, pp 112- 131.

Corvalán, O.Tardif, J \& Montero, P. (2013). Metodologías para la innovación curricular universitaria basada en el desarrollo de competencias. Perfiles Educativos. vol. XXXVII, núm. 147, 2015 | IISUE-UNAM.

Cosme Casulo, J. (2018). Los Objetivos de Desarrollo Sostenible y la academia. MEDISAN, 22(8), 1089-1099. Retrieved from http://search.ebscohost.com/login.aspx?direct=true\&db=aph\&AN=132570850\&lang=es\&s ite=ehost-live

Crespo, L. V., y Cota, M. P. (2012). Integración curricular de las TIC en la enseñanza no universitaria: modelo de ajuste y hoja de ruta. CISTI (Iberian Conference On Information Systems \& Technologies / Conferência Ibérica De Sistemas E Tecnologias De Informação) Proceedings, 433-438 
Cubero, J (1991). Análisis de los medios de enseñanza. Sevilla. Ediciones Alfar.

Da Costa, Ricardo (2006). Las definiciones de las siete artes liberales y mecánicas en la obra de Ramon Llull, Revista Anales del Seminario de Historia de la Filosofía. Madrid: Publicaciones Universidad Complutense de Madrid (UCM), vol. 23 (2006), p. 131-164

Da Silva, Tomaz (1999). Documentos de Identidad Una introducción a las teorías del currículo, $2^{\circ}$ Edición Autêntic. a Editorial. Belo Horizonte

Darwin C. (1859) El origen de las especies. Feedbooks. http://www.cervantesvirtual.com

Deardorff, D. K. (2009). Implementing Intercultural Competence Assessment. En D.K. Deardorff (Ed.). The SAGE Handbook of Intercultural Competence (pp. 477-491). Thousand Oaks, CA: Sage.

Del Cerro, Francisco \& Lozano, Fernando (2018) Estudio de un caso de enseñanza de materias STEM a través del ecourbanismo apoyado por herramientas avanzadas de diseño, en el horizonte 2030 de objetivos de desarrollo sostenible (ODS) Revista de Educación a Distancia. No 58. Art 12. DOI: http://dx.doi.org/10.6018/red/58/12

De la Rosa , Alberto., Soto, Ovidia \& Martín, Victoria (2018) Integración de la Sostenibilidad Curricular Mediante la Elaboración de Materiales Didácticos Digitales Interactivos. Repositorio Institucional Universidad de la laguna. España.

De Sosoaga López de Robles, A. L. (2013). El método interpretativo de Von Savigny en el análisis de la legislación educativa: un estudio de casos sobre el currículo de Primaria. Revista de Educación y Derecho, (9), 1-28.

De Zan, A., \& Paipa Galeano, L. (2012). Elementos de diseño de un currículo basado en el enfoque de procesos. Revista Educación en Ingeniería, 7(14), 22-34. doi:http://dx.doi.org/10.26507/rei.v7n14.239

Del Carmen Ramírez Hernández, D., Ramírez Montoya, M. S., \& Ramírez Moreno, P. P. (2015). Formación Profesional: Integrando Saberes Éticos Y De Desarrollo Sostenible. Caso Práctico Para Ingeniería. Sinéctica, (45), 1-20. Retrieved from http://search.ebscohost.com/login.aspx?direct=true\&db=fua\&AN=115136593\&lang=es\&si te=ehost-live

Delors, J. et al. (1996), Learning: The Treasure Within, UNESCO, París.

Deslandes, R. (2009 a). Internacional Perspectives on Student Outcomes and Homework. Family - school - community partnerships. Editado por Rollande Deslandes. Routledge: Contexts of learning

Díaz Barriga, Ángel. (1984). Ensayos sobre la problemática curricular (primera edición). Editorial Trillas. México.

Díaz Barriga, A. (2008). El enfoque de competencias en educación. ¿Una alternativa o un disfraz de cambio? Perfiles educativos, 28(111), 7-36. 
Díaz Barriga Arceo, F., \& Barroso Bravo, R. (2014). Diseño Y Validación De Una Propuesta De Evaluación Auténtica De Competencias En Un Programa De Formación De Docentes De Educación Básica En México. Perspectiva Educacional, Formación de Profesores, 53 (1), 36-56.

Díaz Duque, J. A. (2015). La Dimensión de la Sostenibilidad en la Enseñanza de las Ingenierías en Cuba. Foro de Educación, 13(19), 241-262. https://doi.org/10.14516/de.2015.013.019.011

Díaz-león, C. A., Hincapié-montoya, E. M., (2014). Descripción de un Framework metodológico para el desarrollo de aplicaciones relacionadas con el patrimonio cultural, $12-18$

Díaz, M. (2007). Lectura crítica de la flexibilidad. Vol. 1 La educación superior frente al reto de la flexibilidad. Bogotá, Colombia: Magisterio

Díez. Emiliano \& Sánchez, Sergio (2015). aula abierta. Aula Abierta, 43(2), 87-93. http://doi.org/10.1016/j.aula.2014.12.002

DNP- Departamento Nacional de Planeación (2017) Inclusión de los Objetivos de Desarrollo Sostenible en los planes de desarrollo territoriales, 2016-2019. Dirección de Seguimiento y Evaluación de Políticas Públicas (DSEPP). Tomado de https://colaboracion.dnp.gov.co/CDT/Sinergia/Documentos/ODS en los PDT.PDF

Dörr (1997). Dörr, Günter y Seel, Norbert M. Instructional Delivery Systems and Multimedia Environments. En: Sanne Dijkstra, Norbert M. Seel, Franz Schoot and Robert D. Tennyson (Eds) Instructional Design: International Perspectives (Volume 2: Solving Instructional Design Problems) (p. 145-182). Lawrence Erlbaum Associates. New Jersey/London, 1997

Ducci, M. A. (1997). El enfoque de competencia laboral en la perspectiva. Seminario Internacional sobre Formación Basada. Guanajuato: Documentos presentados. Montevideo: Cinterfor/OIT.

Duncan, Kevin (2015) El libro de los diagramas: 50 soluciones visuales para resolver problemas. Ed. Lid

Dumrauf, A., \& Menegaz, A. (2013). La construcción de un currículo intercultural a partir del diálogo de saberes: descripción y análisis de una experiencia de formación docente continua. Revista Electrónica de Enseñanza de las Ciencias, 12(1), 85-109.

Dussel, I. i. (2014). ¿Es el curriculum escolar relevante en la cultura digital? Debates y desafíos sobre la autoridad cultural contemporánea. (Spanish). Education Policy Analysis Archives, 22(21-25), 1-21. doi:10.14507/epaa.v22n24.2014

Dworkin, R. (1981) "What is Equality? Part 2: Equality of Resources," Philosophy \& Public Affairs 10 (4), pp. 283-345 
Echeverri, Jaime, Aristizábal, Miguel, Moreno, Francisco, \& Bedoya, Alejandra. (2012).

Diseño de un Sistema Difuso para Valoración de Aportes en Sistemas

Colaborativos. Revista Ingenierías Universidad de Medellín, 11(20), 139-152.

Retrieved Jun 16, 2017, from

http://www.scielo.org.co/scielo.php?script=sci_arttext\&pid=S1692-

$33242012000100012 \& \operatorname{lng}=\mathrm{en} \& \operatorname{tlng}=\mathrm{es}$

Egido, G. (2010) Las competencias clave como elemento central del currículo de la enseñanza obligatoria: un repaso a las experiencias europeas. Revista Española de Educación Comparada. 17 (2011): 239-262

Egido, G. (2011) Las competencias clave como elemento central del currículo de la enseñanza obligatoria: un repaso a las experiencias europeas. Revista Española de Educación Comparada. 17 (2011): 239-262

Erikson Erik (2000). El ciclo vital completado. Barcelona: Ediciones Paidós Ibérica

Escudero, J. M (2012) Claros y oscuros del Espacio Europeo de Educación Superior como innovación educativa, en Calinda Leite y Miguel Zabalza (Coords.) Ensino Superior. Innovaçao e Qualidade na Docencia. CIIE. (http://www.fpce.up.pt/ciie/cidu/index.html)

Estellés Frade, M. (2013). Indicios de Estandarización Curricular: la Pedagogía del Entorno en los Currículos Oficiales de Educación Primaria de Chile y España. (Spanish). Education Policy Analysis Archives, 21(82), 1-31.

Estévez Nenninger, E. e. (2014). Entramado del currículo y desarrollo de innovaciones en educación. (Spanish). Revista Mexicana de Investigación Educativa, 19(63), 1291 1295

Fandiño Parra, Yamith (2014). Bogotá bilingüe: tensión entre política, currículo y realidad escolar. (Spanish). Latin American Journal Of Content \&LanguageIntegratedLearning, 17(2), 215-236. doi:10.5294/edu.2014.17.2.1.

Ferguson, C. A., Houghton, C. \& Wells, M. H. (1977). Bilingual education: An international perspective. En Spolsky B. \& Cooper, R. (eds.). Frontiers of bilingual education (pp. 154-179). Rowley, MA: Newbury House

Fernández, Andrés (2010). Creatividad e Innovación en empresas y organizaciones: Técnicas para la resolución de problemas. Ed. Diaz de Santos S.A. Madrid-Buenos Aires.

Ferreira, Luana., Bezanilla, María \& Elexpuru, Iciar. (2018) Integrando la Competencia Intercultural en el curriculum mediante la Telecolaboración. Propuesta de una secuencia de tareas para la Educación Superior. Revista de Educación a Distancia. No 58. DOI: http://dx.doi.org/10.6018/red/58/7. 
Fidalgo, Ángel. (2007) ¿Qué es innovación educativa? Recuperado el 19-03-2018 de https://innovacioneducativa.wordpress.com/2007/01/09/que-es-innovacioneducativa/

Fidalgo, A. (2011). La innovación docente y los estudiantes, (January 2012), 84-91. Retrieved from http://innovacioneducativa.wordpress.com/2012/02/05/la-innovaciondocente-y-los-estudiantes/

Fidalgo, Á., Conde, M. Á., Sein-Echaluce, M., García-Peñalvo, F. J. (2014). “Diseño y desarrollo de un sistema basado en Learning Analytics para evaluar la competencia de trabajo en equipo". En Sistemas y Tecnologías de Información. Actas de la $9^{\mathrm{a}}$ Conferencia Ibérica de Sistemas y Tecnologías de Información (Barcelona, España, 18 al 21 de Junio de 2014). Á. Rocha, D. Fonseca, E. Redondo, L. P. Reis, M. Pérez Cota (Eds.). Vol. I Artículos. Páginas 1138-1143. AISTI (Asociación Ibérica de Sistemas y Tecnologías de Información).

Finquelievich, S. (2007). Innovación, tecnología y prácticas sociales en las ciudades: hacia los laboratorios vivientes. Revista Iberoamericana de Ciencia, Tecnología y Sociedad - CTS, 3 (9), 135-152.

Fitch, Rosa Isela Gluyas; Parga, Rodrigo Esparza; Sanchez, María del Carmen Romero and Barrios, Julio Ernesto Rubio.Modelo de Educación Holística: Una Propuesta para la Formación del Ser Humano. Rev. Actual. Investig. Educ [online]. 2015, vol.15, n.3, pp. 462-486. ISSN 1409-4703.

Flick, Uwe (2004) Introducción a la investigación cualitativa. Morata

Foucault, M. (1982): Vigilar y castigar. Madrid. Siglo XXI, 7.a ed.

Francés, A (2006). Estrategia y planes para la empresa: con el cuadro de mando integral. Ed. Pearson Educación.

Freeman, Edwar (2010) Bien Comun y Stakeholders: La propuesta de Edwar Freeman. EUNSA. Ediciones Universidad de Navarra, S.A.

Freud Sigmun. (1905). Tres ensayos de la teoría Sexual. CreateSpace Independent Publishing Platform 2017

Galeano, José (2009). Innovar el currículo universitario. Una propuesta de observatorio de objetos curriculares. Uni-pluiversidad. Vol 7. Universidad de Antioquia

Gallart, M. A., \& Jacinto, C. (1997). Competencias laborales: tema clave en la articulación educación trabajo. Cuestiones actuales de la formación. Montevideo: Cinterfor/OIT.

Gallego, Teresita (2010). Sobre la interdisciplinariedad en los programas de formación de maestros en la Facultad de Educación de la Universidad de Antioquia Estado actual y proyecciones. Uni-Pluri/Versidad. Vol.10 No.2, 2010. Versión Digital. Facultad de Educación- Universidad de Antioquia. Medellín Col. 
Gallino (1978), Dizionario di Sociologia. Turín: UTET

Galgano, Alberto (1995) Los siete instrumentos de la calidad total. Ediciones Díaz de Santos

García García, José Joaquín. "La solución de situaciones problemáticas: una estrategia didáctica para la enseñanza de la química." Enseñanza de las ciencias: revista de investigación y experiencias didácticas [online], 2000, Vol. 18, Núm. 1, p. 113129. https://www.raco.cat/index.php/Ensenanza/article/view/21645 [Consulta: 1206-17]

García García, José Joaquín (2009). Enseñar ciencias en un mundo en riesgo. Antecedentes y propuestas curriculares y didácticas. Uni-Pluri/Versidad. Vo19. №2. Versión Digital. Facultad de Educación- Universidad de Antioquia. Medellín, Col.

García, Jenny \& García, Cristina (2007) Percepciones y acciones de las y los estudiantes de la universidad autónoma del estado de México respecto a la educación en el desarrollo sostenible. Revista iberoamericana para la investigación y el desarrollo educativo. ISSN 2007- 7467

García, Lorenzo. Ruiz, Marta \& García, Miriam (2009). Claves para la educación: actores, agentes escenarios en la sociedad actual. Narcea, S.A. Ediciones. España

García, Miríam (2018) Educación para el Desarrollo Sostenible y Educación Intercultural como elementos claves para de la educación para la ciudadanía (planetaria). XXXVII Seminario Interuniversitario de Teoría de la educación. Educación en la Sociedad de Conocimiento y Desarrollo Sostenible. La laguna 11 al 14 de noviembre de 2018. Universidad de la laguna. Tenerife. España.

García, Romano (1970) Origen, significado y crítica de las humanidades. Encuentro: Revista Académica de la Universidad Centroamericana (14). pp. 31-44. ISSN 0424 $-9674$

García, Rosa., Junyent, Mercè \& Fonolleda, Marta (2017) Competencias Profesionales en Educación para la Sostenibilidad desde la Complejidad. X Congreso Internacional Sobre Investigación en Didáctica de las Ciencias. Sevilla 5 de septiembre de 2017.

Gee, James Paul (2010). New digital media and learning as an emerging area and "worked examples" asone way forward, Massachusetts: Th e mit Press.

Gil-Lafuente, Anna \& Luis Bassa, Carolina (2011). La Innovación centrada en el cliente utilizando el modelo de inferencias en una estrategia CRM. Investigaciones Europeas de dirección y economia de la empresa. Vol. 17. Pag. 15-32

Giraldo-Gil, E. (2014). Revisando las Prácticas Educativas: una Mirada Posmoderna a la Juventud, 12(1), 211-223. 
Giraldo Majía, Gloria Eugenia; González Agudelo, Elvia María. Acerca de la participación de los profesores en el currículo. Uni-pluriversidad, [S.1.], v. 9, n. 1, june 2009. ISSN 2665-2730. Disponible en: $<$ https://aprendeenlinea.udea.edu.co/revistas/index.php/unip/article/view/1841

Giroux, H. (1987) Escola crítica e política cultural. São Paulo: Cortez.

González Agudelo, E. (2012). Sobre la evaluación de la renovación curricular. Unipluriversidad, $\quad 11(3), \quad 83 \quad$ - $\quad 92 . \quad$ Recuperado de https://aprendeenlinea.udea.edu.co/revistas/index.php/unip/article/view/11839

González Castro, V.: Medios de enseñanza. Editorial Pueblo y Educación. La Habana, 1979

González Díaz, C. c., \& Sánchez Santos, L. (2014). La formulación de los objetivos instructivos en el contexto del currículo docente. (Spanish). Revista Cubana De Educación Medica Superior, 28(3), 467-481

González, E., \& Betancourt, M. (2013). Un nuevo sentido en la educación por proyectos a través del pensamiento del mestizaje en el programa de traducción de la universidad de Antioquia. Mutatis Mutandis: Revista Latinoamericana de Traducción, 6(1), 213-262.

González Fiegehen, Luis \& Espinoza, Oscar. (2008). Calidad de la educación superior: concepto y modelos 2008-08. Calidad en la Educación. 28. 10.31619/caledu.n28.210.

González, L., González, M., Echeverri, J., Herrera, J. (2014) Las redes sociales como factor potenciador de la co-creación: un experimento en la universidad de Medellín. Revista QUID, (23), 47-54.

González, M., \& González, L. (2015). La co-creación como estrategia para abordar la gobernanza de TI en una organización. RISTI - Revista Ibérica de Sistemas e Tecnologias de Informação, 2015(15), 1-16. http://doi.org/10.17013/risti.15.1-16

González, Vicente. (1989). Profesión comunicador. La Habana: Ed. Pablo de la Torriente Brau

Gonzci , A., \& Athanasou, J. (1996). Instrumentación de la educación basada en competencias: Perspectivas de la teoría y práctica en Australia. Competencia Laboral y Educación Basada en Normas de Competencia. México: Limusa.

Goodson, I. F.(2000): El cambio en el currículum, Octaedro

Goodson, I. F \& Dowbiggin I.R. (2003) La historia del currículum, la profesionalización y la organización social del conocimiento», en GOODSON, I. F.: Estudio del currículum. Casos y métodos. Buenos Aires, Amorrortu Editores.

Gotehlf Jeff \& Seiden Josh (2014) Lean ux como aplicar los principios de lean mejora experiencia usuario. Unir 
Gough, I. (2007). Capacidades de M. Nussbaum : Un análisis comparado con nuestra teoría de las necesidades humanas. Centro de Investigación para la Paz. Papeles de relaciones ecosociales y cambio Global .http://www.otrodesarrollo.com/desarrollohumano/GoughEnfoqueCapacidadesNusbaum.pd f

Grundy, Shirley (1987) Producto o praxis del curriculum. Morata.

Grundy, S. (1998), Producto o praxis del currículo, Madrid, Morata

Guber, Peter (2011) Storytelling para el éxito. Empresa activa

Guber. Rosana (2011) La etnografia. Metodo, campo y reflexividad

Guillermo, María. \& Alonso, Carlos. (1977). Medios de Enseñanza. Material para el autoaprendizaje. Ediciones de la Universidad Autónoma de Yucatán. Tomado de https://books.google.com.co/books?id=CSjZMgKZxJUC\&pg=PA9\&dq=Medios+de+ense\%C 3\%B1anza\&hl=es\&sa=X\&ved=0ahUKEwiA950Vw43eAhUP01kKHbFBB8AQ6AEIKDAA\#v=on epage \&q=Medios\%20de\%20ense\%C3\%B1anza\&f=false

Gutiérrez, P. M. (2007) "Mapas sociales: método y ejemplos prácticos", documento bajado del sitio www.preval.org, sin fecha

Halbach, A. (2008). Una metodología para la enseñanza bilingüe en la etapa de primaria. Revista de Educación, 346, 455-466. Recuperado el 28 de junio de 2013 de: http://www.revistaeducacion.mec.es/re346/re346 17.pdf

Havelock. K. y Huberman. A. (1980). Innovación y Problemas de la Educación. Ginebra: UNESCO/OIE

Heinich (1990). Heinich, Robert, Molenda, Michael y Russell, James D. Instructional media and the new technologies of instruction.Macmillan, 3rd ed. New York, 1990.

Hernández R, Fernández C \& Baptista L., (2014), Metodología de la investigación. Sexta edición. Mexico: Mc. Graw-Hill/ Interamericana de editores S.A. de C.V.

Hernández, R., Fernández C. y Baptista, P. (2015). Metodología de la Investigación. $6^{\circ}$ edición. México: Editorial McGraw Hill

Hoover Dempsey, K. V y Sandler, H. M. (1995): Parental Involvement in Children's Education: why does it make a difference? Teachers College Record, 97, (2) 310331.

ICFES- Instituto Colombiano para la Evaluación de la Educación (2017). Guía de Orientación de PISA 2018: Competencia Global en Colombia. Documento retomado de la traducción del marco de referencia original de la OCDE para la competencia global: PISA Governing Board (2016, Octubre). Draft framework of 
the PISA 2018 Global Competence Assessment. EDU/PISA/GB(2016)17. [42a.

Reunión del Consejo de Gobierno de PISA] Brasil: Autor

Illán Romeu, Nuria, \& Molina Saorín, Jesús. (2011). Integración Curricular: Respuesta al reto de educar en y desde la diversidad.Educar em Revista, (41), 17-

40. https://dx.doi.org/10.1590/S0104-40602011000300003

Imbernon, F. (2017) A vueltas (de caracol hace tiempo) con la formación del profesorado. La revolución silenciosa siempre pendiente. Aula de Innovación educativa. ISSN 1131-995X, № 267, 2017, págs. 49-51

Innovación y Cualificación (2003). Planificación y Diseño de Programas Formativos. Ed Innovación y Cualificación

INTEF-Freeman, A., Adams Becker, S., Cummins, M., Davis, A., y Hall Giesinger, C. (2017). NMC/CoSN Horizon Report: 2017 K-12 Edition. Austin, Texas: The New Media Consortium

Instituto Nacional de Tecnologías Educativas y de Formación del Profesorado (INTEF) (2007) Departamento de Proyectos Europeos. Resumen Informe Horizon 2017 Educación Superior. INTEF Tomado de http://educalab.es/documents/10180/38496/Resumen Informe Horizon 2017/44457ade -3316-418e-9ff9-fd5e86fc6707

ISI Argonauta. García, Paloma, Borja, Carmen \& Fundación Vicente Ferrer (2017) Guía de los ODS para organizaciones del tercer sector. Tomado el 28 de septiembre de 2018 de http://fundacionvicenteferrerodsmadrid.org/wpcontent/uploads/2017/10/GuiaODSorganizaciones3Sector -F.VicenteFerrer.pdf

Ismail, Salim (2016). Organizaciones Exponenciales. Bubok Editorial

Jackson, P. W. (1981) El currículo y sus descontentos, traducción por Cecilia Palacios Suárez de la ENEP- Zaragoza, UNAM, para el Seminario de Evaluación Curricular: Concepciones, Perspectivas y Propuestas, México, CESU-UNAM, mayo de 1987

Jäger, Werner (2001). Paideia: Los ideales de la cultura griega. Fondo de Cultura Económica. México. Decimoquita reimpresión. Traducción Joaquin Xiral.

Julia, D. (1996) La culture scolaire comme objet historique, en Colonial Experience in Education. Historical Issues and Perspectives, Gent, Paedagogica Historica. Supplementary Series, vol. I, pp. 353- 382 (cita en p. 354), y «Riflessioni sulla recente storiografia dell'educazione in Europa: per una storia comparata delle culture scolastiche», Annali di Storia dell'Educazione e delle Istituzioni Scolastiche, 3 , pp. 119-147 (cita en p. 129).

Julia, D. (2000): «La construcción de las disciplinas escolares en Europa», en Viñao Antonio (2006): La historia de las disciplinas escolares. The history of the school subjects, Ediciones Universidad de Salamanca. Revista Historia de la educación. 
Kalil-Alves, T., \& de Oliveira, W. (2011). O ensino de história da América Latina no Brasil: sobre currículos e programas. Magis: Revista Internacional De Investigación En Educación, 3(6), 283-298.

Kaliym A. Islam \& M. Ed (2013) Agile Methodology for Developing \& Measuring Learning

Know about People: 100 cosas sobre la gente que todo diseñador necesita saber. Anaya

Koa, Lee (2013). Powerful 5w2h/Ipo Method for Business Pocesses: How to Hold Entire Processes of an Organization Within One Database Table?. Createspace Independent Pub.

Kochansky, J. (1998). El sistema de competencies. Training and Development digest. Madrid.

Kohlberg, Lawrence. 1981. The Philosophy of Moral Development. Moral Stages and the Idea of Justice. San Francisco, CA: Harper \& Row Pubs.

Kotter, John (2015) Acelerar. Penguin Random House Grupo Editorial Colombia

Kreisel, M. (2016). El enfoque intercultural en el currículo de telesecundaria -elementos para una reflexión crítica. Sinéctica, (46), 1-18

Krishnan, Armin (2009). What are academic disciplines? Some observations on the disciplinarity vs. interdisciplinarity debate, ncrm Working Paper Series 03/09, Reino Unido: esrc National Centre for Research Methods

La, C. O. N., En, C. D. E. V., Silva, F. B., Autónoma, U., Juárez, D. C., Francisco, I., Juárez, D. C. (2012). Francisco Bribiescas Silva, Ignacio Francisco Romero Magaña, Francisco Manuel Solórzano Chavira, , 65-93.

Lave, J. \& Wenger, E. (2002). Legitimate peripheral participation in communities of practice. En Lea, M.R. \& Nicoll, K. (Eds), Distributed Learnig. Social and cultural approaches to practice (pp.56-63). London; Routledge Falmer

Le Boterf, G. (1998). La ingeniería de las competencias. París: D'organisation.

Leffingwell, Dean (2018) SAFe 4. 5 Reference Guide: Scaled Agile Framework for Lean Software and Systems Engineering. Addison Wesley Professional

Ley No 5. Congreso de la República de Colombia, Santa Fe de Bogotá, Colombia. 19 de junio de 2002.

Ley No 115. Congreso de la República de Colombia, Santa Fe de Bogotá, Colombia. 8 de Febrero de 1994. Recuperado de http://www.mineducacion.gov.co/1621/articles85906 archivo pdf.pdf

Lockheed; Marlaine; Hanushek, Eric. 1998. Improving Educational Efficiency in Developing Countries: What Do We Know? en Compare, Vol. 18, No. 1. 
Londoño, O., Henao, R, \& Posada, J. (2010) Propuesta de modelo de gestión por competencias para mejorar la productividad de las empresas en Antioquia. Tomado del Repositorios Universidad de Medellín https://repository.udem.edu.co/handle/11407/32

López, Amando \& Martínez, Aurora (2012). Aprendizaje y enseñanza de la lengua castellana y literatura: currículo de la educación secundaria obligatoria. Contextos educativos. Vol. 15. 27-40.

Luengo, Florencio (2006). El proyecto Atlántida: experiencias para fortalecer el eje de la escuela, familia y municipio. Revista de educación vol. 339.pp 177-199.

Luna-García, Huizilopoztli, Álvarez-Rodríguez, Francisco Javier, \& Mendoza-González, Ricardo. (2015). Modelo de gestión para diseño curricular basado en prácticas de ingeniería de software. Revista electrónica de investigación educativa, 17(3), 61-78. 2016, de http://www.scielo.org. mx/scielo.php?script=sci arttext\&pid=S1607$\underline{40412015000300005 \& \operatorname{lng}=\mathrm{es} \& \operatorname{tlng}=\mathrm{es}}$

Llach, Juan J.(2004) Escuelas ricas para los pobres Propuestas para una educación de calidad en la Argentina. Revista Criterio, Buenos Aires, año 77, n. 2.297

Malthus, T. R. Ensayo sobre el principio de la población. (Original de 1798). (www.eumed. Net. Enciclopedia Multimedia Virtual de Economía.EMVI. ISBN.84-607-2111-6).

Marcelo, Carlos (2001). Aprender a enseñar para la sociedad del conocimiento. Revista complutense de educación. Volumen 12. 531-593.

Martínez, E., \& Manuel, P. (2015). Empleo de Twitter en la docencia universitaria : hacia un modelo de aprendizaje basado en la co-creación .

Martínez, María., Lloret, maría \& Mas, Sara (2018) ¿Universidad socialmente responsable? : Visiones del alumnado ante el desarrollo sostenible. Villa, Aurelio. Foro Internacional de innovación universitaria. España. ISBN. 978-84-15045- 19-9.

Martínez, Miquel (2018). La "Ciudad Educadora" como Propuesta Pedagógica para Avanzar en el Logro de los ODS. XXXVII Seminario Interuniversitario de Teoría de la educación. Educación en la Sociedad de Conocimiento y Desarrollo Sostenible. La laguna 11 al 14 de noviembre de 2018. Universidad de la laguna. Tenerife. España.

Martínez, R., Charterina, O \& Araujo, A. (2010). Un modelo causal de competitividad empresarial planteado desde la vbr : capacidades directivas, de innovación, marketing y calidad, 16, 165-188. http://doi.org/10.1016/S1135-2523(12)60117-8

Marzano, R. (2003). What works in schools. Translating research into action. Virginia, USA: Association for Supervision and Curriculum Development 
Marzano, R., Waters, T., \& McNulty, B. (2005). School leadership that works: From research to results. Alexandria, Virginia, USA: Association for Supervision and Curriculum Development (ASCD).

Medellín cómo vamos. (2018). Informe calidad de vida Medellín 2012-2017, Recuperado de http://www.medellincomovamos.org/download/informe-de-indicadores-objetivos-sobrela-calidad-de-vida-en-medellin-20122017/?utm source=Documentos\%20Home\&utm campaign=Encuesta\%202016\&utm mediu $\underline{m}=$ Botones\%20Sidebar\&utm term=Informe

MEC (1987). Proyecto para la reforma de la enseñanza. Propuesta para debate. Madrid: MEC.

MEN- Ministerio de Educación Nacional. Derechos Básicos de Aprendizaje. Tomado de https://aprende.colombiaaprende.edu.co/sites/default/files/naspublic/DBA_sociales. pdf

MEN. (2006). Estandares Básicos de Competencia. Bogotá: Imprenta Nacional de Colombia.

MEN. (2015). Derechos Básicos de Aprendizaje. Bogotá: Imprenta Nacional de Colombia.

Méndez Alonso, D., Fernández-Río, J., Méndez Giménez, A., \& Prieto Saborit, J. A. (2015). Análisis de los currículos autonómicos LOMCE de Educación Física en Educación Primaria. Retos: Nuevas Perspectivas de Educación Física, Deporte y Recreación, (28), 15-20.

Mertens, L. (1996). Competencia Laboral: sistemas, surgimiento y modelos. Montevideo: Cinterfor/OIT.

Michalko, Michael (2006). Thinkpak: A Brainstorming Card Deck

Michel Foucault. (1999). Arqueología de las ciencias humanas. México : Editorial Siglo XXI.

Miles, M (1964). Innovación educativa: recursos, estrategias y preguntas sin respuesta American Behavioral Scientist , 7 ( 6 ) ( 1964 ), pp. 10 - 14 https://doi.org/10.1177/000276426400700604

Ministerio de Educación de España. (2011). Evaluaciòn general de diagnóstico 2010: Educación básica obligatoria.Segundo curso.Informe de resutados . Madrid: Catálogo general de publicaciones oficiales .

Miranda, M. (2003). Transformación de La Educación Media Técnico-Profesional" en Politicas Educacionales en el Cambio de Siglo. La Reforma del Sistema Escolar de Chile. Santiago: Cristian Cox.

Miriam, R., \& Aguilar, M. (2010). De los Objetivos de Desarrollo del Milenio en la localidad de Suba ( Bogotá, Colombia ). Revista Universidad Nacional de Colombia BDigital Portal de revistan UN 119-146. 
Moore, Geoffrey A. (2015) Cruzando el abismo. Cómo vender productor disruptivos a consumidores generalistas

Mora-García, J. p. (2013). Las reformas en la historia del currículo en Venezuela (El proceso de implantación de la Educación Básica 1980-1998). (Spanish).Revista Historia De La Educación Latinoamericana, 15(21), 51-88. doi:10.9757/Rhela. 21.02

Moreno, Juan (1999). Con trampa y con cartón. El fraude en la educación, o cómo la corrupción también se aprende. Cuadernos de pedagogía, ISSN 02100630, págs. 71-77.

Müller, Anna Katherine. (1985) Guía para la concepción y elaboración de un manual de diseño curricular para un sistema de educación a Distancia. Unesco - Icfes, tomado de http://www.unesco.org/education/pdf/53 21.pdf

Muñoz de Priego Alvear, J. (1998). Implantación de un sistema de selección por competencias: Training and Development. Madrid: $\mathrm{N}^{\circ} 10$.

Nanclares, R. (2014). Cocreación: una propuesta para la recolección, sistematización y análisis de la información en la investigación cualitativa.Enl@ce Revista Venezolana de Información, Tecnología y Conocimiento. 11 (1), 11-24

Neef, Manfred M. (1994) Desarrollo a Escala Humana: conceptos, aplicaciones y algunas reflexiones. Editorial Nordan-Comunidad

Niño Zafra, L. S., \& Bermúdez, A. G. (2013). Los estándares en el currículo y la evaluación: ¿relaciones de medición, control y homogenización o, posibilidad de formación, diversidad y evaluación crítica?. Revista Electrónica Interuniversitaria de Formación del Profesorado, 16(3), 185-198. doi:10.6018/reifop.16.3.18678

Noguera, Álvarez \& Castro (2000) La ciudad como espacio educativo. Bogotá y Medellín en la primera mitad del siglo XX. Arango Editores, Bogotá.

NU- Naciones Unidas Asamble General (2015) Transformar nuestro mundo: la agenda 2030 para el Desarrollo Sostenible. Tomado el 4 de octubre de 2018 de https://unctad.org/meetings/es/SessionalDocuments/ares70d1 es.pdf

Nussbaum, Martha (2005). El cultivo de la humanidad. Una defensa clásica de la reforma a la educación liberal. (J. Pailaya, Trad). Barcelona: Paidós

Nusbaum, M. (2012). Crear capacidades: Propuesta para el desarrollo Humano. Paidos Ibérica 
Observatorio Internacional de la democracia participativa (2003). IX edición de la distinción IODP "Buenas Prácticas en Participación Ciudadana impulsada desde los gobiernos locales". Recuperado de https://goo.gl/CqMjfF

OCDE (2005) Oslo Manual, Guidelines for Collecting and Interpreting Innovation Data, $3 d . d$

OCDE (2005) Manual de Oslo de la OCDE. Pautas para recopilar e interpretar la innovación ( $3^{\mathrm{a}}$ ed. ) , OECD Publishing. https://doi.org/10.1787/9789264013100

OCDE (2005b) La definición y selección de competencias clave. Editorial OCDE

OCDE- Board Goveming (2016) Draft Framework of the PISA 2018. Global Competence Assessment. 42nd meeting of the PISA Governing Board. Brasilia, Brazil, p. 6.

OCDE. (2016). OECD BetterPoliciesforBetterLives. Obtenido de Programmefor International StudentAssesment (PISA):https://www.oecd.org/pisa/pisa-2015-resultsin-focus-ESP.pdf

OCDE (2017), Marco de Evaluación y de Análisis de PISA para el Desarrollo : Lectura, matemáticas y ciencias, Versión preliminar, OECD Publishing, Paris. Tomado de https://www.oecd.org/pisa/aboutpisa/ebook\%20-\%20PISAD\%20Framework_PRELIMINARY\%20version_SPANISH.pdf

Ohno, Taiichi (1991). El sistema de producción Toyota. Más allá de la producción a gran escala. eBook Publisched

OIT - Organización Internacional del Trabajo. (Cinterfor/OIT) (2002) Competencia Laboral. Manual de conceptos y aplicaciones de zen el sector salud. pp. 247-252 ISBN 92-9088-138-0. Recuperado el 12 de junio de 2017 de https://www.oitcinterfor.org/sites/default/files/file publicacion/man ops.pdf

OIT-Organización Internacional del Trabajo (2003) Directrices sobre las buenas prácticas: identificación, análisis, estructuración, difusión y aplicación. Programa internacional para la erradicación del trabajo infantil. Recuperado de https://goo.glQ1Rmf8.

OIT. (2004). Las 40 preguntas sobre competencias. Montevideo: Departamento de Publicaciones de Cinterfor/OIT.

Oliva, J. J. (2014). El perfil profesional de líder escolar: Una guía para la elaboración de programas y currículos educativos. Revista De La Universidad Del Valle De Guatemala, (29), 62-70.

Olivera A., Hernández Días, A., \& Haramboure, R. (2012). Logros y desafíos para un currículo inclusivo. Pedagogía Universitaria,17(3), 61-74

Olveira, María \& Rodríguez, Antonio (2018) La educación para el Desarrollo Sostenible en la formación de los profesionales de la educación. . XXXVII Seminario Interuniversitario de Teoría de la educación. Educación en la Sociedad de 
Conocimiento y Desarrollo Sostenible. La laguna 11 al 14 de noviembre de 2018. Universidad de la laguna. Tenerife. España.

ONU (Organización de Naciones Unidas Objetivos de Desarrollo) (2015). Tomado de http://www.un.org/sustainabledevelopment/es/

OREALC/UNESCO (2007). Educación de Calidad para Todos: Un asunto de Derechos Humanos. Documento de discusión sobre políticas educativas en el marco de la II Reunión Intergubernamental del Proyecto Regional de Educación para América Latina y el Caribe (EPT/PRELAC), 29 y 30 de marzo de 2007; Buenos Aires, Argentina. Santiago de Chile.

Organización de las Naciones Unidas para la Educación, la Ciencia y la Cultura (2005): Informe Mundial de la UNESCO 2005: Hacia las sociedades del conocimiento

Osborn, Alex (1953). Imaginación aplicada: principios y procedimientos de la solución creativa de problemas Nueva York: Hijos de Charles Scribner. OCLC. 641122686

Osorio Álvarez, M. M. (2008). La investigación formativa o la posibilidad de generar cultura investigativa en la educación superior: el caso de la práctica pedagógica de la licenciatura en educación básica con énfasis en humanidades, lengua castellana de la Universidad de Antioquia (Tesis de Maestría). Universidad de Antioquia, Medellín

Osterwalder. Alexander, Pigneur. Yves (2011) Generación de modelos de negocio

Pacheco, J. j. (2013). Estudos curriculares Génese e consolidação em Portugal.

(Portuguese). Educação, Sociedade \& Culturas, (38), 151-214

Pais. Joaquín, Font, Luis (2016) La revolución de las ventas: Cómo cambiar la forma de vender en tu empresa con Agile Sales e Inbound Marketing

País Vasco- Departamento de educación (2010). Competencias Básicas en el Sistema Educativo de la Comunidad Autónoma País Vasco. Tomado de http://www.euskadi.eus/contenidos/informacion/dig publicaciones innovacion/es curric ul/adjuntos/14 curriculum competencias 300/300002c Pub BN Competencias Basicas c.pdf

Palazzo, J., Alberto Gomes, C., \& Rêgo Pimentel, G. S. (2016). La práctica en la formación de educadores en Brasil: currículos fracturados. Revista Electrónica Interuniversitaria de Formación del Profesorado, 19(2), 45-59. doi:10.6018/reifop.19.2.253911

Pascual, Roberto (1998). La gestión educativa ante la innovación y el cambio. Madrid

Pedrajas, M. (2006). "El desarrollo humano en la economía ética de Amartya Sen” [en línea], disponible en: http:// http://www.tesisenxarxa. net/TDX-0302107131313/index_cs.htmlg, recuperado: 3 de febrero de 2018. 
Peña Rincón, P. A. (2014). Etnomatemáticas y currículo: Una relación necesaria. Revista Latinoamericana de Etnomatemática, 7(2), 170-180.

Piaget, J. (1936). Origins of intelligence in the child. London: Routledge \& Kegan Paul

Pinchot, Gifford (1985). Intrapreneuring. Harper \& Row

Pino-Fan, L. R., Castro, W. F., Godino, J. D., \& Font, V. (2013). Idoneidad epistémica del significado de la derivada en el currículo de bachillerato. Paradigma, 34(2), 123150.

Pizarro Barrera, Sandra; Valenzuela Urra, Cristiã jn. (2013) Establecimiento de un modelo educativo institucional para la orientaci $\tilde{A}^{3} n$ del proceso de innovaci $\tilde{A}^{3} n$ curricular de las carreras de la Universidad de Playa Ancha. Disponible en $<$ http://www.scielo.org.ar/scielo.php?script=sci arttext\&pid=S185399122013000100004\&lng=es\&nrm=iso $>$.

Peña, B., Flaborea, R. y Guzmán, M. (2011). Propuesta para el fortalecimiento del área de inglés en un colegio no bilingüe de Bogotá. Apuntes desde la experiencia de un estudio de caso. En López, A., Peña, B. y De Mejía, A. (eds.). Bilingüismo en el contexto colombiano: iniciativas y perspectivas en el siglo XXI (pp. 115-165). Bogotá: Ediciones Uniandes.

Pérez Arias, J., \& Ramírez Izasa, E., \& Aedo, J. (2014). Las redes de conocimiento como escenarios para la gestión de conocimiento. Estudio de caso REDCO.Enl@ce: Revista Venezolana de Información, Tecnología y Conocimiento, 11 (1), 51-63.

Pérez Ortega, I. (2016). La competencia mediática en el currículo escolar: ¿espacio para innovaciones educativas con tecnologías de la información y la comunicación? (Spanish). Journal Educational Innovation / Revista Innovación Educativa, 61-83

Perrenoud, Philippe (1998). "From formative evaluation to controlled regulation of learning processes. Towards a wider conceptual fi eld", Assessment in Education, vol. 5, núm. 1.

Piñeiro-Otero, T., \& Costa-Sánches, C. (2015). ARG (juegos de realidad alternativa). Contribuciones, limitaciones y potencialidades para la docencia universitaria. Comunicar, XXII (44), 141-148

PNUD- Programa de Naciones Unidas para el Desarrollo: Los objetivos de Desarrollo Sostenible. Tomado de https://www.undp.org/content/undp/es/home/sustainabledevelopment-goals.html

Poblete, X., Sepúlveda, P., Orellana, V., \& Abarca, G. (2013). Situación Educativa de América Latina y El Caribe. Unesco, 209.

Retrievedfromhttp://works.bepress.com/cgi/viewcontent.cgi?article=1009\&context=cesar guadalupe 
Popkewitz, T. S. (1994). Política, conocimiento y poder. Algunas cuestiones para el estudio de las Reformas Educativas», Revista de Educación, Ed. 305, pp. 103-137.

Popkewitz, Thomas (1994). Sociología Política de las Reformas Educativas: El poder/saber en la enseñanza, la formación del profesorado y la investigación.Madrid: Ediciones Morata.

Popkewitz, Thomás (2000). Sociología política de las reformas educativas. 3 ed. Madrid,Morata, p. 44-54.

Portela Guarín, H. (2012). El currículo y la formación: en los laberintos de un mundo apalabrado. Revista Latinoamericana De Estudios Educativos (1900-9895), 8(1), 54-74.

Porter, A. (2004). Curriculum assessment. En J. Green, G. Camilli, \& P. Elmore (Eds.), Complementary Methods for Research in Education (pp. 141-159). Washington, DC: American Educational Research Association

Porter, A. C. \& Smithson, J. L. (2001). Defining, developing, and using curriculum indicators. Philadelphia: University of Pennsylvania, Consortium for Policy Research in Education.

Porter, Michael (2017) Ser competitivo: Edición actualizada y aumentada. Deusto.

Porto, A. (1995) Tareas para capacitarse en el trabajo con los medios. Tesis de Doctorado, ISPETP

Programa de Naciones Unidas para el Desarrollo (1990). Desarrollo Humano Informe 1990. Tercer Mundo Editores, S.A

Programa de Naciones Unidas para el Desarrollo (2010). Informe sobre Desarrollo Humano 2010: La verdadera riqueza de las naciones: Caminos al desarrollo Humano. Publicado por el Programa de las Naciones Unidas para el Desarrollo (PNUD).

Qualifications and Curriculum Authority. (s.f.). (QCA). Inglaterra: www.qca.org.uk.

Quero, M., \& Ventura, R. (2014). Análisis de las Relaciones de Co-creación de valor. Un estudio de casos de crowdfunding. Universia Business Review, (43), 128-143.

Quintanilla, M. (1993-1994). Seis conferencias sobre filosofía de la tecnología, Plural. revista de la Administración de Colegios Regionales, 11-12 (1-2).

Rangel Torrijo, H. h. (2015). Una mirada internacional de la construcción curricular. Por un currículo vivo, democrático y deliberativo. (Spanish). Revista Electrónica De Investigación Educativa, 17(1), 1-16.

Rawls, John. (1990): Teoría de la justicia. México, Fondo de Cultura Económica. 
Reichheld. Fred, Markey. Rob (2012) La pregunta decisiva 2.0

Reimes, Fernando. ¿Cultiva la escuela la desigualdad? Boletín de la Unesco, 2000. Disponible en: . Consultado en: 14 ago. 2000.

Res. N 555/96, Consejo Federal de Cultura y Educación, Argentina, Boletín Cinterfor/OIT. (s.f.).

Restrepo Jaramillo, Á. (2013). Formación por competencias y acreditación de calidad: su convergencia en el curriculum. Itinerario Educativo, 27(61), 207-224

Ribes, G; Peralt, A. (2014). Métodos y técnicas facilitadoras de la co-creation innovation en programas máster para el mercado del postgrado. Intangible capital, vol. 10, núm. 1, p. 101-124.

Ricardo, C. c., Borjas, M. m., Velásquez, I. i., Colmenares, J. j., \& Serje, A. a. (2013). Caracterización de la integración de las TIC en los currículos escolares de instituciones educativas en Barranquilla. (Spanish). Zona Próxima, (18), 32-45.

Ries, E (2012) El método Lean Startup: Cómo crear empresas de éxito utilizando la innovación continua. Grupo planeta

RIPLEY B.D., 1978. Spectral analysis and the analysis of pattern in plant communities. J Ecol 66, 965-981.

Risco de Domínguez, G. (2014). Diseño e implementación de un currículo por competencias para la formación de médicos. (Spanish). Revista Peruana De Medicina Experimental y Salud Pública, 31(3), 572-581

Rivas, Manuel (2000). La innovación educativa. Edit. Síntesis, Madrid.

Riveros. Paula (2014) Coolhunting y tendencias. A la caza grandes ideas para la innovación.

Robalino, M. y Eroles, D. (2010). Nuevos tiempos, nuevos desafíos: calidad de la Educación con enfoque de derecho e innovaciones educativas. Oficina de UNESCO, Quito y Red Innovemos (OREALC/UNESCO). Presentación para el Encuentro "Educación e Innovación 2010", organizado por el Ministerio de Educación de Ecuador y VVOB, 2 y 3 de diciembre 2010, Cuenca, Ecuador

Roberth Uribe Álvarez (2010), sobre el plan de estudios: ¿Reforma o mampostería curricular?, Revista Dialogos de Derecho y política. Número 4.

Rodríguez, N. G., Álvarez, B. Álvarez, \& Vijande, M. L. S. (2010). Aplicación de la Lógica Dominante del servicio (LDS) en el sector turístico: El marketing interno como 
antecedente de la cultura de co-creación de innovaciones con clientes y empleados. Cuadernos de Gestion, 11(2), 53-75. http://doi.org/10.5295/cdg.100238ng

Rodríguez-izquierdo, R. M. (2014). aula abierta. Aula Abierta, 42(2), 106-113. http://doi.org/10.1016/j.aula.2014.03.002.

Romer. Paul (1990) Endogenous Technological Change, en Jorunal of Political Economy.

Romiszowski (1988). Romiszowski, Alexander. The Selection and Use of Instructional Media. Kogan Page. London, 1988

Rosales, J. (2010) Los discursos sobre el cuerpo en el currículo oficial: una aproximación al Diseño Curricular Nacional. Revista de Educación: Departamento de educación PUCP. Perú.

Rostow, Walt. W. (1960): The Stages of Economic Growth, a Non-Communist Manifesto. Londres. Cambridge, University Press

Ruiz-Moreno, A., Ortega-Egea, T., Haro-Domínguez, C., \& Roldán-Bravo, M. (2014). El proceso de co-creación de valor y su impacto en la estrategia de innovación en empresas de servicios, 10(2), 266-293. http://doi.org/10.3926/ic.504

Ruiz Ruiz, José María. (1996). Teoría del currículo: diseño y desarrollo curricular. Editorial Universitas, Madrid.

Russell T. 1987a Learning the professional knowledge of teaching: Views of the relationship between theory and practice, article présenté au congres annuel de l'association américaine de recherche en éducation (Aprendizaje del conocimiento profesional para la enseñanza: Perspectivas sobre la relación entre la teoría y la práctica, artículo presentado en el Congreso Anual de la Asociación Americana de Investigación sobre la Educación) (AERA), Washington, Avril 1987.

Sánchez Fajardo, H., \& Gonzáles Agudelo, E. M. (2009). La integración curricular en el proceso de transformación del programa de odontología de la Universidad de Antioquia : un problema en la gestión curricular. Uni-pluri/versidad, 9(1), 73-80.

Sánchez, Y., García, F., \& Mendoza, E. (2015). en las regiones de México. Estudios Gerenciales, 31(136), 243-252. http://doi.org/10.1016/i.estger.2015.04.001

Santomé, J. T. (2012). Un currículo más justo para otra globalización. Cuadernos de Pedagogía, (424), 88-91

Saracho, J. M. (2005). Un modelo general de gestión por competencias: Modelos y metodologías para la identificación y construcción de competencias. Santiago: Ril

Saviani, D (1983). Escola e democracia. São Paulo: Cortez/Autores Asociados. 
SCANS. (1991). Secretary's Commission on Achieving Necessary Skills.

Scharmer, C. Otto (2016) Theory U: Leading from the Future as It Emerges. BerrettKoehler Publishers

Secretaria de Educación Medellín (2014). Plan de estudios de la educación formal: orientaciones básicas. Medellín. Impresos Begon S.A.S. Sitio Web: http://www.medellin.edu.co/index.php/m-institucional/mi-calidad/ desarrollocontenidos

Sen A. (2002). Nueva Economía de Bienestar.Valencia. Servicio de publicaciones de la Universidad de Valencia

SENA. (2002). Dirección de Formación Profesional, Manual para diseñar estructuras curriculares y módulos de formación para el desarrollo de competencias en la formación profesional integral. Bogota.

SENAI. (2002). Metodologia de Elaboração de Perfis Profissionais. Brasilia.

Sibbet, David (2013) Liderazgo Visual / Visual leadership: Nuevas Herramientas Visuales Para Dinamizar Y Reinventar Tu Empresa

Sierra Z., Siniguí S., Henao A. (2010) Acortando la distancia entre la escuela y la comunidad - Experiencia de construcción de un currículo intercultural en la Institución Educativa Karmata Rúa del Resguardo Indígena de Cristianía, Colombia. Visão Global (Universidad do Oeste de Santa Catarina, Brasil) 13(1): 219-252

Siguan, M. (1986). Educación y Bilingüismo. Madrid: Santillana

Silva Montes, C. c. (2015). La Reforma Curricular en Competencias: La Experiencia en las Preparatorias Federales por Cooperación. (Spanish). Education Policy Analysis Archives, 23(67/68), 1-26. doi:10.14507/epaa.v23.1727

Skinner, B. F. (1970). Ciencia y conducta humana. Barcelona: Fontanella. (Trabajo original publicado en 1953).

Smithh. A 1988 Abduction and the signs of expertise, article présenté au congres annuel de l'association américaine de recherche en éducation (Síntesis y los signos de la experiencia, artículo presentado en el Congreso Anual de la Asociación Americana de Investigación sobre la Educación) (AERA), La Nouvelle-Orléans, Abril 1988.

Smith, Adam. (1999): Investigación sobre la naturaleza y causas de la riqueza de las naciones. (Original de 1776). Barcelona, Ediciones Planeta.

Sola Martínez, T. (2016). Un currículo para múltiples adaptaciones. (Spanish). Enseñanza \& Teaching, 34(1), 202-203 
Sousa, A. C., \& Uceda-Maza, F. X. (2017). Más Allá De Los Desafíos Del Decenio De La Educación Para El Desarrollo Sostenible: Una Reflexión Necesaria. HOLOS, (5), 136-150. https://doi.org/10.15628/holos.2017.6107

Souza, Patrícia Alves de, Zeferino, Angelica Maria Bicudo, \& Da Ros, Marco Aurélio. (2011). Currículo integrado: entre o discurso e a prática. Revista Brasileira de Educação Médica, 35(1), 20-25. https://dx.doi.org/10.1590/S0100$\underline{55022011000100004}$

Steinar, Kvale (2011) Las Entrevistas En Investigación Cualitativa. Ed Morata.

Stickdorn. Marc , Schneider. Jakob (2010) This is Service Design Thinking: Basics, Tools, Cases

Suárez, J. A. G., \& Fernández, J. I. P. (2015). Creacity, una propuesta de índice para medir la creatividad turística. Aplicación en tres destinos urbanoculturales españoles. Revista de Estudios Regionales, 7585(103), 69-108

Taba, H (1974). Elaboración del currículum: teoría y práctica. Argentina: Troquel.

Taborda, M. a., \& Posada, R. r. (2014). Las reformas como dispositivos de cambios curriculares. (Spanish). Uni-Pluri/Versidad, 14(3), 70-80

Thomas, K. \& Kilmann, R. (1974) Thomas - Kilmann Conflict Mode Instrument. Ed. Xicom

Tobón, S., 2008 "La formación basada en competencias en la educación Superior: el enfoqu ecomplejo". Curso IGLU, 2008, Guadalajara, México

Tochon, F. V. 1991 L'enseignement stratégique (La enseñanza estratégica), Toulouse, France: Editeurs Universitaires du Sud.

Tondeur, J., Van Braak, J., y Valcke, M. (2007). Curricula and the use of ITC: Two worlds apart? British Journal of Educational Technology, 38(6), 962-976. Recuperado de: http://onlinelibrary.wiley.com/doi/10.1111/j.1467-8535.2006.00680.x/abstract

Toribio, L. (2010). Las competencias básicas: el nuevo paradigma curricular en Europa. Foro de Educación, 12, 25-44.

Torre, S. De La (1992). Innovaciones en Didáctica. Mirando al año 2000 . Innovación Educativa, núm. 1, p. 7-16

Tovar, M. C., \& Sarmiento, P. (2011). El diseño curricular, una responsabilidad compartida. (Spanish). Colombia Medica, 42(4), 508-517

Tyler, R (1973). Principios básicos del currículum. Argentina: Troquel 
UNESCO- Organización de Naciones Unidas para la Educación la Ciencia y la Cultura: La Unesco y los Objetivos de Desarrrollo Sostenible. Tomado de https://es.unesco.org/sdgs

Unesco (2003). Best practices. Recuperado de https://unesco.org/most/bphome/htm\#1

UNESCO (2005) Organización de las Naciones Unidas para la Educación, la Ciencia y la Cultura. Informe Mundial de la UNESCO 2005: Hacia las sociedades del conocimiento.

UNESCO (2011a) La UNESCO y la educación "Toda persona tiene derecho a la educación" tomado la Unesco en de http://unesdoc.unesco.org/images/0021/002127/212715s.pdf

UNESCO (2011b) CINE Clasificación Internacional Normalizada de la Educación 2011. Instituto de estadística de la UNESCO. Tomado de http://unesdoc.unesco.org/images/0022/002207/220782s.pdf

UNESCO. (2013). Intercultural Competences: Conceptual and Operational Framework. UNESCO.

UNESCO. (2014a). Documento de posición sobre la educación después de 2015, tomado de la biblioteca digital de la UNESCODOC de https://unesdoc.unesco.org/ark:/48223/pf0000227336_spa.

UNESCO. (2014b). Global Citizenship Education: Preparing learners for the challenges of the 21 st century. UNESCO.

UNESCO (2014c), Learning to Live Together: Education Policies and Realities in the AsiaPacific, UNESCO, París.

UNESCO (2015). Declaración de Incheon y Marco de Acción para la realización del Objetivo de Desarrollo Sostenible 4. Tomado de http://unesdoc.unesco.org/images/0024/002456/245656s.pdf

UNESCO (2016a). Innovación Educativa: serie herramientas de apoyo para el trabajo docente. Texto 1. Representación de la UNESCO en Perú. Tomado de http://unesdoc.unesco.org/images/0024/002470/247005s.pdf

UNESCO. (2016b). Global Education Monitoring Report. UNESCO.

UNESCO. (2016c) Innovación educativa, texto 1. Serie herramientas de apoyo para el trabajo docente. Tomado de https://unesdoc.unesco.org/ark:/48223/pf0000247005

UNESCO (2016d). La educación al servicio de los pueblos y el planeta: creación de futuros sostenibles para todos, resumen del informe de seguimiento de la educación en el mundo 2016. Tomado de https://unesdoc.unesco.org/ark:/48223/pf0000245745 spa 
Urquijo, M. J. (2014). La teoría de las capacidades en Amartya Sen, 63-80.

Valero, A. L., \& Ezquerro, A. M. (2012). Aprendizaje y enseñanza de la lengua castellana y literatura: currículo de educación secundaria obligatoria. Contextos Educativos, 1527-40

Vargo, S., \& Lusch, R. (2011). It's all B2B... and beyond: Toward a systems perspective of the market. Industrial Marketing Management, 40(2), 181-187. doi: http://dx.doi.org/10.1016/j.indmarman.2010.06.026

Velasco E., Zamanillo, I., Elguezabal., Gurutze I, M. (2007). Evolución de los modelos sobre el proceso de innovación desde el modelo lineal hasta los sistemas de innovación. Decisiones basadas en el conocimiento y en el papel social de la empresa: XX Congreso anual de AEDEM, Vol. 2, 2007 (Comunicaciones), pág. 28

Velasco, P. p., \& Cancino, H. c. (2012). Los retos de la educación bilingüe en inglés y español en las escuelas públicas de Nueva York: objetivos, modelos y currículos. (Spanish). International Review Of Education / Internationale Zeitschrift Für Erziehungswissenschaft, 58(5), 649-674. doi:10.1007/s11159-012-9328-y

Vera, Julio (2018). La implicación de la universidad en los Objetivos de Desarrollo Sostenible. El caso de la universidad de Málaga. XXXVII Seminario Interuniversitario de Teoría de la educación. Educación en la Sociedad de Conocimiento y Desarrollo Sostenible. La laguna 11 al 14 de noviembre de 2018. Universidad de la laguna. Tenerife. España.

Vicealcaldía de Educación, Cultura, Participación, Recreación y Deporte. (2015). Indicadores de la Educación Medellín 2004-2014

Vila, Eduardo., Caride, José \& Buxarrais, María ( 2018) Educación, sostenibilidad y ética: Desafíos ante los Objetivos de Desarrollo Sostenible (ODS). XXXVII Seminario Interuniversitario de Teoría de la educación. Educación en la Sociedad de Conocimiento y Desarrollo Sostenible. La laguna 11 al 14 de noviembre de 2018. Universidad de la laguna. Tenerife. España.

Vilches Peña, Amparo; Gil Pérez, Daniel; Calero, María. «Contribución de la educación científica a la apropiación de los objetivos de desarrollo sostenible». Enseñanza de las ciencias, Núm. Extra (2013), p. 3717-3721. <https://ddd.uab.cat/record/175696> [Consulta: 3 abril 2019].

Volante, Paulo, Bogolasky, Francisca, Derby, Fabián, \& Gutiérrez, Gabriel. (2015). Hacia una teoría de acción en gestión curricular: Estudio de caso de enseñanza secundaria en matemática. Psicoperspectivas, 14(2), 96108.https://dx.doi.org/10.5027/PSICOPERSPECTIVAS-VOL14-ISSUE2FULLTEXT-445

Vygotsky, L. S. (1978). Mind in society: The development of higher psychological processes. Cambridge, MA: Harvard University Press 
Watson, J. B. (1955). El conductismo. Buenos Aires: Paidós. (Trabajo original publicado en 1924).

Webb, N. (2007). Issues related to judging the alingment of curriculum standards and assessments. Applied Measurement in Education, 20(1), 7-25

Weinschenk, Susan M. (2013) Diseno inteligente / 100 Things Every Designer Needs to

Werner, J. (2001). Paideia. Los ideales de la cultura griega. Tomos I, II, III, IV. Fondo de la Cultura Económica de México. Traducción de Joaquin Xiral, Decimo Quinta Impresión

Wheeler, D. K. (1967) Curriculum Process. Londres: University of London Press.

White, DW (2014). ¿Qué es la educación STEM y por qué es importante? Asociación de Florida Teacher Educators Journal , 1 (14), 1-8. Obtenido de http://www.fate1.org/journals/2014/white.pdf

Whiting, Charles (1958). Creative Thinking (Reinhold management science series). Reinhold edition

Wilcoxon, F. (1945) "Individual Comparisons by Ranking Methods". Biometrics 1, 80-83

William Lareau, Kaufman, Roger (2003) Office Kaizen: Cómo Controlar y Reducir Los Costes de Gestión en la Empresa

World Commision on Environment and Development. Our Common Future Report (1987). Environmental Science: In Context.Tomado el 21 de noviembre de 2018 de http://www.un-documents.net/our-common-future.pdf

Wulfen, Gijs (2011), Creating Innovative Products and Services: The Forth Innovation Method. Gower Publishing.

Wunker, Stephen. Wattman. Jessica. Farber, David (2016) Jobs to Be Done: A Roadmap for Customer-Centered Innovation.Amacom

Zabalza Beraza, M. A. (2012). Articulación y rediseño curricular: el eterno desafío institucional. Revista de Docencia Universitaria, 10(3), 17-48 


\author{
ANEXOS \\ Anexo 1 "Diagnóstico del Contexto Institucional" \\ Evaluación Diagnóstica \\ Objetivos de Desarrollo Sostenible
}

Estimado miembro de la comunidad educativa

Las siguientes preguntas tienen como objetivo identificar los niveles de adopción de medidas para poner fin a la pobreza, proteger el planeta y garantizar que todas las personas de la comunidad del área de influencia de la institución educativa gocen de paz y prosperidad.

Los ODS (Objetivos de Desarrollo Sostenible) conllevan un espíritu de colaboración y pragmatismo para elegir las mejores opciones con el fin de mejorar la vida, de manera sostenible, para las generaciones futuras. Proporcionan orientaciones y metas claras para su adopción por todos los países en conformidad con sus propias prioridades y los desafíos ambientales del mundo en general (ONU, 2015).

Se aclara que la información suministrada tendrá un tratamiento confidencial y sólo se utilizará en el marco del proceso experimental de la investigación para la validación del "modelo de coordenadas curriculares" por tal razón no existen respuestas ni buenas ni malas.

Solicitamos su apoyo en el diligenciamiento de esta encuesta la cual le tomará aproximadamente diez minutos.

Tenga en cuenta la siguiente escala valorativa para indicar su grado de acuerdo o desacuerdo con cada enunciado que se presenta, marcando con una equis (x) en el espacio correspondiente, siendo:

1. Muy satisfecho - 2. Satisfecho - 3. Neutral - 4. Insatisfecho - 5. Muy insatisfecho Agradecemos su valiosa colaboración. 


\begin{tabular}{|c|c|c|c|c|c|c|c|c|}
\hline \multirow{2}{*}{ Eje } & \multirow{2}{*}{$\begin{array}{c}\% \\
\text { Valoración }\end{array}$} & \multirow{2}{*}{ ODS } & \multirow{2}{*}{ Descripción } & \multicolumn{5}{|c|}{ Calificación } \\
\hline & & & & 1 & 2 & 3 & 4 & 5 \\
\hline \multirow{5}{*}{ 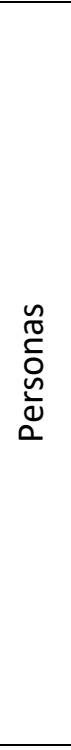 } & \multirow{5}{*}{20} & 1 & $\begin{array}{l}\text { Cobertura de sistemas de protección social para pobres y vulnerables, acceso a recursos económicos y a servicios } \\
\text { básicos, resiliencia frente a fenómenos extremos relacionados con el clima y otras crisis y desastres económicos, } \\
\text { sociales y ambientales. }\end{array}$ & & & & & \\
\hline & & 2 & $\begin{array}{l}\text { Seguridad alimentaria, prácticas agrícolas resilientes, capacidad de adaptación al cambio climático, gestión y } \\
\text { diversificación de los bancos de semillas y plantas, inversiones que incrementen la capacidad de producción agrícola, } \\
\text { distorsiones comerciales en los mercados agropecuarios, acceso oportuno a información sobre los mercados }\end{array}$ & & & & & \\
\hline & & 3 & $\begin{array}{l}\text { Personas portadoras de SIDA, tuberculosis, malaria y las enfermedades tropicales desatendidas, prevención y } \\
\text { tratamiento del abuso de sustancias adictivas, acceso universal a los servicios de salud sexual y reproductiva, cobertura } \\
\text { sanitaria universal, muertes producidas por productos químicos peligrosos y la contaminación del aire, el agua y el } \\
\text { suelo, capacidad en materia de alerta temprana }\end{array}$ & & & & & \\
\hline & & 4 & $\begin{array}{l}\text { Cobertura en educación gratuita, equitativa y de calidad para niños y niñas, acceso en condiciones de igualdad a todos } \\
\text { los niveles de enseñanza, para todos incluyendo población vulnerable, educación para el desarrollo sostenible y la } \\
\text { adopción de estilos de vida sostenibles, instalaciones escolares seguras e inclusivas, becas educativas disponibles y } \\
\text { formación de los docentes. }\end{array}$ & & & & & \\
\hline & & 5 & $\begin{array}{l}\text { Discriminación, casos de violencia contra las mujeres y las niñas, promoción de la responsabilidad compartida en el } \\
\text { hogar y la familia, participación plena y efectiva de las mujeres, igualdad de oportunidades de liderazgo, acceso } \\
\text { universal a la salud sexual y reproductiva y los derechos reproductivos, además del empoderamiento de la mujer a } \\
\text { través de la tecnología. }\end{array}$ & & & & & \\
\hline \multirow{4}{*}{$\begin{array}{l}\frac{0}{\frac{\pi}{0}} \\
\frac{0}{2} \\
\frac{0}{n} \\
\frac{0}{2} \\
\frac{0}{2}\end{array}$} & \multirow{4}{*}{20} & 7 & $\begin{array}{l}\text { Acceso universal a servicios de energía asequibles, confiables y modernos, energía renovable, eficiencia energética, } \\
\text { acceso a la investigación y las tecnologías energéticas no contaminantes, infraestructura y tecnología para prestar } \\
\text { servicios de energía modernos y sostenibles }\end{array}$ & & & & & \\
\hline & & 8 & $\begin{array}{l}\text { Productividad económica, producción y el consumo eficiente de los recursos, empleabilidad de los jóvenes, trabajo } \\
\text { forzoso, derechos laborales, entorno de trabajo seguro y protegido, turismo sostenible, acceso a los servicios bancarios, } \\
\text { financieros y de seguros }\end{array}$ & & & & & \\
\hline & & 9 & $\begin{array}{l}\text { Acceso de las pequeñas empresas industriales a los servicios financieros, adopción de tecnologías y procesos } \\
\text { industriales limpios y ambientalmente racionales, investigación científica y capacidad tecnológica de los sectores } \\
\text { industriales, entorno normativo propicio a la diversificación industrial, acceso a la tecnología de la información y las } \\
\text { comunicaciones, acceso universal y asequible a Internet. }\end{array}$ & & & & & \\
\hline & & 10 & $\begin{array}{l}\text { Crecimiento de los ingresos del } 40 \% \text { más pobre de la población, inclusión social, económica y política de todas las } \\
\text { personas, eliminación de las leyes, políticas y prácticas discriminatorias, reglamentación y vigilancia de las } \\
\text { instituciones y los mercados financieros mundiales, migración y movilidad ordenadas, seguras, regulares y } \\
\text { responsables. }\end{array}$ & & & & & \\
\hline
\end{tabular}




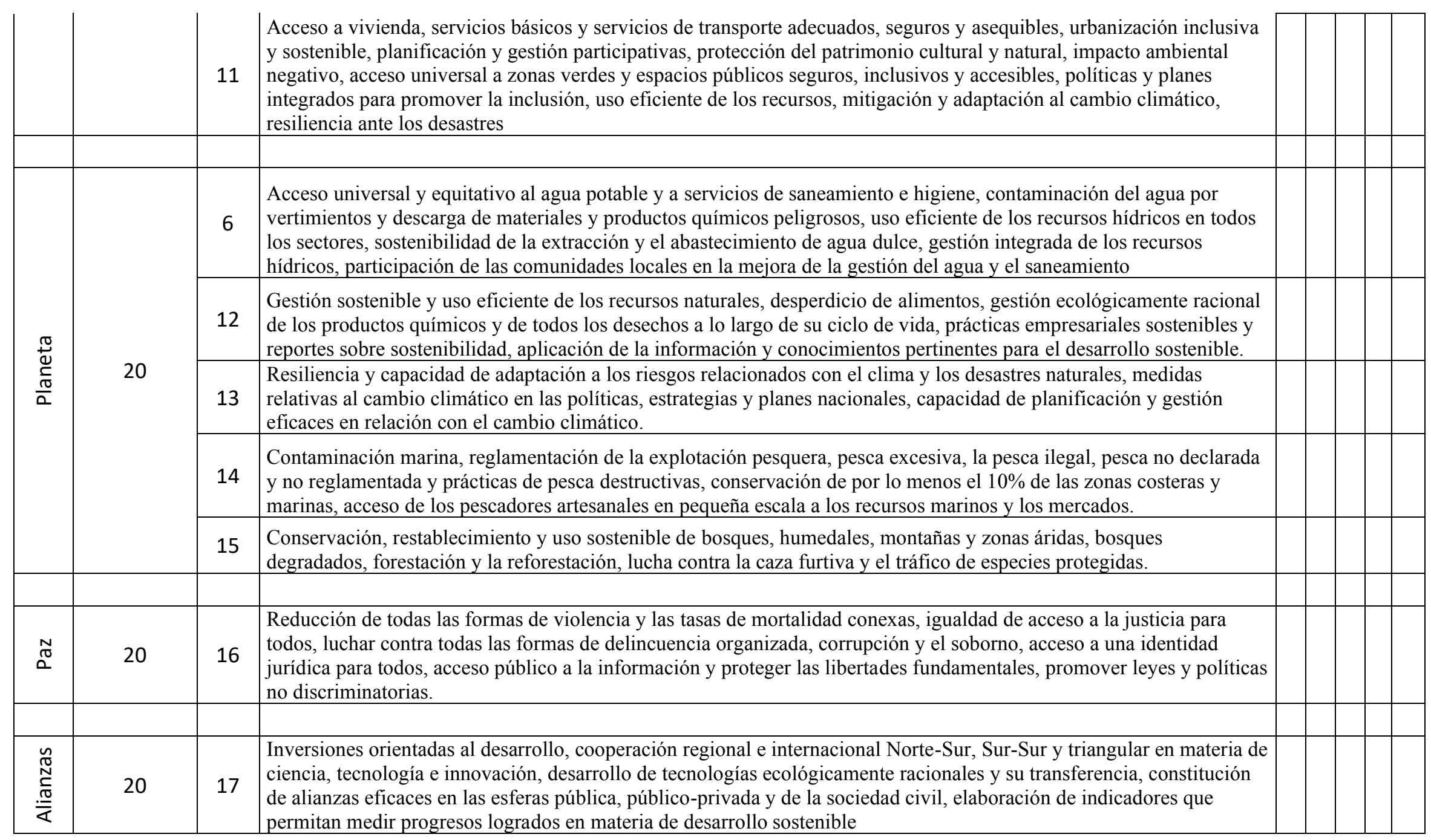


Anexo 2: Clasificación de los Ejes ODS - Pareto-

\begin{tabular}{|l|c|c|c|c|c|c|}
\hline \multicolumn{1}{|c|}{ Eje } & $\begin{array}{c}\text { Promedio } \\
\text { Calificación }\end{array}$ & $\begin{array}{c}\% \\
\text { Valoración }\end{array}$ & $\begin{array}{c}\% \\
\text { Valoración } \\
\text { acumulada }\end{array}$ & $\begin{array}{c}\% \\
\text { Calificación }\end{array}$ & $\begin{array}{c}\% \\
\text { calificación } \\
\text { acumulada }\end{array}$ & Clasificación \\
\hline Eje 1 & & 20 & 20 & & & \multirow{2}{*}{8} \\
\hline Eje 2 & & 20 & 40 & & & \\
\hline Eje 3 & & 20 & 60 & & & \\
\hline Eje 4 & & 20 & 80 & & \\
\hline Eje 5 & & 20 & 100 & & & \\
\hline Total & 0 & 100 & & 100 & - & \\
\cline { 1 - 4 }
\end{tabular}

Resolución de columnas:

Eje: Ejes definidos por los ODS.

Promedio de Calificación: Escala valorativa obtenida en el diagnóstico (de 0 a 5), se ubica en la tabla de mayor a menor.

\% Valoración: Porcentaje de participación de cada eje $(100 \% / 5$ ejes $=20 \%)$

$\%$ Valoración acumulada: Porcentaje acumulado por eje (sumatoria de frecuencias absolutas por valoración)

\% Calificación: Representa el \% de representación sobre calificación institucional $\%$ Calificación acumulada: Porcentaje acumulado por eje (sumatoria de frecuencias absolutas por calificación)

Clasificación: Identificación eje de mayor valor de acuerdo con la regla (80/20 o 20/80)

En el gráfico de barras se representa bajo el siguiente ejemplo:

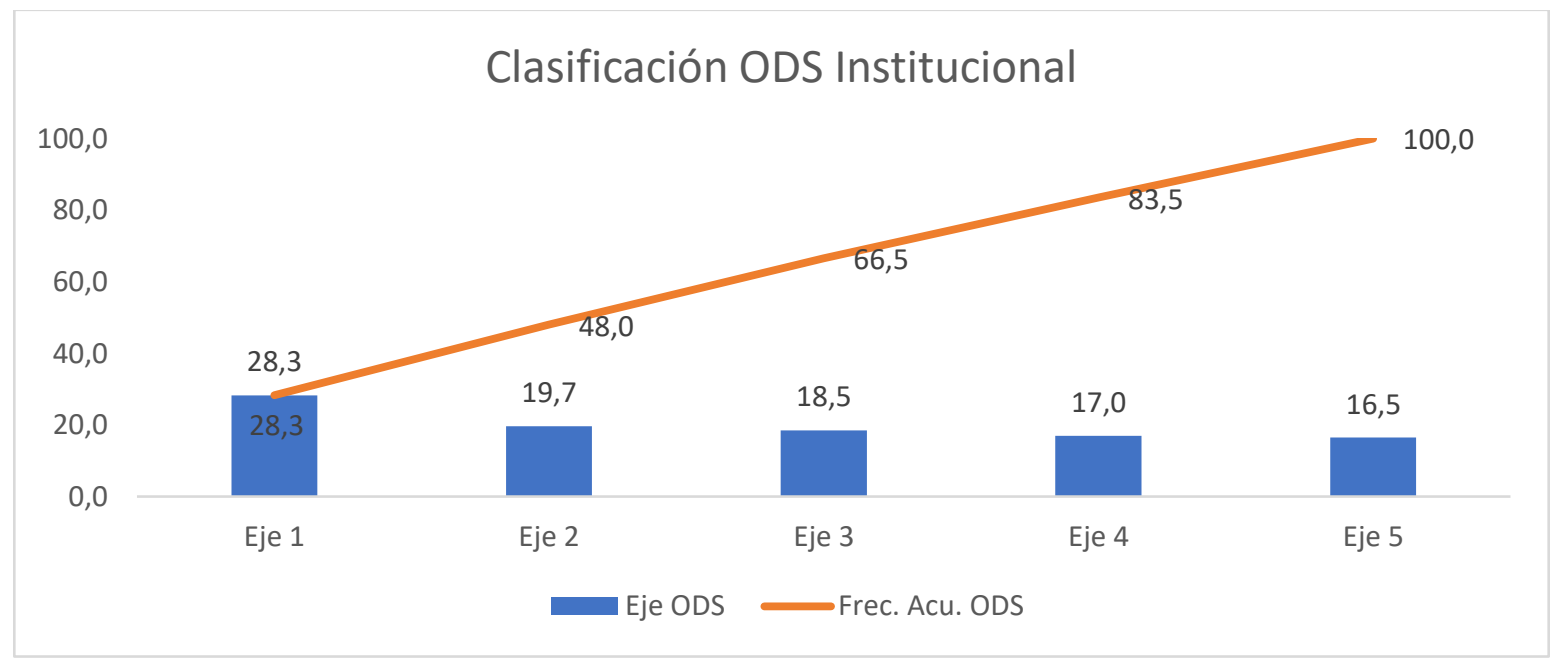


Anexo 3: Metas de los Objetivos de Desarrollo Sostenible.

\section{OBJETIVO 1. PONER FIN A LA POBREZA EN TODAS SUS FORMAS Y EN TODO EL MUNDO}

1.1. Erradicar para todas las personas y en todo el mundo la pobreza extrema.

1.2. Reducir al menos a la mitad la proporción de personas que viven en pobreza en todas sus dimensiones con arreglo a las definiciones nacionales.

1.3. Poner en práctica a nivel nacional sistemas y medidas apropiadas de protección social para todos.

1.4. Garantizar los mismos derechos a los recursos económicos, así como acceso a los servicios básicos, la propiedad y el control de la tierra y otros bienes, la herencia, los recursos naturales, las nuevas tecnologías apropiadas y los servicios financieros, incluida la micro financiación

1.5. Fomentar la resiliencia a las personas que se encuentran en situaciones vulnerables y reducir su exposición y vulnerabilidad a los fenómenos extremos relacionados con el clima y otras crisis y desastres económicos, sociales y ambientales

OBJETIVO 2. PONER FIN AL HAMBRE, LOGRAR LA SEGURIDAD ALIMENTARIA Y LA MEJORA DE LA NUTRICIÓN Y PROMOVER LA AGRICULTURA SOSTENIBLE

2.1. Poner fin al hambre y asegurar el acceso de todas las personas, a una alimentación sana, nutritiva y suficiente durante todo el año.

2.2. Poner fin a todas las formas de malnutrición, y abordar las necesidades de nutrición de las adolescentes, las mujeres embarazadas y lactantes y las personas de edad

2.3. Duplicar la productividad agrícola y los ingresos de los productores de alimentos en pequeña escala, respetando el medio ambiente y la biodiversidad de cada región.

2.4. Asegurar la sostenibilidad de los sistemas de producción de alimentos y aplicar prácticas agrícolas resilientes que aumenten la productividad y la producción, contribuyan al mantenimiento de los ecosistemas, fortalezcan la capacidad de adaptación al cambio climático, los fenómenos meteorológicos extremos, las sequías, las inundaciones y otros desastres, y mejoren progresivamente la calidad del suelo y la tierra.

2.5. Mantener la diversidad genética de las semillas, las plantas cultivadas y los animales de granja y domesticados y sus correspondientes especies silvestres, entre otras cosas mediante una buena gestión y diversificación de los bancos de semillas y plantas a nivel nacional, regional e internacional, y promover el acceso a los beneficios que se deriven de la utilización de los recursos genéticos y los conocimientos tradicionales conexos y su distribución justa y equitativa, según lo convenido internacionalmente 
OBJETIVO 3. GARANTIZAR UNA VIDA SANA Y PROMOVER EL BIENESTAR DE TODOS EN TODAS LAS EDADES.

3.1. Reducir la tasa mundial de mortalidad materna a menos de 70 por cada 100.000 nacidos vivos

3.2. Poner fin a las muertes evitables de recién nacidos y de niños menores de 5 años.

3.3. Poner fin a las epidemias del SIDA, la tuberculosis, la malaria y las enfermedades tropicales desatendidas y combatirla hepatitis, las enfermedades transmitidas por el agua y otras enfermedades transmisibles.

3.4. Reducir en un tercio la mortalidad prematura por enfermedades no transmisibles.

3.5. Fortalecer la prevención y el tratamiento del abuso de sustancias adictivas, incluido el uso indebido de estupefacientes y el consumo nocivo de alcohol.

3.6. Para 2020, reducir a la mitad el número de muertes y lesiones causadas por accidentes de tráfico en el mundo

3.7. Garantizar el acceso universal a servicios de salud sexual y reproductiva, incluidos la planificación familiar, información y educación, y la integración de la salud reproductiva en las estrategias y los programas nacionales

3.8. Lograr la cobertura sanitaria universal, incluida la protección contra los riesgos financieros, el acceso a servicios básicos de salud de calidad y el acceso a medicamentos y vacunas inocuos, eficaces, asequibles y de calidad para todos.

3.9. Reducir considerablemente el número de muertes y enfermedades causadas por productos químicos peligrosos y por la polución y contaminación del aire, el agua y el suelo.

OBJETIVO 4. GARANTIZAR UNA EDUCACIÓN INCLUSIVA, EQUITATIVA Y DE CALIDAD Y PROMOVER OPORTUNIDADES DE APRENDIZAJE DURANTE TODA LA VIDA PARA TODAS Y TODOS

4.1. Asegurar que todas las niñas y todos los niños terminen la enseñanza primaria y secundaria, que ha de ser gratuita, equitativa y de calidad y producir resultados de aprendizaje pertinentes y efectivos

4.2. Garantizar que niñas y niños tengan acceso a servicios de atención y desarrollo en la primera infancia y educación preescolar de calidad, a fin de que estén preparados para la enseñanza primaria.

4.3. Asegurar el acceso en condiciones de igualdad para todos los hombres y las mujeres a formación técnica, profesional y superior de calidad, incluida la enseñanza universitaria.

4.4. Aumentar el número de jóvenes y adultos que tienen las competencias necesarias, en particular técnicas y profesionales, para acceder al empleo, el trabajo decente y el emprendimiento. 
4.5. Eliminar las disparidades de género en la educación y garantizar el acceso igualitario de las personas vulnerables, incluidas las personas con discapacidad, los pueblos indígenas y los niños en situaciones de vulnerabilidad, a todos los niveles de la enseñanza y la formación profesional.

4.6. Asegurar que todos los jóvenes y una proporción considerable de los adultos, tanto hombres como mujeres, estén alfabetizados y tengan nociones elementales de aritmética.

4.7. Garantizar que todos los estudiantes adquieran los conocimientos teóricos y prácticos necesarios para promover el desarrollo sostenible, en particular mediante la educación para el desarrollo sostenible y la adopción de estilos de vida sostenibles, los derechos humanos, la igualdad entre los géneros, la promoción de una cultura de paz y no violencia, la ciudadanía mundial y la valoración de la diversidad cultural y de la contribución de la cultura al desarrollo sostenible, entre otros medios.

OBJETIVO 5. LOGRAR LA IGUALDAD DE GÉNERO Y EMPODERAR A TODAS LAS MUJERES Y LAS NIÑAS

5.1. Poner fin a todas las formas de discriminación contra todas las mujeres y las niñas en todo el mundo.

5.2. Eliminar todas las formas de violencia contra todas las mujeres y las niñas en los ámbitos público y privado, incluidas la trata y la explotación sexual y otros tipos de explotación.

5.3. Eliminar todas las prácticas nocivas, como el matrimonio infantil, precoz y forzado y la mutilación genital femenina.

5.4. Reconocer y valorar los cuidados y el trabajo doméstico no remunerado mediante la prestación de servicios públicos, infraestructuras y la formulación de políticas de protección social, y promoviendo la responsabilidad compartida en el hogar y la familiar, según proceda en cada país.

5.5. Asegurar la participación plena y efectiva de las mujeres y la igualdad de oportunidades de liderazgo a todos los niveles decisorios en la vida política, económica y pública.

5.6. Garantizar el acceso universal a la salud sexual y reproductiva y los derechos reproductivos.

\section{OBJETIVO 6. GARANTIZAR LA DISPONIBILIDAD Y LA GESTIÓN SOSTENIBLE DEL AGUA Y EL SANEAMIENTO PARA TODAS Y TODOS}

6.1. Lograr el acceso universal y equitativo al agua potable segura y asequible para todos.

6.2. Lograr el acceso a servicios de saneamiento e higiene adecuados y equitativos para todos y poner fin a la defecación al aire libre, prestando especial atención a las necesidades de las mujeres y las niñas y las personas en situaciones de vulnerabilidad.

6.3. Mejorar la calidad del agua reduciendo la contaminación, eliminando el vertimiento y minimizando la emisión de productos químicos y materiales peligrosos, reduciendo a la mitad 
del porcentaje de aguas residuales sin tratar y aumentado considerablemente el reciclado y la reutilización sin riesgos a nivel mundial.

6.4. Aumentar el uso eficiente de los recursos hídricos en todos los sectores y asegurar la sostenibilidad de la extracción y el abastecimiento de agua dulce para hacer frente a la escasez de agua y reducir considerablemente el número de personas que sufren falta de agua.

6.5. Implementar la gestión integrada de los recursos hídricos a todos los niveles, incluso mediante la cooperación transfronteriza, según proceda.

6.6. Proteger y restablecer los ecosistemas relacionados con el agua, incluidos los bosques, las montañas, los humedales, los ríos, los acuíferos y los lagos.

OBJETIVO 7. GARANTIZAR EL ACCESO A UNA ENERGÍA ASEQUIBLE, FIABLE, SOSTENIBLE Y MODERNA PARA TODAS Y TODOS

7.1. Garantizar el acceso universal a servicios energéticos asequibles, fiables y modernos.

7.2. Aumentar considerablemente la proporción de energía renovable en el conjunto de fuentes energéticas

7.3. Duplicar la tasa mundial de mejora de la eficiencia energética.

OBJETIVO 8. PROMOVER EL CRECIMIENTO ECONÓMICO SOSTENIDO, INCLUSIVO Y SOSTENIBLE, EL EMPLEO PLENO Y PRODUCTIVO Y EL TRABAJO DECENTE PARA TODAS Y TODOS

8.1. Mantener el crecimiento económico per cápita de conformidad con las circunstancias nacionales y, en particular, un crecimiento del producto interno bruto de al menos el 7\% anual en los países menos adelantados.

8.2. Lograr niveles más elevados de productividad económica mediante la diversificación, la modernización tecnológica y la innovación, centrándose en los sectores con gran valor añadido y un uso intensivo de la mano de obra.

8.3. Promover políticas orientadas al desarrollo que apoyen las actividades productivas, la creación de empleos decentes, el emprendimiento, la creatividad y la innovación y alentar la formalización y el crecimiento de las microempresas y las pequeñas y medianas empresas, entre otras cosas mediante el acceso a servicios financieros.

8.4. Mejorar la producción y el consumo eficientes de los recursos mundiales y procurar desvincular el crecimiento económico de la degradación del medio ambiente, conforme al Marco Decenal de Programas sobre Modalidades de Consumo y Producción Sostenibles, empezando por los países desarrollados.

8.5. Lograr el empleo pleno y productivo y el trabajo decente para todos los hombres y mujeres, incluidos los jóvenes y las personas con discapacidad, y la igualdad de remuneración por trabajo de igual valor. 
8.6. Reducir la proporción de jóvenes que no están empleados y no cursan estudios ni reciben capacitación

8.7. Adoptar medidas inmediatas y eficaces para erradicar el trabajo forzoso y, a más tardar en 2025, poner fin al trabajo infantil en todas sus formas, incluidos el reclutamiento y la utilización de niños soldados.

8.8. Proteger los derechos laborales y promover un entorno de trabajo seguro y protegido para todos los trabajadores, incluidos los trabajadores migrantes, en particular las mujeres migrantes y las personas con empleos precarios

8.9. Elaborar y poner en práctica políticas encaminadas a promover un turismo sostenible que cree puestos de trabajo y promueva la cultura y los productos locales.

8.10. Fortalecer la capacidad de las instituciones financieras nacionales para alentar y ampliar el acceso a los servicios bancarios, financieros y de seguros para todos.

OBJETIVO 9. CONSTRUIR INFRAESTRUCTURAS RESILIENTES, PROMOVER LA INDUSTRIALIZACIÓN INCLUSIVA $\quad \mathrm{Y}$ SOSTENIBLE $\quad \mathrm{Y}$ FOMENTAR LA INNOVACIÓN

9.1. Desarrollar infraestructuras fiables, sostenibles, resilientes y de calidad, incluidas las infraestructuras regionales y transfronterizas, para apoyar el desarrollo económico y el bienestar humano, con especial hincapié en el acceso asequible y equitativo para todos.

9.2. Promover una industrialización inclusiva y sostenible y, de aquí a 2030, aumentar de manera significativa la cuota de la industria en el empleo y el producto interno bruto, de acuerdo con las circunstancias nacionales, y duplicar su participación en los países menos adelantados.

9.3. Aumentar el acceso de las pequeñas industrias y otras empresas, en particular en los países en desarrollo, a los servicios financieros, incluidos créditos asequibles, y su integración en las cadenas de valor y los mercados.

9.4. Modernizar la infraestructura y reconvertir las industrias para que sean sostenibles, utilizando los recursos con mayor eficacia y promoviendo la adopción de tecnologías y procesos industriales limpios y ambientalmente racionales, y que todos los países adopten medidas de acuerdo con sus capacidades respectivas.

9.5. Aumentar la investigación científica y mejorar la capacidad tecnológica de los sectores industriales de todos los países, el fomento a la innovación y el aumento de trabajadores en la esfera de investigación y desarrollo por cada millón de personas y los gastos en investigación y desarrollo de los sectores público y privado.

\section{OBJETIVO 10. REDUCIR LA DESIGUALDAD EN LOS PAÍSES Y ENTRE ELLOS}

10.1. Lograr progresivamente y mantener el crecimiento de los ingresos del $40 \%$ más pobre de la población a una tasa superior a la media nacional. 
10.2. Potenciar y promover la inclusión social, económica y política de todos, independientemente de su edad, sexo, discapacidad, raza, etnia, origen, religión o situación económica $u$ otra condición.

10.3. Garantizar la igualdad de oportunidades y reducir la desigualdad de resultados, incluso eliminando las leyes, políticas y prácticas discriminatorias y promoviendo legislaciones, políticas y medidas adecuadas a ese respecto.

10.4. Adoptar políticas, especialmente fiscales, salariales y de protección social, y lograr progresivamente una mayor igualdad.

10.5. Mejorar la reglamentación y vigilancia de las instituciones y los mercados financieros mundiales y fortalecer la aplicación de esos reglamentos.

10.6. Asegurar una mayor representación y voz de los países en desarrollo en la adopción de decisiones en las instituciones económicas y financieras internacionales para que estas sean más eficaces, fiables, responsables y legítimas.

10.7. Facilitar la migración y la movilidad ordenadas, seguras, regulares y responsables de las personas, incluso mediante la aplicación de políticas migratorias planificadas y bien gestionadas.

OBJETIVO 11. LOGRAR QUE LAS CIUDADES Y LOS ASENTAMIENTOS HUMANOS SEAN INCLUSIVOS, SEGUROS, RESILIENTES Y SOSTENIBLES

11.1. Asegurar el acceso de todas las personas a viviendas y servicios básicos adecuados, seguros y asequibles y mejorar los barrios marginales.

11.2. Proporcionar acceso a sistemas de transporte seguros, asequibles, accesibles y sostenibles para todos y mejorar la seguridad vial, mediante la ampliación de transporte público.

11.3. Para 2030, aumentar la urbanización inclusiva y sostenible y la capacidad para la planificación y la gestión participativas, integradas y sostenibles de los asentamientos humanos en todos los países.

11.4. Redoblar los esfuerzos para proteger y salvaguardar el patrimonio cultural y natural del mundo.

11.5. Reducir de forma significativa el número de muertes por desastres y reducir las pérdidas económicas en relación con el producto interno bruto causadas por desastres

11.6. Reducir el impacto ambiental negativo per capita de las ciudades, lo que incluye prestar especial atención a la calidad del aire y la gestión de los desechos municipales y de otro tipo.

11.7. Proporcionar acceso universal a zonas verdes y espacios públicos seguros, inclusivos y accesibles, en particular para las mujeres y los niños, las personas de edad y las personas con discapacidad. 
OBJETIVO 12. GARANTIZAR MODALIDADES DE CONSUMO Y PRODUCCIÓN SOSTENIBLES

12.1. Aplicar el Marco Decenal de Programas sobre Modalidades de Consumo y Producción Sostenibles, con la participación de todos los países y bajo el liderazgo de los países desarrollados, teniendo en cuenta el grado de desarrollo y las capacidades de los países en desarrollo.

12.2. Lograr la gestión sostenible y el uso eficiente de los recursos naturales

12.3. Reducir a la mitad el desperdicio mundial de alimentos per capita en la venta al por menor y a nivel de los consumidores y reducir las pérdidas de alimentos en las cadenas de producción y distribución

12.4. Para 2020, lograr la gestión ecológicamente racional de los productos químicos y de todos los desechos.

12.5. Disminuir de manera sustancial la generación de desechos mediante políticas de prevención, reducción, reciclaje y reutilización. Alentar a

12.6. Alentar a las empresas, en especial las grandes empresas y las empresas transnacionales, a que adopten prácticas sostenibles e incorporen información sobre sostenibilidad en su ciclo de presentación de informes.

12.7. Promover prácticas de contratación pública que sean sostenibles, de conformidad con las políticas y prioridades nacionales.

12.8. Velar por que las personas de todo el mundo dispongan de información pertinente sobre el desarrollo sostenible y los estilos de vida en armonía con la naturaleza.

OBJETIVO 13. ADOPTAR MEDIDAS URGENTES PARA COMBATIR EL CAMBIO CLIMÁTICO

13.1. Fortalecer la resiliencia y la capacidad de adaptación a los riesgos relacionados con el clima y los desastres naturales en todos los países.

13.2. Incorporar medidas relativas al cambio climático en las polí- ticas, estrategias y planes nacionales

13.3. Mejorar la educación, la sensibilización y la capacidad humana e institucional respecto de la mitigación del cambio climático, la adaptación a él, la reducción de sus efectos y la alerta temprana.

OBJETIVO 14. CONSERVAR Y UTILIZAR SOSTENIBLEMENTE LOS OCÉANOS, LOS MARES Y LOS RECURSOS MARINOS

14.1. Para 2025, prevenir y reducir de manera significativa la contaminación marina de todo tipo. 
14.2. De aquí a 2020, gestionar y proteger sosteniblemente los ecosistemas marinos y costeros para evitar efectos adversos importantes, incluso fortaleciendo su resiliencia, y adoptar medidas para restaurarlos a fin de restablecer la salud y la productividad de los océanos.

14.3. Minimizar y abordar los efectos de la acidificación de los océanos, incluso mediante una mayor cooperación científica a todos los niveles.

14.4. Para 2020, reglamentar eficazmente la explotación pesquera y poner fin a la pesca excesiva, la pesca ilegal, no declarada y no reglamentada y las prácticas de pesca destructivas, y aplicar planes de gestión con fundamento científico a fin de restablecer las poblaciones de peces en el plazo más breve posible.

14.5. Para 2020, conservar al menos el $10 \%$ de las zonas costeras y marinas, de conformidad con las leyes nacionales y el derecho internacional y sobre la base de la mejor información científica disponible.

14.6. Para 2020, prohibir ciertas formas de subvenciones a la pesca que contribuyen a la pesca excesiva y la sobreexplotación pesquera, eliminar las subvenciones que contribuyen a la pesca ilegal, no declarada y no reglamentada y abstenerse de introducir nuevas subvenciones.

14.7. Aumentar los beneficios económicos que los pequeños Estados insulares en desarrollo y los países menos adelantados.

OBJETIVO 15. PROTEGER, RESTABLECER Y PROMOVER EL USO SOSTENIBLE DE LOS ECOSISTEMAS TERRESTRES, GESTIONAR SOSTENIBLEMENTE LOS BOSQUES, LUCHAR CONTRA LA DESERTIFICACIÓN, DETENER E INVERTIR LA DEGRADACIÓN DE LAS TIERRAS Y DETENER LA PÉRDIDA DE BIODIVERSIDAD

15.1. Para 2020, velar por la conservación, el restablecimiento y el uso sostenible de los ecosistemas terrestres y los ecosistemas interiores de agua dulce y los servicios que proporcionan.

15.2. Para 2020, promover la gestión sostenible de todos los tipos de bosques, poner fin a la deforestación, recuperar los bosques degradados e incrementar la forestación y la reforestación a nivel mundial.

15.3. Luchar contra la desertificación, rehabilitar las tierras y los suelos degradados, incluidas las tierras afectadas por la desertificación, la sequía y las inundaciones, y procurar lograr un mundo con efecto neutro en la degradación del suelo.

15.4. Asegurar la conservación de los ecosistemas montañosos, incluida su diversidad biológica, a fin de mejorar su capacidad de proporcionar beneficios esenciales para el desarrollo sostenible. 
15.5. Adoptar medidas urgentes y significativas para reducir la degradación de los hábitats naturales, detener la pérdida de la diversidad biológica y, para 2020, proteger las especies amenazadas y evitar su extinción.

15.6. Promover la participación justa y equitativa en los beneficios derivados de la utilización de los recursos genéticos y promover el acceso adecuado a esos recursos.

15.7. Adoptar medidas urgentes para poner fin a la caza furtiva y el tráfico de especies protegidas de flora y fauna.

15.8. Para 2020, adoptar medidas para prevenir la introducción de especies exóticas invasoras y reducir significativamente sus efectos en los ecosistemas terrestres y acuáticos y controlar o erradicar las especies prioritarias.

15.9. Para 2020, integrar los valores de los ecosistemas y la diversidad biológica en la planificación nacional y local, los procesos de desarrollo, las estrategias de reducción de la pobreza y la contabilidad

OBJETIVO 16. PROMOVER SOCIEDADES PACÍFICAS E INCLUSIVAS PARA EL DESARROLLO SOSTENIBLE, FACILITAR EL ACCESO A LA JUSTICIA PARA TODOS Y CONSTRUIR A TODOS LOS NIVELES INSTITUCIONES EFICACES E INCLUSIVAS QUE RINDAN CUENTAS

16.1. Reducir significativamente todas las formas de violencia y las correspondientes tasas de mortalidad en todo el mundo.

16.2. Poner fin al maltrato, la explotación, la trata y todas las formas de violencia y tortura contra los niños.

16.3. Promover el estado de derecho en los planos nacional e internacional y garantizar la igualdad de acceso a la justicia para todos.

16.4. De aquí a 2030, reducir significativamente las corrientes financieras y de armas ilícitas, fortalecer la recuperación y devolución de los archivos robados y luchar contra todas las formas de delincuencia organizada

16.5. Reducir considerablemente la corrupción y el soborno en todas sus formas

16.6. Crear a todos los niveles instituciones eficaces y transparentes que rindan cuentas

16.7. Garantizar la adopción en todos los niveles de decisiones inclusivas, participativas y representativas que respondan a las necesidades.

16.8. Ampliar y fortalecer la participación de los países en desarrollo en las instituciones de gobernanza mundial.

16.9. De aquí a 2030, proporcionar acceso a una identidad jurídica para todos, en particular mediante el registro de nacimientos. 
16.10. Garantizar el acceso público a la información y proteger las libertades fundamentales, de conformidad con las leyes nacionales y los acuerdos internacionales.

OBJETIVO 17. FORTALECER LOS MEDIOS DE IMPLEMENTACIÓN Y REVITALIZAR LA ALIANZA MUNDIAL PARA EL DESARROLLO SOSTENIBLE

17.1. Fortalecer la movilización de recursos internos, con el fin de mejorar la capacidad nacional para recaudar ingresos fiscales y de otra índole

17.2. Velar por que los países desarrollados cumplan cabalmente sus compromisos en relación con la asistencia oficial para el desarrollo, lo que incluye asignar el $0,7 \%$ del ingreso nacional bruto al rubro de asistencia oficial para el desarrollo destinada a países en desarrollo.

17.3. Movilizar recursos financieros adicionales de múltiples fuentes para los países en desarrollo.

17.4. Ayudar a los países en desarrollo a lograr la sostenibilidad de la deuda a largo plazo con políticas coordinadas orientadas a fomentar la financiación, el alivio y la reestructuración de la deuda, y hacer frente a la deuda externa.

17.5. Adoptar y aplicar sistemas de promoción de las inversiones en favor de los países menos adelantados.

\subsection{Tecnología}

Mejorar la cooperación regional e internacional Norte-Sur, Sur-Sur y triangular en materia de ciencia, tecnología e innovación y el acceso a ellas.

17.7. Promover el desarrollo, la transferencia, la divulgación y la difusión de tecnologías ecológicamente racionales a los países en desarrollo en condiciones favorables, incluso en condiciones concesionarias y preferenciales, por mutuo acuerdo.

17.8. Poner en pleno funcionamiento, a más tardar en 2017, el banco de tecnología y el mecanismo de apoyo a la ciencia, la tecnología y la innovación para los países menos adelantados y aumentar la utilización de tecnología instrumental, en particular de la tecnología de la información y las comunicaciones.

\subsection{CREACIÓN DE CAPACIDAD}

Aumentar el apoyo internacional a la ejecución de programas de fomento de la capacidad eficaces y con objetivos concretos en los países en desarrollo a fin de apoyar los planes nacionales orientados a aplicar todos los Objetivos de Desarrollo Sostenible

\subsection{COMERCIO}

Promover un sistema de comercio multilateral universal, basado en normas, abierto, no discriminatorio y equitativo en el marco de la Organización Mundial del Comercio, incluso mediante la conclusión de las negociaciones en el marco del Programa de Doha para el Desarrollo. 
17.11. Aumentar significativamente las exportaciones de los países en desarrollo, en particular con miras a duplicar la participación de los países menos adelantados en las exportaciones mundiales de aquí a 2020.

17.12. Lograr la consecución oportuna del acceso a los mercados libre de derechos y contingentes de manera duradera para todos los países menos adelantados, conforme a las decisiones de la Organización Mundial del Comercio, incluso velando por que las normas de origen preferenciales aplicables a las importaciones de los países menos adelantados sean transparentes y sencillas y contribuyan a facilitar el acceso a los mercados.

\subsection{CUESTIONES SISTÉMICAS}

Coherencia normativa e institucional

Aumentar la estabilidad macroeconómica mundial, incluso mediante la coordinación y coherencia de las políticas.

17.14. Mejorar la coherencia de las políticas para el desarrollo sostenible.

17.15. Respetar el margen normativo y el liderazgo de cada país para establecer y aplicar políticas de erradicación de la pobreza y desarrollos sostenible

17.16. Alianzas entre múltiples interesados

Mejorar la Alianza Mundial para el Desarrollo Sostenible, complementada por alianzas entre múltiples interesados que movilicen e intercambien conocimientos, especialización, tecnología y recursos financieros, a fin de apoyar el logro de los Objetivos de Desarrollo Sostenible en todos los países, particularmente los países en desarrollo.

17.17. Fomentar y promover la constitución de alianzas eficaces en las esferas pública, público-privada y de la sociedad civil, aprovechando la experiencia y las estrategias de obtención de recursos de las alianzas.

17.18. Datos, vigilancia y rendición de cuentas Al 2020, mejorar el apoyo a la creación de capacidad prestado a los países en desarrollo, incluidos los países menos adelantados y los pequeños Estados insulares en desarrollo, para aumentar significativamente la disponibilidad de datos oportunos, fiables y de gran calidad desglosados por ingresos, sexo, edad, raza, origen étnico, estatus migratorio, discapacidad, ubicación geográfica y otras características pertinentes en los contextos nacionales.

17.19. Aprovechar las iniciativas existentes para elaborar indicadores que permitan medir los progresos en materia de desarrollo sostenible y complemente el producto interno bruto, y apoyar la creación de capacidad estadística en los países en desarrollo. 
Anexo 4 Prueba Diagnóstica Institucional ODS

\begin{tabular}{|c|c|c|c|c|c|c|c|c|c|}
\hline \multirow{2}{*}{ Eje } & \multirow{2}{*}{ \% Valoración } & \multirow{2}{*}{ ODS } & \multirow{2}{*}{ Descripción } & \multicolumn{5}{|c|}{ Calificación } & \multirow{2}{*}{$\begin{array}{c}\text { № Part. } 70 \\
\text { Promedio }\end{array}$} \\
\hline & & & & 1 & 2 & 3 & 4 & 5 & \\
\hline \multirow{6}{*}{ 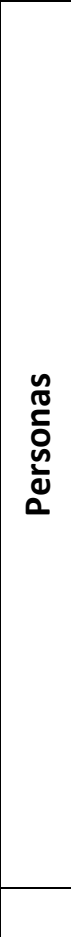 } & \multirow{5}{*}{20} & 1 & $\begin{array}{l}\text { Cobertura de sistemas de protección social para pobres y vulnerables, acceso a recursos } \\
\text { económicos y a servicios básicos, resiliencia frente a fenómenos extremos relacionados } \\
\text { con el clima y otras crisis y desastres económicos, sociales y ambientales. }\end{array}$ & & 28 & 54 & 128 & 30 & 3,428571429 \\
\hline & & 2 & $\begin{array}{l}\text { Seguridad alimentaria, prácticas agrícolas resilientes, capacidad de adaptación al cambio } \\
\text { climático, gestión y diversificación de los bancos de semillas y plantas, inversiones que } \\
\text { incrementen la capacidad de producción agrícola, distorsiones comerciales en los mercados } \\
\text { agropecuarios, acceso oportuno a información sobre los mercados }\end{array}$ & & 20 & 36 & 124 & 80 & 3,714285714 \\
\hline & & 3 & $\begin{array}{l}\text { Personas portadoras de SIDA, tuberculosis, malaria y las enfermedades tropicales } \\
\text { desatendidas, prevención y tratamiento del abuso de sustancias adictivas, acceso universal } \\
\text { a los servicios de salud sexual y reproductiva, cobertura sanitaria universal, muertes } \\
\text { producidas por productos químicos peligrosos y la contaminación del aire, el agua y el } \\
\text { suelo, capacidad en materia de alerta temprana }\end{array}$ & & 28 & 30 & 128 & 70 & 3,657142857 \\
\hline & & 4 & $\begin{array}{l}\text { Cobertura en educación gratuita, equitativa y de calidad para niños y niñas, acceso en } \\
\text { condiciones de igualdad a todos los niveles de enseñanza, para todos incluyendo población } \\
\text { vulnerable, educación para el desarrollo sostenible y la adopción de estilos de vida } \\
\text { sostenibles, instalaciones escolares seguras e inclusivas, becas educativas disponibles y } \\
\text { formación de los docentes. }\end{array}$ & 4 & 72 & 6 & 88 & & 2,428571429 \\
\hline & & 5 & $\begin{array}{l}\text { Discriminación, casos de violencia contra las mujeres y las niñas, promoción de la } \\
\text { responsabilidad compartida en el hogar y la familia, participación plena y efectiva de las } \\
\text { mujeres, igualdad de oportunidades de liderazgo, acceso universal a la salud sexual y } \\
\text { reproductiva y los derechos reproductivos, además del empoderamiento de la mujer a } \\
\text { través de la tecnología. }\end{array}$ & 4 & 28 & 18 & 160 & 30 & 3,428571429 \\
\hline & & & & \multicolumn{5}{|c|}{ Total } & 3,331428571 \\
\hline \multirow{2}{*}{ 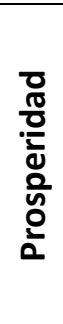 } & \multirow{2}{*}{20} & 7 & $\begin{array}{l}\text { Acceso universal a servicios de energía asequibles, confiables y modernos, energía } \\
\text { renovable, eficiencia energética, acceso a la investigación y las tecnologías energéticas no } \\
\text { contaminantes, infraestructura y tecnología para prestar servicios de energía modernos y } \\
\text { sostenibles }\end{array}$ & & 68 & 30 & 96 & 30 & 3,2 \\
\hline & & 8 & $\begin{array}{l}\text { Productividad económica, producción y el consumo eficiente de los recursos, } \\
\text { empleabilidad de los jóvenes, trabajo forzoso, derechos laborales, entorno de trabajo } \\
\text { seguro y protegido, turismo sostenible, acceso a los servicios bancarios, financieros y de } \\
\text { seguros }\end{array}$ & & 28 & 36 & 160 & 20 & 3,485714286 \\
\hline
\end{tabular}




\begin{tabular}{|c|c|c|c|c|c|c|c|c|c|}
\hline & & 9 & $\begin{array}{l}\text { Acceso de las pequeñas empresas industriales a los servicios financieros, adopción de } \\
\text { tecnologías y procesos industriales limpios y ambientalmente racionales, investigación } \\
\text { científica y capacidad tecnológica de los sectores industriales, entorno normativo propicio } \\
\text { a la diversificación industrial, acceso a la tecnología de la información y las } \\
\text { comunicaciones, acceso universal y asequible a Internet. }\end{array}$ & 12 & 28 & 12 & 124 & 30 & 2,942857143 \\
\hline & & 10 & $\begin{array}{l}\text { Crecimiento de los ingresos del } 40 \% \text { más pobre de la población, inclusión social, } \\
\text { económica y política de todas las personas, eliminación de las leyes, políticas y prácticas } \\
\text { discriminatorias, reglamentación y vigilancia de las instituciones y los mercados } \\
\text { financieros mundiales, migración y movilidad ordenadas, seguras, regulares y } \\
\text { responsables. }\end{array}$ & & 24 & 24 & 152 & 60 & 3,714285714 \\
\hline & & 11 & $\begin{array}{l}\text { Acceso a vivienda, servicios básicos y servicios de transporte adecuados, seguros y } \\
\text { asequibles, urbanización inclusiva y sostenible, planificación y gestión participativas, } \\
\text { protección del patrimonio cultural y natural, impacto ambiental negativo, acceso universal } \\
\text { a zonas verdes y espacios públicos seguros, inclusivos y accesibles, políticas y planes } \\
\text { integrados para promover la inclusión, uso eficiente de los recursos, mitigación y } \\
\text { adaptación al cambio climático, resiliencia ante los desastres }\end{array}$ & & 60 & 30 & 84 & 20 & 2,771428571 \\
\hline & & & & \multicolumn{5}{|c|}{ Total } & 3,222857143 \\
\hline \multirow{4}{*}{ 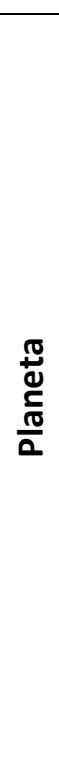 } & \multirow{4}{*}{20} & 6 & $\begin{array}{l}\text { Acceso universal y equitativo al agua potable y a servicios de saneamiento e higiene, } \\
\text { contaminación del agua por vertimientos y descarga de materiales y productos químicos } \\
\text { peligrosos, uso eficiente de los recursos hídricos en todos los sectores, sostenibilidad de la } \\
\text { extracción y el abastecimiento de agua dulce, gestión integrada de los recursos hídricos, } \\
\text { participación de las comunidades locales en la mejora de la gestión del agua y el } \\
\text { saneamiento }\end{array}$ & 4 & 64 & 18 & 88 & 20 & 2,771428571 \\
\hline & & 12 & $\begin{array}{l}\text { Gestión sostenible y uso eficiente de los recursos naturales, desperdicio de alimentos, } \\
\text { gestión ecológicamente racional de los productos químicos y de todos los desechos a lo } \\
\text { largo de su ciclo de vida, prácticas empresariales sostenibles y reportes sobre } \\
\text { sostenibilidad, aplicación de la información y conocimientos pertinentes para el desarrollo } \\
\text { sostenible. }\end{array}$ & 2 & 40 & 30 & 128 & 30 & 3,285714286 \\
\hline & & 13 & $\begin{array}{l}\text { Resiliencia y capacidad de adaptación a los riesgos relacionados con el clima y los } \\
\text { desastres naturales, medidas relativas al cambio climático en las políticas, estrategias y } \\
\text { planes nacionales, capacidad de planificación y gestión eficaces en relación con el cambio } \\
\text { climático. }\end{array}$ & 2 & 32 & 36 & 128 & 40 & 3,4 \\
\hline & & 14 & $\begin{array}{l}\text { Contaminación marina, reglamentación de la explotación pesquera, pesca excesiva, la } \\
\text { pesca ilegal, pesca no declarada y no reglamentada y prácticas de pesca destructivas, } \\
\text { conservación de por lo menos el } 10 \% \text { de las zonas costeras y marinas, acceso de los } \\
\text { pescadores artesanales en pequeña escala a los recursos marinos y los mercados. }\end{array}$ & 2 & 16 & 42 & 128 & 70 & 3,685714286 \\
\hline
\end{tabular}




\begin{tabular}{|c|c|c|c|c|c|c|c|c|c|}
\hline & & 15 & $\begin{array}{l}\text { Conservación, restablecimiento y uso sostenible de bosques, humedales, montañas y zonas } \\
\text { áridas, bosques degradados, forestación y la reforestación, lucha contra la caza furtiva y el } \\
\text { tráfico de especies protegidas. }\end{array}$ & & 32 & 30 & 128 & 60 & 3,571428571 \\
\hline & & & & \multicolumn{5}{|c|}{ Total } & 3,342857143 \\
\hline \multirow[t]{2}{*}{ N } & 20 & 16 & $\begin{array}{l}\text { Reducción de todas las formas de violencia y las tasas de mortalidad conexas, igualdad de } \\
\text { acceso a la justicia para todos, luchar contra todas las formas de delincuencia organizada, } \\
\text { corrupción y el soborno, acceso a una identidad jurídica para todos, acceso público a la } \\
\text { información y proteger las libertades fundamentales, promover leyes y políticas no } \\
\text { discriminatorias. }\end{array}$ & & 18 & 30 & 184 & 30 & 3,742857143 \\
\hline & & & & \multicolumn{5}{|c|}{ Total } & 3,742857143 \\
\hline 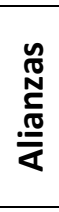 & 20 & 17 & $\begin{array}{l}\text { Inversiones orientadas al desarrollo, cooperación regional e internacional Norte-Sur, Sur- } \\
\text { Sur y triangular en materia de ciencia, tecnología e innovación, desarrollo de tecnologías } \\
\text { ecológicamente racionales y su transferencia, constitución de alianzas eficaces en las } \\
\text { esferas pública, público-privada y de la sociedad civil, elaboración de indicadores que } \\
\text { permitan medir progresos logrados en materia de desarrollo sostenible }\end{array}$ & 6 & 20 & 30 & 112 & 50 & 3,114285714 \\
\hline & & & & \multicolumn{5}{|c|}{ Total } & 3,114285714 \\
\hline
\end{tabular}


Anexo 5: Guía de intervención pedagógica

Anexo digital PDF Propuesta de Intervención

\section{Propuesta de intervención pedagógica}

Enmarcada en el numeral 16 de los

Objetivos de Desarrollo Sostenible

Promover socledades pacificas e Inclusivas para el desarrollo sostenible, facilitar el acceso a la

Justicla para todos y crear Instituclones eficaces, responsables e inclusivas a todos los niveles

Secuencias didácticas grado noveno

Áreas de conocimiento

Espańol y Literatura

Matemáticas

Clenclas Soclales

Clenclas Naturales

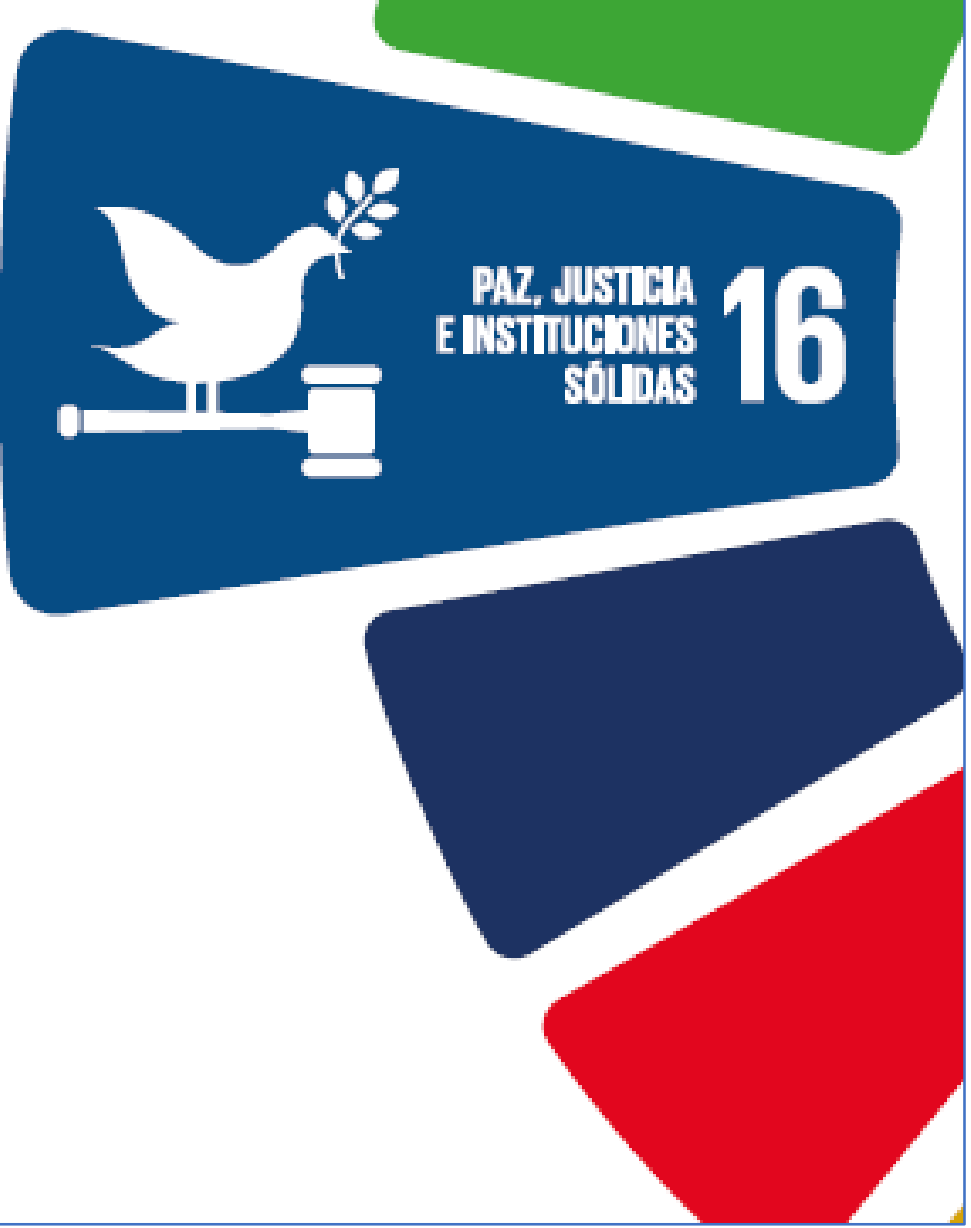




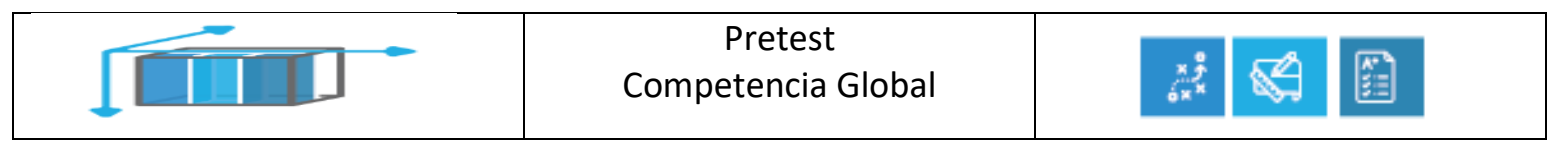

Anexo 6: Prueba Escrita Pretest

PRETEST COMPETENCIA GLOBAL ${ }^{40}$

Esta prueba consta de preguntas acerca de estudios de caso y responden a preguntas que evalúan la capacidad para comprender la complejidad y las múltiples perspectivas de los diversos actores involucrados en la cotidianidad.

Los contextos o escenarios utilizados expondrán a los estudiantes a un rango de diferentes situaciones y pondrán a prueba su capacidad para aplicar los conocimientos previos y las habilidades de pensamiento para analizar la situación y sugerir soluciones.

Las preguntas hacen referencia a asuntos de la vida real y de estos se derivan varias preguntas, las cuales pueden ser de selección múltiple y/o de respuesta abierta corta. Pueden presentarse en diferentes formatos que asignan un papel particular y motivan a participar en las tareas.

Debes responder en un tiempo máximo de 1 hora. Recuerda marcar con una " $\mathrm{X}$ " en los espacios designados.

\section{NORMAS}

- Toda la prueba debe realizarse con lápiz o bolígrafo negro.

- Toda pregunta con dos o más respuestas señaladas será anulada

- Al finalizar entregue la prueba PRETEST COMPETENCIA GLOBAL.

\footnotetext{
${ }^{40}$ Las preguntas planteadas corresponden a las formuladas por el Marco de Referencia preliminar para la competencia global PISA 2018 para Colombia, tomado de http:/www2.icfes.gov.co/docman/institucioneseducativas-y-secretarias/evaluaciones-internacionales-investigadores/pisa/pisa-2018/2991-marco-dereferencia-para-competencia-global-pisa-2018/file?force-download=1
} 


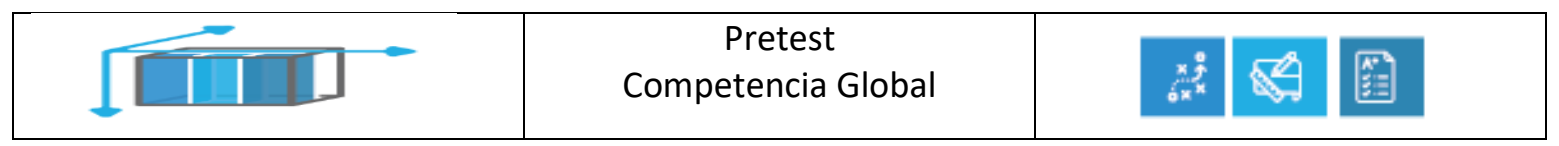

\section{CUESTIONARIO DEL ALUMNO RELACIONADO CON LA COMPETENCIA GLOBAL}

1. ¿Qué tanto lo describen a usted cada una de las siguientes afirmaciones?

(Por favor seleccione una respuesta en cada fila marcando con " $X$ ”)

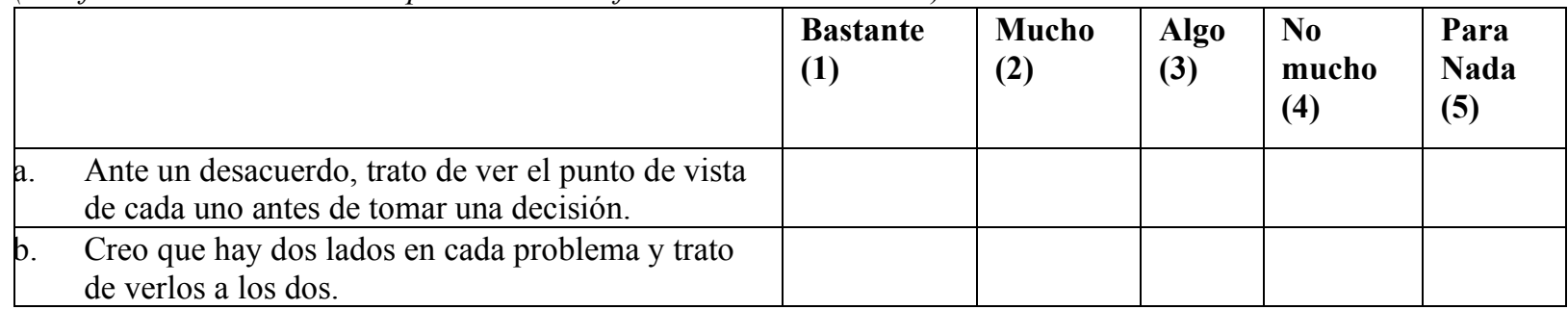

\section{2. ¿Hasta qué punto está usted de acuerdo con las siguientes afirmaciones?}

(Por favor seleccione una respuesta en cada fila marcando con " $X$ ")

\begin{tabular}{|c|c|c|c|c|c|}
\hline & & $\begin{array}{l}\text { Totalmente } \\
\text { en } \\
\text { desacuerdo } \\
\text { (1) }\end{array}$ & $\begin{array}{l}\text { En desacuerdo } \\
\text { (2) }\end{array}$ & $\begin{array}{l}\text { De } \\
\text { acuerdo } \\
\text { (3) }\end{array}$ & $\begin{array}{l}\text { Totalmente de } \\
\text { acuerdo (4) }\end{array}$ \\
\hline a. & $\begin{array}{l}\text { Pienso en mí mismo como un ciudadano } \\
\text { del mundo. }\end{array}$ & & & & \\
\hline b. & $\begin{array}{l}\text { Cuando veo las malas condiciones en } \\
\text { que viven algunas personas en el mundo, } \\
\text { siento la responsabilidad de hacer algo al } \\
\text { respecto. }\end{array}$ & & & & \\
\hline & $\begin{array}{l}\text { Pienso que mi comportamiento puede } \\
\text { tener impacto sobre la gente en otros } \\
\text { países. }\end{array}$ & & & & \\
\hline
\end{tabular}

\section{3. ¿Qué tanto lo describen a usted cada una de las siguientes afirmaciones?}

(Por favor seleccione una respuesta en cada fila marcando con " $X$ ”)

\begin{tabular}{|l|l|l|l|l|l|}
\hline & Bastante (1) & Mucho (2) & $\begin{array}{l}\text { Algo } \\
\text { (3) }\end{array}$ & $\begin{array}{l}\text { No } \\
\text { mucho } \\
\text { (4) }\end{array}$ & $\begin{array}{l}\text { Para } \\
\text { Nada } \\
\text { (5) }\end{array}$ \\
\hline a. Puedo lidiar con situaciones inusuales. & & & & \\
\hline $\begin{array}{l}\text { b. Puedo cambiar mi comportamiento para } \\
\text { cubrir las necesidades de nuevas situaciones. }\end{array}$ & & & & \\
\hline $\begin{array}{l}\text { c. Puedo adaptarme a diferentes situaciones } \\
\text { incluso cuando estoy bajo presión o estrés. }\end{array}$ & & & & & \\
\hline
\end{tabular}




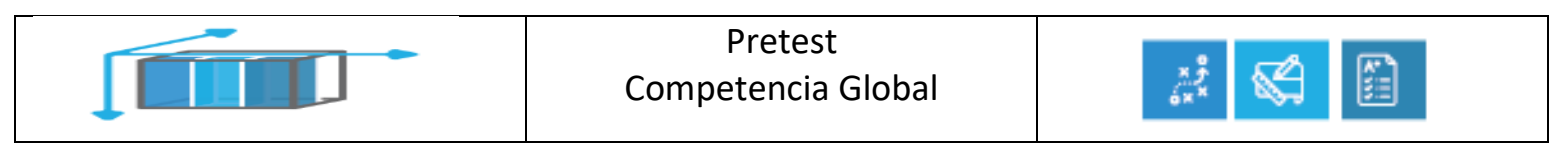

4. ¿Hasta qué punto está usted de acuerdo con las siguientes afirmaciones? (Por favor seleccione una respuesta en cada fila marcando con " $X$ ")

\begin{tabular}{|l|l|l|l|l|}
\hline & $\begin{array}{l}\text { Totalmente en } \\
\text { desacuerdo (1) }\end{array}$ & $\begin{array}{l}\text { En desacuerdo } \\
\text { (2) }\end{array}$ & $\begin{array}{l}\text { De } \\
\text { acuerdo } \\
\text { (3) }\end{array}$ & $\begin{array}{l}\text { Totalmente de } \\
\text { acuerdo (4) }\end{array}$ \\
\hline a. & $\begin{array}{l}\text { Observo cuidadosamente sus } \\
\text { reacciones. }\end{array}$ & & & \\
\hline b. & $\begin{array}{l}\text { Verifico con frecuencia que nos } \\
\text { estemos entendiendo mutuamente. }\end{array}$ & & & \\
\hline c. & $\begin{array}{l}\text { Escucho cuidadosamente lo que } \\
\text { dicen. }\end{array}$ & & & \\
\hline
\end{tabular}

5. ¿Con qué facilidad piensa usted que podría realizar las siguientes tareas por su cuenta?

(Por favor seleccione una respuesta en cada fila marcando con " $X$ ”)

\begin{tabular}{|ll|l|l|l|l|}
\hline & & $\begin{array}{l}\text { No } \\
\text { podría } \\
\text { hacer } \\
\text { esto } \\
\mathbf{( 1 )}\end{array}$ & $\begin{array}{l}\text { Me } \\
\text { costaría } \\
\text { mucho } \\
\text { trabajo } \\
\text { hacerlo } \\
\text { solo (2) }\end{array}$ & $\begin{array}{l}\text { Podría } \\
\text { hacerlo } \\
\text { con algo } \\
\text { de } \\
\text { esfuerzo } \\
\text { (3) }\end{array}$ & $\begin{array}{l}\text { Podría } \\
\text { hacerlo } \\
\text { con } \\
\text { fácilmente } \\
\text { (4) }\end{array}$ \\
\hline a. & $\begin{array}{l}\text { Predecir cómo los cambios en un entorno afectarán la } \\
\text { supervivencia de ciertas especies. }\end{array}$ & & & \\
\hline b. & $\begin{array}{l}\text { Explicar cómo las emisiones de dióxido de carbono } \\
\text { influyen sobre el cambio climático a nivel global. }\end{array}$ & & & & \\
\hline c. & $\begin{array}{l}\text { Establecer una relación entre los precios de los textiles y } \\
\text { las condiciones laborales en los países productores. }\end{array}$ & & & & \\
\hline
\end{tabular}

\section{6. ¿Qué tan informado está usted sobre los siguientes temas?}

(Por favor seleccione una respuesta en cada fila marcando con " $X$ ")

\begin{tabular}{|l|l|l|l|l|}
\hline & $\begin{array}{l}\text { Nunca } \\
\text { he oído } \\
\text { sobre } \\
\text { esto (1) }\end{array}$ & $\begin{array}{l}\text { He oído } \\
\text { sobre esto, } \\
\text { pero no } \\
\text { podría } \\
\text { explicar } \\
\text { de qué se } \\
\text { trata } \\
\text { realmente } \\
\text { (2) }\end{array}$ & $\begin{array}{l}\text { Sé algo } \\
\text { sobre esto } \\
\text { y podría } \\
\text { explicar el } \\
\text { asunto en } \\
\text { general (3) }\end{array}$ & $\begin{array}{l}\text { Estoy } \\
\text { familiarizado } \\
\text { sobre con esto } \\
\text { y sería capaz } \\
\text { de explicarlo } \\
\text { bien (4) }\end{array}$ \\
\hline a. $\quad$ Cambio climático y calentamiento global & & & & \\
\hline b. $\quad$ Salud en el mundo (p. ej., epidemias) & & & & \\
\hline c. $\quad$ Crecimiento poblacional & & & & \\
\hline d. $\quad$ Migración (desplazamiento de personas) & & & & \\
\hline e. $\quad \begin{array}{l}\text { Impactos de los desarrollos en la economía } \\
\text { global }\end{array}$ & & & & \\
\hline f. $\quad$ Contaminación del aire & & & & \\
\hline
\end{tabular}




\begin{tabular}{|c|c|c|}
\hline$\sqrt{1 \mid}-\infty$ & Pretest & Competencia Global \\
\hline
\end{tabular}

7. La gente se traslada, cada vez más, de un país a otro ¿Qué tanto está usted de acuerdo con las siguientes afirmaciones sobre los inmigrantes?

(Por favor seleccione una respuesta en cada fila marcando con " $X$ ”)

\begin{tabular}{|c|c|c|c|c|}
\hline & $\begin{array}{l}\text { Totalmente } \\
\text { en } \\
\text { desacuerdo } \\
\text { (1) }\end{array}$ & $\begin{array}{l}\text { En } \\
\text { desacuerdo } \\
\text { (2) }\end{array}$ & $\begin{array}{l}\text { De } \\
\text { acuerdo } \\
\text { (3) }\end{array}$ & $\begin{array}{l}\text { Totalmente de } \\
\text { acuerdo (4) }\end{array}$ \\
\hline $\begin{array}{l}\text { a. Se debería animar a los inmigrantes a que } \\
\text { continúen hablando su propio idioma. }\end{array}$ & & & & \\
\hline $\begin{array}{l}\text { b. Los niños inmigrantes deberían tener las mismas } \\
\text { oportunidades para la educación que otros niños } \\
\text { en el país. }\end{array}$ & & & & \\
\hline $\begin{array}{l}\text { c. Los inmigrantes que viven en el país durante } \\
\text { varios años deberían tener derecho a votar en las } \\
\text { elecciones. }\end{array}$ & & & & \\
\hline
\end{tabular}

\section{Con respecto a los profesores de su colegio: ¿a cuántos de ellos aplican las siguientes afirmaciones? \\ (Por favor seleccione una respuesta en cada fila marcando con " $X$ ”)}

\begin{tabular}{|c|c|c|c|c|}
\hline & $\begin{array}{l}\text { A ninguno } \\
\text { o casi } \\
\text { ninguno de } \\
\text { ellos }(1)\end{array}$ & $\begin{array}{l}\text { Alguno de } \\
\text { ellos (2) }\end{array}$ & $\begin{array}{l}\text { A la } \\
\text { mayoría } \\
\text { de ellos } \\
\text { (3) }\end{array}$ & $\begin{array}{l}\text { A todos o casi } \\
\text { a todos ellos } \\
\text { (4) }\end{array}$ \\
\hline $\begin{array}{l}\text { a. Hablan de forma respetuosa sobre las } \\
\text { personas de todos los grupos culturales. }\end{array}$ & & & & \\
\hline $\begin{array}{l}\text { b. Tienen ideas erróneas sobre la historia de } \\
\text { algunos grupos culturales. }\end{array}$ & & & & \\
\hline $\begin{array}{ll}\text { c. } & \text { Están abiertos al contacto personal con } \\
\text { personas de todos los grupos culturales. }\end{array}$ & & & & \\
\hline $\begin{array}{l}\text { d. Dicen cosas negativas sobre las personas de } \\
\text { algunos grupos culturales. }\end{array}$ & & & & \\
\hline $\begin{array}{l}\text { e. Culpan a las personas de algunos grupos } \\
\text { culturales por los problemas que enfrenta } \\
<\text { país de la prueba }>\end{array}$ & & & & \\
\hline
\end{tabular}

\section{EVALUACIÓN COGNITIVA DE LA COMPRENSIÓN GLOBAL}

\section{Estudio de caso}

\section{¿Cultura o improductividad?}

En clase de Sociales se discuten las diferentes festividades, carnavales y reinados que se celebran en un país llamado Turalia. Un estudiante del programa de intercambio, proveniente de otro país llamado Mirtonga, dice que se encuentra fascinado con el asunto, 


\begin{tabular}{|c|c|c|}
\hline$\sqrt{11}-$ & $\begin{array}{c}\text { Pretest } \\
\text { Competencia Global }\end{array}$ & 传 \\
\hline
\end{tabular}

por lo cual hace constantes preguntas al docente. Algunos de sus compañeros se molestan con él. Al final de la clase tienen la siguiente conversación:

Me da rabia que siempre insinúes que los turalianos somos subdesarrollados. Lo que quisiste decir en clase fue que tenemos todas nuestras fiestas por perezosos.

Mauricio: Es cierto Adam. Nos criticas sin tener en cuenta que varios de los carnavales turalianos son reconocidos internacionalmente como patrimonio. Ni por eso dejas de menospreciarnos.

Adam: A mí me gustó el tema de la clase, pues en Mirtonga no hay muchas celebraciones. Por eso participé mucho en clase. La gran variedad de fiestas turalianas me parecen un fenómeno divertido y pintoresco, pero también creo que puede dificultar el crecimiento económico de su país. Yo solo intentaba entender los pros y los contras de tantos días no laborales.

Lorena: No estoy de acuerdo Adam. Creo que la gente se adapta a todo y puede cumplir sus obligaciones antes y después de las fiestas. Lo tuyo son solo críticas disfrazadas. Además, no me gusta que me digas que mi país es pintoresco.

\section{Pregunta 9.}

Elija dos los siguientes argumentos, para justificar la molestia de Lorena por los comentarios de Adam:

1. El humor es de carácter universal que comparten las personas independientemente del país que provengan.

2. La cultura es un patrimonio que debe protegerse y no debe someterse a críticas.

3. A veces, al intentar decir algo positivo, una persona puede hacer comentarios ofensivos hacia las costumbres de otros.

4. Cuando las críticas se plantean de modo respetuoso, las personas deberían estar en capacidad de recibirlas con agrado.

5. Las prácticas culturales deben analizarse en su propio contexto y no juzgarse a partir de otros valores o principios.

\section{Respuestas}
A. Argumentos 3 y 4
B. Argumento 3
C. Argumento 2
D. Argumentos 1 y 2 


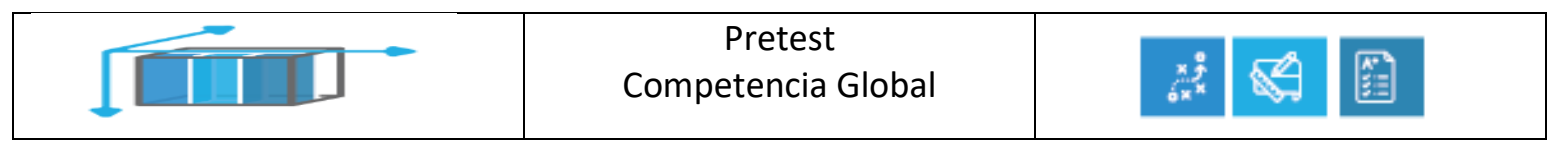

\section{Pregunta 10.}

Lorena decide hablar con Daniel, el personero del colegio, para presentar una queja ante el rector. De acuerdo con Lorena, el programa de intercambio debería ser más riguroso para evitar que estudiantes como Adam, quienes desprecian la cultura de otros países distintos al de él, no puedan llegar al colegio. Lorena dice que puede redactar una propuesta para mejorar el programa de intercambio y le pide a Daniel que la apoye. Daniel le contesta que la propuesta es apresurada.

¿Por qué Daniel considera que la propuesta de Lorena es apresurada?

\section{ESTRUCTURA DE LAS PREGUNTAS}

\begin{tabular}{|c|c|}
\hline $\mathrm{N}^{\mathbf{0}}$ pregunta & Constructo \\
\hline 1 & Adopción de perspectivas \\
\hline 2 & Mentalidad Global \\
\hline 3 & Flexibilidad/ Adaptabilidad \\
\hline 4 & $\begin{array}{l}\text { Conocimiento de la comunicación } \\
\text { intercultural }\end{array}$ \\
\hline 5 & $\begin{array}{l}\text { Autoeficacia con respecto a asuntos } \\
\text { globales }\end{array}$ \\
\hline 6 & Conocimiento sobre asuntos globales \\
\hline 7 & Actitudes frente a los inmigrantes \\
\hline 8 & $\begin{array}{l}\text { Clima escolar - Clima escolar } \\
\text { multicultural }\end{array}$ \\
\hline
\end{tabular}




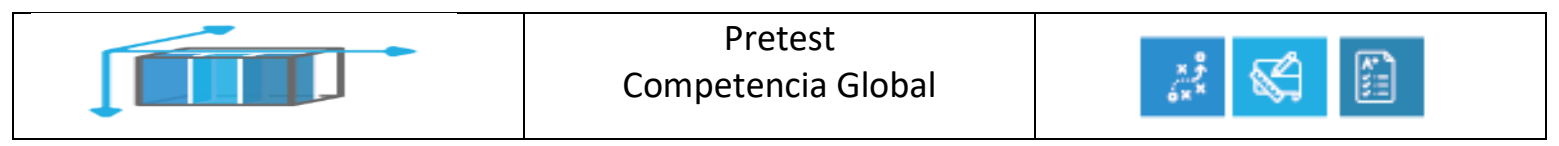

\section{Pregunta 9.}

\begin{tabular}{|l|l|}
\hline Crédito total & C y E \\
\hline Crédito parcial & $\mathrm{C}$ \\
\hline Crédito parcial & $\mathrm{E}$ \\
\hline Sin crédito & Otras respuestas \\
\hline Procesos cognitivos & Entender diferencias en la comunicación \\
\hline
\end{tabular}

\section{Pregunta 10.}

\begin{tabular}{|l|l|}
\hline Crédito total & $\begin{array}{l}\text { Respuestas que incluyan una de las siguientes razones: } \\
\text { - Daniel quiere conocer más sobre lo sucedido, antes de apoyar la } \\
\end{array}$ \\
& $\begin{array}{l}\text { - Dropuesta de Lorena. } \\
\text { - Daniel cree que por un solo caso no se puede generalizar. }\end{array}$ \\
& $\begin{array}{l}\text { Daniel quiere contrastar primero la información, antes de tomar una } \\
\text { posición en el problema. }\end{array}$ \\
\hline Sin crédito & Otras respuestas \\
\hline $\begin{array}{l}\text { Procesos } \\
\text { cognitivos }\end{array}$ & $\begin{array}{l}\text { Evaluar información, formular argumentos y explicar asuntos o } \\
\text { situaciones. }\end{array}$ \\
\hline
\end{tabular}




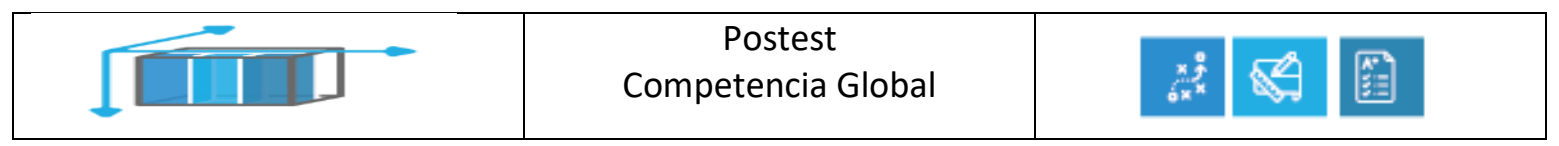

Anexo 7: Prueba Escrita Postest POSTEST COMPETENCIA GLOBAL ${ }^{41}$

Esta prueba consta de preguntas acerca de estudios de caso y responden a preguntas que evalúan la capacidad para comprender la complejidad y las múltiples perspectivas de los diversos actores involucrados en la cotidianidad.

Los contextos o escenarios utilizados expondrán a los estudiantes a un rango de diferentes situaciones y pondrán a prueba su capacidad para aplicar los conocimientos previos y las habilidades de pensamiento para analizar la situación y sugerir soluciones.

Las preguntas hacen referencia a asuntos de la vida real y de estos se derivan varias preguntas, las cuales pueden ser de selección múltiple y/o de respuesta abierta corta. Pueden presentarse en diferentes formatos que asignan un papel particular y motivan a participar en las tareas. Debes responder en un tiempo máximo de 1 hora. Recuerda marcar con una "X" en los espacios designados.

\section{NORMAS}

- Toda la prueba debe realizarse con lápiz o bolígrafo negro.

- Toda pregunta con dos o más respuestas señaladas será anulada

- Al finalizar entregue la prueba PROSTEST COMPETENCIA GLOBAL

\footnotetext{
${ }^{41}$ Las preguntas planteadas corresponden a las formuladas por el Marco de Referencia preliminar para la competencia global PISA 2018 para Colombia, tomado de http:/www2.icfes.gov.co/docman/institucioneseducativas-y-secretarias/evaluaciones-internacionales-investigadores/pisa/pisa-2018/2991-marco-dereferencia-para-competencia-global-pisa-2018/file?force-download=1
} 


\begin{tabular}{|c|c|c|}
\hline$\sqrt{1 \mid}-\infty$ & Postest & Competencia Global \\
\hline
\end{tabular}

\section{CUESTIONARIO DEL ALUMNO RELACIONADO CON LA COMPETENCIA GLOBAL}

1. ¿Qué tanto lo describen a usted cada una de las siguientes afirmaciones?

(Por favor seleccione una respuesta en cada fila marcando con " $X$ ”)

\begin{tabular}{|c|c|c|c|c|c|}
\hline & $\begin{array}{l}\text { Bastante } \\
\text { (1) }\end{array}$ & $\begin{array}{l}\text { Mucho } \\
\text { (2) }\end{array}$ & $\begin{array}{l}\text { Algo } \\
\text { (3) }\end{array}$ & $\begin{array}{l}\text { No } \\
\text { mucho } \\
\text { (4) }\end{array}$ & $\begin{array}{l}\text { Para } \\
\text { Nada } \\
\text { (5) }\end{array}$ \\
\hline $\begin{array}{l}\text { a. A veces trato de entender mejor a mis amigos } \\
\text { imaginando cómo se ven las cosas desde su } \\
\text { perspectiva. }\end{array}$ & & & & & \\
\hline $\begin{array}{l}\text { b. Antes de criticar a alguien, trato de imaginar cómo } \\
\text { me sentiría si estuviera en su lugar. }\end{array}$ & & & & & \\
\hline
\end{tabular}

2. ¿Hasta qué punto está usted de acuerdo con las siguientes afirmaciones? (Por favor seleccione una respuesta en cada fila marcando con " $X$ ")

\begin{tabular}{|c|c|c|c|c|}
\hline & $\begin{array}{l}\text { Totalmente } \\
\text { en } \\
\text { desacuerdo } \\
\text { (1) }\end{array}$ & $\begin{array}{l}\text { En } \\
\text { desacuerdo } \\
\text { (2) }\end{array}$ & $\begin{array}{l}\text { De } \\
\text { acuerdo } \\
\text { (3) }\end{array}$ & $\begin{array}{l}\text { Totalmente } \\
\text { de acuerdo } \\
\text { (4) }\end{array}$ \\
\hline $\begin{array}{l}\text { a. Es correcto boicotear las empresas de las que } \\
\text { se sabe que ofrecen malas condiciones en el } \\
\text { sitio de trabajo para sus empleados. }\end{array}$ & & & & \\
\hline $\begin{array}{l}\text { b. Puedo hacer algo sobre los problemas del } \\
\text { mundo. }\end{array}$ & & & & \\
\hline $\begin{array}{l}\text { c. Cuidar del ambiente global es importante para } \\
\text { mí. }\end{array}$ & & & & \\
\hline
\end{tabular}

\section{3. ¿Qué tanto lo describen a usted cada una de las siguientes afirmaciones? (Por favor seleccione una respuesta en cada fila marcando con " $X$ ")}

\begin{tabular}{|l|l|l|l|l|l|}
\hline & $\begin{array}{l}\text { Bastante } \\
\text { (1) }\end{array}$ & $\begin{array}{l}\text { Mucho } \\
\mathbf{( 2 )}\end{array}$ & $\begin{array}{l}\text { Algo } \\
\mathbf{( 3 )}\end{array}$ & $\begin{array}{l}\text { No } \\
\text { mucho } \\
\text { (4) }\end{array}$ & $\begin{array}{l}\text { Para } \\
\text { Nada } \\
\text { (5) }\end{array}$ \\
\hline a. Puedo adaptarme fácilmente a una nueva cultura. & & & & & \\
\hline $\begin{array}{l}\text { b. } \text { Cuando me encuentro situaciones difíciles con otras } \\
\text { personas, puedo pensar en una manera de } \\
\text { resolverlas. }\end{array}$ & & & & & \\
\hline $\begin{array}{l}\text { c. Soy capaz de superar mis dificultades al interactuar } \\
\text { con personas de otras culturas. }\end{array}$ & & & & & \\
\hline
\end{tabular}




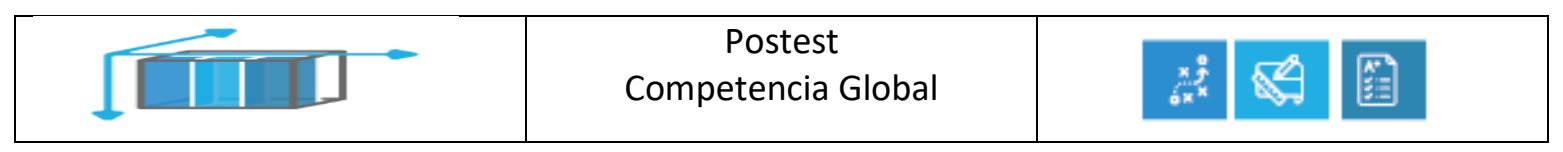

4. ¿Hasta qué punto está usted de acuerdo con las siguientes afirmaciones?

(Por favor seleccione una respuesta en cada fila marcando con " $X$ ")

\begin{tabular}{|l|l|l|l|l|}
\hline & $\begin{array}{l}\text { Totalmente } \\
\text { en } \\
\text { desacuerdo } \\
\text { (1) }\end{array}$ & $\begin{array}{l}\text { En } \\
\text { desacuerdo } \\
\mathbf{( 2 )}\end{array}$ & $\begin{array}{l}\text { De } \\
\text { acuerdo } \\
\mathbf{( 3 )}\end{array}$ & $\begin{array}{l}\text { Totalmente } \\
\text { de acuerdo } \\
\text { (4) }\end{array}$ \\
\hline a. Elijo mis palabras cuidadosamente. & & & & \\
\hline $\begin{array}{l}\text { b. Doy ejemplos concretos para } \\
\text { explicar mis ideas. }\end{array}$ & & & & \\
\hline $\begin{array}{l}\text { c. Explico las cosas con mucho } \\
\text { cuidado. }\end{array}$ & & & & \\
\hline
\end{tabular}

\section{5. ¿Con qué facilidad piensa usted que podría realizar las siguientes tareas por su cuenta? \\ (Por favor seleccione una respuesta en cada fila marcando con “ $X$ ”)}

\begin{tabular}{|c|c|c|c|c|}
\hline & $\begin{array}{l}\text { No } \\
\text { podría } \\
\text { hacer } \\
\text { esto } \\
\text { (1) }\end{array}$ & $\begin{array}{l}\text { Me } \\
\text { costaría } \\
\text { mucho } \\
\text { trabajo } \\
\text { hacerlo } \\
\text { solo (2) }\end{array}$ & $\begin{array}{l}\text { Podría } \\
\text { hacerlo } \\
\text { con algo } \\
\text { de } \\
\text { esfuerzo } \\
\text { (3) }\end{array}$ & $\begin{array}{l}\text { Podría } \\
\text { hacerlo con } \\
\text { fácilmente } \\
\text { (4) }\end{array}$ \\
\hline \begin{tabular}{|l} 
a. \\
Discutir las diferentes razones por las que las \\
personas se convierten en refugiados.
\end{tabular} & & & & \\
\hline $\begin{array}{l}\text { b. Explicar por qué algunos países sufren más que } \\
\text { otros por el cambio climático global. }\end{array}$ & & & & \\
\hline $\begin{array}{l}\text { c. Explicar cómo las crisis económicas de cada país } \\
\text { afectan la economía mundial. }\end{array}$ & & & & \\
\hline
\end{tabular}

\section{6. ¿Qué tan informado está usted sobre los siguientes temas?}

(Por favor seleccione una respuesta en cada fila marcando con " $X$ ")

\begin{tabular}{|c|c|c|c|c|}
\hline & $\begin{array}{l}\text { Nunca } \\
\text { he oído } \\
\text { sobre } \\
\text { esto }\end{array}$ & $\begin{array}{l}\text { He oído } \\
\text { sobre esto } \\
\text { pero no } \\
\text { podría } \\
\text { explicar de } \\
\text { qué se trata } \\
\text { realmente } \\
\end{array}$ & $\begin{array}{l}\text { Sé algo } \\
\text { sobre esto } \\
\text { y podría } \\
\text { explicar } \\
\text { el asunto } \\
\text { en } \\
\text { general }\end{array}$ & $\begin{array}{l}\text { Estoy } \\
\text { familiarizado } \\
\text { sobre con } \\
\text { esto y sería } \\
\text { capaz de } \\
\text { explicarlo } \\
\text { bien } \\
\end{array}$ \\
\hline a. Conflictos internacionales & & & & \\
\hline $\begin{array}{ll}\text { b. Hambruna o desnutrición en distintos } \\
\text { lugares del mundo }\end{array}$ & & & & \\
\hline c. $\quad$ Causas de la pobreza & & & & \\
\hline $\begin{array}{ll}\text { d. } & \begin{array}{l}\text { El ritmo del desarrollo tecnológico en el } \\
\text { mundo }\end{array} \\
\end{array}$ & & & & \\
\hline $\begin{array}{l}\text { e. } \begin{array}{l}\text { El impacto del envejecimiento en las } \\
\text { poblaciones }\end{array}\end{array}$ & & & & \\
\hline $\begin{array}{ll}\text { f. } & \begin{array}{l}\text { La igualdad entre mujeres y hombres en } \\
\text { diferentes partes del mundo }\end{array} \\
\end{array}$ & & & & \\
\hline
\end{tabular}




\begin{tabular}{|c|c|c|}
\hline$\sqrt{1 \mid}-\infty$ & Postest & Competencia Global \\
\hline
\end{tabular}

7. La gente se traslada, cada vez más, de un país a otro ¿Qué tanto está usted de acuerdo con las siguientes afirmaciones sobre los inmigrantes?

(Por favor seleccione una respuesta en cada fila marcando con " $X$ ”)

\begin{tabular}{|c|c|c|c|c|}
\hline & $\begin{array}{l}\text { Totalmente } \\
\text { en } \\
\text { desacuerdo } \\
\text { (1) }\end{array}$ & $\begin{array}{l}\text { En } \\
\text { desacuerdo } \\
\text { (2) }\end{array}$ & $\begin{array}{l}\text { De } \\
\text { acuerdo } \\
\text { (3) }\end{array}$ & $\begin{array}{l}\text { Totalmente } \\
\text { de acuerdo } \\
\text { (4) }\end{array}$ \\
\hline $\begin{array}{l}\text { a. Los inmigrantes deberían tener la oportunidad d } \\
\text { continuar con sus costumbres y estilo de vida. }\end{array}$ & & & & \\
\hline $\begin{array}{l}\text { b. Los inmigrantes deberían tener los mismos } \\
\text { derechos que cualquier otra persona en el país. }\end{array}$ & & & & \\
\hline $\begin{array}{l}\text { c. Se debería restringir la inmigración cuando no } \\
\text { hay muchos empleos disponibles. }\end{array}$ & & & & \\
\hline
\end{tabular}

\section{Con respecto a los profesores de su colegio: ¿a cuántos de ellos aplican las siguientes afirmaciones? \\ (Por favor seleccione una respuesta en cada fila marcando con " $X$ ”)}

\begin{tabular}{|c|c|c|c|c|}
\hline & $\begin{array}{l}\text { A ninguno } \\
\text { o casi } \\
\text { ninguno de } \\
\text { ellos }\end{array}$ & $\begin{array}{l}\text { Alguno de } \\
\text { ellos }\end{array}$ & $\begin{array}{l}\text { A la } \\
\text { mayoría } \\
\text { de ellos }\end{array}$ & $\begin{array}{l}\text { A todos o casi } \\
\text { a todos ellos }\end{array}$ \\
\hline $\begin{array}{l}\text { a. Demuestran comprensión de la diversidad } \\
\text { de mentalidades dentro de distintos grupos } \\
\text { culturales. }\end{array}$ & & & & \\
\hline $\begin{array}{l}\text { b. Tratan por igual a los estudiantes de todos } \\
\text { los grupos culturales. }\end{array}$ & & & & \\
\hline $\begin{array}{l}\text { c. Tienen menores expectativas académicas } \\
\text { sobre los estudiantes de algunos grupos } \\
\text { culturales. }\end{array}$ & & & & \\
\hline $\begin{array}{l}\text { d. Aplican los mismos criterios para calificar a } \\
\text { los estudiantes, sin importar su grupo } \\
\text { cultural. }\end{array}$ & & & & \\
\hline $\begin{array}{l}\text { e. Aplican los mismos criterios para castigar el } \\
\text { mal comportamiento de los estudiantes sin } \\
\text { importar su grupo cultural. }\end{array}$ & & & & \\
\hline
\end{tabular}

\section{EVALUACIÓN COGNITIVA DE LA COMPRENSIÓN GLOBAL}

\section{Estudio de caso}

\section{¿Cultura o improductividad?}

En clase de Sociales se discuten las diferentes festividades, carnavales y reinados que se celebran en un país llamado Turalia. Un estudiante del programa de intercambio, 


\begin{tabular}{|c|c|c|}
\hline$\sqrt{11}-$ & $\begin{array}{c}\text { Postest } \\
\text { Competencia Global }\end{array}$ & 传 \\
\hline
\end{tabular}

proveniente de otro país llamado Mirtonga, dice que se encuentra fascinado con el asunto, por lo cual hace constantes preguntas al docente. Algunos de sus compañeros se molestan con él. Al final de la clase tienen la siguiente conversación:

Me da rabia que siempre insinúes que los turalianos somos subdesarrollados. Lo que quisiste decir en clase fue que tenemos todas nuestras fiestas por perezosos.

Mauricio: Es cierto Adam. Nos criticas sin tener en cuenta que varios de los carnavales turalianos son reconocidos internacionalmente como patrimonio. Ni por eso dejas de menospreciarnos.

Adam: A mí me gustó el tema de la clase, pues en Mirtonga no hay muchas celebraciones. Por eso participé mucho en clase. La gran variedad de fiestas turalianas me parecen un fenómeno divertido y pintoresco, pero también creo que puede dificultar el crecimiento económico de su país. Yo solo intentaba entender los pros y los contras de tantos días no laborales.

Lorena: No estoy de acuerdo Adam. Creo que la gente se adapta a todo y puede cumplir sus obligaciones antes y después de las fiestas. Lo tuyo son solo críticas disfrazadas. Además, no me gusta que me digas que mi país es pintoresco.

\section{Pregunta 9.}

¿Cuál de las siguientes razones explica que Adam piense que los carnavales y fiestas del país al que llegó pueden tener un efecto económico negativo?

A. Mirtonga posee una cultura que valora mucho el uso del tiempo y la productividad.

B. Adam no posee una actitud abierta hacia otras costumbres distintas de la de su propia cultura.

C. Para Adam solo las costumbres de su país son apropiadas, y por eso considera que otras culturas deberían adoptarlas.

D. Mirtonga es un país rico en el que no existen los carnavales ni otro tipo de celebraciones

\section{Pregunta 10.}

El profesor de Sociales se enteró de la discusión de sus estudiantes luego de la clase sobre carnavales y fiestas. En la siguiente clase, el docente les pide a los jóvenes que cada uno investigue sobre una fiesta o celebración en el mundo (que no sea de Turalia) y prepare argumentos para defender en un debate la importancia de esa fiesta y se "apropien de ella" llevando vestimentas, objetos típicos, canciones, entre otros.

¿Cuál de las siguientes es una consecuencia indeseada de la tarea asignada por el profesor? 


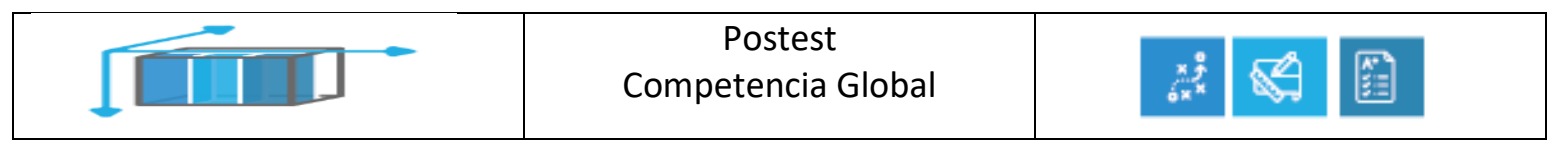

A. Que los estudiantes aprendan sobre las costumbres de otros países y valoren la diversidad cultural.

B. Que los estudiantes logren interesarse por otras culturas y decidan inscribirse en un programa de intercambio.

C. Que los estudiantes se apropien tanto de su papel que se generen nuevas discusiones y peleas durante la clase.

D. Que los estudiantes aprendan más sobre su propia cultura al compararla con las tradiciones de otros países.

ESTRUCTURA DE LAS PREGUNTAS

\begin{tabular}{|c|c|}
\hline $\mathbf{N}^{0}$ pregunta & Constructo \\
\hline 1 & Adopción de perspectivas \\
\hline 2 & Mentalidad Global \\
\hline 3 & Flexibilidad/ Adaptabilidad \\
\hline 4 & $\begin{array}{l}\text { Conocimiento de la comunicación } \\
\text { intercultural }\end{array}$ \\
\hline 5 & $\begin{array}{l}\text { Autoeficacia con respecto a asuntos } \\
\text { globales }\end{array}$ \\
\hline 6 & Conocimiento sobre asuntos globales \\
\hline 7 & Actitudes frente a los inmigrantes \\
\hline 8 & $\begin{array}{l}\text { Clima escolar - Clima escolar } \\
\text { multicultural }\end{array}$ \\
\hline
\end{tabular}

Pregunta 9.

\begin{tabular}{|l|l|}
\hline Crédito total & A \\
\hline Sin crédito & Otras respuestas \\
\hline Procesos cognitivos & $\begin{array}{l}\text { Identificar y analizar múltiples } \\
\text { perspectivas }\end{array}$ \\
\hline
\end{tabular}

Pregunta 10.

\begin{tabular}{|l|l|}
\hline Crédito total & C \\
\hline Sin crédito & Otras respuestas \\
\hline Procesos cognitivos & Evaluar acciones y consecuencias \\
\hline
\end{tabular}


Anexo 8: Validación de instrumento Guía de intervención pedagógica

\begin{tabular}{|l|l|l|}
\hline \multicolumn{3}{|c|}{ Validación de la intervención } \\
\hline Nombre de la intervención & \\
\hline Docente Guía & \\
\hline Nombre del evaluador & \\
\hline Califique cada ítem siendo 5 el máximo valor y 0 el mínimo valor \\
\hline Diseño del curso & Nota & Observaciones \\
\hline Presentación de la metodología de trabajo & & \\
\hline $\begin{array}{l}\text { Existe orientación hacia la construcción del } \\
\text { aprendizaje }\end{array}$ & & \\
\hline $\begin{array}{l}\text { Existe Coherencia entre los resultados de } \\
\text { aprendizaje y las actividades } \\
\text { propuestas. }\end{array}$ & & \\
\hline $\begin{array}{l}\text { Los tiempos de las actividades están bien } \\
\text { planificados. }\end{array}$ & & \\
\hline $\begin{array}{l}\text { Los recursos son pertinentes para desarrollar } \\
\text { las actividades propuestas. }\end{array}$ & \\
\hline $\begin{array}{l}\text { Están establecidos los criterios de evaluación } \\
\text { de unidades temáticas. }\end{array}$ & \\
\hline Son claros los criterios de evaluación. & \\
\hline $\begin{array}{l}\text { Considera que la metodología está bien } \\
\text { orientada hacia desarrollo de la competencia } \\
\text { global }\end{array}$ & & \\
\hline Total Puntaje & & \\
\hline Promedio Calificación & & \\
\hline
\end{tabular}




\title{
Anexo 9 Artículo publicado.
}

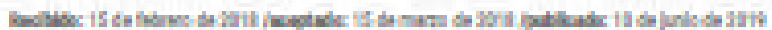

\section{El currículo para el contexto: análisis bibliográfico sobre tendencias para diseñar el currículo de básica secundaria}

\author{
The curriculum for the context: a bibliographical \\ analysis on trends to design the secondary basics on \\ the curriculum
}

Jonte Amado Renietia Veri'

Etwin Mauribio Hincapie Montoya"

Sandra MIlena Hincspit Monbya

\section{Resumeti}

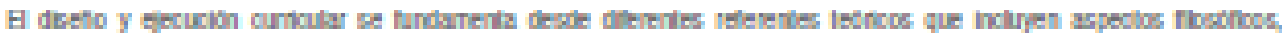

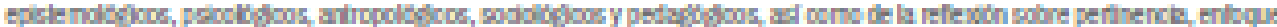

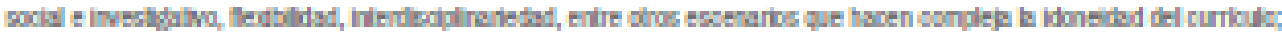

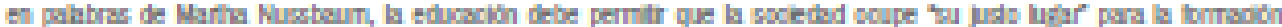

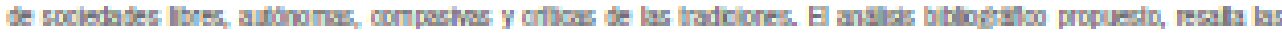

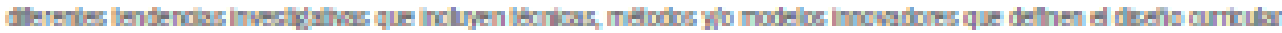

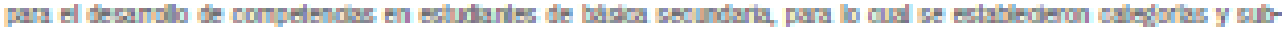

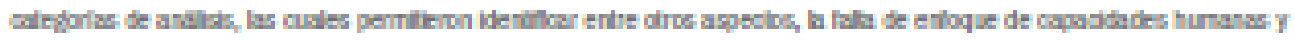

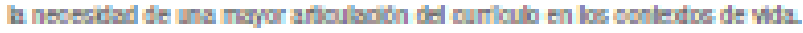

\section{Palsbras clave}

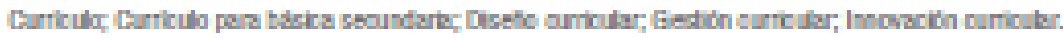

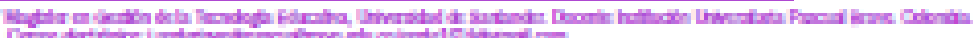

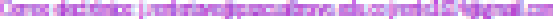

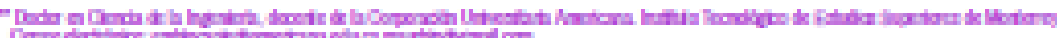

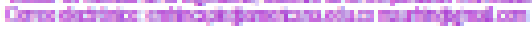

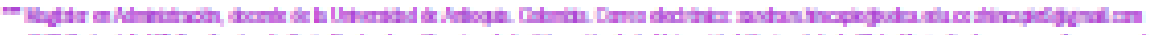

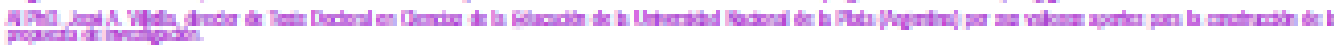


Anexo 10: Certificado ponencia ELE 2018.

ENCUENTRD LATINDAMERICAND DE EDUCACIÓN

MEDELLIN - ANTIOQUIA

Octubre $10-12$ de 2018

\section{ELE 2D18}

\section{ENCUENTRO LATINDAMERICAND DE EDUCACIÍN}

HACE CONSTAR QUE

\section{Jorge Amado lientería 界.}

Institucián Universitaria Pascual Bravo - Colambia

\section{Participó como PDNENTE en el Encuentro y presentú el trabajo}

Framework metodológico para el diseño curricular en básica secundaria

\section{Coautores}

Mauricio Hincapié M.

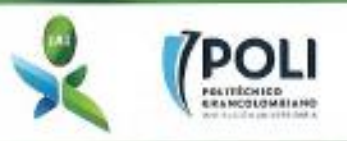

(C) 2018 Instituto Antioqueño de Investigación 
Anexo 11: certificado capítulo de libro resultado de investigación ELE 2018.

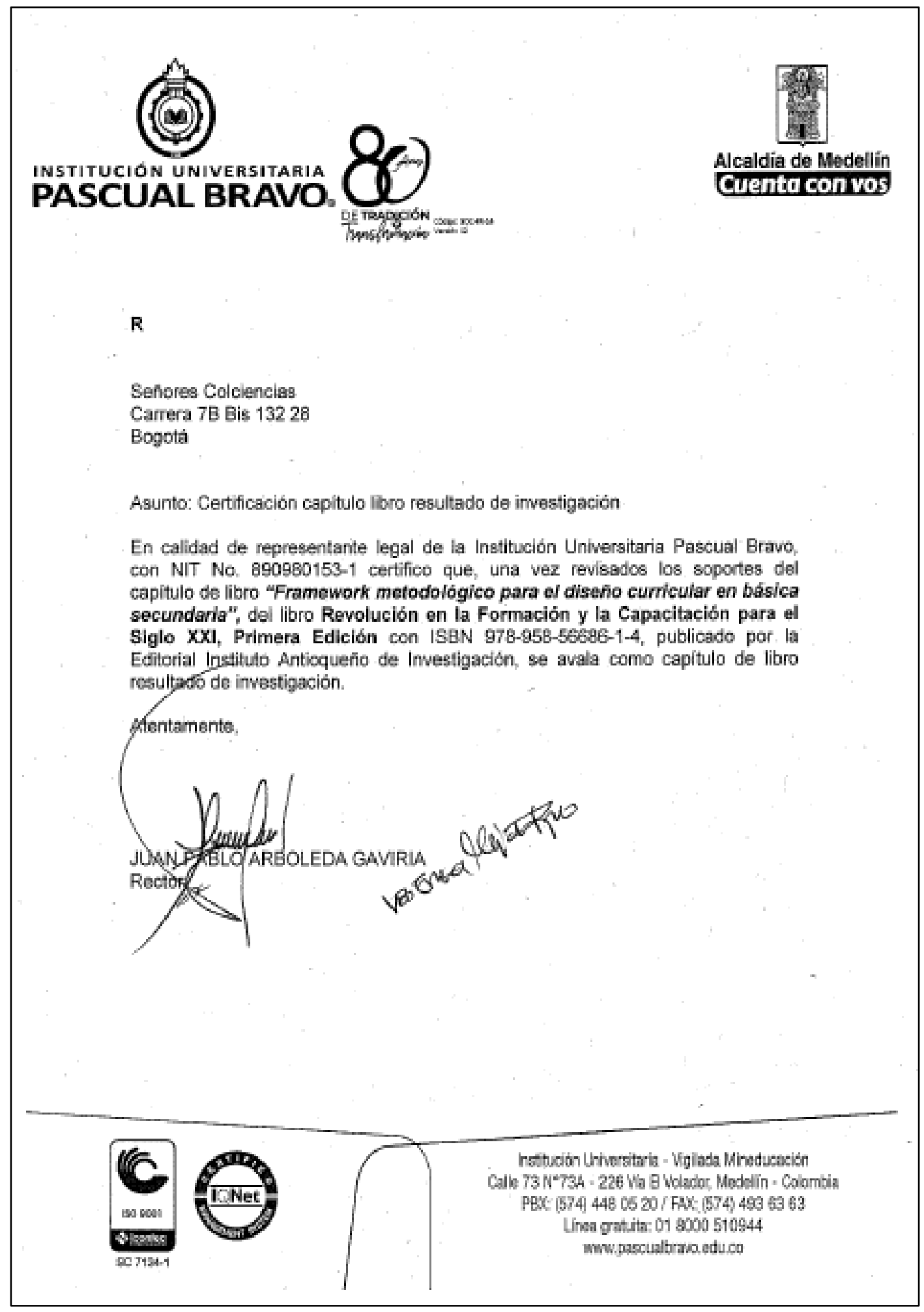


Anexo 12: Ponencia IV Congreso Internacional de Política educativa en América Latina 2019

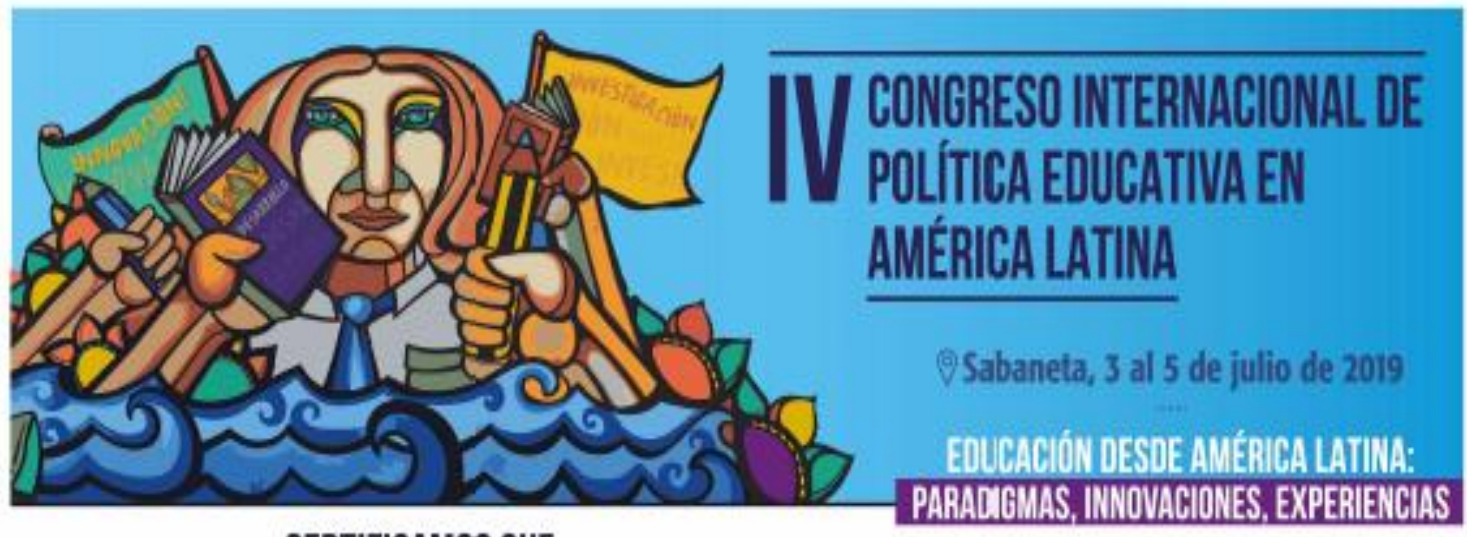

CERTIFICAMOS QUE:

\section{JORGE AMADO RENTERÍA VERA}

Asistió al IV Congreso Internacional de Política Educativa en América Latina: "Educación desde América Latina: paradigmas, innovaciones, experiencias" realizado en Sabaneta, Antioquia del 3 al 5 de julio de 2019 en calidad de:

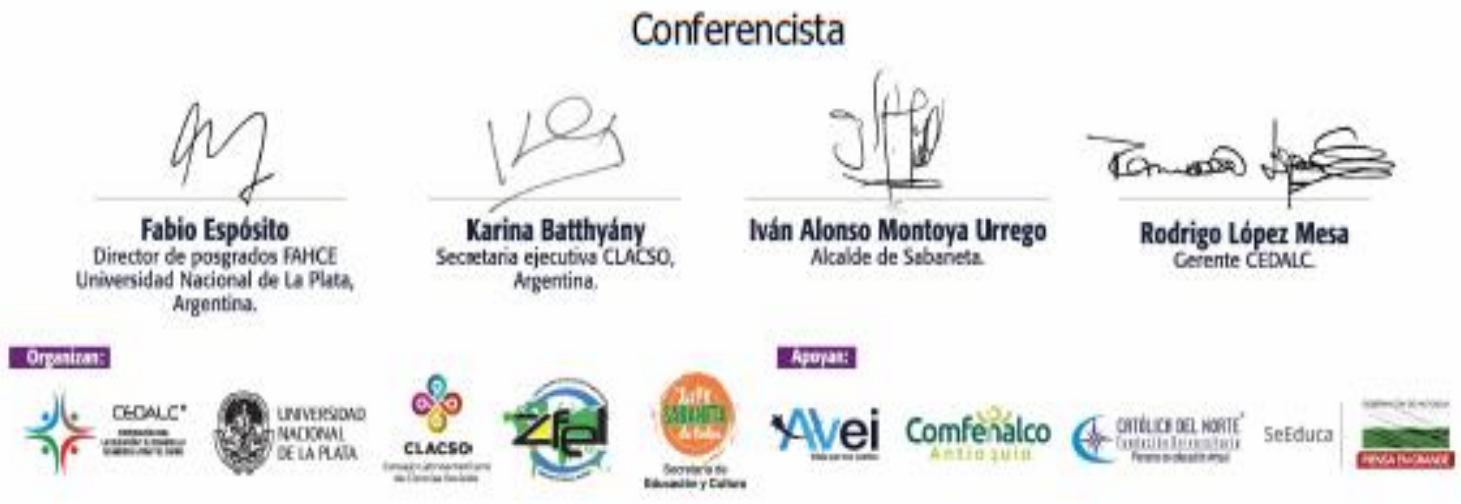


Anexo 13: Marco metodológico para el fortalecimiento de la competencia global. Anexo digital PDF: Guía metodológica de Aplicación modelo de coordenadas curriculares para básica secundaria

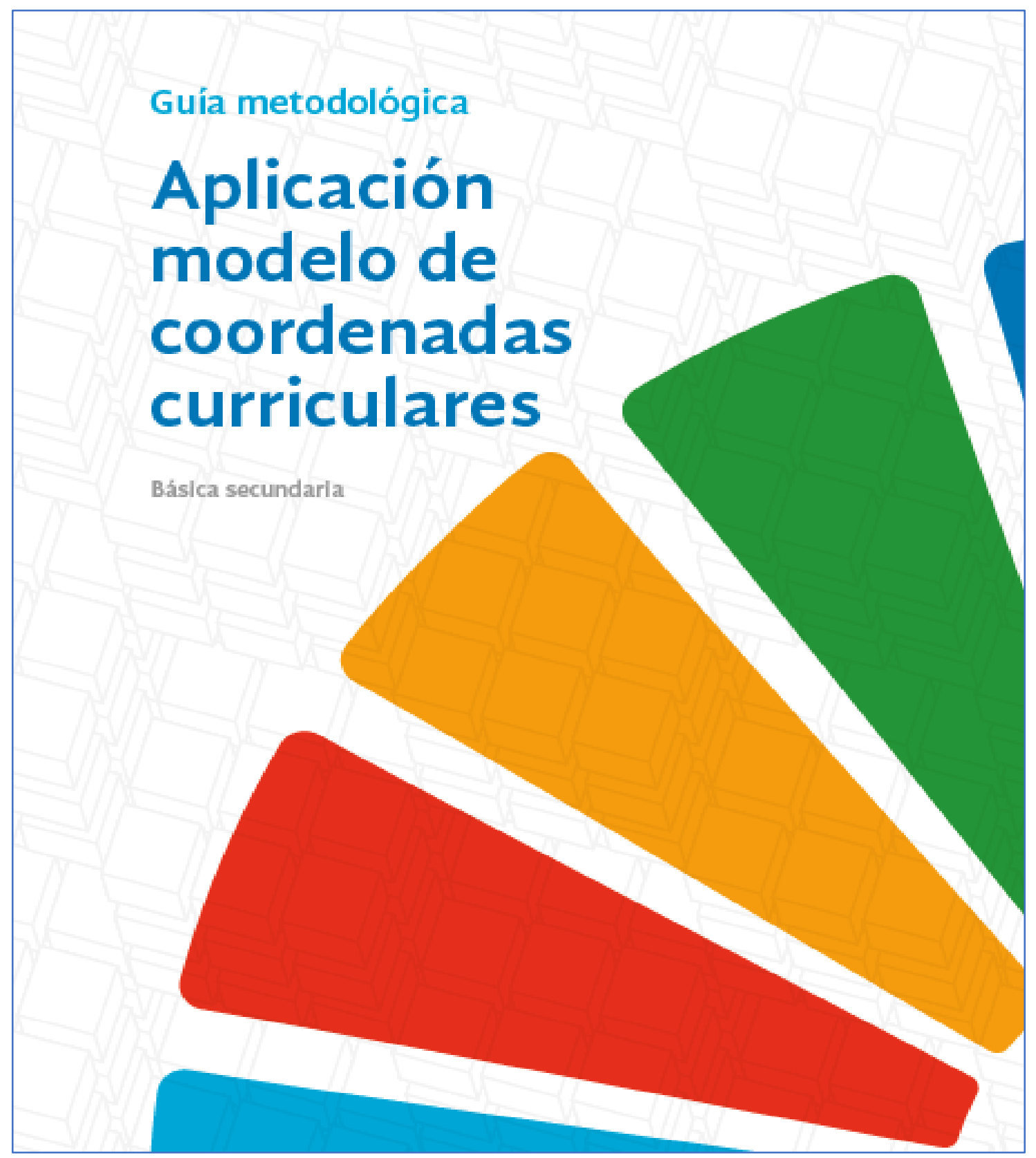




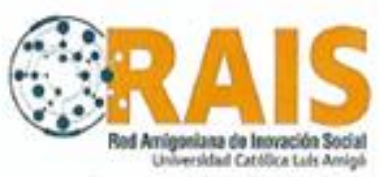

La Red Amigoniana de Innovación Social RAIS y la Facultad de Ciencias Administrativas, Económicas y Contables hacen constar que:

\section{Jorge Amado Rentería Vera}

Realizó el dia 10 de abril de 2019 la ponencia titulada:

Modelo de reforoncla para el delseīo curricular en educación superior: OOS, industria 4.0 y grupos educativos como direcelonamiento estrategloo de pais

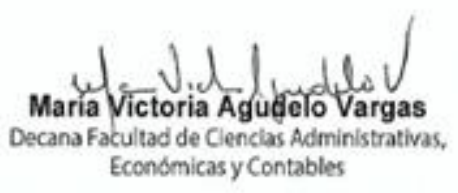

OIIDIE

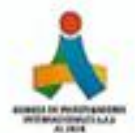

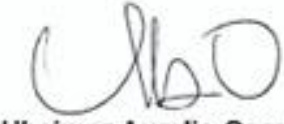

Ubeimar Aurelio Osorio Atehortúa Director Red Amigoniana de Innovación Social RMIS 
Anexo 15: Certificado capitulo de libro resultado de investigación RAIS 2019.

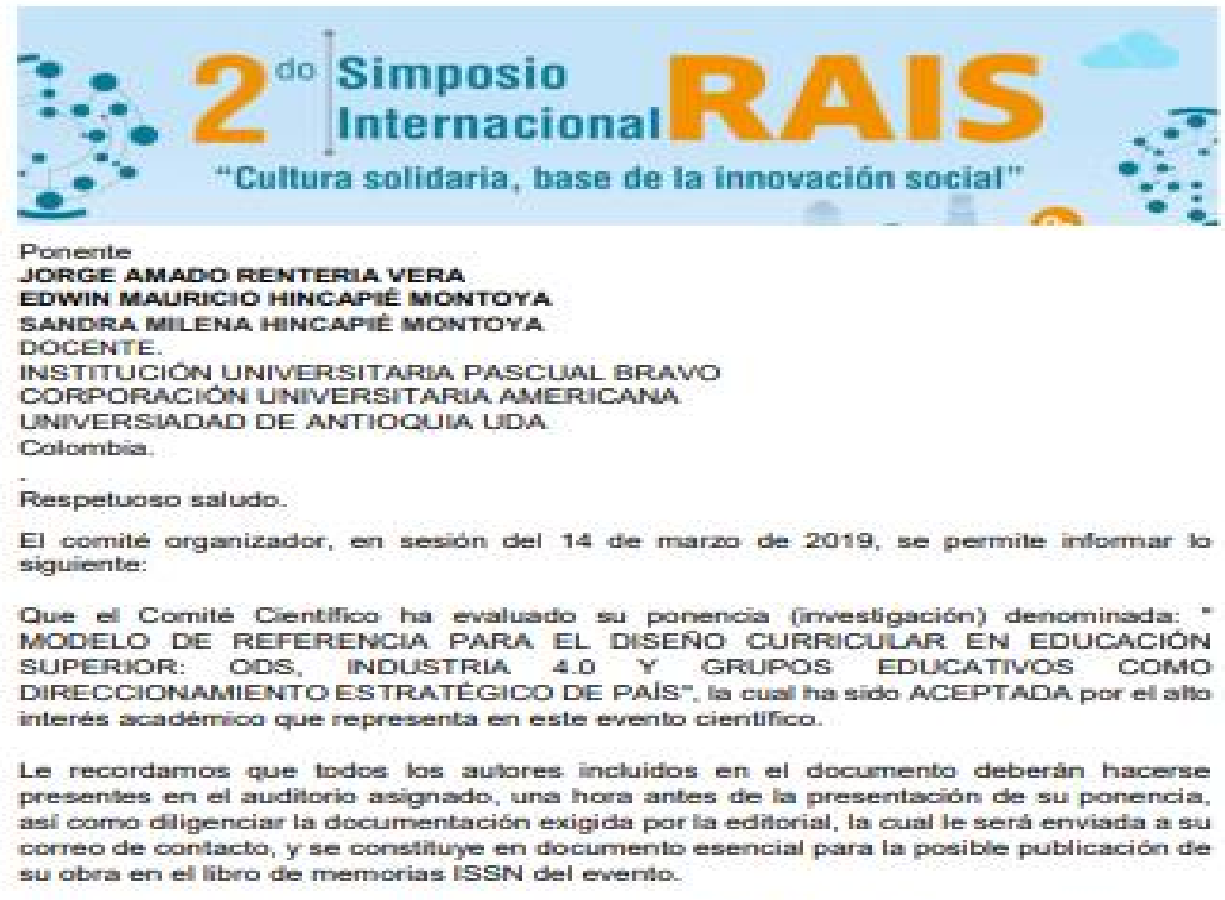

Felicitaindole por la aceptación de su trabajo, reciba un atento saludo.

Cardialmente.

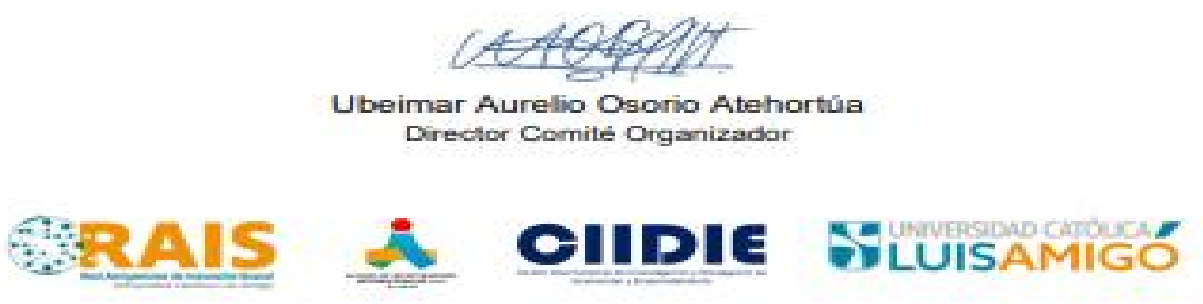

Extendido el plazo de convocatoria a publicar en el volumen VII del libro: “Tendencias en la Investigación Universitaria. Una Visión desde Latinoamérica Recibidos x

Yamaru Chirinos

르 8 may. 2019 17:55 (hace 10 días) है h :

para Yamaru, bcc: mí v

Estimados investigadores, por petición de la comunidad científica que nos respalda se extiende el plazo para publicar en el Volumen VII del LIBRO TENDENCIAS EN LA INVESTIGACIÓN UNIVERSITARIA. UNA VISIÓN DESDE LATINOAMÉRICA, se aprecian sus aportes y recomendaciones para hacer más amplia esta alianza y en conjunto podamos lograr realizar otras actividades de investigación con visibilidad internacional, por demás está decirle que estamos abiertos ante cualquier propuesta e invitación para desarrollar actividades en conjunto.Gracias por su amable atención siempre es un placer atenderle, quedo atenta. 